JEANNE APARECIDA GIROTO

ESTUDO DA DEGRADAÇÃO FOTOQUÍMICA DE SOLUÇÕES AQUOSAS DE POLIETILENOGLICOL, POLIACRILAMIDA E POLIVINILPIRROLIDONA

Tese apresentada à Escola Politécnica da Universidade de São Paulo para a obtenção do título de Doutora em Engenharia 
JEANNE APARECIDA GIROTO

\section{ESTUDO DA DEGRADAÇÃO FOTOQUÍMICA DE SOLUÇÕES AQUOSAS DE POLIETILENOGLICOL, POLIACRILAMIDA E POLIVINILPIRROLIDONA}

Tese apresentada à Escola Politécnica da Universidade de São Paulo para a obtenção do título de Doutora em Engenharia

Área de Concentração:

Engenharia Química

Orientador:

Roberto Guardani 
Este exemplar foi revisado e alterado em relação à versão original, sob responsabilidade única do autor e com a anuência de seu orientador.

São Paulo, de agosto de 2007.

Assinatura do autor

Assinatura do orientador

FICHA CATALOGRÁFICA

Giroto, Jeanne Aparecida

Estudo da degradação fotoquímica de soluções aquosas de polietilenoglicol, poliacrilamida e polivinilpirrolidona / J.A. Giroto. -- São Paulo, 2007.

$254 \mathrm{p}$.

Tese (Doutorado) - Escola Politécnica da Universidade de São Paulo. Departamento de Engenharia Química.

1.Polímeros sintéticos 2.Fotoquímica 3.Efluentes (Tratamento químico) 4.Modelagem molecular 5.Soluções aquosas I.Universidade de São Paulo. Escola Politécnica. Departamento de Engenharia Química II.t. 


\section{AGRADECIMENTOS}

À minha família: Arlindo, Luci, Kristian e Rodrigo.

Ao meu orientador Prof. Dr. Roberto Guardani.

Ao Prof. Dr. Antonio Carlos Silva Costa Teixeira pela orientação em Modelagem Molecular e co-orientação do trabalho.

À Sílvia M. Baeder pela constante ajuda e boa vontade na resolução dos problemas técnicos computacionais do laboratório.

Ao Prof. Dr. João Henrique G. Lago pela ajuda na proposição dos mecanismos de oxidação da poliacrilamida.

Ao Prof. Dr. Josefredo R. Pliego Jr.pela ajuda com a Modelagem Molecular.

Ao Prof. Dr Miguel G. Neumann e a Dra. Carla C. Schmitt Cavalheiro pelo treinamento inicial na técnica de GPC no IQSC.

À Dra. Cláudia Larini pela orientação e análises de HPLC e GCMS.

À Dra. Maria Anita Mendes pelas análises de LCMS.

À Nara Zacharias pela orientação e desenvolvimento conjunto do método de HPLC para detecção de ácidos.

Ao Wendell Pereira dos Santos pela ajuda na realização dos experimentos.

Ao Laboratório de Computação Científica Avançada da Universidade de São Paulo - LCCA, especialmente a Francisco Ribacionka pelo suporte técnico.

Aos meus companheiros de laboratório de fotoquímica do Departamento de Engenharia Química da USP: Isabela, José Ermírio, Ricardo, Amílcar, Douglas, Airton, Kátia, Cínthia, Yuri, Fernanda, Daniela, Fúlvia e Leidi.

À Carminha, secretária do Laboratório de Simulação e Controle de Processos da USP, e aos amigos: Rita, Patrícia, Verônica, Antônio, Francisco, Maria Cristina, Galo L. Noriega e Terezinha.

Às técnicas de laboratório: Denise, Miriam, Audrey, Deine e Sabrina.

Aos colegas de Natal que tive oportunidade de conhecer pelo projeto PROCAD: André, Emannuelle, Cátia, Adriana, Liana, Roseanne e Sara.

À CAPES e ao CEPEMA pelo suporte financeiro que possibilitou a realização deste trabalho. 


\section{SUMÁRIO}

RESUMO

$\begin{array}{lll}\text { ABSTRACT } & \text { ii }\end{array}$

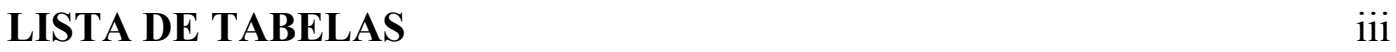

LISTA DE FIGURAS vii

LISTA DE SÍMBOLOS Xiv

1. INTRODUÇÃO 1

2. REVISÃo BIBLIOGRÁFICA 3

2.1. Processos Oxidativos Avançados 4

2.1.1. Processo UV/ $\mathrm{H}_{2} \mathrm{O}_{2} \quad 5$

2.1.2. Processo foto-Fenton 6

2.1.3. Degradação de Polímeros Solúveis em Água 10

2.1.3.1 Polietilenoglicol (PEG) 11

2.1.3.2 Poliacrilamida (PAM) 14

2.1.3.3 Polivinilpirrolidona (PVP) 18

2.2. Degradação Oxidativa de Polímeros 21

2.2.1. Mecanismo de Radicais Livres na Autoxidação 21

2.2.2. Produtos da Oxidação de Polímeros 25

2.2.3. Mecanismos Sugeridos para a Oxidação de PEG, PAM e 26

2.3. Modelagem Molecular $\quad 34$

2.3.1. Mecânica Molecular $\quad 34$

2.3.2. Teoria da Estrutura Eletrônica $\quad 36$

2.3.3. Teoria do Estado de Transição 39

3. MATERIAIS E METODOLOGIA 42

3.1. Equipamento 42

3.2. Materiais $\quad 44$

3.3. Análises 44

3.4. Procedimento Experimental 46

3.5. Concentrações 47

4. RESULTADOS EXPERIMENTAIS 49

4.1. Experimentos Exploratórios 49

4.1.1. Polietilenoglicol 49

4.1.2. Poliacrilamida 51

4.1.3. Polivinilpirrolidona 52 
4.2. Planejamento experimental 54

4.2.1. Análise de Carbono Orgânico Dissolvido 54

4.2.1.1. Polietilenoglicol-Processo Foto-Fenton 54

4.2.1.2 Polietilenoglicol-Processo $\mathrm{UV} / \mathrm{H}_{2} \mathrm{O}_{2} \quad 58$

4.2.1.3 Poliacrilamida-Processo Foto-Fenton 61

4.2.1.4 Polivinilpirrolidona-Processo Foto-Fenton 64

4.2.2. Análise Estatística 67

4.3. Análises de HPLC 85

$\begin{array}{ll}\text { 4.3.1. Polietilenoglicol } & 87\end{array}$

4.3.2. Poliacrilamida 96

4.4. Análises de GPC 100

4.4.1 Verificação dos efeitos da Fotólise e do $\mathrm{H}_{2} \mathrm{O}_{2}$ para PEG 102

4.4.2 Análises de GPC para PEG 106

4.4.3 Análises de GPC para PAM 119

4.5. Conclusões da Parte Experimental 124

5. MODELAGEM MOLECULAR 127

5.1. Procedimentos Computacionais 127

5.2. Reações para Polietilenoglicol 130

5.3. Resultados para Polietilenoglicol 134

5.4. Discussões para Polietilenoglicol 148

5.5. Reações para Poliacrilamida 155

5.6 Reações para Modelagem Molecular da 162 Poliacrilamida

$\begin{array}{lll}5.7 & \text { Resultados para Poliacrilamida } & 167\end{array}$

5.8 Discussões para Poliacrilamida 193

5.9 Conclusões da Modelagem Molecular 200

6. CONCLUSÕES 203

7. REFERÊNCIAS BIBLIOGRÁFICAS 205

$\begin{array}{ll}\text { APÊNDICES } & 220\end{array}$ 


\section{RESUMO}

Este trabalho visa estudar a viabilidade do emprego de processos oxidativos avançados na degradação de soluções aquosas de polímeros que são comumente utilizados em aplicações industriais e estão presentes em seus efluentes. Para maior entendimento das reações envolvidas no processo oxidativo utilizou-se modelagem molecular nos cálculos de constantes cinéticas.

$\mathrm{Na}$ parte experimental estudou-se a degradação de polietilenoglicol (PEG), polivinilpirrolidona (PVP) e poliacrilamida (PAM) pelos processos foto-Fenton e $\mathrm{UV} / \mathrm{H}_{2} \mathrm{O}_{2}$. Realizaram-se análises de carbono orgânico dissolvido (COD), cromatografia líquida de alto desempenho (HPLC) e cromatografia de permeação em gel (GPC). Observou-se separação de fases para PVP e PAM, o que contribuiu para uma remoção final de COD de até 85\%. Nas análises de HPLC foram detectados como intermediários da reação os ácidos: oxálico, fórmico, malônico e acético. Os resultados de GPC indicaram comportamentos distintos das distribuições de pesos moleculares em função do tempo de reação para os processos $\mathrm{UV} / \mathrm{H}_{2} \mathrm{O}_{2}$ e fotoFenton. No conjunto, os resultados comprovam a viabilidade dos processos estudados na degradação destes polímeros, embora a análise de intermediários para PAM não tenha sido conclusiva quanto à formação de acrilamida.

A modelagem molecular confirma que a reação de abstração de hidrogênio de uma cadeia polimérica pelos radicais alquilperoxila é de fato a etapa mais lenta do processo oxidativo para PEG e PAM. Para PAM os resultados da modelagem mostram que o ataque dos radicais hidroxila acontece preferencialmente no hidrogênio ligado ao carbono terciário e que a abstração de hidrogênio do grupo lateral amida parece pouco viável, ou acontece por um mecanismo diferente do modelado. A reação de formação da acrilamida de acordo com o mecanismo proposto também apresentou uma constante cinética muito baixa, o que está de acordo com os resultados experimentais, já que não foi detectada acrilamida como produto da degradação de poliacrilamida pelos processos foto-Fenton e $\mathrm{UV} / \mathrm{H}_{2} \mathrm{O}_{2}$, com limite de detecção de 50 ppb. 
ABSTRACT

The aim of this work is to apply advanced oxidative processes to study the degradation of industrial wastewater containing water-soluble polymers. Kinetic constants of reactions involved in the oxidation processes were calculated by molecular modeling.

In the experimental part the degradation of polyvinylpirrolidone (PVP), polyacrylamide (PAM) and polyethyleneglycol (PEG) was studied by photo-Fenton and $\mathrm{UV} / \mathrm{H}_{2} \mathrm{O}_{2}$ processes. Intermediates of the degradation processes were identified by HPLC and the molecular weight distribution was monitored by GPC. In the experiments with PAM and PVP phase separation was observed, and more than $85 \%$ of the DOC was removed. The following intermediate acids were identified: acetic, malonic, formic and oxalic. The molecular weight distribution curves measured by GPC indicate that distinct reaction paths exist for each process studied, although the analysis of intermediates formed during the degradation of PAM was not conclusive with respect to acrylamide formation.

The kinetic constants for the reactions involving hydrogen abstraction from PEG chain by hydroxyl and alkylperoxy radicals were calculated. The molecular modeling results confirm that hydrogen abstraction from polymeric chain by alkylperoxy radicals is the determinant step in the oxidation process for PEG and PAM. Polyacrylamide possesses three sites for attack by hydroxyl radicals and the favored path is the abstraction of tertiary hydrogen atom, followed by secondary hydrogen. The abstraction of the amide hydrogen was more difficult. The mechanism proposed for acrylamide formation was not the preferential reaction path. This was expected since acrylamide was not detected in the experiments with a limit detection of $50 \mathrm{ppb}$. 


\section{LISTA DE TABELAS}

$\begin{array}{lll}\text { Tabela 3.1 Níveis das variáveis nos experimentos. } & 48\end{array}$

$\begin{array}{lll}\text { Tabela 4.1 } & \text { Respostas analisadas para PEG, processo foto-Fenton. } & 73\end{array}$

$\begin{array}{llll}\text { Tabela 4.2 Parâmetros estimados e valores } P \text { dos componentes da } & 74\end{array}$ análise de regressão para PEG, processo foto-Fenton.

$\begin{array}{lll}\text { Tabela 4.3 } & \text { Respostas analisadas para PEG, processo } \mathrm{UV} / \mathrm{H}_{2} \mathrm{O}_{2} . & 76\end{array}$

$\begin{array}{llll}\text { Tabela 4.4 Parâmetros estimados e valores } P \text { dos componentes da } & 78\end{array}$ análise de regressão para $\mathrm{PEG}$, processo $\mathrm{UV} / \mathrm{H}_{2} \mathrm{O}_{2}$.

Tabela 4.5 Respostas analisadas para PAM, processo foto-Fenton.

Tabela 4.6 Parâmetros estimados e valores $P$ dos componentes da análise de regressão para PAM, processo foto-Fenton.

Tabela 4.7 Respostas analisadas para PVP, processo foto-Fenton.

Tabela 4.8 Parâmetros estimados e valores $P$ dos componentes da análise de regressão para PVP, processo foto-Fenton.

Tabela 4.9 Níveis das variáveis nos experimentos que foram analisados por GPC e HPLC.

Tabela 4.10 Valores de massa molar média numérica $(\mathrm{Mn})$, massa molar média mássica $(\mathrm{Mw})$, e polidispersidade $(\mathrm{Mw} / \mathrm{Mn})$, para alguns tempos de reação dos experimentos de fotólise e comparativos de $\mathrm{H}_{2} \mathrm{O}_{2}$, para PEG 6000 e $2000 \mathrm{~g}$ $\mathrm{mol}^{-1}$.

Tabela 4.11 Valores de massa molar média numérica $(\mathrm{Mn})$, massa molar média mássica $(\mathrm{Mw})$, e polidispersidade $(\mathrm{Mw} / \mathrm{Mn})$, para alguns tempos de reação, com as condições experimentais $\mathrm{PC}$ e $\mathrm{P} 1$, para o processo foto-Fenton, para PEG.

Tabela 4.12 Valores de massa molar média numérica $(\mathrm{Mn})$, massa molar média mássica $(\mathrm{Mw})$, e polidispersidade $(\mathrm{Mw} / \mathrm{Mn})$, para alguns tempos de reação para os processos fotoFenton e UV/ $\mathrm{H}_{2} \mathrm{O}_{2}$, para PAM.

Tabela 5.1 Características dos recursos computacionais do LCCACCE/USP, utilizados neste trabalho. 
$\begin{array}{lll}\text { Tabela 5.2 } & \text { Espécies participantes das reações de oxidação do PEG. } 133\end{array}$

Tabela 5.3 Resultados para PEG: freqüências vibracionais corrigidas 140 com o fator 0,8929 , obtidas com o modelo HF/6-31G(d), para os reagentes e produtos das reações 5.1 a 5.8 e para as estruturas de transição encontradas.

Tabela 5.4 Resultados para PEG: parâmetros termoquímicos obtidos 141 com o modelo $\mathrm{HF} / 6-31 \mathrm{G}(\mathrm{d})$, corrigidos com o fator 0,9135, para reagentes e produtos das reações 5.1 a 5.8 e para as estruturas de transição encontradas.

Tabela 5.5 Resultados para PEG: energias eletrônicas calculadas 142 somando-se a energia single point, obtidas com diferentes modelos químicos, à energia do ponto zero corrigida com o fator 0,9135 , obtidas com o modelo $\mathrm{HF} / 6-31 \mathrm{G}(\mathrm{d})$, para reagentes e produtos das reações 5.1 a 5.8 .

Tabela 5.6 Resultados para PEG: energias eletrônicas, calculadas somando-se a energia single point, obtidas com diferentes modelos químicos à energia do ponto zero corrigida com o fator 0,9135 , obtidas com o modelo $\mathrm{HF} / 6-31 \mathrm{G}(\mathrm{d})$, para reagentes e produtos das reações de 5.1 a 5.8 e para as estruturas de transição encontradas.

Tabela 5.7 Entalpias de reação para as reações 5.1 a 5.8.

Tabela 5.8 Energia livre de Gibbs de reação para as reações 5.1 a 145 5.8 .

Tabela 5.9 Entropias de reação para as reações 5.1 a 5.8, calculadas com HF/6-31Gd(p).

Tabela 5.10 Barreiras de ativação para as Reações 5.1, 5.3 e 5.7.

Tabela 5.11 Resultados para a Reação 5.1.

Tabela 5.12 Resultados para a Reação 5.3.

Tabela 5.13 Resultados para a Reação 5.7.

Tabela 5.14 Entalpias de reação para as reações 5.1 à 5.8, para as estruturas otimizadas com B3LYP /6-31Gd(p).

Tabela 5.15 Energia livre de Gibbs de reação para as reações 5.1 à 5.8 , para as estruturas otimizadas com B3LYP /6$31 \mathrm{Gd}(\mathrm{p})$. 
Tabela 5.16 Entropias de reação para as reações 5.1 a 5.8, calculadas com HF/6-31Gd(p) e B3LYP/6-31G(d).

Tabela 5.17 Resultados para PAM: freqüências vibracionais corrigidas com o fator 0.8929 , obtidas com o modelo HF/6-31G(d), para os reagentes e produtos das reações 5.40 a 5.50 e para as estruturas de transição encontradas.

Tabela 5.18 Resultados para PAM: freqüências vibracionais corrigidas com o fator 0,8929 , obtidas com o modelo $\mathrm{HF} / 6-31 \mathrm{G}(\mathrm{d})$, para as estruturas de transição encontradas.

Tabela 5.19 Resultados para PAM: freqüências vibracionais corrigidas 179 com o fator 0,8929 , obtidas com o modelo $\mathrm{HF} / 6-31 \mathrm{G}(\mathrm{d})$, para os reagentes e produtos da reação 5.51 de formação da acrilamida.

Tabela 5.20 Resultados para PAM: parâmetros termoquímicos obtidos com o modelo $\mathrm{HF} / 6-31 \mathrm{G}(\mathrm{d})$, corrigidos com o fator 0.9135 , para reagentes e produtos das reações de $5.40 \mathrm{a}$ 5.51e para as estruturas de transição encontradas.

Tabela 5.21 Resultados para PAM: Energias eletrônicas calculadas 181 somando-se a energia single point obtidas com diferentes modelos químicos à energia do ponto zero corrigida com o fator 0,9135 , obtidas com o modelo $\mathrm{HF} / 6-31 \mathrm{G}(\mathrm{d})$, para reagentes e produtos das reações de 5.40 a 5.50 .

Tabela 5.22 Resultados para PAM: Energias eletrônicas calculadas somando-se a energia single point obtidas com diferentes modelos químicos à energia do ponto zero corrigida com o fator 0,9135 , obtidas com o modelo $\mathrm{HF} / 6-31 \mathrm{G}(\mathrm{d})$, para as estruturas de transição das reações 5.40, 5.42, 5.43, $5.45,5.47,5.48$ e 5.50 .

Tabela 5.23 Entalpias de reação para as reações 5.40 a 5.50.

Tabela 5.24 Energia livre de Gibbs de reação para as reações 5.40 a 184 5.50 .

Tabela 5.25 Resultados para PAM: energias eletrônicas, calculadas somando-se a energia single point, obtidas com diferentes modelos químicos à energia do ponto zero corrigida com o fator 0,9135 , obtidas com o modelo $\mathrm{HF} / 6-31 \mathrm{G}(\mathrm{d})$, para a reação 5.51 de formação da acrilamida. 
Tabela 5.26 Entropias de reação para a PAM, calculadas com HF/6- 186 $31 \mathrm{Gd}(\mathrm{p})$.

Tabela 5.27 Barreira de ativação para as reações 5.40, 5.42, 5.43, 187 $5.45,5.47,5,48$ e 5,50 .

$\begin{array}{lll}\text { Tabela 5.28 } & \text { Resultados para a Reaçãol do Caminho } 1 \text { (5.40). } & 188\end{array}$

$\begin{array}{lll}\text { Tabela 5.29 } & \text { Resultados para a Reação3_1 do Caminho } 1 \text { (5.42). } & 188\end{array}$

Tabela 5.30 Resultados para a Reação3_2 do Caminho 1 (5.43). 189

Tabela 5.31 Resultados para a Reação 1 do Caminho 2 (5.45). 189

Tabela 5.32 Resultados para a Reação 3_1 do Caminho 2 (5.47). 190

Tabela 5.33 Resultados para a Reação 3_2 do Caminho 2 (5.48). 190

Tabela 5.34 Resultados para a Reação 1 do Caminho 3 (5.50). 191

Tabela 5.35 Resultados para a reação 5.51 de formação da acrilamida. 192

Tabela 5.36 Comprimentos de ligação para a acrilamida e as 198 distâncias correspondentes na estrutura de transição e no reagente PAM4_Radical.

Tabela 5.37 Constantes cinéticas calculadas com o modelo MP2/6- 200 $31 \mathrm{G}(\mathrm{d}, \mathrm{p}) / / \mathrm{HF} / 6-31 \mathrm{G}(\mathrm{d})$.

Tabela 5.38 Tempo de processamento para a Reação 5.42. Cluster 202 Beowulf, 4GB de memória e 23 GB de disco. 


\section{LISTA DE FIGURAS}

Figura 2.1 Especiação dos complexos de $\mathrm{Fe}(\mathrm{II})$ e $\mathrm{Fe}(\mathrm{III})$ em solução aquosa, em função do pH.(CESQ)

Figura 2.2 (a) Unidade de repetição da poliacrilamida, (b), (c) e (d) sítios de ataque para o radial hidroxila.

Figura 2.3 Esquema de reações para a degradação foto-oxidativa da 32 polivilipirrolidona (Kaczmarek et al., 1998).

Figura 2.4 Figura 2.4. (a) e (b) Possíveis sítios de ataque para os radicais hidroxila na polivinilpirrolidona.

Figura 3.1 Esquema do equipamento.

Figura 3.2 Distribuição espectral da lâmpada de média pressão (Philips HPLN) usada nos experimentos.

Figura 4.1 Carbono Orgânico Dissolvido (COD) em função do tempo de reação para $[\mathrm{PEG}]=550 \mathrm{mgC} \mathrm{L}{ }^{-1}$. o Fotólise, $\mathrm{T}=30^{\circ} \mathrm{C}$; $\mathrm{UV} / \mathrm{H}_{2} \mathrm{O}_{2}, \quad\left[\mathrm{H}_{2} \mathrm{O}_{2}\right]=85,23 \mathrm{mM}, \quad \mathrm{T}=30{ }^{\circ} \mathrm{C} ; \quad \square \mathrm{UV} / \mathrm{H} 2 \mathrm{O} 2$, $\left[\mathrm{H}_{2} \mathrm{O}_{2}\right]=113.6 \mathrm{mM}, \mathrm{T}=30{ }^{\circ} \mathrm{C}$; $\bullet$ Foto-Fenton, $\left[\mathrm{H}_{2} \mathrm{O}_{2}\right]=113.6$ $\mathrm{mM},\left[\mathrm{Fe}^{2+}\right]=1.13 \mathrm{mM}, \mathrm{T}=30{ }^{\circ} \mathrm{C} ; \diamond \mathrm{UV} / \mathrm{H}_{2} \mathrm{O}_{2},\left[\mathrm{H}_{2} \mathrm{O}_{2}\right]=113.6$ $\mathrm{mM}, \mathrm{T}=50^{\circ} \mathrm{C}$.

Figura 4.2 Carbono Orgânico Dissolvido (COD) em função do tempo de reação para $[\mathrm{PAM}]=1000 \mathrm{mgC} \mathrm{L}^{-1}$. o Fotólise, $\mathrm{T}=50{ }^{\circ} \mathrm{C}$; Foto-Fenton, $\left[\mathrm{H}_{2} \mathrm{O}_{2}\right]=281,7 \mathrm{mM},[\mathrm{Fe}(\mathrm{II})]=1,4 \mathrm{mM}, \mathrm{T}=30^{\circ} \mathrm{C}$; Foto-Fenton, $\left[\mathrm{H}_{2} \mathrm{O}_{2}\right]=281,7 \mathrm{mM},[\mathrm{Fe}(\mathrm{II})]=1,4 \mathrm{mM}, \mathrm{T}=50$ ${ }^{\circ} \mathrm{C} ; \boldsymbol{\Delta U V} / \mathrm{H}_{2} \mathrm{O}_{2},\left[\mathrm{H}_{2} \mathrm{O}_{2}\right]=281,7 \mathrm{mM}, \mathrm{T}=30{ }^{\circ} \mathrm{C} ; . \times \mathrm{UV} / \mathrm{H}_{2} \mathrm{O}_{2}$, $\left[\mathrm{H}_{2} \mathrm{O}_{2}\right]=281,7 \mathrm{mM}, \mathrm{T}=50{ }^{\circ} \mathrm{C}$.

Figura 4.3 Carbono Orgânico Dissolvido (COD) em função do tempo de reação para $[\mathrm{PVP}]=4000 \mathrm{mgC} \mathrm{L}^{-1}$. o Foto-Fenton, $\left[\mathrm{H}_{2} \mathrm{O}_{2}\right]=485,9 \mathrm{mM},\left[\mathrm{Fe}^{2+}\right]=2.7 \mathrm{mM}, \mathrm{T}=30^{\circ} \mathrm{C} ; \boldsymbol{\Delta}$ Foto-Fenton, $\left[\mathrm{H}_{2} \mathrm{O}_{2}\right]=485,9 \mathrm{mM},\left[\mathrm{Fe}^{2+}\right]=2.7 \mathrm{mM}, \mathrm{T}=50{ }^{\circ} \mathrm{C} ; \times \mathrm{UV} / \mathrm{H}_{2} \mathrm{O}_{2}$, $\left[\mathrm{H}_{2} \mathrm{O}_{2}\right]=485,7 \mathrm{mM}, \mathrm{T}=30{ }^{\circ} \mathrm{C} ;$; $\mathrm{UV} / \mathrm{H}_{2} \mathrm{O}_{2},\left[\mathrm{H}_{2} \mathrm{O}_{2}\right]=485,9$ $\mathrm{mM}, \mathrm{T}=50^{\circ} \mathrm{C}$. 
Figura 4.4 COD em função do tempo de reação para PEG no processo foto-Fenton. Concentração inicial (a) $1689 \pm 10 \mathrm{mgC} \mathrm{L}^{-1}$ e (b) $592 \pm 17 \mathrm{mgC} \mathrm{L}^{-1} . \diamond++; \square+-; \Delta-+; \bullet$ - - Primeiro sinal nível de $\left[\mathrm{Fe}^{2+}\right]$ e segundo nível de $\left[\mathrm{H}_{2} \mathrm{O}_{2}\right]$.

Figura 4.5 Comparação entre os três experimentos realizados no ponto 58 central para o processo foto-Fenton. $[\mathrm{PEG}]=1000 \mathrm{mgC} \mathrm{L}^{-1}$ $\left[\mathrm{Fe}^{2+}\right]=1,0 \mathrm{mM}$ e $\left[\mathrm{H}_{2} \mathrm{O}_{2}\right]=110 \mathrm{mM}$.

Figura 4.6 COD em função do tempo de reação para $\mathrm{PEG}$, no processo 60

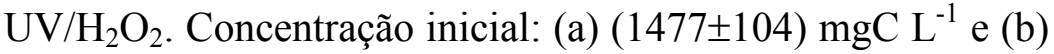

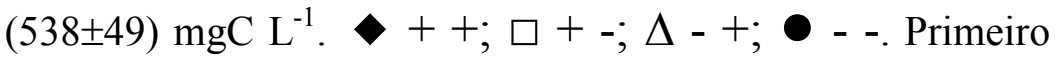
sinal nível de $\mathrm{T}$ e segundo nível de $\left[\mathrm{H}_{2} \mathrm{O}_{2}\right]$.

Figura 4.7 Comparação entre os três experimentos realizados no ponto central, para o processo $\mathrm{UV} / \mathrm{H}_{2} \mathrm{O}_{2}$. $[\mathrm{PEG}]=1000 \mathrm{mgC} \mathrm{L} \mathrm{L}^{-1}$ $[\mathrm{T}]=40^{\circ} \mathrm{C}$ e $\left[\mathrm{H}_{2} \mathrm{O}_{2}\right]=110 \mathrm{mM}$.

Figura 4.8 $\mathrm{pH}$ em função do tempo de reação para $\mathrm{PEG}$, durante o 61 processo $\mathrm{UV} / \mathrm{H}_{2} \mathrm{O}_{2}$. Concentração inicial (a) $1435 \pm 35 \mathrm{mgC} \mathrm{L}{ }^{-}$ ${ }^{1}$ and (b) $562 \pm 26 \mathrm{mgC} \mathrm{L}^{-1}$. $\bullet++$; $\square+$-; $\Delta$ - +; • - -. Primeiro sinal nível de $\mathrm{T}$ e segundo nível de $\left[\mathrm{H}_{2} \mathrm{O}_{2}\right]$.

Figura 4.9 COD em função do tempo de reação para PAM. Concentração 63 inicial: (a) (1477 \pm 104$) \mathrm{mgC} \mathrm{L}^{-1}$ and (b) $(538 \pm 49) \mathrm{mgC} \mathrm{L}^{-1}$. $\diamond++; \square+$-; $\Delta$ - +; $\bullet$ - -. Primeiro sinal nível de [Fe(II)] e segundo nível de $\left[\mathrm{H}_{2} \mathrm{O}_{2}\right]$.

Figura 4.10 Comparação entre os três experimentos realizados no ponto central para o processo Foto-Fenton. $[\mathrm{PAM}]=1000 \mathrm{mgC} \mathrm{L}^{-1}$ $\left[\mathrm{Fe}^{2+}\right]=1,5 \mathrm{mM}$ e $\left[\mathrm{H}_{2} \mathrm{O}_{2}\right]=500 \mathrm{mM}$.

Figura 4.11 COD em função do tempo de reação para PVP. Concentração 66 inicial: (a) (1591 \pm 53$) \mathrm{mgC} \mathrm{L}^{-1}$ e (b) $(546 \pm 16) \mathrm{mgC} \mathrm{L}^{-1}$ $++; \square+$-; $\Delta$ - +; $\bullet$ - -. Primeiro sinal nível de [Fe(II)] e segundo nível de $\left[\mathrm{H}_{2} \mathrm{O}_{2}\right]$.

Figura 4.12 Comparação entre os três experimentos realizados no ponto central para o processo Foto-Fenton. $[\mathrm{PVP}]=1000 \mathrm{mgC} \mathrm{L}^{-1}$ $\left[\mathrm{Fe}^{2+}\right]=1,0 \mathrm{mM} \mathrm{e}\left[\mathrm{H}_{2} \mathrm{O}_{2}\right]=200 \mathrm{mM}$.

Figura 4.13 Respostas utilizadas na análise estatística. [PAM] $=1384 \mathrm{mgC}$ $\mathrm{L}^{-1},[\mathrm{Fe}(\mathrm{II})]=0.5 \mathrm{mM}$ e $\left[\mathrm{H}_{2} \mathrm{O}_{2}\right]=300 \mathrm{mM}$.. 
Figura 4.14 Pareto padronizado para PEG, processo foto-Fenton.

Figura 4.15 Pareto padronizado para $\mathrm{PEG}$, processo $\mathrm{UV} / \mathrm{H}_{2} \mathrm{O}_{2}$.

Figura 4.16 Pareto padronizado para PAM, processo foto-Fenton.

Figura 4.17 Pareto padronizado para PVP, processo foto-Fenton.

Figura 4.18 Cromatograma obtido com o método para separação de ácidos 85 orgânicos. Concentração de $300 \mu \mathrm{g} \mathrm{mL} \mathrm{m}^{-1}, \lambda=220 \mathrm{~nm}$.

Figura 4.19 Cromatograma obtido com o método para separação de oxamida, acrilamida, ácido oxálico e ácido oxâmico. Concentração de $100 \mu \mathrm{g} \mathrm{mL}{ }^{-1}, \lambda=205 \mathrm{~nm}$.

Figura 4.20

COD em função do tempo de reação para PEG. PC:

$\mathrm{Mw}=20000 \mathrm{~g} \mathrm{~mol}^{-1}$; $\mathrm{Mw}=6000 \mathrm{~g} \mathrm{~mol}^{-1} ; \mathrm{P} 1: \Delta \mathrm{Mw}=6000$ $\mathrm{g} \mathrm{mol}^{-1} ; * \mathrm{Mw}=20000 \mathrm{~g} \mathrm{~mol}^{-1}$.

Figura 4.21 Variação do pH em função do tempo para PEG de 6000 e $20000 \mathrm{~g} \mathrm{~mol}{ }^{-1}$, processo $\mathrm{UV} / \mathrm{H}_{2} \mathrm{O}_{2}$, nas condições experimentais PC.

Figura 4.22 Concentração dos ácidos detectados durante a oxidação do PEG para o processo foto-Fenton. $\mathrm{Mw}=6000 \mathrm{~g} \mathrm{~mol}^{-1}$ : (a) $\mathrm{PC} \mathrm{e}$

(c) P1. $\mathrm{Mw}=20000 \mathrm{~g} \mathrm{~mol}^{-1}$ (b) PC e (d) P1. Ácidos: fórmico, - acético, $\bigcirc$ glicólico.

Figura 4.23 Concentração dos ácidos detectados durante a oxidação do 92 PEG para o processo $\mathrm{UV} / \mathrm{H}_{2} \mathrm{O}_{2}$. $\mathrm{Mw}=6000 \mathrm{~g} \mathrm{~mol}^{-1}$ : (a) $\mathrm{PC} \mathrm{e}$ (c) P1. Mw=20000 $\mathrm{g} \mathrm{mol}^{-1}$ (b) PC e (d) P1. Ácidos: fórmico, - acético, $\bullet$ malônico.

Figura 4.24

TOC medido e calculado para PEG. TOC medido:

Fenton, $\square \mathrm{UV} / \mathrm{H}_{2} \mathrm{O}_{2}$. TOC calculado: $\bullet$ foto-Fenton, $\Delta$ $\mathrm{UV} / \mathrm{H} 2 \mathrm{O} 2$

Figura 4.25 Possível caminho para mineralização de etilenoglicol. 94 (McGinnes et al., 2000).

Figura 4.26 Reações propostas para a formação e oxidação dos ácidos 95 acético e malônico. (Mantzavinos et al., 1996). 
Figura 4.27 COD em função do tempo de reação para PAM. • Foto-

Fenton. $* \mathrm{UV} / \mathrm{H}_{2} \mathrm{O}_{2}$. o Valores de $\mathrm{pH}$ em função do tempo para o processo $\mathrm{UV} / \mathrm{H}_{2} \mathrm{O}_{2}$.

Figura 4.28 Concentração de ácidos e oxamida em função do tempo 98 durante a degradação de PAM (a) e (b) Foto-Fenton. (c) $\mathrm{UV} / \mathrm{H}_{2} \mathrm{O}_{2}$. - Oxamida. Ácidos: $\square$ Fórmico;• Malônico; $\Delta$ Oxálico.

Figura 4.29

TOC medido e calculado para PAM. TOC medido:

Fenton, $\square \mathrm{UV} / \mathrm{H}_{2} \mathrm{O}_{2}$. TOC calculado: • foto-Fenton, $\Delta$ $\mathrm{UV} / \mathrm{H}_{2} \mathrm{O}_{2}$.

Figura 4.30 Curva de calibração, com padrões de PEG, desenvolvida para 101 as análises de GPC.

Figura 4.31 Cromatogramas obtidos por GPC para PEG 6000, com as 101 condições do PC, para a amostra de 60 minutos.

Figura 4.32 COD em função do tempo para PEG. Fotólise: $\bullet \mathrm{Mw}=6000 \square$ 102 $\mathrm{Mw}=20000 \mathrm{~g} \mathrm{~mol}^{-1}$. Comparativo de $\mathrm{H}_{2} \mathrm{O}_{2}: \Delta \mathrm{Mw}=6000 \times$ $\mathrm{Mw}=20000 \mathrm{~g} \mathrm{~mol}^{-1}$.

Figura 4.33 Distribuição de pesos moleculares para PEG $6000 \mathrm{~g} \mathrm{~mol}^{-1}$. (a) 104 Comparativo de $\mathrm{H}_{2} \mathrm{O}_{2}$ (b) Fotólise.

Figura 4.34 Distribuição de pesos moleculares para PEG $20000 \mathrm{~g} \mathrm{~mol}^{-1}$. 105 (a) Comparativo de $\mathrm{H}_{2} \mathrm{O}_{2}$ (b) Fotólise.

Figura 4.35 Cromatogramas obtidos por GPC para PEG $6000 \mathrm{~g} \mathrm{~mol}^{-1}$, com 109 as condições experimentais do ponto central. Processos: (a) foto-Fenton, (b) $\mathrm{UV} / \mathrm{H}_{2} \mathrm{O}_{2}$.

Figura 4.36 Distribuição de pesos moleculares para PEG $6000 \mathrm{~g} \mathrm{~mol}^{-1}$, 110 com as condições experimentais do ponto central. Processos (a) Foto-Fenton, (b) $\mathrm{UV} / \mathrm{H}_{2} \mathrm{O}_{2}$.

Figura 4.37 Cromatogramas obtidos por GPC para PEG $20000 \mathrm{~g} \mathrm{~mol}^{-1}$, com as condições experimentais do ponto central. Processos: (a) foto-Fenton, (b) $\mathrm{UV} / \mathrm{H}_{2} \mathrm{O}_{2}$.

Figura 4.38 Distribuição de pesos moleculares para PEG $6000 \mathrm{~g} \mathrm{~mol}^{-1}$, 113 com as condições experimentais do ponto central. Processos (a) Foto-Fenton, (b) $\mathrm{UV} / \mathrm{H}_{2} \mathrm{O}_{2}$. 
Figura 4.39 Cromatogramas obtidos por GPC para PEG $6000 \mathrm{~g} \mathrm{~mol}^{-1}$, com as condições experimentais do ponto P1. Processos: (a) fotoFenton, (b) $\mathrm{UV} / \mathrm{H}_{2} \mathrm{O}_{2}$.

Figura 4.40 Distribuição de pesos moleculares para PEG $6000 \mathrm{~g} \mathrm{~mol}^{-1}$, 116 com as condições experimentais do ponto P1. Processos (a) Foto-Fenton, (b) $\mathrm{UV} / \mathrm{H}_{2} \mathrm{O}_{2}$.

Figura 4.41 Cromatogramas obtidos por GPC para PEG $20000 \mathrm{~g} \mathrm{~mol}^{-1}$, com as condições experimentais do ponto P1. Processos: (a) foto-Fenton, (b) $\mathrm{UV} / \mathrm{H}_{2} \mathrm{O}_{2}$.

Figura 4.42 Distribuição de pesos moleculares para PEG $20000 \mathrm{~g} \mathrm{~mol}^{-1}$, 118 com as condições experimentais do ponto. Processos (a) FotoFenton, (b) $\mathrm{UV} / \mathrm{H}_{2} \mathrm{O}_{2}$.

Figura 4.43 Cromatogramas obtidos por GPC para PAM $10000 \mathrm{~g} \mathrm{~mol}^{-1}$ Processos: (a) foto-Fenton, (b) $\mathrm{UV} / \mathrm{H}_{2} \mathrm{O}_{2}$.

Figura 4.44 Distribuição de pesos moleculares para PAM $10000 \mathrm{~g} \mathrm{~mol}^{-1}$. Processos (a) Foto-Fenton, (b) $\mathrm{UV} / \mathrm{H}_{2} \mathrm{O}_{2}$.

Figura 5.1 Esquema da seqüência de cálculos realizada na modelagem 129 molecular das reações.

Figura 5.2 Geometria do Di-etilenoglicol otimizada com o modelo químico $\mathrm{HF} / 6-31 \mathrm{G}(\mathrm{d})$.

Figura 5.3 Geometria do radical alquila otimizada com o modelo 136 químico HF/6-31G(d).

Figura 5.4 Geometria do radical alquilperoxila otimizada com o modelo químico $\mathrm{HF} / 6-31 \mathrm{G}(\mathrm{d})$.

Figura 5.5 Geometria do hidroperóxido secundário otimizada com o modelo químico $\mathrm{HF} / 6-31 \mathrm{G}(\mathrm{d})$.

Figura 5.6 Geometria do radical alcoxila otimizada com o modelo 137 químico $\mathrm{HF} / 6-31 \mathrm{G}(\mathrm{d})$.

Figura 5.7 Geometria do etilenoglicol monoformato otimizada com o modelo químico HF/6-31G(d).

Figura 5.8 Geometria dos radicais: (a) alquila primário e (b) 138 alquilperoxila primário, otimizadas com o modelo químico $\mathrm{HF} / 6-31 \mathrm{G}(\mathrm{d})$. 
Figura 5.9 Geometria dos radicais: (a) hidroperóxido primário e (b) 138 alcoxila primário, otimizadas com o modelo químico HF/6$31 \mathrm{G}(\mathrm{d})$.

Figura 5.10 Geometria da estrutura de transição da Reação 5.1, otimizada 138 com o modelo químico HF/6-31G(d).

Figura 5.11 Geometria da estrutura de transição da Reação 5.3 otimizada com o modelo químico HF/6-31G(d).

Figura 5.12 Geometria da estrutura de transição da Reação 5.7 otimizada com o modelo químico $\mathrm{HF} / 6-31 \mathrm{G}(\mathrm{d})$.

Figura 5.13 Energias calculadas para o Radical Alquila com a estrutura otimizada com o modelo HF/6-31g(d).

Figura 5.14 Possíveis caminhos de reação para a poliacrilamida, 162 considerando três locais para abstração de hidrogênio.

Figura 5.15 Geometria do 2-metil pentanodiamida otimizada com o 169 modelo químico $\mathrm{HF} / 6-31 \mathrm{G}(\mathrm{d})$.

Figura 5.16 Geometria do radical PAM_alquila1 otimizada com o modelo químico $\mathrm{HF} / 6-31 \mathrm{G}(\mathrm{d})$.

Figura 5.17 Geometria do radical PAM_alquilperoxila1 otimizada com o modelo químico $\mathrm{HF} / 6-31 \mathrm{G}(\mathrm{d})$.

Figura 5.18 Geometria do PAM_hidroperoxido1 secundário otimizada 170 com o modelo químico HF/6-31G(d).

Figura 5.19 Geometria do radical PAM_alquila2 otimizada com o modelo 170 químico $\mathrm{HF} / 6-31 \mathrm{G}(\mathrm{d})$.

Figura 5.20 Geometria do radical PAM_alquilperoxila2 otimizada com o modelo químico $\mathrm{HF} / 6-31 \mathrm{G}(\mathrm{d})$.

Figura 5.21 Geometria do PAM_hidroperoxido2 secundário otimizada 171 com o modelo químico HF/6-31G(d).

Figura 5.22 Geometria do radical PAM alquila3 otimizada com o modelo químico $\mathrm{HF} / 6-31 \mathrm{G}(\mathrm{d})$.

Figura 5.23 Geometria da estrutura de transição para a reação 1 caminho1, PAM1_Reação1_TS, otimizada com o modelo químico HF/6$31 \mathrm{G}(\mathrm{d})$. 
Figura 5.24 Geometria da estrutura de transição da reação1 caminho2, 172 PAM2_Reação1_TS, otimizada com o modelo químico HF/6$31 \mathrm{G}(\mathrm{d})$.

Figura 5.25 Geometria da estrutura de transição da reaçãol caminho3, PAM3_Reação1_TS, otimizada com o modelo químico HF/6$31 \mathrm{G}(\mathrm{d})$.

Figura 5.26 Geometria da estrutura de transição da reação3 caminho1, PAM1_Reação3_1_TS, otimizada com o modelo químico $\mathrm{HF} / 6-31 \mathrm{G}(\mathrm{d})$.

Figura 5.27 Geometria da estrutura de transição da reação3 caminho1, PAM1_Reação3_2_TS, otimizada com o modelo químico $\mathrm{HF} / 6-31 \mathrm{G}(\mathrm{d})$.

Figura 5.28 Geometria da estrutura de transição da reação3 caminho2, PAM2_Reação3_1_TS, otimizada com o modelo químico $\mathrm{HF} / 6-31 \mathrm{G}(\mathrm{d})$.

Figura 5.29 Geometria da estrutura de transição da reação3 caminho2, PAM2_Reação3_2_TS, otimizada com o modelo químico $\mathrm{HF} / 6-31 \mathrm{G}(\mathrm{d})$.

Figura 5.30 Geometria acrilamida, otimizada com o modelo químico $\mathrm{HF} / 6-31 \mathrm{G}(\mathrm{d})$.

Figura 5.31 Geometria do radical alquila PAM4_Radical otimizado com o modelo químico HF/6-31G(d).

Figura 5.32 Geometria do radical alquila PAM3_Radical otimizado com o 175 modelo químico $\mathrm{HF} / 6-31 \mathrm{G}(\mathrm{d})$.

Figura 5.33 Geometria da estrutura de transição da reação de formação da acrilamida, otimizada com o modelo químico HF/6-31G(d).

Figura 5.34 Diferenças de energia eletrônica entre as estruturas de

Figura 5.35 Geometria da acrilamida com os valores de comprimento de ligação. 


\section{LISTA DE SÍMBOLOS}

\begin{tabular}{|c|c|}
\hline AM1 & Modelo Austin 1 \\
\hline B3LYP & $\begin{array}{l}\text { Método híbrido HF/DTF, usando a correlação de funcional de } \\
\text { Becke-Lee-Yang-Parr }\end{array}$ \\
\hline $\mathrm{CG}$ & Cromatografia gasosa \\
\hline $\mathrm{CCD}, \mathrm{CCSD}$ & Métodos Coupled Cluster \\
\hline $\mathrm{CMC}$ & Carboximetilcelulose \\
\hline CONAMA & Conselho Nacional de Meio Ambiente \\
\hline COD & Teor de carbono orgânico dissolvido $\left(\mathrm{mgC} \mathrm{L}^{-1}\right)$ \\
\hline DEG & Dietilenoglicol \\
\hline DQO & Demanda química de oxigênio $\left(\mathrm{mgO}_{2} / \mathrm{L}\right)$ \\
\hline DTF & Teoria do Funcional de Densidade \\
\hline EPA & Environmental Protection Agency \\
\hline$[\mathrm{Fe}(\mathrm{II})]$ & Concentração de íons ferrosos (mM) \\
\hline $\mathrm{HF}$ & Hartree-Fock \\
\hline$\left[\mathrm{H}_{2} \mathrm{O}_{2}\right]$ & Concentração de peróxido de hidrogênio (mM) \\
\hline HPLC & Cromatografia líquida de alta efíciência \\
\hline GPC & Cromatografia de permeação em gel \\
\hline LCMS & Cromatografia líquida acoplada à massa \\
\hline LSI & Intensidade de espalhamento de luz \\
\hline $\operatorname{mgC~L}{ }^{-1}$ & Unidade de concentração mássica de carbono $\left(\mathrm{mg} \mathrm{L}^{-1}\right)$ \\
\hline MNDO & Método: modified neglect of differential overlap \\
\hline MP & Möller-Plesset \\
\hline $\mathrm{Mw}$ & Massa molar média mássica $\left(\mathrm{g} \mathrm{mol}^{-1}\right)$ \\
\hline $\mathrm{Mn}$ & Massa molar média numérica $\left(\mathrm{g} \mathrm{mol}^{-1}\right)$ \\
\hline PAA & Ácido Poliacrílico \\
\hline PAM & Poliacrilamida \\
\hline $\mathrm{PC}$ & Ponto central \\
\hline PEG & Polietilenoglicol \\
\hline PEO & Óxido de Polietileno \\
\hline PMA & Ácido Polimetacrílico \\
\hline PM3 & Modelo de Parametrização 3 \\
\hline POA & Processos oxidativos avançados \\
\hline
\end{tabular}




$\begin{array}{ll}\text { [Pol] } & \text { Concentração de polímero (PEG, PAM ou PVP) }\left(\mathrm{mgC} \mathrm{L}^{-1}\right) \\ \text { PPG } & \text { Polipropilenoglicol } \\ \text { ppb } & \text { Concentração mássica em partes por bilhão }\left(\mathrm{mg} \mathrm{L}^{-1}\right) \\ \text { ppm } & \text { Concentração mássica em partes por milhão }\left(\mu \mathrm{g} \mathrm{L}^{-1}\right) \\ \text { PVA } & \text { Álcool Polivinílico } \\ \text { PVP } & \text { Polivinilpirrolidona } \\ \text { QCISD } & \text { Método de Interação de Configurações Quadráticas } \\ \text { SPE } & \text { Extração de Fase Sólida } \\ \text { TOC } & \text { Carbono Orgânico Total } \\ \text { TST } & \text { Teoria do Estado de Transição } \\ \text { UV } & \text { Radiação ultravioleta } \\ \text { UV-A } & \text { Radiação ultravioleta na região espectral de } 320-400 \mathrm{~nm} \\ \text { UV-B } & \text { Radiação ultravioleta na região espectral de } 290-320 \mathrm{~nm} \\ \text { UV-C } & \text { Radiação ultravioleta na região espectral de } 100 \text { - 290nm } \\ \text { VIS } & \text { Espectro visível } \\ \text { WAO } & \text { Oxidação via Úmida (Wet Air Oxidation) } \\ \text { WVN } & \text { Correlação de funcional de Wilk, Vosko e Nusair }\end{array}$




\section{INTRODUÇÃO}

A indústria no século 21, especialmente a química, tem sua atenção voltada para questões como globalização, retorno financeiro aos acionistas, uso eficiente do capital, minimização do impacto ambiental, aumento do retorno de investimentos, aumento e uso mais eficiente da pesquisa e emprego eficiente de pessoas. A indústria química alcançará estes objetivos investigando o uso e aplicações de novas tecnologias (Dixon e Feller, 1999).

Uma grande área de investimento é a pesquisa de novas tecnologias para o tratamento de agentes poluidores de origem industrial que muitas vezes são não biodegradáveis ou até biocidas. A questão ambiental tem se tornado relevante na medida em que a consciência ecológica toma força política e os órgãos governamentais passam a cobrar dos setores privados e públicos o cumprimento da legislação ambiental (Silva, 1998).

Outra nova tecnologia que tem um papel importante na indústria química é a modelagem e simulação, principalmente devido ao desenvolvimento dos computadores, o que permitiu um avanço em algoritmos e programas computacionais. Dentro desta área de modelagem e simulação a sub-área de química computacional é uma das maiores beneficiadas com tais avanços. A química computacional fornece o entendimento qualitativo do comportamento químico e estas informações podem direcionar experimentos. Por outro lado, informações quantitativas obtidas por cálculos computacionais podem ser usadas para substituir dados experimentais não confiáveis ou mesmo estimar aqueles muito difíceis de serem obtidos (Dixon e Feller, 1999).

O principal objetivo deste trabalho é a integração de uma ferramenta teórica, que é a química computacional, com o desenvolvimento experimental de uma tecnologia alternativa e não convencional voltada para o tratamento de efluentes industriais, conhecida como "Processos de Oxidação Avançados".

O modo como a pesquisa foi conduzida e os resultados são dispostos nos próximos capítulos da seguinte forma:

- Capítulo 2. Revisão bibliográfica, abrangendo processos oxidativos avançados e principalmente sua aplicação aos polímeros de interesse deste 
trabalho: polivinilpirrolidona (PVP), poliacrilamida (PAM) e polietilenoglicol (PEG); processo oxidativo de polímeros; modelagem molecular e cálculo de constantes cinéticas pela Teoria do Estado de Transição.

- Capítulo 3. Materiais e Metodologia, com a descrição do equipamento, procedimento experimental, materiais e demais informações da parte experimental.

- Capítulo 4. Apresenta resultados da parte experimental para os três polímeros estudados, para dois processos: $\mathrm{UV} / \mathrm{H}_{2} \mathrm{O}_{2}$ e foto-Fenton. Está dividido em 5 partes: experimentos exploratórios; planejamento experimental e respectivos resultados, mostrando os resultados em termos de carbono orgânico dissolvido (COD) e análise estatística; análises de cromatografia líquida de alto desempenho (HPLC); análises de cromatografia de permeação em gel (GPC) e conclusões da parte experimental.

- Capítulo 5. Apresenta os resultados da modelagem molecular: escolha das moléculas representativas das cadeias poliméricas, determinação das reações modeladas para PEG e PAM e o cálculo das constantes cinéticas, terminando com as conclusões da parte de modelagem molecular.

- Capítulo 6. Conclusões finais do trabalho. 


\section{REVISÃO BIBLIOGRÁFICA}

O crescimento populacional e o aumento por demandas industriais e agrícolas vêm agravando o problema da disponibilidade mundial de água. Se o ritmo do crescimento da poluição continuar acompanhando o da população, a Terra poderá perder 18 mil quilômetros quadrados de águas doces até 2050 (Como Cuidar da Nossa Água, 2004). A atividade industrial está, inevitavelmente, associada a uma certa degradação do ambiente, uma vez que não existem processos de fabricação totalmente limpos. A periculosidade das emissões industriais varia com o tipo de indústria, matérias usadas, processos de fabricação empregados, produtos fabricados ou substâncias produzidas que contenham componentes que afetam o ecossistema. O controle da poluição das águas envolve ampliar o alcance do tratamento dos efluentes gerados por esgotos domésticos, agricultura e indústria; descobrir substâncias menos nocivas ao meio-ambiente; o desenvolvimento de processos que produzam bens de consumo com um mínimo de rejeitos e um máximo de reciclagem e o desenvolvimento de novas tecnologias para tratamento de efluentes.

O controle da poluição das águas pode ser feito por tecnologia de transferência de fase, na qual os poluentes da fase aquosa são transferidos para a fase sólida, por exemplo, pela adição de carvão ativado. Porém a poluição não é eliminada, apenas deixa de ser veiculada pelo meio aquoso para ser transformada em resíduos sólidos ou ser emitida para a atmosfera. Também podem ser usadas tecnologias destrutivas, que se baseiam na oxidação química, podendo levar à mineralização completa da matéria orgânica, tendo como vantagem a ausência de sub-produtos e como desvantagem o alto custo de tais processos. Entretanto, esses processos de oxidação podem ser aplicados visando tratar parcialmente poluentes recalcitrantes, encaminhando-os para um posterior tratamento biológico convencional e mais barato. Neste sentido, têm sido pesquisados processos de degradação oxidativos de compostos orgânicos aplicando métodos catalíticos ou fotoquímicos geralmente chamados de processos de oxidação avançados (POA). 


\subsection{Processos Oxidativos Avançados}

Processos Oxidativos Avançados (POA) são definidos como aqueles capazes de gerar radicais hidroxila em quantidades suficientes para oxidar as substâncias químicas presentes em efluentes. Estes processos podem ser homogêneos ou heterogêneos, e utilizar ou não a radiação UV. Alguns exemplos de POA: cavitação, gerada por meio de radiação ultra-sônica ou por constrições (Gogate e Pandit, 2001a); oxidação fotocatalítica utilizando semicondutores, por exemplo, $\mathrm{TiO}_{2}$, (Bhatkhande et al., 2002); reações de Fenton (Fenton, 1894) e foto-Fenton (Lei et al., 1998; Pérez et al., 2002; Teixeira et al., 2004); processos envolvendo peróxido de hidrogênio e ozônio: $\mathrm{UV} / \mathrm{H}_{2} \mathrm{O}_{2}, \mathrm{O}_{3} / \mathrm{UV}, \mathrm{O}_{3} / \mathrm{H}_{2} \mathrm{O}_{2} / \mathrm{UV}, \mathrm{O}_{3} / \mathrm{H}_{2} \mathrm{O}_{2}$ (Balcioglu e Arslan, 2001; Andreozzi et al., 2000); oxidação via úmida (Matzavinos et al., 1996); oxidação com água em estado super-crítico (Ding et al., 1996); irradiação direta do contaminante ou fotólise, irradiação com feixes de elétrons, raios $\mathrm{X}$ ou raios gama; descarga elétrica não térmica e oxidação química com hipoclorito (Szpyrkowicz, et al., 2001).

Os radicais hidoxila $\left(\mathrm{HO}^{\bullet}\right)$ são potentes agentes oxidantes, com potencial de oxidação de aproximadamente $2,80 \mathrm{~V}$. Reagem de forma rápida e não seletiva com a maioria dos poluentes orgânicos em solução aquosa, degradando-os. O principal mecanismo da reação dos radicais $\mathrm{HO}^{\bullet}$ é a abstração de hidrogênio (reação 2.1), formando radicais orgânicos que reagem com o oxigênio molecular gerando radicais peroxila (reação 2.2), que iniciam reações de degradação oxidativas produzindo compostos intermediários e produtos finais, podendo chegar até mesmo a $\mathrm{CO}_{2}$ e água (Legrini et al, 1993).

$$
\begin{aligned}
& \mathrm{HO}^{\bullet}+\mathrm{RH} \rightarrow \mathrm{R}^{\bullet}+\mathrm{H}_{2} \mathrm{O} \\
& \mathrm{R}^{\bullet}+\mathrm{O}_{2} \rightarrow \mathrm{RO}_{2}^{\bullet}
\end{aligned}
$$

Uma característica de qualquer processo de degradação, incluindo os POA, é a possibilidade de formação de sub-produtos com toxicidade maior que a do contaminante original. Mesmo que tais sub-produtos possam ser mineralizados 
completamente pelos POA, as velocidades podem ser baixas, tornando o processo economicamente inviável (Chang e Young, 2000).

A seguir, serão descritos com mais detalhes os processos foto-Fenton e $\mathrm{UV} / \mathrm{H}_{2} \mathrm{O}_{2}$, que foram os estudados neste trabalho.

\subsubsection{Processo $\mathrm{UV} / \mathrm{H}_{2} \mathrm{O}_{2}$}

$\mathrm{O}$ processo UV/ $\mathrm{H}_{2} \mathrm{O}_{2}$ usa a radiação ultravioleta para quebrar a ligação $\mathrm{O}-\mathrm{O}$ do peróxido de hidrogênio e gerar os radicais hidroxila (reação 2.3), que podem oxidar a matéria orgânica (reação 2.1), iniciarem uma reação de degradação do peróxido de hidrogênio (reações 2.4 e 2.5) ou pode haver recombinação de radicais formando novamente $\mathrm{H}_{2} \mathrm{O}_{2}$ (reações 2.6 e 2.7) (Chang e Young, 2000).

$$
\begin{aligned}
& \mathrm{H}_{2} \mathrm{O}_{2} \stackrel{\mathrm{hv}}{\longrightarrow} \mathrm{HO}^{\bullet}+\mathrm{HO}^{\bullet} \\
& \mathrm{H}_{2} \mathrm{O}_{2}+\mathrm{HO}_{2}^{\bullet} \longrightarrow \mathrm{HO}^{\bullet}+\mathrm{O}_{2}+\mathrm{H}_{2} \mathrm{O} \\
& \mathrm{H}_{2} \mathrm{O}_{2}+\mathrm{HO}^{\bullet} \longrightarrow \mathrm{HO}_{2}^{\bullet}+\mathrm{H}_{2} \mathrm{O} \\
& 2 \mathrm{HO}^{\bullet} \rightarrow \mathrm{H}_{2} \mathrm{O}_{2} \\
& 2 \mathrm{HO}_{2}^{\bullet} \rightarrow \mathrm{H}_{2} \mathrm{O}_{2}+\mathrm{O}_{2}
\end{aligned}
$$

O peróxido de hidrogênio é foto-reativo na faixa de comprimento de onda de 185 a $400 \mathrm{~nm}$, embora comprimentos de onda na faixa de 200 a $280 \mathrm{~nm}$ resultem em uma produção maior de radicais hidroxila. A absortividade molar do peróxido de hidrogênio a $253,7 \mathrm{~nm}$ é $19,6 \mathrm{M}^{-1} \mathrm{~cm}^{-1}$ e o rendimento quântico para a produção de $\mathrm{HO}^{\bullet}$ partindo de $\mathrm{H}_{2} \mathrm{O}_{2}$ é de aproximadamente 1 a 253,7, 301 e $351 \mathrm{~nm}$ (Chang e Young, 2000).

Quando em excesso no meio reacional, o peróxido de hidrogênio pode atuar como "seqüestrante" de radicais $\mathrm{HO}^{\bullet}$ (reação 2.5), por isso sua concentração deve ser cuidadosamente determinada. A magnitude do valor ótimo para a concentração de $\mathrm{H}_{2} \mathrm{O}_{2}$ depende da concentração e do tipo de efluente a ser tratado, isto é, da constante cinética de velocidade para a reação entre os radicais livres e o poluente e da 
constante cinética para as reações de recombinação de radicais. A presença de compostos que absorvam fortemente a luz incidente pode levar a um aumento da quantidade de peróxido necessária para realizar a oxidação na extensão desejada. Quando não há indicações na literatura, é necessário realizar experimentos em escala de laboratório para se determinar a concentração ótima de $\mathrm{H}_{2} \mathrm{O}_{2}$. Outras substâncias, como ácido húmico, carbonatos e bicarbonatos, também podem reagir com os radicais hidroxila, retirando-os do meio reacional, comprometendo assim a eficiência global do processo. Se a concentração desses agentes seqüestrantes de radicais for muito alta pode ser necessário um pré-tratamento para reduzir seus níveis a valores que não interfiram no processo $(\mathrm{Ku}$ et al, 1998). O efeito de seqüestrantes de radicais, principalmente os iônicos, também pode ser minimizado, operando-se a baixos valores de $\mathrm{pH}$ (Gogate e Pandit, 2001b).

Do ponto de vista do projeto de reatores, a modelagem cinética do processo $\mathrm{UV} / \mathrm{H}_{2} \mathrm{O}_{2}$ é o fator mais importante a ser desenvolvido. Um modelo cinético realista deve contemplar todas as reações fotoquímicas e químicas (o número pode estar entre 50 e 100), além de incluir efeitos da presença dos seqüestrantes de radicais e da variação do pH durante o processo (Gogate e Pandit, 2001b).

Exemplos de aplicação do processo $\mathrm{UV} / \mathrm{H}_{2} \mathrm{O}_{2}$ em estudos de degradação de algumas substâncias são: fenol (De et al., 1997); derivados clorofenólicos (Benitez et al., 2001); benzotiazol, 2-mercaptobenzotiazol e 2-hidroxibenzotiazol (Andreozzi et al., 2001); purificação de águas subterrâneas contaminadas com tri e tetracloroetileno (Hirvonen et al., 1996); e tratamento de efluentes reais provenientes do processamento de resinas fotossensíveis para fabricação de chips (Hou et al., 2001).

\subsubsection{Processo foto-Fenton}

O processo Fenton, ou Fenton-térmico, descoberto em 1894 por J. H. Fenton, (Fenton, 1894), promove a oxidação de moléculas orgânicas usando um catalisador de ferro solúvel e peróxido de hidrogênio, não sendo necessárias altas pressões, altas temperaturas ou equipamentos complicados (Bigda, 1995).

Harber e Weiss (1934) propuseram um mecanismo simples para este processo, baseado em uma reação redox, em que o $\mathrm{Fe}(\mathrm{II})$ é oxidado a $\mathrm{Fe}$ (III) e o peróxido reduzido ao íon hidroxila, gerando ao mesmo tempo o radical hidroxila, 
(reação 2.8) $\left(\mathrm{k}_{2.8}=76 \mathrm{~L} \mathrm{~mol}^{-1} \mathrm{~s}^{-1}\right.$, Walling, 1975). O íon Fe(III) produzido pela reação (2.8) é reduzido na reação (2.9) $\left(\mathrm{k}_{2.9}=0,01-0,02 \mathrm{~L} \mathrm{~mol}^{-1} \mathrm{~s}^{-1}\right.$, Walling e Goosen, 1973), porém esta etapa é mais lenta e acaba sendo o passo determinante da cinética global.

$$
\begin{aligned}
& \mathrm{Fe}_{\mathrm{aq}}^{2+}+\mathrm{H}_{2} \mathrm{O}_{2} \rightarrow \mathrm{Fe}_{\mathrm{aq}}^{3+}+\mathrm{HO}^{\bullet}+\mathrm{OH}^{-} \\
& \mathrm{Fe}_{\mathrm{aq}}^{3+}+\mathrm{H}_{2} \mathrm{O}_{2} \rightarrow \mathrm{Fe}_{\mathrm{aq}}^{2+}+\mathrm{HO}_{2}^{\bullet}+\mathrm{H}^{+}
\end{aligned}
$$

Esta reação de redução térmica apresenta as seguintes etapas, segundo Bossmann et al. (1998): formação de um complexo hidratado entre os íons $\mathrm{Fe}_{\mathrm{aq}}^{3+} \mathrm{e}$ $\mathrm{H}_{2} \mathrm{O}_{2}$, conforme a reação 2.10; redução do $\mathrm{Fe}_{\mathrm{aq}}^{3+}$ para $\mathrm{Fe}_{\mathrm{aq}}^{2+}$ nesse complexo (reação 2.11) $\left(\mathrm{k}_{2.11}=0,0201 \mathrm{e} \mathrm{k}_{-2.11}=1,2 \times 10^{6} \mathrm{~L} \mathrm{~mol}^{-1} \mathrm{~s}^{-1}\right)$; reação de transferência de elétrons, entre um segundo complexo aquoso $\mathrm{Fe}^{3+}\left(\left[\mathrm{Fe}(\mathrm{OH})\left(\mathrm{H}_{2} \mathrm{O}\right)_{5}\right]^{2+}\right)$ e o radical hidroperoxila $\mathrm{HO}_{2}{ }^{\bullet}$ que também regenera a espécie $\mathrm{Fe}^{2+}\left(\left[\mathrm{Fe}(\mathrm{OH})\left(\mathrm{H}_{2} \mathrm{O}\right)_{5}\right]^{+}\right)$, de acordo com a reação (2.12) $\left(\mathrm{k}_{2.12}=2,8 \times 10^{4} \mathrm{~L} \mathrm{~mol}^{-1} \mathrm{~s}^{-1}\right)$.

$$
\begin{aligned}
& {\left[\mathrm{Fe}(\mathrm{OH})\left(\mathrm{H}_{2} \mathrm{O}\right)_{5}\right]^{+2}+\mathrm{H}_{2} \mathrm{O}_{2} \rightleftarrows\left[\mathrm{Fe}(\mathrm{OH})\left(\mathrm{HO}_{2}\right)\left(\mathrm{H}_{2} \mathrm{O}\right)_{4}\right]^{+}+\mathrm{H}_{3} \mathrm{O}^{+}} \\
& {\left[\mathrm{Fe}(\mathrm{OH})\left(\mathrm{HO}_{2}\right)\left(\mathrm{H}_{2} \mathrm{O}\right)_{4}\right]^{+}+\mathrm{H}_{2} \mathrm{O} \rightleftarrows\left[\mathrm{Fe}(\mathrm{OH})\left(\mathrm{H}_{2} \mathrm{O}\right)_{5}\right]^{+}+\mathrm{HO}_{2}^{\cdot}} \\
& {\left[\mathrm{Fe}(\mathrm{OH})\left(\mathrm{H}_{2} \mathrm{O}\right)_{5}\right]^{2+}+\mathrm{H}_{2} \mathrm{O}+\mathrm{HO}_{2}^{\bullet} \rightarrow\left[\mathrm{Fe}(\mathrm{OH})\left(\mathrm{H}_{2} \mathrm{O}\right)_{5}\right]^{+}+\mathrm{O}_{2}+\mathrm{H}_{3} \mathrm{O}^{+}}
\end{aligned}
$$

A reação Fenton térmica é eficiente para a remoção de poluentes orgânicos, mas requer quantidades estequiométricas de Fe (II) e é retardada após a conversão completa de $\mathrm{Fe}(\mathrm{II})$ a $\mathrm{Fe}(\mathrm{III})$. Porém, um modo de acelerar a redução de espécies contendo Fe (III) a Fe (II) é utilizando radiação UV/visível, de acordo com a reação 2.13. Deste modo a reação Fenton passa a ser designada de foto-Fenton ou Fenton foto-assistida, intensificando a degradação de poluentes orgânicos.

$$
\mathrm{Fe}(\mathrm{OH})_{\mathrm{aq}}^{2+}+\mathrm{h} v \rightarrow \mathrm{Fe}_{\mathrm{aq}}^{2+}+\mathrm{HO}^{\bullet}
$$


O mecanismo apresentado dessa forma é simplificado; de fato ele ainda é motivo de discussão e estudo entre pesquisadores. Pignatello et al. (1999) apontam a formação de um complexo entre ferro e peróxido, $\left[\mathrm{FeO}_{2} \mathrm{H}\right]^{2+}$, que absorve radiação na região visível (290-410 nm) a pH entre 2 e 3, como outro oxidante além do radical hidroxila na reação foto-Fenton. Bossmann et al. (1998) relataram a formação do íon ferrila $\left[\mathrm{Fe}(\mathrm{OH})_{3}\left(\mathrm{H}_{2} \mathrm{O}\right)_{4}\right]^{+}$(abreviado como $\mathrm{Fe}_{\mathrm{aq}}{ }^{4+}$ ), em vez do radical hidroxila, como o intermediário para a reação foto-Fenton, durante a degradação da 2,4 xilidina. A redução fotoquímica do $\mathrm{Fe}_{\mathrm{aq}}{ }^{3+}$, no mecanismo proposto por Bossmann et al. (1998), ocorre por transferência de elétrons dentro do complexo $\mathrm{Fe}(\mathrm{III})-\mathrm{H}_{2} \mathrm{O}_{2}$ excitado $\left(\left[\mathrm{Fe}(\mathrm{OH})\left(\mathrm{HO}_{2}\right)\left(\mathrm{H}_{2} \mathrm{O}\right)_{4}\right]^{+*}\right)$ (reação 2.14).

$$
\left[\mathrm{Fe}(\mathrm{OH})\left(\mathrm{HO}_{2}\right)\left(\mathrm{H}_{2} \mathrm{O}\right)_{4}\right]^{+*}+\mathrm{H}_{2} \mathrm{O} \rightarrow\left[\mathrm{Fe}(\mathrm{OH})\left(\mathrm{H}_{2} \mathrm{O}\right)_{5}\right]^{+}+\mathrm{HO}_{2}^{*}
$$

Além de $\mathrm{H}_{2} \mathrm{O}_{2}$, moléculas orgânicas, e mesmo intermediários formados durante a degradação, podem reduzir o $\mathrm{Fe}(\mathrm{III})$ dissolvido via mecanismo de transferência de elétrons (reação 2.15).

$$
[\mathrm{Fe}(\mathrm{OOC}-\mathrm{R})]^{2+} \stackrel{\mathrm{h} v}{\longrightarrow} \mathrm{Fe}^{2+}+\mathrm{R}^{\bullet}+\mathrm{CO}_{2}
$$

Kim e Vogelpohl (1998) e Nogueira et al. (1999), também caracterizam a utilização de oxalato de $\mathrm{Fe}(\mathrm{III})$, com peróxido de hidrogênio e radiação UV/Visível como processo foto-Fenton. O oxalato possui bandas de absorção que se estendem até $570 \mathrm{~nm}$, aumentando o coeficiente de absorção, e seus complexos têm maior rendimento quântico para a formação de $\mathrm{Fe}(\mathrm{II}), 1,2$ a $313 \mathrm{~nm}$, que a reação 2.14 , com valor de 0,14 no mesmo comprimento de onda (Faust e Hoigné, 1990).

O processo foto-Fenton tem sido aplicado com sucesso no estudo da degradação de um grande número de substâncias, como o tratamento de herbicidas (Kaichouh, 2004), pesticidas (Pérez et al., 2006), efluentes fotográficos (Stalikas et al., 2001; Lin et al., 1998), chorume (Kim et al., 1997; Kurniavan et al., 2006), efluentes reais da indústria têxtil (Balcioglu e Arslan, 1999) inclusive o tratamento de efluentes industriais em escala piloto (em reator com volume de 500 L) (Oliveros et al., 1997). 
$\mathrm{O}$ pH é um dos fatores cruciais que afetam as taxas de degradação no processo foto-Fenton. Para valores de $\mathrm{pH}$ superiores a 6 começa a ocorrer precipitação dos íons ferro na forma de hidróxidos (Kwon et al., 1999) e abaixo de 2 o peróxido de hidrogênio é protonado, originando a espécie $\mathrm{H}_{3} \mathrm{O}_{2}{ }^{+}$, que é mais estável, reduzindo a sua reatividade com os íons Fe(II), além disso, para valores de pH muito baixo a concentração de espécies foto-ativas é baixa. Oliveros et al. (1997) encontraram como faixa ótima de operação de $\mathrm{pH}$ valores entre 2 e 3 para a fotooxidação da 2,4 e da 3,4-xilidina, diluída em água, pelo processo foto-Fenton. Para valores de $\mathrm{pH}$ em torno de 3 a espécie de $\mathrm{Fe}(\mathrm{III})$ dominante em solução aquosa é $\mathrm{Fe}(\mathrm{OH})^{2+}$ (Bauer e Fallmann, 1997), conforme pode ser visto na Figura 2.1 que mostra a especiação dos complexos de Fe(II) e Fe(III) em função do pH (Gonzalez e Braun, 1995).

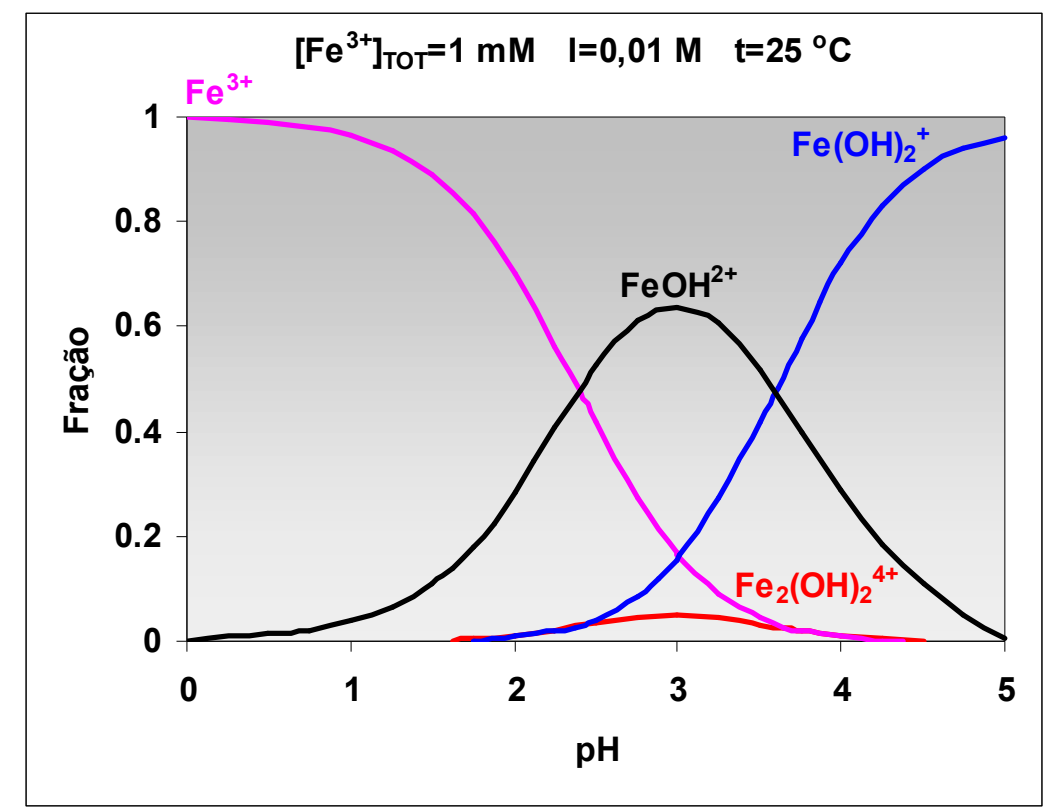

Figura 2.1 - Especiação dos complexos de Fe(II) e Fe(III) em solução aquosa, em função do $\mathrm{pH}$.

Como o pH de operação ótimo é ácido, pode ser necessária a neutralização do efluente se o objetivo for um posterior tratamento biológico ou mesmo o descarte do efluente tratado em matrizes ambientais. Outra preocupação visando a disposição final do efluente é a eliminação do ferro, cujo padrão de emissão estabelecido pelo 
CONAMA é de $15 \mathrm{mg} \mathrm{L}^{-1}$, o que levaria a uma etapa subseqüente do processo de remoção dos íons ferro da fase aquosa.

Um dos grandes problemas para a aplicação industrial de qualquer processo oxidativo que utiliza a radiação UV é o grande custo da energia elétrica utilizada pelas lâmpadas. Baycan et al. (2005) relatam que o custo total (investimento e operação) para a remoção de $80 \%$ do carbono orgânico total de efluentes contendo fenol $\left(1000 \mathrm{mg} \mathrm{L}^{-1}\right)$, é de $20 € \mathrm{~m}^{-3}$, pelo processo $\mathrm{UV} / \mathrm{H}_{2} \mathrm{O}_{2}$ num reator $\mathrm{UV}$ de superfície livre (UV-FSR). Bauer e Fallmann (1997) estimaram o custo total para a remoção de $13 \%$ de TOC de chorume de aterro sanitário $\left(545 \mathrm{mgC} \mathrm{L}^{-1}\right)$ como

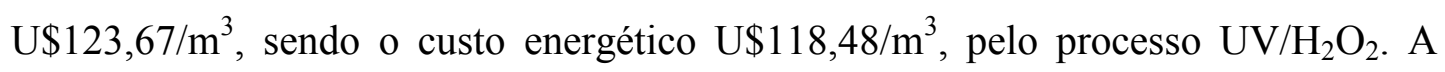
utilização das radiações UV-A e UV-B, emitidas pelo sol, somadas à luz visível nos processos oxidativos (Malato et al., 1997), pode ser importante na redução dos custos operacionais.

\subsubsection{Degradação de Polímeros Solúveis em Água}

Polímeros solúveis em água são produzidos em grandes volumes e largamente utilizados pela indústria farmacêutica, têxtil, de papel e celulose, cerâmica, borracha e outras. Há poucos polímeros solúveis biodegradáveis. Após seu uso, dependendo de suas características e aplicação particulares, são descartados como soluções aquosas diluídas. As correntes de efluentes freqüentemente passam por uma estação de tratamento para remediação e são posteriormente liberadas no meio ambiente. Para polímeros solúveis em água, normalmente a remediação consiste em absorção em lodos ativados e uma remoção final por deposição em aterros ou incineração (Swift, 1998). Polímeros que são levados à estação de tratamento de efluentes podem permanecer em solução ou adsorver parcialmente ou completamente no componente sólido do lodo ou biomassa. Aqueles que permanecem em solução passam através da planta de tratamento e são descartados nos corpos receptores. Nenhuma das opções de recuperação de plásticos, como, por exemplo, reciclagem, é aplicada a polímeros em solução. Assim, os processos oxidativos avançados surgem como uma solução promissora de tratamentos alternativos e/ou complementares ao tratamento convencional desses efluentes. 
A degradação de polímeros solúveis tem sido estudada por processos oxidativos ou biológicos, buscando-se microorganismos específicos capazes de degradar determinado polímero ou através de um processo anaeróbico. Teixeira et al. (2004) conseguiram remediar emulsões aquosas diluídas contendo polidimetilsiloxanos (silicones), utilizando o processo foto-Fenton. O mesmo processo foi empregado com êxito para tratamento de soluções de álcool polivinílico (PVA) com concentrações simulando efluentes da indústria têxtil brasileira (Giroto et al., 2006). Imamura et al. (1981), estudaram a degradação de polipropilenoglicol (PPG), álcool polivinílico; ácido poliacrílico (PAA) e carboximetilcelulose (CMC) por oxidação via úmida. Kaczmarek et al. (1998), empregaram $\mathrm{H}_{2} \mathrm{O}_{2}, \mathrm{FeCl}_{3}$ e radiação UV para degradar ácido poliacrílico e ácido polimetacrílico (PMA). Estes são alguns exemplos de pesquisa que tem sido feita com o objetivo de degradar polímeros solúveis.

A escolha dos polímeros estudados neste trabalho foi baseada nos seguintes critérios: sua degradação já estar sendo estudada por um processo alternativo e possuir unidades de repetição com estruturas diferentes. Este segundo quesito visando estudar a influência no processo de oxidação, de diferentes grupos laterais e a presença de um heteroátomo na cadeia principal, por exemplo, levando a um ataque preferencial dos radicais hidroxila a determinados pontos. Assim, os polímeros escolhidos foram polietilenoglicol (PEG), que possui a estrutura mais simples, poliacrilamida (PAM) e polivinilpirrolidona (PVP). Será feita, portanto, uma revisão mais detalhada de cada um deles.

\subsubsection{Polietilenoglicol (PEG)}

Etilenoglicol e seus oligômeros e polímeros são usados na produção de substâncias tais como surfactantes, explosivos, cosméticos, fluidos para transferência de calor, lubrificantes solúveis em água para a indústria têxtil, solventes e plásticos. Polietilenoglicol (PEG) também foi detectado por Swisher (1970), como um produto da biodegradação de surfactantes não iônicos de cadeias lineares alquílicas.

Métodos biológicos, que são usualmente adotados para o tratamento de efluentes, não podem ser satisfatoriamente empregados para a eliminação de polietilenoglicol de alto peso molecular. A efetividade do processo de degradação 
biológica é fortemente ou quase completamente reduzida para cadeias poliméricas que excedem 10 unidades monoméricas (Andreozzi et al., 1996). Haines e Alexander (1975) estudaram a degradação aeróbica de PEG isolando um microorganismo do solo, Pseudomonas aeruginosa, capaz de degradar PEG-400 $(1 \% \mathrm{~m} / \mathrm{m})$ em 5 dias e PEG-1000, na mesma concentração, em 10 dias. Porém, para PEG-20000 não foi mostrada a extensão da degradação. Watson e Jones (1977) estudaram o efeito do peso molecular do PEG (200 $\left.\mathrm{mg} \mathrm{L}^{-1}\right)$ em sua biodegradabilidade, causada por três tipos de bactérias: Acinetobacter SC 25, Pseudomonas KW 8 e Flavobacterium BT 1, isoladas de águas de esgoto. A velocidade de crescimento de todas as bactérias isoladas foi muito baixa e foram necessários em média 15 dias para obter-se uma degradação baixa, mesmo testando-se outros substratos. PEG-4000 não foi biodegradado, apenas PEG com pesos moleculares menores. A degradação anaeróbica de PEG também foi estudada por Dwyer e Tiedje (1983), utilizando Methanogenic Consortia obtida de lodo de esgotos. Esses autores conseguiram 82\% de degradação do PEG-20000 (0,1 mM) em 12 dias e verificaram que a taxa de degradação foi inversamente proporcional ao número de unidades de etilenoglicol presentes na molécula. Nakamiya et al. (1997) degradaram PEG-4000000 (1g L $\left.{ }^{-1}\right)$ em 1 hora, com a enzima hidroquinona peroxidase (1,2 unidades $\left.\mathrm{mL}^{-1}\right)$ extraída de uma bactéria do solo (Azotobacter beijerinckii HM 121), peróxido de hidrogênio (5 $\mathrm{mM})$ e tetrametil hidroquinona $(5 \mu \mathrm{M})$. No mecanismo proposto a enzima reage com o peróxido de hidrogênio para gerar radicais hidroxila e estes reagem com a tetrametil hidroquinona para formar o radical tetrametilsemiquinona que somente então abstrairia hidrogênio das cadeias poliméricas.

Um consenso entre os autores que estudaram a degradação biológica de PEG é que o aumento do peso molecular diminui a taxa de biodegradação, tornando PEG de alto peso molecular praticamente não biodegradável. Assim, uma alternativa interessante seria o emprego de um pré-tratamento para quebrar as cadeias maiores em oligômeros e outros compostos não poliméricos que podem ser mais facilmente biodegradados.

Suzuki et al. (1978) empregaram ozonização como um pré-tratamento, diminuindo o peso molecular do PEG de $8000\left(800 \mathrm{mgC} \mathrm{L}^{-1}\right)$ para $250 \mathrm{em}$ duas horas. Após a ozonização, 0,2\% da solução ozonizada (substrato), $10 \mathrm{~g}$ de lodo 
fresco do leito de um rio (inóculo) e alguns sais, totalizando $250 \mathrm{~mL}$ de solução, foram cultivados a $37^{\circ} \mathrm{C}$, resultando numa queda de carbono orgânico dissolvido de $75 \%$ após 5 dias de incubação e de 95\% após 20 dias. Andreozzi et al. (1996) estudaram a fragmentação oxidativa de PEG por ozônio, utilizando dois compostos modelos: etilenoglicol $(3,3 \mathrm{mM})$ e dietilenoglicol $(5,5 \mathrm{mM})$, obtendo remoção total do DEG a pH 8 em 90 minutos de reação. Os autores propõem um mecanismo cinético radicalar para altos valores de $\mathrm{pH}$.

Mantzavinos et al. (1996) utilizaram oxidação via úmida (WAO wet air oxidation) para a oxidação de PEG de vários pesos moleculares $\left(1 \mathrm{~g} \mathrm{~L}^{-1}\right)$, sendo o maior de peso 35000, diminuindo até oligômeros e etilenoglicol. Empregaram pressão total de $10 \mathrm{MPa}$, temperaturas de $383,403,423$ e $463 \mathrm{~K}$ com pressão parcial de oxigênio de $3 \mathrm{MPa}$ e temperatura de $513 \mathrm{~K}$ com pressão parcial de oxigênio de 2 MPa. Foi obtida para o PEG-10000 remoção do carbono orgânico total (TOC) de $80 \%$ a $513 \mathrm{~K}$ em 240 minutos de reação. A temperaturas menores o TOC apresentou um patamar a partir de 5 minutos, não passando de $20 \%$ de remoção. Resultados de cromatografia de permeação em gel (GPC) mostraram que o PEG foi quebrado em frações oligoméricas e análises de cromatografia líquida de alto desempenho (HPLC) detectaram a formação de ácidos orgânicos. Com o objetivo de caracterizar os intermediários formados para integrar o processo de oxidação via úmida a um posterior processo biológico Mantzavinos et al. (2000a) utilizaram PEG-10000 (1 g $\mathrm{L}^{-1}$ ) como um composto modelo para um processo contínuo. Posteriormente um sistema de separação por membrana foi intercalado entre o pré-tratamento com WAO e o tratamento biológico final (Mantazavinos et al, 2000b). Os produtos que não foram suficientemente oxidados ficaram retidos na membrana e foram reciclados para o reator de WAO e o permeato foi submetido à oxidação biológica. Após 0,5 hora de tempo de residência no reator de WAO $(403 \mathrm{~K}, 10 \mathrm{MPa}$, pressão parcial de $\mathrm{O}_{2} 3 \mathrm{MPa}$ ) o efluente foi filtrado com uma membrana AFC 40, com limite de exclusão de peso molecular de $300 \mathrm{~g} \mathrm{~mol}^{-1}$. Para o processo biológico foi utilizada uma cultura mista isolada de uma estação de tratamento de Sevilha (Espanha) que foi adaptada por mais de 2 anos ao PEG-10000. Após a filtração foram obtidos até $60 \%$ de remoção de TOC com 1,5 h de tempo de retenção no processo biológico e 92\% com 6 horas. Além de reter os compostos orgânicos acima de um certo peso 
molecular, a membrana deve ser estável ao ataque químico pelo efluente; resistente à oxidação pelos agentes oxidantes presentes na corrente vinda do processo WAO e também deve suportar altas temperaturas.

$\mathrm{O}$ processo foto-Fenton e $\mathrm{UV} / \mathrm{H}_{2} \mathrm{O}_{2}$ foram utilizados por McGinnis et al. (2000), para a degradação de etilenoglicol (EG), um dos possíveis subprodutos da degradação do PEG. A concentração de EG foi variada de 50 a $1000 \mathrm{mg} \mathrm{L}^{-1}$, de $\mathrm{Fe}(\mathrm{III})$ de 2 a $100 \mathrm{mg} \mathrm{L}^{-1}$ e a concentração de $\mathrm{H}_{2} \mathrm{O}_{2}$ foi de $500 \mathrm{mg} \mathrm{L}^{-1}$ para todos os experimentos.Vários ácidos orgânicos foram identificados como intermediários da degradação nos processos. Os melhores resultados de remoção de TOC foram obtidos para o processo $\mathrm{UV} / \mathrm{H}_{2} \mathrm{O}_{2}$ e os autores ressaltam a importância de otimizar as variáveis no processo foto-Fenton para aumentar a produção de radicais hidroxila.

\subsubsection{Poliacrilamida (PAM)}

A família de polímeros e copolímeros de poliacrilamida é um grupo altamente versátil, usado em muitas aplicações, incluindo floculante para o tratamento de água potável, operações em campo petrolífero, retenção de água em solo arenoso, processo de recuperação de carvão, refinarias de açúcar, minas de lixiviação mineral, gel para eletroforese, floculantes na manufatura de papel e adesivos, cimento usado como barreira contra infiltração de água subterrânea e aplicações biomédicas. Uma maior aplicação é como redutor de espalhamento de jato usado em aplicações de herbicidas. O polímero aumenta a viscosidade da solução de herbicida, permitindo uma aplicação mais uniforme e também aumentando o tempo de contato com o vegetal (Vers, 1999; Caulfield et al., 2002).

Entretanto a neurotoxidade do monômero acrilamida leva a algumas considerações e relutância para aceitar a poliacrilamida como um material seguro, particularmente se o polímero entrar em contato direto com fluidos corporais (ex. diálise renal, filtração sangüínea etc.) ou quando o polímero é usado para fazer produtos terapêuticos. Há uma longa discussão a respeito da possibilidade da acrilamida residual presente no material polimérico e se a poliacrilamida pode degradar e voltar ao monômero (Caulfield et al., 2002).

Acrilamida é um irritante agudo dos olhos, pele e trato respiratório. Pode ser absorvida por todas as rotas de exposição, incluindo intravenosa, intramuscular, 
intraperitonial, subcutânea, oral e dérmica. Em animais superiores, uma vez absorvida, a acrilamida causa danos no sistema nervoso central, produzindo axonopatia central/periférica ascendente. A axonopatia é caracterizada pela interrupção das funções sensoriais, motoras e autonômicas dos tratos periféricos e ascendentes da corda espinhal, sua severidade e extensão dependem do nível de intoxicação. Acrilamida tem sido classificada pela Agência de Proteção Ambiental Americana (U. S. Environmental Protection Agency EPA) como um provável carcinogênico do grupo B2. A EPA recomenda como dose segura de exposição ou referência para a acrilamida $0,0002 \mathrm{ppm}$, que é freqüentemente cotada como $0,3 \mathrm{ppb}$ (Caulfield et al., 2002). No Brasil o Conselho Nacional de Meio Ambiente (CONAMA) estabelece como limite para descarte de acrilamida em águas doces do tipo I a concentração de 0,5 ppb.

As duas principais áreas de preocupação associadas com o uso da poliacrilamida são a presença de monômero residual no produto polimérico e a possível formação de acrilamida ou outras toxinas originadas por algum mecanismo de degradação da poliacrilamida. Poliacrilamida não é tóxica a nenhum tipo de organismo, entretanto é suscetível a diferentes processos degradativos dependendo da natureza do polímero, impurezas presentes e condições a que ele é exposto. Reações de degradação são geralmente irreversíveis e alteram as propriedades físicas e químicas do polímero. Os subprodutos da degradação também são de interesse porque eles podem contribuir para a toxicidade do sistema degradado.

Smith et al. (1996) estudaram a degradação de um espessante, PATA, formulado com poliacrilamida (Nalco Chemical Company) e água destilada juntamente com um herbicida, glifosato (Monsanto) sob condições de luz, temperatura e $\mathrm{pH}$ simulando as condições ambientais às quais tais soluções são expostas quando utilizadas na agricultura. Os autores relatam que a concentração de acrilamida, presente inicialmente nas amostras, permaneceu constante ou aumentou para a mistura glifosato-PATA, sugerindo que o glifosato poderia promover a degradação da poliacrilamida em acrilamida. Em um trabalho subseqüente, Smith et al. (1997) estudaram o efeito de condições ambientais reais, expondo as soluções glifosato-PATA, em garrafas de vidro cobertas com plástico, por seis semanas. Os autores detectaram um aumento na concentração de acrilamida tanto para as soluções 
contendo a mistura glifosato-PATA, como para as soluções de PATA, sugerindo que a poliacrilamida degradou em acrilamida.

Em 1999, Leonard M. Ver Vers da Nalco Chemical Company (Vers, 1999) desenvolveu um método de HPLC para analisar acrilamida. O autor repete os experimentos de Smith et al. (1997) e conclui que a poliacrilamida não degrada em acrilamida, mesmo na presença de glifosato e que a acrilamida detectada é residual do processo de polimerização. Vers critica o método analítico usado por Smith, desde a falta de filtração da amostra até a interferência de ácido acrílico residual da polimerização e do próprio glifosato na análise cromatográfica. Estes resultados são controversos, uma vez que o polímero é usado em aplicações industriais e agronômicas em que está diretamente exposto à luz solar.

Caulfield et al. (2003) estudaram a estabilidade de PAM polimerizada com quatro diferentes iniciadores, sob aquecimento e radiação UV. Especial atenção foi dada à purificação da PAM sintetizada, retirando-se toda a acrilamida residual através de três precipitações com metanol seguidas de bromação. Soluções de PAM $1 \% \mathrm{~m} / \mathrm{m}$ mantidas em um banho a $95{ }^{\circ} \mathrm{C}$ por 15 dias não liberaram acrilamida. Porém quando exposta à radiação UV (254 nm), PAM liberou 50 ppm de unidades monoméricas em 10 dias, o que foi atribuído à cisão aleatória da cadeia.

Há poucos trabalhos na literatura relatando a biodegradação de poliacrilamida de alto peso molecular. Nakamiya e Kinoshita (1995) isolaram dois microorganismos do solo, Enterobacter agglomerans e Azomonas macrocytogenes, conseguindo uma redução de TOC de 20\% após 27 horas de incubação e o peso molecular foi diminuído de 2 milhões para 500000. A enzima hidroquinona peroxidase (1,2 unidades $\mathrm{mL}^{-1}$ ) também foi utilizada por Nakamiya et al. (1997), para degradar poliacrilamida $\left(1 \mathrm{~g} \mathrm{~L}^{-1}\right)$, conseguindo a diminuição do peso molecular de 2000000 para menos de 1000 em 30 minutos, com peróxido de hidrogênio $(5 \mathrm{mM})$ e tetrametil hidroquinona $(5 \mu \mathrm{M})$.

O pré-tratamento por ozonização de PAM seguido de um tratamento biológico foi estudado por Suzuki et al. (1978). Foi conseguida uma redução do peso molecular de PAM (800 mgC L ${ }^{-1}$ ) de 280000 para 340 com 4 horas de ozonização, porém a biodegradabilidade da solução ozonizada piorou se comparada à do polímero antes do pré-tratamento. Produtos da ozonização de peso molecular de 
aproximadamente 100 quase não sofreram biodegradação com 8 dias de incubação. Os autores sugerem que a baixa biodegradabilidade da poliacrilamida não só se deve ao alto peso molecular do polímero, mas também à sua estrutura molecular, que contém grupos amida.

Suzuki et al. (1979) ozonizaram soluções aquosas de poliacrilamida de concentração 0,1 e $1 \% \mathrm{~m} / \mathrm{m}$ sob radiação UV com uma lâmpada de vapor de mercúrio de baixa pressão. Houve uma remoção de TOC de $80 \%$ em 7,5 horas de reação e a degradação da cadeia principal foi acompanhada pela formação de formaldeído (detectado por colorimetria) e grupos carbonila, indicada pelo aumento da absorção ótica na região de $265 \mathrm{~nm}$. Além disso, a formação de ácido oxâmico e oxamida foi detectada por infravermelho. Os autores sugerem que estes produtos finais são formados através de uma reação em cadeia radicalar iniciada pela abstração do átomo de hidrogênio terciário da cadeia de PAM pelos radicais hidroxila.

A degradação oxidativa de soluções diluídas de PAM $\left(1 \mathrm{~g} \mathrm{~L}^{-1}\right)$ induzida por radicais livres gerados por radiólise pulsada $(16 \mathrm{MeV})$ foi estudada por Gröllmannn e Schnabel (1982). Também foram detectados acrilamida, oxamida e formaldeído durante a oxidação. Uma interessante análise da influência do oxigênio na oxidação foi realizada comparando-se experimentos feitos em soluções que foram previamente borbulhadas com oxigênio por 10 minutos e soluções saturadas com argônio. As soluções saturadas com oxigênio sofreram quebra de cadeia, detectada por uma diminuição da intensidade de espalhamento de luz; as soluções saturadas com argônio apresentaram aumento da intensidade do espalhamento de luz provocado por reações cruzadas.

Ramsden e McKay (1986) estudaram a degradação de PAM (0,5\% m/m em solução aquosa) pelos reagentes de Fenton: Fe(II) (1, 10, 20 e 50 ppm) e $\mathrm{H}_{2} \mathrm{O}_{2}$ com concentrações iguais às de $\mathrm{Fe}(\mathrm{II})$. Os resultados da degradação foram acompanhados por viscosimetria da solução, uma vez que a redução da viscosidade reflete a diminuição do peso molecular do polímero. Mesmo concentrações de $\mathrm{Fe}$ (II) tão baixas quanto 1 ppm já tornaram o fluido newtoniano e não pseudoplástico. A adição de seqüestrantes de radicais hidroxila resultou num aumento da viscosidade na medida em que Fe(II) era oxidado pelo peróxido, formando Fe(III), e reagia com o 
polímero não degradado. Uma possibilidade levantada é a de que Fe(III) possa se coordenar com os grupos amida de moléculas adjacentes.

Alguns trabalhos buscaram a quebra de PAM com o objetivo de adequar a distribuição de pesos moleculares de amostras comerciais para aplicações específicas. Kurenkov e Tazieva (1994) promoveram a degradação da PAM 0,4\% $\mathrm{m} / \mathrm{m}$, utilizando os agentes oxidantes: persulfato de potássio, persulfato de amônio e $\mathrm{H}_{2} \mathrm{O}_{2}-\mathrm{FeSO}_{4}$, com relação de concentração agente oxidante/PAM variando de 1 a 5 . Medidas viscosimétricas mostraram uma redução do peso molecular médio de $5,3 \times 10^{6}$ para $2 \times 10^{5}$ em 4 horas de reação, a $50{ }^{\circ} \mathrm{C}$. Os autores explicam o processo por um mecanismo de quebra estocástico, sem despolimerização, acompanhado de quebra da cadeia principal. Gao et al. (1999) obtiveram resultados semelhantes utilizando persulfato de sódio, potássio e peróxido de hidrogênio para degradar PAM de peso molecular $1,2 \times 10^{7}(0,4-0,8 \% \mathrm{~m} / \mathrm{m})$. O efeito da recombinação de radicais, diminuindo a degradação, foi observada para altas concentrações de $\mathrm{K}_{2} \mathrm{~S}_{2} \mathrm{O}_{8}$ $\left(0,05962 \mathrm{~mol} \mathrm{~L}^{-1}\right)$. Yen e Yang (2003) realizaram a degradação ultra-sônica de soluções aquosas de $\operatorname{PAM}\left(0,75 \mathrm{~g} \mathrm{dL}^{-1} ; 30{ }^{\circ} \mathrm{C}\right)$ obtendo uma redução no peso molecular de $2.7 \times 10^{6}$ para $5,6 \times 10^{5}$ em 64 minutos de reação.

\subsubsection{Polivinilpirrolidona (PVP)}

Polivinilpirrolidona (PVP) tem aplicações muito amplas, por exemplo, na indústria de cosméticos (spray para cabelo), farmacêutica (cápsula para comprimido), medicina (extensor do plasma sangüíneo), indústria de construção civil (material impermeabilizante, madeira compensada), adesivos, membranas seletivas, eletrotécnica e eletro-óptica.

Trimpin et al. (2001) caracterizaram por espectrometria de massa PVP (10 $\mathrm{mg} \mathrm{L}^{-1}$ ) durante o processo de degradação biológico conduzido em um bio-reator de leito fixo. Após 30 dias de reação não houve oxidação dos grupos terminais e nem alteração nas unidades monoméricas de PVP, indicando a baixa biodegradabilidade deste polímero. Os autores realizaram um teste de adsorção misturando-se lodo seco de esgoto com uma solução de PVP (100 $\left.\mathrm{mg} \mathrm{L}^{-1}\right)$ na razão de 500:1 em massa. Após 1 hora a concentração de PVP presente no sobrenadante era de $10 \mathrm{mg} \mathrm{L}^{-1}$ e após 2,5 horas de $1 \mathrm{mg} \mathrm{L}^{-1}$ mostrando a rápida adsorção do PVP no lodo de esgoto. Além 
disso, análises de GPC detectaram apenas oligômeros após 1 hora, indicando que as frações maiores adsorvem preferencialmente.

Soluções diluídas de PVP foram submetidas a radiólise pulsada (6 MeV, 1-3 $\mu$ s) e analisadas por espalhamento de luz, por Rosiak et al. (1990). Em soluções de PVP $\left(0,028 \mathrm{~mol} \mathrm{~L}^{-1}\right)$ saturadas com argônio foram identificadas predominantemente reações de recombinação de radicais e para soluções saturadas com $\mathrm{O}_{2}$ (PVP 0,015 mol L ${ }^{-1}$ ) reações de degradação. Foram detectados dois tipos de radicais, um com sítio radicalar localizado na cadeia principal, responsável pela quebra da cadeia principal e diminuição do peso molecular, e o outro no anel pirrolidínico.

Panarin e Gravilova (1997) estudaram a degradação de PVP $(0,6 \% \mathrm{~m} / \mathrm{m})$, sob ação do $\mathrm{H}_{2} \mathrm{O}_{2}(0,018 \% \mathrm{~m} / \mathrm{m})$ a temperaturas de 40,60 e $80{ }^{\circ} \mathrm{C}$. Houve diminuição do peso molecular de $5 \times 10^{5}$ para $1,2 \times 10^{5}$ em 4 horas de reação a $80^{\circ} \mathrm{C}$. Os autores concluem que PVP sofre oxidação, com quebra da cadeia principal, o que foi indicado pelo aumento dos grupos carboxila $(\mathrm{COOH})$. $\mathrm{O}$ aumento da temperatura aumentou a velocidade de degradação.

A foto-degradação de soluções aquosas de PVP $(1 \% \mathrm{~m} / \mathrm{m})$ na presença de $\mathrm{H}_{2} \mathrm{O}_{2}(1 \% \mathrm{~m} / \mathrm{m})$ ou $\mathrm{FeCl}_{3}(1 \% \mathrm{~m} / \mathrm{m})$ foi estudada por Kaczmarek et al. (1998). Foi empregada uma lâmpada de vapor de mercúrio de alta pressão $(125 \mathrm{~W})$. No sistema $\mathrm{PVP} / \mathrm{H}_{2} \mathrm{O}_{2}$ o peso molecular diminuiu $96 \%$ em 4 horas de irradiação e, no sistema $\mathrm{PVP} / \mathrm{FeCl}_{3}, 70 \%$. Observaram a formação de gel, atribuído a ocorrência de reações cruzadas, após 30 minutos de reação para o sistema $\mathrm{PVP} / \mathrm{H}_{2} \mathrm{O}_{2}$, atingindo $7 \% \mathrm{~m} / \mathrm{m}$ em 1 hora de reação. A iniciação da degradação por radicais livres gerados pelo $\mathrm{H}_{2} \mathrm{O}_{2}$ e a rápida oxidação das macromoléculas são apontados como causa principal da maior degradação no caso $\mathrm{PVP} / \mathrm{H}_{2} \mathrm{O}_{2}$.

Horikoshi et al. (2001) utilizaram o processo $\mathrm{TiO}_{2} / \mathrm{UV}$ para degradar PVP. Partículas de $\mathrm{TiO}_{2}(100 \mathrm{mg})$ e PVP $(10 \mathrm{mg})$ em dispersão aquosa $(50 \mathrm{~mL})$ foram sonicadas por 5 minutos, depois purgadas com excesso de oxigênio por 15 minutos e então irradiadas com uma lâmpada de vapor de mercúrio (75 W), sob agitação magnética. Análises de GPC mostraram a diminuição da distribuição de pesos moleculares, com um pico indo de 18641 para $3329 \mathrm{~g} \mathrm{~mol}^{-1}$ e outro de 1437 para 566 $\mathrm{g} \mathrm{mol}^{-1}$, em 2 horas de reação. Os resultados mostraram que primeiramente ocorre a adsorção de PVP nas partículas de $\mathrm{TiO}_{2}$ através da função $\mathrm{N}-\mathrm{C}=\mathrm{O}$ do grupo lateral 
(anel pirrolidínico), seguida da reação foto-oxidativa dos anéis laterais e formação de amina primária (metilamina) e ácido propanóico como intermediários. Devido à adsorção da cadeia principal de PVP nos agregados de $\mathrm{TiO}_{2}$, os sítios ativos do catalisador foram cobertos e não houve foto-oxidação dos intermediários, mesmo durante alguns dias de irradiação. 


\subsection{Degradação Oxidativa de Polímeros}

Após a abstração de hidrogênio pelos radicais hidroxila, gerados nos processos oxidativos avançados, há a formação de um radical orgânico que reage com o oxigênio molecular e inicia-se uma cadeia de reações de degradação oxidativa. As reações e radicais envolvidos na degradação oxidativa de polímeros são descritas a seguir com base principalmente em Jellinek (1978).

\subsubsection{Mecanismo de Radicais Livres na Autoxidação}

A degradação oxidativa de polímeros é uma reação radicalar, ou seja, acontece por mecanismo de radicais livres, consistindo de três importantes passos:

\section{Iniciação}

É a etapa de produção de radicais livres, que pode ser iniciada térmica, fotoquímica, mecanicamente ou por radiação por fontes com alta energia, como os raios gama. A eficiência da produção de radicais é normalmente menor que 1 devido ao efeito gaiola (cage effect). Os radicais livres que escapam da gaiola reagem imediatamente com oxigênio para formar radicais peroxila e, assim, iniciar a cadeia oxidativa.

O efeito gaiola é um importante fenômeno no passo de iniciação de polímeros em meios com alta viscosidade. Isso porque os radicais tornam-se menos móveis com o aumento da viscosidade do meio e radicais geminados produzidos muito próximos têm uma maior chance de se recombinar antes de se difundirem até as moléculas orgânicas.

Outra fonte de produção de radicais é a decomposição térmica do alquil hidroperóxido, $\mathrm{ROOH}$ (reação 2.16), originando radicais alcoxila $\mathrm{RO}^{\bullet}$. A energia de dissociação da ligação oxigênio-oxigênio do alquil hidroperóxido é relatada como da ordem de $42 \mathrm{kcal} \mathrm{mol}^{-1}$ (Benson, 1964), e, dessa forma, a decomposição unimolecular ocorre predominantemente na decomposição térmica do alquil hidroperóxido. 
$\mathrm{ROOH} \rightarrow \mathrm{RO}^{\bullet}+{ }^{\bullet} \mathrm{OH}$

Se a concentração de hidroperóxido for superior a 1,9 M (Jellinek, 1978), sua decomposição procede via um estado de transição ligado com hidrogênio (reação 2.17).

$\underset{\mathrm{H}}{\mathrm{ROO}^{--}} \mathrm{HOOR} \longrightarrow \mathrm{RO}^{\bullet}+\mathrm{H}_{2} \mathrm{O}+\mathrm{RO}_{2}^{\bullet}$

\section{Propagação}

Tão logo um radical alquila $\left(\mathrm{R}^{\bullet}\right)$ é gerado pela reação de iniciação, ele quase sempre reage facilmente com oxigênio. O próprio oxigênio é um di-radical e a reação de um radical alquila com oxigênio é praticamente uma ligação de radicais.

$$
\mathrm{R}^{\bullet}+{ }^{\bullet} \mathrm{O}-\mathrm{O}^{\bullet} \stackrel{\mathrm{k}_{0}}{\longrightarrow} \mathrm{RO}_{2}^{\bullet}
$$

A constante de velocidade para as reações de oxigênio com a maioria dos radicais alquila, aproximadamente $10^{-9} \mathrm{M}^{-1} \mathrm{~s}^{-1}$, é da mesma ordem de grandeza para a interação de dois radicais alquila.

A estabilidade dos radicais peroxila $\left(\mathrm{RO}_{2}^{*}\right)$ em relação à dissociação depende da força da ligação formada entre o radical $\mathrm{R}^{\bullet}$ e o oxigênio. A força da ligação para alquila-OO ${ }^{\bullet}$ é da ordem de $26-19 \mathrm{kcal} \mathrm{M}^{-1}$.

A abstração de hidrogênio do substrato, pelos radicais alquilperoxila, é o passo mais importante e determinante da velocidade na autoxidação.

$$
\mathrm{RO}_{2}^{\bullet}+\mathrm{RH} \stackrel{\mathrm{k}_{\mathrm{p}}}{\longrightarrow} \mathrm{ROOH}+\mathrm{R}^{\bullet}
$$

Alguns fatores afetam a reação dos radicais alquilperoxila, como, por exemplo, efeito estérico, polaridade e efeito do solvente. Em geral, radicais primários e secundários parecem ser muitas vezes mais reativos à abstração de hidrogênio que radicais terciários, devido a efeitos de impedimento estérico. A reatividade do radical 
peroxila aumenta com o aumento da capacidade de retirada de elétrons do substituinte $\alpha$. Por isso, radicais acilperoxila são muito reativos à abstração de hidrogênio, devido à grande facilidade de oxidação dos aldeídos. Embora o efeito da polaridade do solvente seja muito menor em reações radicalares que em reações iônicas, ele ainda tem um importante papel na determinação da velocidade e da rota de algumas reações radicalares. O efeito da polaridade do solvente na velocidade de oxidação de hidrocarbonetos tem sido estudado por vários grupos e foi observado que a velocidade de oxidação aumenta, em geral, com o aumento da constante dielétrica do meio. $\mathrm{O}$ aumento da velocidade de oxidação é explicado principalmente pela contribuição da solvatação do estado de transição dipolar envolvido no passo de propagação. Outra questão importante é a formação de pontes de hidrogênio dos radicais peroxila com grupos hidroxila ou mesmo intramoleculares, o que os torna menos reativos para abstração de hidrogênio.

Embora a reação de propagação 2.19 normalmente ocorra por uma abstração de hidrogênio intermolecular, ela também pode ser intramolecular através da formação de um intermediário cíclico de transição, especialmente para baixas concentrações do polímero. Reações intramoleculares são importantes na oxidação de polímeros de cadeia ramificada, enquanto que as intermoleculares dominam no caso de polímeros de cadeia reta (Mantzavinos et al., 1996).

Radicais alcoxila são importantes transferidores de cadeia na auto-oxidação, pois podem abstrair hidrogênio ou causar quebra. A importância relativa destas duas reações competidoras é dependente das variáveis reacionais, como temperatura, concentração e reatividade dos doadores de hidrogênio e solvente. Walling e Wagner, (1964) verificaram que solventes polares e olefínicos aceleram a quebra, enquanto a abstração de hidrogênio foi relativamente indiferente ao solvente.

A solubilidade dos polímeros em solventes também é um importante fator. Polímeros tornam-se expandidos em bons solventes e enrolados em solventes pobres. Outro efeito do solvente é devido à viscosidade. Com o aumento da viscosidade do meio, a mobilidade dos radicais diminui e isso pode afetar a velocidade e a rota da oxidação.

A abstração de hidrogênio de polímeros por radicais alcoxila e peroxila é um passo importante na determinação da velocidade de oxidação dos polímeros. 
Numerosos dados indicam que a reatividade do hidrogênio para radicais livres aumenta na ordem: primário $<$ secundário $<$ terciário, de acordo com a diminuição da energia de dissociação da ligação. O átomo de hidrogênio em polímeros também tem a mesma tendência para sua reatividade.

A reatividade aparente de polímeros com radicais alcoxila é em geral menor que a de seus compostos modelo, principalmente devido à configuração helicoidal de polímeros em solução. Poliestireno de alto peso molecular deve ter uma reatividade menor devido à menor fração de hidrogênios abstraíveis expostos ao ataque de radicais.

\section{Terminação}

$\mathrm{Na}$ maioria das condições experimentais, a etapa de terminação na autoxidação ocorre quase exclusivamente pela reação de dois radicais peroxila (reação 2.20), desde que a reação dos radicais alquila com o oxigênio molecular seja muito rápida. Entretanto, a pressões de oxigênio muito baixas, abaixo de 1 atm (Bateman e Morris, 1953) ou quando o radical alquila é muito estável para o oxigênio as reações 2.21 e 2.22 passam a ser importantes.

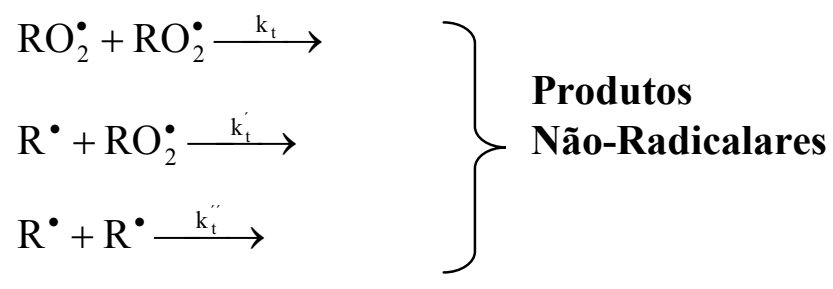

$\mathrm{Na}$ presença de radicais hidroxila e hidroperoxila as seguintes reações podem ocorrer:

$$
\begin{aligned}
& \mathrm{RO}_{2}^{\bullet}+\mathrm{HO}^{\bullet} \stackrel{\mathrm{k}_{\mathrm{t}}}{\longrightarrow} \mathrm{ROH}+\mathrm{O}_{2} \\
& \mathrm{RO}_{2}^{\bullet}+\mathrm{HO}_{2}^{\bullet} \stackrel{\mathrm{k}_{\mathrm{t}}}{\longrightarrow} \mathrm{ROOH}+\mathrm{O}_{2} \\
& \mathrm{RO}_{2}^{\bullet}+\mathrm{HO}_{2}^{\bullet} \stackrel{\mathrm{k}_{\mathrm{t}}}{\longrightarrow} \mathrm{R}=\mathrm{O}+\mathrm{H}_{2} \mathrm{O}+\mathrm{O}_{2}
\end{aligned}
$$


As constantes de velocidade de terminação de cadeia aumentam ao longo da série: peroxila terciário < peroxila secundário < peroxila primário. A lenta reação para o peroxila terciário é devida principalmente ao fato de que a decomposição do intermediário tetróxido em radicais alcoxila necessita de uma energia de ativação significativa. As diferenças nas constantes de reação para reações mútuas entre radicais peroxila são devidas a diferenças na energia de ativação para decomposição do tetróxido.

\subsubsection{Produtos da Oxidação de Polímeros}

É crucial para a elucidação da natureza da reação de oxidação o conhecimento dos produtos da reação dos polímeros. Isto é também importante do ponto de vista da poluição secundária causada pelos polímeros fotodegradáveis. Os produtos e suas distribuições dependem da conversão e das variáveis experimentais como temperatura, taxa de iniciação, comprimento de cadeia, presença ou ausência de catalisadores metálicos ou luz, mecanismo de oxidação etc. Uma vez que os produtos da oxidação primária são normalmente mais facilmente oxidados que os polímeros de origem, numerosos tipos de produtos podem ser formados com o aumento da conversão.

O mais importante produto primário da propagação, especialmente sob condições brandas, é hidroperóxido, como observado na oxidação de muitos hidrocarbonetos simples.

A dissociação homolítica do hidroperóxido na ligação do peróxido pode tornar-se importante a altas temperaturas e na presença de luz. A degradação induzida por radicais oxila e íons de metais de transição também é muito significativa.

Aldeídos, álcoois, cetonas e ácidos são produtos importantes da oxidação de polímeros e também de hidrocarbonetos simples. Estes são formados nas etapas de propagação e nas reações de terminação. Álcoois podem ser formados pela abstração de átomos de hidrogênio por radicais alcoxila e na interação de terminação de radicais peroxila. Aldeídos podem ser formados pela desidratação de hidroperóxidos primários, interações de terminação de radicais peroxila primários e abstração de 
hidrogênio de radicais acila. Cetona pode ser produzida pela cisão $\beta$ de radicais alcoxila e interações de terminação de radicais peroxila. Ácido é o maior produto da oxidação de aldeído e sua interação com álcool forma éster.

\section{Mecanismos sugeridos para oxidação de PEG, PAM e PVP}

Gröllmann e Schnabel (1980), estudaram a degradação de PEO ${ }^{1}-4000000$, $\left(0,011-0,057 \mathrm{~mol} \mathrm{~L}^{-1}\right)$ promovida por radiólise pulsada $(16 \mathrm{MeV}, 100 \mathrm{~ns})$, em soluções aquosas e de acetonitrila saturadas com $\mathrm{O}_{2}$ ou com argônio. O seguinte mecanismo foi sugerido:

Abstração de hidrogênio:

$\mathrm{PH}+{ }^{\bullet} \mathrm{OH} \rightarrow \mathrm{P}^{\bullet}+\mathrm{H}_{2} \mathrm{O}$

Formação dos radicais alquilperoxila $\left(\mathrm{PO}_{2}^{*}\right)$ :

$\mathrm{P}^{\bullet}+\mathrm{O}_{2} \rightarrow \mathrm{PO}_{2}^{\bullet}$

Formação dos radicais alcoxila $\left(\mathrm{PO}^{\bullet}\right)$ :

$\mathrm{PO}_{2}^{\bullet}+\mathrm{PO}_{2}^{\bullet} \rightarrow 2 \mathrm{PO}^{\bullet}+\mathrm{O}_{2}$

Quebra da cadeia principal (decomposição dos radicais alcoxila), formando um polímero de cadeia menor $\left(\mathrm{F}_{1}\right)$, e um radical polimérico $\left(\mathrm{F}_{2}^{\bullet}\right)$ :

$\mathrm{PO}^{\bullet} \rightarrow \mathrm{F}_{1}+\mathrm{F}_{2}^{\bullet}$

O radical polimérico formado pela reação 2.29 também pode sofrer reações do tipo:

$\mathrm{F}_{2}^{\bullet}+\mathrm{PH} \rightarrow \mathrm{F}_{2} \mathrm{H}+\mathrm{P}^{\bullet}$

$\mathrm{F}_{2}^{\bullet}+\mathrm{O}_{2} \rightarrow \mathrm{F}_{2} \mathrm{O}_{2}^{\bullet}$

$\mathrm{F}_{2}^{\bullet}+\mathrm{F}_{2}^{\bullet} \rightarrow$ produtos

$\mathrm{F}_{2}^{\bullet}+\mathrm{PO}_{2}^{\bullet} \rightarrow$ produtos

${ }^{1}$ Geralmente a demoninação óxido de polietileno (PEO) se refere a polietilenoglicóis (PEG) com pesos moleculares maiores que 20000 (Harris, 1992) 
Com análises de intensidade de espalhamento de luz (LSI), Gröllmann e Schnabel (1980) concluíram que na irradiação de soluções aquosas de PEO, para baixas concentrações de oxigênio, ocorrem os processos de rompimento da cadeia principal e de formação de ligações cruzadas. Já em soluções saturadas com $\mathrm{O}_{2}$ ocorre apenas rompimento da cadeia principal. Também inferiram da análise de LSI, que a quebra da cadeia principal ocorre como conseqüência de uma reação bimolecular, que é a reação 2.28 cuja velocidade é bem menor que a das reações 2.27 e 2.29. Os autores também sugerem que, devido à distribuição heterogênea de radicais no sistema, o mecanismo deve ser elucidado utilizando-se um método cinético estocástico e não determinístico.

Mantzavinos et al. (1996) estudaram a oxidação via úmida do PEG e propuseram o mecanismo descrito a seguir. $\mathrm{O}$ primeiro passo nas reações fotooxidativas é a abstração de hidrogênio da cadeia por radicais formados em processos de oxidação avançados ou por excitação fotônica de espécies cromóforas, gerando um radical polimérico alquila (reação 2.34).

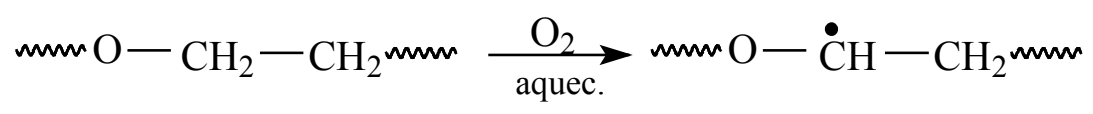

O radical alquila reage com oxigênio, formando o radical alquilperoxila, (reação 2.35), que abstrai hidrogênio de moléculas originais, formando hidroperóxidos secundários (reação 2.36). A degradação térmica e fotoquímica desses hidroperóxidos forma radicais alcoxila (reação 2.37).<smiles>CCC([O-])OCCO[18O]C[14CH2]OC</smiles> 


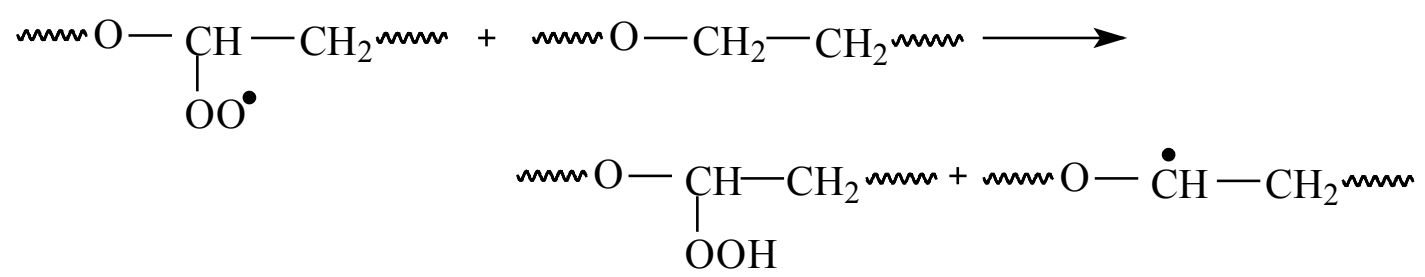<smiles>COC(O)CCCCCOC([O-])C[N+](=O)O</smiles>

A principal rota de evolução dos radicais alcoxila é a cisão $\beta$ com formação de éster fórmico e macroradicais (reação 2.38).<smiles>CO[CH+]CCCCOC(=O)[OH2+]</smiles>

Os macroradicais são oxidados formando radicais hidroperoxila (reação 2.39) e abstraem hidrogênio de cadeias originais, formando hidroperóxidos primários (reação 2.40). Estes se decompõem formando radicais alcoxila primários (reação 2.41), que se fragmentam formando aldeídos (reação 2.42) e posteriormente ácidos carboxílicos.

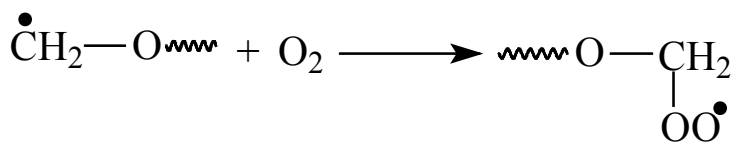<smiles>CC(C)CO[C@H](OCO)OCCCCO</smiles> 
$\underset{\mathrm{OOH}}{\operatorname{CH}} \longrightarrow \underset{\mathrm{O} \mathrm{O}_{2}}{\mathrm{O}^{\bullet}}$<smiles>COCCNC=O</smiles>

O radical formado em (2.42) pode fragmentar, formando oligômeros e etilenoglicol), ou sofrer abstração de hidrogênio e formar compostos de natureza aldeídica (reação 2.43).<smiles>COCCOCCOCC=O</smiles>

Morlat et al. (2001) estudaram a foto-oxidação de filmes de PEO sob irradiação a comprimentos de onda longos $(\lambda>300 \mathrm{~nm})$ na presença de oxigênio, a 35 ${ }^{\circ} \mathrm{C}$. Os resultados foram comparados com experimentos de termo-oxidação a $50{ }^{\circ} \mathrm{C}$. Foi averiguado que na termo-oxidação foram formadas iguais quantidades de formatos e ésteres, enquanto na foto-oxidação a proporção foi de 5:1.

O mecanismo proposto pelos autores é similar ao de Mantzavinos et al. (1996), com a diferença de duas outras possíveis reações dos radicais alcoxila. Uma delas é a reação com radicais hidroxila, através de uma reação de gaiola, (cage reaction) formando funções éster (reação 2.44). A segunda é a abstração de hidrogênio de uma cadeia polimérica, formando um hemiacetal que é termodinamicamente instável e se decompõe formando álcoois e ácidos carboxílicos (reações 2.45 e 2.46).<smiles></smiles> 

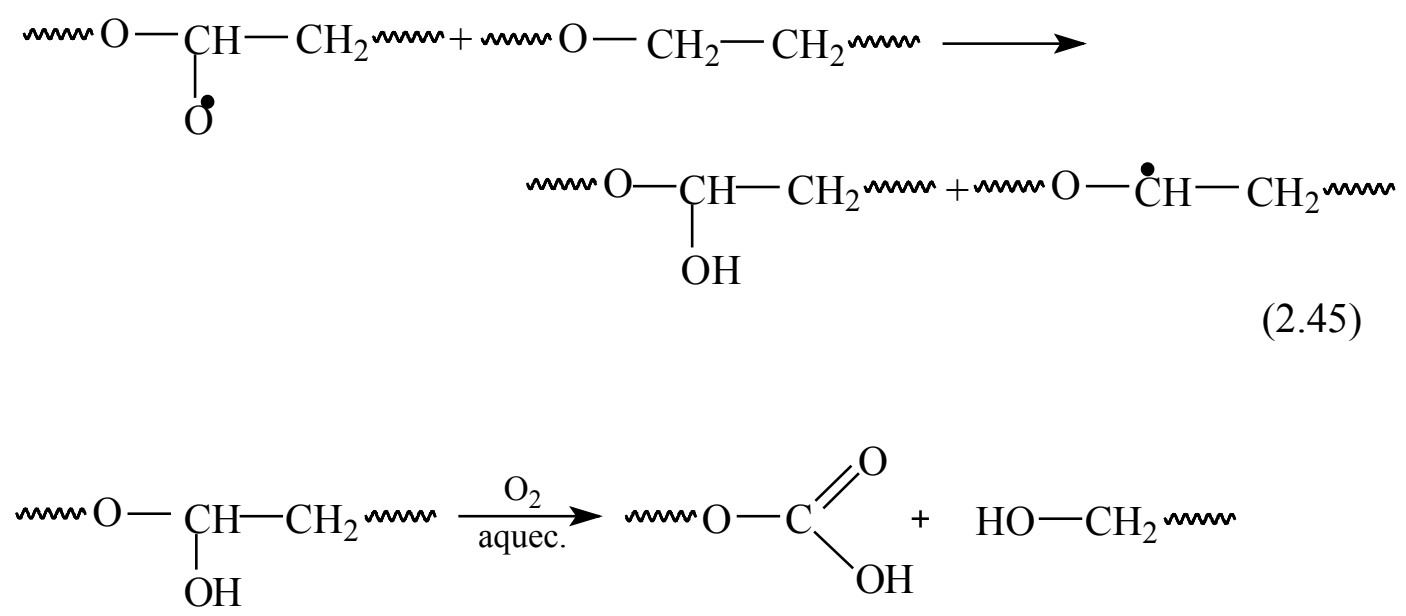

Em 2003, Morlart e Gardet repetiram os experimentos de irradiação ( $\lambda>300$ $\mathrm{nm}, 20^{\circ} \mathrm{C}$ ) do PEO, agora em solução aquosa (1 e 10\%), na presença de oxigênio a pH 3, 8 e 12, durante 520 horas de irradiação. A pH 12 não houve modificação da distribuição de pesos moleculares nem detecção de produtos. Para pH 8 houve quebra de cadeias e foram detectados três produtos: ácido fórmico, grupos terminais formato e éster, sendo a proporção éster:formato de 3:1. A pH 3 só houve quebra de cadeias e detecção de produtos após um período de indução de 50 horas de irradiação, com bandas características de formato e éster muito menores que as detectadas a $\mathrm{pH}$ 8. A principal diferença dos produtos detectados para o polímero no estado sólido e em solução foi a formação de ácido fórmico em $\mathrm{pH}$ neutro. Os autores não propõem outro mecanismo para as reações em solução e afirmam que seus resultados não permitem concluir que os mecanismos sejam os mesmos para as duas situações. Apesar da especulação da importância de reações iônicas, fica aberta a questão da reatividade próxima para o estado sólido e para soluções a pH ácido e neutro, uma vez que somente reações radicalares ocorrem no polímero sólido.

Gröllmann e Schnabel (1982) estudaram a degradação oxidativa por radiólise pulsada da poliacrilamida. Os autores mostram que, diferentemente do óxido de polietileno (PEO), a unidade de repetição da poliacrilamida tem três sítios de ataque para os radicais hidroxila (Figura 2.2). 
<smiles>CCC(C)C(N)=O</smiles>

(a)<smiles>CCC(C)C(N)=O</smiles>

(b)<smiles>C[CH]C(C)C(N)=O</smiles>

(c)<smiles>CCC(C)C(N)=O</smiles>

(d)

Figura 2.2 - (a): Unidade de repetição da poliacrilamida. (b), (c) e (d): Sítios de ataque para o radical hidroxila.

Lichtin (1971) realizou medidas de velocidades de abstração de hidrogênio por radicais hidroxila em meio aquoso de sítios específicos de amidas alifáticas de baixo peso molecular e mostrou que a razão de reatividade para os três sítios mostrados na Figura 2.2 é (b):(c):(d)=1:2:8. Os radicais (b), (c) e (d) podem ser formados simultaneamente e reagirem entre si ou com o $\mathrm{O}_{2}$ de acordo com as reações (2.26)-(2.29). A situação geral em relação à formação de produtos finais é, desta forma, muito mais complicada que no caso do PEO. Gröllmann e Schnabel (1982) mostraram que somente uma pequena fração dos radicais hidroxila que atacam a poliacrilamida leva à quebra da cadeia principal, que é acompanhada da formação de formaldeído. Concluíram pelas medidas cinéticas que um processo bimolecular (reação 2.28) é o passo determinante das reações que levam a cisão da cadeia principal, porém inferiram que os produtos dessa reação sofreram poucas reações envolvendo cisão de cadeias. Parece que PAM é muito menos efetivamente degradada sob ataque dos radicais hidroxila que PEO, que sofre quebra da cadeia principal, o que pode ser atribuído ao fato da unidade de repetição da poliacrilamida ter diferentes sítios de ataque para os radicais hidroxila, resultando em radicais com diferentes reatividades para a reação com o oxigênio. Pelo mesmo motivo a alta concentração de sítios radicalares leva a reações intramoleculares que desativam os radicais. Por fim os autores alertam para o fato de que suas conclusões foram 
baseadas em cinética determinística e que um tratamento baseado em cinética estocástica poderia levar a outras conclusões.

Kaczmarek et al. (1998) estudando a degradação foto-oxidativa da polivinilpirrolidona (PVP) em soluções aquosa, na presença de $\mathrm{H}_{2} \mathrm{O}_{2}$, propuseram as reações mostradas no esquema da Figura 2.3.

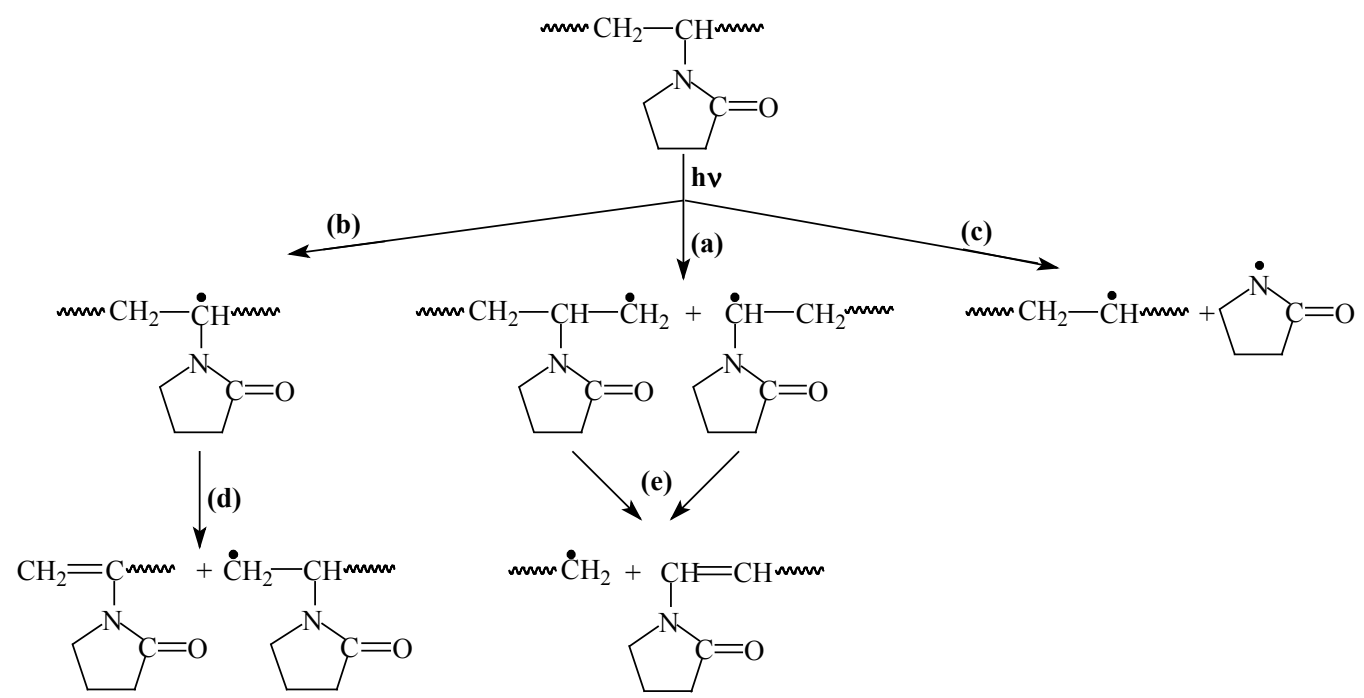

Figura 2.3. Esquema de reações para a degradação foto-oxidativa da polivilipirrolidona (Kaczmarek et al., 1998).

Os autores propõem os seguintes processos para a degradação da PVP:

- Abstração de hidrogênio: reação (b)

- Abstração do anel lateral: reação (c)

- Quebra da cadeia principal: reações (d) e (a)

- Despolimerização: reação (e)

- Oxidação, dada pela seguinte reação: $\mathrm{P}^{\bullet}+\mathrm{O}_{2} \rightarrow \mathrm{POO}^{\bullet}$

Não é apresentada no trabalho nenhuma seqüência de reações a partir da formação do radical alquilperoxila ( $\left.\mathrm{POO}^{\bullet}\right)$ e nem um estudo no sentido de identificar sítios preferenciais de ataque para a abstração de hidrogênio pelos radicais hidroxila.

Davis et al. (1981) degradaram vinilpirrolidona e polivinilpirrolidona por radiólise pulsada e propuseram dois possíveis sítios de ataque para os radicais hidroxila, um ocorrendo no grupo metileno adjacente ao nitrogênio no anel lateral e 
outro no carbono metino da cadeia principal, gerando os radicais mostrados na Figura 2.4 (a) e (b), respectivamente.

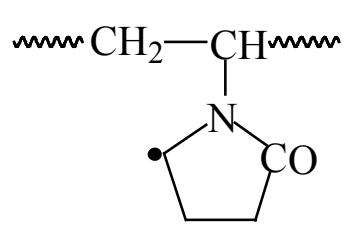

(a)

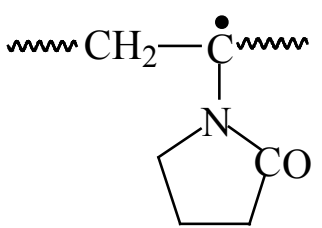

(b)

Figura 2.4. (a) e (b) Possíveis sítios de ataque para os radicais hidroxila na polivinilpirrolidona. 


\subsection{Modelagem Molecular}

Com auxílio de técnicas de modelagem molecular podem-se modelar estruturas moleculares e mecanismos reacionais, relacionando propriedades moleculares a processos macroscópicos e gerar informações quantitativas para substituir dados ou informações empíricas. Alguns métodos podem ser usados para modelar intermediários instáveis e até mesmo estados de transição, permitindo assim obter informações sobre moléculas e reações que são impossíveis de serem obtidas através da observação direta. Tais técnicas podem ser abordadas de duas formas: a Mecânica Molecular (MM) e a Teoria da Estrutura Eletrônica (ou Química Quântica); baseadas em:

i. cálculo da energia de uma estrutura molecular (arranjo espacial de núcleos atômicos e elétrons);

ii. otimização da geometria, que permite localizar estruturas moleculares de mínima energia, que correspondem a conformações permitidas;

iii. determinação das freqüências vibracionais resultantes dos movimentos atômicos intramoleculares.

\subsubsection{Mecânica Molecular}

Métodos de campo de força, também conhecidos como mecânica molecular, ignoram os movimentos eletrônicos e calculam a energia de um sistema como uma função somente das posições nucleares. Assim, a mecânica molecular é normalmente utilizada para realizar cálculos em sistemas contendo um número relativamente grande de átomos. Entretanto tais métodos não podem ser utilizados para calcular propriedades que dependem da distribuição eletrônica da molécula. Um dos principais atributos dos campos de força é a transferência de parâmetros, o que permite que um grupo de parâmetros desenvolvidos e testados para um número de casos relativamente pequeno seja aplicado a um grande número de problemas. Além disso, parâmetros desenvolvidos com dados de moléculas pequenas podem ser usados para estudar moléculas muito maiores, como por exemplo, polímeros (Leach, 2001). 
As técnicas de Mecânica Molecular baseiam-se nas leis da mecânica clássica e nos chamados campos de força, definidos por: i) uma função que determina como a energia potencial molecular varia em função das coordenadas nucleares, considerando contribuições das interações átomo-átomo, interações de van der Waals, interações eletrostáticas, e as energias envolvidas em torsões de ligações e em distorções de ângulos entre ligações; ii) propriedades atômicas que caracterizam os elementos químicos e seu comportamento quando em arranjos moleculares; iii) um ou mais conjuntos de parâmetros, que ajustam os cálculos a dados experimentais (Foresman e Frisch, 1996).

Muitos dos campos de força utilizados em modelagem molecular podem ser interpretados por quatro componentes que representam as forças inter e intramoleculares no sistema. As variações de energia são associadas com desvios de ligações e ângulos dos seus valores de referência ou equilíbrio. Há uma função que descreve como a energia varia quando a ligação é rotacionada. Finalmente, há um termo que descreve as interações entre as partes não ligadas do sistema. A equação E1 mostra um campo de força básico que soma essas quatro componentes energéticas para descrever o sistema molecular.

$$
\begin{array}{r}
v\left(\mathbf{r}^{\mathrm{N}}\right)=\sum_{\text {ligações }} \frac{k_{\mathrm{i}}}{2}\left(I_{\mathrm{i}}-I_{\mathrm{i}, 0}\right)^{2}+\sum_{\text {ângulos }} \frac{k_{\mathrm{i}}}{2}\left(\theta_{\mathrm{i}}-\theta_{\mathrm{i}, 0}\right)^{2}+\sum_{\text {torsões }} \frac{\mathrm{V}_{\mathrm{n}}}{2}(1+\cos (\mathrm{n} \omega-\gamma)) \\
+\sum_{\mathrm{i}=1}^{\mathrm{N}} \sum_{\mathrm{j}=\mathrm{i}+1}^{\mathrm{N}}\left(4 \varepsilon_{\mathrm{ij}}\left[\left(\frac{\sigma_{\mathrm{ij}}}{\mathrm{r}_{\mathrm{ij}}}\right)^{12}-\left(\frac{\sigma_{\mathrm{ij}}}{\mathrm{r}_{\mathrm{ij}}}\right)^{6}\right]+\frac{\mathrm{q}_{\mathrm{i}} \mathrm{q}_{\mathrm{j}}}{4 \pi \varepsilon_{0} \mathrm{r}_{\mathrm{ij}}}\right)
\end{array}
$$

Em que:

$v\left(\mathbf{r}^{\mathrm{N}}\right)$ : representa a energia potencial, que é uma função da distância $(\mathbf{r})$ de N partículas.

$k_{i}$ : constante de força

I: comprimento de ligação

$\varepsilon_{\mathrm{ij}}$ e $\sigma_{\mathrm{ij}}$ : parâmetros de Lennard-Jones para os átomos i e j

$\mathrm{q}_{\mathrm{i}}$ : carga parcial do átomo $\mathrm{i}$

$\mathrm{q}_{\mathrm{j}}$ : carga parcial do átomo $\mathrm{j}$ 
$\theta$ : ângulo de valência

$\varepsilon_{0}$ : constante dielétrica no vácuo

$\mathrm{V}_{\mathrm{n}}$ : barreira relativa da energia de torsão

$\omega$ : ângulo de torsão

n: multiplicidade

$\gamma$ : fator de fase

O primeiro termo da equação, modelado como um potencial harmônico fornece a variação da energia quando a ligação, de comprimento $l$ entre dois átomos varia de seu valor de referência $l_{0}$. O segundo termo, que é modelado como o primeiro, representa a variação da energia potencial devido a modificações dos ângulos de valência da molécula. Ângulo de valência é o ângulo formado entre os átomos $\mathrm{A}-\mathrm{B}-\mathrm{C}$ em que $\mathrm{A}$ e $\mathrm{C}$ estão ambos ligados a $\mathrm{B}$. $\mathrm{O}$ terceiro termo representa como a energia muda quando as ligações são rotacionadas e o quarto é a contribuição dos termos não ligados, isto é, pares de átomos i e j que podem estar em moléculas diferentes ou na mesma molécula, mas distantes por pelo menos três ligações. Em campos de força simples este termo considera as interações eletrostáticas como interações Coulômbicas e calcula as interações de van der Waals como o potencial de Lennard-Jones (Leach, 2001).

Uma das limitações da mecânica molecular é que um determinado campo de força geralmente não pode ser utilizado para todos os sistemas moleculares de interesse. Um campo de força fornece bons resultados somente para moléculas relacionadas com aquelas para os quais tal campo foi parametrizado. Outra limitação, já citada, é que a não inclusão dos elétrons não permite que a mecânica molecular seja empregada para tratar problemas em que os efeitos eletrônicos predominam, como, por exemplo, formação e quebra de ligações (Foresman e Frish, 1996).

\subsubsection{Teoria da Estrutura Eletrônica}

As técnicas baseadas na Teoria da Estrutura Eletrônica fundamentam-se nas leis da Mecânica Quântica, que representam explicitamente os elétrons, tornando possível obter propriedades que dependem da distribuição eletrônica, particularmente a investigação de reações químicas com quebra e formação de ligações. O ponto de 
partida da mecânica quântica é a consideração de que a energia de uma partícula e suas propriedades podem ser obtidas resolvendo-se a equação de Schrödinger, equação E2:

$$
\left\{-\frac{\hbar^{2}}{2 \mathrm{~m}}\left(\frac{\partial^{2}}{\partial \mathrm{x}^{2}}+\frac{\partial^{2}}{\partial \mathrm{y}^{2}}+\frac{\partial^{2}}{\partial \mathrm{z}^{2}}\right)+\mathrm{v}\right\} \Psi(\mathbf{r}, \mathrm{t})=\mathrm{i} \hbar \frac{\partial \Psi(\mathbf{r}, \mathrm{t})}{\partial \mathrm{t}}
$$

A equação 2 se refere a uma partícula simples, por exemplo, um elétron movendo-se através do espaço (cuja posição é dada pelo vetor: $\mathbf{r}=\mathrm{x} \mathbf{i}+\mathrm{y} \mathbf{j}+\mathrm{z} \mathbf{k}$ ) e do tempo (t) sob a influência de um campo potencial. $\hbar$ é a constante de Planck dividida por $2 \pi$ e 'i' é a raiz quadrada de -1 . $\Psi$ é a função de onda que caracteriza o movimento da partícula. É a partir dela que muitas propriedades da partícula são derivadas. Quando o potencial externo é independente do tempo, a equação de Schrödinger pode ser escrita como um produto de uma parte temporal e uma espacial: $\Psi(\mathbf{r}, \mathrm{t})=\varphi(\mathbf{r}) \mathrm{T}(\mathrm{t})$, tornando a equação mais simplificada:

$$
\left\{-\frac{\hbar^{2}}{2 \mathrm{~m}} \nabla^{2}+v\right\} \Psi(\mathbf{r})=\mathrm{E} \Psi(\mathbf{r})
$$

Em que

$$
\nabla^{2}=\frac{\partial^{2}}{\partial \mathrm{x}^{2}}+\frac{\partial^{2}}{\partial \mathrm{y}^{2}}+\frac{\partial^{2}}{\partial \mathrm{z}^{2}}
$$

O lado esquerdo da equação E3 é o operador Hamiltoniano:

$$
\mathbf{H}=-\frac{\hbar^{2}}{2 \mathrm{~m}} \nabla^{2}+v
$$

O que reduz a equação de Schrödinger à forma:

$$
\mathbf{H} \Psi=\mathrm{E} \Psi
$$

Para uma molécula a forma desta equação é bastante similar, e neste caso a função de onda depende das coordenadas de todas as partículas do sistema. A energia e outras propriedades podem ser obtidas resolvendo-se a equação E2 para $\psi(\vec{r}) \operatorname{com}$ condições de contorno apropriadas. Várias soluções são possíveis, correspondendo a 
diferentes estados estacionários do sistema molecular, cada qual caracterizado por uma energia diferente. No conjunto estas soluções definem uma superfície de energia potencial, cujos mínimos correspondem a espécies moleculares estáveis, e os pontos de cela representam estados de transição.

Diversas aproximações são usadas para simplificar a solução de equação de Schrödinger, tais como Born-Oppenheimer, Métodos semi-empíricos, métodos ab initio, ou métodos baseados na Teoria do Funcional de Densidade.

\section{Aproximação de Born-Oppenheimer}

É baseada na grande diferença de massa entre elétrons e núcleos. Considera que a distribuição eletrônica num sistema molecular depende da posição dos núcleos atômicos, mas não das velocidades com que se movem em relação aos elétrons. Esta aproximação permite que a equação de Schrödinger seja resolvida separadamente para o núcleo e os elétrons.

\section{Métodos semi-empíricos:}

Consideram apenas os elétrons da camada de valência e os demais são tratados utilizando-se parâmetros empíricos. O número de interações elétron-elétron é reduzido desconsiderando-se parcial ou totalmente as sobreposições dos orbitais atômicos. Métodos semi-empíricos só podem ser empregados para sistemas em que parâmetros tenham sido desenvolvidos para todos os átomos componentes. Podem ser aplicados como auxiliares nos cálculos de moléculas muito grandes, por exemplo, para uma pré-otimização gerando assim uma estrutura inicial que será otimizada com métodos mais precisos. Alguns métodos semi-empíricos bem conhecidos são: AM1 (Austin model 1) (Dewer et al., 1985), PM3 (parametrization model 3) (Stewart, 1989) e MNDO (modified neglect of differential overlap) (Dewer e Thiel, 1978).

\section{Métodos ab initio:}

Ab initio significa "do início" ou "dos primeiros princípios" o que implica que um cálculo usando tal aproximação necessitará como dados de entrada somente constantes físicas como velocidade da luz, constante de Planck, massas e cargas dos 
elétrons e dos núcleos, ou seja, não utilizará nenhum parâmetro experimental. Cálculos $a b$ initio são inteiramente baseados nas leis da mecânica quântica e envolvem procedimentos teóricos e conjuntos de bases (basis set). As bases são representações matemáticas de orbitais atômicos, podendo ser interpretadas como restrições à localização espacial dos elétrons. Conjuntos de bases mais amplos impõem menos restrições aos elétrons e aproximam os orbitais moleculares como uma combinação linear de orbitais atômicos.

Uma aproximação simples, que considera a molécula como um sistema eletrônico de camada fechada e descreve a energia de um elétron no campo médio dos outros (n-1) elétrons, conduz à solução de Hartree-Fock (HF). De fato os movimentos dos elétrons estão correlacionados e eles tendem a evitar um ao outro mais do que a teoria Hartree-Fock sugere, fornecendo sempre energias menores. De fato, os movimentos de elétrons de spins opostos não são correlacionados na teoria Hartree-Fock. A energia proveniente destas interações é conhecida como energia de correlação eletrônica.

Métodos mais sofisticados, conhecidos como Métodos de Correlação Eletrônica, procuram incluir os efeitos de correlação eletrônica, desprezadas pela teoria Hartree-Fock. Alguns desses métodos são: teoria da perturbação de MöllerPlesset (MP2, MP3, MP4 e MP5) (Pople et al., 1976; Krishnan e Pople, 1978), interações de configurações quadráticas (QCISD), métodos coupled cluster (CCD, CCSD) (Pople et al., 1978).

\section{Métodos baseados na Teoria do Funcional de Densidade (DTF)}

Procuram modelar a densidade eletrônica através de funcionais generalizados. Os funcionais de densidade representam a energia eletrônica nas componentes: energia cinética, energia de interação eletrônica nuclear, repulsão eletrostática coulômbica e um termo de energia de substituição-correlação, que considera as interações elétron-elétron restantes. Alguns exemplos de parametrizações do método DTF são: B3LYP e WVN (Parr e Yang, 1989; Becke, 1993). 


\subsubsection{Teoria do Estado de Transição}

Um dos conceitos fundamentais em dinâmica química é a idéia de que os átomos dentro das moléculas se movem de acordo com forças derivadas de um campo potencial que é determinado pelas interações eletrônicas. Uma descrição da energia em função de todas as possíveis coordenadas dos átomos é chamada de superfície potencial e em princípio pode ser obtida por cálculos de mecânica quântica. A trajetória de qualquer átomo na superfície de energia potencial, isto é, sua posição e momento em qualquer tempo, pode ser obtida resolvendo-se as equações clássicas de movimento. Uma avaliação clássica do coeficiente de velocidade pode ser obtida calculando-se um grande número de trajetórias e as velocidades das trajetórias que começam nos reagentes e terminam nos produtos na superfície de energia potencial. (Heuts et al., 1995).

A descrição matemática deste processo pode ser muito simplificada fazendose as suposições do Estado de Transição. Na Teoria do Estado de Transição (TST) supõe-se que existe uma geometria crítica na superfície de energia potencial de modo que todas as trajetórias que passam através desta geometria se originam nos reagentes e terminam nos produtos. A estrutura que tem esta geometria é chamada de Estado de Transição (TS) e sua energia normalmente é máxima no caminho de reação entre reagentes e produtos (Heuts et al., 1995).

Baseados na Teoria do Estado de transição McQuarrie e Simon (1997) apresentam a equação E7 para o cálculo da constante de velocidade.

$$
\mathrm{k}(\mathrm{T})=\frac{\mathrm{k}_{\mathrm{B}} \mathrm{T}}{\mathrm{hc}^{0}} \exp \left(\frac{-\Delta^{\ddagger} \mathrm{G}^{0}}{\mathrm{RT}}\right)
$$

Em que:

$\mathrm{k}(\mathrm{T})$ : constate de reação à temperatura $\mathrm{T}\left(\mathrm{L} \mathrm{mol}^{-1} \mathrm{~s}^{-1}\right)$

$\Delta^{\ddagger} \mathrm{G}^{0}$ : energia livre de Gibbs de ativação $\left(\mathrm{J} \mathrm{mol}^{-1}\right)$

$\mathrm{T}$ : temperatura $(\mathrm{K})$

$\mathrm{R}$ : constante universal dos gases $\left(8,314 \mathrm{~J} \mathrm{~mol}^{-1} \mathrm{~K}^{-1}\right)$

$\mathrm{K}_{\mathrm{B}}$ : constante de Boltzmann $\left(1,381 \times 10^{-23} \mathrm{~J} \mathrm{~K}^{-1}\right)$ 
h: constante de Planck $\left(6,626 \times 10^{-34} \mathrm{~J} \mathrm{~s}\right)$

$\mathrm{c}^{0}$ : concentração (normalmente $1 \mathrm{~mol} \mathrm{~L}^{-1}$ )

Pliego e Almeida (1999) apresentam com base na TST as expressões E8, E9 e E10 que permitem o cálculo da energia de ativação (Ea) e do fator pré-exponencial (A).

$\mathrm{Ea}=\Delta^{\ddagger} \mathrm{H}^{0}+\mathrm{RT}$

$$
\mathrm{A}=\frac{\mathrm{k}_{\mathrm{B}} \mathrm{T}}{\mathrm{hc^{0 }}} \exp \left(\frac{\Delta^{\ddagger} \mathrm{S}^{0}}{\mathrm{R}}+1\right)
$$

$\mathrm{k}(\mathrm{T})=\mathrm{A} \exp \left[\frac{-\mathrm{Ea}}{\mathrm{RT}}\right]$

Em que a entropia de ativação $\left(\Delta^{\ddagger} \mathrm{S}^{0}\right)$ pode ser calculada através da energia livre de Gibbs e da entalpia de ativação $\left(\Delta^{\ddagger} H^{0}\right)$ (equação E11), que são obtidos diretamente dos cálculos do Gaussian (Oshterski, 2000).

$$
\Delta^{\ddagger} \mathrm{S}^{0}=\frac{\Delta^{\ddagger} \mathrm{H}^{0}-\Delta^{\ddagger} \mathrm{G}^{0}}{\mathrm{~T}}
$$




\section{MATERIAIS E METODOLOGIA}

\subsection{Equipamento}

Utilizou-se um reator fotoquímico anular de $0,8 \mathrm{~L}$, com uma lâmpada de vapor de mercúrio de média pressão (Philips HPLN, $400 \mathrm{~W}$, sem o bulbo externo), envolvida por uma camisa de resfriamento, imersa no meio reacional. O reator foi conectado a um tanque de recirculação de $2 \mathrm{~L}$, encamisado e a um banho termostático (Tecnal Te-184). O reator foi isolado por uma caixa metálica vedada, para evitar perda da radiação e para proteção contra a radiação da lâmpada. As conexões entre o reator e o tanque de recirculação foram feitas por meio de mangueiras de silicone e o volume total de solução nas mangueiras foi de aproximadamente $150 \mathrm{~mL}$. A vazão de solução do reator para o tanque de recirculação foi de 2,4 L/min. A temperatura da solução no tanque de recirculação foi indicada por meio de um termômetro digital (Oakton, 90080-00) e o pH foi medido por um pH-metro digital (Quimis, Q-400BC). A solução foi agitada para manter a homogeneidade por um agitador mecânico (Ética 3600). A solução de peróxido de hidrogênio foi dosada por uma bomba peristáltica (ISMATEC, IPC-4 V3.01) com vazões de 1,11 e $0,67 \mathrm{~mL} \mathrm{~min}^{-1}$, dependendo das condições experimentais detalhadas adiante. A Figura 3.1 apresenta o esquema do equipamento.

As distribuições espectrais de uma lâmpada de vapor de mercúrio de média pressão Ace Hanovia, fornecida pelo fabricante e da lâmpada HPLN Philips utilizada nos experimentos são mostradas nas Figuras 3.2 (a) e (b). 


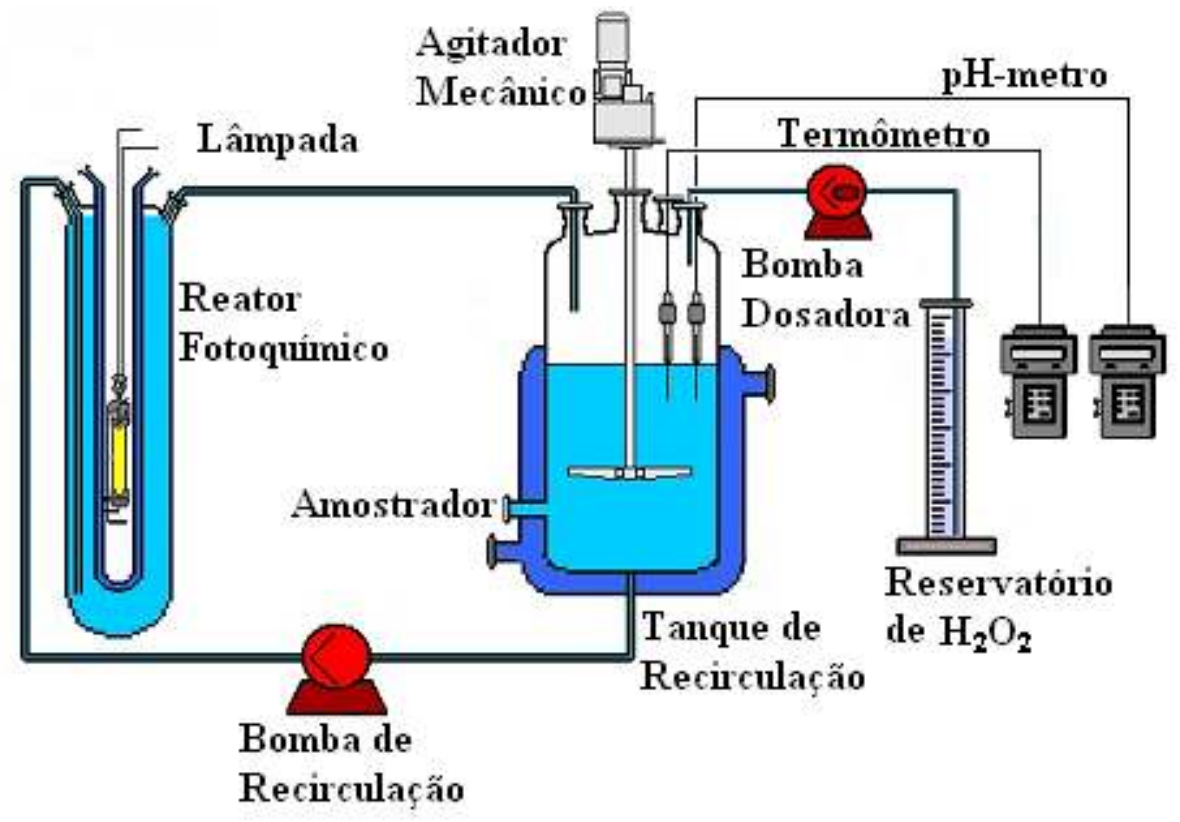

Figura 3.1 - Esquema do equipamento.

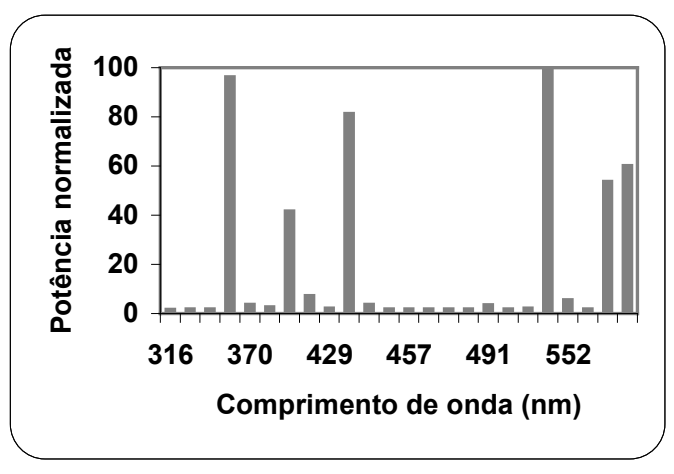

(a) Philips HPLN

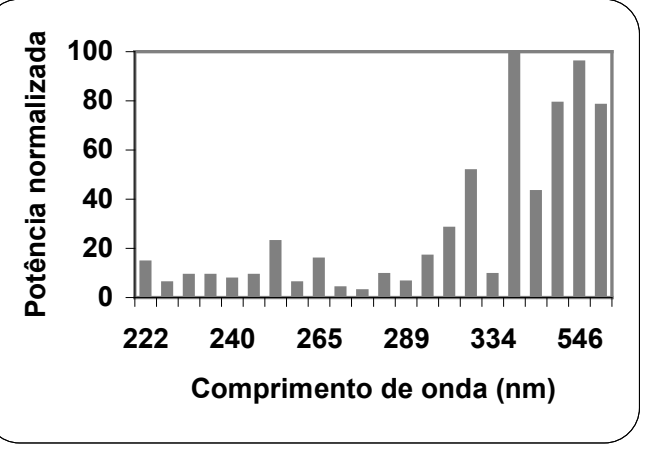

(b) Ace Hanovia

Figura 3.2 - Distribuições espectrais das lâmpadas de vapor de mercúrio de media pressão fornecidas pelos fabricantes.

A lâmpada Philips é comercializada com um bulbo que filtra os comprimentos de onda abaixo de $315 \mathrm{~nm}$, pois é utilizada normalmente para fins de iluminação, por isso o fabricante só disponibiliza os dados a partir deste valor como mostrado na Figura 3.2(a). Porém, para sua aplicação nos experimentos de degradação este bulbo foi cortado. $\mathrm{O}$ espectro de uma lâmpada equivalente, Ace Hanovia, que é normalmente utilizada em experimentos fotoquímicos é mostrado na Figura 3.2(b). Pode-se observar que ambas têm potência máxima em comprimentos de onda próximos: 364, 404, 432, 546, 576 e $580 \mathrm{~nm}$ para a Philips e 366, 404, 436, 
546 e $578 \mathrm{~nm}$ para a Hanovia. Como se trata do mesmo tipo de lâmpada pode-se deduzir que a Philips também tem potência significativa em 253,7 e $265 \mathrm{~nm}$ como a Hanovia.

\subsection{Materiais}

Foram utilizados os seguintes materiais para análise (PA): sulfato ferroso penta-hidratado, peróxido de hidrogênio $30 \% \mathrm{~m} / \mathrm{m}$, hidróxido de sódio, iodeto de potássio, sulfito de sódio anidro, ácido sulfúrico, PEG 6000 Vetec, PEG 20000 Merck, PVP Vetec, PAM Aldrich 50 wt\% densidade 1,189 kg/L.

Para construção da curva de calibração para GPC, utilizaram-se padrões de polietilenoglicol, Phenomenex, com pesos moleculares: 106, 194, 400, 580, 940, $1470,4240,6000$ e $22400 \mathrm{~g} \mathrm{~mol}^{-1}$. Para a construção das curvas de calibração para HPLC utilizaram-se os seguintes ácidos: acético glacial, Merck 100\%; acrílico, Aldrich 99\%; cítrico, Fluka 99,5\%; fórmico, Sigma-Aldrich 95\%; fumárico, Carlo Erba 99,5\%; glicólico, J. T. Baker 98\%; glioxílico, Aldrich 98\%; malônico, Acros Organics 99\%; oxâmico, Sigma-Aldrich 98\%; oxálico, Mallink Kropt 100\% e tartárico, Fluka 99,5\%. Acrilamida, Aldrich 99\% e oxamida, Merck 98\%.

As soluções de polímero, ferro e peróxido foram preparadas com água destilada. As soluções para a fase móvel e as soluções padrões para análises de GPC e HPLC foram preparadas com água milli-Q.

Utilizaram-se seringas e agulhas descartáveis, filtros Millipore GV Millex, com membrana durapore, $0,22 \mu \mathrm{m}$ de poro e $13 \mathrm{~mm}$ de diâmetro e papel de filtro quantitativo de filtragem lenta (porosidade $2 \mu \mathrm{m}$ ). A extração de fase sólida para análise de HPLC foi feita com filtros Waters Sep-Pak ${ }^{\circledR}$ C18 Cartridges.

\subsection{Análises}

A concentração do carbono orgânico dissolvido (COD) foi analisada no equipamento Shimadzu 5000A, em função do tempo de reação. Fizeram-se análises de cromatografia líquida de alta eficiência (HPLC), em um cromatógrafo Shimadzu Class-VP com detector UV-Visível de arranjo de diodos SPDM-10AVP, com coluna 
de exclusão iônica Hamilton PRP-X300. No mesmo cromatógrafo foram feitas análises de cromatografia de permeação em gel (GPC), com detector de índice de refração RID-10A e coluna Phenomenex polySep-GFC-P3000 e polySep-GFCP2000.

Para as análises de COD, as amostras do processo foto-Fenton foram tratadas com uma solução inibidora para impedir que a reação Fenton continuasse após estas serem retiradas do reator. A reação Fenton independe da luz e continua ocorrendo, mesmo nos tubos de ensaio, desde que os reagentes Fenton, $\mathrm{Fe}(\mathrm{II}) \mathrm{e}_{2} \mathrm{H}_{2}$, estejam presentes no meio. Outro motivo para se usar a solução inibidora é a própria análise de carbono orgânico, pois o equipamento é sensível à presença de sais acima de $3 \%$, podendo haver interferência na leitura e danificando-o após algum tempo de uso.

A solução inibidora utilizada foi proposta por Lei et al. (1998), e consiste em uma solução contendo $\mathrm{Na}_{3} \mathrm{PO}_{4}, \mathrm{KI}$ e $\mathrm{Na}_{2} \mathrm{SO}_{3}$, na concentração de 0,1 molar cada. As reações dos componentes desta solução com os íons ferro e o peróxido são dadas nas equações de 3.1 a 3.5 .

O fosfato precipita os íons ferro:

$$
\begin{aligned}
& \mathrm{PO}_{4}^{3+}+\mathrm{Fe}^{2+} \rightarrow \mathrm{Fe}_{3}\left(\mathrm{PO}_{4}\right)_{2} \\
& \mathrm{PO}_{4}^{3+}+\mathrm{Fe}^{3+} \rightarrow \mathrm{FePO}_{4}
\end{aligned}
$$

$\mathrm{O}$ iodeto reduz o peróxido a $\mathrm{H}_{2} \mathrm{O}$.

$$
2 \mathrm{H}^{+}+2 \mathrm{I}^{-}+\mathrm{H}_{2} \mathrm{O}_{2} \rightarrow \mathrm{I}_{2}+2 \mathrm{H}_{2} \mathrm{O}
$$

O sulfito de sódio também reduz o peróxido à água e o iodo proveniente da reação 3.3 .

$$
\begin{aligned}
& \mathrm{Na}_{2} \mathrm{SO}_{3}+\mathrm{H}_{2} \mathrm{O}_{2} \rightarrow \mathrm{Na}_{2} \mathrm{SO}_{4}+\mathrm{H}_{2} \mathrm{O} \\
& \mathrm{Na}_{2} \mathrm{SO}_{3}+\mathrm{I}_{2}+\mathrm{H}_{2} \mathrm{O} \rightarrow \mathrm{Na}_{2} \mathrm{SO}_{4}+2 \mathrm{HI}
\end{aligned}
$$

A solução inibidora foi adicionada às amostras na proporção $3: 2 \mathrm{v} / \mathrm{v}$ (amostra:solução) e depois foram filtradas com filtro Millipore GV Millex 0,22 $\mu \mathrm{m}$ 
de poro. As amostras do processo $\mathrm{UV} / \mathrm{H}_{2} \mathrm{O}_{2}$ não receberam tratamento antes da análise de COD.

Quando se formou muito precipitado na seringa, após a adição do inibidor, as amostras para análise de COD foram centrifugadas (Bio-Eng BE-4004), a $3200 \mathrm{rpm}$ durante 30 minutos, para facilitar a filtragem posterior com filtro Millipore.

Para análise de HPLC e GPC, no processo foto-Fenton, adicionaram-se 2 gotas de $\mathrm{NaOH} 10 \mathrm{~mol} \mathrm{~L}^{-1}$ em $10 \mathrm{~mL}$ de amostra retirada do reator, e filtrou-se a solução com filtro Millipore, acidificando a solução filtrada com $\mathrm{H}_{2} \mathrm{SO}_{4}$ concentrado até atingir $\mathrm{pH}$ de aproximadamente 3. No processo $\mathrm{UV} / \mathrm{H}_{2} \mathrm{O}_{2}$ as amostras foram simplesmente filtradas, com filtros Millipore, após a coleta. Antes das análises de HPLC estas amostras filtradas ainda foram submetidas à extração de fase sólida (SPE), com o seguinte procedimento: adaptaram-se os filtros Waters em seringas de vidro e fixou-se o conjunto em suportes, na vertical, com a ponta para baixo. Os filtros foram ativados com $4 \mathrm{~mL}$ de metanol, seguidos de $8 \mathrm{~mL}$ de água Milli-Q, passados em duas vezes. Logo após filtrou-se uma solução de $2 \mathrm{~mL}$ de amostra em $3 \mathrm{~mL}$ de água milli-Q. Esta solução filtrada foi submetida à análise de HPLC. Todo o processo de filtração foi feito por gravidade, sem que o êmbolo da seringa fosse empurrado.

\subsection{Procedimento Experimental}

As soluções de polímero foram obtidas dissolvendo-se pequenas quantidades deste em $50 \mathrm{~mL}$ de água, sob aquecimento e agitação, em um agitador magnético (Quimis, Q-621-2). A agitação foi controlada para evitar formação de espuma.

Todos os experimentos foram realizados com um volume total de 2 litros de solução no sistema. As amostras foram retiradas pela mangueira que conectava o reator ao tanque de recirculação. O procedimento experimental pode ser resumido da seguinte forma:

- Preparar $100 \mathrm{~mL}$ de solução de $\mathrm{FeSO}_{4} \cdot 7 \mathrm{H}_{2} \mathrm{O}$, com a massa total de ferro necessária para atingir a concentração definida para o experimento.

- Preparar $100 \mathrm{~mL}$ de solução de $\mathrm{H}_{2} \mathrm{O}_{2}$, com a massa total de peróxido necessária para atingir a concentração definida para o experimento. 
- Preparar $100 \mathrm{~mL}$ de solução do polímero com a massa total definida para o experimento.

- Adicionar água destilada ao sistema de forma que a soma dos volumes das soluções de polímero, $\mathrm{Fe}(\mathrm{II}), \mathrm{H}_{2} \mathrm{O}_{2}$ e da água seja de 2 litros.

- Ligar a bomba de recirculação.

- Ligar o agitador mecânico.

- Ligar o banho termostático, ajustado para a temperatura estabelecida para o ensaio.

- Adicionar a solução de polímero.

- Acionar a água de resfriamento da lâmpada.

- Quando a temperatura atingir o valor desejado, retirar a primeira amostra.

- Fechar a caixa do reator.

- Ao mesmo tempo: ligar a lâmpada, acionar o cronômetro, ligar a bomba peristáltica para começar a dosar a solução de peróxido e adicionar a solução de ferro.

- Acidificar a solução do sistema com ácido sulfúrico concentrado, obtendo o pH com valor próximo a 3 .

- Retirar a segunda amostra, no tempo estabelecido. Para análise de COD, no processo foto-Fenton, adicionar, logo após a amostra ser retirada, $4 \mathrm{~mL}$ de inibidor em $6 \mathrm{~mL}$ de amostra. Para o processo $\mathrm{UV} / \mathrm{H}_{2} \mathrm{O}_{2}$ a amostra foi levada imediatamente para análise, sem tratamento.

- Agitar a solução com inibidor dentro da seringa; se necessário fazer uma préfiltragem a vácuo e/ou centrifugar a amostra. Adaptar o filtro Millex GV à ponta da seringa e filtrar a amostra. Levar a amostra filtrada para análise de COD.

- Repetir o procedimento para as demais amostras retiradas em outros intervalos de tempo.

\subsection{Concentrações}

Realizaram-se experimentos seguindo um planejamento experimental composto por projetos fatoriais completos para três variáveis: para o processo fotoFenton: concentração de $\mathrm{Fe}(\mathrm{II})$, concentração de polímero e concentração de $\mathrm{H}_{2} \mathrm{O}_{2}$; 
para o processo $\mathrm{UV} / \mathrm{H}_{2} \mathrm{O}_{2}$ : temperatura, concentração de polímero e concentração de $\mathrm{H}_{2} \mathrm{O}_{2}$. A Tabela 3.1 representa os níveis escolhidos para as variáveis do planejamento e as condições experimentais para os três polímeros: processo utilizado, temperatura, tempo total de reação, vazão da solução de $\mathrm{H}_{2} \mathrm{O}_{2}$ e valor do $\mathrm{pH}$. O nível superior é representado por +1 o inferior por -1 e o ponto central por PC. A concentração de polímero, ferro e peróxido de hidrogênio são representadas por: [Pol]; [Fe(II)] e $\left[\mathrm{H}_{2} \mathrm{O}_{2}\right]$, respectivamente. A resposta foi a concentração de carbono orgânico dissolvido e os experimentos foram realizados aleatoriamente.

Tabela 3.1 - Níveis das variáveis e condições dos experimentos.

\begin{tabular}{c|c|c|c}
\hline Variáveis & $\mathbf{+ 1}^{\mathbf{a}}$ & $\mathbf{- 1}^{\mathbf{b}}$ & $\mathbf{P C}^{\mathbf{c}}$ \\
\hline$[$ Pol $]\left(\mathbf{m g C ~ L ~ L}^{\mathbf{1}}\right)$ & 1500 & 500 & 1000 \\
\hline
\end{tabular}

PEG Foto-Fenton

\begin{tabular}{c|c|c|c}
$\left(30{ }^{\circ} \mathrm{C} ; \mathrm{pH}=3 ; 120\right.$ minutos de reação, $\left.{ }^{\mathrm{d}} \mathrm{Q}_{\mathrm{H} 2 \mathrm{O} 2}=1,11 \mathrm{~mL} \mathrm{~min}^{-1}\right)$ \\
\hline$\left[\mathbf{H}_{2} \mathbf{O}_{2}\right](\mathbf{m M})$ & 160 & 60 & 110 \\
{$[\mathbf{F e}(\mathbf{I I})](\mathbf{m M})$} & 1,5 & 0,5 & 1,0 \\
\hline
\end{tabular}

\section{PEG UV/ $/ \mathrm{H}_{2} \mathrm{O}_{2}$}

(pH livre; 120 minutos de reação, $\mathrm{Q}_{\mathrm{H} 2 \mathrm{O} 2}=1,11 \mathrm{~mL} \mathrm{~min}^{-1}$ )

\begin{tabular}{c|c|c|c}
\hline$\left[\mathrm{H}_{2} \mathbf{O}_{2}\right](\mathbf{m M})$ & 160 & 60 & 110 \\
Temperatura $\left({ }^{\circ} \mathbf{C}\right)$ & 50 & 30 & 40 \\
\hline
\end{tabular}

\section{PAM Foto-Fenton}

\begin{tabular}{c|c|c|c}
$\left(50{ }^{\circ} \mathrm{C} ; \mathrm{pH}=3 ; 180\right.$ minutos de reação, $\left.\mathrm{Q}_{\mathrm{H} 2 \mathrm{O} 2}=0,67 \mathrm{~mL} \mathrm{~min}^{-1}\right)$ \\
\hline$\left[\mathbf{H}_{\mathbf{2}} \mathbf{O}_{\mathbf{2}}\right](\mathbf{m M})$ & 700 & 300 & 500 \\
{$[\mathbf{F e}(\mathbf{I I})](\mathbf{m M})$} & 2,5 & 0,5 & 1,5 \\
\hline
\end{tabular}

\section{PVP Foto-Fenton}

$\left(50{ }^{\circ} \mathrm{C} ; \mathrm{pH}=3 ; 180\right.$ minutos de reação, $\left.\mathrm{Q}_{\mathrm{H} 2 \mathrm{O} 2}=0,67 \mathrm{~mL} \mathrm{~min}^{-1}\right)$

\begin{tabular}{c|c|c|c}
\hline$\left[\mathbf{H}_{2} \mathbf{O}_{2}\right](\mathbf{m M})$ & 450 & 150 & 300 \\
{$[\mathbf{F e}(\mathbf{I I})](\mathbf{m M})$} & 2,5 & 0,5 & 1,5 \\
\hline $\mathbf{a}, \mathbf{b}, \mathbf{c}$ representam a concentração da variável no nível máximo
\end{tabular}
$(+1)$; mínimo (-1) e no ponto central, respectivamente.

${ }^{d} \mathbf{Q}_{\mathbf{H} 2 \mathrm{O} 2}$ vazão de peróxido de hidrogênio dosado até 30 minutos antes do término do experimento. 


\section{RESULTADOS EXPERIMENTAIS}

\subsection{Experimentos Exploratórios}

Os experimentos exploratórios tiveram por objetivo determinar qual dos dois processos, $\mathrm{UV} / \mathrm{H}_{2} \mathrm{O}_{2}$ ou foto-Fenton, é mais adequado para degradação dos polímeros estudados, assim como os efeitos das variáveis consideradas sobre a taxa de degradação.

\subsubsection{Polietilenoglicol}

$\mathrm{Na}$ literatura pesquisada não se havia encontrado aplicação de processo fotoFenton e/ou $\mathrm{UV} / \mathrm{H}_{2} \mathrm{O}_{2}$ para a degradação de polietilenoglicol. Encontraram-se referências à oxidação via úmida (WAO) (Matzavinos et al., 1996) e ozonização (Andreozzi et al., 1996). A concentração inicial utilizada nesses trabalhos era de $1 \mathrm{~g}$ $\mathrm{L}^{-1}$ de PEG para WAO e, no caso da ozonização, $0,024 \mathrm{~g} \mathrm{~L}^{-1}$.

Baseado em Giroto et al. (2006), e Lei et al. (1998), determinou-se a concentração de $\mathrm{H}_{2} \mathrm{O}_{2}$ de acordo com sua quantidade estequiométrica necessária para oxidar as unidades monoméricas do polímero de PEG $\left(\mathrm{C}_{2} \mathrm{H}_{4} \mathrm{O}\right)$, segundo a reação:

$$
\mathrm{C}_{2} \mathrm{H}_{4} \mathrm{O}+5 \mathrm{H}_{2} \mathrm{O}_{2} \longrightarrow 2 \mathrm{CO}_{2}+7 \mathrm{H}_{2} \mathrm{O}
$$

A concentração de Fe(II) seguiu a relação:

$$
\frac{\mathrm{n}(\mathrm{Fe}(\mathrm{II}))}{\mathrm{n}\left(\mathrm{C}_{2} \mathrm{H}_{4} \mathrm{O}\right)}=\frac{1}{20}
$$

Em que:

$\mathrm{n}((\mathrm{Fe}(\mathrm{II})) \quad$ Número de moles de $\mathrm{Fe}(\mathrm{II})$.

$\mathrm{n}\left(\mathrm{C}_{2} \mathrm{H}_{4} \mathrm{O}\right) \quad$ Número de moles de unidade monomérica.

Assim, para uma concentração inicial de PEG de $1 \mathrm{~g} / \mathrm{L}\left(550 \mathrm{mgC}^{-1}\right)$ utilizaram-se 1,13 mM de $\mathrm{Fe}(\mathrm{II})$ e $113,6 \mathrm{mM}$ de $\mathrm{H}_{2} \mathrm{O}_{2}$ equivalente a $100 \%$ da quantidade estequiométrica de $\mathrm{H}_{2} \mathrm{O}_{2}$ de acordo com a reação 4.1 e 85,23 mM, 
equivalente, a $75 \%$ da quantidade estequiométrica. Os resultados de alguns experimentos exploratórios são apresentados na Figura 4.1.

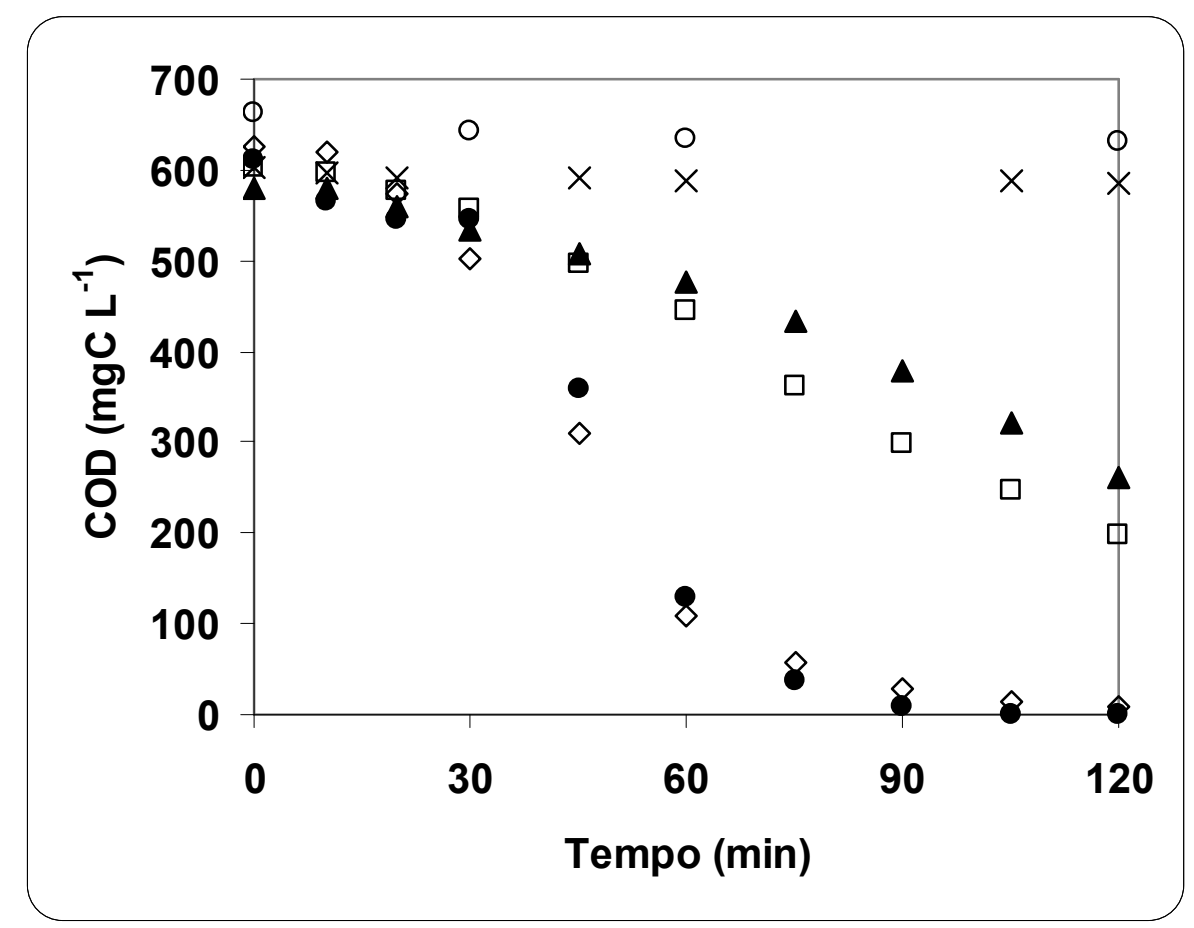

Figura 4.1 - Carbono Orgânico Dissolvido (COD) em função do tempo de reação para $[\mathrm{PEG}]=550 \mathrm{mgC} \mathrm{L}{ }^{-1}$. o Fotólise, $\mathrm{T}=30{ }^{\circ} \mathrm{C} \times$ Fotólise, $\mathrm{T}=50{ }^{\circ} \mathrm{C}$; $\mathrm{UV} / \mathrm{H}_{2} \mathrm{O}_{2},\left[\mathrm{H}_{2} \mathrm{O}_{2}\right]=85,23 \mathrm{mM}, \mathrm{T}=30{ }^{\circ} \mathrm{C} ; \square \mathrm{UV} / \mathrm{H}_{2} \mathrm{O}_{2},\left[\mathrm{H}_{2} \mathrm{O}_{2}\right]=113,6 \mathrm{mM}, \mathrm{T}=30{ }^{\circ} \mathrm{C}$;

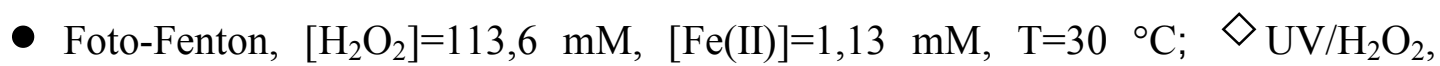
$\left[\mathrm{H}_{2} \mathrm{O}_{2}\right]=113,6 \mathrm{mM}, \mathrm{T}=50{ }^{\circ} \mathrm{C}$.

Durante a fotólise não houve adição de peróxido nem de ferro. A solução de PEG foi irradiada durante 240 minutos, com a temperatura sendo mantida em $30^{\circ} \mathrm{C}$, ou em $50{ }^{\circ} \mathrm{C}$. Na Figura 4.1 são mostrados resultados até 2 horas de reação porque a concentração de COD permaneceu praticamente constante durante as 4 horas de experimento, ou seja, só a ação da lâmpada não foi suficiente para diminuir a carga orgânica. No processo $\mathrm{UV} / \mathrm{H}_{2} \mathrm{O}_{2}$, o aumento da concentração de peróxido de 85,23 para $113,6 \mathrm{mM}$ aumentou a remoção final de COD de 55 para $67 \%$ e o aumento da temperatura de 30 para $50{ }^{\circ} \mathrm{C}$ levou a $100 \%$ de remoção em 120 minutos. O processo foto-Fenton a $30{ }^{\circ} \mathrm{C}$ foi equivalente ao $\mathrm{UV} / \mathrm{H}_{2} \mathrm{O}_{2}$ a $50{ }^{\circ} \mathrm{C}$ alcançando remoção total de COD em duas horas de experimento. Considerando-se as vantagens de um 
processo em que não é necessário utilizar ferro, cujo limite de descarte estabelecido pelo CONAMA é de $15 \mathrm{mg} \mathrm{L}^{-1}$, e de outro que pode ser realizado a temperatura mais baixa, optou-se por estudar ambos os processos para PEG e estabeleceram-se os limites mostrados na Tabela 3.1.

\subsubsection{Poliacrilamida}

A concentração de PAM utilizada no trabalho de Ramsden e McKay, (1996), para o processo foto-Fenton foi de $5 \mathrm{~g} \mathrm{~L}^{-1}\left(2535 \mathrm{mgC} \mathrm{L}^{-1}\right)$ no trabalho de Susuki et al. (1979), para ozonização foi de $1 \mathrm{~g} \mathrm{~L}^{-1}\left(507 \mathrm{mgC} \mathrm{L}^{-1}\right)$ e no de Imamura et al. (1981), de 0,98 $\mathrm{g} \mathrm{L}^{-1}$ (500 $\mathrm{mgC} \mathrm{L}^{-1}$ ) para WAO. Como no trabalho de Ramsden não foi feito o acompanhamento do carbono orgânico ao longo da reação, somente de viscosidade, e as concentrações de ferro (II) e peróxido de hidrogênio foram muito baixas, máximo de 0,89 mM, optou-se por utilizar $2 \mathrm{~g} \mathrm{~L}^{-1}\left(1014 \mathrm{mgC} \mathrm{L}^{-1}\right)$ de PAM nos experimentos exploratórios. A concentração de $\mathrm{H}_{2} \mathrm{O}_{2}$ foi calculada em relação às reações (4.2) e (4.3), sendo utilizada $281,67 \mathrm{mM}$ equivalente a $100 \%$ da quantidade estequiométrica de $\mathrm{H}_{2} \mathrm{O}_{2}$. A concentração de ferro (II) seguiu a relação molar de 1:20 $\mathrm{Fe}(\mathrm{II}):\left(\mathrm{C}_{3} \mathrm{H}_{5} \mathrm{ON}\right)$.

$$
\begin{aligned}
& \mathrm{C}_{3} \mathrm{H}_{5} \mathrm{ON}+5 \mathrm{O}_{2} \longrightarrow 3 \mathrm{CO}_{2}+2 \mathrm{H}_{2} \mathrm{O}+1 \mathrm{HNO}_{3} \\
& \mathrm{H}_{2} \mathrm{O}_{2} \longrightarrow 1 / 2 \mathrm{O}_{2}+\mathrm{H}_{2} \mathrm{O}
\end{aligned}
$$

Na Figura 4.2 são apresentados os valores de COD em função do tempo para fotólise (a $50{ }^{\circ} \mathrm{C}$ ), processo $\mathrm{UV} / \mathrm{H}_{2} \mathrm{O}_{2}$ a 30 e $50{ }^{\circ} \mathrm{C}$ e processo foto-Fenton a 30 e 50 ${ }^{\circ} \mathrm{C}$. Observa-se que o COD praticamente não se alterou somente com a ação da luz, fotólise, e que as temperaturas maiores foram mais eficientes, em termos de remoção final de COD em ambos os processos. Porém, como no caso do PEG, a opção entre $\mathrm{UV} / \mathrm{H}_{2} \mathrm{O}_{2}$ e foto-Fenton não é clara e apesar de ambos os processos merecerem maior investigação neste trabalho será estudado apenas o foto-Fenton para PAM. Assim, optou-se por aumentar as concentrações de reagentes no plano experimental e trabalhar-se à temperatura de $50^{\circ} \mathrm{C}$. 


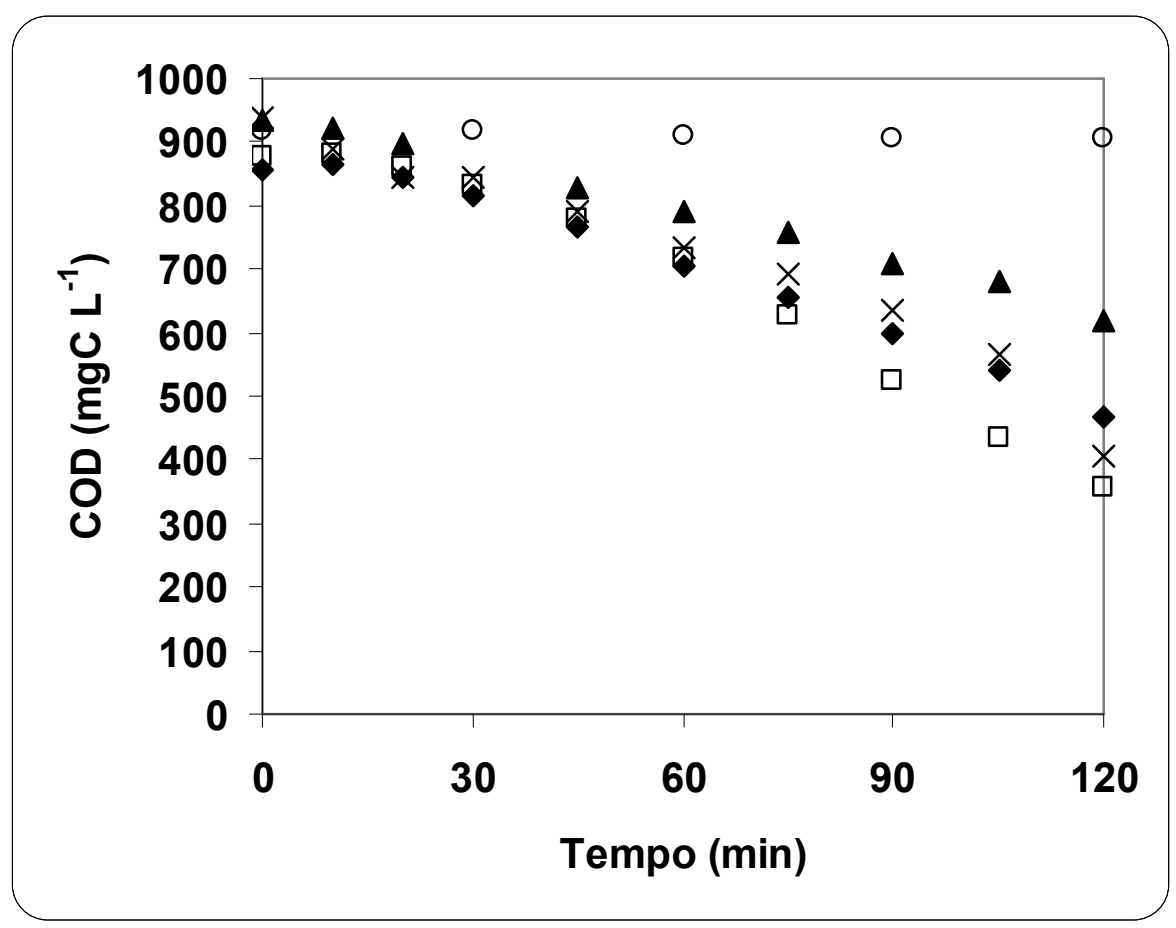

Figura 4.2 - Carbono Orgânico Dissolvido (COD) em função do tempo de reação para $[\mathrm{PAM}]=1000 \mathrm{mgC} \mathrm{L}^{-1}$. o Fotólise, $\mathrm{T}=50^{\circ} \mathrm{C}$; $\diamond$ Foto-Fenton, $\left[\mathrm{H}_{2} \mathrm{O}_{2}\right]=281,7 \mathrm{mM},[\mathrm{Fe}(\mathrm{II})]=1,4 \mathrm{mM}, \mathrm{T}=30^{\circ} \mathrm{C}$; $\square$ Foto-Fenton, $\left[\mathrm{H}_{2} \mathrm{O}_{2}\right]=281,7 \mathrm{mM}$, $[\mathrm{Fe}(\mathrm{II})]=1,4 \mathrm{mM}, \mathrm{T}=50^{\circ} \mathrm{C} ; \boldsymbol{\Delta} \mathrm{UV} / \mathrm{H}_{2} \mathrm{O}_{2},\left[\mathrm{H}_{2} \mathrm{O}_{2}\right]=281,7 \mathrm{mM}, \mathrm{T}=30^{\circ} \mathrm{C} ; . \times \mathrm{UV} / \mathrm{H}_{2} \mathrm{O}_{2}$, $\left[\mathrm{H}_{2} \mathrm{O}_{2}\right]=281,7 \mathrm{mM}, \mathrm{T}=50^{\circ} \mathrm{C}$.

\subsubsection{Polivinilpirrolidona}

Kaczmarek et al. (1998) e Panarin e Gravilova (1997), estudaram a degradação de soluções aquosas de PVP sob ação de $\mathrm{H}_{2} \mathrm{O}_{2}$, porém com concentrações de PVP superiores $6 \mathrm{~g} \mathrm{~L}^{-1}$, ou seja, $4000 \mathrm{mgC} \mathrm{\textrm {L } ^ { - 1 }}$ e concentrações de peróxido de hidrogênio muito baixas, de 1 a $3 \%$ em massa relativo à concentração de PVP. Assim, nos experimentos exploratórios utilizou-se esta concentração de PVP, porém a concentração de $\mathrm{H}_{2} \mathrm{O}_{2}$ foi de $50 \%$ da quantidade estequiométrica necessária para oxidar as unidades monoméricas de PVP conforme as reações (4.4) e (4.5), 485,9 mM. A concentração de $\mathrm{Fe}(\mathrm{II})$ seguiu a relação molar de 1:20 $\mathrm{Fe}(\mathrm{II}):\left(\mathrm{C}_{6} \mathrm{H}_{9} \mathrm{ON}\right)$. Os resultados de $\mathrm{COD}$ em função do tempo são apresentados na Figura 4.3.

$\mathrm{C}_{6} \mathrm{H}_{9} \mathrm{ON}+9 \mathrm{O}_{2} \longrightarrow 6 \mathrm{CO}_{2}+4 \mathrm{H}_{2} \mathrm{O}+1 \mathrm{HNO}_{3}$ 
$\mathrm{H}_{2} \mathrm{O}_{2} \longrightarrow 1 / 2 \mathrm{O}_{2}+\mathrm{H}_{2} \mathrm{O}$

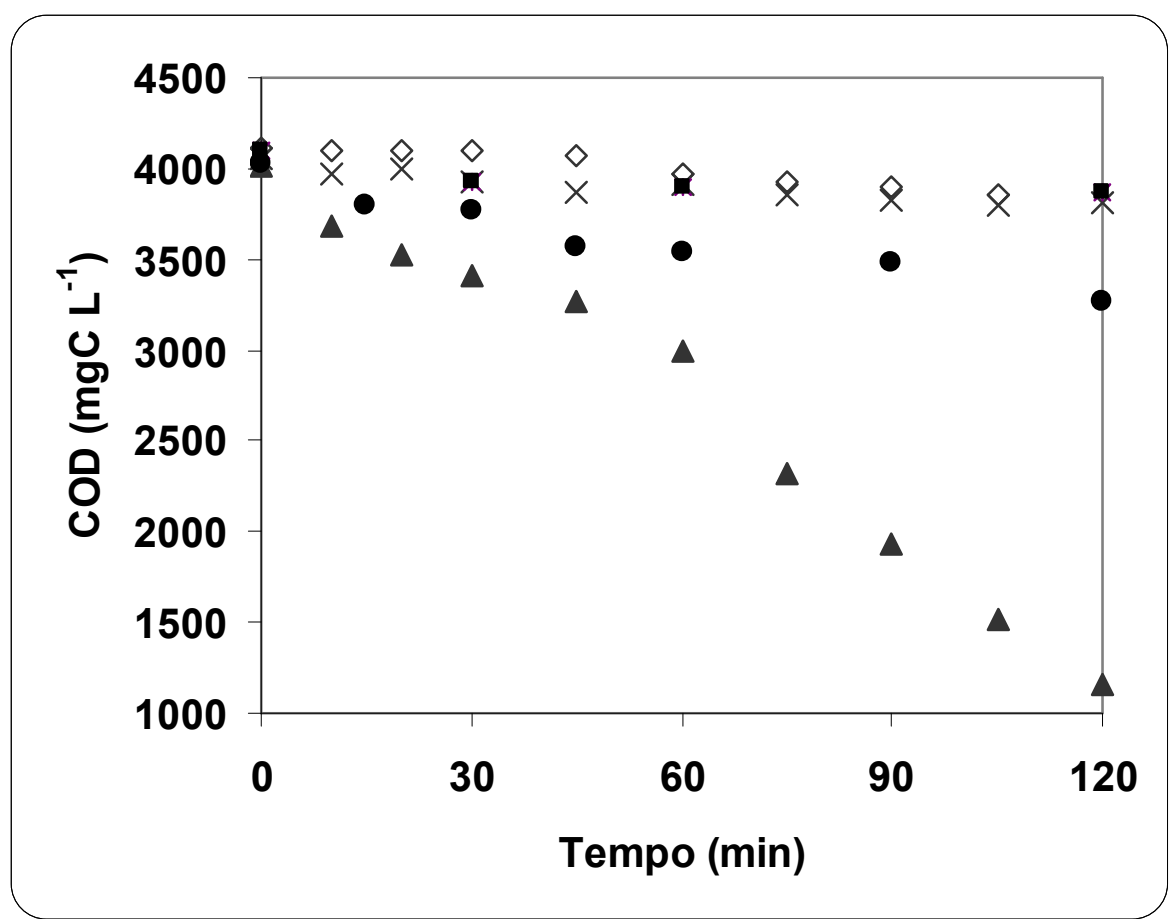

Figura 4.3 - Carbono Orgânico Dissolvido (COD) em função do tempo de

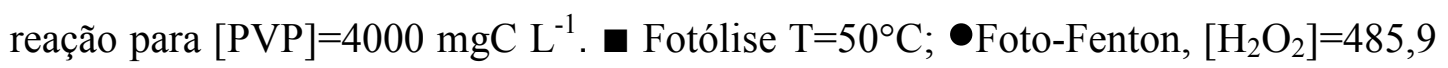
$\mathrm{mM},[\mathrm{Fe}(\mathrm{II})]=2,7 \mathrm{mM}, \mathrm{T}=30{ }^{\circ} \mathrm{C} ; \boldsymbol{\Delta}$ Foto-Fenton, $\left[\mathrm{H}_{2} \mathrm{O}_{2}\right]=485,9 \mathrm{mM},[\mathrm{Fe}(\mathrm{II})]=2,7$ $\mathrm{mM}, \quad \mathrm{T}=50{ }^{\circ} \mathrm{C} ; \quad \times \quad \mathrm{UV} / \mathrm{H}_{2} \mathrm{O}_{2}, \quad\left[\mathrm{H}_{2} \mathrm{O}_{2}\right]=485,7 \mathrm{mM}, \quad \mathrm{T}=30 \quad{ }^{\circ} \mathrm{C} ; . \diamond \mathrm{UV} / \mathrm{H}_{2} \mathrm{O}_{2}$, $\left[\mathrm{H}_{2} \mathrm{O}_{2}\right]=485,9 \mathrm{mM}, \mathrm{T}=50{ }^{\circ} \mathrm{C}$.

Para PVP as curvas de fotólise e $\mathrm{UV} / \mathrm{H}_{2} \mathrm{O}_{2}$ a 30 e $50{ }^{\circ} \mathrm{C}$, Figura 4.3, têm o mesmo comportamento e levam a remoções finais de COD de no máximo 6,6\%. Para fotólise e para o processo $\mathrm{UV} / \mathrm{H}_{2} \mathrm{O}_{2}$ não houve separação de fases, o que aconteceu para o processo foto-Fenton para 30 e $50{ }^{\circ} \mathrm{C}$, chegando a prejudicar o bombeamento. Como pode ser observado na Figura 4.3, a temperatura influenciou fortemente o processo foto-Fenton levando a remoções finais de COD de $19 \%$ para $30{ }^{\circ} \mathrm{C}$ e $71 \%$ para $50^{\circ} \mathrm{C}$. Com base nesses resultados optou-se pelo processo foto-Fenton com temperatura de $50{ }^{\circ} \mathrm{C}$ e tempo de reação de 180 minutos para realizar o planejamento experimental. Apesar dos experimentos exploratórios para PVP terem sido realizados com concentrações iniciais de $4000 \mathrm{mgC} \mathrm{L}^{-1}$, baseado nos trabalhos citados, utilizou- 
se a concentração de PVP de 500 a $1500 \mathrm{mgC} \mathrm{L}^{-1}$ no planejamento experimental, visando estudar os três polímeros na mesma faixa de concentração.

\subsection{Planejamento Experimental}

\subsubsection{Análise de Carbono Orgânico Dissolvido}

Os resultados da concentração de COD foram normalizados com relação ao valor inicial e os resultados em função do tempo de reação são mostrados nas Figuras 4.4, 4.6, 4.9 e 4.11 para os três polímeros. As curvas para a maior concentração de polímero, correspondente ao nível superior do plano experimental são apresentadas separadamente das de menor concentração. Os valores experimentais de COD em função do tempo para todos os ensaios são mostrados nas tabelas do Apêndice A.

Com relação à taxa de remoção de COD, as curvas mostradas nas Figuras 4.4, 4.6, 4.9 e 4.11 podem ser divididas em três etapas: um primeiro período durante o qual a taxa é relativamente lenta, seguido por um período em que a remoção de COD é mais acentuada e finalmente um período de estabilização perto do fim do experimento. No primeiro período, embora o processo oxidativo aconteça, há baixa mineralização dos compostos orgânicos levando muitas vezes a um patamar inicial. O segundo período em que há uma aceleração da taxa de remoção é mais pronunciado em experimentos em que há formação de sólidos, provavelmente a mineralização ocorre simultaneamente com a transferência dos compostos orgânicos para a fase sólida. No último período a taxa de remoção de COD é lenta devido à baixa concentração de carbono orgânico e dos reagentes ferro e peróxido de hidrogênio. Estas características gerais das curvas de COD em função do tempo variam conforme o polímero e as concentrações de reagentes utilizadas, mas servem para orientar a análise dos resultados.

\subsubsection{Polietilenoglicol-Processo Foto-Fenton}

Nos experimentos para PEG a tonalidade da solução no início do experimento era amarelada, devido à solução de Fe(II), ficando mais escura até mesmo marrom durante alguns experimentos e transparente no final. No ensaio com concentrações correspondentes ao nível +1 das três variáveis houve formação de sólidos de 
coloração marrom. Esse fenômeno já foi observado na degradação de emulsões aquosas de silicone por Teixeira et al. (2004) e na degradação de álcool polivinílico por Giroto et al. (2006).

Na Figura 4.4(a) para a maior concentração de PEG (1689 $\left.\pm 104 \mathrm{mgC} \mathrm{L}^{-1}\right)$ as curvas de $\mathrm{COD} / \mathrm{COD}_{0}$ em função do tempo para o nível +1 de $\left[\mathrm{H}_{2} \mathrm{O}_{2}\right](160 \mathrm{mM})$ têm o mesmo comportamento ao longo do tempo. Há uma queda muito lenta até 45 minutos e a partir deste ponto a velocidade aumenta levando a remoções finais de COD de $63 \%$ e $69 \%$ para [Fe(II)] nos níveis +1 e -1 , respectivamente. O nível de ferro não influenciou muito a queda de COD para um mesmo nível de $\left[\mathrm{H}_{2} \mathrm{O}_{2}\right]$, porém, o nível de $\left[\mathrm{H}_{2} \mathrm{O}_{2}\right]$ influencia a queda de $\mathrm{COD}$, como pode ser visto na Figura 4.4(a) para as duas curvas correspondentes ao nível -1 de $\left[\mathrm{H}_{2} \mathrm{O}_{2}\right](60 \mathrm{mM})$. Ambas têm o mesmo comportamento e caem lentamente levando a remoções finais de COD de aproximadamente $20 \%$ independente do nível de [Fe(II)]. Como o peróxido foi dosado até 90 minutos, nos últimos 30 minutos a reação somente continuaria se houvesse peróxido residual para reagir. Isto pode ser observado para as curvas correspondentes ao nível +1 de $\left[\mathrm{H}_{2} \mathrm{O}_{2}\right]$, que mantém a queda de $\mathrm{COD}$ mesmo depois do término da adição de peróxido. Já para o nível -1 de $\left[\mathrm{H}_{2} \mathrm{O}_{2}\right]$ a queda de COD torna-se muito lenta, praticamente constante, após a adição de peróxido.

Na Figura 4.4(b) a carga orgânica de PEG foi diminuída (592 $\left.\pm 17 \mathrm{mgC} \mathrm{L}^{-1}\right)$ levando a curvas de $\mathrm{COD} / \mathrm{COD}_{0}$ em função do tempo com comportamentos bem diferentes daquelas da Figura 4.4(a). Para o nível +1 de $\left[\mathrm{H}_{2} \mathrm{O}_{2}\right]$ as três etapas de reação podem ser observadas, a remoção de COD atingiu 95\% aos 60 minutos de reação chegando em $100 \%$ até 120 minutos. Para o nível -1 de $\left[\mathrm{H}_{2} \mathrm{O}_{2}\right]$ a queda de COD é lenta até 45 minutos, e então se torna mais rápida havendo um distanciamento das curvas com diferentes níveis de [Fe(II)]. Para o nível -1 de [Fe(II)] a remoção de COD foi de $92 \%$ e para +1 de $67 \%$, mostrando uma influência negativa do ferro na queda de COD. Segundo Bossmann et al. (2001a) o ferro forma complexos com o polímero, que podem se aglomerar levando a formação de partículas. Além disso, a eficiência quântica da foto-redução do Fe(III) que está nestes complexos torna-se mais difícil levando a uma diminuição da remoção de COD.

O erro experimental foi calculado como a média dos desvios padrões de cada ponto, para as três repetições do ensaio realizado no ponto central do plano 
experimental. Para PEG no processo foto-Fenton obteve-se um desvio médio de $39,75 \mathrm{mgC} \mathrm{L}^{-1}$. A concordância das repetições pode ser observada na Figura 4.5. 


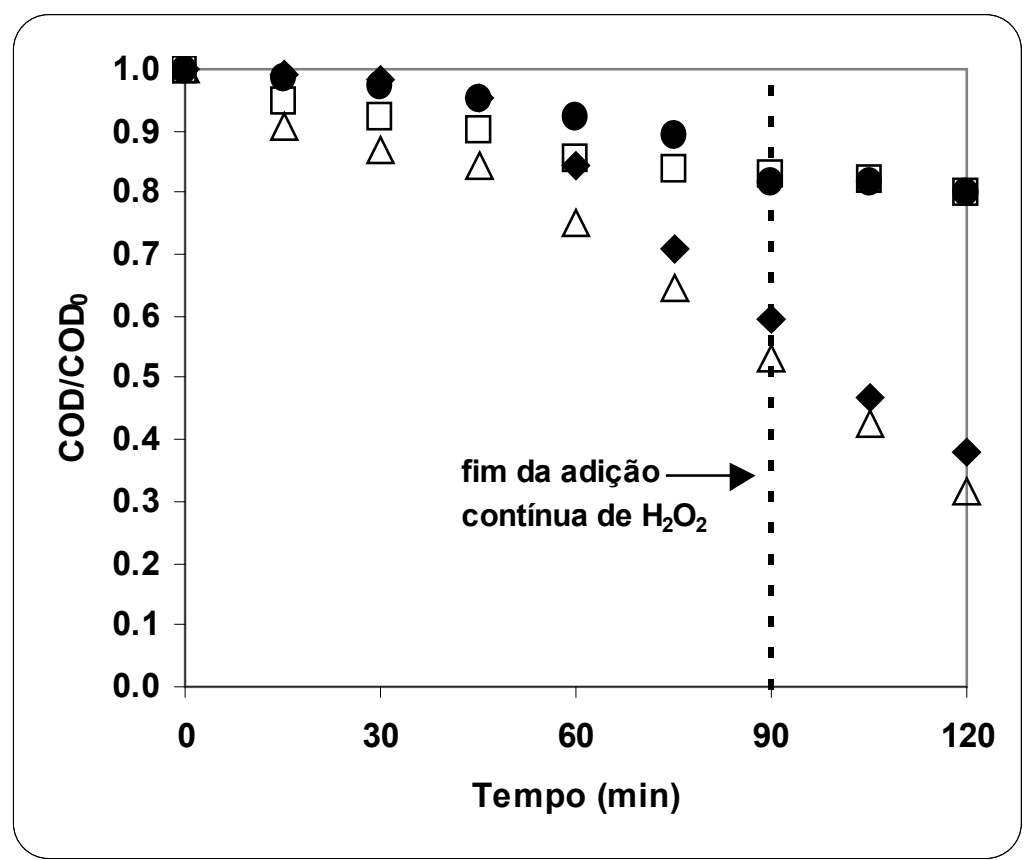

(a)

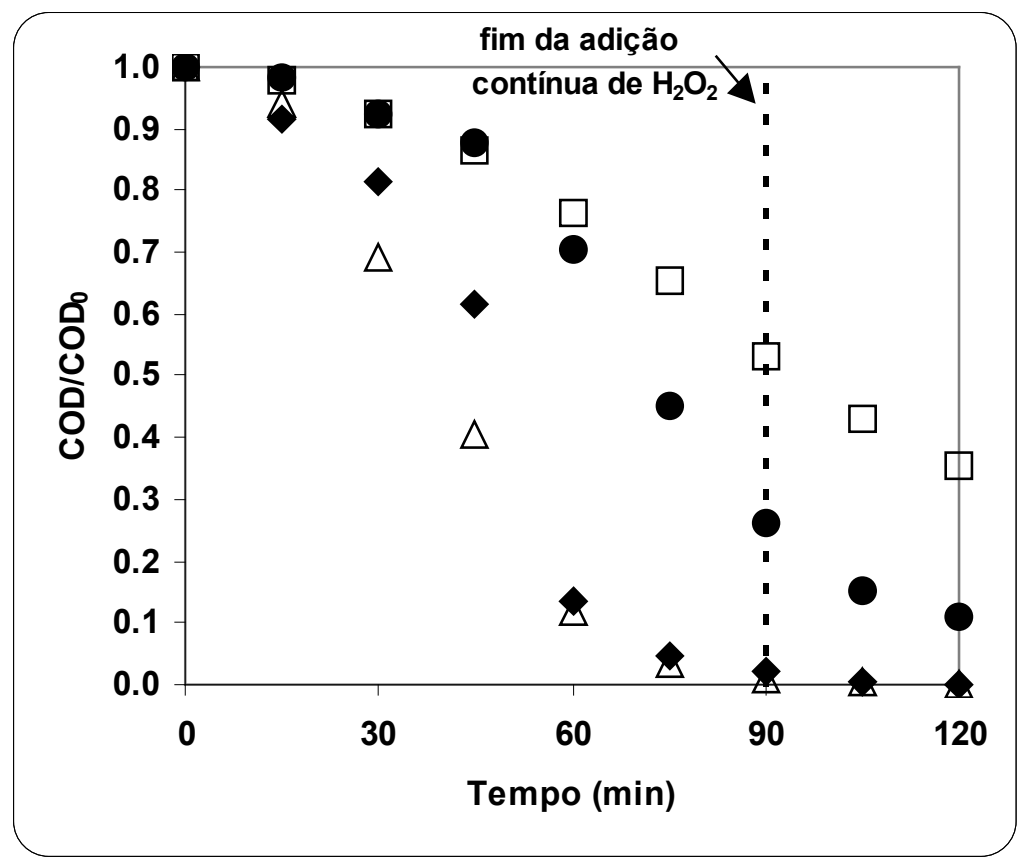

(b)

Figura 4.4 - COD em função do tempo de reação para PEG no processo foto-Fenton. Concentração inicial (a) $1689 \pm 104 \mathrm{mgC} \mathrm{L}^{-1}$ e (b) $592 \pm 17 \mathrm{mgC} \mathrm{L}^{-1}$. $\bullet++$ +; $\square+$ +; $\Delta$ - +; • - - Primeiro sinal nível de [Fe(II)] e segundo nível de $\left[\mathrm{H}_{2} \mathrm{O}_{2}\right]^{2}$.

\footnotetext{
${ }^{2}$ Os valores das concentrações utilizadas em cada nível e das condições experimentais podem ser vistos na Tabela 3.1.
} 


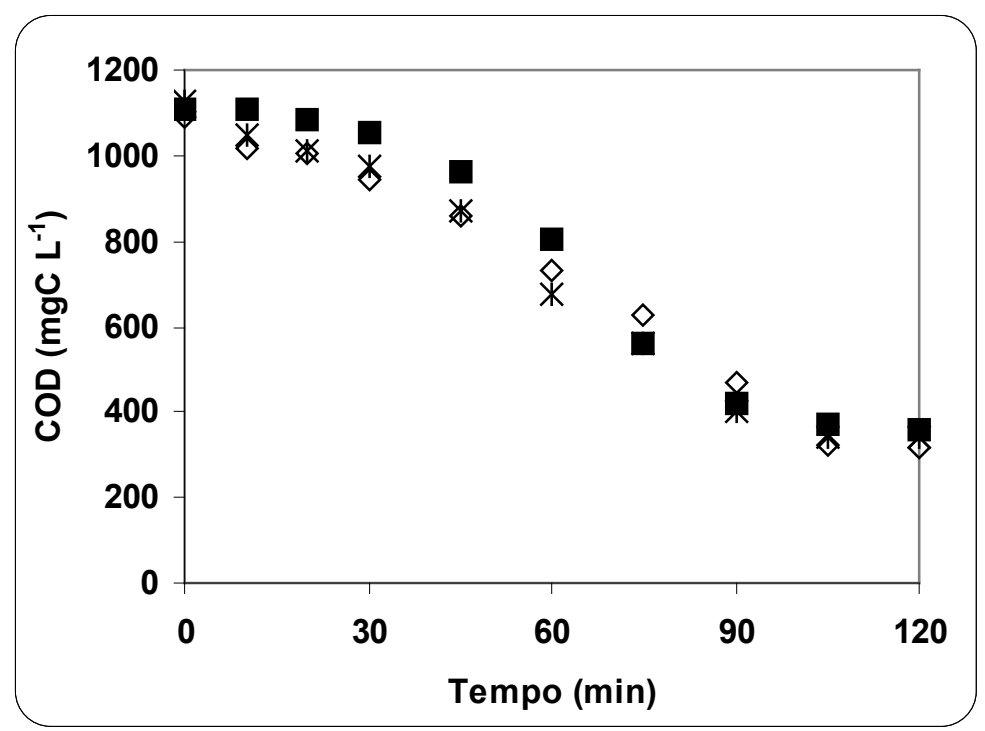

Figura 4.5 - Comparação entre os três experimentos realizados no ponto central para o processo foto-Fenton. $[\mathrm{PEG}]=1000 \mathrm{mgC} \mathrm{L}^{-1}[\mathrm{Fe}(\mathrm{II})]=1,0 \mathrm{mM} \mathrm{e}\left[\mathrm{H}_{2} \mathrm{O}_{2}\right]=110 \mathrm{mM}$.

\subsubsection{Polietilenoglicol (PEG) - Processo UV/H $\mathrm{H}_{2} \mathrm{O}_{2}$}

No processo $\mathrm{UV} / \mathrm{H}_{2} \mathrm{O}_{2}$ não houve separação de fases em nenhum experimento. No ensaio com concentrações correspondentes ao nível +1 das três variáveis e nos pontos centrais houve uma mudança da coloração passando de incolor para levemente amarelado no final do experimento. Em todos os experimentos formaram-se pequenas bolhas e a solução apresentou um odor forte a partir de 10 minutos de reação.

Para a maior concentração de PEG, correspondente ao nível +1 $(1477 \pm 104$ $\operatorname{mgC~} \mathrm{L}^{-1}$ ), Figura 4.6(a), observa-se a importância da concentração de $\left[\mathrm{H}_{2} \mathrm{O}_{2}\right]$ na queda de COD, comparando-se as curvas com mesma temperatura, por exemplo, $\mathrm{T}$ $+1\left(50{ }^{\circ} \mathrm{C}\right)$ e $\left[\mathrm{H}_{2} \mathrm{O}_{2}\right]-1(60 \mathrm{mM})$ com remoção final de $17 \%$ e a curva para mesma temperatura e $\left[\mathrm{H}_{2} \mathrm{O}_{2}\right]+1(160 \mathrm{mM})$, com $67 \%$ de remoção de COD. A temperatura também tem um efeito positivo na remoção de COD. Para o maior nível de $\left[\mathrm{H}_{2} \mathrm{O}_{2}\right]$, as curvas para $\mathrm{T}-1\left(30^{\circ} \mathrm{C}\right)$ e $\mathrm{T}+1\left(50{ }^{\circ} \mathrm{C}\right)$ apresentam um primeiro período de reação com um patamar até 30 minutos e depois começam a distanciar-se com a curva para $50{ }^{\circ} \mathrm{C}$, tendo uma segunda etapa de aceleração na remoção de COD mais acentuada até o término da adição de $\mathrm{H}_{2} \mathrm{O}_{2}$ iniciando-se a partir deste ponto $\mathrm{o}$ terceiro período de estabilização, em que o COD permanece praticamente constante. 
Para a menor concentração de PEG (nível -1, 562 $\pm 26 \mathrm{mgC} \mathrm{L}^{-1}$ ), Figura 4.6(b), todas as curvas de $\mathrm{COD} / \mathrm{COD}_{0}$ em função do tempo mostram as três etapas de reação bem caracterizadas com exceção do nível -1 para $\mathrm{T}$ e $\left[\mathrm{H}_{2} \mathrm{O}_{2}\right]$. Para a maior concentração de $\left[\mathrm{H}_{2} \mathrm{O}_{2}\right](160 \mathrm{mM})$ há um pequeno patamar até 10 minutos de reação e as conversões chegam a 95\% em 120 minutos. Para o nível -1 de $\left[\mathrm{H}_{2} \mathrm{O}_{2}\right](60 \mathrm{mM})$ as curvas para $\mathrm{T}-1\left(30^{\circ} \mathrm{C}\right)$ e $\mathrm{T}+1\left(50^{\circ} \mathrm{C}\right)$ têm um patamar inicial até 30 minutos atingindo no final de 120 minutos conversões de 70 e $80 \%$, respectivamente. A temperatura também apresenta um efeito positivo para as curvas para um mesmo nível de $\left[\mathrm{H}_{2} \mathrm{O}_{2}\right]$ e temperatura maior $\left(50^{\circ} \mathrm{C}\right)$, tendo sempre um valor de COD menor que a curva para $30^{\circ} \mathrm{C}$ após o período inicial em que o COD permanece num patamar.

O erro experimental foi calculado para os três ensaios realizados no ponto central do plano experimental, obtendo-se um desvio médio de $28,89 \mathrm{mgC} \mathrm{L}^{-1}$. A concordância das repetições pode ser observada na Figura 4.7.

$\mathrm{O} \mathrm{pH}$ do meio reacional não foi controlado durante o processo $\mathrm{UV} / \mathrm{H}_{2} \mathrm{O}_{2}$. Os valores do $\mathrm{pH}$ em função do tempo de reação para os experimentos nos níveis +1 de e -1 da concentração de PEG são apresentados na Figura 4.8 (a) e (b) respectivamente. Mesmo nos experimentos com menor remoção de COD, como para o realizado com maior concentração de PEG e níveis -1 de temperatura e $\left[\mathrm{H}_{2} \mathrm{O}_{2}\right]$, Figura 4.8(a), o pH cai e permanece constante até o final da reação. A queda do pH está relacionada à formação de ácidos orgânicos, que são de difícil oxidação e permanecem no meio reacional, mantendo o COD elevado. Nos casos em que houve maior remoção de COD, por exemplo, para menor concentração de PEG e níveis +1 de temperatura e $\left[\mathrm{H}_{2} \mathrm{O}_{2}\right]$, Figura 4.8(b), o pH volta a subir, neste caso a partir de 60 minutos, indicando a oxidação de tais ácidos. A caracterização de intermediários será abordada no item de análise de HPLC. 


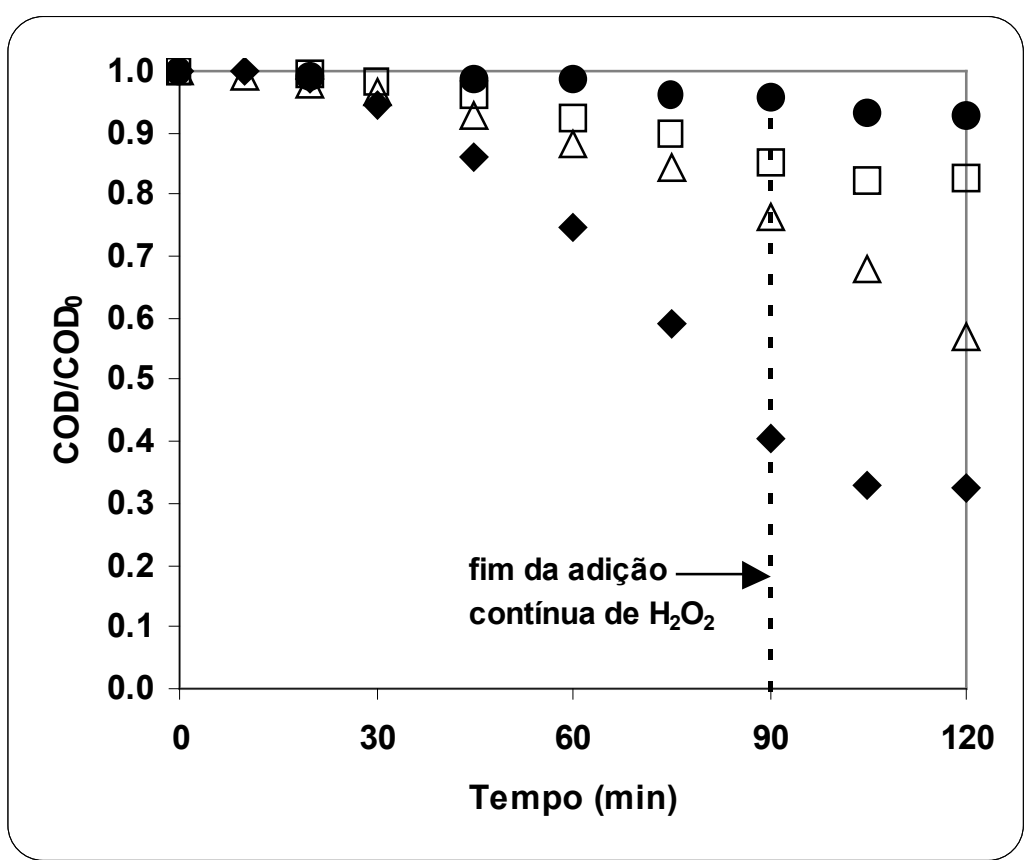

(a)

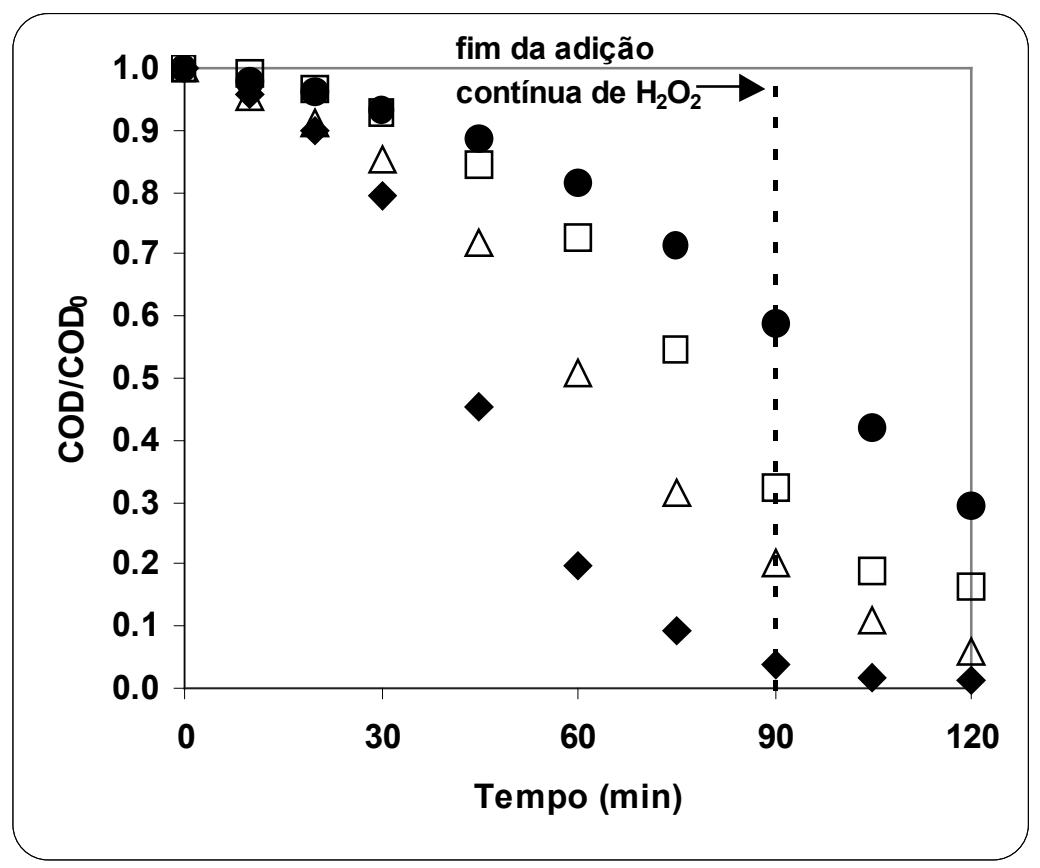

(b)

Figura 4.6 - COD em função do tempo de reação para PEG, no processo UV/ $\mathrm{H}_{2} \mathrm{O}_{2}$.

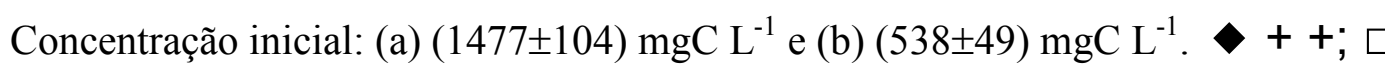
$+-; \Delta-+; \bullet-$-. Primeiro sinal nível de T e segundo nível de $\left[\mathrm{H}_{2} \mathrm{O}_{2}\right]^{3}$.

\footnotetext{
${ }^{3}$ Os valores das concentrações utilizadas em cada nível e das condições experimentais podem ser vistos na Tabela 3.1.
} 


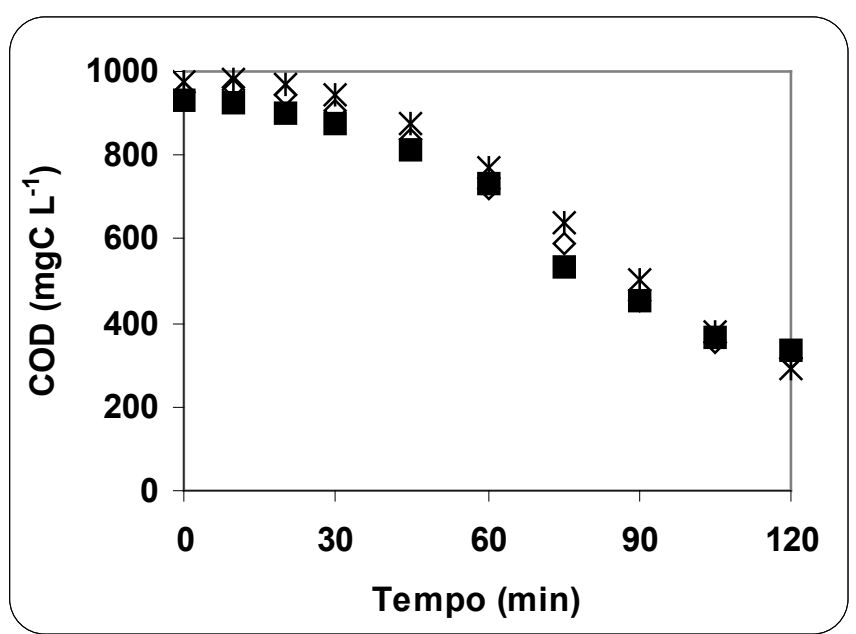

Figura 4.7 - Comparação entre os três experimentos realizados no ponto central, para o processo $\mathrm{UV} / \mathrm{H}_{2} \mathrm{O}_{2}$. $[\mathrm{PEG}]=1000 \mathrm{mgC} \mathrm{L}{ }^{-1}[\mathrm{~T}]=40{ }^{\circ} \mathrm{C}$ e $\left[\mathrm{H}_{2} \mathrm{O}_{2}\right]=110 \mathrm{mM}$.

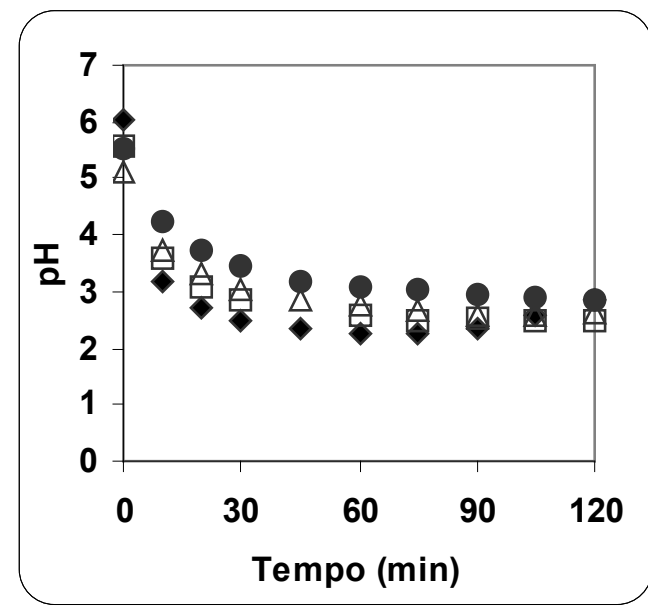

(a)

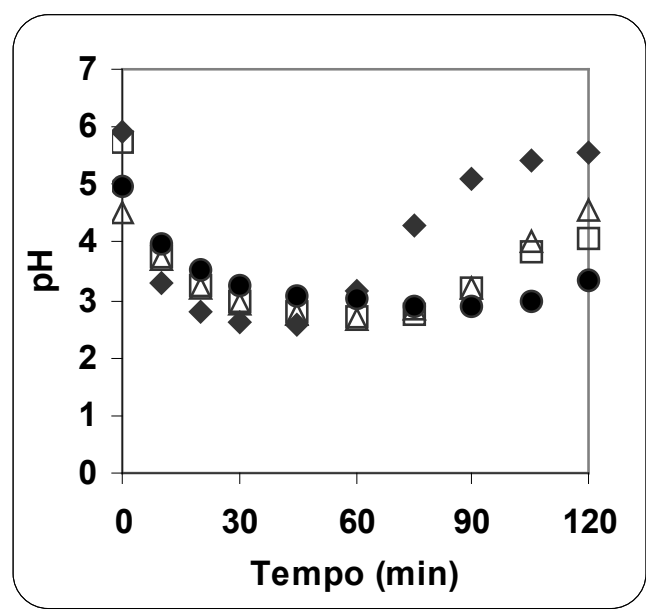

(b)

Figura 4.8 - pH em função do tempo de reação para PEG, durante o processo $\mathrm{UV} / \mathrm{H}_{2} \mathrm{O}_{2}$. Concentração inicial (a) $1435 \pm 35 \mathrm{mgC} \mathrm{L}^{-1}$ and (b) $562 \pm 26 \mathrm{mgC} \mathrm{L}^{-1}$. $\bullet+$ $+; \square+-; \Delta-+; \bullet-$ - . Primeiro sinal nível de T e segundo nível de $\left[\mathrm{H}_{2} \mathrm{O}_{2}\right]$.

\subsubsection{Poliacrilamida - Processo Foto-Fenton}

Em todos os experimentos para PAM a cor da solução era amarela no início ficando mais escura e turva, voltando a ficar amarela mais clara no final da reação, com tonalidades variando em alguns experimentos. Outras características comuns em 
todos os ensaios foram separação de fases e tendência do $\mathrm{pH}$ aumentar durante o experimento sendo constantemente controlado para permanecer em 3. Este aumento do $\mathrm{pH}$ pode ser atribuído à formação de compostos de natureza alcalina. Suzuki et al. (1979), atribuem uma forte banda de absorção em $1400 \mathrm{~cm}^{-1}$ no espectro infravermelho de soluções aquosas de PAM, submetidas a ozonização com radiação UV, à formação de nitratos, provenientes da oxidação dos grupos amida da PAM. A hidrólise dos grupos laterais amida também pode levar à liberação dos íons amônio, o que elevaria o pH da solução (Caufield et al., 2003).

A separação de fases leva a uma queda brusca de COD, porque parte da matéria orgânica que estava em solução passa para a fase sólida, diminuindo a carga orgânica da solução, que é analisada. Este efeito pode ser observado na Figura 4.5(a) para o ensaio com concentrações nos níveis $[\mathrm{Fe}(\mathrm{II})]+1(2.5 \mathrm{mM})$ e $\left[\mathrm{H}_{2} \mathrm{O}_{2}\right]-1(300$ $\mathrm{mM}$ ) em que a remoção de COD está em 20\% aos 120 minutos e passa a $67 \%$ aos 150 minutos.

Para a maior concentração de PAM (1477 $\left.\pm 104 \mathrm{mgC} \mathrm{L}^{-1}\right)$, Figura 4.9(a), as curvas de $\mathrm{COD} / \mathrm{COD}_{0}$ em função do tempo apresentam um comportamento semelhante atingindo $94 \%$ de remoção de COD, com exceção da correspondente ao ponto $[\mathrm{Fe}(\mathrm{II})]+1$ e $\left[\mathrm{H}_{2} \mathrm{O}_{2}\right]-1$. Neste caso há uma acentuada etapa inicial em que o COD praticamente não varia, até aproximadamente 120 minutos, caindo abruptamente quando houve separação de fases, voltando a ter uma queda lenta após 150 minutos, quando a adição de peróxido foi interrompida. A comparação desta curva com a de $[\mathrm{Fe}(\mathrm{II})]+1$ e $\left[\mathrm{H}_{2} \mathrm{O}_{2}\right]+1(700 \mathrm{mM})$, mostra a influência positiva do peróxido na remoção de COD para PAM.

Para a menor concentração de PAM (538 $\left.\pm 49 \mathrm{mgC} \mathrm{L}^{-1}\right)$, Figura 4.9(b), as remoções de COD atingiram mais de $95 \%$ em todos os experimentos, mas muito mais rapidamente que para as concentrações mais altas de PAM. As curvas para [Fe(II) $]-1(0.5 \mathrm{mM})$ apresentam uma queda de COD muito mais rápida que as do nível $[\mathrm{Fe}(\mathrm{II})]+1$, atingindo $100 \%$ de remoção em aproximadamente 90 minutos de reação. As curvas para $[\mathrm{Fe}(\mathrm{II})]+1$ têm uma queda mais lenta de COD mostrando a influência negativa do ferro em altas concentrações. 


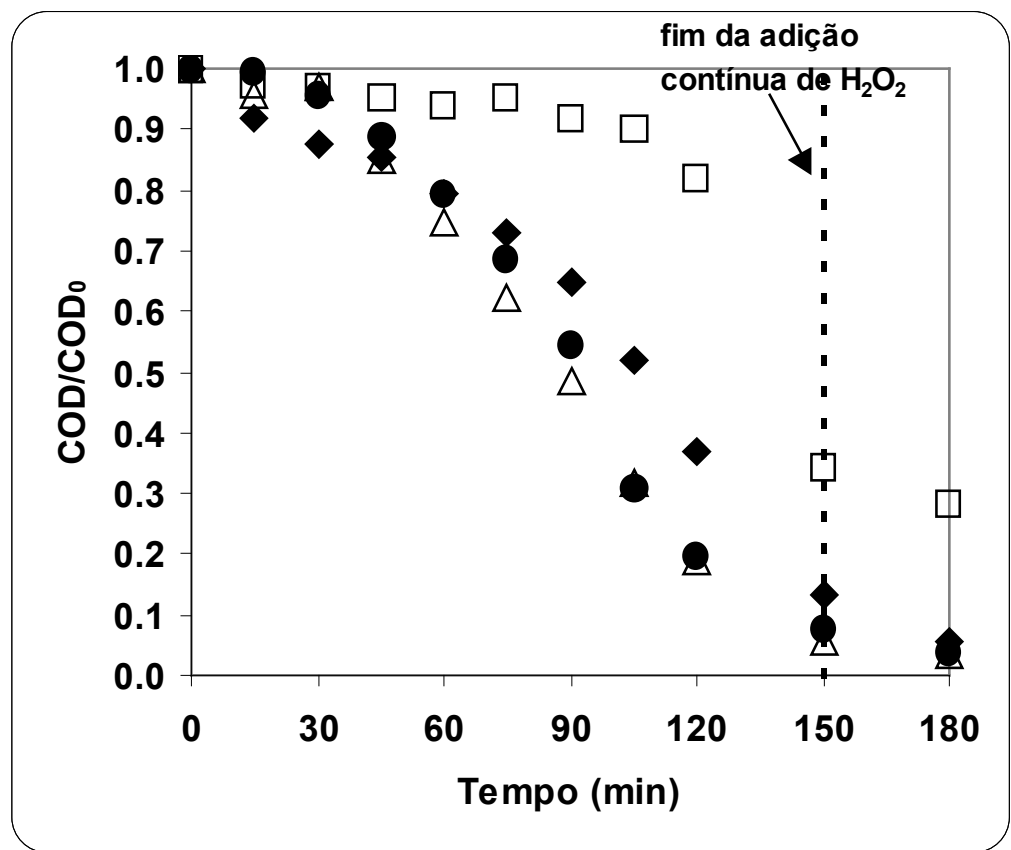

(a)

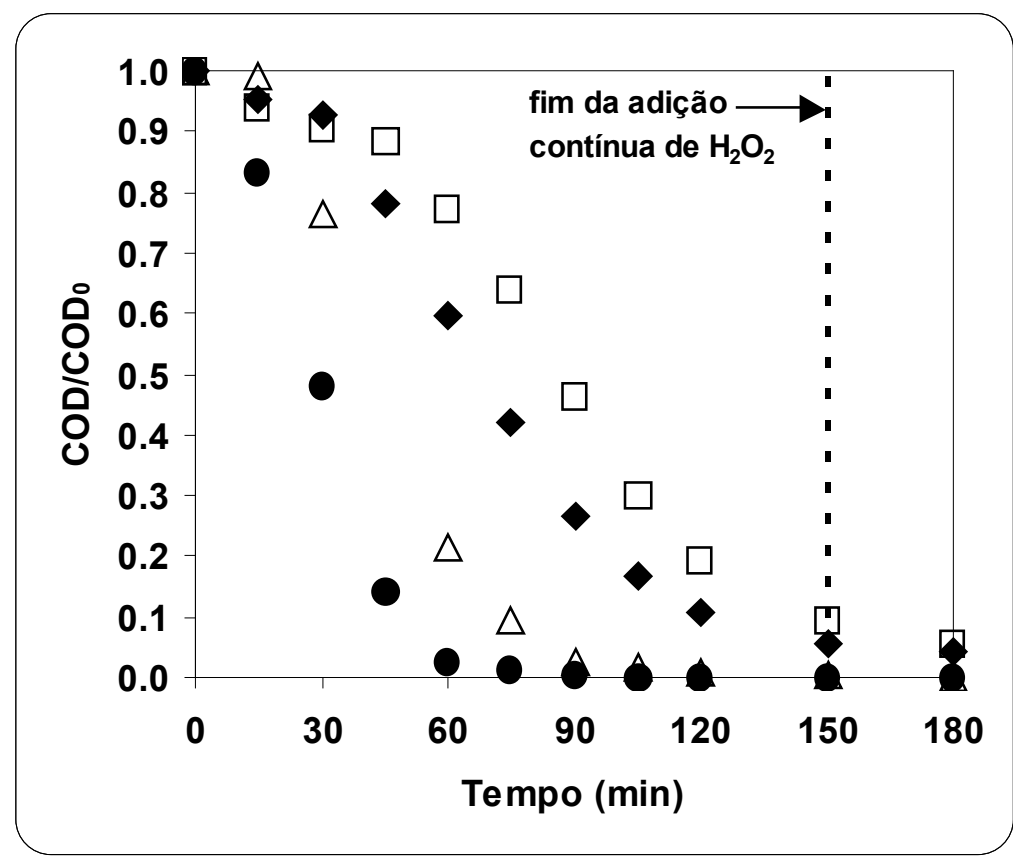

(b)

Figura 4.9 - COD em função do tempo de reação para PAM. Concentração inicial: (a) $(1477 \pm 104) \mathrm{mgC} \mathrm{L}^{-1}$ and (b) $(538 \pm 49) \mathrm{mgC} \mathrm{L}^{-1}$. $\bullet++$; $\square+-; \Delta-+$; $\bullet$ - -. Primeiro sinal nível de $[\mathrm{Fe}(\mathrm{II})]$ e segundo nível de $\left[\mathrm{H}_{2} \mathrm{O}_{2}\right]^{4}$.

\footnotetext{
${ }^{4}$ Os valores das concentrações utilizadas em cada nível e das condições experimentais podem ser vistos na Tabela 3.1.
} 
O erro experimental foi calculado nos três ensaios realizados no ponto central do plano experimental, obtendo-se um desvio médio de $65,2 \mathrm{mgC} \mathrm{L}^{-1}$. As repetições são apresentas na Figura 4.10. Observa-se que os maiores desvios ocorrem no início do experimento.

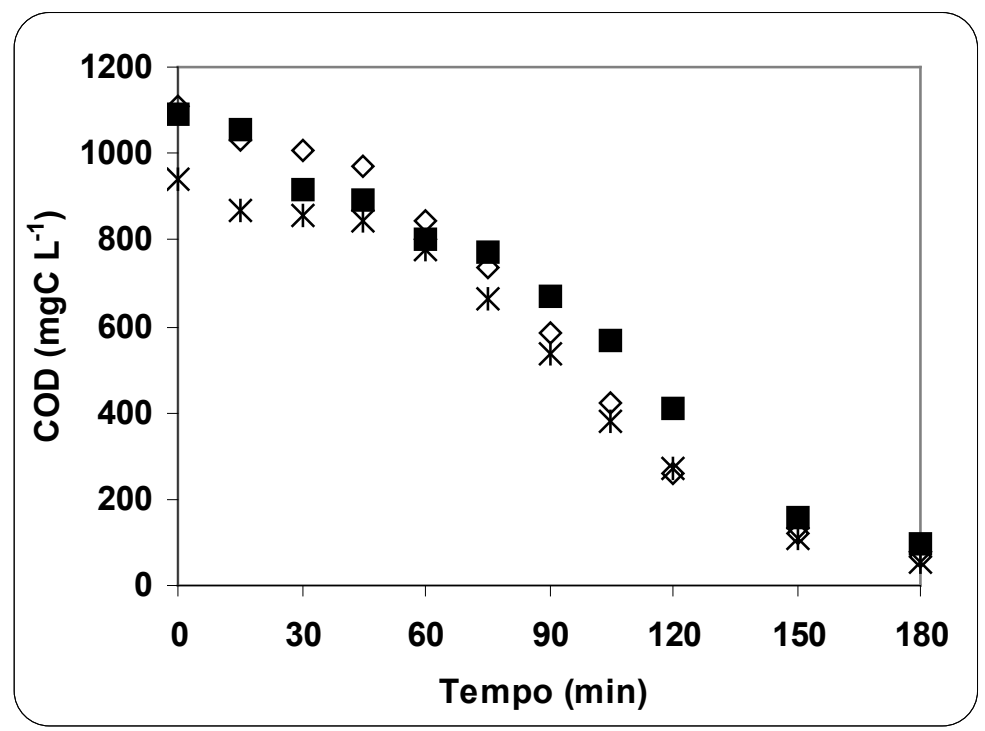

Figura 4.10 - Comparação entre os três experimentos realizados no ponto central para o processo foto-Fenton. $[\mathrm{PAM}]=1000 \mathrm{mgC} \mathrm{L}^{-1}[\mathrm{Fe}(\mathrm{II})]=1,5 \mathrm{mM} \mathrm{e}\left[\mathrm{H}_{2} \mathrm{O}_{2}\right]=500$ $\mathrm{mM}$.

\subsubsection{Polivinilpirrolidona - Processo Foto-Fenton}

Em todos os experimentos com PVP houve separação de fases, formação de espuma e a solução apresentou coloração variando de amarelo inicialmente escurecendo até ficar marrom e haver formação de partículas voltando a clarear no final do experimento.

Como no caso da poliacrilamida o efeito da separação de fases na queda de COD para PVP pode ser observado na Figura 4.11(a) para o nível [Fe(II)] $-1(0.5$ $\mathrm{mM})$ e $\left[\mathrm{H}_{2} \mathrm{O}_{2}\right]-1(150 \mathrm{mM})$ em que a remoção de COD vai de $4 \%$ aos 45 minutos para $63 \%$ aos 60 minutos e também para a menor concentração de PVP, Figura 4.11(b) para o nível [Fe(II)] +1 (1.5 mM) e $\left[\mathrm{H}_{2} \mathrm{O}_{2}\right]-1$, em que a remoção de COD vai de $9 \%$ aos 15 minutos para $86 \%$ aos 30 minutos. Observa-se na Figura 4.11(a) que todos os experimentos apresentaram curvas de COD com as três etapas de reação 
bem caracterizadas. O efeito negativo do ferro pode ser observado comparando-se as curvas para um mesmo nível de $\left[\mathrm{H}_{2} \mathrm{O}_{2}\right]$.

Para a menor concentração de PVP, Figura 4.11(b), em todos os ensaios a remoção de COD atingiu 100\% em 180 minutos e 95\% em 75 minutos, indicando que mesmo os níveis -1 das variáveis $[\mathrm{Fe}(\mathrm{II})]$ e $\left[\mathrm{H}_{2} \mathrm{O}_{2}\right]$, são concentrações altas o suficiente para mineralizar completamente $546 \pm 16 \mathrm{mgC}^{-1}$ de PVP. Outra característica destes experimentos é que as curvas para o nível $\left[\mathrm{H}_{2} \mathrm{O}_{2}\right]+1(250 \mathrm{mM})$ apresentam uma queda de COD um pouco mais lenta que as do nível $\left[\mathrm{H}_{2} \mathrm{O}_{2}\right]-1$, independente do nível de [Fe(II)]. Porém, as curvas para o nível $\left[\mathrm{H}_{2} \mathrm{O}_{2}\right]-1$, foram as que apresentaram as maiores quedas de COD devido à formação de sólidos. Para o nível -1 de [PVP] o peróxido pode estar em excesso quando sua concentração está no nível $+1(500 \mathrm{mM})$, de tal forma que o próprio peróxido age como seqüestrante dos radicais hidroxila (Chang e Young, 2000), apresentando remoções menores, quando comparado ao nível -1 de $\left[\mathrm{H}_{2} \mathrm{O}_{2}\right]$, na Figura 4.11(b).

O erro experimental foi calculado para os três ensaios realizados no ponto central do plano experimental, obtendo-se um desvio médio de $35,4 \mathrm{mgC} \mathrm{L}^{-1}$. A concordância das repetições pode ser observada na Figura 4.12. 


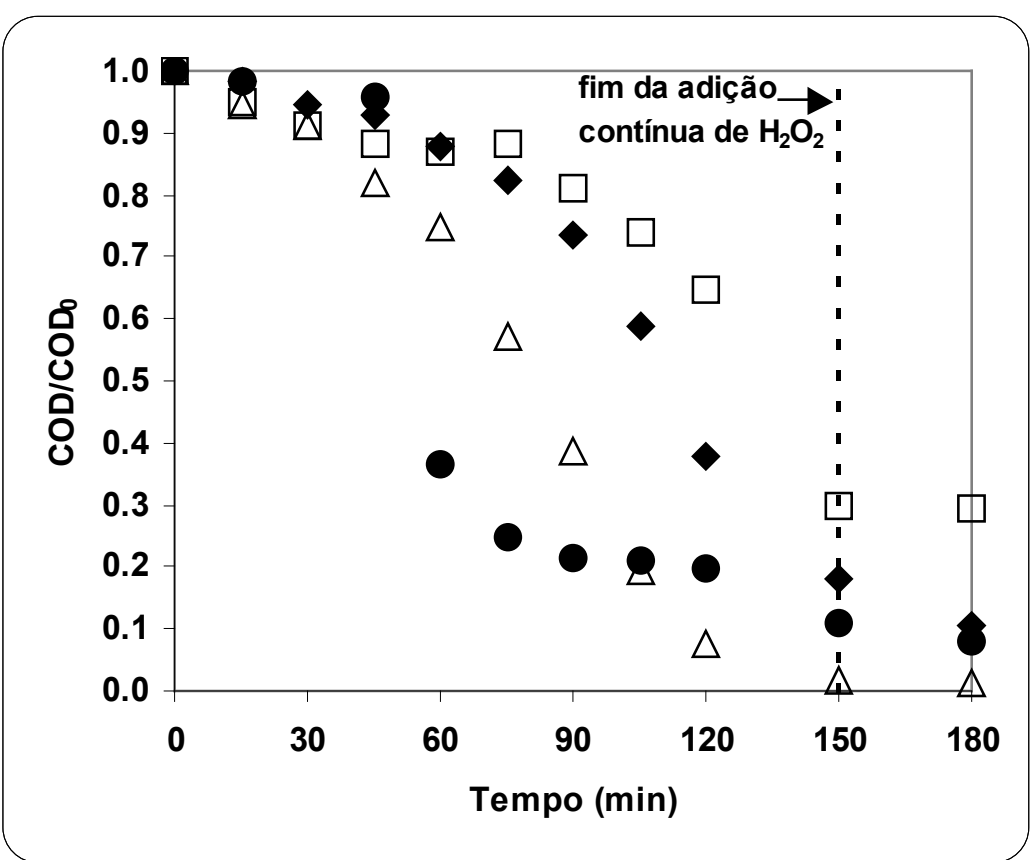

(a)

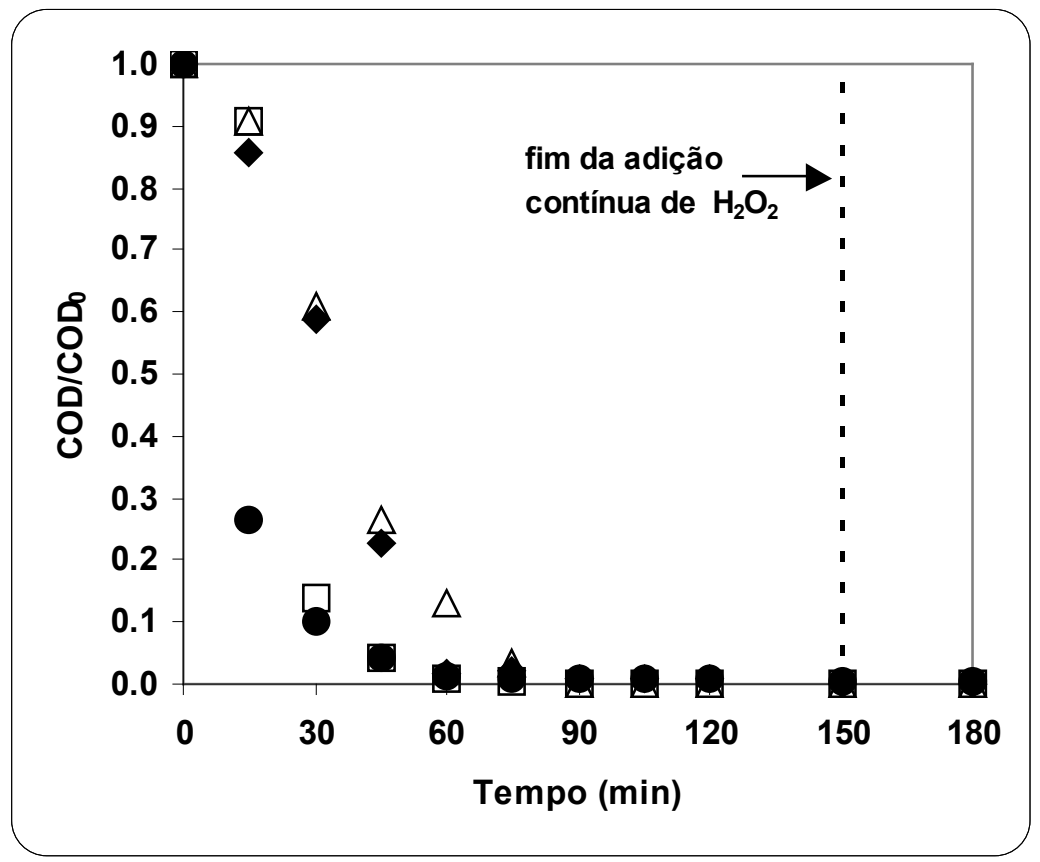

(b)

Figura 4.11 - COD em função do tempo de reação para PVP. Concentração inicial:

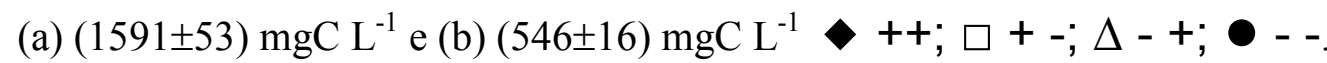
Primeiro sinal nível de $[\mathrm{Fe}(\mathrm{II})]$ e segundo nível de $\left[\mathrm{H}_{2} \mathrm{O}_{2}\right]^{5}$.

\footnotetext{
${ }^{5}$ Os valores das concentrações utilizadas em cada nível e das condições experimentais podem ser vistos na Tabela 3.1
} 


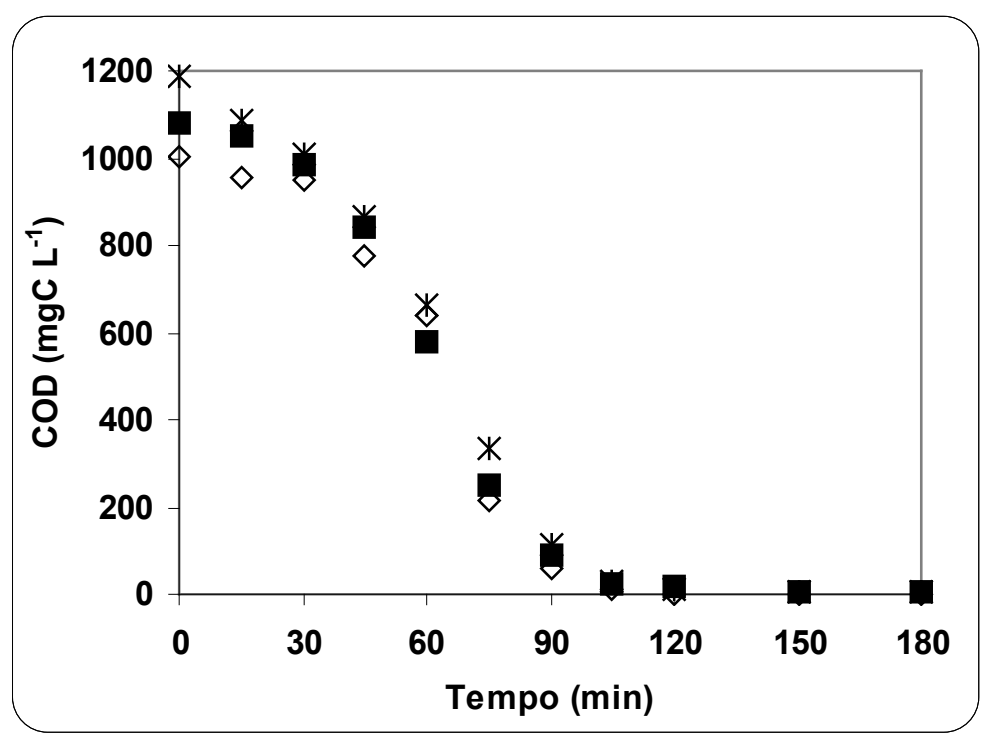

Figura 4.12 - Comparação entre os três experimentos realizados no ponto central para o processo foto-Fenton. $[\mathrm{PVP}]=1000 \mathrm{mgC} \mathrm{L}^{-1}[\mathrm{Fe}(\mathrm{II})]=1,0 \mathrm{mM} \mathrm{e}\left[\mathrm{H}_{2} \mathrm{O}_{2}\right]=200$ $\mathrm{mM}$.

\subsubsection{Análise Estatística}

Para quantificar a importância das variáveis de processo, os resultados experimentais de COD foram usados em uma análise de sensibilidade baseada na técnica de resposta (Box et al., 1978). Embora todas as curvas de COD em função do tempo sugiram uma dependência não linear das respostas sobre as variáveis dependentes, o projeto fatorial é baseado em um modelo linear e, desta forma, devese considerar que não serão avaliadas contribuições quadráticas ou cúbicas para [Pol], [Fe(II)] e $\left[\mathrm{H}_{2} \mathrm{O}_{2}\right]$, exceto sua interação. O modelo estatístico para o projeto fatorial completo $2^{3}$ é dado pela equação E12, em que $b$ são os coeficientes, $x$ as variáveis independentes $\left(x_{1}\right.$ : [Pol], $x_{2}[\mathrm{Fe}(\mathrm{II})]$ ou $\mathrm{T}$ e $\left.x_{3}\left[\mathrm{H}_{2} \mathrm{O}_{2}\right]\right)$ e $\hat{y}\left(x_{1} x_{2} x_{3}\right)$ é a resposta.

$$
\begin{aligned}
\hat{y}\left(x_{1}, x_{2}, x_{3}\right)= & b_{0}+b_{1} x_{1}+b_{2} x_{2}+b_{3} x_{3}+b_{12} x_{1} x_{2}+b_{13} x_{1} x_{3} \\
& +b_{23} x_{2} x_{3}+b_{123} x_{1} x_{2} x_{3}
\end{aligned}
$$


Como variáveis resposta foram utilizadas: a taxa média de degradação $R_{A v}$, a taxa máxima de degradação $R_{\max }$, a porcentagem de COD removido até o final da reação \%Rem e o tempo em que o COD permanece em um patamar, correspondente a primeira etapa do processo $T_{1}$. A escolha destas quatro respostas é uma tentativa de avaliar o comportamento das curvas de COD em função do tempo para cada polímero. A taxa média de degradação $R_{A v}$, baseada no tempo em que cessa a adição de peróxido (Equação E13), é um compromisso entre a taxa de degradação inicial, que é difícil de calcular devido a patamares (plateaus) em algumas curvas de COD em função do tempo, e a taxa de degradação calculada para todo o experimento, que pode ser confundida para experimentos com curvas de COD em função do tempo completamente diferentes. A \%Rem (Equação E14) avalia a eficiência do processo em termos de queda de COD durante todo o experimento, mas não considera o comportamento das curvas ao longo do tempo. A presença de patamares, ou seja, uma remoção inicial muito lenta é avaliada por $T_{l}$ que é dado pelo encontro da reta que define o patamar inicial com a reta correspondente à maior velocidade de queda de COD, cuja inclinação corresponde à taxa máxima de degradação, $R_{\max }$. A Figura 4.13 mostra como foram calculados $T_{1}$ e $R_{\max }$ e também os tempos em que $\%$ Rem e $R_{A v}$ são calculados de acordo com as equações E13 e E14 para PAM com concentrações: $[\mathrm{PAM}]=1384 \mathrm{mgC} \mathrm{L}^{-1} ;[\mathrm{Fe}(\mathrm{II})]=0.5 \mathrm{mM} \mathrm{e}\left[\mathrm{H}_{2} \mathrm{O}_{2}\right]=300 \mathrm{mM}$.

$$
\begin{aligned}
& R_{A v}=\frac{\mathrm{COD}_{\text {inicial }}-\mathrm{COD}_{\mathrm{H} 2 \mathrm{O} 2}}{\mathrm{t}_{\mathrm{H} 2 \mathrm{O} 2}-\mathrm{t}_{\text {inicial }}} \\
& \% \mathrm{Rem}=100 \cdot \frac{\left(\mathrm{COD}_{\text {inicial }}-\mathrm{COD}_{\text {final }}\right)}{\mathrm{COD}_{\text {inicial }}}
\end{aligned}
$$

Em que $\mathrm{COD}_{\text {inicial }}$ e $\mathrm{COD}_{\text {final }}$ são os valores de $\mathrm{COD}$ medidos no início e no final do experimento $t_{\text {inicial }}$ e $t_{\text {final, }}$, respectivamente, e $\mathrm{COD}_{\mathrm{H} 2 \mathrm{O} 2}$ é o valor de COD medido quando cessa a adição de peróxido de hidrogênio, $t_{\mathrm{H} 2 \mathrm{O} 2}$. Para estas respostas calcularam-se os efeitos das variáveis: [Pol] (concentração inicial de cada polímero), $[\mathrm{Fe}(\mathrm{II})]$ ou $\mathrm{T}$ e $\left[\mathrm{H}_{2} \mathrm{O}_{2}\right]$ designadas como $x_{1}, x_{2}$ e $x_{3}$ respectivamente, bem como de suas interações, utilizando-se o programa de estatística STATGRAPHICS®. 


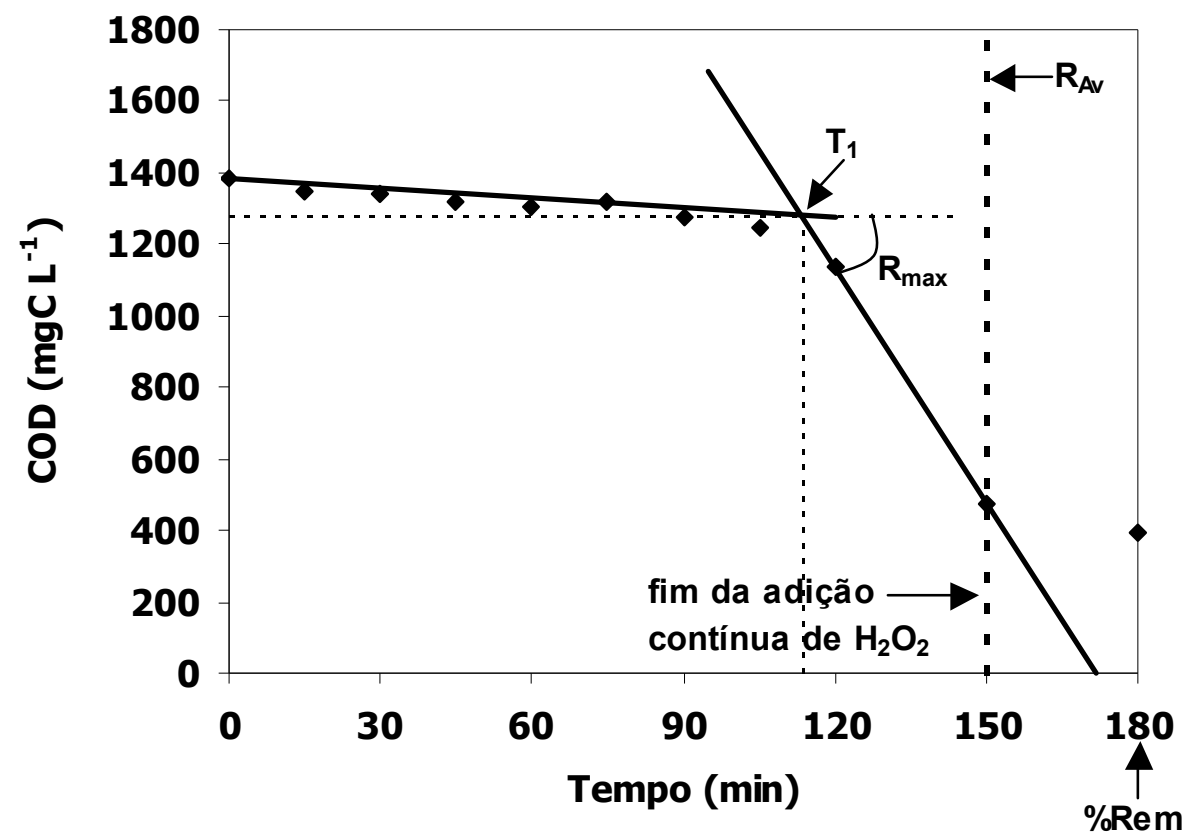

Figura 4.13 - Respostas utilizadas na análise estatística. [PAM] $=1384 \mathrm{mgC} \mathrm{L}^{-1}$, $[\mathrm{Fe}(\mathrm{II})]=0.5 \mathrm{mM}$ e $\left[\mathrm{H}_{2} \mathrm{O}_{2}\right]=300 \mathrm{mM}$.

Os valores das respostas: taxa média de degradação $\left(R_{A v}\right)$, taxa máxima de degradação $\left(\mathrm{R}_{\max }\right), T_{1}$ e porcentagem de remoção (\%Rem), para PEG, processos fotoFenton e UV/ $\mathrm{H}_{2} \mathrm{O}_{2}$, PAM e PVP são apresentados nas Tabelas 4.1, 4.3, 4.5 e 4.7, respectivamente. Os valores dos parâmetros do modelo estatístico, para cada resposta, o valor $P$ obtido pela análise de variância e os coeficientes de determinação são mostrados nas Tabelas 4.2, 4.4, 4.6 e 4.8 para cada polímero. Em geral o ajuste foi bom, com coeficientes de determinação acima de 0.9 , exceto no caso de $T_{1}$ para os experimentos com PEG. Isto é devido a grande dificuldade encontrada em medir este tempo inicial para experimentos do PEG em que não houve separação de fases e o COD apresentou uma queda muito lenta durante todo o experimento.

As Figuras 4.14 a 4.17 mostram o diagrama de Pareto para PEG foto-fenton e $\mathrm{UV} / \mathrm{H}_{2} \mathrm{O}_{2}$, PAM e PVP, respectivamente. O diagrama de Pareto apresenta o valor de cada um dos efeitos estimados em ordem decrescente de magnitude. O comprimento de cada barra corresponde ao efeito estimado dividido pelo desvio-padrão. Isto é equivalente a estatística $t$-Student para cada efeito. 
O tempo correspondente à primeira etapa do processo $T_{1}$, Figuras 4.14 a 4.17 (a), para os três polímeros, para o processo foto-Fenton, apresenta efeitos similares, com concentração do polímero e de ferro com influência positiva e $\left[\mathrm{H}_{2} \mathrm{O}_{2}\right]$ negativa. A concentração de $\mathrm{H}_{2} \mathrm{O}_{2}$ afeta a formação de radicais hidroxila, assim quando $\left[\mathrm{H}_{2} \mathrm{O}_{2}\right]$ está no nível -1 há menos ataque e quebra das moléculas, e os radicais poliméricos e produtos de cadeia grande formados podem se complexar com o ferro. Bossmann et al. (2001a e 2001b) e Lei et al. (1998) verificaram a formação de complexos entre álcool polivinílico e ferro durante o processo foto-Fenton e que tais complexos são menos suscetíveis ao ataque de radicais hidroxila e podem se combinar e coalescer. Atribui-se a formação de partículas sólidas para PAM e PVP a um mecanismo semelhante ao do PVA, proposto por estes autores. Portanto um aumento na quantidade de ferro e de polímero leva a uma queda inicial mais lenta de COD, período $T_{1}$ maior, seguido da precipitação. Para $\mathrm{PEG}$, no processo $\mathrm{UV} / \mathrm{H}_{2} \mathrm{O}_{2}$ a temperatura e a $\left[\mathrm{H}_{2} \mathrm{O}_{2}\right]$ apresentam um efeito negativo em $T_{1}$, pois um aumento nestas variáveis leva a uma queda inicial mais acentuada, diminuindo o patamar. Para PEG para ambos os processos, nenhum dos efeitos foi significativo para esta resposta $(P<0.05)$, conforme mostram os valores de $P$ na Tabela 4.2 e 4.4 e para PAM e PVP foram significativos [Fe(II)] e [Pol] (Tabelas 4.6 e 4.8).

A porcentagem final de remoção de COD (\%Rem), Figuras 4.14, 4.16 e 4.17 (b), também apresentou respostas similares para o processo foto-Fenton para os três polímeros com [Pol] e [Fe(II)] com influência negativa e $\left[\mathrm{H}_{2} \mathrm{O}_{2}\right]$ com influência positiva. Para altas concentrações dos polímeros maiores quantidades de reagentes são necessárias para converter uma dada quantidade inicial de COD, o que leva a influência negativa da [Pol]. De um modo geral, para o processo foto-Fenton pode-se concluir que para obter maiores porcentagens de remoção final de COD é necessário diminuir a concentração de ferro e aumentar a concentração de $\left[\mathrm{H}_{2} \mathrm{O}_{2}\right]$. Nos diagramas de Pareto, Figuras 4.14, 4.16 e 4.17 (b), a interação $\left[\mathrm{H}_{2} \mathrm{O}_{2}\right]$-[Fe(II)] é positiva, como esperado para o processo foto-Fenton. Para PEG no processo $\mathrm{UV} / \mathrm{H}_{2} \mathrm{O}_{2}$ o aumento da temperatura e da concentração de $\mathrm{H}_{2} \mathrm{O}_{2}$ também aumentam a porcentagem máxima de COD removido até o final do processo.

Para a taxa média de degradação $R_{A v}$, Figuras 4.14 a 4.17 (c), a concentração de $\left[\mathrm{H}_{2} \mathrm{O}_{2}\right]$ e [Pol] tiveram influência positiva para o processo foto-Fenton, uma vez 
que a taxa média de degradação depende da concentração de reagentes. A concentração de $[\mathrm{Fe}(\mathrm{II})]$ teve efeito negativo, embora este seja também um dos reagentes, devido ao excesso de sua concentração no nível +1 , o que favorece a formação de complexos solúveis com os polímeros e seus fragmentos e intermediários poliméricos, afetando negativamente o processo de degradação. Para o processo $\mathrm{UV} / \mathrm{H}_{2} \mathrm{O}_{2}$ a temperatura também favorece o aumento da taxa média de degradação.

A taxa máxima de reação $R_{\max }$, Figuras 4.14 a 4.17 (d), indica a máxima inclinação da curva de COD em função do tempo, que é diretamente afetada pela separação de fases, como observado para PAM e PVP. Na Tabela 4.5, por exemplo, para [PAM] no nível +1 , [Fe(II)] +1 e $\left[\mathrm{H}_{2} \mathrm{O}_{2}\right]-1$, apesar de $R_{\max }$ apresentar um valor alto a porcentagem final de COD removida $(\%$ Rem) é a mais baixa de todos os experimentos e o tempo de indução $\left(T_{1}\right)$ é o maior. Para PEG e PVP a $\left[\mathrm{H}_{2} \mathrm{O}_{2}\right]$ tem influência positiva sobre $R_{\max }$, já para PAM seu efeito é negativo. Como discutido anteriormente a concentração de $\left[\mathrm{H}_{2} \mathrm{O}_{2}\right]$ pode estar em excesso levando à formação de moléculas menores que não formam complexos com o ferro e conseqüentemente não coalescem. A [Fe(II)] favoreceu o aumento de $R_{\max }$ somente para PVP e a concentração de polímero teve influência positiva somente para PAM. Das quatro respostas estudadas $R_{\max }$ é a menos clara para o processo foto-Fenton, provavelmente devido ao baixo número de pontos experimentais durante o tempo relativamente curto de formação de sólidos. Para o processo UV/ $\mathrm{H}_{2} \mathrm{O}_{2}$, a concentração de PEG é a única variável que prejudica a taxa máxima de remoção.

Analisando-se as quatro respostas e o intervalo estudado pode-se concluir que para PEG e PAM, no processo foto-Fenton, o nível mínimo de $\left[\mathrm{H}_{2} \mathrm{O}_{2}\right]$ pode ser aumentado para levar a maiores valores de $R_{A v}, R_{\max }$ e $\%$ Rem principalmente quando a concentração destes polímeros for máxima $\left(1500 \mathrm{mgC} \mathrm{L}^{-1}\right)$. O nível máximo de Fe(II) pode ser diminuído porque além de seu efeito ser negativo para estas respostas, e aumentar o tempo de indução $T_{1}$, é sempre importante, do ponto de vista de aplicação, trabalhar com as menores concentrações possíveis de reagentes.

Com relação às interações das variáveis, as Figuras 4.14 a 4.17, mostram que os efeitos dependem de cada polímero. Possivelmente isto é devido às diferentes 
razões de concentrações de reagentes utilizados em cada caso e também a diferentes estruturas dos polímeros estudados.

A característica mais importante para PVP foi o efeito do $\left[\mathrm{H}_{2} \mathrm{O}_{2}\right]$ ser baixo e não significativo para todas as respostas com exceção de $R_{\max }$, o que indica que o intervalo desta variável está em uma faixa em que sua influência não pôde ser avaliada. Como os valores de \%Rem são muito altos, seria interessante diminuir os níveis máximo e mínimo de $\left[\mathrm{H}_{2} \mathrm{O}_{2}\right]$ e $[\mathrm{Fe}(\mathrm{II})]$ para poder avaliar seu efeito nas respostas. Uma possível explicação para a escolha desta faixa equivocada de concentrações é que os experimentos exploratórios para PVP foram realizados com uma concentração inicial de $4000 \mathrm{mgC} \mathrm{L}^{-1}$, e no plano experimental este valor foi mudado para $1500 \mathrm{mgC} \mathrm{L}^{-1}$ como máximo. Apesar da diminuição da concentração dos reagentes, com relação aos experimentos exploratórios, estas ainda foram superestimadas para as concentrações de PVP utilizadas. Inclusive o tempo de reação poderia ser de 120 minutos, como para o PEG.

Para o processo $\mathrm{UV} / \mathrm{H}_{2} \mathrm{O}_{2}$ o aumento da $\left[\mathrm{H}_{2} \mathrm{O}_{2}\right]$ e da temperatura favorecem as respostas $R_{A v}, R_{\max }$ e \%Rem e prejudica $\mathrm{T}_{1}$, ou seja diminui o patamar inicial, já o aumento da concentração de polímero tem o efeito inverso. 
Tabela 4.1 - Respostas analisadas para PEG, processo foto-Fenton.

\begin{tabular}{|c|c|c|c|c|c|c|}
\hline \multicolumn{3}{|c|}{ Níveis } & \multicolumn{4}{|c|}{ Respostas } \\
\hline $\begin{array}{l}{[\mathrm{PEG}]} \\
\left(\mathrm{mgC} \mathrm{L}{ }^{-1}\right)\end{array}$ & $\begin{array}{l}{[\mathrm{Fe}(\mathrm{II})]} \\
(\mathrm{mM})\end{array}$ & $\begin{array}{l}{\left[\mathrm{H}_{2} \mathrm{O}_{2}\right]} \\
(\mathrm{mM})\end{array}$ & $\begin{array}{c}R_{A v} \\
\left(\mathrm{mgC} \mathrm{L}^{-1} \min ^{-1}\right)\end{array}$ & $\begin{array}{c}R_{\max } \\
\left(\operatorname{mgC~L}^{-1} \min ^{-1}\right)\end{array}$ & $\begin{array}{c}T_{1} \\
(\min )\end{array}$ & $\begin{array}{c}\% \operatorname{Rem} \\
(\%)\end{array}$ \\
\hline+1 & +1 & +1 & 9,6 & 13,8 & 30,0 & 63,2 \\
\hline+1 & +1 & -1 & 3,5 & 4,5 & 45,0 & 20,1 \\
\hline+1 & -1 & +1 & 11,5 & 12,9 & 24,0 & 69,1 \\
\hline+1 & -1 & -1 & 3,2 & 7,7 & 50,4 & 21,2 \\
\hline-1 & +1 & +1 & 6,3 & 18,6 & 21,9 & 100,0 \\
\hline-1 & +1 & -1 & 3,7 & 4,5 & 29,1 & 37,3 \\
\hline-1 & -1 & +1 & 6,6 & 17,9 & 12,5 & 100,0 \\
\hline-1 & -1 & -1 & 5,8 & 10,1 & 34,2 & 91,8 \\
\hline 0 & 0 & $\mathbf{0}$ & 7,1 & 10,9 & 42,6 & 70,8 \\
\hline $\mathbf{0}$ & $\mathbf{0}$ & 0 & 7,6 & 15,8 & 43,9 & 67,7 \\
\hline 0 & 0 & $\mathbf{0}$ & 7,8 & 10,4 & 37,8 & $69, .8$ \\
\hline
\end{tabular}




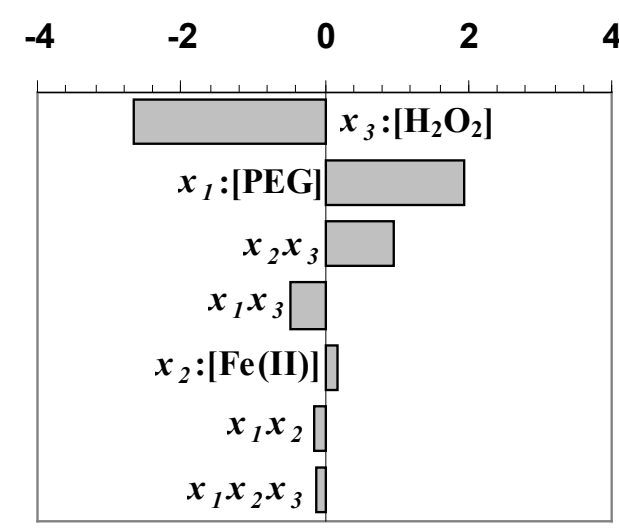

(a) $T_{1}$

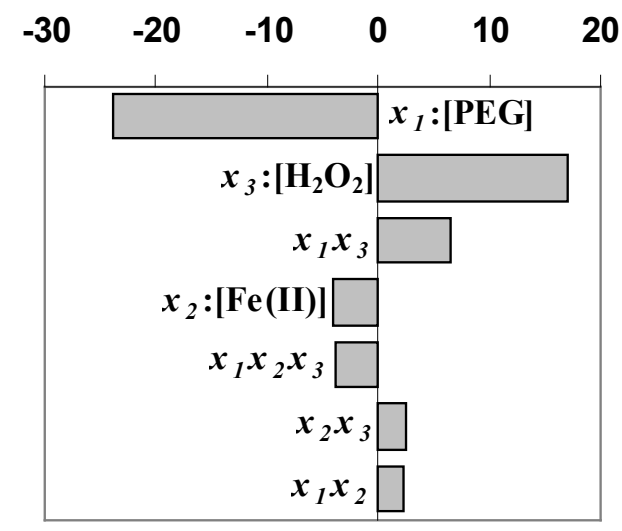

(b) $\%$ Rem

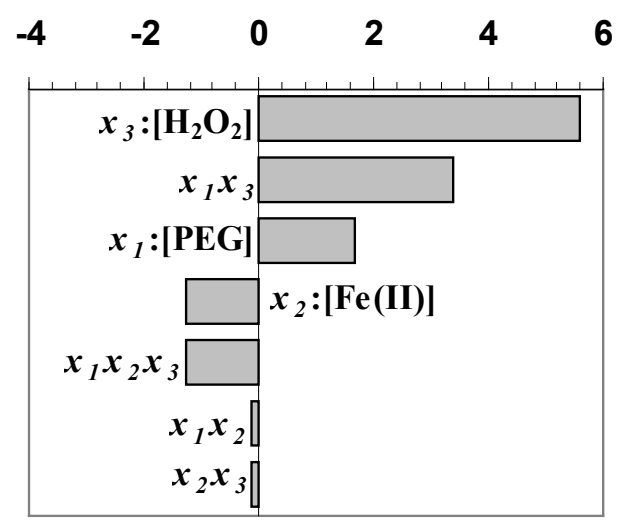

(c) $R_{A v}$

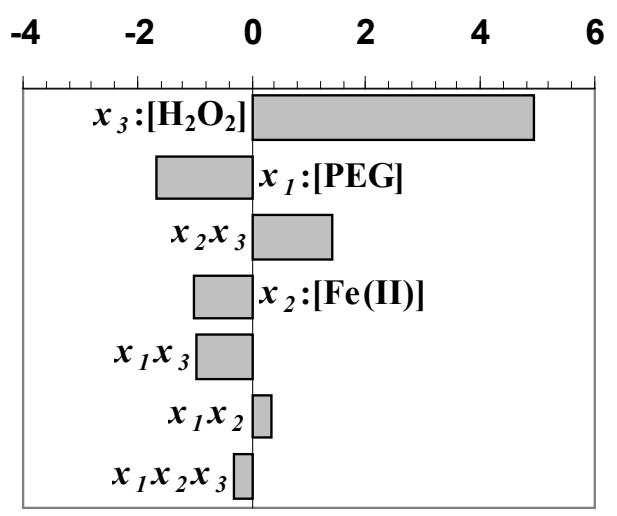

(d) $R_{\max }$

Figura 4.14 - Pareto padronizado para PEG, processo foto-Fenton. 
Tabela 4.2 - Parâmetros estimados e valores $P$ dos componentes da análise de regressão para PEG, processo foto-Fenton.

\begin{tabular}{|c|c|c|c|c|c|c|c|c|}
\hline \multirow[b]{2}{*}{ Parâmetros } & \multicolumn{2}{|l|}{$\boldsymbol{R}_{A v}$} & \multicolumn{2}{|c|}{$\boldsymbol{R}_{\max }$} & \multicolumn{2}{|l|}{$T_{1}$} & \multicolumn{2}{|c|}{ \%Rem } \\
\hline & Coeficientes & ${ }^{\mathrm{a}} \boldsymbol{P}$ & Coeficientes & $P$ & Coeficientes & $P$ & Coeficientes & $P$ \\
\hline Intersecção & 6,624 & & 24,551 & & 33,763 & & 67,371 & \\
\hline$x_{1}:[\mathrm{PEG}]$ & 0,666 & 0,193 & 5,219 & 0,197 & 6,462 & 0,146 & $-23,204$ & 0,000 \\
\hline$x_{2}:[\mathrm{Fe}(\mathrm{II})]$ & $-0,501$ & 0,267 & $-4,939$ & 0,395 & 0,612 & 0,865 & $-3,928$ & 0,027 \\
\hline$x_{3}:\left[\mathrm{H}_{2} \mathrm{O}_{2}\right]$ & 2,224 & 0,011 & $-8,201$ & 0,016 & $-8,787$ & 0,077 & 16,466 & 0,000 \\
\hline$x_{1} x_{2}$ & 0,086 & 0,842 & $-5,167$ & 0,751 & $-0,432$ & 0,898 & 2,199 & 0,107 \\
\hline$x_{1} x_{3}$ & 1,356 & 0,042 & $-0,729$ & 0,398 & $-1,562$ & 0,669 & 6,264 & 0,007 \\
\hline$x_{2} x_{3}$ & $-0,051$ & 0,906 & 5,921 & 0,257 & 3,237 & 0,400 & 2,459 & 0,085 \\
\hline$x_{1} x_{2} x_{3}$ & $-0,499$ & 0,299 & 4,895 & 0,765 & $-0,387$ & 0,914 & $-3,669$ & 0,032 \\
\hline$R^{2}(\times 100)$ & 94,2 & & 91,2 & & 80,1 & & 99,7 & \\
\hline
\end{tabular}

${ }^{\text {a }}$ valores de $P$ menores que 0,05 indicam que o fator correspondente foi significativo para o intervalo de confiança de $95 \%$. 
Tabela 4.3 - Respostas analisadas para PEG, processo $\mathrm{UV} / \mathrm{H}_{2} \mathrm{O}_{2}$.

\begin{tabular}{|c|c|c|c|c|c|c|}
\hline \multicolumn{3}{|c|}{ Níveis } & \multicolumn{4}{|c|}{ Respostas } \\
\hline $\begin{array}{l}{[\mathrm{PEG}]} \\
\left(\mathrm{mgC} \mathrm{L}^{-1}\right)\end{array}$ & $\begin{array}{l}\mathrm{T} \\
(\mathrm{mM})\end{array}$ & $\begin{array}{l}{\left[\mathrm{H}_{2} \mathrm{O}_{2}\right]} \\
(\mathrm{mM})\end{array}$ & $\begin{array}{c}R_{A v} \\
\left(\mathrm{mgC} \mathrm{L}^{-1} \min ^{-1}\right)\end{array}$ & $\begin{array}{c}R_{\max } \\
\left(\operatorname{mgC~L}^{-1} \min ^{-1}\right)\end{array}$ & $\begin{array}{c}T_{1} \\
(\min )\end{array}$ & $\begin{array}{c}\% \operatorname{Rem} \\
(\%)\end{array}$ \\
\hline+1 & +1 & +1 & 67,5 & 17,4 & 42.7 & 9,6 \\
\hline+1 & +1 & -1 & 12,3 & 3,2 & 32,0 & 2,2 \\
\hline+1 & -1 & +1 & 43,2 & 10,8 & 70,0 & 3,8 \\
\hline+1 & -1 & -1 & 7,2 & 1,7 & 76,0 & 0,7 \\
\hline-1 & +1 & +1 & 98,6 & 12,9 & 26,0 & 6,1 \\
\hline-1 & +1 & -1 & 83,7 & 7,9 & 50,6 & 4,0 \\
\hline-1 & -1 & +1 & 94,2 & 7,8 & 25,4 & 4,9 \\
\hline-1 & -1 & -1 & 70,7 & 6,8 & 65,1 & 2,7 \\
\hline 0 & 0 & 0 & 66,8 & 8.5 & 34,0 & 5,5 \\
\hline 0 & 0 & 0 & 63,7 & 8.8 & 34,6 & 5,3 \\
\hline 0 & 0 & 0 & 63,5 & 8.7 & 37,1 & 5,3 \\
\hline
\end{tabular}




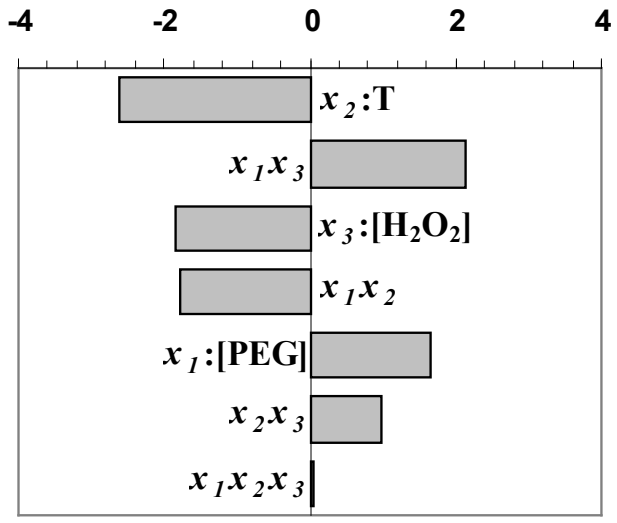

(a) $T_{1}$

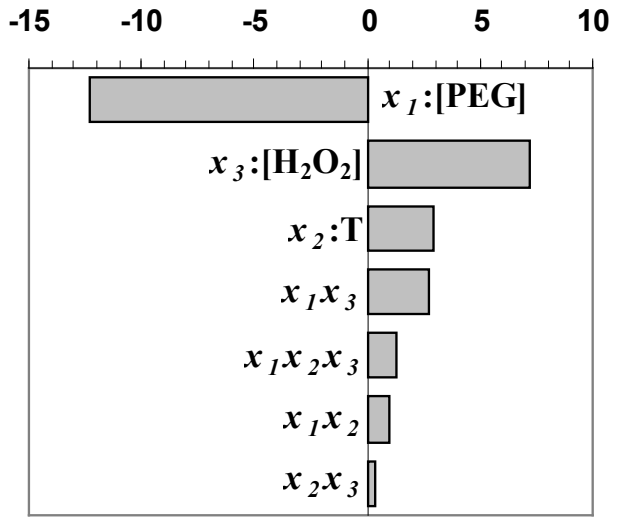

(b) $\%$ Rem

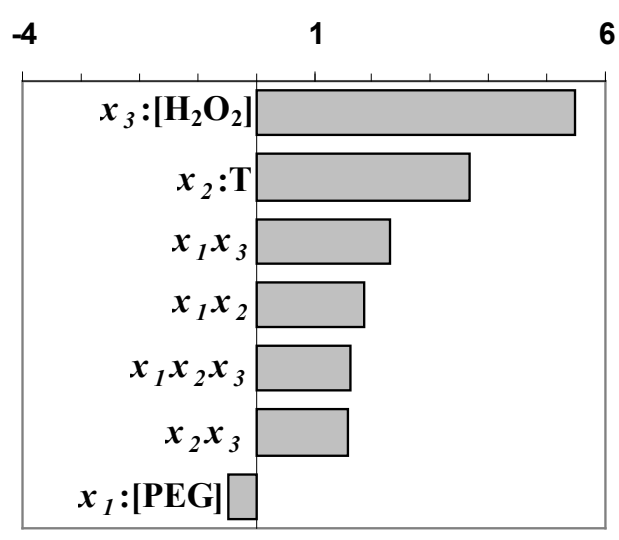

(c) $R_{A v}$ $\begin{array}{llllllll}6 & -40 & -20 & 0 & 20 & 40 & 60 & 80\end{array}$

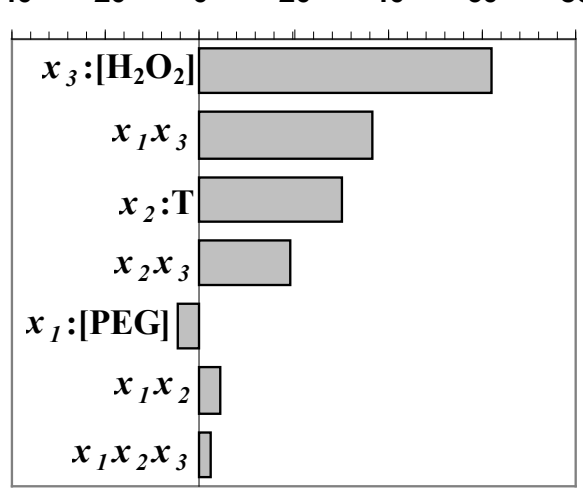

(d) $R_{\max }$

Figura 4.15 - Pareto padronizado para PEG, processo $\mathrm{UV} / \mathrm{H}_{2} \mathrm{O}_{2}$. 
Tabela 4.4 - Parâmetros estimados e valores $P$ dos componentes da análise de regressão para PEG, processo UV/ $\mathrm{H}_{2} \mathrm{O}_{2}$.

\begin{tabular}{|c|c|c|c|c|c|c|c|c|}
\hline & \multicolumn{2}{|c|}{$\boldsymbol{R}_{A v}$} & \multicolumn{2}{|c|}{$\boldsymbol{R}_{\max }$} & \multicolumn{2}{|l|}{$T_{1}$} & \multicolumn{2}{|c|}{$\% \operatorname{Rem}$} \\
\hline Parâmetros & Coeficientes & ${ }^{a} P$ & Coeficientes & $P$ & Coeficientes & $P$ & Coeficientes & $P$ \\
\hline Intersecção & 4,556 & & 8,593 & & 44,840 & & 62,089 & \\
\hline$x_{1}:[\mathrm{PEG}]$ & $-0,162$ & 0,663 & $-0,277$ & 0,018 & 6,692 & 0,197 & $-26,515$ & 0,001 \\
\hline$x_{2}: T$ & 1,237 & 0,035 & 1,775 & 0,000 & $-10,665$ & 0,078 & 6,472 & 0,058 \\
\hline$x_{3}:\left[\mathrm{H}_{2} \mathrm{O}_{2}\right]$ & 1,842 & 0,012 & 3,657 & 0,000 & $-7,450$ & 0,163 & 15,567 & 0,005 \\
\hline$x_{1} x_{2}$ & 0,622 & 0,162 & 0,247 & 0,024 & $-7,165$ & 0,175 & 2,117 & 0,399 \\
\hline$x_{1} x_{3}$ & 0,777 & 0,104 & 2,160 & 0,000 & 8,620 & 0,123 & 5,967 & 0,070 \\
\hline$x_{2} x_{3}$ & 0,527 & 0,216 & 1,127 & 0.000 & 3,977 & 0,399 & 0,700 & 0,767 \\
\hline$x_{1} x_{2} x_{3}$ & 0,552 & 0,199 & 0,130 & 0,114 & 0,192 & 0,965 & 2,865 & 0,277 \\
\hline$R^{2}(\times 100)$ & 95,0 & & 99,9 & & 87,8 & & 98,7 & \\
\hline
\end{tabular}

$\bar{a}$ valores de $P$ menores que 0,05 indicam que o fator correspondente foi significativo para o intervalo de confiança de $95 \%$. 
Tabela 4.5 - Respostas analisadas para PAM.

\begin{tabular}{|c|c|c|c|c|c|c|}
\hline \multicolumn{3}{|c|}{ Níveis } & \multicolumn{4}{|c|}{ Respostas } \\
\hline $\begin{array}{l}\text { PAM }] \\
\left(\mathrm{mgC} \mathrm{L}^{-1}\right)\end{array}$ & $\begin{array}{l}{[\mathrm{Fe}(\mathrm{II})]} \\
(\mathrm{mM})\end{array}$ & $\begin{array}{l}{\left[\mathrm{H}_{2} \mathrm{O}_{2}\right]} \\
(\mathrm{mM})\end{array}$ & $\begin{array}{c}R_{A v} \\
\left(\mathrm{mgC} \mathrm{L}^{-1} \min ^{-1}\right)\end{array}$ & $\begin{array}{c}R_{\max } \\
\left(\mathrm{mgC} \mathrm{L}^{-1} \min ^{-1}\right)\end{array}$ & $\begin{array}{c}T_{1} \\
(\min )\end{array}$ & $\begin{array}{c}\text { \%Rem } \\
(\%)\end{array}$ \\
\hline+1 & +1 & +1 & 8,1 & 13,2 & 79,7 & 94,6 \\
\hline+1 & +1 & -1 & 6,4 & 21,9 & 112,3 & 72,4 \\
\hline+1 & -1 & +1 & 9,4 & 16,6 & 59,1 & 96,5 \\
\hline+1 & -1 & -1 & 9,8 & 25,2 & 67,6 & 95,9 \\
\hline-1 & +1 & +1 & 3,3 & 6,9 & 33,4 & 95,8 \\
\hline-1 & +1 & -1 & 3,0 & 5,6 & 54,9 & 94,6 \\
\hline-1 & -1 & +1 & 4,0 & 11,1 & 15,0 & 100,0 \\
\hline-1 & -1 & -1 & 3,5 & 12,1 & 0,0 & 100,0 \\
\hline $\mathbf{0}$ & $\mathbf{0}$ & $\mathbf{0}$ & 6,6 & 10,4 & 65,1 & 93,9 \\
\hline $\mathbf{0}$ & $\mathbf{0}$ & $\mathbf{0}$ & 6,2 & 10,6 & 67,3 & 91,3 \\
\hline 0 & 0 & 0 & 5,5 & 9,4 & 63,4 & 94,3 \\
\hline
\end{tabular}




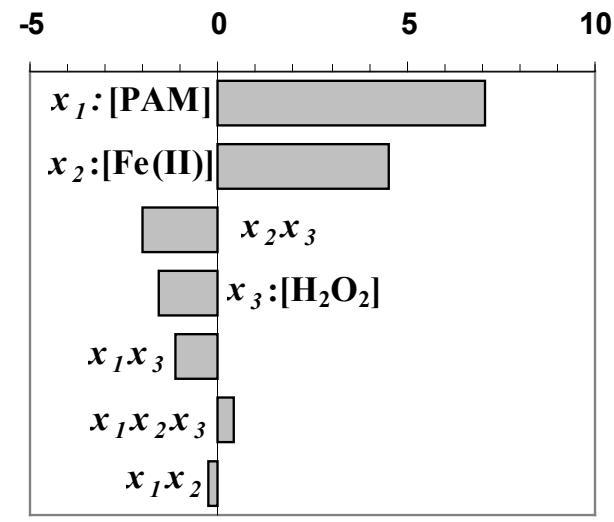

(a) $T_{1}$

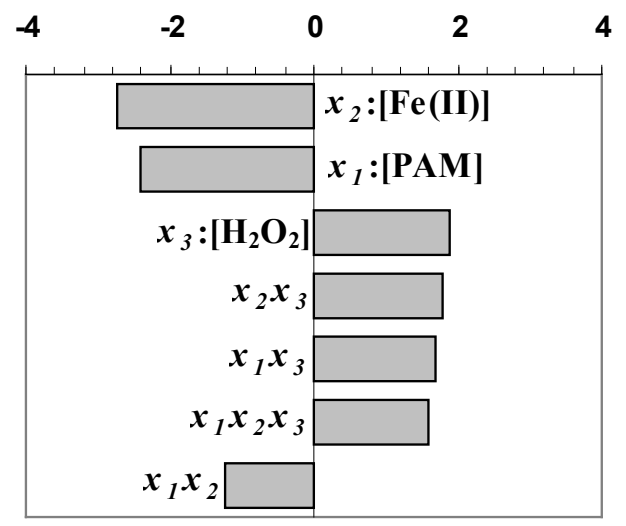

(b) $\%$ Rem

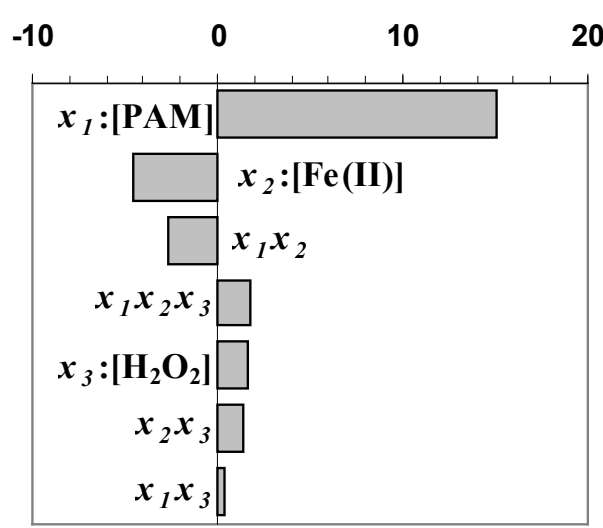

(c) $R_{A v}$
20

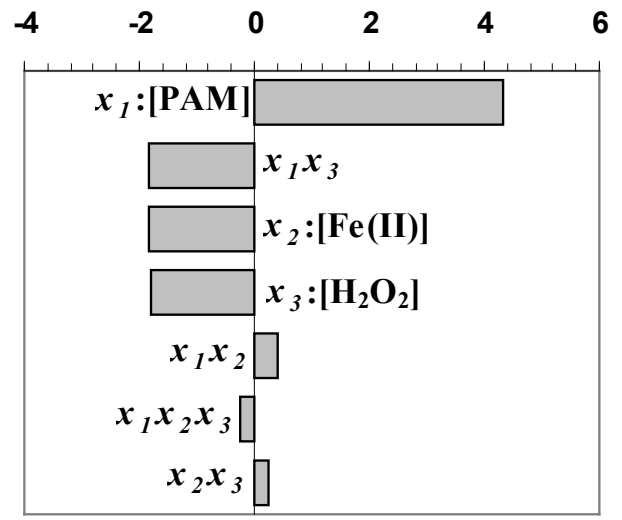

(d) $R_{\max }$

Figura 4.16 - Pareto padronizado para PAM, processo foto-Fenton. 
Tabela 4.6 - Parâmetros estimados e valores $P$ dos componentes da análise de regressão para PAM.

\begin{tabular}{|c|c|c|c|c|c|c|c|c|}
\hline \multirow[b]{2}{*}{ Parâmetros } & \multicolumn{2}{|c|}{$\boldsymbol{R}_{A v}$} & \multicolumn{2}{|c|}{$\boldsymbol{R}_{\max }$} & \multicolumn{2}{|l|}{$T_{1}$} & \multicolumn{2}{|c|}{$\% \operatorname{Rem}$} \\
\hline & Coeficientes & ${ }^{a} P$ & Coeficientes & $P$ & Coeficientes & $P$ & Coeficientes & $P$ \\
\hline Intersecção & 5,598 & & 13,001 & & 56,167 & & 93,592 & \\
\hline$x_{1}:[\mathrm{PAM}]$ & 2,477 & 0,000 & 5,164 & 0,023 & 26,927 & 0,006 & $-3,857$ & 0,005 \\
\hline$x_{2}:[\mathrm{Fe}(\mathrm{II})]$ & $-0,745$ & 0,021 & $-2,180$ & 0,165 & 17,320 & 0,020 & $-4,377$ & 0,003 \\
\hline$x_{3}:\left[\mathrm{H}_{2} \mathrm{O}_{2}\right]$ & 0,277 & 0,191 & $-2,131$ & 0,172 & $-5,930$ & 0,218 & 3,000 & 0,009 \\
\hline$x_{1} x_{2}$ & $-0,445$ & 0,074 & 0,503 & 0,702 & $-1,000$ & 0,810 & $-1,985$ & 0,029 \\
\hline$x_{1} x_{3}$ & 0,060 & 0,739 & $-2,203$ & 0,162 & $-4,320$ & 0,340 & 2,692 & 0,013 \\
\hline$x_{2} x_{3}$ & 0,232 & 0,252 & 0,274 & 0,833 & $-7,572$ & 0,142 & 2,857 & 0,011 \\
\hline$x_{1} x_{2} x_{3}$ & 0,295 & 0,170 & $-0,307$ & 0,813 & 1,537 & 0,714 & 2,550 & 0,015 \\
\hline$R^{2}(\times 100)$ & \multicolumn{2}{|c|}{98,87} & \multicolumn{2}{|c|}{90,61} & \multicolumn{2}{|c|}{96,30} & \multicolumn{2}{|c|}{98,90} \\
\hline
\end{tabular}

$\bar{a}$ valores de $P$ menores que 0,05 indicam que o fator correspondente foi significativo para o intervalo de confiança de $95 \%$. 
Tabela 4.7 - Respostas analisadas para PVP.

\begin{tabular}{|c|c|c|c|c|c|c|}
\hline \multicolumn{3}{|c|}{ Levels } & \multicolumn{4}{|c|}{ Answers for PVP } \\
\hline $\begin{array}{l}{[\mathrm{PVP}]} \\
\left(\mathrm{mgC} \mathrm{L}^{-1}\right)\end{array}$ & $\begin{array}{l}{[\mathrm{Fe}(\mathrm{II})]} \\
(\mathrm{mM})\end{array}$ & $\begin{array}{l}{\left[\mathrm{H}_{2} \mathrm{O}_{2}\right]} \\
(\mathrm{mM})\end{array}$ & $\begin{array}{c}R_{A v} \\
\left(\mathrm{mgC} \mathrm{L}^{-1} \min ^{-1}\right)\end{array}$ & $\begin{array}{c}R_{\max } \\
\left(\mathrm{mgC}^{-1} \min ^{-1}\right)\end{array}$ & $\begin{array}{c}T_{1} \\
(\min )\end{array}$ & $\begin{array}{c}\% \operatorname{Rem} \\
(\%)\end{array}$ \\
\hline+1 & +1 & +1 & 8,7 & 22,1 & 81,0 & 89,3 \\
\hline+1 & +1 & -1 & 7,3 & 18,3 & 108,8 & 70,6 \\
\hline+1 & -1 & +1 & 10,9 & 20,7 & 50,6 & 98,8 \\
\hline+1 & -1 & -1 & 9,1 & 60,2 & 45,0 & 92,1 \\
\hline-1 & +1 & +1 & 3,7 & 13,7 & 17,6 & 100,0 \\
\hline-1 & +1 & -1 & 3,5 & 26,5 & 15,0 & 100,0 \\
\hline-1 & -1 & +1 & 3,6 & 11,1 & 15,0 & 100,0 \\
\hline-1 & -1 & -1 & 3,7 & 28,1 & 2,6 & 99,5 \\
\hline $\mathbf{0}$ & $\mathbf{0}$ & 0 & 6,7 & 27,5 & 49,7 & 100,0 \\
\hline 0 & 0 & $\mathbf{0}$ & 7,1 & 20,9 & 47,6 & 99,5 \\
\hline $\mathbf{0}$ & $\mathbf{0}$ & $\mathbf{0}$ & 7,9 & 20,8 & 46,0 & 99,6 \\
\hline
\end{tabular}




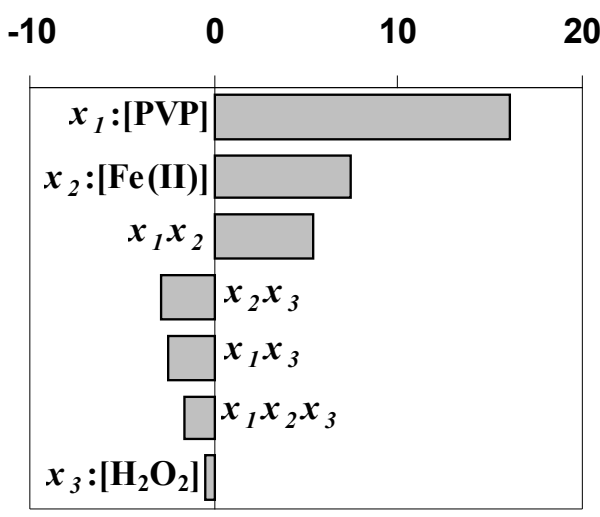

(a) $T_{1}$
20

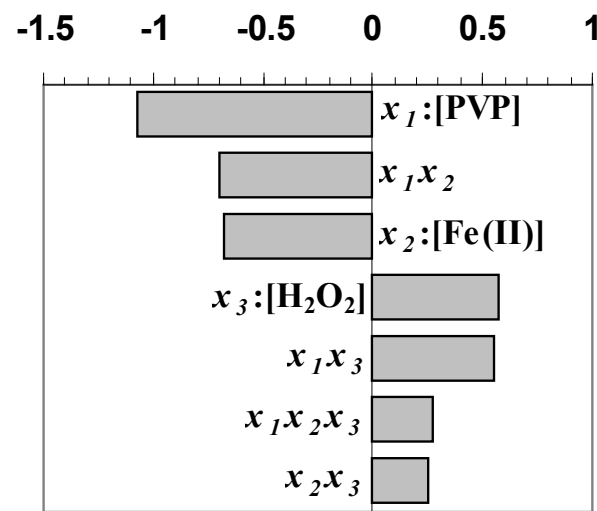

(b) $\%$ Rem

\begin{tabular}{|l|l|}
$-5 \quad 0$ & 5 \\
\hline$x_{1}:[\mathrm{PVP}]$ & \\
\hline & $x_{2}:[\mathrm{Fe}(\mathrm{II})]$ \\
\hline & $x_{1} x_{2}$ \\
\hline$x_{3}:\left[\mathrm{H}_{2} \mathrm{O}_{2}\right]$ & $\square$ \\
$x_{1} x_{3}$ & $\square$ \\
$x_{1} x_{2} x_{3}[$ & \\
$x_{2} x_{3}$ & \\
&
\end{tabular}

(c) $R_{A v}$

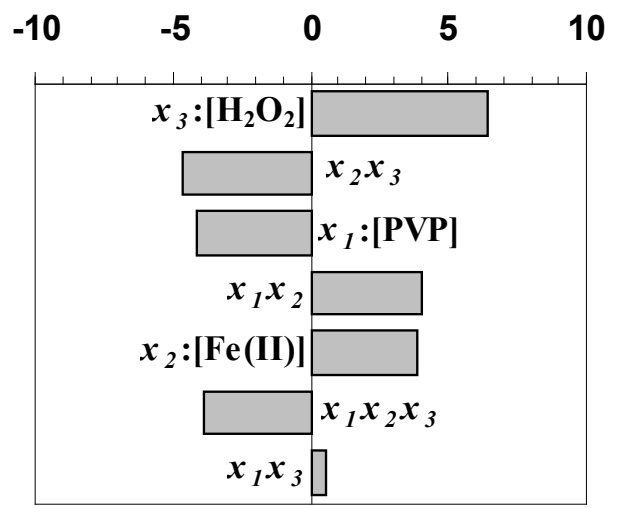

(d) $R_{\max }$

Figura 4.17 - Pareto padronizado para PVP, processo foto-Fenton. 
Tabela 4.8 - Parâmetros estimados e valores $P$ dos componentes da análise de regressão para PVP.

\begin{tabular}{|c|c|c|c|c|c|c|c|c|}
\hline & \multicolumn{2}{|c|}{$\boldsymbol{R}_{A v}$} & \multicolumn{2}{|c|}{$\boldsymbol{R}_{\max }$} & \multicolumn{2}{|l|}{$T_{1}$} & \multicolumn{2}{|c|}{$\% \operatorname{Rem}$} \\
\hline Parâmetros & Coeficientes & ${ }^{a} P$ & Coeficientes & $P$ & Coeficientes & $P$ & Coeficientes & $P$ \\
\hline Intersecção & 6,574 & & $-24,551$ & & 43,526 & & 95,405 & \\
\hline$x_{1}:[\mathrm{PVP}]$ & 2,691 & 0,004 & $-5,219$ & 0,026 & 29,403 & 0,0005 & $-6,080$ & 0,0418 \\
\hline$x_{2}:[\mathrm{Fe}(\mathrm{II})]$ & $-0,514$ & 0,211 & 4,939 & 0,030 & 13,654 & 0,0050 & $-3,812$ & 0,1212 \\
\hline$x_{3}:\left[\mathrm{H}_{2} \mathrm{O}_{2}\right]$ & 0,399 & 0,307 & 8,201 & 0,008 & $-0,904$ & 0,6563 & 3,235 & 0,1662 \\
\hline$x_{1} x_{2}$ & $-0,489$ & 0,229 & 5,167 & 0,027 & 9,904 & 0,0125 & $-3,932$ & 0,1137 \\
\hline$x_{1} x_{3}$ & 0,384 & 0,322 & 0,729 & 0,606 & $-4,654$ & 0,0850 & 3,115 & 0,1778 \\
\hline$x_{2} x_{3}$ & $-0,016$ & 0,963 & $-5,922$ & 0,019 & $-5,404$ & 0,0603 & 1,442 & 0,4763 \\
\hline$x_{1} x_{2} x_{3}$ & $-0,101$ & 0,775 & $-4,895$ & 0,030 & $-2,939$ & 0,2077 & 1,562 & 0,4439 \\
\hline$R^{2}(\times 100)$ & 96,0 & & 97,6 & & 99,17 & & 90,6 & \\
\hline
\end{tabular}

$\bar{a}$ valores de $P$ menores que 0,05 indicam que o fator correspondente foi significativo para o intervalo de confiança de $95 \%$. 


\subsection{Análises de HPLC}

Com o objetivo de caracterizar intermediários formados durante a degradação de PEG e PAM, desenvolveram-se métodos para a identificação e quantificação de alguns ácidos orgânicos, além de acrilamida e oxamida. As condições de realização das análises, como vazão, eluente, temperatura, coluna, tempos de retenção e substâncias identificadas podem ser vistas nas Figuras 4.18 e 4.19. Apenas o ácido acrílico não foi mostrado, pois seu tempo de retenção de 29,2 minutos prolongaria o eixo das abscissas prejudicando a visualização dos primeiros compostos.

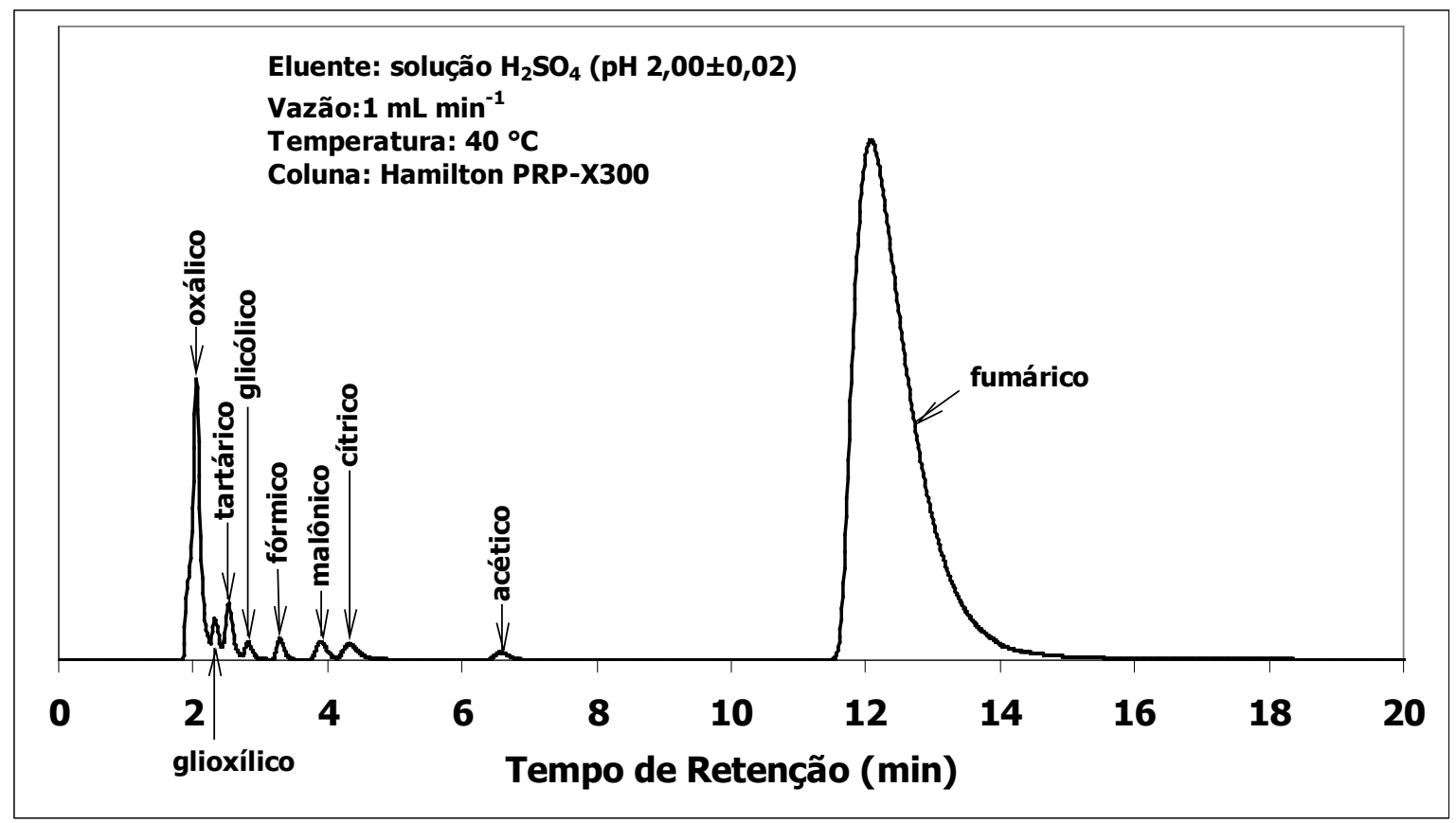

Figura 4.18 - Cromatograma obtido com o método para separação de ácidos orgânicos. Concentração de $300 \mu \mathrm{g} \mathrm{mL}{ }^{-1}, \lambda=220 \mathrm{~nm}$.

As concentrações mínima e máxima utilizadas para levantamento da curva de calibração para os ácidos orgânicos foram de 25 e $500 \mu \mathrm{g} \mathrm{mL}{ }^{-1}$, respectivamente. 


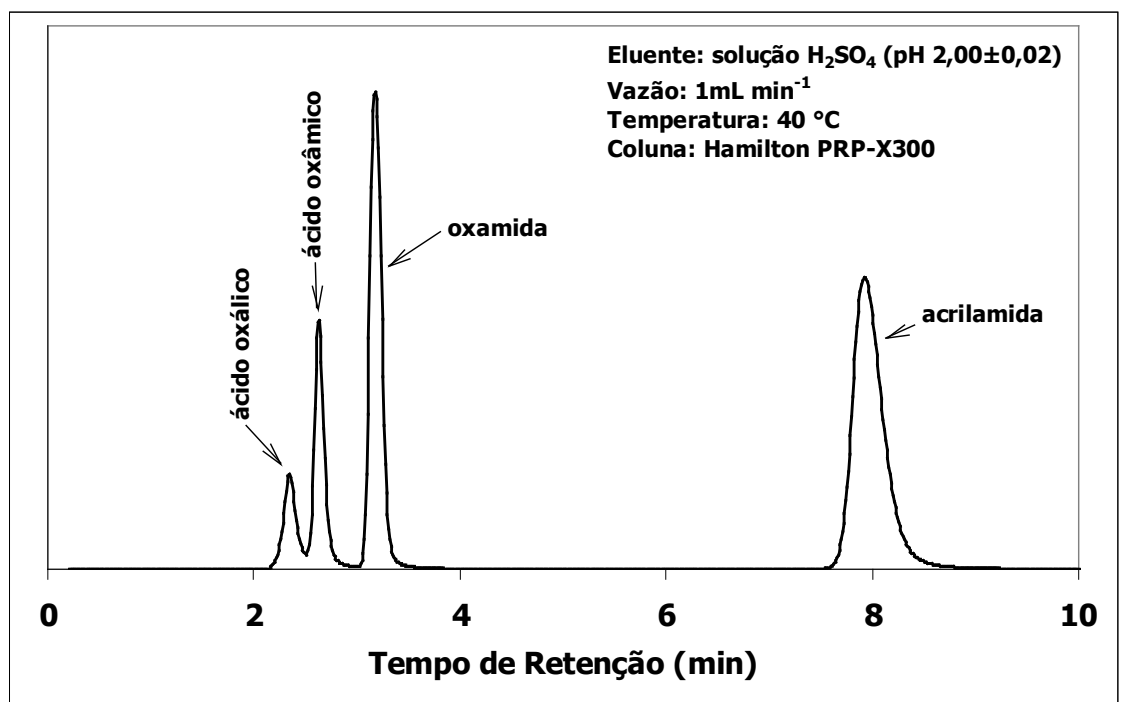

Figura 4.19 - Cromatograma obtido com o método para separação de oxamida, acrilamida, ácido oxálico e ácido oxâmico. Concentração de $100 \mu \mathrm{g} \mathrm{mL}{ }^{-1}, \lambda=205 \mathrm{~nm}$.

Em relação à PAM, buscou-se a caracterização, principalmente de seu monômero, acrilamida, seguido de oxamida e ácido oxâmico, citados como intermediários da degradação de PAM por Gröllmann e Schnabel (1982). Os métodos encontrados na literatura utilizam coluna C18 para determinação de acrilamida, mas os outros dois compostos não são citados: Caulfield et al. (2002, 2003); Smith et al. (1996, 1997) e Vers (1999) utilizaram uma coluna de ácido em série com a C18, precedendo-a. Durante todo o desenvolvimento do método, considerou-se que outros ácidos orgânicos, como fórmico e acético estariam presentes nas amostras de PAM que seriam analisadas. Por isso testaram-se soluções contendo além dos três compostos também alguns ácidos. Assim, após muitos testes com a C18, optou-se por utilizar somente a coluna para ácidos PRP X-300, que separou muito bem a acrilamida e a oxamida, porém o tempo de retenção do ácido oxâmico se sobrepôs ao ácido glioxílico, 2,35 e 2,42 minutos, respectivamente, não sendo possível separar estes dois compostos. A Figura 4.20 mostra o cromatograma obtido para uma solução sem ácido glioxílico.

O limite inferior de detecção da acrilamida e da oxamida, para este método, foi de $50 \mathrm{ppb}$ e o superior de $500 \mu \mathrm{g} \mathrm{mL}^{-1}$ para a acrilamida e $340 \mu \mathrm{g} \mathrm{mL}^{-1}$ para a oxamida. 


\subsubsection{Polietilegnoglicol}

Com o objetivo de acompanhar a formação de intermediários e a quebra de cadeias, trabalhou-se com PEG de dois tamanhos de cadeia iniciais: massas molares de 6000 e $20000 \mathrm{~g} \mathrm{~mol}^{-1}$. Determinaram-se duas condições experimentais, chamadas PC e P1 detalhadas na Tabela 4.9, para as análises de HPLC e GPC.

Tabela 4.9 - Níveis das variáveis nos experimentos que foram analisados por HPLC e GPC.

\begin{tabular}{|c|c|c|c|}
\hline Variáveis & [Pol] $\left(\mathrm{mgC} \mathrm{L}^{-1}\right)$ & {$[\mathrm{Fe}(\mathrm{II})](\mathrm{mM})$} & {$\left[\mathrm{H}_{2} \mathrm{O}_{2}\right](\mathrm{mM})$} \\
\hline \multicolumn{4}{|c|}{ PEG Foto-Fenton $\left(30^{\circ} \mathrm{C}\right)$} \\
\hline PC & 1000 & 1,0 & 110 \\
\hline P1 & 1000 & 0,5 & 60 \\
\hline \multicolumn{4}{|c|}{ PEG UV/ $/ \mathrm{H}_{2} \mathrm{O}_{2}$} \\
\hline & {$[\mathrm{Pol}]\left(\mathrm{mgC} \mathrm{L}^{-1}\right)$} & $\mathbf{T}\left({ }^{\circ} \mathrm{C}\right)$ & {$\left[\mathrm{H}_{2} \mathrm{O}_{2}\right](\mathrm{mM})$} \\
\hline PC & 1000 & 40 & 110 \\
\hline P1 & 1000 & 30 & 60 \\
\hline
\end{tabular}

O ponto PC corresponde ao ponto central do planejamento experimental; o ponto P1 tem a concentração de PEG do ponto central e as demais do nível -1 do plano. Buscou-se com isto uma degradação mais lenta, de modo que possíveis intermediários permanecessem em solução o tempo suficiente e em concentração suficiente para sua análise. O valor máximo da massa molar de PEG foi de $20000 \mathrm{~g}$ $\mathrm{mol}^{-1}$ devido à limitação das colunas para GPC disponíveis (máximo de $50000 \mathrm{~g} \mathrm{~mol}^{-}$ ${ }^{1}$ ). Os valores de COD em função do tempo são mostrados na Figura 4.20, para os oito experimentos analisados. 


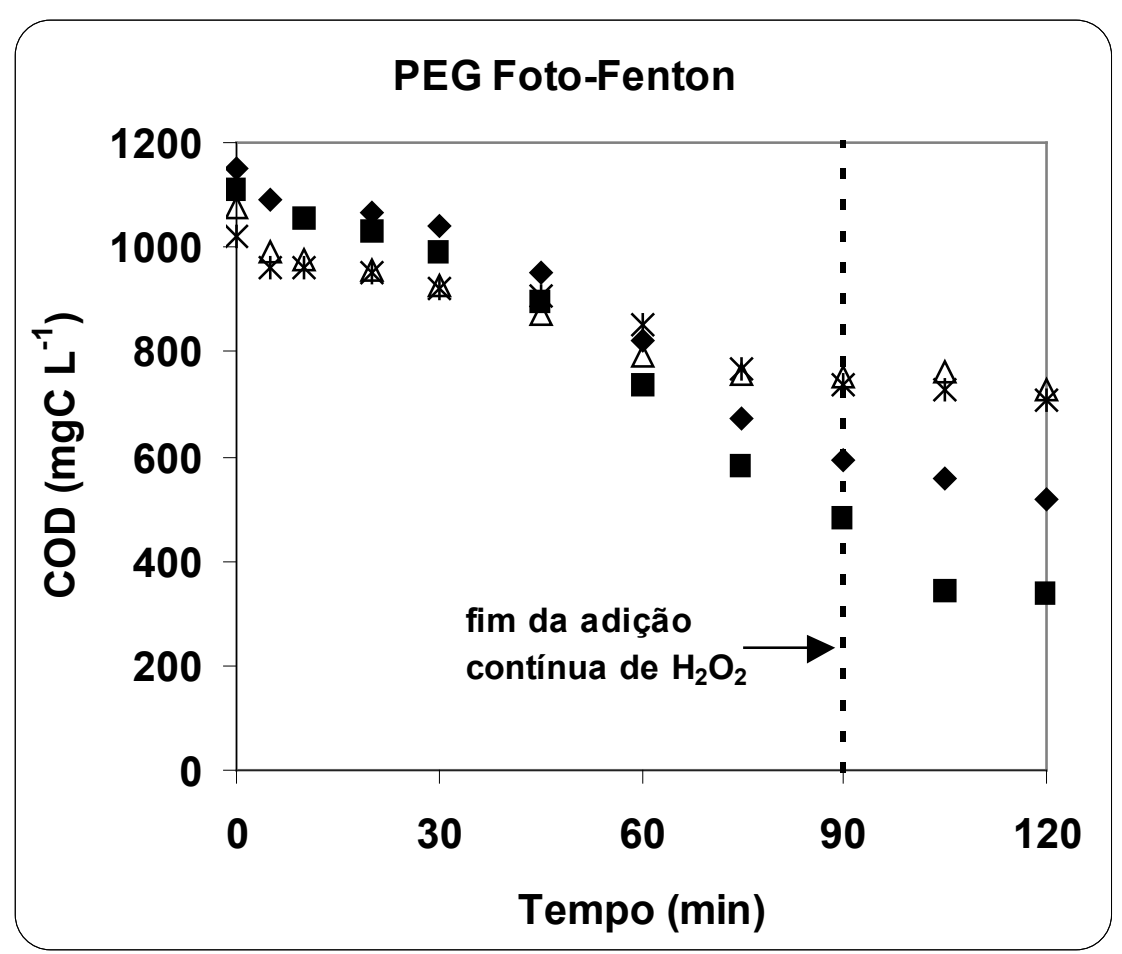

(a)

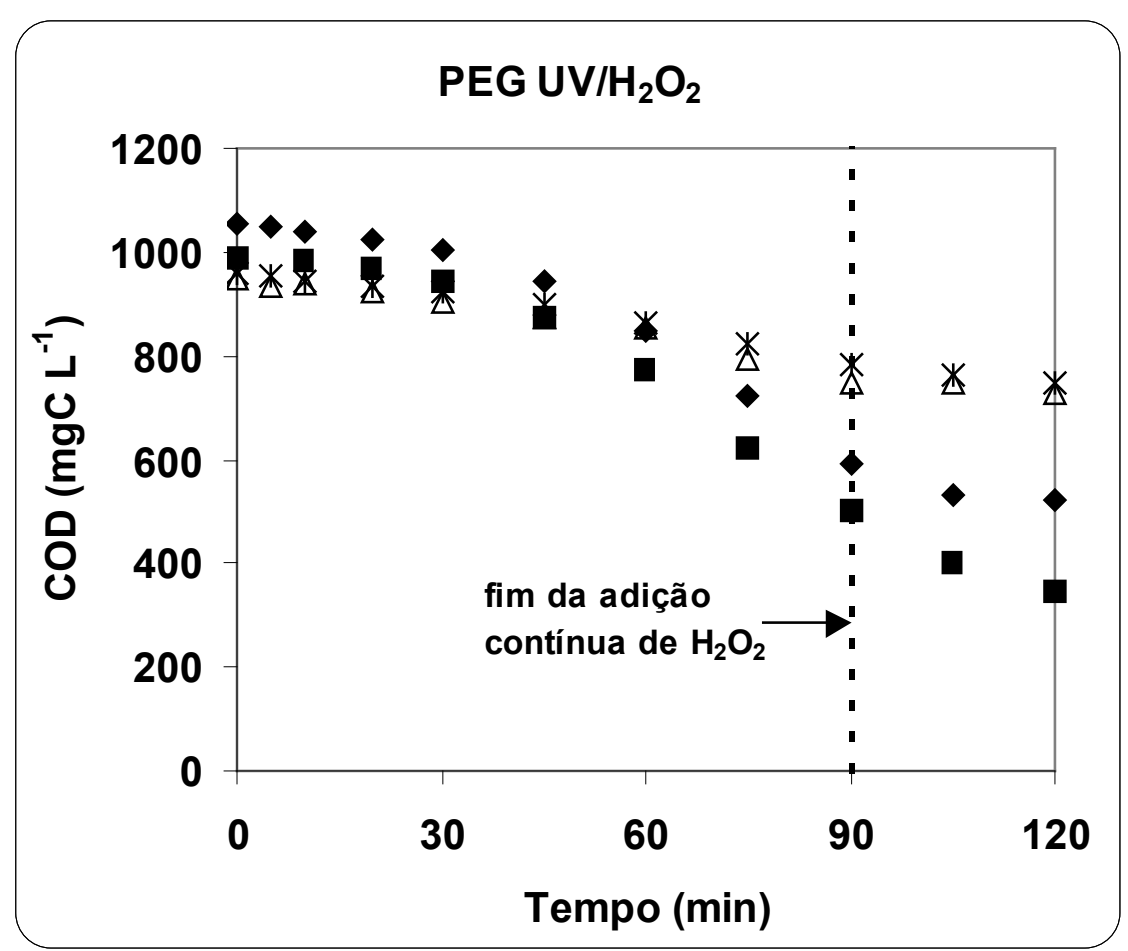

(b)

Figura 4.20 - COD em função do tempo de reação para PEG. PC: $\diamond \mathrm{Mw}=20000 \mathrm{~g}$ $\mathrm{mol}^{-1} ; \mathbf{M w}=6000 \mathrm{~g} \mathrm{~mol}^{-1} ; \mathrm{P} 1: \Delta \mathrm{Mw}=6000 \mathrm{~g} \mathrm{~mol}^{-1} ; * \mathrm{Mw}=20000 \mathrm{~g} \mathrm{~mol}^{-1}$. 
Como pode ser observado nas Figuras 4.20 (a) e (b), os experimentos do ponto P1 tiveram uma menor remoção de COD, para ambos os processos, independentemente do tamanho inicial da cadeia polimérica. Apenas para os experimentos do PC houve uma diferença na remoção final de COD de 14\%, tanto para foto-Fenton, quanto para $\mathrm{UV} / \mathrm{H}_{2} \mathrm{O}_{2}$, quando a massa molar foi aumentada de 6000 para $20000 \mathrm{~g} \mathrm{~mol}^{-1}$. A variação do $\mathrm{pH}$ em função do tempo, Figura 4.21, para o processo $\mathrm{UV} / \mathrm{H}_{2} \mathrm{O}_{2}$ evidencia como as duas condições experimentais P1 e PC influenciaram na formação de compostos intermediários. Para os experimentos P1 o pH permanece constante após 60 minutos e para os PC o pH começa a subir após 60 minutos, indicando a oxidação dos intermediários ácidos.

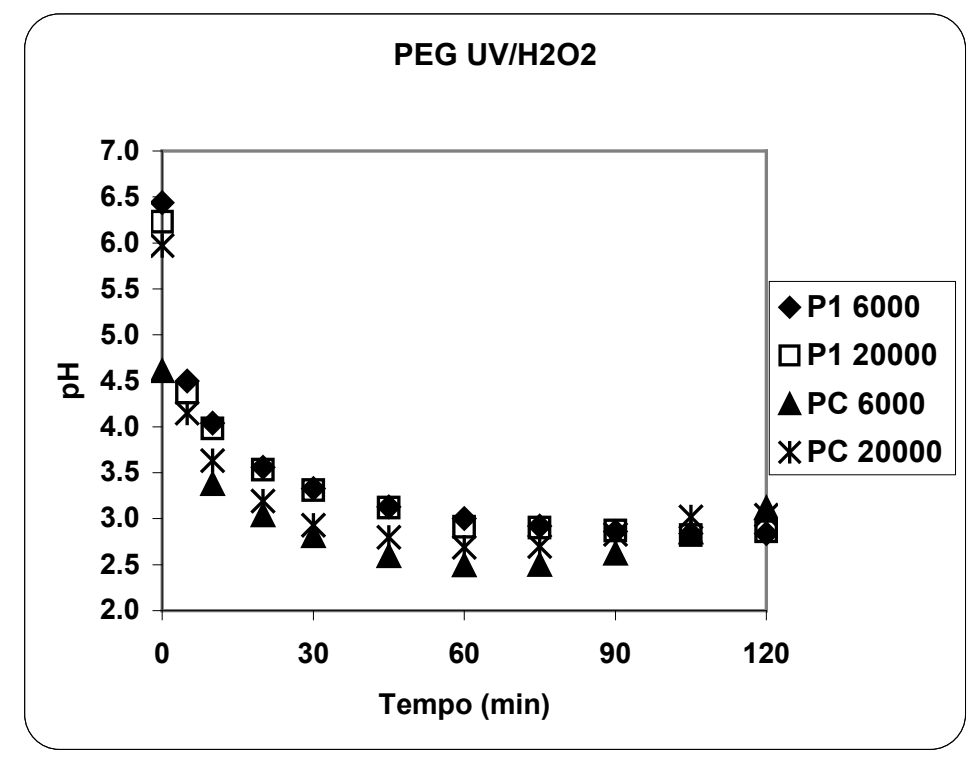

Figura 4.21 - Variação do pH em função do tempo para PEG de 6000 e $20000 \mathrm{~g} \mathrm{~mol}^{-}$ , processo $\mathrm{UV} / \mathrm{H}_{2} \mathrm{O}_{2}$, nas condições experimentais PC.

As Figuras 4.22 e 4.23 mostram a variação da concentração dos ácidos detectados durante os processos $\mathrm{UV} / \mathrm{H}_{2} \mathrm{O}_{2}$ e foto-Fenton, para PEG de massa molar 6000 e $20000 \mathrm{~g} \mathrm{~mol}^{-1}$, para as condições experimentais PC e P1.

Os gráficos $(\mathrm{a}, \mathrm{b})$ da Figura 4.22 permitem avaliar o efeito do aumento do tamanho da cadeia de $6000 \mathrm{~g} \mathrm{~mol}^{-1}$ para $20000 \mathrm{~g} \mathrm{~mol}^{-1}$, no processo foto-Fenton, para experimentos realizados com as condições experimentais do ponto central. Os ácidos detectados para a condição PC são os mesmos para ambos os tamanhos de cadeia, ácidos: acético, fórmico e glicólico. O tamanho da cadeia polimérica 
influenciou na máxima concentração de ácido fórmico e no tempo em que este valor foi atingido: para o PEG 6000 foi de $31 \mathrm{mM}$ aos 30 minutos e para o PEG 2000012 $\mathrm{mM}$ aos 60 minutos de reação. Outra característica comum para PC foi a oxidação total do ácido fórmico a partir de 75 minutos para PEG 6000 e 105 minutos para PEG 20000. O ácido glicólico apresenta concentração máxima de 1,77 mM para PEG 6000 PC caindo para $0,91 \mathrm{mM}$ e ficando constante até o final da reação. Para o PEG 20000 PC a concentração máxima de ácido glicólico é 0,95 mM e permanece praticamente constante até o final da reação, terminando em 0,69 mM. A concentração de ácido acético atingiu um valor máximo próximo de $6 \mathrm{mM}$ para os dois casos e permaneceu constante até o final da reação. $\mathrm{O}$ ácido oxálico aparece em concentrações muito baixas, $0,20 \mathrm{mM}$ e o malônico apenas em traços para os dois casos.

Os ácidos detectados para a condição experimental PC, com maior concentração de reagentes e P1, com menor, foram os mesmos como mostra a Figura 4.22 (c) e (d). Para a condição P1 o tamanho da cadeia polimérica praticamente não influenciou na formação dos ácidos orgânicos. A concentração máxima de ácido fórmico para PEG 6000 e 20000 tem valores próximos, 10,5 e 11,3 mM, é atingida quase ao mesmo tempo e cai muito pouco até o final de experimento. A formação de ácido glicólico também é pouco afetada pelo tamanho da cadeia, suas concentrações máximas têm valores próximos, PEG 6000 3,43mM e PEG 20000 3,22 mM, e suas curvas de concentração ao longo do tempo têm comportamento similares. As curvas de ácido acético para P1 permanecem num patamar até o final da reação para ambos os tamanhos de cadeia.

Para o processo $\mathrm{UV} / \mathrm{H}_{2} \mathrm{O}_{2}$, Figura 4.23, os principais ácidos encontrados também são o fórmico e o acético, porém foi detectado ácido malônico e não glicólico como para foto-Fenton. Para a condição PC, Figuras 4.23 (a) e (b), PEG 6000 apresenta a máxima concentração de ácido fórmico $12,8 \mathrm{mM}$ aos 45 minutos e PEG 20000 12,3 mM aos 60 minutos e em ambos os casos este é completamente oxidado até o final da reação. A formação de ácido acético é praticamente idêntica para PEG 6000 e 20000 e atinge o valor máximo de aproximadamente $8 \mathrm{mM}$ até o final da reação. $\mathrm{O}$ ácido malônico aparece em concentrações baixas, sendo a maior de 1,45 mM para o PEG 6000 e é formado após 45 minutos, sendo totalmente 
consumido até o final da reação. Para a condição P1, Figuras 4.23 (c) e (d), os ácidos detectados são os mesmos e aparecem em concentrações menores que em PC. O ácido fórmico, como para a condição P1 no sistema foto-Fenton, não chega a ser oxidado no final da reação, permanecendo em concentrações altas no meio reacional. O ácido acético como em todos os outros casos permanece num patamar no final da reação.

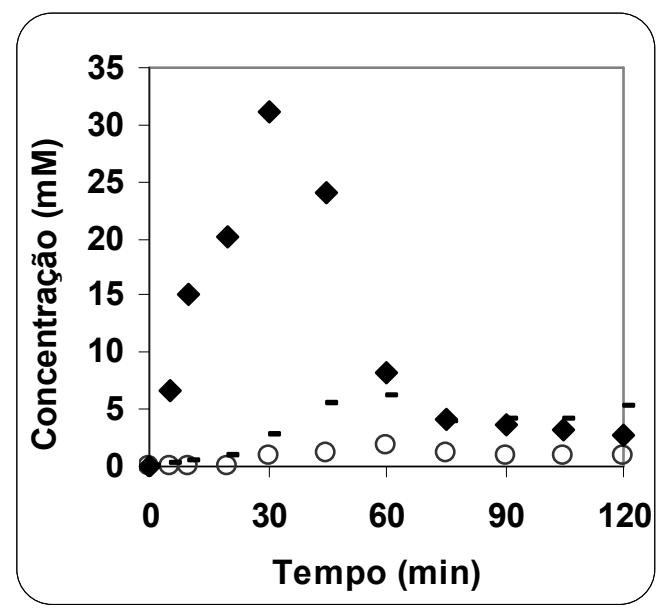

(a) $\mathrm{PC} \mathrm{Mw}=6000 \mathrm{~g} \mathrm{~mol}^{-1}$

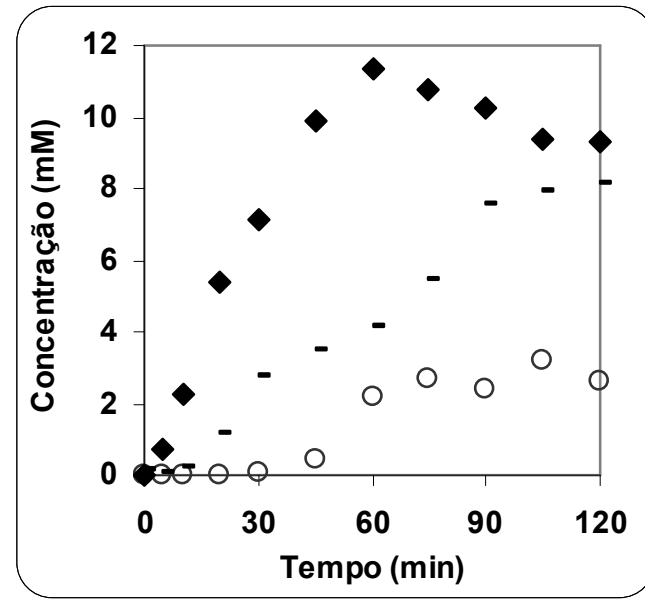

(c) $\mathrm{P} 1 \mathrm{Mw}=6000 \mathrm{~g} \mathrm{~mol}^{-1}$

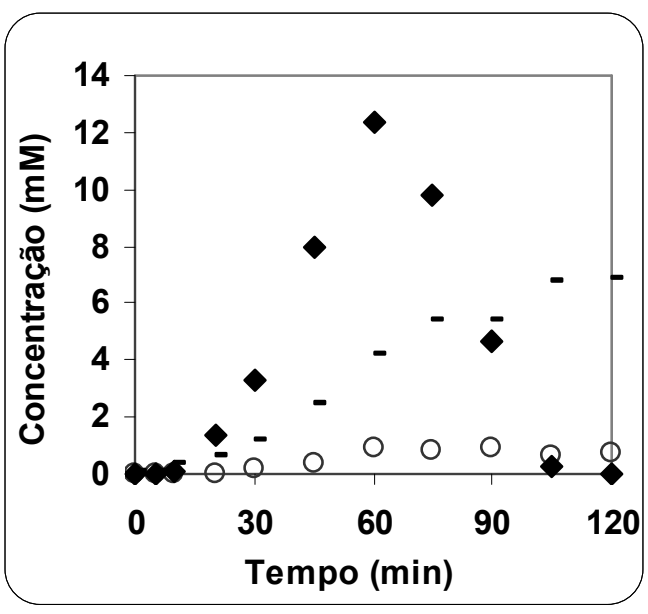

(b) $\mathrm{PC} \mathrm{Mw}=20000 \mathrm{~g} \mathrm{~mol}^{-1}$

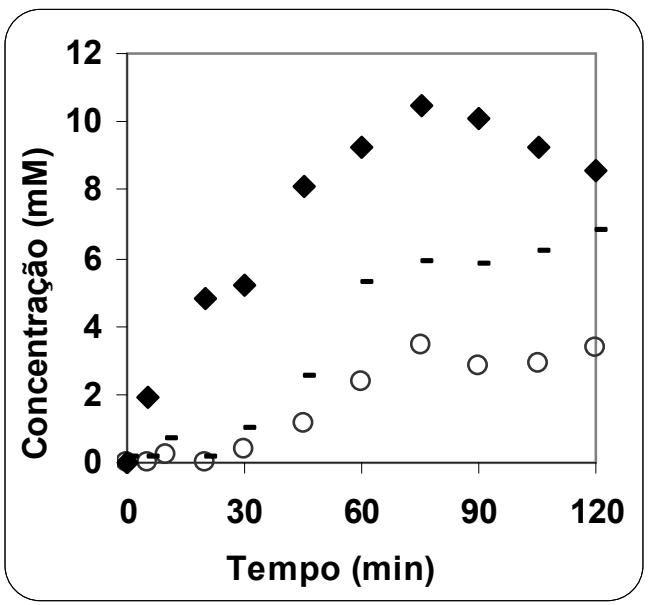

(d) P1 Mw=20000 $\mathrm{g} \mathrm{mol}^{-1}$ (d)

Figura 4.22 - Concentração dos ácidos detectados durante a oxidação do PEG para o processo foto-Fenton. $\mathrm{Mw}=6000 \mathrm{~g} \mathrm{~mol}^{-1}$ : (a) PC e (c) $\mathrm{P} 1$. Mw $=20000 \mathrm{~g} \mathrm{~mol}^{-1}$ (b) PC e (d) P1. Ácidos: $\diamond$ fórmico, - acético, $\bigcirc$ glicólico. 


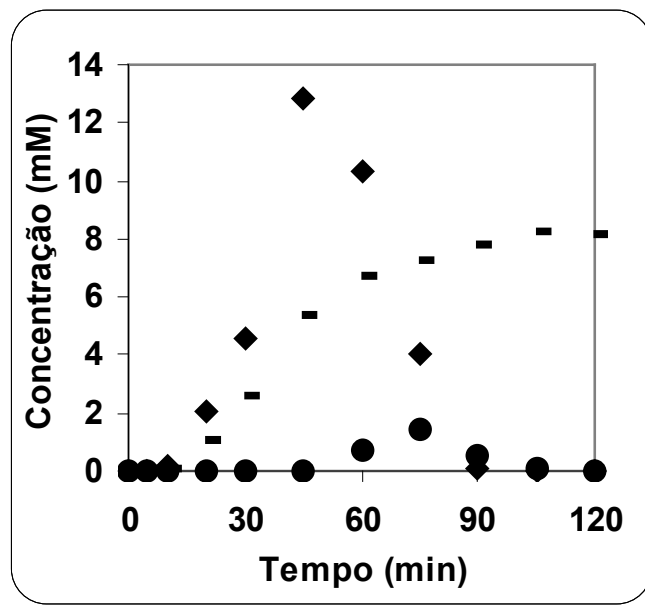

(a) $\mathrm{PC} \mathrm{Mw}=6000 \mathrm{~g} \mathrm{~mol}^{-1}$

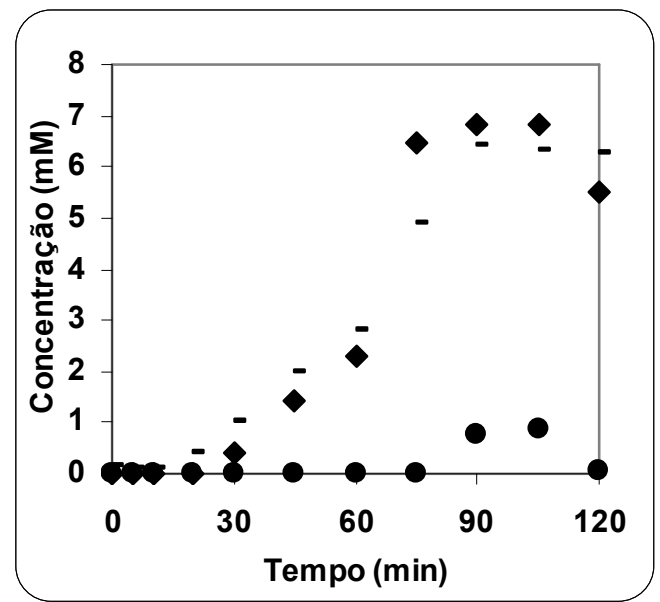

(c) $\mathrm{P} 1 \mathrm{Mw}=6000 \mathrm{~g} \mathrm{~mol}^{-1}$

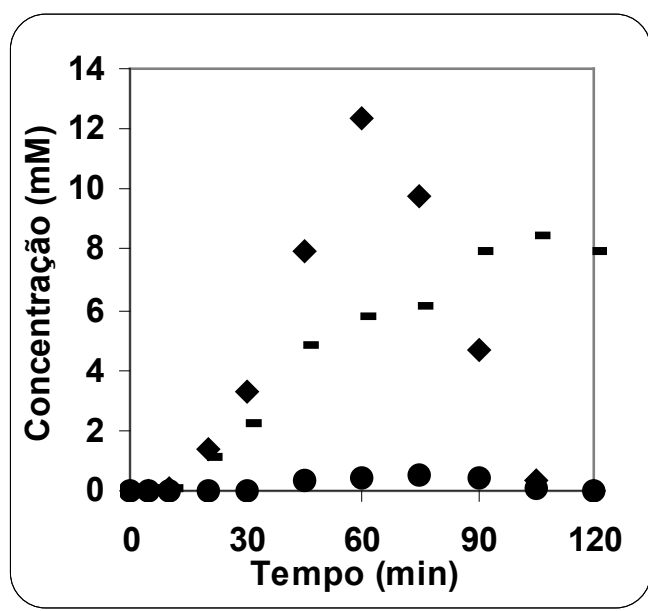

(b) $\mathrm{PC} \mathrm{Mw}=20000 \mathrm{~g} \mathrm{~mol}^{-1}$

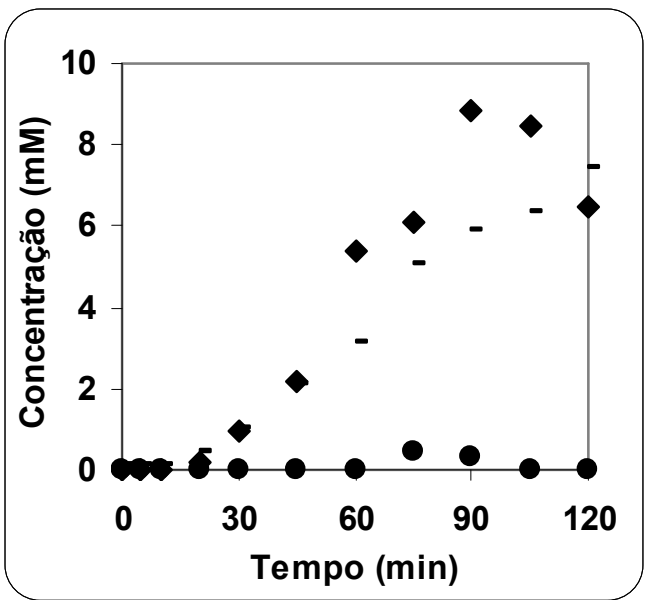

(d) $\mathrm{P} 1 \mathrm{Mw}=20000 \mathrm{~g} \mathrm{~mol}^{-1}$

Figura 4.23- Concentração dos ácidos detectados durante a oxidação do PEG para o processo $\mathrm{UV} / \mathrm{H}_{2} \mathrm{O}_{2}$. Mw $=6000 \mathrm{~g} \mathrm{~mol}^{-1}$ : (a) $\mathrm{PC} \mathrm{e} \mathrm{(c)} \mathrm{P} 1$. Mw $=20000 \mathrm{~g} \mathrm{~mol}^{-1}$ (b) PC e

(d) P1. Ácidos: $\diamond$ fórmico, - acético, malônico.

A principal diferença entre os processos foto-fenton e $\mathrm{UV} / \mathrm{H}_{2} \mathrm{O}_{2}$ foi a formação de um pico, bem definido, de grande intensidade e tempo de retenção idêntico ao do ácido glioxílico, somente no processo $\mathrm{UV} / \mathrm{H}_{2} \mathrm{O}_{2}$, porém, se integrado como este ácido, sua concentração seria superior à de carbono orgânico dissolvido (COD), obtido na análise de carbono orgânico total. Para o processo foto-Fenton, este composto não foi detectado. A concentração de carbono orgânico dissolvido (COD) obtida pela análise de carbono orgânico total e a somatória das concentrações dos ácidos orgânicos para os processos $\mathrm{UV} / \mathrm{H}_{2} \mathrm{O}_{2}$ e foto-Fenton são mostradas na Figura 4.24. 


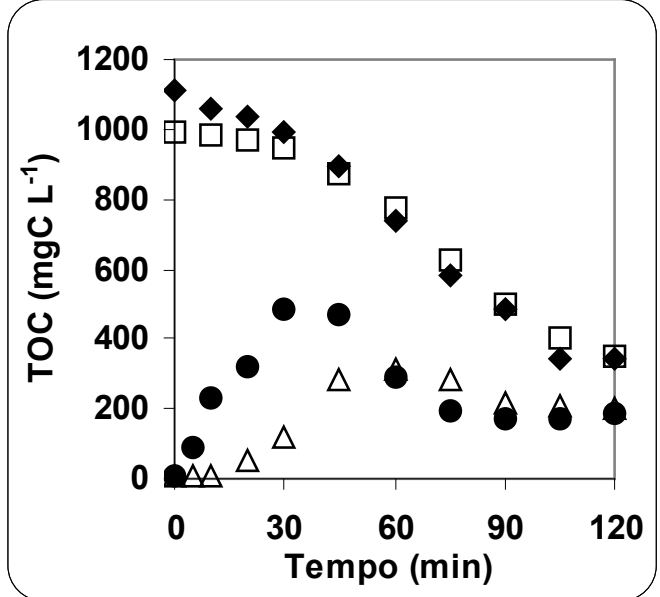

(a) PEG 6000 PC

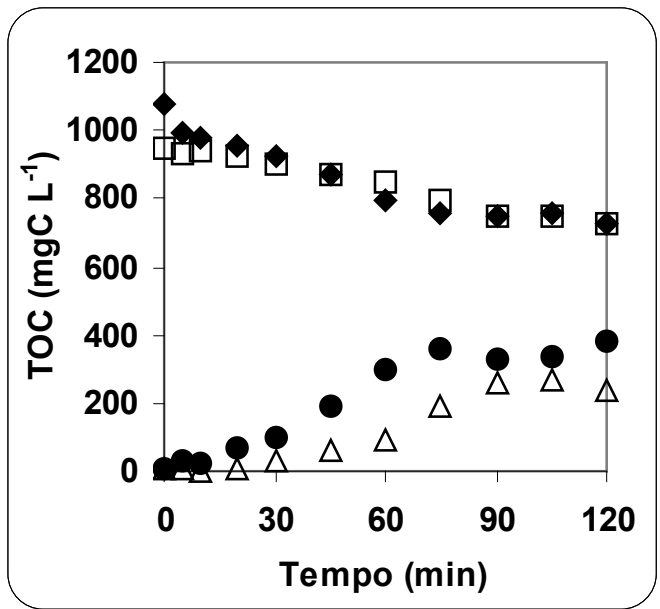

(c) PEG 6000 P1

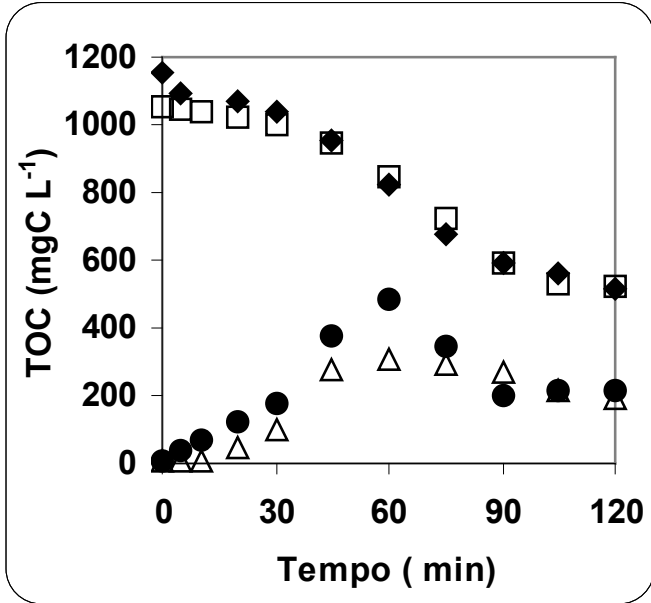

(b) PEG 20000 PC

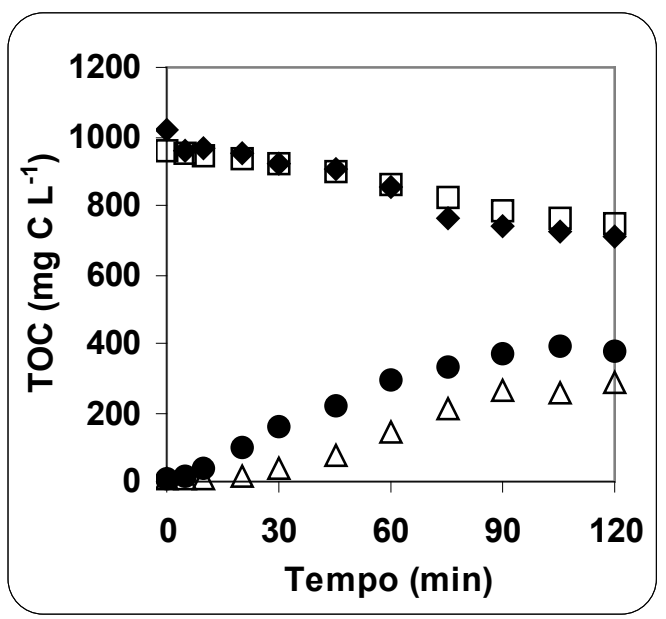

(d) PEG 20000 P1

Figura 4.24 - TOC medido e calculado para PEG. TOC medido: $\bullet$ foto-Fenton, $\mathrm{UV} / \mathrm{H}_{2} \mathrm{O}_{2}$. TOC calculado: $\bullet$ foto-Fenton, $\Delta \mathrm{UV} / \mathrm{H} 2 \mathrm{O} 2$

Nas Figuras 4.24 (a) e (b) para o processo foto-Fenton na condição PC, observa-se que o TOC calculado após atingir um valor máximo, começa a diminuir, indicando a oxidação dos ácidos. Já para o mesmo processo na condição P1, Figuras 4.24 (c) e (d), o TOC calculado permanece praticamente constante após atingir um valor máximo, indicando que os ácidos formados permanecem no meio reacional até o término do experimento. Para o processo $U V / \mathrm{H}_{2} \mathrm{O}_{2}$ também há uma pequena diminuição do TOC calculado para PC e estabilização para P1. Entretanto, como mencionado anteriormente, em todos os experimentos, para este processo houve a 
formação de um composto não identificado, com tempo de retenção idêntico ao do ácido glioxílico.

A diferença entre o TOC medido e o calculado é atribuída a frações de PEG de menor peso molecular e oligômeros, que foram retidos na extração de fase sólida realizada antes da análise de HPLC e também a compostos não identificados como o detectado no processo $\mathrm{UV} / \mathrm{H}_{2} \mathrm{O}_{2}$.

Um provável intermediário não identificado neste trabalho é o glicoaldeído, segundo o esquema proposto por McGinnis et al. (2000), para explicar a mineralização do etilenoglicol, Figura 4.25. McGinnis identificou como principal intermediário do processo foto-Fenton ácido fórmico e pequenas quantidades de ácido oxálico e acetaldeído. Para o processo $\mathrm{UV} / \mathrm{H}_{2} \mathrm{O}_{2}$ foram identificados os mesmos compostos do foto-Fenton mais os ácidos glicólico, glioxílico e oxálico em maior quantidade. A diferença entre ambos os processos, segundo McGinnis, é que a presença de $\mathrm{Fe}^{3+}$ no sistema foto-Fenton pode sensibilizar o ácido oxálico à fotodegradação pela formação de ferrioxalato, segundo a reação 4.6

$$
\mathrm{Fe}\left(\mathrm{C}_{2} \mathrm{O}_{4}\right)_{3}^{3-}+\mathrm{h} v \Rightarrow \mathrm{Fe}^{2+}+2 \mathrm{C}_{2} \mathrm{O}_{4}^{2-}+\mathrm{CO}_{2}+\mathrm{CO}_{2}^{\bullet-}
$$

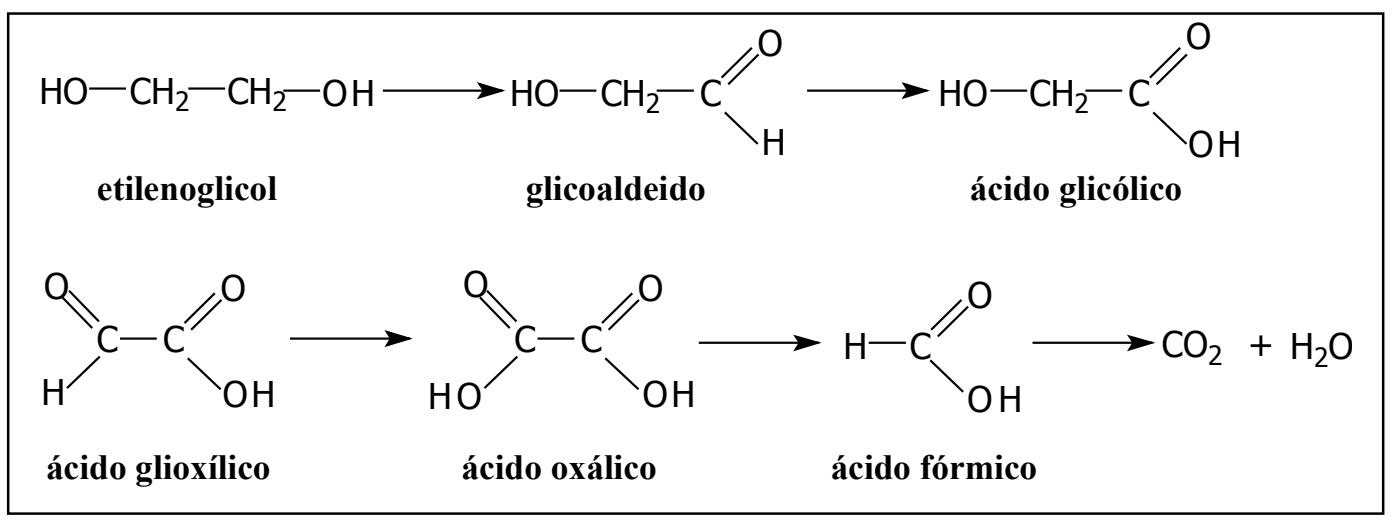

Figura 4.25 - Possível caminho para mineralização de etilenoglicol (McGinnis et al., 2000).

No presente trabalho, a concentração de ácido oxálico encontrada para o processo foto-Fenton foi $0,50 \mathrm{mM}$ e para o $\mathrm{UV} / \mathrm{H}_{2} \mathrm{O}_{2}$ de $0,31 \mathrm{mM}$ para as condições PC. Neste caso, a argumentação de McGinnis é invalidada em relação ao ácido oxálico, mas pode ser aplicada à substância não identificada. É possível que esta 
substância reaja com o ferro no processo foto-Fenton, mas estaria livre no processo $\mathrm{UV} / \mathrm{H}_{2} \mathrm{O}_{2}$, sendo então detectada.

A formação dos ácidos acético e malônico é proposta segundo o esquema apresentado na Figura 4.26, sugerido por Mantzavinos et al. (1996). O ácido malônico é formado a partir da abstração de hidrogênio e oxidação do dietilenoglicol. O ácido acético é formado pela desidratação do etilenoglicol.

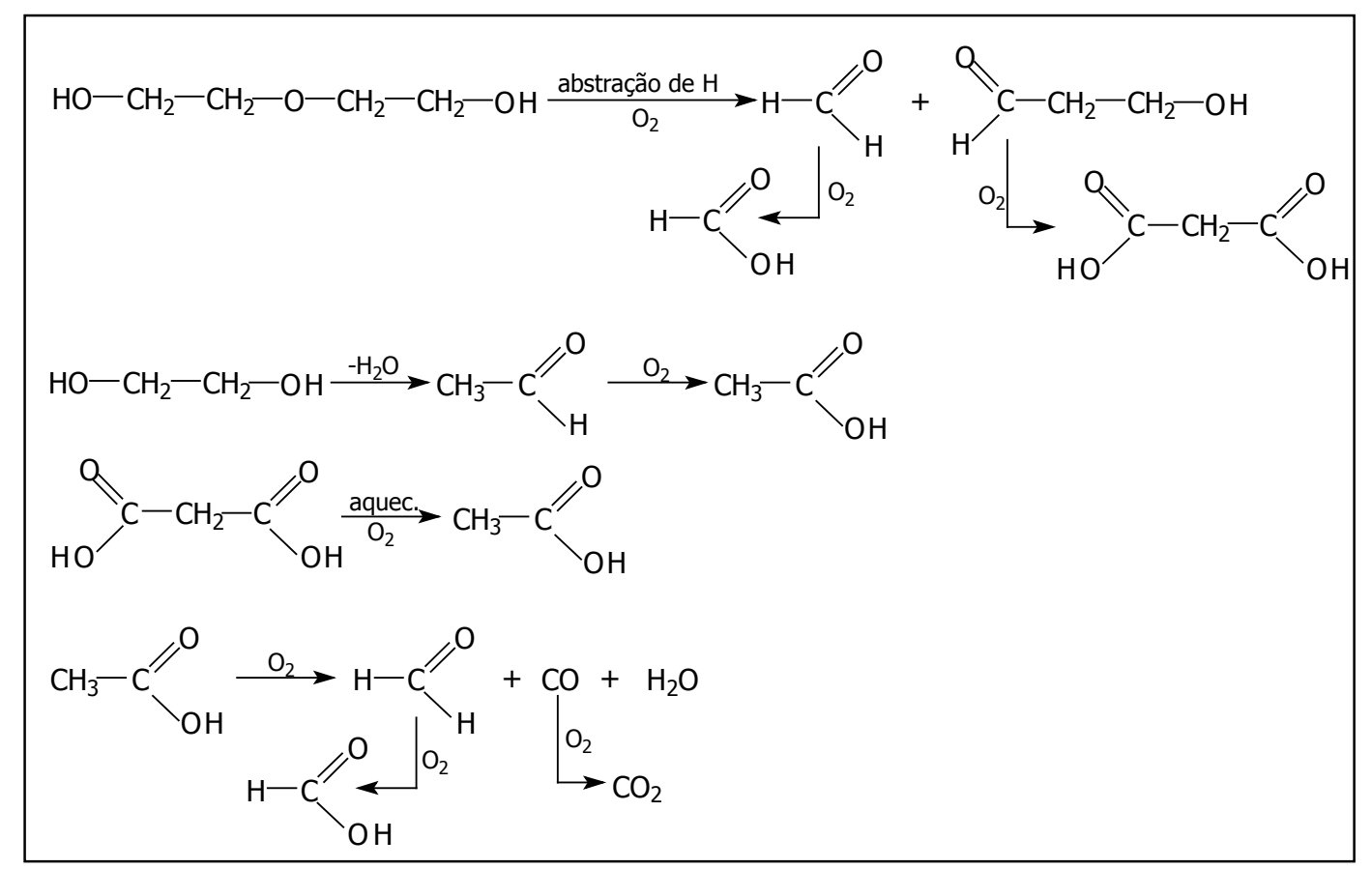

Figura 4.26 - Reações propostas para a formação e oxidação dos ácidos acético e malônico (Mantzavinos et al., 1996).

Embora oligômeros não tenham sido detectados, apesar de tentativas por GC/MS, trabalhos de degradação de polietilenoglicol os identificaram durante a degradação de PEG (Mantzavinos et al, 1996; 1997), e as análises de GPC indicam a rápida quebra das moléculas em frações menores. Assim, os mecanismos propostos, partindo de etilenoglicol e dietilenoglicol, são perfeitamente aplicáveis ao presente estudo.

Outro fato observado na análise dos ácidos orgânicos, que está de acordo com trabalhos de degradação de PEG, é a difícil oxidação destes ácidos, principalmente o acético. Mantzavinos et al. (1996), relataram que o ácido acético submetido à oxidação via úmida a $513 \mathrm{~K}$ e $2 \mathrm{MPa}$, permaneceu com concentração constante, após 
60 minutos de reação. Nas Figuras 4.22 e 4.23 observa-se que o ácido acético permanece com concentração constante e que nas condições de oxidação mais brandas, P1, nenhum dos ácidos formados tende a ser oxidado, permanecendo com concentração constante.

\subsubsection{Poliacrilamida}

Com o objetivo de acompanhar a formação de intermediários durante a oxidação da poliacrilamida, realizou-se um experimento com o processo $\mathrm{UV} / \mathrm{H}_{2} \mathrm{O}_{2}$, com a concentração de polímero $[\mathrm{PAM}]$, peróxido de hidrogênio $\left[\mathrm{H}_{2} \mathrm{O}_{2}\right]$ e temperatura iguais às utilizadas no ponto central do planejamento experimental. Os valores de COD em função do tempo para PAM para ambos os processos e do $\mathrm{pH}$ para o UV/ $\mathrm{H}_{2} \mathrm{O}_{2}$, são mostrados na Figura 4.27.

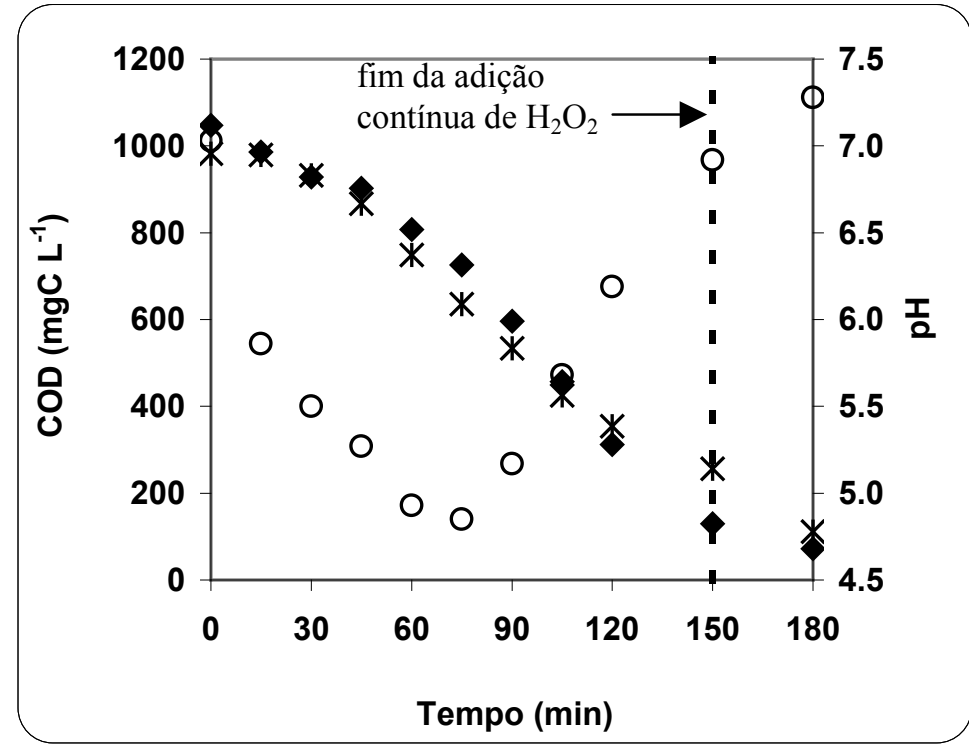

Figura 4.27 - COD em função do tempo de reação para PAM. • Foto-Fenton. * $\mathrm{UV} / \mathrm{H}_{2} \mathrm{O}_{2}$. o Valores de $\mathrm{pH}$ em função do tempo para o processo $\mathrm{UV} / \mathrm{H}_{2} \mathrm{O}_{2}$.

A diminuição da concentração de COD em ambos os processos teve comportamento semelhante e levou a remoções finais próximas: 93\% para fotoFenton e $88,6 \%$ para $\mathrm{UV} / \mathrm{H}_{2} \mathrm{O}_{2}$. O pH cai até 75 minutos de reação e depois sobe até um valor maior que o da solução inicial de PAM. Analogamente ao observado para o 
PEG, pode-se atribuir a queda do $\mathrm{pH}$ à formação de compostos de natureza ácida, mas, neste caso, como o pH tende a subir, estaria indicando não só a degradação dos ácidos formados, como também a formação de compostos de natureza alcalina. Suzuki et al., 1979, atribuem uma forte banda de absorção em $1400 \mathrm{~cm}^{-1}$ no espectro infravermelho de soluções aquosas de PAM, submetidas a ozonização com radiação UV, à formação de nitratos, provenientes da oxidação dos grupos amida de PAM. A hidrólise dos grupos laterais amida também pode levar à liberação dos íons amônio, o que elevaria o pH da solução (Caufield et al., 2003). Infelizmente, como não se realizaram análises para identificação e quantificação de íons amônio ou nitratos, não é possível comprovar esta explicação para o aumento do $\mathrm{pH}$.

Nos trabalhos pesquisados sobre a degradação da PAM e a caracterização dos intermediários formados, foram encontrados os seguintes compostos: ácido oxâmico, oxamida e formaldeído (Gröllmann e Schnabel, 1982 e Suzuki et al., 1979); acrilamida e amônia (Smith et al., 1996). Não foram desenvolvidos métodos para análise de formaldeído e amônia e não foi detectado ácido oxâmico pelo método desenvolvido devido à sua sobreposição com o ácido glioxílico. Os intermediários detectados na degradação de PAM, quando submetida aos processos foto-Fenton e $\mathrm{UV} / \mathrm{H}_{2} \mathrm{O}_{2}$, são mostrados na Figura 4.28.

As principais diferenças entre os processos é a formação de ácido fórmico somente no foto-Fenton e a maior concentração de ácido malônico neste processo. $\mathrm{O}$ ácido oxálico e a oxamida foram formados nos dois processos com o primeiro em maior concentração no foto-Fenton e a segunda no $\mathrm{UV} / \mathrm{H}_{2} \mathrm{O}_{2}$. A acrilamida, que é o composto de maior interesse devido à sua toxicidade, não foi detectada em nenhum dos processos pelo método desenvolvido, cujo limite mínimo é de 50 ppb. Comparativamente à análise de ácidos de PEG a de PAM mostrou-se muito mais complexa mesmo com a repetição dos experimentos e análises. O ácido acético foi detectado em concentrações abaixo do limite mínimo de concentração do método analítico $\left(25 \mu \mathrm{g} \mathrm{mL} \mathrm{m}^{-1}, 0,42 \mathrm{mM}\right)$ alcançando $1 \mathrm{mM}$ aos 90 minutos e caindo novamente após 150 minutos, para ambos os processos 


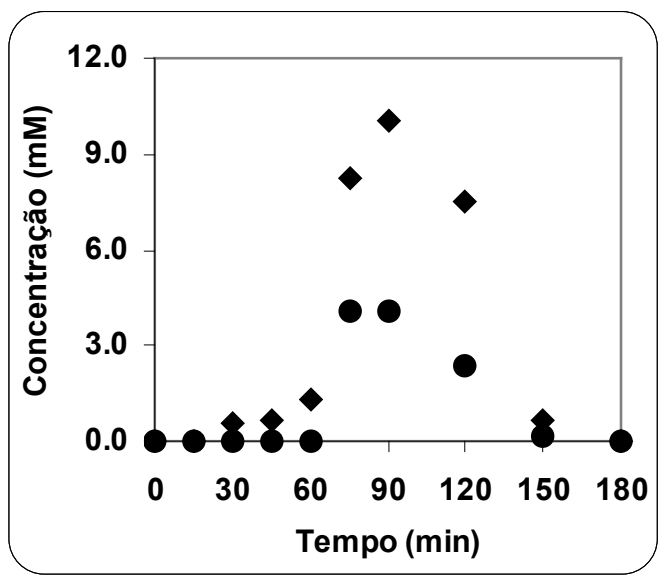

(a)

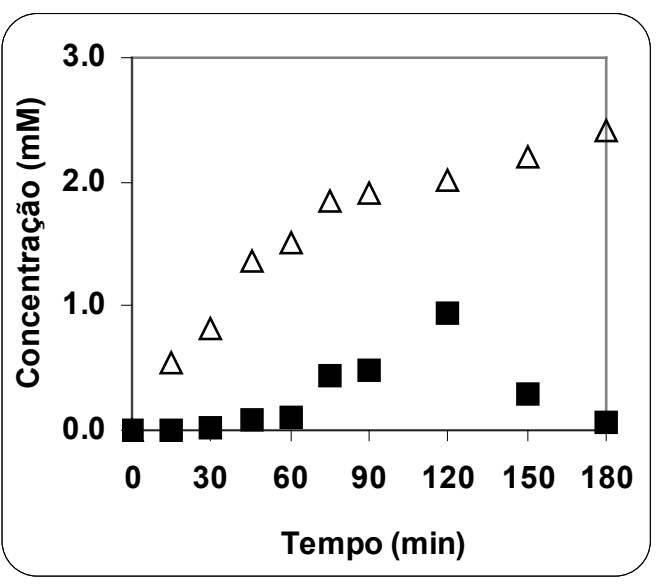

(b)

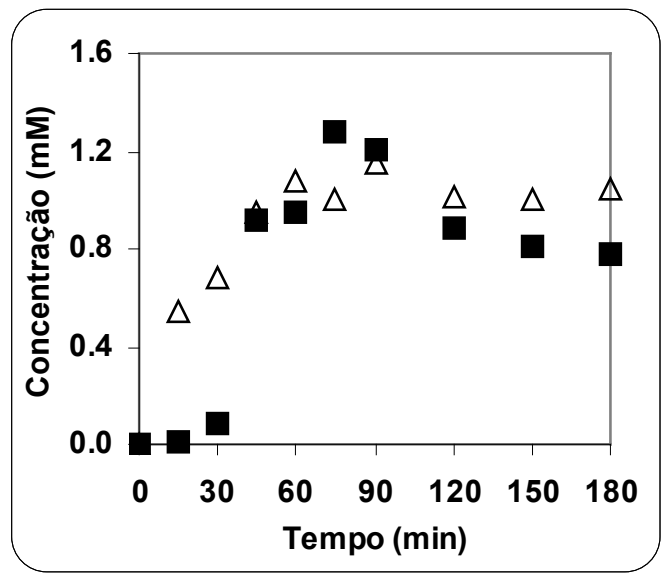

(c)

Figura 4.28 - Concentração de ácidos e oxamida em função do tempo durante a degradação de PAM (a) e (b) Foto-Fenton. (c) $\mathrm{UV} / \mathrm{H}_{2} \mathrm{O}_{2}$. a Oxamida. Ácidos: Fórmico; Malônico; $\Delta$ Oxálico.

A Figura 4.29 mostra as concentrações dos intermediários detectados para os processos foto-Fenton e $\mathrm{UV} / \mathrm{H}_{2} \mathrm{O}_{2}$ calculadas em $\mathrm{mgC} \mathrm{L} \mathrm{L}^{-1}$ para PAM. Como pode ser visto há uma grande distância entre o TOC calculado e medido para o processo $\mathrm{UV} / \mathrm{H}_{2} \mathrm{O}_{2}$, já para o processo foto-Fenton, devido a alta concentração de ácido fórmico em 75, 90 e 120 minutos de reação os valores de TOC calculados correspondentes a estes pontos, se aproximam mais da curva de TOC medido. Esta análise indica que no processo $\mathrm{UV} / \mathrm{H}_{2} \mathrm{O}_{2}$, há mais intermediários não detectados, como no caso do PEG para o mesmo processo, ou compostos de maior peso molecular que ficaram retidos na extração de fase sólida. 


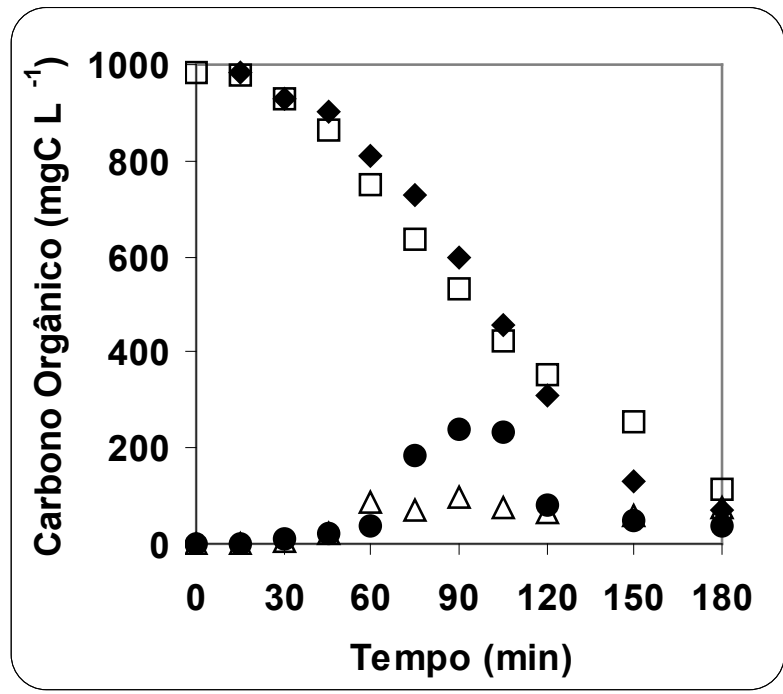

Figura 4.29 - TOC medido e calculado para PAM. TOC medido: $\bullet$ foto-Fenton, $\square$ $\mathrm{UV} / \mathrm{H}_{2} \mathrm{O}_{2}$. TOC calculado: foto-Fenton, $\Delta \mathrm{UV} / \mathrm{H}_{2} \mathrm{O}_{2}$. 


\subsection{Análises de GPC}

A variação da distribuição de pesos moleculares de PEG e PAM, durante os processos oxidativos estudados, foi acompanhada por GPC. A curva de calibração, obtida com padrões de PEG, e as condições do método desenvolvido são mostradas na Figura 4.30. A equação de calibração, ajustada pelo programa de GPC é dada pela equação E15, com coeficiente de determinação $\left(R^{2}\right)$ de 99,50\%.

$\log (M W)=-3,016 \times 10^{-3} \times \mathrm{t}^{3}+0,163 \times \mathrm{t}^{2}-3.163 \times \mathrm{t}+24,588$

E15

Em que ' $t$ ' representa o tempo de retenção.

O padrão de menor peso molecular utilizado foi o etilenoglicol, com massa molar de $96 \mathrm{~g} \mathrm{~mol}^{-1}$ e tempo de retenção de 21,25 minutos. O padrão de maior massa molar foi PEG de $22400 \mathrm{~g} \mathrm{~mol}^{-1}$, com tempo de retenção de 13,07 minutos. Portanto, estes são os limites da curva de calibração e nenhum pico com tempo de retenção fora deste intervalo foi analisado para evitar-se a extrapolação da curva. Embora o limite de exclusão da coluna (PolySep-GFC-P 3000) fosse de $50000 \mathrm{~g} \mathrm{~mol}^{-1}$, a falta de padrões com maiores massas molares não permitiu ampliar o intervalo válido para análise. A Figura 4.31 mostra dois cromatogramas típicos das amostras de PEG, um para o processo foto-Fenton e outro para o $\mathrm{UV} / \mathrm{H}_{2} \mathrm{O}_{2}$, este último com alguns picos que não puderam ser analisados, pois estavam fora da faixa, para a qual a curva de calibração foi obtida. 


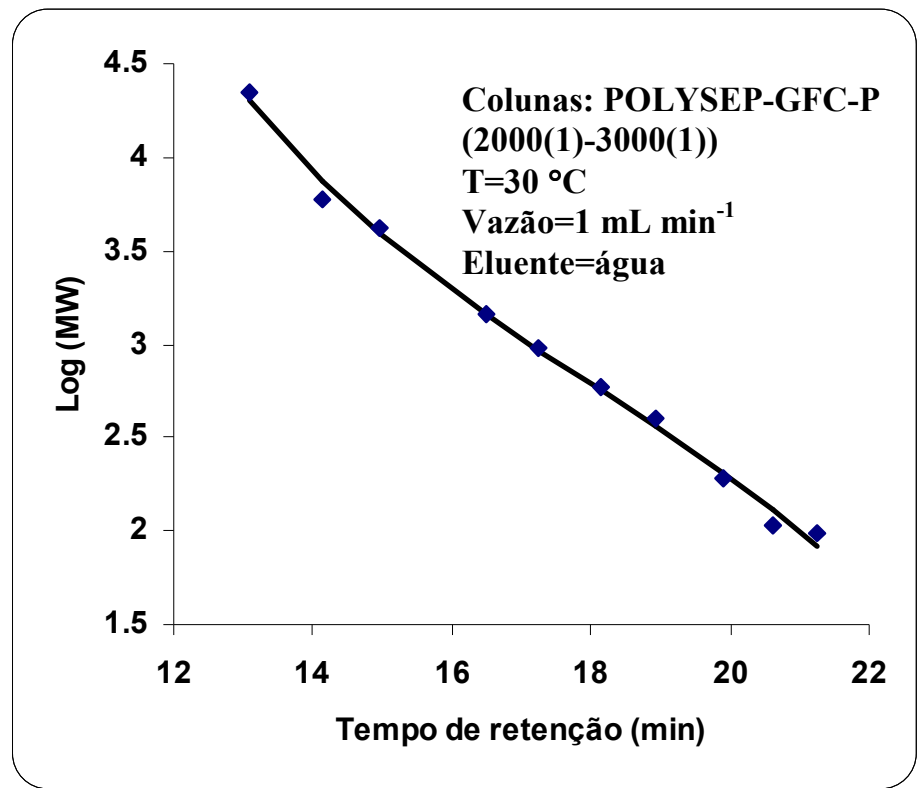

Figura 4.30 - Curva de calibração, com padrões de PEG, desenvolvida para as análises de GPC.

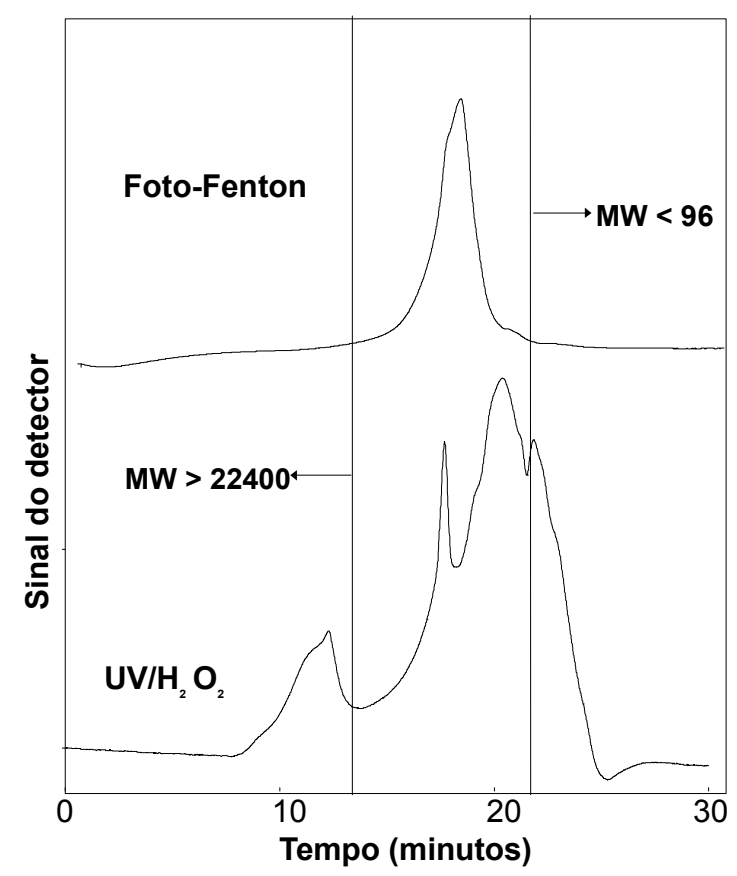

Figura 4.31 - Cromatogramas obtidos por GPC para PEG 6000, com as condições do PC, para a amostra de 60 minutos. 


\subsubsection{Verificação dos efeitos da Fotólise e do $\mathrm{H}_{2} \mathrm{O}_{2}$ para PEG}

Com o objetivo de avaliar o efeito da radiação da lâmpada e do peróxido de hidrogênio sobre a distribuição de pesos moleculares de polietilenoglicol fizeram-se experimentos de fotólise e um experimento comparativo na ausência de luz, com a adição de $\mathrm{H}_{2} \mathrm{O}_{2}$. Assim, para PEG 6000 e 20000 com concentração de $1000 \mathrm{mgC} \mathrm{L}^{-1}$, foram realizados experimentos somente com a lâmpada ligada, sem adição de ferro ou $\mathrm{H}_{2} \mathrm{O}_{2}$, denominados fotólise e outros adicionando-se $\mathrm{H}_{2} \mathrm{O}_{2}$ continuamente, até 90 minutos, sem ligar a lâmpada ou adicionar ferro. A vazão da adição de peróxido e sua concentração foram às utilizadas no ponto central do plano experimental: 1,11

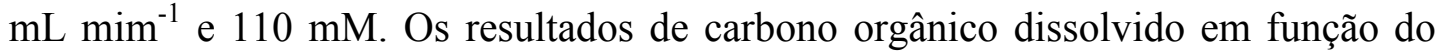
tempo de reação, são apresentados na Figura 4.32.

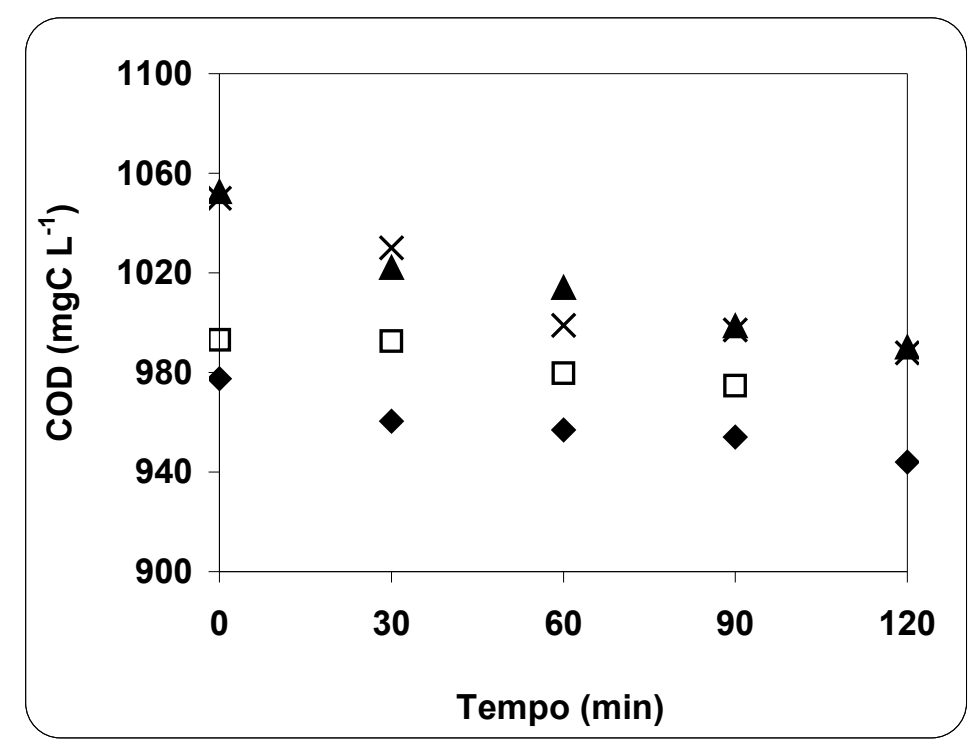

Figura 4.32 - COD em função do tempo para PEG. Fotólise: $\bullet \mathrm{Mw}=6000$ $\mathrm{Mw}=20000 \mathrm{~g} \mathrm{~mol}^{-1}$. Comparativo de $\mathrm{H}_{2} \mathrm{O}_{2}: \Delta \mathrm{Mw}=6000 \times \mathrm{Mw}=20000 \mathrm{~g} \mathrm{~mol}^{-1}$.

Como pode ser observado na Figura 4.32 a concentração de COD sofreu apenas uma pequena diminuição para os experimentos com $\mathrm{H}_{2} \mathrm{O}_{2}$ e quase nenhuma para fotólise. A porcentagem de remoção final de COD para os experimentos de fotólise foi: 3,42 e 2,19\% para o PEG 6000 e 20000 respectivamente e para os comparativos de $\mathrm{H}_{2} \mathrm{O}_{2}$ de: 5,94 e $5,92 \%$. 
As distribuições de pesos moleculares para PEG 6000 e $20000 \mathrm{~g} \mathrm{~mol}^{-1}$, para os experimentos comparativos de $\mathrm{H}_{2} \mathrm{O}_{2}$ e fotólise são mostrados nas Figuras 4.33 e 4.34, respectivamente. A Tabela 4.10 mostra os valores da massa molar média numérica $(\mathrm{Mn})$, massa molar média mássica $(\mathrm{Mw})$ e polidispersidade $(\mathrm{Mw} / \mathrm{Mn})$ para os valores iniciais e para alguns tempos de reação destes experimentos.

Tabela 4.10 - Valores de massa molar média numérica $(\mathrm{Mn})$, massa molar média mássica $(\mathrm{Mw})$ e polidispersidade $(\mathrm{Mw} / \mathrm{Mn})$, para alguns tempos de reação dos experimentos de fotólise e comparativos de $\mathrm{H}_{2} \mathrm{O}_{2}$ para PEG 6000 e $20000 \mathrm{~g} \mathrm{~mol}^{-1}$.

\begin{tabular}{|c|c|c|c|}
\hline $\begin{array}{c}\text { Tempo de } \\
\text { Reação (min) }\end{array}$ & Mn & Mw & Mw/Mn \\
\hline \multicolumn{4}{|c|}{ PEG 6000 - Fotólise } \\
\hline Inicial & 6064 & 6973 & 1.150 \\
\hline 10 & 5387 & 6610 & 1.227 \\
\hline 30 & 1833 & 3352 & 1.828 \\
\hline 60 & 799 & 2427 & 3.037 \\
\hline 90 & 533 & 1803 & 3.381 \\
\hline 120 & 634 & 1718 & 2.709 \\
\hline \multicolumn{4}{|c|}{ PEG 20000 - Fotólise } \\
\hline Inicial & 10790 & 25299 & 2.344 \\
\hline 10 & 8411 & 22419 & 2.503 \\
\hline 30 & 5084 & 10884 & 2.141 \\
\hline 60 & 2072 & 7004 & 2.941 \\
\hline 90 & 943 & 3414 & 5.178 \\
\hline 120 & 409 & 2674 & 6.546 \\
\hline \multicolumn{4}{|c|}{ PEG 6000 - Comparativo de $\mathrm{H}_{2} \mathrm{O}_{2}$} \\
\hline Inicial & 4589 & 5151 & 1.122 \\
\hline 10 & 3323 & 4770 & 1.435 \\
\hline 30 & 4216 & 5018 & 1.190 \\
\hline 60 & 3972 & 4836 & 1.217 \\
\hline 90 & 3633 & 4656 & 1.282 \\
\hline 120 & 3103 & 4383 & 1.412 \\
\hline \multicolumn{4}{|c|}{ PEG 20000 - Comparativo de $\mathrm{H}_{2} \mathrm{O}_{2}$} \\
\hline Inicial & 11707 & 20487 & 1,750 \\
\hline 10 & 10739 & 19768 & 1.841 \\
\hline 30 & 10689 & 19433 & 1.818 \\
\hline 60 & 9284 & 17927 & 1.931 \\
\hline 90 & 8020 & 16144 & 2.013 \\
\hline 120 & 7230 & 15486 & 2.142 \\
\hline
\end{tabular}




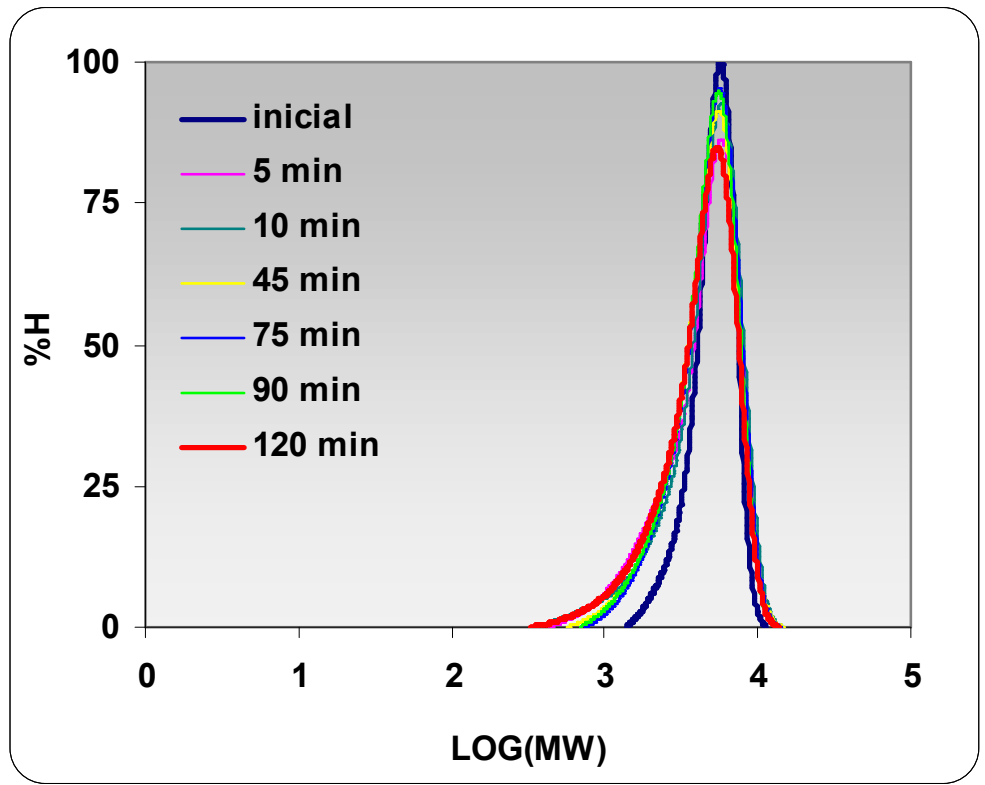

(a)

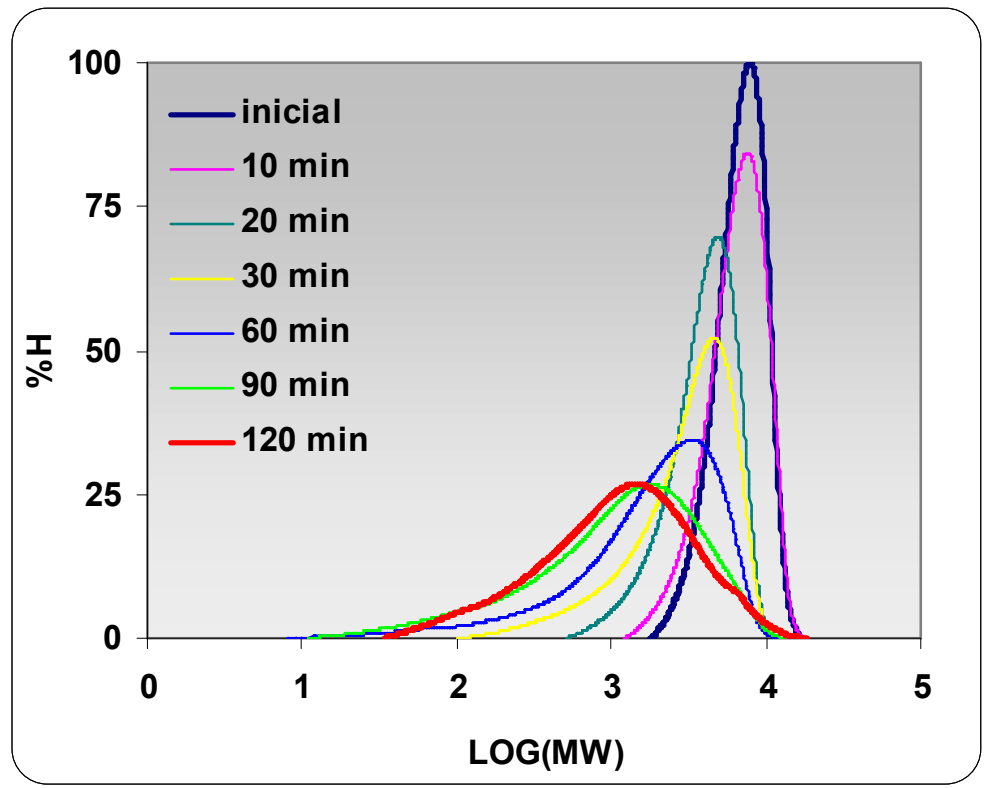

(b)

Figura 4.33 - Distribuição de pesos moleculares para PEG $6000 \mathrm{~g} \mathrm{~mol}^{-1}$. (a) Comparativo de $\mathrm{H}_{2} \mathrm{O}_{2}$ (b) Fotólise. 


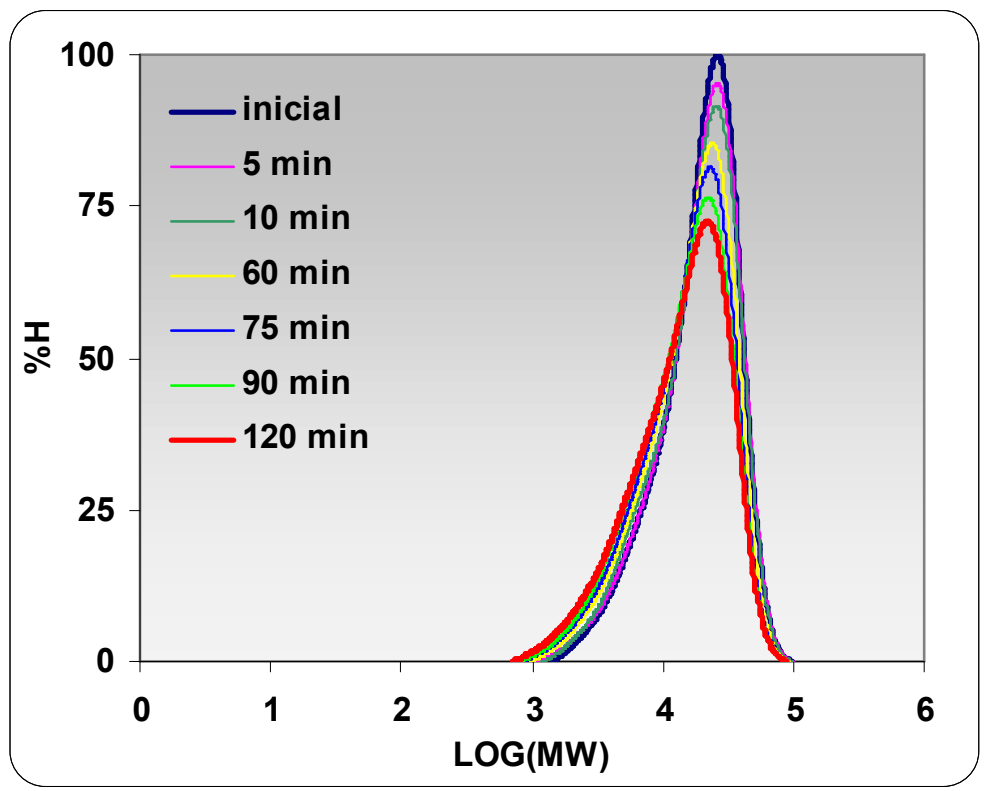

(a)

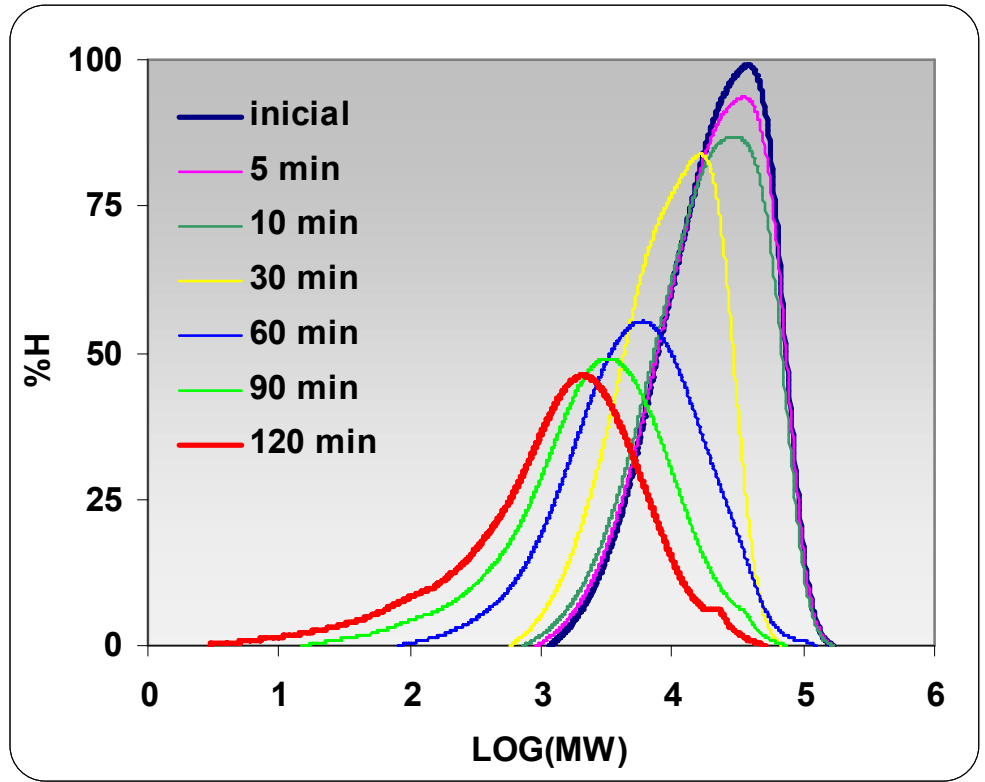

(b)

Figura 4.34 - Distribuição de pesos moleculares para PEG $20000 \mathrm{~g} \mathrm{~mol}^{-1}$. (a) Comparativo de $\mathrm{H}_{2} \mathrm{O}_{2}$ (b) Fotólise.

Embora os experimentos de fotólise apresentem menores remoções de COD que os comparativos de $\mathrm{H}_{2} \mathrm{O}_{2}$, as distribuições de pesos moleculares, obtidas por GPC, mostram que as cadeias sofreram cisão muito maior durante a fotólise, tanto para PEG 6000 como para 20000. As distribuições apresentadas nestas figuras 
mostram padrões em concordância com processos aleatórios com deslocamento em direção a menores pesos moleculares e aumento da polidispersidade. Como pode ser observado na Tabela 4.10 os valores de $\mathrm{Mw}$ para a fotólise sofreram um queda de 75,4 e $89,4 \%$ para PEG 6000 e 20000 respectivamente e de 14,9 e $24,4 \%$ para os experimentos comparativos de $\mathrm{H}_{2} \mathrm{O}_{2}$.

No caso da fotólise a luz UV atua apenas como um iniciador do processo de degradação oxidativa descrito na secção 2.2, uma vez que o oxigênio está disponível como nos outros processos estudados, pois o sistema é aberto e agitado. Já o $\mathrm{H}_{2} \mathrm{O}_{2}$, sem a ação da luz UV não gera radicais suficientes para levar a uma degradação significativa. Esta informação é importante considerando-se que as amostras analisadas por GPC não sofreram um tratamento para eliminação do $\mathrm{H}_{2} \mathrm{O}_{2}$ residual.

\subsubsection{Análises de GPC para PEG}

As Figuras 4.35, 4.37, 4.39 e 4.43 mostram os cromatogramas obtidos por GPC, para PEG para ambos os processos, em que a ordenada é a resposta do detector (que é o índice de refração) convertido em voltagem e a abscissa é o tempo de retenção das colunas cromatográficas. As Figuras 4.36, 4.38, 4.40 e 4.44 apresentam as distribuições de pesos moleculares obtidas pela análise dos cromatogramas, respeitando os limites do método. A Tabela 4.11 mostra os valores da massa molar média numérica $(\mathrm{Mn})$, massa molar média mássica $(\mathrm{Mw})$ e polidispersidade (Mw/Mn) para os valores iniciais e para alguns tempos de reação do PEG, no processo foto-Fenton. Infelizmente, como para o processo $\mathrm{UV} / \mathrm{H}_{2} \mathrm{O}_{2}$ há formação de mais de um pico, caracterizando diferentes populações, e nem todos puderam ser analisados devido à limitação do método, não serão mostrados os valores de $\mathrm{Mw}, \mathrm{Mn}$ e polidispersidade para este processo.

Para PEG $6000 \mathrm{~g} \mathrm{~mol}^{-1}$, com as condições do ponto central, os cromatogramas da Figura 4.35 (a) mostram um deslocamento em direção a maiores tempos de retenção, o que indica quebra de cadeias, porém também há formação de uma cauda em direção a menores tempos de retenção devido à formação de cadeias maiores. Os cromatogramas de GPC apresentados nesta figura mostram padrões em concordância com processos aleatórios, embora nenhum modelo matemático tenha sido testado para confirmar esta tendência. As distribuições de pesos moleculares, 
Figura 4.36 (a) mostram um espalhamento em ambas as direções, principalmente aos 10, 30 e 60 minutos de reação, indicando que a quebra de cadeias e a recombinação de macro-radicais provavelmente competem. A Tabela 4.11 mostra a diminuição de Mw para PEG 6000, no PC, de 5141 inicialmente para $639 \mathrm{~g} \mathrm{~mol}^{-1}$ aos 120 minutos. Diferentemente dos resultados dos demais experimentos mostrados na Tabela 4.11, para PEG 6000 no PC a queda de MW foi mais gradual, devido à formação da cauda em direção a menores tempos de retenção o que pode ser observado nos cromatogramas da Figura 4.35 (a).

Tabela 4.11 - Valores de massa molar média numérica (Mn), massa molar média mássica $(\mathrm{Mw})$ e polidispersidade $(\mathrm{Mw} / \mathrm{Mn})$, para alguns tempos de reação com as condições experimentais PC e P1, para o processo foto-Fenton, para PEG.

\begin{tabular}{|c|c|c|c|}
\hline $\begin{array}{c}\text { Tempo de } \\
\text { Reação (min) }\end{array}$ & Mn & Mw & $\mathbf{M w} / \mathbf{M n}$ \\
\hline \multicolumn{4}{|c|}{ PEG 6000 - Ponto Central (PC) } \\
\hline Inicial & 3980 & 5141 & 1,292 \\
\hline 10 & 3675 & 4826 & 1,313 \\
\hline 30 & 1864 & 2894 & 1,552 \\
\hline 60 & 1054 & 1695 & 1,607 \\
\hline 90 & 620 & 810 & 1,437 \\
\hline 120 & 581 & 639 & 1,100 \\
\hline \multicolumn{4}{|c|}{ PEG 20000 - Ponto Central (PC) } \\
\hline Inicial & 14571 & 20418 & 1,401 \\
\hline 10 & 736 & 841 & 1,142 \\
\hline 30 & 829 & 965 & 1,164 \\
\hline 60 & 761 & 1114 & 1,463 \\
\hline 90 & 921 & 1210 & 1,314 \\
\hline 120 & 920 & 1290 & 1,402 \\
\hline \multicolumn{4}{|c|}{ PEG 6000 - Ponto P1 } \\
\hline Inicial & 4647 & 5807 & 1,249 \\
\hline 10 & 1222 & 1577 & 1,290 \\
\hline 30 & 769 & 1005 & 1,361 \\
\hline 60 & 797 & 1066 & 1,337 \\
\hline 90 & 665 & 781 & 1,210 \\
\hline 120 & 577 & 627 & 1,076 \\
\hline \multicolumn{4}{|c|}{ PEG 20000 - Ponto P1 } \\
\hline Inicial & 12009 & 20296 & 1,690 \\
\hline 10 & 528 & 577 & 1,093 \\
\hline 30 & 501 & 577 & 1,152 \\
\hline 60 & 523 & 585 & 1,119 \\
\hline 90 & 544 & 608 & 1,117 \\
\hline 120 & 544 & 604 & 1,109 \\
\hline
\end{tabular}


Para o processo $\mathrm{UV} / \mathrm{H}_{2} \mathrm{O}_{2}$, Figura 4.35(b), os padrões das curvas de GPC mostram um comportamento totalmente diferente do processo foto-Fenton. Aos 5 minutos de reação há formação de uma distribuição trimodal, com uma população com massas molares maiores e uma com massas molares menores que os da distribuição inicial. Aos 10 minutos há formação de quatro picos, e após 2 horas de reação as cadeias estão totalmente quebradas, com um único pico deslocado em direção às menores massas molares. As curvas de distribuição de pesos moleculares, Figura 4.36 (b), mostram as diferentes populações obtidas analisando-se apenas os picos dentro do limite do método. A forma das curvas de distribuição exclui um processo puramente estatístico, pois quebra e recombinações de macro-radicais acontecem ao mesmo tempo, formando diferentes populações. 
a) Foto-Fenton

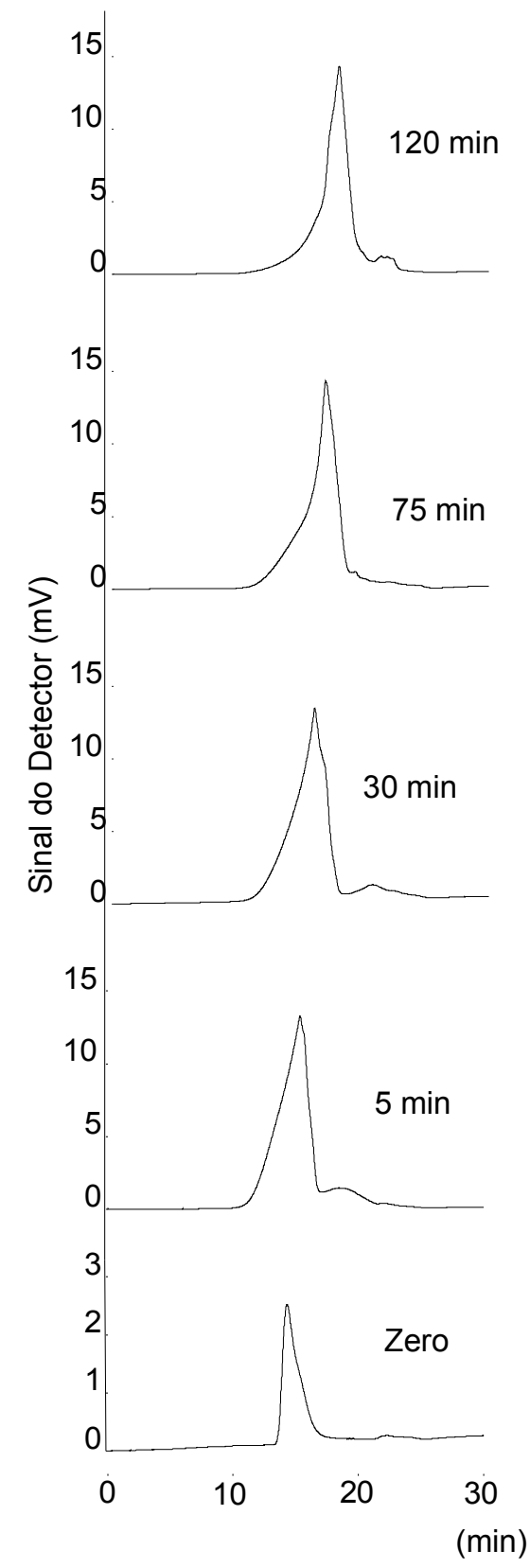

b) $\mathrm{UV} / \mathrm{H}_{2} \mathrm{O}_{2}$

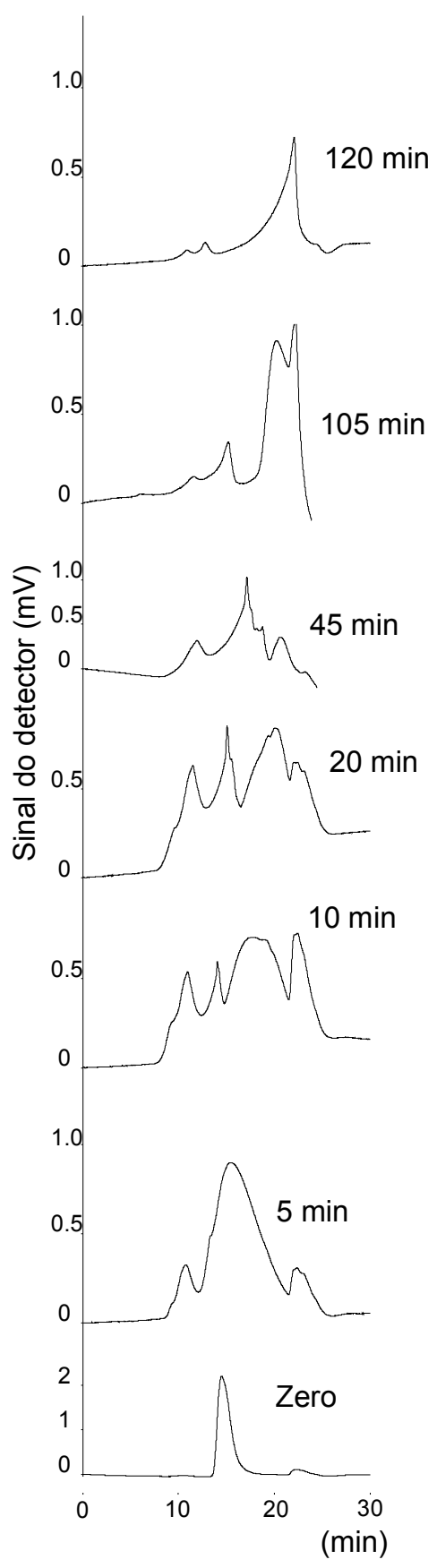

Figura 4.35 - Cromatogramas obtidos por GPC para PEG $6000 \mathrm{~g} \mathrm{~mol}^{-1}$, com as condições experimentais do ponto central. Processos: (a) foto-Fenton, (b) $\mathrm{UV} / \mathrm{H}_{2} \mathrm{O}_{2}$. 


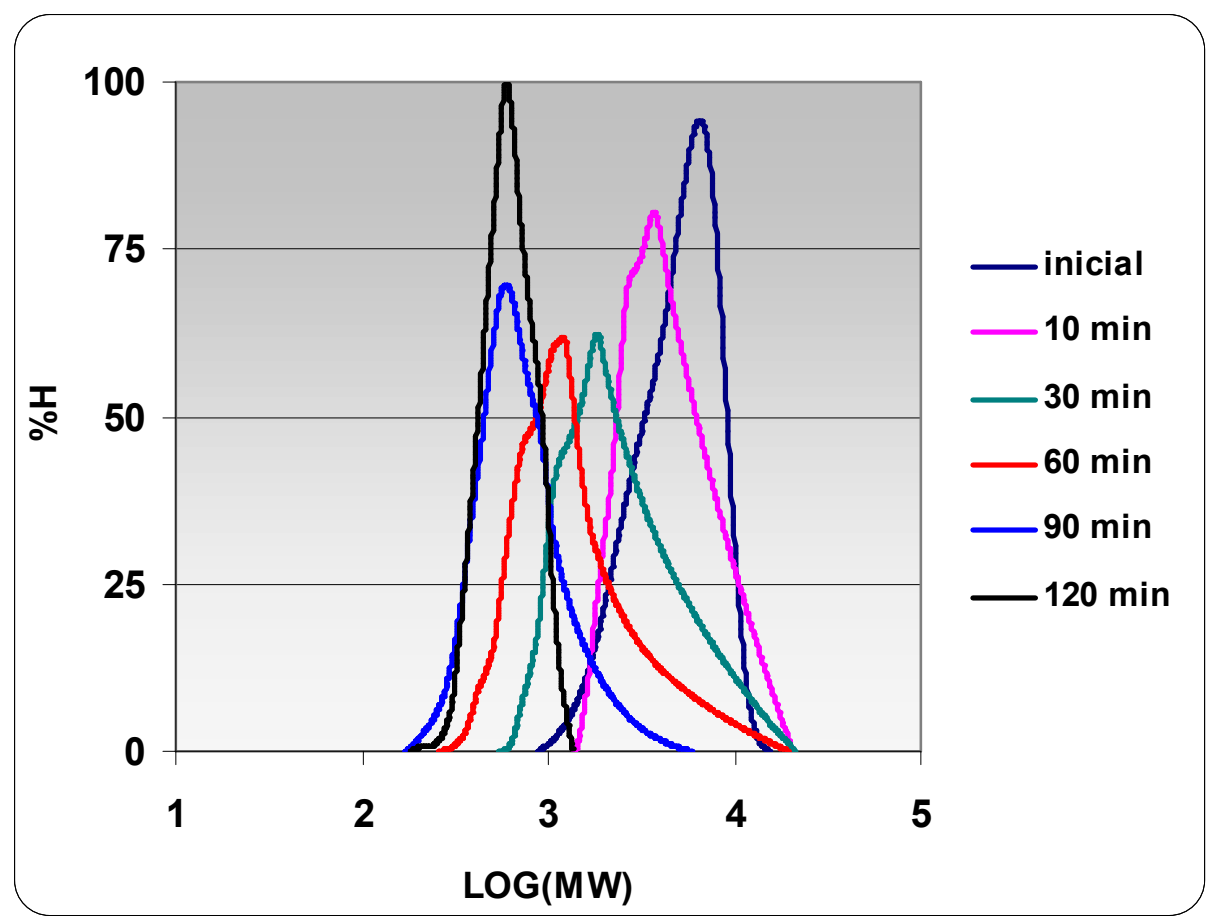

(a) Foto-Fenton

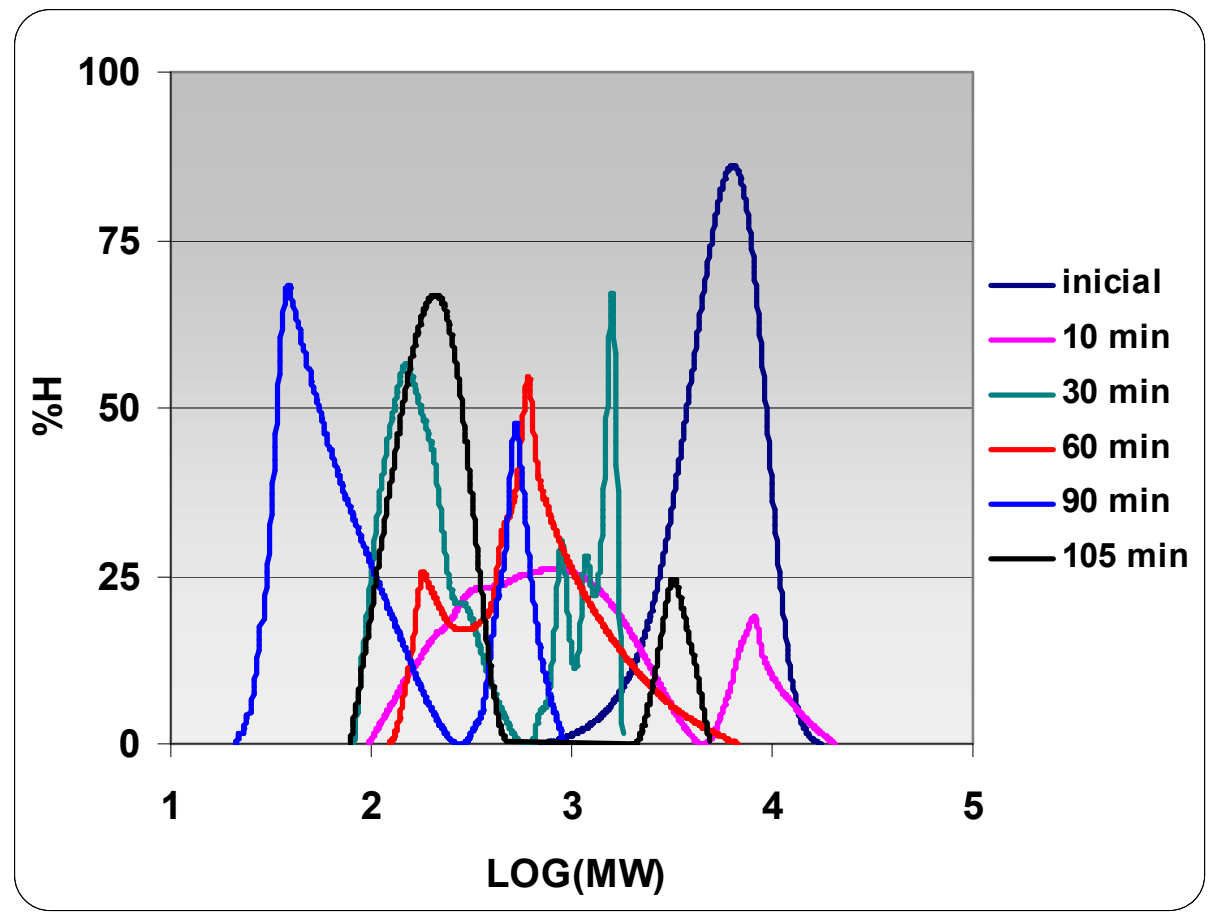

(b) $\mathrm{UV} / \mathrm{H}_{2} \mathrm{O}_{2}$

Figura 4.36 - Distribuição de pesos moleculares para PEG $6000 \mathrm{~g} \mathrm{~mol}^{-1}$, com as condições experimentais do ponto central. Processos (a) Foto-Fenton, (b) $\mathrm{UV} / \mathrm{H}_{2} \mathrm{O}_{2}$. 
Para PEG 20000, processo foto-Fenton, com as condições experimentais do PC, Figura 4.37 (a), os cromatogramas apresentam um comportamento semelhante aos de PEG 6000, com a diferença de manterem o tempo de retenção praticamente constante após 5 minutos e só apresentarem uma cauda em direção aos maiores tempos de retenção após 60 minutos. A Tabela 4.11 mostra que os valores de $\mathrm{Mw}$ e Mn são praticamente constantes, após 10 minutos de reação. As distribuições de pesos moleculares, mostradas na Figura 4.38 (a), confirmam que praticamente não houve mudanças nas distribuições, somente havendo um deslocamento para maiores Mw após 30 minutos. Os padrões das curvas caracterizam cisão aleatória de cadeias.

Para o processo $\mathrm{UV} / \mathrm{H}_{2} \mathrm{O}_{2}$, a cisão ocorre não aleatoriamente, com os cromatogramas mostrando vários picos, Figura 4.37 (b), tanto na direção dos maiores tempos de retenção e menores pesos moleculares, quanto na direção de menores tempos de retenção e maiores pesos moleculares. A diferença com o caso anterior do UV/ $\mathrm{H}_{2} \mathrm{O}_{2}$ para PEG 6000 é que em 120 minutos ainda há frações do polímero com pesos moleculares maiores, o que pode ser observado na Figura 4.37 (b), para este tempo de reação.

Tanto para o processo $\mathrm{UV} / \mathrm{H}_{2} \mathrm{O}_{2}$ como para o foto-Fenton, a principal influência do aumento do tamanho do polímero inicial foi um 'atraso' nos processos que aconteceram para PEG 20000 quando comparado ao PEG 6000. A recombinação de macro-radicais no processo foto-Fenton, que ocorreu desde o início para PEG 6000, aconteceu também para PEG 20000 após 60 minutos e a quebra total das cadeias poliméricas, que aconteceu no processo UV/ $\mathrm{H}_{2} \mathrm{O}_{2}$ para PEG 6000 em 120 minutos, provavelmente seria o próximo resultado para PEG 20000, por exemplo, em 150 minutos. 
(a) Foto-Fenton

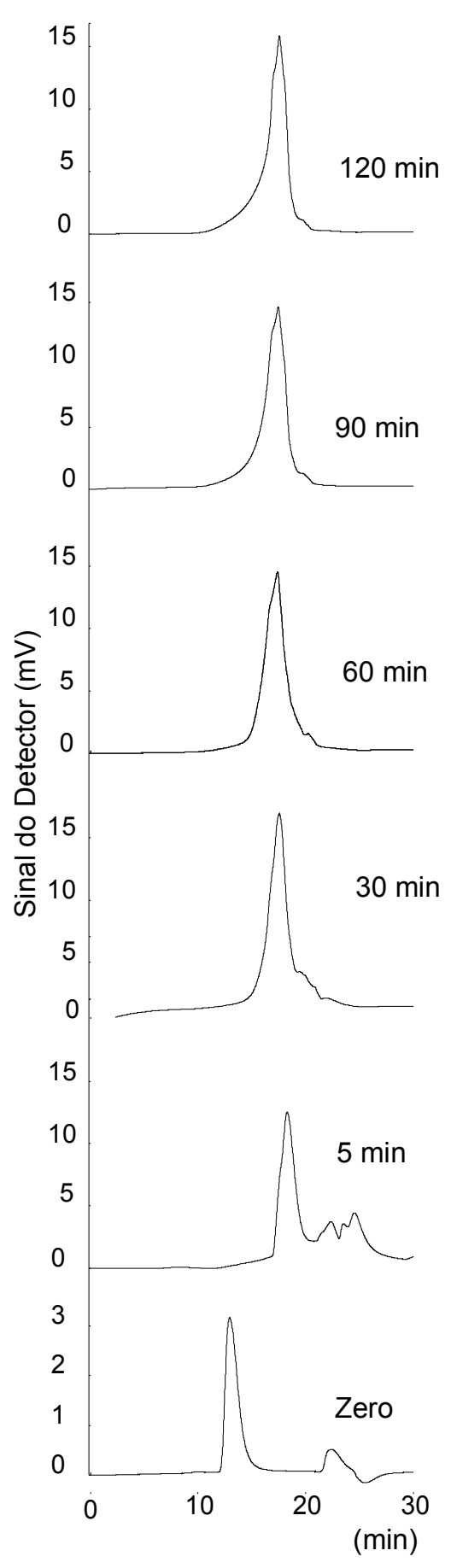

(b) $\mathrm{UV} / \mathrm{H}_{2} \mathrm{O}_{2}$

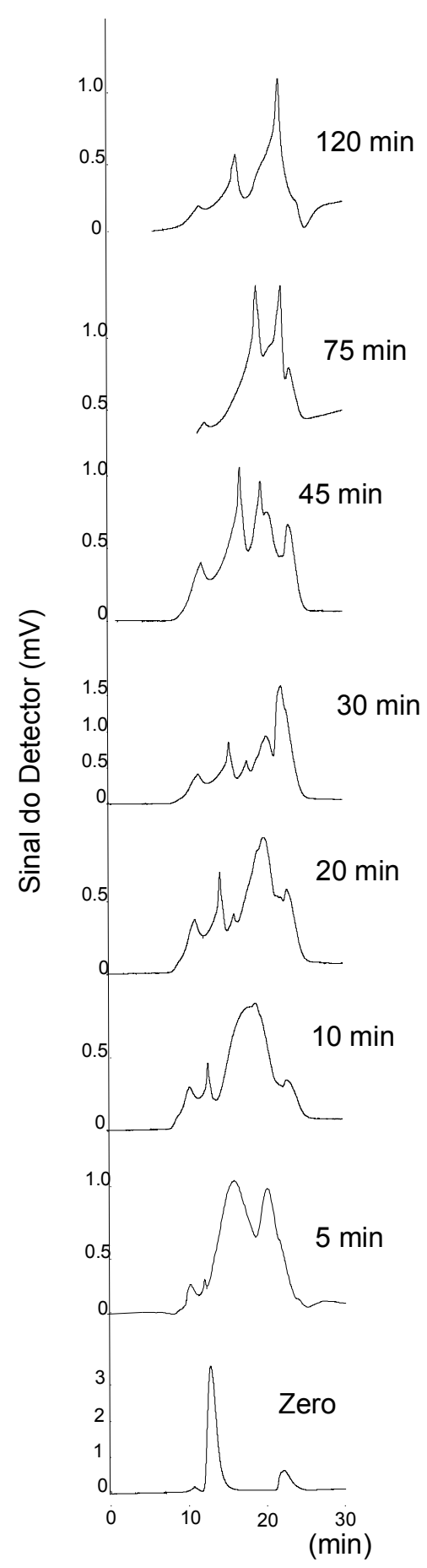

Figura 4.37 - Cromatogramas obtidos por GPC para PEG $20000 \mathrm{~g} \mathrm{~mol}^{-1}$, com as condições experimentais do ponto central. Processos: (a) foto-Fenton, (b) $\mathrm{UV} / \mathrm{H}_{2} \mathrm{O}_{2}$. 


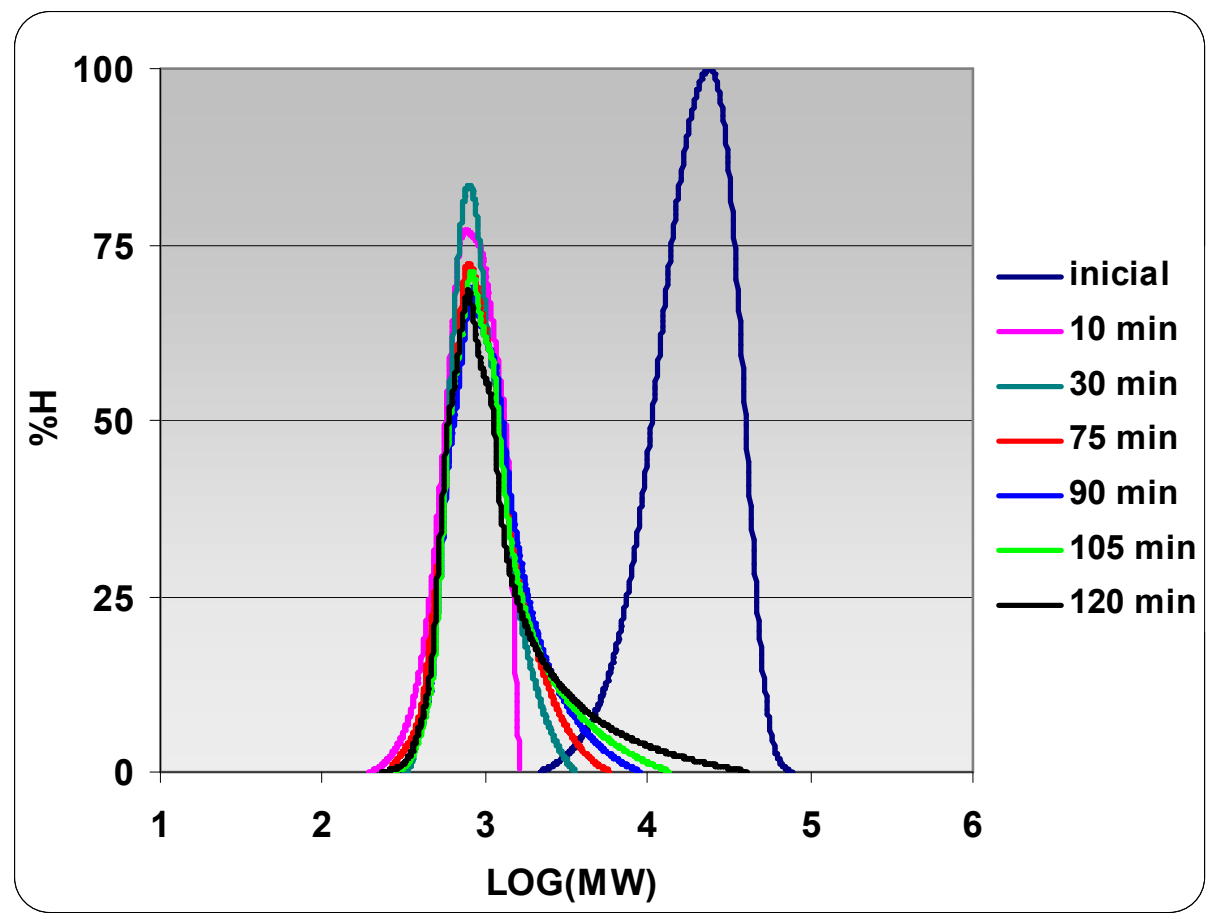

(a) Foto-Fenton

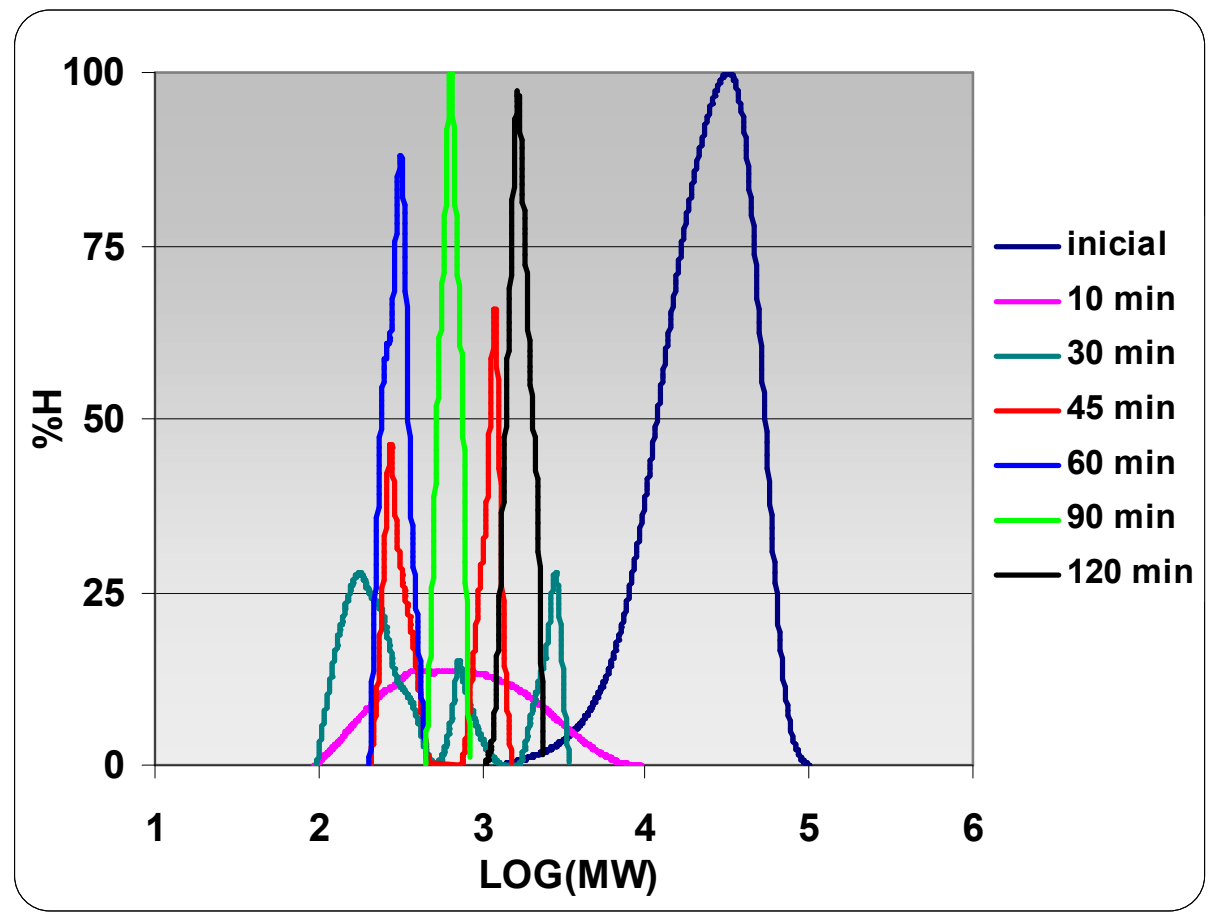

(b) $\mathrm{UV} / \mathrm{H}_{2} \mathrm{O}_{2}$

Figura 4.38 - Distribuição de pesos moleculares para PEG $20000 \mathrm{~g} \mathrm{~mol}^{-1}$, com as condições experimentais do ponto central. Processos (a) Foto-Fenton, (b) $\mathrm{UV} / \mathrm{H}_{2} \mathrm{O}_{2}$. 
Os experimentos realizados com as condições P1 tiveram por objetivo uma oxidação mais lenta, possibilitando caracterizar melhor os intermediários formados e as mudanças que ocorrem nas distribuições de pesos moleculares do polímero durante o processo de degradação. Para o processo foto-Fenton, as Figuras 4.39 (a) e 4.41 (a) mostram os cromatogramas obtidos para PEG 6000 e 20000, respectivamente, com as condições experimentais P1. Para PEG 6000 o efeito da cauda nos cromatogramas, Figura 4.39 (a), reflete-se nas distribuições mostradas na Figura 4.40 (a) pelo deslocamento das curvas de distribuição em direção aos maiores pesos moleculares, até 90 minutos. Após este tempo estas frações maiores já somem completamente. Para PEG 20000 as curvas de Mw, Figura 4.42 (a), se sobrepõem, indicando que o processo de cisão foi muito rápido, acontecendo nos primeiros 10 minutos e depois praticamente cessando. A Tabela 4.11 mostra os valores de $\mathrm{Mw}$ quase constantes para PEG 20000 após 10 minutos de reação e com uma queda mais gradual para PEG 6000. Os padrões das curvas de Mw para PEG 6000 indicariam cisão aleatória de cadeias se não fosse a permanência das frações de maiores Mw até 90 minutos, o que pode indicar a recombinação de macro-radicais. Para o PEG 20000, não há aumento de Mw porque, provavelmente, os macro-radicais sofreram terminação por outra forma além da recombinação, ou porque foram formados em pequena quantidade.

Para o processo UV/ $\mathrm{H}_{2} \mathrm{O}_{2}$ os cromatogramas das Figuras 4.39(b) e 4.41(b) mostram a fragmentação e a formação de um pico com tempo de retenção menor que 13 minutos, que caracteriza uma distribuição com Mw maior que $22400 \mathrm{~g} \mathrm{~mol}^{-1}$, que permanece até o final do processo oxidativo, de 120 minutos. Como este pico na direção de maiores Mw está fora da abrangência da curva de calibração, ele não foi analisado e não aparece nas distribuições de Mw para o PEG 6000 nem para o PEG 20000, Figuras 4.40 (b) e 4.42 (b), respectivamente. As distribuições de peso molecular descartam um mecanismo de cisão puramente estatístico. Como no caso PC, fragmentação de cadeias e recombinação de radicais provavelmente competem. 
(a) Foto-Fenton

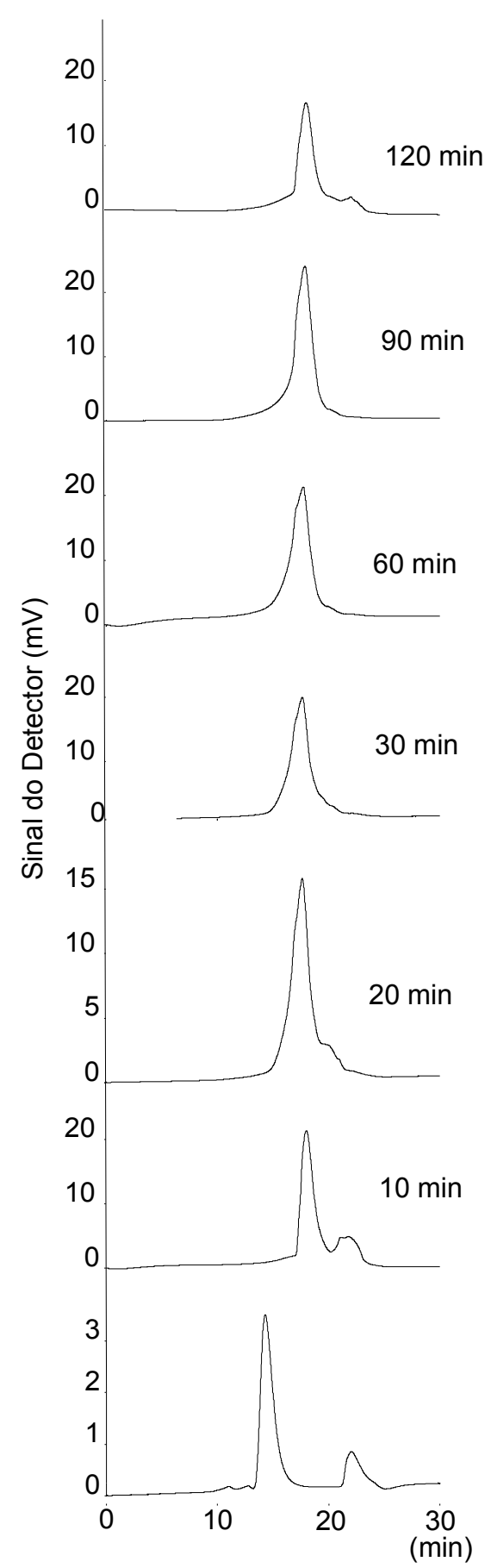

(b) $\mathrm{UV} / \mathrm{H}_{2} \mathrm{O}_{2}$

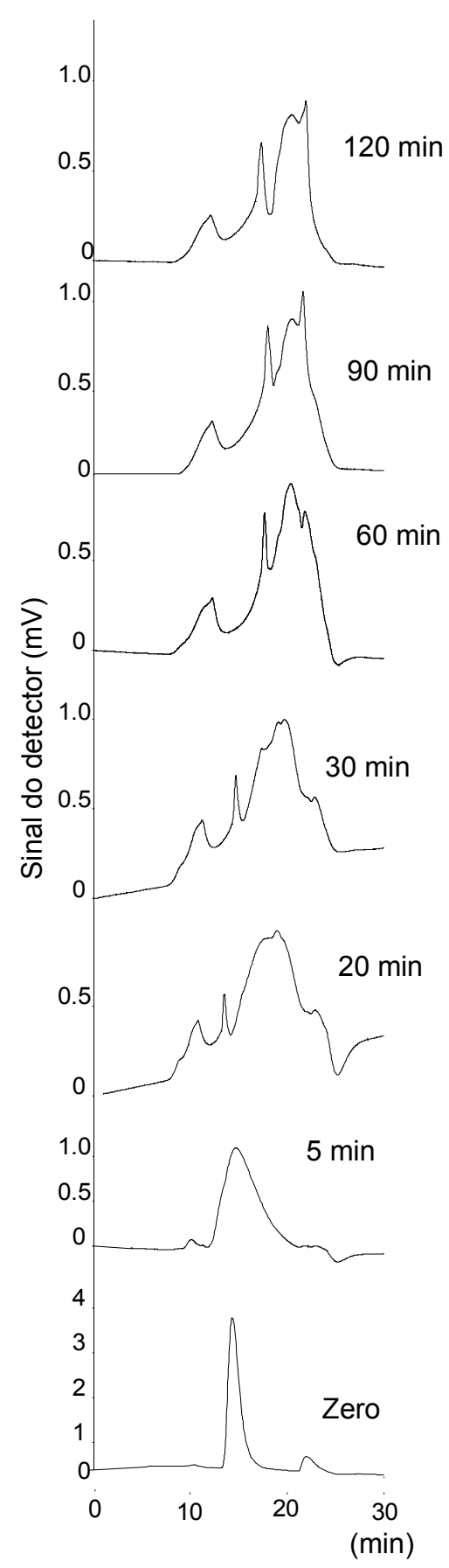

Figura 4.39 - Cromatogramas obtidos por GPC para PEG $6000 \mathrm{~g} \mathrm{~mol}^{-1}$, com as condições experimentais do ponto P1. Processos: (a) foto-Fenton, (b) $\mathrm{UV} / \mathrm{H}_{2} \mathrm{O}_{2}$. 


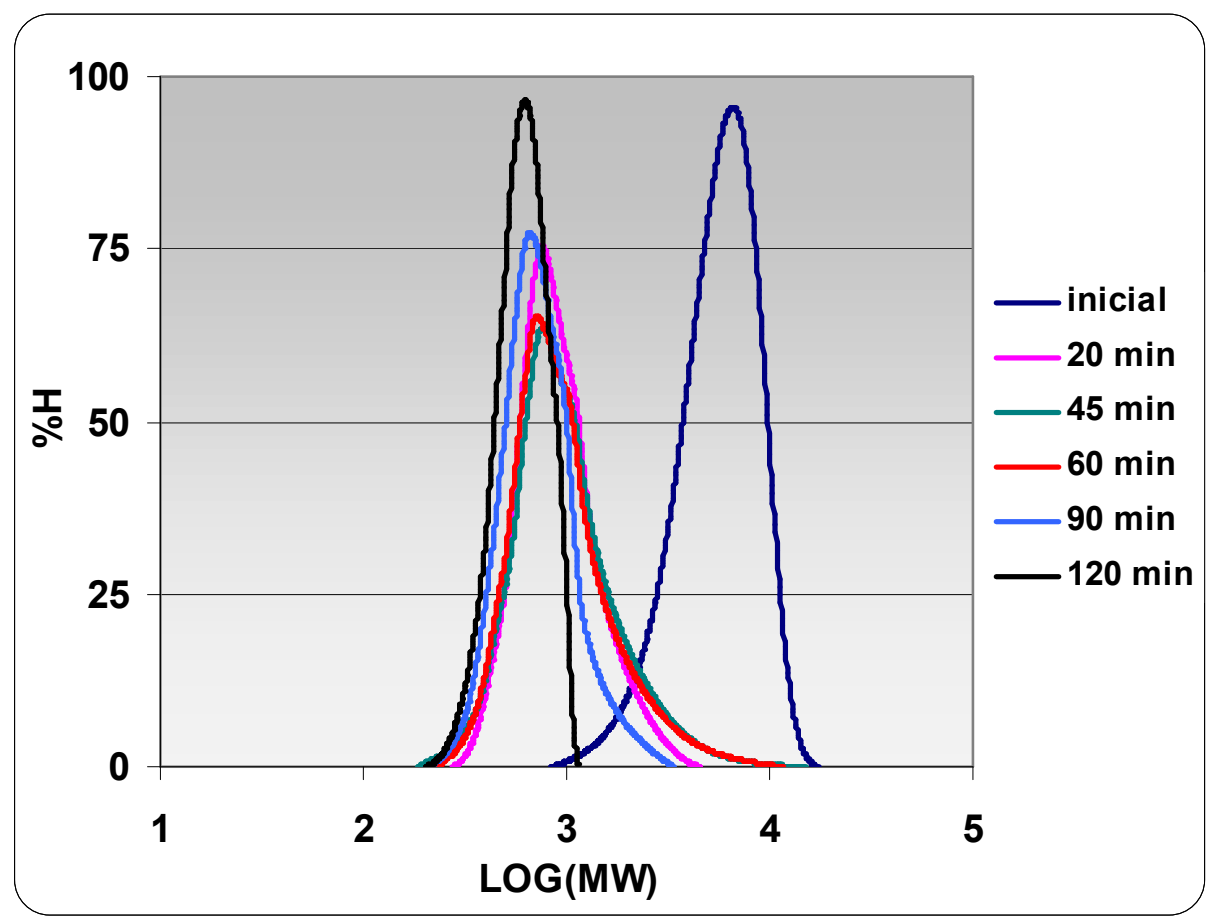

(a) Foto-Fenton

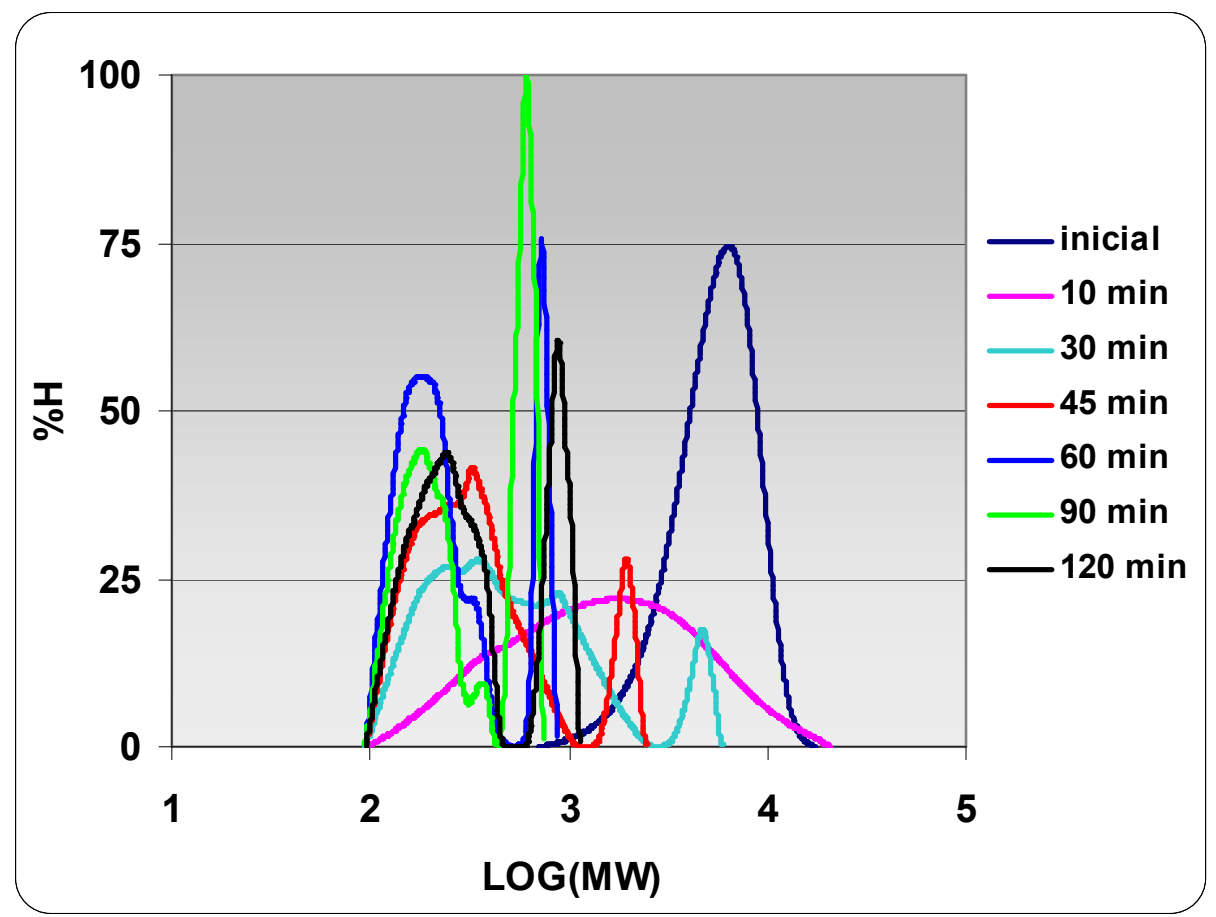

(b) $\mathrm{UV} / \mathrm{H}_{2} \mathrm{O}_{2}$

Figura 4.40 - Distribuição de pesos moleculares para PEG $6000 \mathrm{~g} \mathrm{~mol}^{-1}$, com as condições experimentais do ponto P1. Processos (a) Foto-Fenton, (b) $\mathrm{UV} / \mathrm{H}_{2} \mathrm{O}_{2}$. 
(a) Foto-Fenton

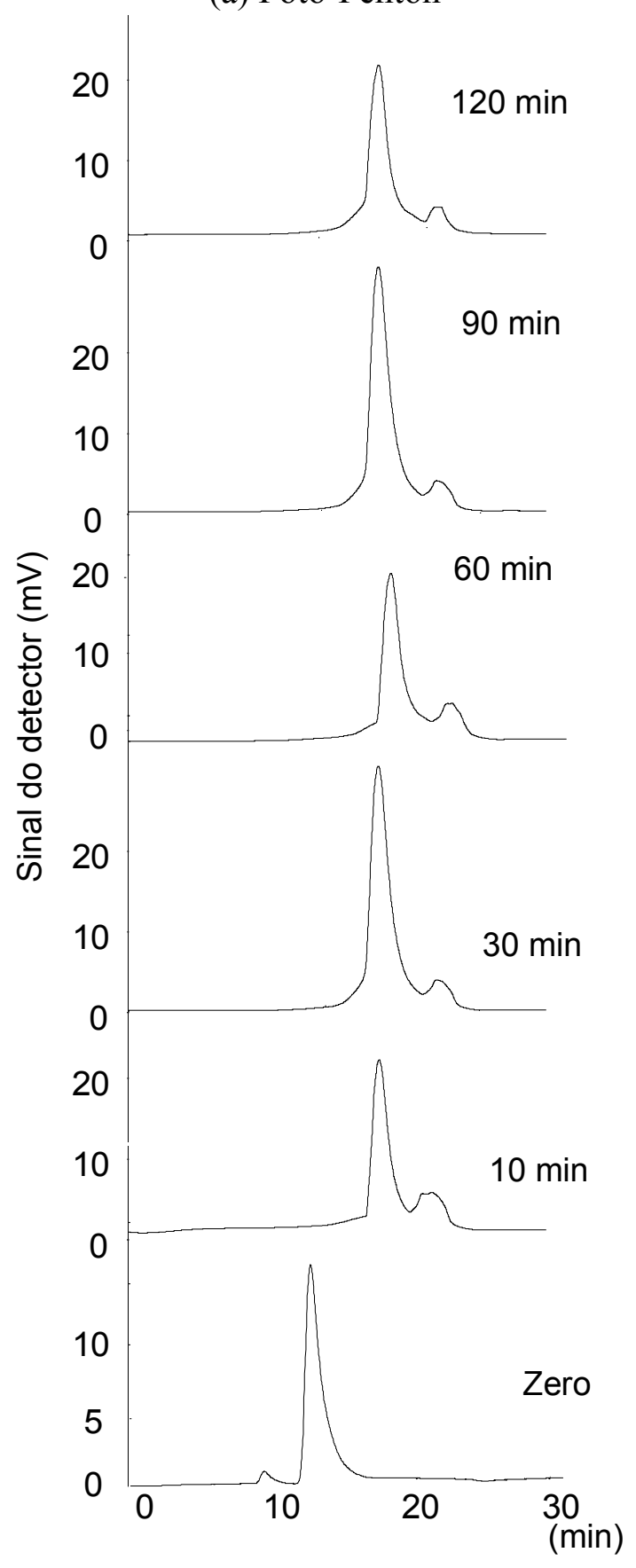

(b) $\mathrm{UV} / \mathrm{H}_{2} \mathrm{O}_{2}$

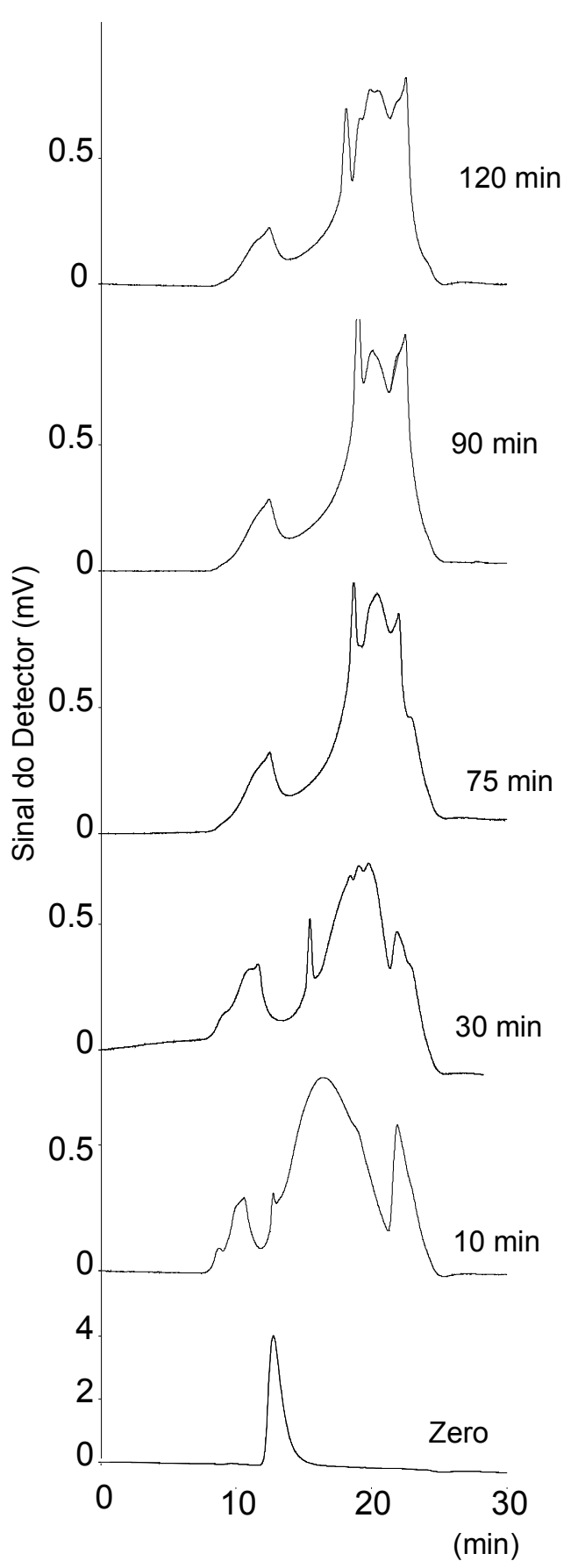

Figura 4.41 - Cromatogramas obtidos por GPC para PEG $20000 \mathrm{~g} \mathrm{~mol}^{-1}$, com as condições experimentais do ponto P1. Processos: (a) foto-Fenton, (b) $\mathrm{UV} / \mathrm{H}_{2} \mathrm{O}_{2}$. 


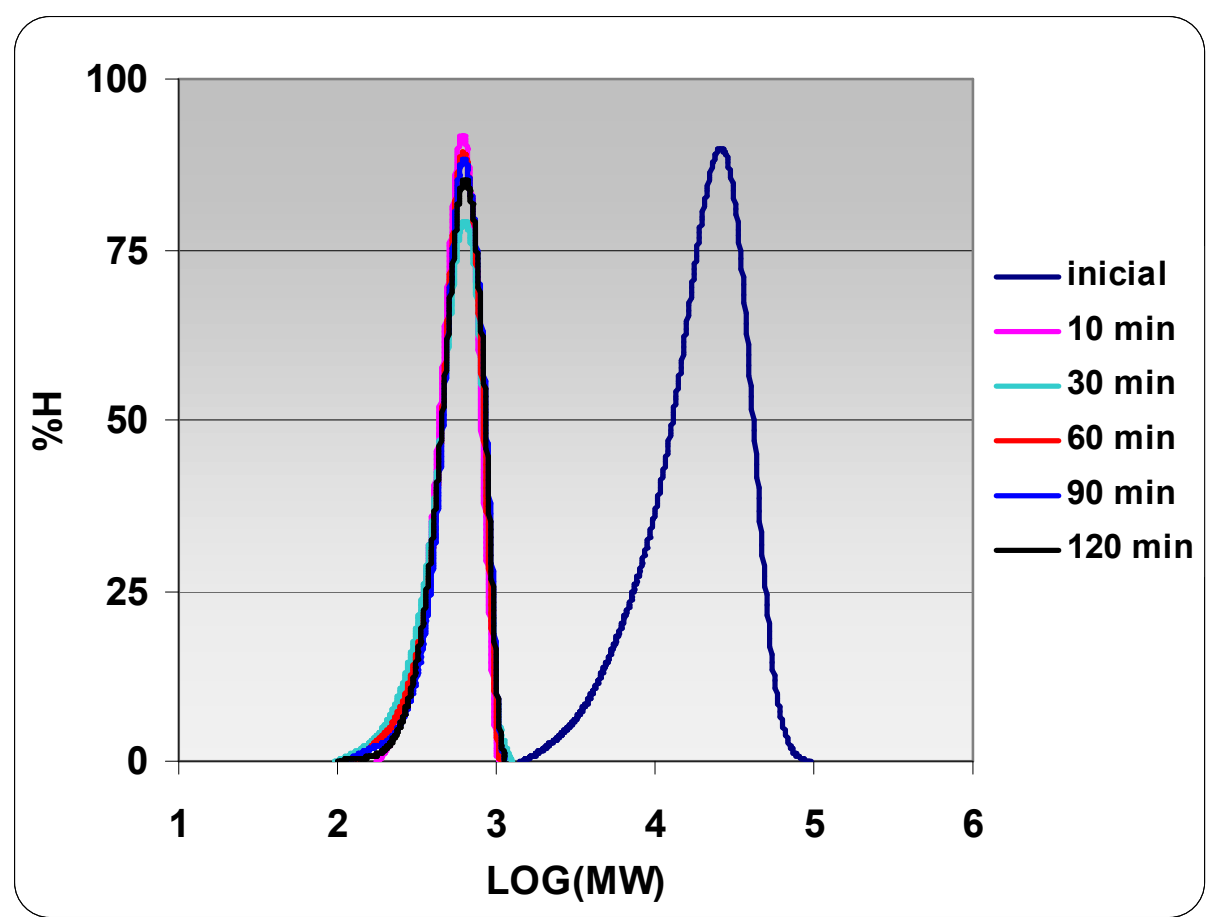

(a) Foto-Fenton

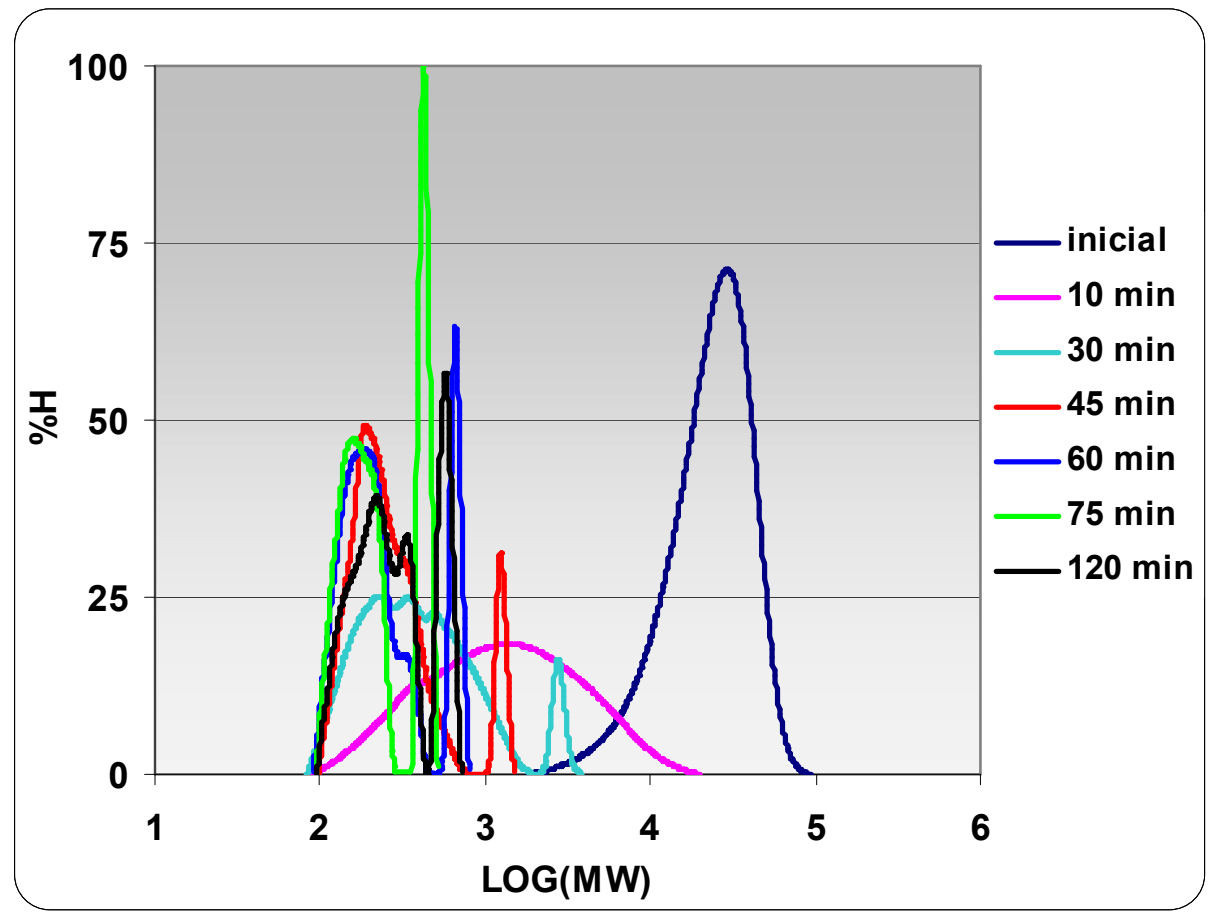

(b) $\mathrm{UV} / \mathrm{H}_{2} \mathrm{O}_{2}$

Figura 4.42 - Distribuição de pesos moleculares para PEG $20000 \mathrm{~g} \mathrm{~mol}^{-1}$, com as condições experimentais do ponto P1. Processos (a) Foto-Fenton, (b) $\mathrm{UV} / \mathrm{H}_{2} \mathrm{O}_{2}$. 


\subsubsection{Análises de GPC para PAM}

A curva de calibração foi calculada utilizando-se padrões de PEG, portanto para a análise da poliacrilamida foi necessário fazer a correção do método através dos parâmetros de Mark-Houwink ( $\alpha$ e K) de acordo com a equação E16.

$\log M_{B}=\frac{1}{1+\alpha_{B}} \log \frac{K_{A}}{K_{B}}+\frac{1+\alpha_{A}}{1+\alpha_{B}} \log M_{A}$

Em que A é o polímero utilizado como padrão para levantamento da curva de calibração (PEG) e B é o polímero que esta sendo analisado (PAM). Deve-se notar que o método dever ser o mesmo para os polímeros A e B. Para PEG os valores de K e $\alpha$ são $12,5 \times 10^{-3} \mathrm{~mL} \mathrm{~g}^{-1}$ e 0,78 e para PAM $6,31 \times 10^{-3} \mathrm{~mL} \mathrm{~g}^{-1}$ e 0,8 , respectivamente (Brandrup e Immergut, 1989).

Como pode ser visto nos cromatogramas da Figura 4.43, tanto para foto-Fenton (a) como para $\mathrm{UV} / \mathrm{H}_{2} \mathrm{O}_{2}$ (b), a amostra inicial apresenta uma distribuição bimodal com dois picos fora do intervalo abrangido pelo método. Neste caso foi aberta uma exceção e as amostras iniciais foram integradas fora do tempo mínimo de retenção da curva, 13,07 minutos. Porém os picos com tempo de retenção acima de 21,3 minutos não foram integrados. Os valores da massa molar média numérica $(\mathrm{Mn})$, massa molar média mássica $(\mathrm{Mw})$ e polidispersidade $(\mathrm{Mw} / \mathrm{Mn})$ para PAM no processo foto-Fenton e $\mathrm{UV} / \mathrm{H}_{2} \mathrm{O}_{2}$ são mostrados na Tabela 4.12. Os valores de $\mathrm{Mw}$ das amostras iniciais estão totalmente fora do esperado já que a especificação do produto era de $20000 \mathrm{~g} \mathrm{~mol}^{-1} \mathrm{e}$ os valores calculados estão na faixa de $255000 \mathrm{~g} \mathrm{~mol}^{-}$ 1 . Esta diferença é devida à extrapolação da curva de calibração.

Infelizmente todos os cromatogramas, mostrados nas Figuras 4.43 (a) e (b), apresentaram uma parte com tempo de retenção abaixo de 10 minutos e foram integrados com uma extrapolação a partir de 10,8 minutos para o processo fotoFenton e 10 minutos para $\mathrm{UV} / \mathrm{H}_{2} \mathrm{O}_{2}$. Para o processo foto-Fenton as distribuições obtidas para PAM são semelhantes às do PEG 20000 com uma quebra rápida inicialmente, até 15 minutos, permanecendo constante até o final. 
Tabela 4.12 - Valores de massa molar média numérica (Mn), massa molar média mássica $(\mathrm{Mw})$ e polidispersidade $(\mathrm{Mw} / \mathrm{Mn})$, para alguns tempos de reação para os processos foto-Fenton e $\mathrm{UV} / \mathrm{H}_{2} \mathrm{O}_{2}$, para PAM.

\begin{tabular}{cccc}
\hline $\begin{array}{c}\text { Tempo de } \\
\text { Reação (min) }\end{array}$ & Mn & Mw & Mw/Mn \\
\hline \multicolumn{4}{c}{ Foto-Fenton } \\
\hline Inicial & 117187 & 255661 & 2,182 \\
15 & 888 & 3111 & 3,502 \\
30 & 925 & 2495 & 2,696 \\
60 & 815 & 2053 & 2,520 \\
90 & 801 & 2595 & 3,238 \\
120 & 786 & 2720 & 3,462 \\
180 & 965 & 4037 & 4,182 \\
\hline \multicolumn{4}{c}{ UV/H2O2 } \\
\hline Inicial & 111798 & 260571 & 2,331 \\
15 & 45764 & 124336 & 2,717 \\
30 & 16289 & 57726 & 3.544 \\
60 & 4217 & 24552 & 5,822 \\
90 & 3836 & 17056 & 4,446 \\
120 & 2804 & 18392 & 6,560 \\
180 & 2824 & 13713 & 4,855 \\
\hline
\end{tabular}

Para o processo $\mathrm{UV} / \mathrm{H}_{2} \mathrm{O}_{2}$ os cromatogramas têm um comportamento semelhante ao PEG, apresentando picos partidos característicos da formação de populações com diferentes $\mathrm{Mw}$, porém isto acontece menos intensamente para a poliacrilamida. A diferença é que os dois picos iniciais continuam separados até o final das três horas de experimento, e o pico de maior tempo de retenção praticamente não sofre deslocamento ou desaparece, diminuindo de intensidade somente na última hora de reação. 
(a) Foto-Fenton

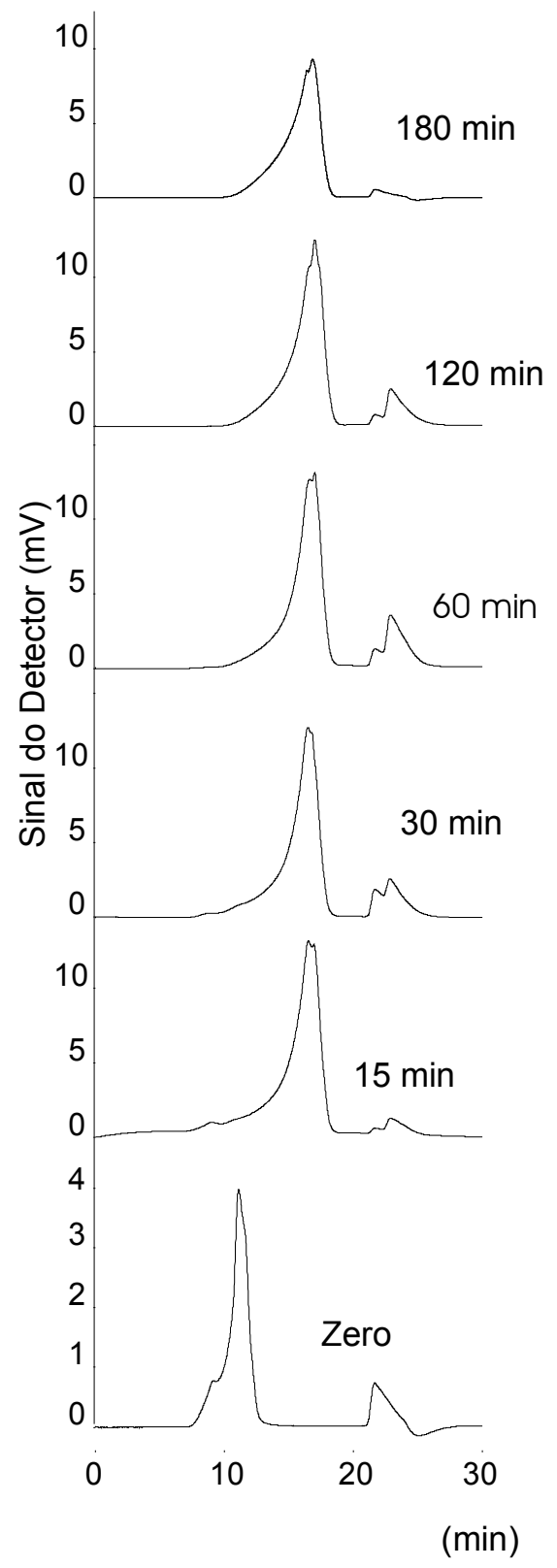

(b) $\mathrm{UV} / \mathrm{H}_{2} \mathrm{O}_{2}$

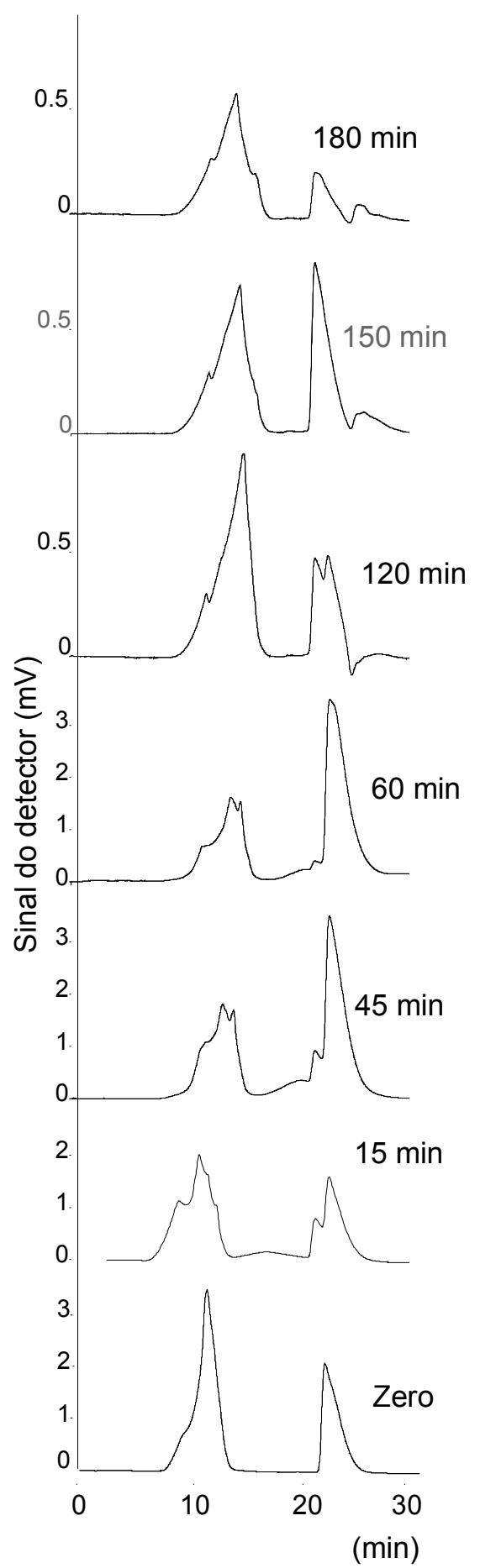

Figura 4.43 - Cromatogramas obtidos por GPC para PAM $10000 \mathrm{~g} \mathrm{~mol}^{-1}$, com as condições experimentais do ponto central. Processos: (a) foto-Fenton, (b) $\mathrm{UV} / \mathrm{H}_{2} \mathrm{O}_{2}$. 


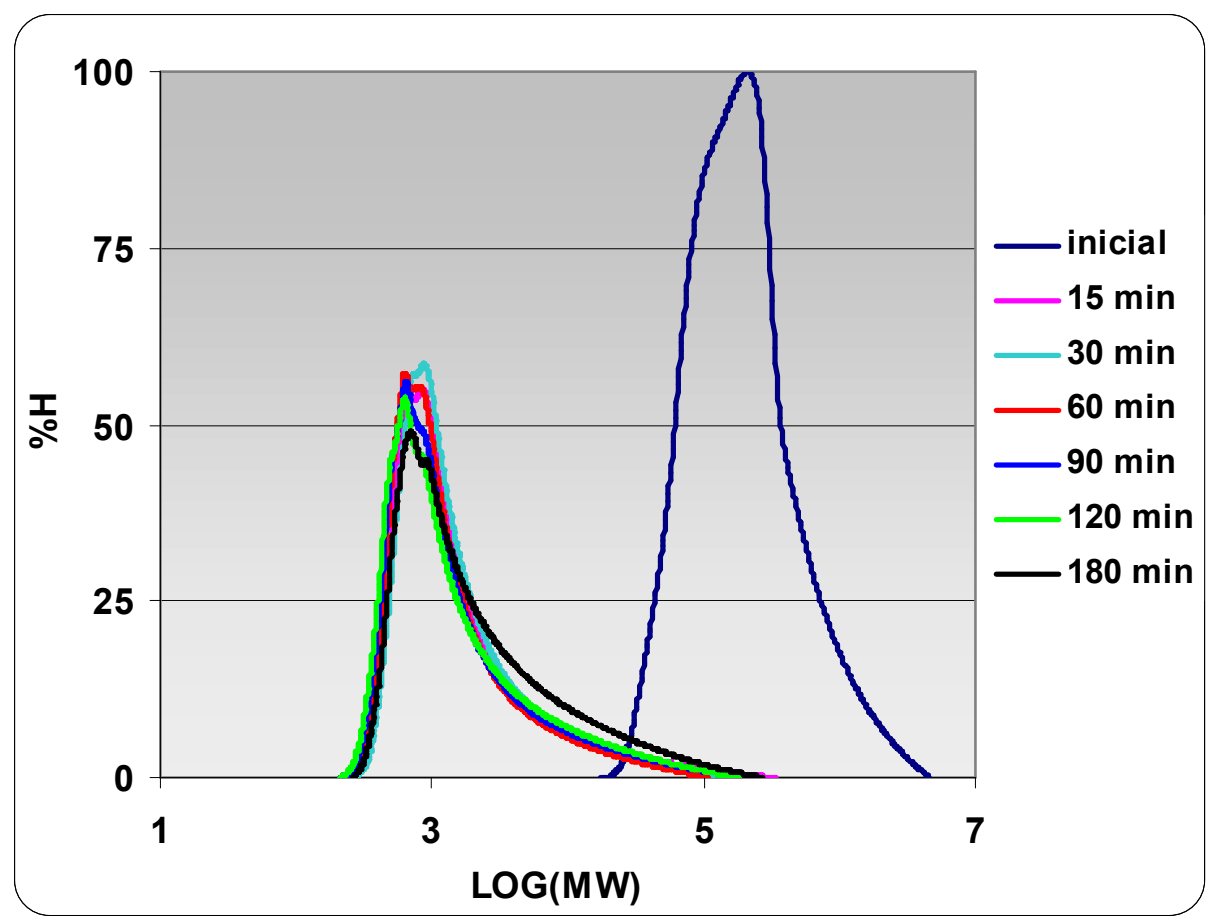

(a) Foto-Fenton

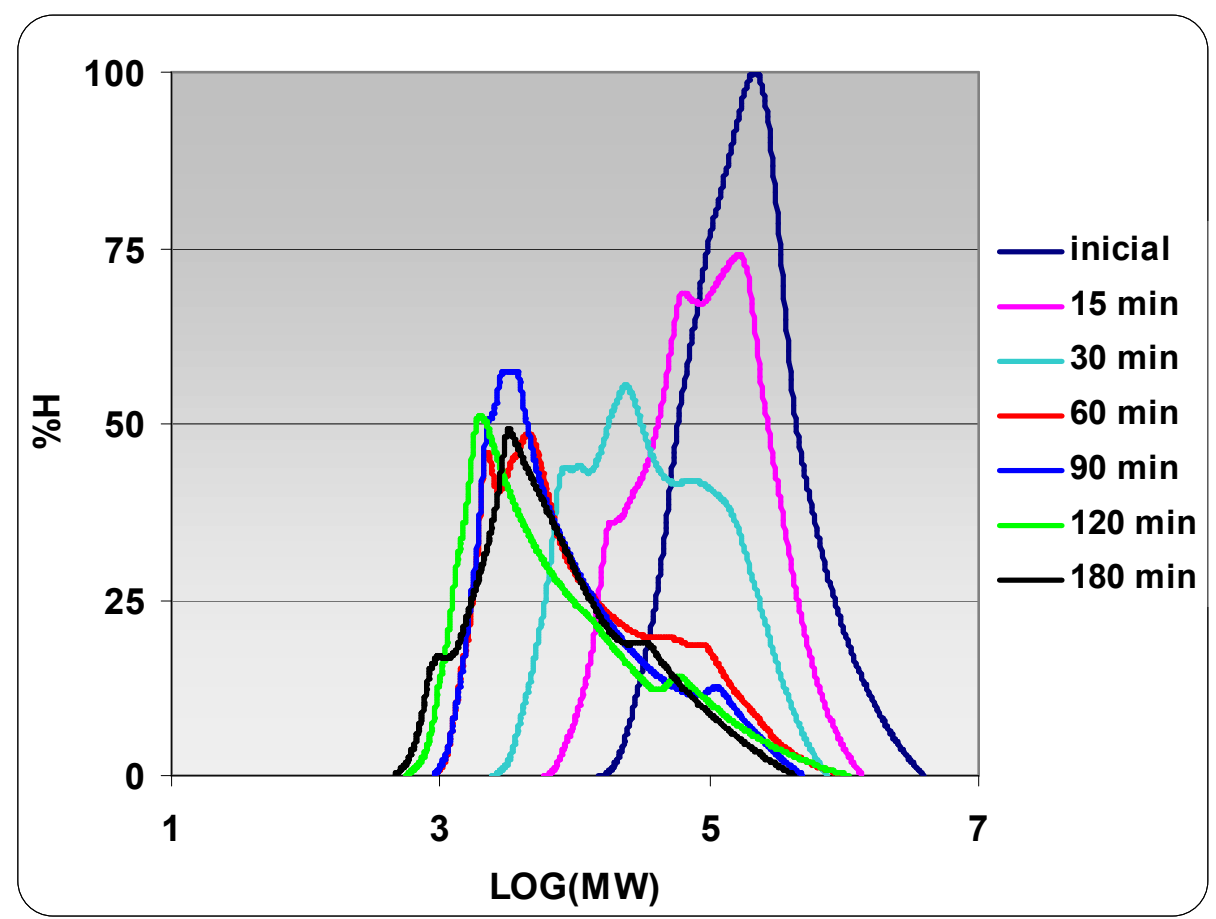

(b) $\mathrm{UV} / \mathrm{H}_{2} \mathrm{O}_{2}$

Figura 4.44 - Distribuição de pesos moleculares para PAM $10000 \mathrm{~g} \mathrm{~mol}^{-1}$, com as condições experimentais do ponto central. Processos (a) Foto-Fenton, (b) $\mathrm{UV} / \mathrm{H}_{2} \mathrm{O}_{2}$. 
Em todos os cromatogramas, tanto para PAM como para PEG, nota-se que o índice de refração, que é proporcional ao sinal do detector, muda à medida que o polímero é oxidado. Para o processo foto-Fenton, ele tende a aumentar e para o $\mathrm{UV} / \mathrm{H}_{2} \mathrm{O}_{2}$ a diminuir, isso provavelmente devido à introdução de diversos grupos funcionais na cadeia polimérica e em suas extremidades. Desta forma, segundo Jellinek (1978), a mudança na distribuição de pesos moleculares, causada pelo processo oxidativo, não pode ser determinada diretamente por cromatografia de permeação em gel obtida por índice de refração. Em tais casos é recomendado o fracionamento por GPC e a subseqüente análise dos pesos de cada fração para se ter uma medida direta das mudanças de pesos moleculares. Mesmo assim, os resultados têm importância qualitativa e permitem uma comparação entre os experimentos feitos com os processos foto-Fenton e $\mathrm{UV} / \mathrm{H}_{2} \mathrm{O}_{2}$. 


\subsection{Conclusões da Parte Experimental}

Os resultados experimentais mostraram que é tecnicamente viável empregar o processo foto-Fenton para degradação de soluções aquosas contendo polietilenoglicol (PEG), poliacrilamida (PAM) e polivinilpirrolidona (PVP). Dependendo das concentrações de $\mathrm{Fe}(\mathrm{II})$ e $\mathrm{H}_{2} \mathrm{O}_{2}$, a mineralização total dos compostos orgânicos foi alcançada, em duas ou três horas de reação. Para PEG o processo $\mathrm{UV} / \mathrm{H}_{2} \mathrm{O}_{2}$ também se mostrou viável, pois leva a remoções de COD quase tão altas quanto às do processo foto-Fenton.

A análise das curvas de COD em função do tempo permitiu concluir que o $\mathrm{H}_{2} \mathrm{O}_{2}$ é o reagente que mais favorece a degradação no processo foto-Fenton, nas faixas de concentração estudadas, e que a concentração de Fe(II), principalmente em seu nível correspondente a +1 no plano experimental poderia ser diminuída. Para todos os experimentos realizados com PAM e PVP houve separação de fases, o que levou a uma queda brusca de COD em alguns casos. A formação de fase sólida é devida possivelmente a complexação entre o polímero e o ferro, ou entre radicais poliméricos formados durante a oxidação e o ferro, formando partículas que coalescem e precipitam como observado por Bossmann et al. (2001a e 2001b), na degradação de soluções aquosas de álcool polivinílico pelo processo foto-Fenton. Os autores sugerem que a formação de complexos entre o PVA e o ferro impede a aproximação do $\mathrm{H}_{2} \mathrm{O}_{2}$ dos centros metálicos. Além disso, a foto-redução do $\mathrm{Fe}(\mathrm{III})$ que está ligado nestas grandes moléculas é menos eficiente.

A separação de fases só foi observada para PEG, no processo foto-Fenton quando a concentração das três variáveis: [PEG], [Fe(II)] e $\left[\mathrm{H}_{2} \mathrm{O}_{2}\right]$, estavam em seus níveis máximos, indicando que a natureza do polímero, o processo de oxidação e a concentração dos reagentes influenciam neste fenômeno. Para o tratamento de efluentes contendo estes polímeros, a separação de fases pode ser uma vantagem se for considerada sua integração com um processo de separação mecânica como, por exemplo, filtração. Porém a disposição e tratamento da fase sólida e a presença de contaminantes ou algum produto da oxidação mais tóxico nesta fase também deve ser analisada. 
$\mathrm{O}$ emprego do processo $\mathrm{UV} / \mathrm{H}_{2} \mathrm{O}_{2}$ para a degradação de $\mathrm{PEG}$ também se mostrou promissor, com a vantagem de que a ausência de ferro elimina uma possível etapa de retirada deste reagente do efluente já tratado para atingir limites de descarte previstos na legislação. Entretanto, os melhores resultados para o processo $\mathrm{UV} / \mathrm{H}_{2} \mathrm{O}_{2}$ foram obtidos à maior temperatura do plano experimental $\left(50^{\circ} \mathrm{C}\right)$ e o processo fotoFenton foi conduzido a $30^{\circ} \mathrm{C}$. Para PAM, os experimentos realizados para a análise de GPC e HPLC com os processos $\mathrm{UV} / \mathrm{H}_{2} \mathrm{O}_{2}$ e foto-Fenton também mostraram resultados semelhantes em termos de remoção de COD e indicam que o processo $\mathrm{UV} / \mathrm{H}_{2} \mathrm{O}_{2}$ também pode ser aplicado para a poliacrilamida.

As análises de GPC mostraram que houve quebra de cadeias e o peso molecular $(\mathrm{Mw})$ dos polímeros foi bastante reduzido por ambos os processos. Isto também torna viável a integração destes processos oxidativos a um processo biológico, cuja principal limitação para o tratamento de efluentes contendo polímeros solúveis é seu alto peso molecular, o que impede que passem pela membrana celular. Assim, após uma etapa inicial de oxidação suficiente para diminuir o peso molecular do polímero, mas sem levar à mineralização completa, o efluente pode ser enviado para uma etapa posterior de tratamento biológico convencional. Neste caso provavelmente seja possível operar com menores concentrações de reagentes, temperaturas e tempo de reação no processo oxidativo, já que o objetivo é a redução do peso molecular. Mesmo assim, o efeito do ferro, do $\mathrm{pH}$ e de altas temperaturas deve ser considerado na integração com o processo biológico.

A análise de intermediários para a degradação de PEG detectou ácidos fórmico e acético em ambos os processos sendo que este último mostrou-se mais recalcitrante à oxidação, acumulando-se no meio reacional nas condições empregadas. A presença de ácido glicólico apenas no processo foto-Fenton e de ácido malônico no $\mathrm{UV} / \mathrm{H}_{2} \mathrm{O}_{2}$, além das diferentes distribuições de pesos moleculares obtidas durante a oxidação, indicam a possibilidade de mecanismos diferentes para estes processos. Dependendo da extensão da oxidação e das concentrações de reagentes, deve-se considerar o impacto dos ácidos formados durante a degradação no processo biológico, no caso de integração com o processo oxidativo. 
Os resultados das análises de intermediários para poliacrilamida mostraram que a acrilamida não é produzida em concentrações acima de 50 ppb. Porém há outros intermediários não detectados. 


\section{MODELAGEM MOLECULAR}

\subsection{Procedimentos Computacionais}

Para cálculos de mecânica molecular utilizou-se o software Cerius $^{2}$ v.4.2 (Molecular Simulations Inc., Cerius 2, 2001) instalado numa estação de trabalho SGI O2 IRIX 6.5 (Silicon Graphics) com processador de $300 \mathrm{MHz}$ R12000; 1MB cache, $256 \mathrm{MB}$ de memória; disco rígido $9 \mathrm{~GB}$ com expansão de memória $256 \mathrm{MB}$ e 128 MB; disco rígido 18GB 10000 RPM UFW Scsi; monitor colorido 21". Este recurso está disponível no CESQ-LSCP (Centro de Engenharia de Sistemas QuímicosLaboratório de Simulação e Controle de Processos, DEQ/EPUSP).

Para cálculos quânticos ab initio utilizaram-se os softwares Gaussian 98 (Frisch et al., 1998) revisão A.7, disponível no CESQ-LSCP, instalado em uma estação de trabalho Compaq XP1000 e também disponível no Laboratório de Computação Científica Avançada do Centro de Computação Eletrônica da Universidade de São Paulo (LCCA-CCE/USP) e o Gaussian 03, somente disponível no LCCA. As características dos recursos computacionais do LCCA são resumidas da Tabela 5.1. Foram utilizados os softwares de visualização GaussView (Gaussian Inc.) e ChemCraft (G. A. Zhurko).

Tabela 5.1 - Características dos recursos computacionais do LCCA-CCE/USP, utilizados neste trabalho.

\begin{tabular}{|c|c|c|c|}
\hline \multicolumn{2}{|c|}{ Gaussian 98} & \multicolumn{2}{|c|}{ Gaussian 03} \\
\hline \multicolumn{2}{|c|}{ Cluster HP-Compaq } & \multicolumn{2}{|c|}{ Cluster Beowulf } \\
\hline Número de máquinas & $\begin{array}{l}1 \mathrm{ES} 45 \\
3 \mathrm{ES} 40\end{array}$ & Número de nós & 32 \\
\hline $\begin{array}{l}\text { Número de } \\
\text { processadores por } \\
\text { máquina }\end{array}$ & $\begin{array}{l}4(\mathrm{ES} 45: 1 \mathrm{GHz}, \\
\text { ES40:667MHz) }\end{array}$ & $\begin{array}{l}\text { Número de } \\
\text { processadores por nó }\end{array}$ & 2 \\
\hline Tecnologia & EV6.8, EV6 & Tecnologia & $\begin{array}{lll}\text { Intel } & \text { Xeon } 2.4 \\
\mathrm{GHz} & & \end{array}$ \\
\hline Memória & $6 \mathrm{~GB}$ & Memória & $2,5 \mathrm{~GB} /$ nó \\
\hline Sistema operacional & Tru64 Unix 5.1b & & \\
\hline
\end{tabular}


Primeiramente construiu-se, para reagentes e produtos das reações estudadas, um modelo simplificado no Cerius $^{2}$; com posterior minimização de energia, utilizando o campo de força Dreiding 2.2.1 (Mayo et al. 1990). A estrutura assim obtida foi submetida a cálculos ab initio no Gaussian. O primeiro foi a otimização com o modelo químico ${ }^{6} \mathrm{HF} / 6-31 \mathrm{G}(\mathrm{d})$, seguido do cálculo de freqüência. Em seguida procedeu-se à busca das estruturas de transição, da seguinte forma: todas as coordenadas, menos a coordenada de reação, foram otimizadas e esta foi variada gradativamente. As estruturas otimizadas que apresentaram neste caminho de reação a mudança esperada que levaria os reagentes em direção aos produtos foram as candidatas à estrutura de transição (TS). Seguiu-se a otimização com a opção QST3 do Gaussian, a qual usa as estruturas dos reagentes, dos produtos e da TS candidata para o cálculo da estrutura de transição. A estrutura resultante do cálculo QST3 foi então submetida a uma nova otimização com a opção $o p t=T S$ para refinar o cálculo da estrutura de transição. A estrutura obtida foi, então, submetida ao cálculo de freqüência, e, se houvesse somente uma freqüência imaginária com deslocamento na direção do caminho de reação estudado, realizava-se o cálculo IRC (Intrinsic Reaction Coordinate) para averiguar se de fato a estrutura de transição unia reagentes a produtos.

Todos os cálculos descritos foram feitos com o modelo químico inicial, HF/631G(d), portanto calculou-se a freqüência utilizando o fator de escala para energia deste modelo: 0,9135, para obtenção dos dados termoquímicos para todas as espécies envolvidas, inclusive a TS. O último passo foi o cálculo de energia com modelos químicos mais complexos. Para os níveis de teoria HF e B3LYP foram utilizados os basis sets: 6-31G(d); 6-31G(d,p); 6-31+G(d,p) e 6-311+G(d,p). Para o MP2 utilizaram-se os basis sets, 6-31G(d), 6-31G(d,p) e 6-31+G(d,p), quando possível, por limitações de memória e espaço em disco. A Figura 5.1 apresenta um esquema dos procedimentos de cálculo realizados na modelagem molecular das reações, na forma de um diagrama de blocos.

\footnotetext{
${ }^{6}$ A combinação do método teórico e do basis set utilizados nos cálculos é denominada modelo químico.
} 


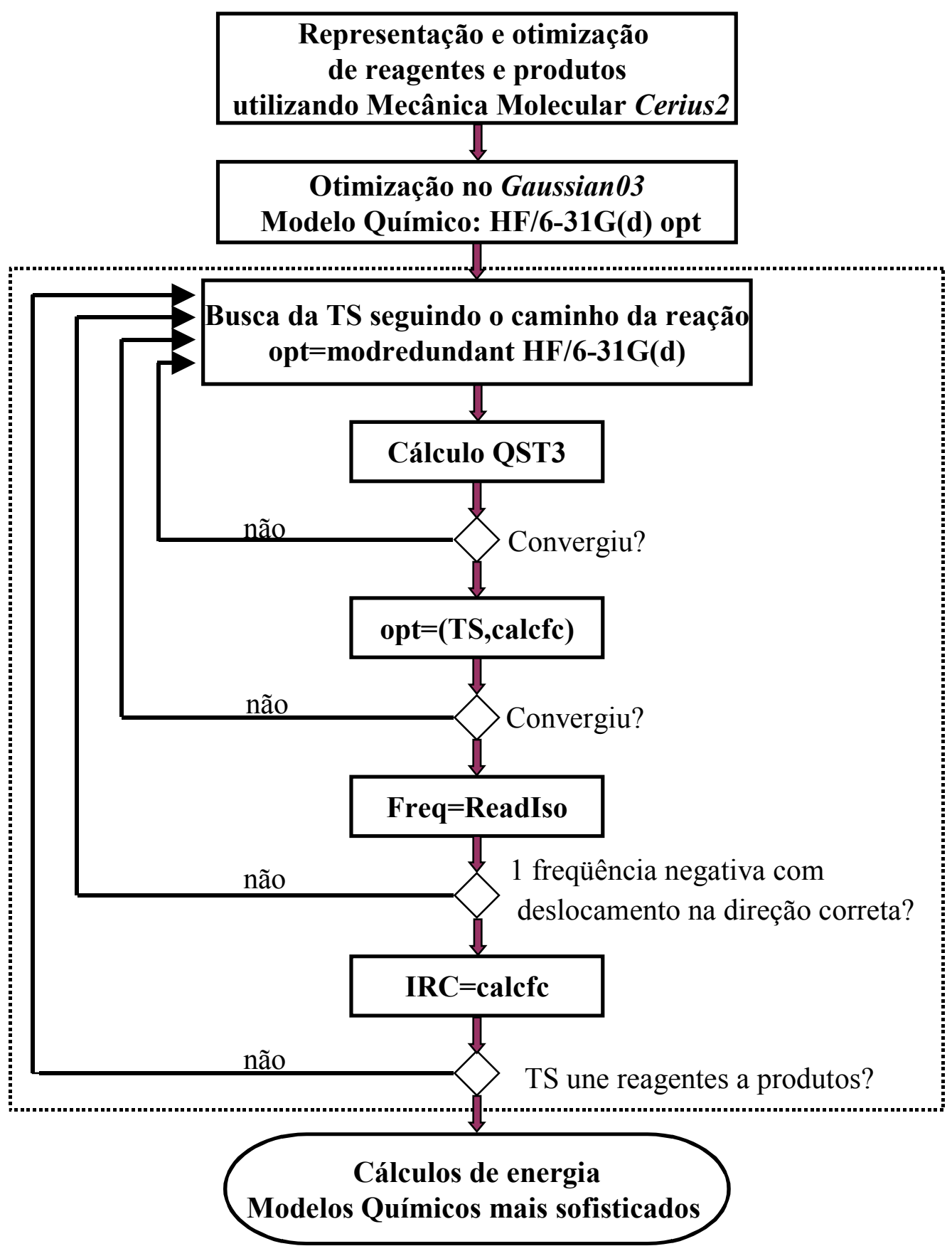

Figura 5.1 - Esquema da seqüência de cálculos realizados na modelagem molecular das reações. 


\subsection{Reações para Polietilenoglicol}

Inicialmente estudou-se a melhor forma de representar a cadeia polimérica utilizando-se como base a unidade monomérica $\left(-\mathrm{CH}_{2}-\mathrm{CH}_{2}-\mathrm{O}-\right)$. Fizeram-se estudos de otimização de estruturas com 2, 4 e 8 unidades de repetição. Para economizar tempo computacional optou-se por representar a cadeia polimérica com 2 unidades de repetição, assim as reações oxidativas apresentadas na seção 2.2 foram escritas para o dietilenoglicol. A Tabela 5.2 apresenta as espécies envolvidas nas reações de oxidação do dietilenoglicol, que foram submetidas aos cálculos quânticos. São apresentadas informações simples, como fórmula química, nome e número de registro no Chemical Abstracts (CAS) e também o nome pelo qual a espécie será tratada no trabalho, por motivo de simplificação. Convém ressaltar que algumas espécies propostas neste estudo não apresentam registro no Chemical Abstracts. A seqüência das reações é assim apresentada:

- Abstração de hidrogênio do dietilenoglicol pelo radical hidroxila e formação do radical alquila.

$$
\mathrm{HO}-\mathrm{CH}_{2}-\mathrm{CH}_{2}-\mathrm{O}-\mathrm{CH}_{2}-\mathrm{CH}_{2}-\mathrm{OH}+\dot{\mathrm{O}} \mathrm{H} \longrightarrow \mathrm{HO}-\mathrm{CH}_{2}-\mathrm{CH}_{2}-\mathrm{O}-\dot{\mathrm{C}} \mathrm{H}-\mathrm{CH}_{2}-\mathrm{OH}+
$$

- Reação do radical alquila com o oxigênio formando o radical alquilperoxila.<smiles>O=[Po+][Hg][Hg]O[CH]CCOC([O+])CO</smiles>

- Reação dos radicais alquilperoxila com o dietilenoglicol formando um hidroperóxido secundário. 
$\mathrm{HO}-\mathrm{CH}_{2}-\mathrm{CH}_{2}-\mathrm{O}-\underset{\mathrm{OO}}{\mathrm{CH}}-\mathrm{CH}_{2}-\mathrm{OH}+\mathrm{HO}-\mathrm{CH}_{2}-\mathrm{CH}_{2}-\mathrm{O}-\mathrm{CH}_{2}-\mathrm{CH}_{2}-\mathrm{OH} \longrightarrow$
$\mathrm{HO}-\mathrm{CH}_{2}-\mathrm{CH}_{2}-\mathrm{O}-\underset{\mathrm{OOH}}{\mathrm{CH}}-\mathrm{CH}_{2}-\mathrm{OH}+\mathrm{HO}-\mathrm{CH}_{2}-\mathrm{CH}_{2}-\mathrm{O}-\dot{\mathrm{CH}}-\mathrm{CH}_{2}-\mathrm{OH}$

- Degradação térmica do hidroperóxido formando o radical alcoxila.<smiles>[O]C(COCC(O)COCCO)OCCO</smiles>

- Cisão $\beta$ do radical alcoxila formando o etilenoglicol monoformato e o radical alquila primário.

$\mathrm{HO}-\mathrm{CH}_{2}-\mathrm{CH}_{2}-\mathrm{O}-\mathrm{CH}-\mathrm{CH}_{2}-\mathrm{OH} \longrightarrow \mathrm{HO}-\mathrm{CH}_{2}-\mathrm{CH}_{2}-\mathrm{O}-\mathrm{C}_{\searrow_{\mathrm{H}}} \stackrel{\mathrm{O}}{\prime}+\dot{\mathrm{CH}}_{2}-\mathrm{OH}$

- Repete-se a seqüência de reações para o radical formado na etapa anterior: reação com oxigênio formando o radical alquilperoxila primário (reação 5.6); abstração de um hidrogênio do dietilenoglicol formando um hidroperóxido primário (reação 5.7) que se decompõe formando o radical alcoxila primário (reação 5.8). Finalmente o radical alcoxila primário formaria aldeídos ou ácidos que são considerados produtos finais da seqüência oxidativa.

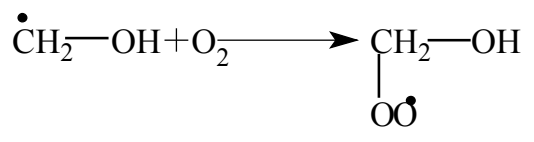

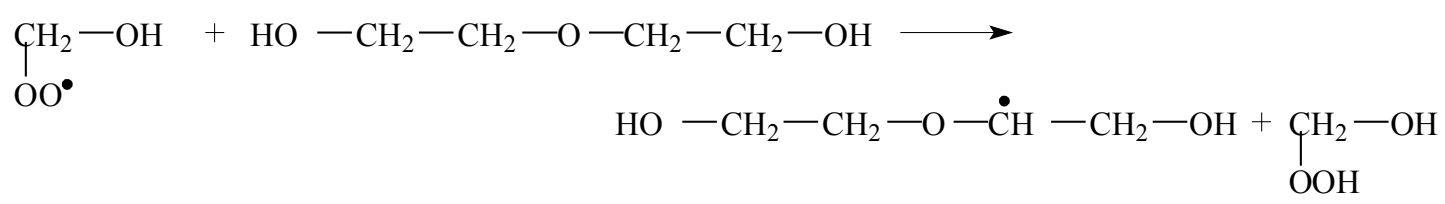




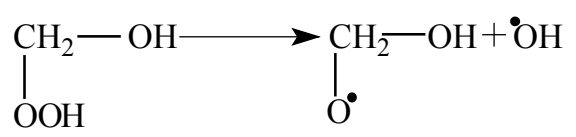


Tabela 5.2 - Espécies participantes das reações de oxidação do PEG.

\begin{tabular}{|c|c|c|}
\hline Nome (Cas) & $\begin{array}{c}\text { Estrutura } \\
\text { Cas Reg Number } \\
\end{array}$ & Identificação no trabalho \\
\hline \multicolumn{3}{|c|}{$\mathrm{HO}-\mathrm{CH}_{2}-\mathrm{CH}_{2}-\mathrm{O}-\mathrm{CH}_{2}-\mathrm{CH}_{2}-\mathrm{OH}$} \\
\hline Ethanol, 2, 2' oxybis & $111-46-6$ & Dietilenoglicol \\
\hline \multicolumn{3}{|c|}{$\mathrm{HO}-\mathrm{CH}_{2}-\mathrm{CH}_{2}-\mathrm{O}-\dot{\mathrm{C}} \mathrm{H}-\mathrm{CH}_{2}-\mathrm{OH}$} \\
\hline $\begin{array}{l}\text { Etanol, 2-hydroxy-1- } \\
\text { (2-hydroxyethoxy) }\end{array}$ & 17031-90-2 & Radical Alquila \\
\hline \multicolumn{3}{|c|}{$\mathrm{HO}-\mathrm{CH}_{2}-\mathrm{CH}_{2}-\mathrm{O}-\underset{\mathrm{O}}{\mathrm{CH}}-\mathrm{CH}_{2}-\mathrm{OH}$} \\
\hline ---------- & ---------- & Radical alquilperoxila \\
\hline \multicolumn{3}{|c|}{$\mathrm{HO}-\mathrm{CH}_{2}-\mathrm{CH}_{2}-\mathrm{O}-\underset{\mathrm{OOH}}{\mathrm{CH}}-\mathrm{CH}_{2}-\mathrm{OH}$} \\
\hline $\begin{array}{l}\text { Hydroperoxyde, 2-hydroxy- } \\
\text { 1-(2-hydroxyethoxy) ethyl }\end{array}$ & $1857772-077$ & Hidroperóxido secundário \\
\hline \multicolumn{3}{|c|}{$\mathrm{HO}-\mathrm{CH}_{2}-\mathrm{CH}_{2}-\mathrm{O}-\underset{\mathrm{O}}{\mathrm{CH}}-\mathrm{CH}_{2}-\mathrm{OH}$} \\
\hline ---------- & ---------- & Radical alcoxila \\
\hline \multicolumn{3}{|c|}{$\mathrm{HO}-\mathrm{CH}_{2}-\mathrm{CH}_{2}-\mathrm{O}-\mathrm{C}_{\backslash_{\mathrm{H}}}^{1 /}$} \\
\hline \multicolumn{3}{|c|}{ 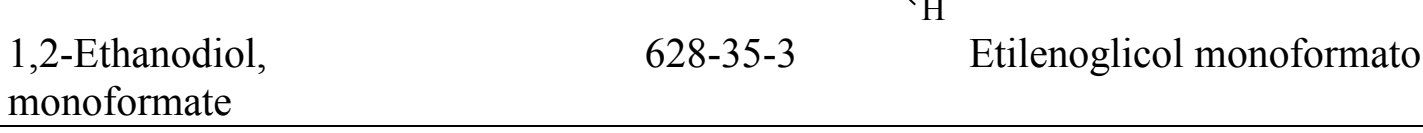 } \\
\hline \multicolumn{3}{|c|}{$\dot{\mathrm{C}} \mathrm{H}_{2}-\mathrm{OH}$} \\
\hline Methyl, hydroxy & $2597-43-5$ & Radical alquila primário \\
\hline \multicolumn{3}{|c|}{$\prod_{\mathrm{O} O}^{\mathrm{CH}_{2}-\mathrm{OH}}$} \\
\hline Methyldioxy, hydroxy & $27828-51-9$ & $\begin{array}{l}\text { Radical alquilperoxila } \\
\text { primário }\end{array}$ \\
\hline \multicolumn{3}{|c|}{$\left.\right|_{\mathrm{OOH}} ^{\mathrm{CH}_{2}-\mathrm{OH}}$} \\
\hline Methanol, hydroperoxy & $15935-89-5$ & Hidroperóxido primário \\
\hline \multicolumn{3}{|c|}{$\left.\right|_{0} ^{\mathrm{CH}_{2}-\mathrm{OH}}$} \\
\hline Methoxy, hydroxy & 72144-78-6 & Radical alcoxila primário \\
\hline
\end{tabular}




\subsection{Resultados para Polietilenoglicol}

Os cálculos para todas as espécies radicalares e para o oxigênio foram realizados com a opção unrestricted (U), pois são sistemas de camada aberta. Para as demais espécies, dietilenoglicol, água, hidroperóxidos primário e secundário e etilenoglicol monoformato, utilizou-se a opção restricted (R). Os símbolos R e U são omitidos para simplificação no restante deste trabalho. Os cálculos consideram as moléculas isoladas, em fase gasosa e não consideram o efeito do solvente.

Os resultados obtidos para as reações 5.1 a 5.8 são apresentados da seguinte forma:

- Estruturas otimizadas com o modelo químico $\mathrm{HF} / 6-31 \mathrm{G}(\mathrm{d})$ são apresentadas nas Figuras 5.2 a 5.12 e dados geométricos como ângulos, diedros e comprimento de ligação são apresentados na forma da matriz $\mathbf{Z}$ no Apêndice B nas Tabelas B.1 a B.11. A matriz $Z$ especifica o comprimento e a localização de ligações entre os átomos, ângulos entre as ligações e ângulos de diedros, representando a estrutura da molécula (Foresman e Frisch, 1996).

- Freqüências vibracionais corrigidas com o fator de escala 0,8929, obtidas com o modelo $\mathrm{HF} / 6-31 \mathrm{G}(\mathrm{d})$, para os reagentes e produtos das reações de 5.1 a 5.8 e para as estruturas de transição encontradas são mostradas na Tabela 5.3. O fator de escala é aplicado para corrigir erros sistemáticos do cálculo de freqüência (Foresman e Frisch, 1996).

- Os parâmetros termoquímicos: energia no ponto zero (ZPE), correção térmica da entalpia $\left(\mathrm{H}_{\text {corr }}\right)$ e correção térmica da energia livre de Gibbs $\left(\mathrm{G}_{\text {corr }}\right)$, obtidos com o modelo $\mathrm{HF} / 6-31 \mathrm{G}(\mathrm{d})$, corrigidos com o fator de escala 0,9135 , para reagentes e produtos das reações de 5.1 a 5.8 e para as estruturas de transição encontradas são apresentados na Tabela 5.4. A energia no ponto zero é a correção da energia eletrônica da molécula para considerar os efeitos das vibrações moleculares que persistem mesmo a $0 \mathrm{~K}$. Segundo Foresman e Frisch (1996), o fator de escala para a correção de erros sistemáticos em ZPE 
para o modelo HF/6-31G(d) é 0,9135, embora seja uma prática comum empregar o mesmo fator utilizado para corrigir freqüência, com este modelo.

- Energias eletrônicas calculadas somando-se a energia single point obtida com os níveis de teoria HF, B3LYP, MP2, MP3 e MP4 para diferentes basis-sets, 6-31G(d), 6-31G(d,p), 6-31+G(d,p), 6-311+G(d,p), à energia do ponto zero corrigida com o fator 0,9135, obtida com o modelo $\mathrm{HF} / 6-31 \mathrm{G}(\mathrm{d})$, para reagentes e produtos das reações de 5.1 a 5.8 e para as estruturas de transição encontradas, são mostradas nas Tabelas 5.5 e 5.6.

- Entalpia, energia livre de reação e entropia de reação, $\Delta \mathrm{H}_{\mathrm{r}}^{0}, \Delta \mathrm{G}_{\mathrm{r}}^{0}, \Delta \mathrm{S}_{\mathrm{r}}^{0}$, são apresentadas nas Tabelas 5.7, 5.8 e 5.9, respectivamente. Foram calculadas somando-se as energias eletrônicas corrigidas com ZPE à correção térmica da entalpia (Hcorr) para $\Delta \mathrm{H}_{\mathrm{r}}^{0}$ e à correção térmica da energia livre de Gibbs (Gcorr) para $\Delta \mathrm{G}_{\mathrm{r}}^{0}$, ambas corrigidas com o fator 0,9135 .

- Barreiras de ativação para as reações 1, 3 e 7, obtidas subtraindo-se a energia eletrônica da estrutura de transição da energia eletrônica dos reagentes para diferentes modelos químicos, são apresentadas na Tabela 5.10. Todos os valores somados com as respectivas energias do ponto zero corrigidas com o fator 0,9135, obtidas com o modelo $\mathrm{HF} / 6-31 \mathrm{G}(\mathrm{d})$.

- Energia de ativação $\left(\mathbf{E}_{\mathbf{a}}\right)$ calculada segundo a equação E8; entalpia de ativação $\left(\Delta^{\sharp} \mathrm{H}^{0}\right)$; entropia de ativação $\left(\Delta^{\sharp} \mathrm{S}^{0}\right)$ calculada segundo a equação E11; energia livre de Gibbs $\left(\Delta^{\ddagger} \mathrm{G}^{0}\right)$ de ativação, fator pré-exponencial (A) equação E9 e constante de velocidade de reação (k) equação E10, são apresentadas nas Tabelas 5.11, 5.12 e 5.13 para as reações 5.1, 5.3 e 5.7, respectivamente. 


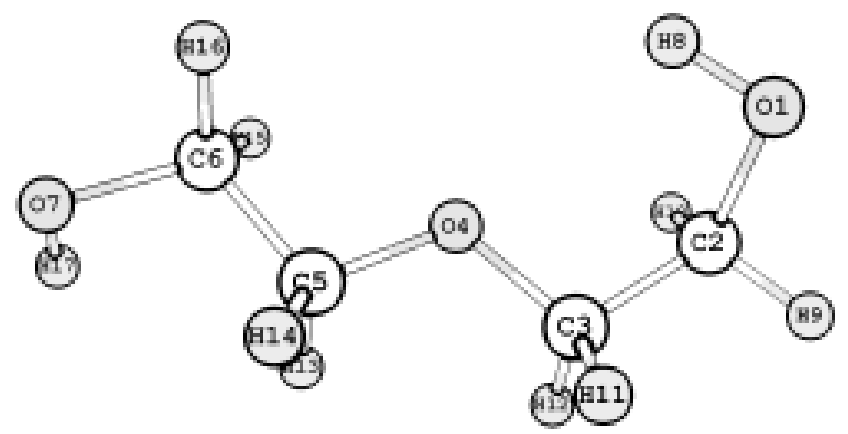

Figura 5.2 - Geometria do Dietilenoglicol otimizada com o modelo químico HF/6$31 \mathrm{G}(\mathrm{d})$.

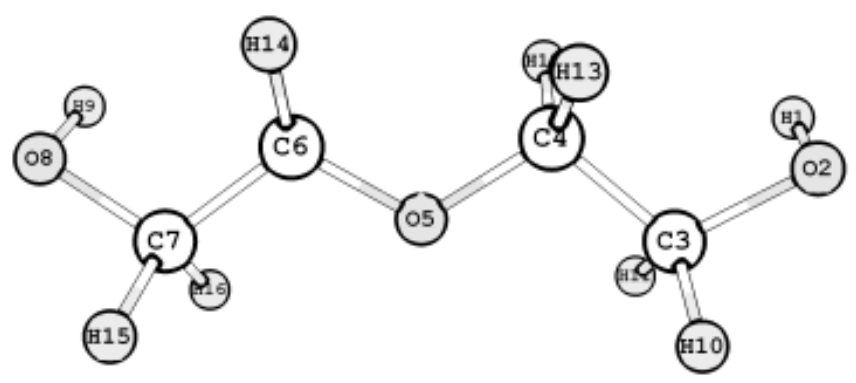

Figura 5.3 - Geometria do radical alquila otimizada com o modelo químico HF/6$31 \mathrm{G}(\mathrm{d})$.

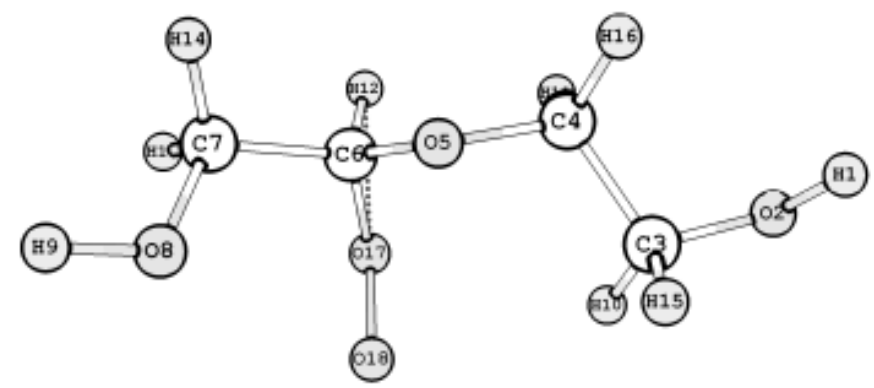

Figura 5.4 - Geometria do radical alquilperoxila otimizada com o modelo químico $\mathrm{HF} / 6-31 \mathrm{G}(\mathrm{d})$. 


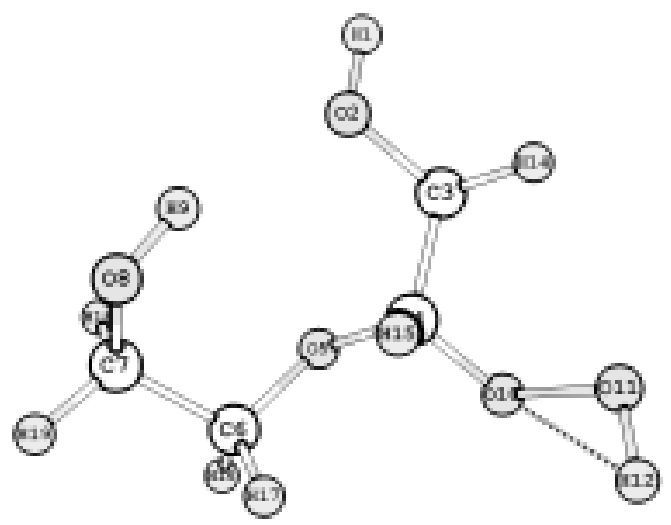

Figura 5.5 - Geometria do hidroperóxido secundário otimizada com o modelo químico $\mathrm{HF} / 6-31 \mathrm{G}(\mathrm{d})$.

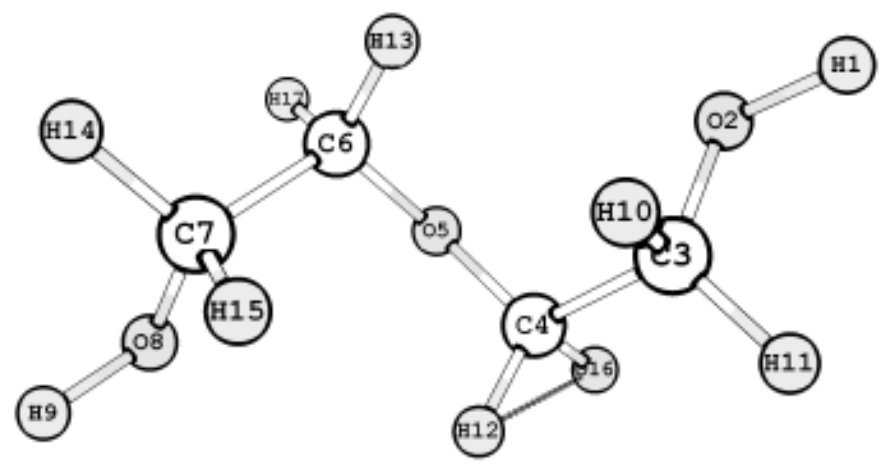

Figura 5.6 - Geometria do radical alcoxila otimizada com o modelo químico HF/6$31 \mathrm{G}(\mathrm{d})$.

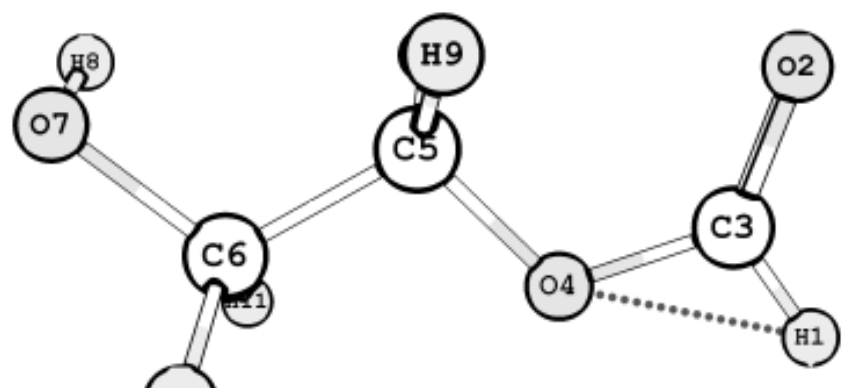

(H12)

Figura 5.7 - Geometria do etilenoglicol monoformato otimizada com o modelo químico $\mathrm{HF} / 6-31 \mathrm{G}(\mathrm{d})$. 


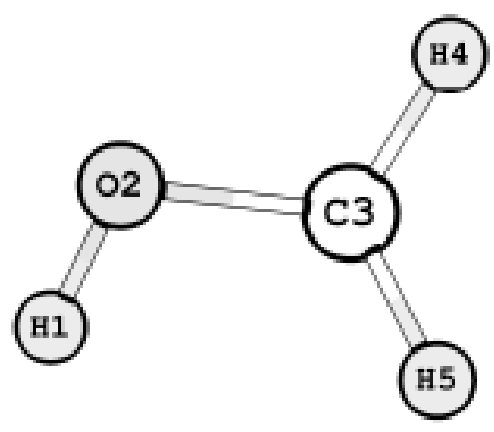

(a)

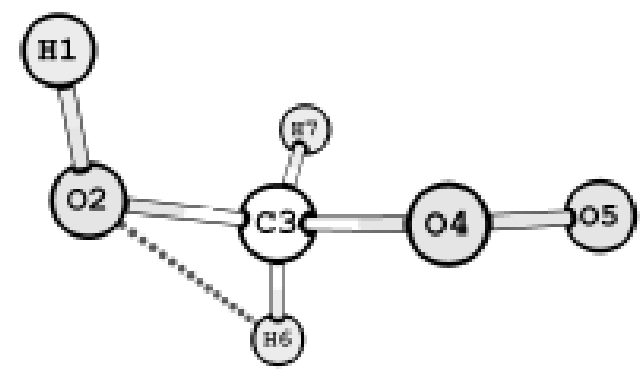

(b)

Figura 5.8 - Geometria dos radicais: (a) alquila primário e (b) alquilperoxila primário, otimizadas com o modelo químico $\mathrm{HF} / 6-31 \mathrm{G}(\mathrm{d})$.

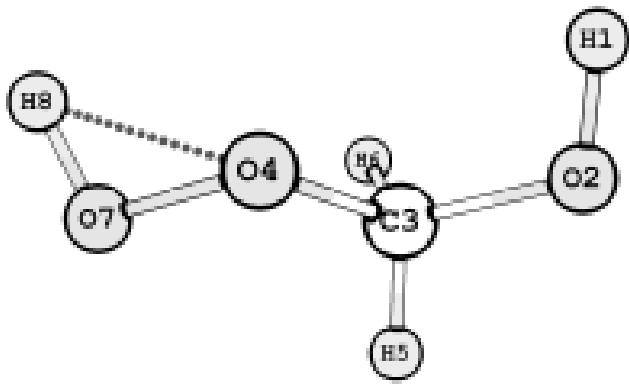

(a)

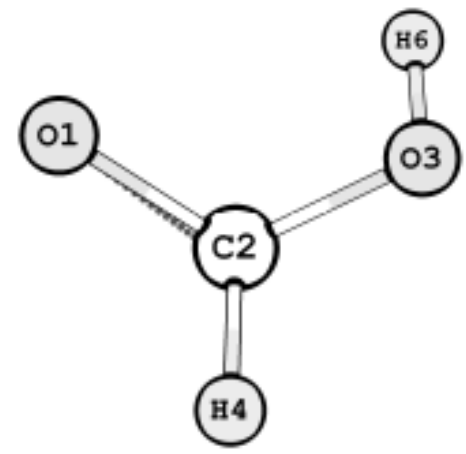

(b)

Figura 5.9 - Geometria dos radicais: (a) hidroperóxido primário e (b) alcoxila primário, otimizadas com o modelo químico $\mathrm{HF} / 6-31 \mathrm{G}(\mathrm{d})$.

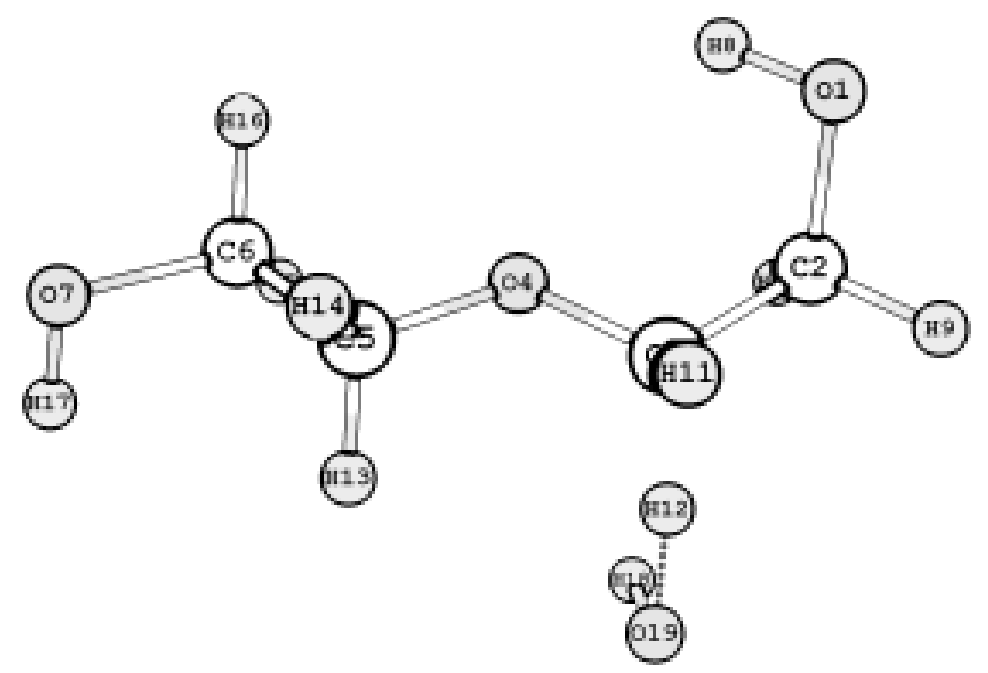

Figura 5.10 - Geometria da estrutura de transição da Reação 5.1, otimizada com o modelo químico HF/6-31G(d). 


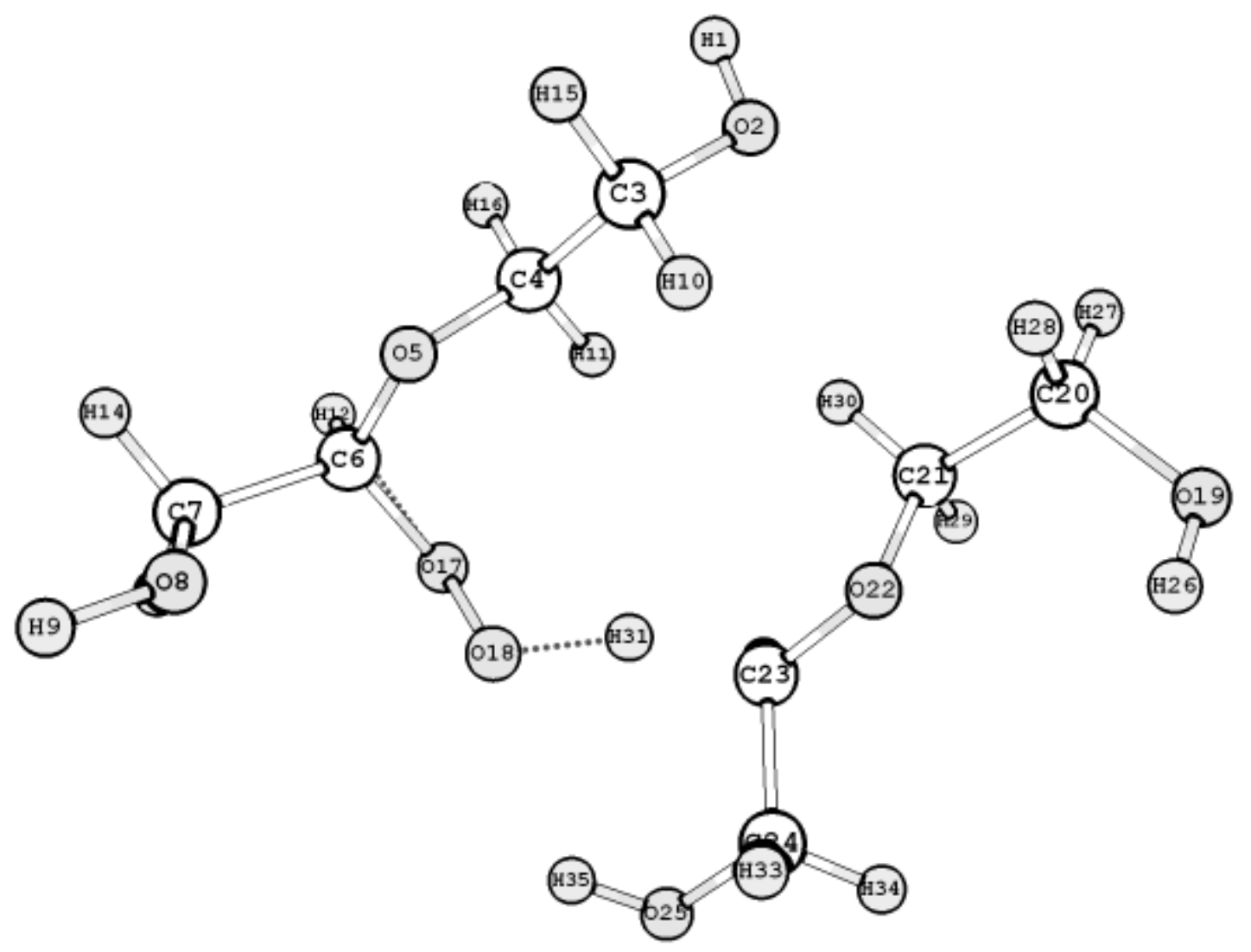

Figura 5.11- Geometria da estrutura de transição da Reação 5.3 otimizada com o modelo químico HF/6-31G(d).

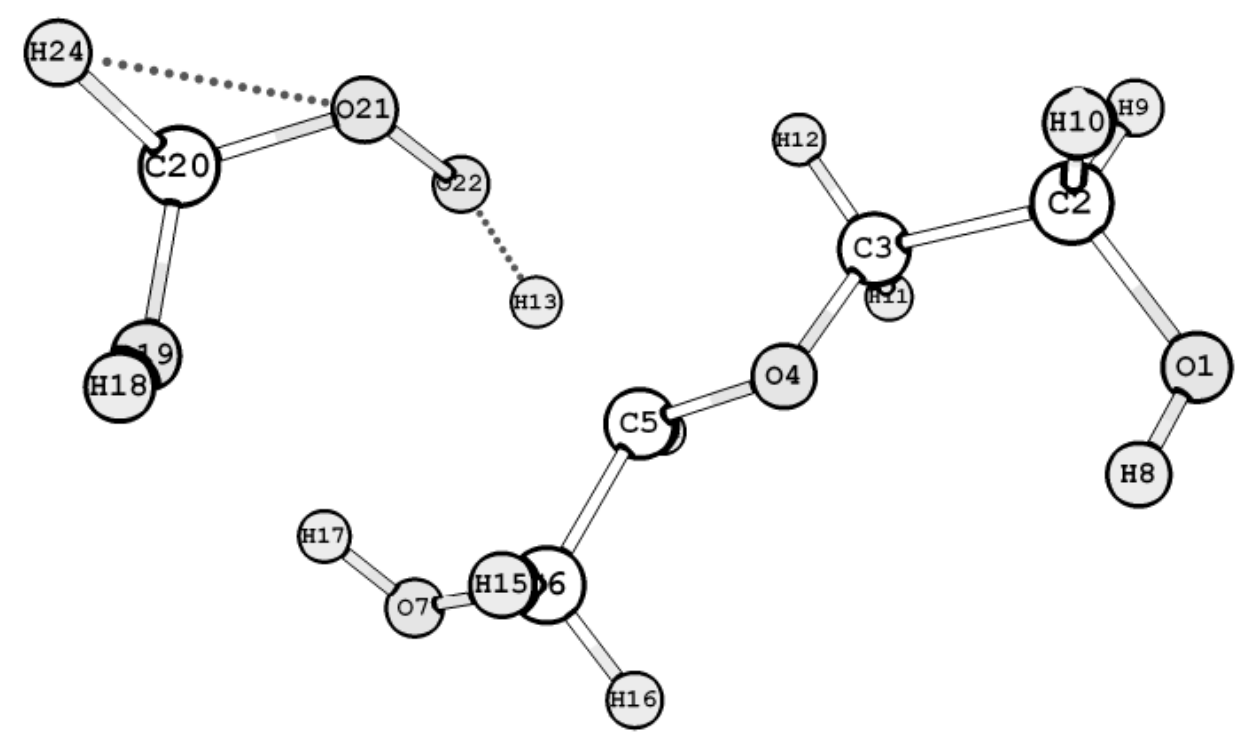

Figura 5.12- Geometria da estrutura de transição da Reação 5.7 otimizada com o modelo químico HF/6-31G(d). 
Tabela 5.3 - Resultados para PEG: freqüências vibracionais corrigidas com o fator 0,8929, obtidas com o modelo HF/6-31G(d), para os reagentes e produtos das reações de 5.1 a 5.8 e para as estruturas de transição encontradas.

\begin{tabular}{|c|c|}
\hline Espécies & Freqüências $\left(\mathrm{cm}^{-1}\right)$ \\
\hline Dietilenoglicol & $\begin{array}{l}57,65,115,151,183,276,286,368,389,424,547,785,850,883,1015,1049,1063,1076,1081,1113,1160,1191,1203,1247,1278,1325, \\
1352,1356,1386,1417,1445,1480,1483,1490,1504,2823,2841,2856,2867,2878,2882,2929,2944,3660,3669\end{array}$ \\
\hline Radical alquila & $\begin{array}{l}46,65,103,118,159,261,282,310,335,451,520,666,783,950,1020,1032,1053,1073,1079,1100,1152,1188,1205,1278,1296,1330, \\
1347,1360,1417,1441,1483,1487,1498,2850,2856,2872,2890,2894,2946,2948,3664,3671\end{array}$ \\
\hline Radical alquilperoxila & $\begin{array}{l}11,72,76,95,143,187,200,241,275,296,337,362,450,593,750,771,840,938,993,1020,1053,1066,1073,1110,1128,1177,1208,1239 \text {, } \\
1268,1305,1322,1359,1383,1392,1430,1462,1480,1487,1491,2851,2876,2881,2885,2890,2917,2966,3671,3677\end{array}$ \\
\hline Hidroperóxido secundário & $\begin{array}{l}50,70,118,127,150,181,216,249,257,296,318,452,508,516,550,583,833,870,900,1000,1037,1059,1072,1092,1104,1128,1175, \\
1206,1213,1235,1289,1350,1368,1375,1397,1404,1410,1459,1475,1482,1489,2859,2883,2887,2917,2923,2932,2939,3618,3650 \text {, } \\
3684\end{array}$ \\
\hline Radical alcoxila & $\begin{array}{l}47,57,107,182,201,222,268,274,340,401,451,564,665,804,852,876,932,1022,1062,1092,1100,1118,1176,1198,1210,1232,1259, \\
1302,1316,1354,1401,1437,1446,1479,1497,1501,2825,2834,2852,2860,2875,2895,2950,3674,3677\end{array}$ \\
\hline Etilenoglicol monoformato & $\begin{array}{l}63,120,153,284,307,317,423,771,777,964,1035,1058,1064,1079,1193,1231,1277,1326,1359,1384,1426,1485,1494,1796,2872, \\
2906,2942,2950,2966,3670\end{array}$ \\
\hline Radical alquila primário & $365,760,1031,1149,1324,1452,2937,3060,3683$ \\
\hline Radical alquilperoxila primário & $74,327,402,518,984,1051,1142,1155,1222,1358,1425,1513,2908,2989,3656$ \\
\hline Hidroperoxido primário & $120,192,309,382,505,997,1053,1096,1139,1222,1357,1397,1431,1523,2874,2970,3654,3660$ \\
\hline Alcoxila primário & $301,531,877,1007,1109,1131,1329,1410,1443,2832,2929,3658$ \\
\hline $\begin{array}{l}\text { Estrutura de transição para a } \\
\text { Reação } 5.1\end{array}$ & $\begin{array}{l}\text { a } 2722 i, 43,62,79,85,123,141,148,202,272,288,352,366,410,480,579,762,787,858,960,1021,1052,1057,1076,1080,1105,1140, \\
1177,1194,1207,1280,1320,1336,1355,1371,1412,1439,1469,1476,1488,1500,2863,2864,2869,2901,2903,2946,2950,3602,3661, \\
3669 .\end{array}$ \\
\hline $\begin{array}{l}\text { Estrutura de transição para a } \\
\text { Reação } 5.3\end{array}$ & $\begin{array}{l}2943 i, 10,22,36,44,59,67,74,86,104,110,126,135,148,175,183,204,229,237,273,286,290,324,362,366,384,421,454,456,486, \\
575,582,766,786,824,837,853,883,941,982,1021,1026,1046,1058,1066,1070,1073,1079,1100,1102,1107,1137,1153,1176,1185, \\
1201,1203,1218,1232,1249,1270,1281,1310,1324,1351,1355,1361,1376,1387,1391,1414,1431,1435,1438,1465,1475,1482,1486, \\
1487,1490,1501,2834,2844,2867,2868,2876,2880,2880,2882,2911,2923,2924,2939,2941,2960,3645,3664,3671,3675\end{array}$ \\
\hline $\begin{array}{l}\text { Estrutura de transição para a } \\
\text { Reação } 5.7\end{array}$ & $\begin{array}{l}2891 \mathbf{i}, 24,38,54,81,89,124,131,148,179,190,275,338,363,383,403,411,424,462,544,553,604,849,852,882,930,1023,1038,1068, \\
1070,1078,1080,1094,1106,1111,1130,1181,1203,1229,1249,1272,1309,1354,1364,1378,1392,1412,1415,1434,1437,1479,1480, \\
1482,1486,2863,2865,2871,2895,2911,2918,2921,2933,3000,3622,3657,3663\end{array}$ \\
\hline
\end{tabular}

\footnotetext{
${ }^{a} i$ indica freqüência imaginária.
} 
Tabela 5.4 - Resultados para PEG: parâmetros termoquímicos obtidos com o modelo $\mathrm{HF} / 6-31 \mathrm{G}(\mathrm{d})$, corrigidos com o fator 0,9135 , para reagentes e produtos das reações de 5.1 a 5.8 e para as estruturas de transição encontradas.

\begin{tabular}{l|ccc}
\hline Espécies & ZPE ${ }^{\mathrm{a}}$ Hartrees) & Hcorr (Hartrees) & Gcorr (Hartrees) \\
\hline Dietilenoglicol & 0,1455 & 0,1553 & 0,1114 \\
\hline Radical alquila & 0,1316 & 0,1417 & 0,0963 \\
\hline Radical alquilperoxila & 0,1415 & 0,1533 & 0,1023 \\
\hline Hidroperóxido secundário & 0,1546 & 0,1664 & 0,1179 \\
\hline Radical alcoxila & 0,1372 & 0,1476 & 0,1014 \\
\hline Radical alquila primário & 0,0367 & 0,0410 & 0,0138 \\
\hline $\begin{array}{l}\text { Radical } \\
\text { primário }\end{array}$ & 0,04830 & 0,05387 & 0,0205 \\
\hline Hidroperoxido primário & 0,0603 & 0,0664 & 0,0329 \\
\hline Alcoxila primário & 0,0433 & 0,0478 & 0,0179 \\
\hline $\begin{array}{l}\text { Estrutura de transição para a } \\
\text { Reação 5.1 }\end{array}$ & 0,1510 & 0,1633 & 0,1122 \\
\hline $\begin{array}{l}\text { Estrutura de transição para a } \\
\text { Reação 5.3 }\end{array}$ & 0,2830 & 0,3045 & 0,2290 \\
\hline $\begin{array}{l}\text { Estrutura de transição para a } \\
\text { Reação 5.7 }\end{array}$ & 0,1906 & 0,2054 & 0,1475 \\
\hline $\begin{array}{l}\text { Radical Hidroxila } \\
\text { Água }\end{array}$ & 0,0083 & 0,0116 & $-0,0086$ \\
\hline \begin{tabular}{l} 
Oxigênio \\
\hline 1 Hartros
\end{tabular} & 0,0210 & 0,0248 & 0,0027 \\
\hline
\end{tabular}

a 1 Hartree é definido como a repulsão Coulômbica entre dois elétrons separados pela distância de 1 bohr.1 Hartree=627,51 kcal mol${ }^{-1}$. 
Tabela 5.5 - Resultados para PEG: energias eletrônicas, calculadas somando-se a energia single point, obtida com diferentes modelos químicos à energia do ponto zero corrigida com o fator 0,9135 , obtidas com o modelo $\mathrm{HF} / 6-31 \mathrm{G}(\mathrm{d})$, para reagentes e produtos das reações de 5.1 a 5.8 .

\begin{tabular}{|c|c|c|c|c|c|c|c|c|c|}
\hline \multirow[b]{2}{*}{$\begin{array}{l}\text { Nível de } \\
\text { Teoria }\end{array}$} & \multirow[b]{2}{*}{ Basis set } & \multicolumn{8}{|c|}{ Energia (Hartrees) } \\
\hline & & Dietilenoglicol & $\begin{array}{c}\text { Radical } \\
\text { alquila }\end{array}$ & $\begin{array}{c}\text { Radical } \\
\text { alquilperoxila }\end{array}$ & $\begin{array}{l}\text { Hidroperoxido } \\
\text { secundário }\end{array}$ & $\begin{array}{l}\text { Radical } \\
\text { alcoxila }\end{array}$ & $\begin{array}{c}\text { Radical } \\
\text { alquila } \\
\text { primário }\end{array}$ & $\begin{array}{c}\text { Radical } \\
\text { alquilperoxila } \\
\text { primário } \\
\end{array}$ & $\begin{array}{l}\text { Hidroperóxido } \\
\text { primário }\end{array}$ \\
\hline \multirow{4}{*}{ HF } & 6-31G(d) & $-381,6946$ & $-381,0797$ & $-530,7100$ & $-531,3049$ & $-455,9297$ & $-114,3720$ & $-264,0587$ & $-264,5928$ \\
\hline & 6-31G(d,p) & $-381,7201$ & $-381,1040$ & $-530,7339$ & $-531,3350$ & $-455,9533$ & $-114,3823$ & $-264,0684$ & $-264,6085$ \\
\hline & $6-31+G(d, p)$ & $-381,7339$ & $-381,1190$ & $-530,7504$ & $-531,3524$ & $-455,9689$ & $-114,3886$ & $-264,0677$ & $-264,6188$ \\
\hline & $6-311+\mathrm{G}(\mathrm{d}, \mathrm{p})$ & $-381,8213$ & $-381,2061$ & $-530,8777$ & $-531,4792$ & $-456,0764$ & $-114,4166$ & $-264,1351$ & $-264,6868$ \\
\hline \multirow{4}{*}{ B3LYP } & 6-31G(d) & $-383,9228$ & $-383,2732$ & $-533,6266$ & $-534,2599$ & $-458,4675$ & $-115,0144$ & $-265,3775$ & $-265,9950$ \\
\hline & 6-31G(d,p) & $-383,9449$ & $-383,2942$ & $-533,6475$ & $-534,2858$ & $-458,4884$ & $-115,0233$ & $-265,4341$ & $-266,0084$ \\
\hline & $6-31+G(d, p)$ & $-383,9697$ & $-383,3207$ & $-533,6677$ & $-534,3180$ & $-458,5172$ & $-115,0344$ & $-265,4434$ & $-266,0288$ \\
\hline & 6-311+G(d,p) & $-384,0643$ & $-383,4152$ & $-533,8125$ & $-534,4543$ & $-458,6326$ & $-115,0649$ & $-265,5133$ & $-266,1009$ \\
\hline \multirow[t]{2}{*}{ MP2 } & 6-31G(d,p) & $-382,8308$ & $-382,1822$ & $-532,1592$ & $-532,8035$ & $-457,1905$ & $-114,6869$ & $-264,6678$ & $-265,2953$ \\
\hline & $6-31+G(d, p)$ & $-382,8613$ & $-382,2141$ & $-532,1982$ & $-532,8458$ & $-457,2265$ & $-114,6987$ & $-264,6857$ & $-265,3187$ \\
\hline MP3 & $6-31+G(d, p)$ & $-382,9049$ & $-382,2566$ & $-532,2402$ & $-532,8853$ & $-457,2735$ & $-114,7131$ & $-264,6972$ & $-265,3322$ \\
\hline MP4 & $6-31+G(d, p)$ & $-382,9556$ & $-382,3070$ & $-532,3134$ & $-532,9667$ & $-457,3319$ & $-114,7267$ & $-264,7326$ & $-265,3649$ \\
\hline
\end{tabular}


Tabela 5.6 - Resultados para PEG: energias eletrônicas, calculadas somando-se a energia single point, obtida com diferentes modelos químicos à energia do ponto zero corrigida com o fator 0,9135 , obtida com o modelo $\mathrm{HF} / 6-31 \mathrm{G}(\mathrm{d})$, para reagentes e produtos das reações de 5.1 a 5.8 e para as estruturas de transição encontradas.

\begin{tabular}{|c|c|c|c|c|c|c|c|c|c|}
\hline \multirow[b]{2}{*}{$\begin{array}{l}\text { Nível de } \\
\text { Teoria }\end{array}$} & \multirow[b]{2}{*}{ Basis set } & \multicolumn{8}{|c|}{ Energia (Hartrees) } \\
\hline & & $\begin{array}{l}\text { Radical } \\
\text { alcoxila } \\
\text { primário } \\
\end{array}$ & $\begin{array}{l}\text { Etilenoglicol } \\
\text { monoformato }\end{array}$ & $\begin{array}{l}\text { Estrutura de } \\
\text { transição } \\
\text { Reação } 5.1 \\
\end{array}$ & $\begin{array}{l}\text { Estrutura de } \\
\text { transição } \\
\text { Reação } 5.3 \\
\end{array}$ & $\begin{array}{l}\text { Estrutura de } \\
\text { transição } \\
\text { Reação } 5.7 \\
\end{array}$ & $\begin{array}{c}\text { Radical } \\
\text { Hidroxila }\end{array}$ & Água & Oxigênio \\
\hline \multirow{4}{*}{ HF } & $6-31 G(d)$ & $-189,2393$ & $-341,5993$ & $-457,0294$ & $-912,3457$ & $-645,6553$ & $-75,3739$ & $-75,9897$ & $-149,5287$ \\
\hline & $6-31 G(d, p)$ & $-189,2489$ & $-341,5937$ & $-457,0641$ & $-912,3983$ & $-645,6934$ & $-75,3800$ & $-76,0026$ & $-149,5287$ \\
\hline & $6-31+G(d, p)$ & $-189,2565$ & $-341,6051$ & $-457,0835$ & $-912,4274$ & $-645,7149$ & $-75,3849$ & $-76,0101$ & $-149,5327$ \\
\hline & $6-311+G(d, p)$ & $-189,3044$ & $-341,6858$ & $-457,1922$ & $-912,6415$ & $-645,8686$ & $-75,4063$ & $-76,0322$ & $-149,5747$ \\
\hline \multirow{4}{*}{ B3LYP } & $6-31 G(d)$ & $-190,2259$ & $-343,4847$ & $-459,6503$ & $-917,5311$ & $-649,2903$ & $-75,7146$ & $-76,3871$ & $-150,2490$ \\
\hline & $6-31 G(d, p)$ & $-190,2342$ & $-343,4971$ & $-459,6808$ & $-917,5769$ & $-649,3234$ & $-75,7197$ & $-76,3981$ & $-150,2490$ \\
\hline & $6-31+G(d, p)$ & $-190,2500$ & $-343,5174$ & $-459,7166$ & $-917,6289$ & $-649,3618$ & $-75,7303$ & $-76,4115$ & $-150,2578$ \\
\hline & $6-311+G(d, p)$ & $-190,3011$ & $-343,6055$ & $-459,8342$ & $-917,8583$ & $-649,5267$ & $-75,7537$ & $-76,4370$ & $-150,3022$ \\
\hline \multirow{2}{*}{ MP2 } & $6-31 G(d, p)$ & $-189,7091$ & $-342,5388$ & $-458,3544$ & $-914,9721$ & $-647,4874$ & $-75,5236$ & $-76,1984$ & 149,8865 \\
\hline & $6-31+G(d, p)$ & $-189,7189$ & $-342,5636$ & $-458,3974$ & $-915,0443$ & $-647,5387$ & $-75,5325$ & $-76,2116$ & $-149,8915$ \\
\hline MP3 & $6-31+G(d, p)$ & $-189,7390$ & $-342,5837$ & b------------ & --------------- & --------------- & $-75,5440$ & $-76,2157$ & $-149,8855$ \\
\hline MP4 & $6-31+G(d, p)$ & $-189,7596$ & $-342,6349$ & --------------- & --------------- & --------------- & $-75,5483$ & $-76,2231$ & $-149,9094$ \\
\hline
\end{tabular}

\footnotetext{
${ }^{\mathrm{b}}$ Não foi possível realizar estes cálculos devido à insuficiência de espaço em disco e memória.
} 
Tabela 5.7 - Entalpias de reação para as reações 5.1 a 5.8.

\begin{tabular}{|c|c|c|c|c|c|c|c|c|c|}
\hline \multicolumn{2}{|c|}{ Modelo Químico } & \multicolumn{8}{|c|}{$\Delta \mathbf{H}_{\mathrm{r}}^{0}\left(\mathrm{kcal} \mathrm{mol}^{-1}\right)$} \\
\hline $\begin{array}{l}\text { Nível de } \\
\text { Teoria } \\
\end{array}$ & Basis set & Reação 5.1 & Reação 5.2 & Reação 5.3 & Reação 5.4 & Reação 5.5 & Reação 5.6 & Reação 5.7 & Reação 5.8 \\
\hline \multirow{4}{*}{ HF } & $6-31 G(d)$ & $-0,85$ & $-60,47$ & 12,23 & $-3,70$ & $-16,08$ & $-95,04$ & 19,74 & $-17,25$ \\
\hline & $6-31 \mathrm{G}(\mathrm{d}, \mathrm{p})$ & $-4,39$ & $-60,26$ & 9,13 & $-3,42$ & $-16,85$ & $-94,63$ & 16,62 & $-17,18$ \\
\hline & $6-31+\mathrm{G}(\mathrm{d}, \mathrm{p})$ & $-6,74$ & $-58,67$ & 7,79 & $-5,40$ & $-18,10$ & $-85,13$ & 15,18 & $-18,62$ \\
\hline & $6-311+\mathrm{G}(\mathrm{d}, \mathrm{p})$ & $-7,00$ & $-57,57$ & 8,30 & $-6,78$ & $-18,80$ & $-83,54$ & 15,28 & $-19,41$ \\
\hline \multirow{4}{*}{ B3LYP } & $6-31 G(d)$ & $-14,58$ & $-62,32$ & 10,00 & 44,37 & $-22,38$ & $-67,57$ & 19,57 & 29,78 \\
\hline & 6-31G(d,p) & $-17,66$ & $-62,20$ & 7,48 & 44,25 & $-22,60$ & $-97,49$ & 16,93 & 29,76 \\
\hline & $6-31+\mathrm{G}(\mathrm{d}, \mathrm{p})$ & $-20,48$ & $-58,89$ & 5,02 & 39,76 & $-24,21$ & $-90,85$ & 8,99 & 26,06 \\
\hline & $6-311+G(d, p)$ & $-21,70$ & $-56,48$ & 4,38 & 38,12 & $-26,21$ & $-87,69$ & 7,71 & 24,50 \\
\hline \multirow{2}{*}{ MP2 } & $6-31 G(d, p)$ & $-16,71$ & $-53,51$ & 2,40 & 51,58 & $-24,63$ & $-55,13$ & 12,56 & 34,93 \\
\hline & $6-31+G(d, p)$ & $-20,23$ & $-54,86$ & $-0,50$ & 49,96 & $-24,96$ & $-53,91$ & 9,85 & 37,81 \\
\hline MP3 & $6-31+\mathrm{G}(\mathrm{d}, \mathrm{p})$ & $-14,98$ & $-58,27$ & 1,73 & 38,07 & $-17,17$ & $-57,76$ & 11,22 & 26,48 \\
\hline MP4 & $6-31+\mathrm{G}(\mathrm{d}, \mathrm{p})$ & $-16,69$ & $-57,64$ & 3,04 & 43,50 & $-21,22$ & $-56,44$ & 13,08 & 31,33 \\
\hline
\end{tabular}


Tabela 5.8 - Energia livre de Gibbs de reação para as reações 5.1 a 5.8 .

\begin{tabular}{|c|c|c|c|c|c|c|c|c|c|}
\hline \multicolumn{2}{|c|}{ Modelo Químico } & \multicolumn{8}{|c|}{$\Delta G_{\mathrm{r}}^{0}\left(\mathrm{kcal} \mathrm{mol}^{-1}\right)$} \\
\hline $\begin{array}{l}\text { Nível de } \\
\text { Teoria } \\
\end{array}$ & Basis set & Reação 5.1 & Reação 5.2 & Reação 5.3 & Reação 5.4 & Reação 5.5 & Reação 5.6 & Reação 5.7 & Reação 5.8 \\
\hline \multirow{4}{*}{ HF } & $6-31 \mathrm{G}(\mathrm{d})$ & $-2,92$ & $-55,30$ & 12,88 & $-14,95$ & $-28,62$ & $-90,21$ & 18,73 & $-27,62$ \\
\hline & $6-31 \mathrm{G}(\mathrm{d}, \mathrm{p})$ & $-6,46$ & $-55,09$ & 9,78 & $-14,67$ & $-29,39$ & $-89,80$ & 15,61 & $-27,55$ \\
\hline & $6-31+\mathrm{G}(\mathrm{d}, \mathrm{p})$ & $-8,81$ & $-53,50$ & 8,44 & $-16,64$ & $-30,64$ & $-80,30$ & 14,16 & $-28,99$ \\
\hline & $6-311+G(d, p)$ & $-9,07$ & $-52,40$ & 8,95 & $-18,03$ & $-31,35$ & $-78,71$ & 14,26 & $-29,78$ \\
\hline \multirow{4}{*}{ B3LYP } & $6-31 \mathrm{G}(\mathrm{d})$ & $-16,65$ & $-57,15$ & 10,65 & 33,13 & $-34,92$ & $-62,74$ & 18,55 & 19,40 \\
\hline & 6-31G(d,p) & $-19,73$ & $-57,03$ & 8,13 & 33,00 & $-35,15$ & $-92,66$ & 15,92 & 19,39 \\
\hline & $6-31+G(d, p)$ & $-22,55$ & $-53,72$ & 5,67 & 28,51 & $-36,75$ & $-86,02$ & 7,98 & 15,68 \\
\hline & $6-311+G(d, p)$ & $-23,77$ & $-51,31$ & 5,03 & 26,87 & $-38,75$ & $-82,86$ & 6,69 & 14,13 \\
\hline \multirow{2}{*}{ MP2 } & $6-31 \mathrm{G}(\mathrm{d}, \mathrm{p})$ & $-18,78$ & $-48,34$ & 3,05 & 40,33 & $-37,17$ & $-50,30$ & 11,55 & 24,56 \\
\hline & $6-31+\mathrm{G}(\mathrm{d}, \mathrm{p})$ & $-22,30$ & $-49,69$ & 0,15 & 38,71 & $-37,50$ & $-49,08$ & 8,84 & 27,44 \\
\hline MP3 & $6-31+G(d, p)$ & $-17,05$ & $-53,10$ & 2,38 & 26,82 & $-29,71$ & $-52,93$ & 10,21 & 16,11 \\
\hline MP4 & $6-31+G(d, p)$ & $-18,76$ & $-52,47$ & 3,69 & 32,25 & $-33,76$ & $-51,61$ & 12,07 & 20,96 \\
\hline
\end{tabular}


Tabela 5.9 - Entropias de reação para as reações 5.1 a 5.8 , calculadas com HF/6-31Gd(p).

\begin{tabular}{c|c}
\hline Reação & $\Delta \mathbf{S}_{\mathbf{r}}^{\mathbf{0}}\left(\mathbf{c a l ~ m o l}^{-\mathbf{1}} \mathbf{K}^{\mathbf{- 1}}\right)$ \\
\hline $\mathbf{5 . 1}$ & 6,95 \\
$\mathbf{5 . 2}$ & $-17,34$ \\
$\mathbf{5 . 3}$ & $-2,18$ \\
$\mathbf{5 . 4}$ & 37,73 \\
$\mathbf{5 . 5}$ & 42,07 \\
$\mathbf{5 . 6}$ & $-16,20$ \\
$\mathbf{5 . 7}$ & 3,39 \\
$\mathbf{5 . 8}$ & 34,79 \\
\hline
\end{tabular}

Tabela 5.10 - Barreiras de ativação para as Reações 5.1, 5.3 e 5.7.

\begin{tabular}{|c|c|c|c|c|}
\hline \multicolumn{2}{|c|}{ Modelo Químico } & \multicolumn{3}{|c|}{ Barreira de Ativação $\left(\mathrm{kcal} \mathrm{mol}^{-1}\right)$} \\
\hline Nível de Teoria & Basis set & Reação 5.1 & Reação 5.3 & Reação 5.7 \\
\hline \multirow{4}{*}{ HF } & $6-31 G(d)$ & 24,54 & 36,98 & 31,14 \\
\hline & $6-31 G(d, p)$ & 22,54 & 34,93 & 29,33 \\
\hline & $6-31+G(d, p)$ & 22,18 & 35,67 & 30,23 \\
\hline & $6-311+G(d, p)$ & 22,25 & 36,11 & 31,22 \\
\hline \multirow{4}{*}{ B3LYP } & $6-31 G(d)$ & $-8,09$ & 11,54 & 6,34 \\
\hline & $6-31 G(d, p)$ & $-10,18$ & 9,71 & 4,59 \\
\hline & $6-31+G(d, p)$ & $-10,46$ & 11,47 & 1,90 \\
\hline & $6-311+G(d, p)$ & $-10,09$ & 11,66 & 1,70 \\
\hline \multirow{2}{*}{ MP2 } & $6-31 G(d, p)$ & $-0,02$ & 11,22 & 7,04 \\
\hline & $6-31+G(d, p)$ & $-2,22$ & 9,56 & 6,77 \\
\hline
\end{tabular}


Tabela 5.11 - Resultados para a Reação 5.1.

\begin{tabular}{l|l|cccc}
\hline \multicolumn{2}{c|}{} & \multicolumn{4}{c}{ Reação 5.1 -PEG } \\
\multicolumn{2}{c}{ Modelo Químico } & $\Delta^{\ddagger} \mathbf{S}^{\mathbf{0}}-27,39\left(\mathrm{cal} \mathrm{K}^{-1} \mathrm{~mol}^{-1}\right) ; \mathbf{A}$ & $1,74 \times 10^{7}$ & $\left(\mathrm{~L} \mathrm{~mol}^{-1} \mathrm{~s}^{-1}\right)$ \\
\hline $\begin{array}{l}\text { Nível de } \\
\text { Teoria }\end{array}$ & Basis set & $\Delta^{\ddagger} \mathbf{G}^{\mathbf{0}}$ & $\Delta^{\ddagger} \mathbf{H}^{\mathbf{0}}$ & $\mathbf{E a}$ & $\mathbf{k}$ \\
$\left(\mathrm{kcal} \mathrm{mol}^{-1}\right)$ & $\left(\mathrm{kcal} \mathrm{mol}^{-1}\right)$ & $\left(\mathrm{kcal} \mathrm{mol}^{-1}\right)$ & $\left(\mathrm{L} \mathrm{mol}^{-1} \mathrm{~s}^{-1}\right)$ \\
\hline \multirow{4}{*}{ HF } & $6-31 \mathrm{G}(\mathrm{d})$ & 30,42 & 22,26 & 22,85 & $3,10 \times 10^{-10}$ \\
& $6-31 \mathrm{G}(\mathrm{d}, \mathrm{p})$ & 28,41 & 20,25 & 20,84 & $9,21 \times 10^{-09}$ \\
& $6-31+\mathrm{G}(\mathrm{d}, \mathrm{p})$ & 28,06 & 19,89 & 20,48 & $1,68 \times 10^{-08}$ \\
& $6-311+\mathrm{G}(\mathrm{d}, \mathrm{p})$ & 28,12 & 19,96 & 20,55 & $1,50 \times 10^{-08}$ \\
\hline \multirow{4}{*}{ B3LYP } & $6-31 \mathrm{G}(\mathrm{d})$ & $-2,21$ & $-10,37$ & $-9,78$ & $2,58 \times 10^{+14}$ \\
& $6-31 \mathrm{G}(\mathrm{d}, \mathrm{p})$ & $-4,30$ & $-12,47$ & $-11,87$ & $8,84 \times 10^{+15}$ \\
& $6-31+\mathrm{G}(\mathrm{d}, \mathrm{p})$ & $-4,59$ & $-12,75$ & $-12,16$ & $1,43 \times 10^{+16}$ \\
& $6-311+\mathrm{G}(\mathrm{d}, \mathrm{p})$ & $-4,21$ & $-12,38$ & $-11,78$ & $7,58 \times 10^{+15}$ \\
\hline \multirow{3}{*}{ MP2 } & $6-31 \mathrm{G}(\mathrm{d}, \mathrm{p})$ & 5,85 & $-2,30$ & $-1,72$ & $3,14 \times 10^{+08}$ \\
& $6-31+\mathrm{G}(\mathrm{d}, \mathrm{p})$ & 3,65 & $-4,51$ & $-3,92$ & $1,30 \times 10^{+10}$ \\
\hline
\end{tabular}

Tabela 12 - Resultados para a Reação 5.3.

\begin{tabular}{|c|c|c|c|c|c|}
\hline \multicolumn{2}{|c|}{ Modelo Químico } & \multicolumn{4}{|c|}{$\begin{array}{c}\text { Reação 5.3 -PEG } \\
\Delta^{\dagger} \mathbf{S}^{\mathbf{0}}-40,87\left(\mathrm{cal} \mathrm{K}^{-1} \mathrm{~mol}^{-1}\right) ; \mathbf{A} 2,02 \times 10^{4}\left(\mathrm{~L} \mathrm{~mol}^{-1} \mathrm{~s}^{-1}\right)\end{array}$} \\
\hline $\begin{array}{l}\text { Nível de } \\
\text { Teoria }\end{array}$ & Basis set & $\begin{array}{c}\Delta^{\ddagger} \mathbf{G}^{\mathbf{0}} \\
\left(\mathrm{kcal} \mathrm{mol}{ }^{-1}\right)\end{array}$ & $\begin{array}{c}\Delta^{\dagger} \mathbf{H}^{\mathbf{0}} \\
\left(\mathrm{kcal} \mathrm{mol}{ }^{-1}\right)\end{array}$ & $\begin{array}{c}\text { Ea } \\
\left(\mathrm{kcal} \mathrm{mol}^{-1}\right) \\
\end{array}$ & $\begin{array}{c}\quad \mathbf{k} \\
\left(\mathrm{L} \mathrm{mol}^{-1} \mathrm{~s}^{-1}\right) \\
\end{array}$ \\
\hline \multirow{4}{*}{ HF } & $6-31 G(d)$ & 46,60 & 34,43 & 35,03 & $4,26 \times 10^{-22}$ \\
\hline & $6-31 G(d, p)$ & 44,56 & 32,39 & 32,98 & $1,34 \times 10^{-20}$ \\
\hline & $6-31+G(d, p)$ & 45,29 & 33,12 & 33,72 & $3,89 \times 10^{-21}$ \\
\hline & $6-311+G(d, p)$ & 45,73 & 33,56 & 34,15 & $1,86 \times 10^{-15}$ \\
\hline \multirow{4}{*}{ B3LYP } & $6-31 G(d)$ & 21,17 & 9,00 & 9,59 & $1,89 \times 10^{-03}$ \\
\hline & 6-31G(d,p) & 19,33 & 7,16 & 7,76 & $4,17 \times 10^{-02}$ \\
\hline & $6-31+\mathrm{G}(\mathrm{d}, \mathrm{p})$ & 21,10 & 8,93 & 9,51 & $2,12 \times 10^{-03}$ \\
\hline & $6-311+G(d, p)$ & 21,28 & 9,11 & 9,71 & $1,55 \times 10^{-03}$ \\
\hline \multirow{2}{*}{ MP2 } & 6-31G(d,p) & 20,84 & 8,67 & 9,27 & $1,55 \times 10^{-03}$ \\
\hline & $6-31 \mathrm{G}+(\mathrm{d}, \mathrm{p})$ & 19,18 & 7,01 & 7,60 & $5,40 \times 10^{-02}$ \\
\hline
\end{tabular}


Tabela 5.13- Resultados para a Reação 5.7.

\begin{tabular}{l|l|cccc}
\hline \multicolumn{2}{c|}{} & \multicolumn{4}{|c}{ Reação 5.7 -PEG } \\
\multicolumn{2}{c}{ Modelo Químico } & $\Delta^{\ddagger} \mathbf{S}^{\mathbf{0}}-40,89\left(\mathrm{cal} \mathrm{K}^{-1} \mathrm{~mol}^{-1}\right) ;$ A $1,95 \times 10^{4}$ & $\left(\mathrm{~L} \mathrm{~mol}^{-1} \mathrm{~s}^{-1}\right)$ \\
\hline $\begin{array}{l}\text { Nível de } \\
\text { Teoria }\end{array}$ & Basis set & $\Delta^{\ddagger} \mathbf{G}^{\mathbf{0}}$ & $\Delta^{*} \mathbf{H}^{\mathbf{0}}$ & $\mathbf{E a}$ & $\mathbf{k}$ \\
$\left(\mathrm{kcal} \mathrm{mol}^{-1}\right)$ & $\left(\mathrm{kcal} \mathrm{mol}^{-1}\right)$ & $\left(\mathrm{kcal} \mathrm{mol}^{-1}\right)$ & $\left(\mathrm{L} \mathrm{mol}^{-1} \mathrm{~s}^{-1}\right)$ \\
\hline \multirow{4}{*}{ HF } & $6-31 \mathrm{G}(\mathrm{d})$ & 40,95 & 28,76 & 29,36 & $5,89 \times 10^{-18}$ \\
& $6-31 \mathrm{G}(\mathrm{d}, \mathrm{p})$ & 39,14 & 26,95 & 27,55 & $1,25 \times 10^{-16}$ \\
& $6-31+\mathrm{G}(\mathrm{d}, \mathrm{p})$ & 40,04 & 27,85 & 28,44 & $2,74 \times 10^{-17}$ \\
& $6-311+\mathrm{G}(\mathrm{d}, \mathrm{p})$ & 41,03 & 28,84 & 29,43 & $5,21 \times 10^{-18}$ \\
\hline \multirow{4}{*}{ B3LYP } & $6-31 \mathrm{G}(\mathrm{d})$ & 16,15 & 3,96 & 4,56 & $8,93 \times 10^{+00}$ \\
& $6-31 \mathrm{G}(\mathrm{d}, \mathrm{p})$ & 14,40 & 2,21 & 2,80 & $1,73 \times 10^{+02}$ \\
& $6-31+\mathrm{G}(\mathrm{d}, \mathrm{p})$ & 11,71 & $-0,48$ & 0,11 & $1,62 \times 10^{+04}$ \\
& $6-311+\mathrm{G}(\mathrm{d}, \mathrm{p})$ & 11,51 & $-0,68$ & $-0,08$ & $2,25 \times 10^{+04}$ \\
\hline \multirow{3}{*}{ MP2 } & $6-31 \mathrm{G}(\mathrm{d}, \mathrm{p})$ & 16,85 & 4,66 & 5,26 & $2,74 \times 10^{+00}$ \\
& $6-31+\mathrm{G}(\mathrm{d}, \mathrm{p})$ & 16,58 & 4,39 & 4,98 & $4,34 \times 10^{+00}$ \\
\hline
\end{tabular}

\subsection{Discussões para Polietilenoglicol}

O efeito do solvente não foi considerado, pois estados de transição radicalmolécula e reações radicalares são normalmente pouco sensíveis à presença do solvente (Heuts e Gilbert, 1995).

As estruturas apresentadas foram otimizadas com o basis set 6-31G(d), que, segundo Foresmam e Frisch (1996), é o menor basis set que fornece resultados satisfatórios para cálculos de freqüência. O nível de teoria Hartree-Fock, apesar de não considerar o efeito da correlação eletrônica, foi empregado na otimização e na busca das estruturas de transição, pois requer menos tempo computacional. Foresmam e Frisch (1996), recomendam que, após o cálculo IRC, todas as moléculas participantes das reações, inclusive as estruturas de transição, sejam otimizadas utilizando-se modelos químicos mais precisos. Entretanto, apenas realizaram-se os cálculos de energia utilizando-se tais modelos em estruturas otimizadas com o nível de teoria mais simples $\mathrm{HF} / 6-31 \mathrm{G}(\mathrm{d})$. 
Além do problema do aumento do tempo computacional, o que torna inviáveis cálculos com modelos mais precisos, o aumento da estrutura molecular leva ao aumento do número de graus de liberdade devido ao maior número de rotações internas da molécula (Van Speybroeck et al., 2001). Nestes casos, muitas condições de mínimos locais existem na superfície de energia potencial e maior cuidado deve ser tomado na otimização de tais sistemas, por exemplo, empregando-se critérios de otimização mais rígidos, recomendados para moléculas flexíveis (floop). Estas rotações são caracterizadas por sua baixa freqüência e impactam diretamente no cálculo das constantes de reação, pois a Teoria do Estado de Transição (TST) supõe a aproximação do oscilador harmônico (Van Speybroeck et al. 2002). A Tabela 5.3 mostra os baixos valores de freqüências para as moléculas maiores, principalmente o radical aquilperoxila, com valores de até $11 \mathrm{~cm}^{-1}$.

A reação 5.1 tem como coordenada de reação a freqüência imaginária $2722 i$ $\mathrm{cm}^{-1}$ (Tabela 5.3), correspondente ao deslocamento do átomo de hidrogênio que está sendo abstraído, H12, em direção ao átomo de oxigênio do radical hidroxila, O19, Figura 5.10. Para as reações 5.3 e 5.7 as freqüências imaginárias $2943 i$ e $2892 i \mathrm{~cm}^{-1}$ correspondem ao deslocamento dos átomos de hidrogênio que estão sendo abstraídos em direção ao átomo de oxigênio dos respectivos radicais alquilperoxila, Figuras 5.11 e 5.12. Os cálculos IRC confirmaram que tais estruturas conectam reagentes e produtos das respectivas reações. As reações 5.2 e 5.6 não apresentam barreira de energia (Niiranen e Gutman, 1993), o que foi confirmado na busca da estrutura de transição. O emprego da mesma técnica para as demais reações, 5.4, 5.5 e 5.8, resultou em estruturas de transição cujas freqüências imaginárias correspondiam a movimentos de rotação e não à coordenada de reação que estava sendo seguida.

Os valores dos parâmetros termoquímicos: energia eletrônica no ponto zero (ZPE), correção térmica para a entalpia e correção térmica para a energia livre de Gibbs, mostrados na Tabela 5.4, obtidos com o modelo HF/6-31G(d), foram corrigidos com o fator 0,9135 , em um posterior cálculo de freqüência das estruturas otimizadas, com a opção freq=ReadIso. Este procedimento é recomendado por Foresmam e Frisch (1996), já que os valores de correção térmica apresentados pelo Gaussian já incluem automaticamente a energia no ponto zero. 
Os cálculos de energia com modelos mais precisos são mostrados nas Tabelas 5.5 e 5.6 e a Figura 5.13 apresenta o gráfico de energia para os diferentes níveis de teoria e basis set para o radical alquila. Os maiores valores de energia são para o nível de teoria Hartree-Fock, o que já era esperado, pois este método não considera os efeitos da correlação eletrônica. Para um mesmo nível de teoria o aumento do basis set provoca a diminuição da energia calculada. O método da Teoria do Funcional de Densidade, B3LYP, apresenta sempre os menores valores de energia, para todas as espécies, e a teoria de Möller-Plesset de segunda (MP2), terceira (MP3) e quarta ordem (MP4) apresentam valores intermediários decrescentes com o aumento da ordem do método e o aumento do basis set.

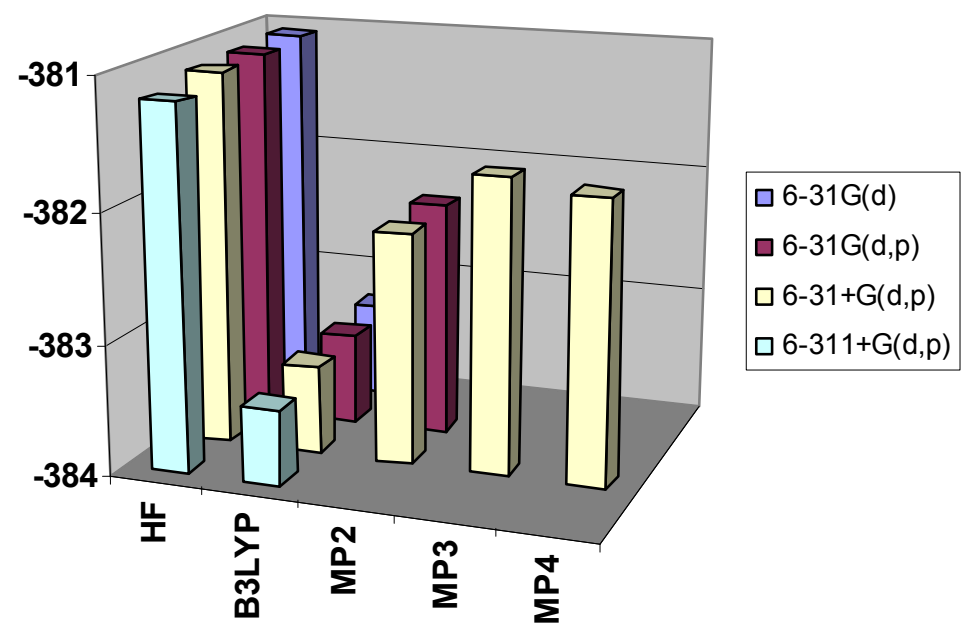

Figura 5.13 - Energias calculadas para o Radical Alquila com a estrutura otimizada com o modelo $\mathrm{HF} / 6-31 \mathrm{~g}(\mathrm{~d})$.

Os resultados dos cálculos das entalpias, energia livre de Gibbs e entropias de reação são apresentados nas Tabelas 5.7, 5.8 e 5.9. Nota-se a grande diferença entre os valores de entalpia e energia livre de Gibbs para as reações 5.4 e 5.8, em que os valores mudam de sinal quando se muda do método Hartree-Fock para o B3LYP. As reações 5.1, 5.2, 5.5 e 5.6 são exotérmicas e, como a reação 5.1 é rápida, de acordo com o postulado de Hamond (1955) sua estrutura de transição apresenta geometria mais próxima dos reagentes, o que é mostrado nas Figuras 5.2 e 5.10. As energias livres das reações cujas entalpias de reação são negativas também resultaram em 
valores negativos e as entropias de reação para as reações 5.2, 5.3 e 5.6 também são negativas para o modelo químico empregado. As reações 5.1 e 5.5 que apresentam $\Delta \mathrm{H}_{\mathrm{r}}^{0}<0, \Delta \mathrm{G}_{\mathrm{r}}^{0}<0$ e $\Delta \mathrm{S}_{\mathrm{r}}^{0}>0$ são favoráveis aos produtos, considerando o critério de espontaneidade a temperatura e pressão constantes. Pelo mesmo critério para a reação 5.3, esta é desfavorável aos produtos. Para verificar estes cálculos todas as estruturas foram otimizadas novamente com o modelo B3LYP/6-31g(d), com o critério opt=tight. Segundo Guner et al. (2003) o nível de teoria B3LYP fornece bons resultados para cálculos de geometrias, barreiras de reação e entalpias de reação. Após a otimização os parâmetros termoquímicos foram obtidos com um cálculo de freqüência escalonada com 1,0119 (Foresmam e Frisch, 1996). As tabelas 5.14 e 5.15 mostram os valores de entalpia e entropia de reação para as reações 5.1 a 5.8, com reagentes e produtos otimizados com este novo modelo. A tabela 5.16 compara os valores da entropia de ativação obtidos com HF/6-31G(d) e B3LYP/6-31G(d).

Tabela 5.14 - Entalpias de reação para as reações 5.1 a 5.8, para as estruturas otimizadas com B3LYP /6-31Gd(p).

\begin{tabular}{c|cccc|c}
\hline & \multicolumn{5}{|c}{$\Delta \mathbf{H}_{\mathbf{r}}^{\mathbf{0}}\left(\mathbf{k c a l ~ m o l}^{-1}\right)$} \\
\hline Reação & $\mathbf{B 3 L Y P}$ & $\mathbf{B 3 L Y P}$ & $\mathbf{B 3 L Y P}$ & $\mathbf{B 3 L Y P}$ & $\mathbf{M P 2}$ \\
& $\mathbf{6 - 3 1 G ( d )}$ & $\mathbf{6 - 3 1 G}(\mathbf{d}, \mathbf{p})$ & $\mathbf{6 - 3 1 + G ( d , p )}$ & $\mathbf{6 - 3 1 1 + G ( d , p )}$ & $\mathbf{6 - 3 1 G ( d , p )}$ \\
\hline $\mathbf{5 . 1}$ & $-12,72$ & $-15,75$ & $-19,09$ & $-19,76$ & $-14,23$ \\
$\mathbf{5 . 2}$ & $-65,87$ & $-65,55$ & $-61,43$ & $-59,91$ & $-61,43$ \\
$\mathbf{5 . 3}$ & 15,95 & 23,37 & 9,95 & 9,45 & 7,45 \\
$\mathbf{5 . 4}$ & 44,02 & 43,89 & 39,44 & 37,52 & 52,98 \\
$\mathbf{5 . 5}$ & $-20,12$ & $-20,41$ & $-22,19$ & $-23,68$ & $-24,06$ \\
$\mathbf{5 . 6}$ & $-67,97$ & $-67,50$ & $-65,63$ & $-63,84$ & $-54,24$ \\
$\mathbf{5 . 7}$ & 21,71 & 19,07 & 15,83 & 15,21 & 14,70 \\
$\mathbf{5 . 8}$ & 28,61 & 28,57 & 24,97 & 23,11 & 37,52 \\
\hline
\end{tabular}

Comparando-se os resultados mostrados nas Tabelas 5.7 e 5.14 para $\Delta \mathrm{H}_{\mathrm{r}}^{0}$ e 5.8 e 5.15 para $\Delta \mathrm{G}_{\mathrm{r}}^{0}$ observa-se que os maiores desvios ocorrem para as reações 5.1, 5.3 e 5.7. As diferenças na entropia de reação, mostradas na Tabela 5.16 para estas 
reações também foram as maiores, notadamente para a reação 5.3 para a qual há uma inversão de sinal.

Tabela 5.15 - Energia livre de Gibbs de reação para as reações 5.1 a 5.8, para as estruturas otimizadas com B3LYP /6-31Gd(p).

\begin{tabular}{c|cccc|c}
\hline & \multicolumn{5}{|c}{$\Delta_{\mathbf{r}}^{\mathbf{0}}\left(\mathbf{k c a l ~ m o l}^{-1}\right)$} \\
\hline Reação & $\mathbf{B 3 L Y P}$ & $\mathbf{B 3 L Y P}$ & $\mathbf{B 3 L Y P}$ & $\mathbf{B 3 L Y P}$ & $\mathbf{M P 2}$ \\
& $\mathbf{6 - 3 1 G ( d )}$ & $\mathbf{6 - 3 1 G}(\mathbf{d}, \mathbf{p})$ & $\mathbf{6 - 3 1 + G}(\mathbf{d}, \mathbf{p})$ & $\mathbf{6 - 3 1 1 + G ( d , p )}$ & $\mathbf{6 - 3 1 G ( d , p )}$ \\
\hline $\mathbf{5 . 1}$ & $-26,50$ & $-29,53$ & $-32,87$ & $-33,54$ & $-28,01$ \\
$\mathbf{5 . 2}$ & $-59,03$ & $-58,70$ & $-54,59$ & $-53,06$ & $-54,59$ \\
$\mathbf{5 . 3}$ & 3,56 & 0,97 & $-2,44$ & $-2,94$ & $-4,95$ \\
$\mathbf{5 . 4}$ & 32,39 & 32,25 & 27,81 & 25,88 & 41,34 \\
$\mathbf{5 . 5}$ & $-32,52$ & $-32,81$ & $-34,60$ & $-36,08$ & $-36,47$ \\
$\mathbf{5 . 6}$ & $-62,86$ & $-62,38$ & $-60,51$ & $-58,73$ & $-49,13$ \\
$\mathbf{5 . 7}$ & 8,65 & 6,00 & 2,77 & 2,15 & 1,64 \\
$\mathbf{5 . 8}$ & 18,02 & 17,97 & 14,38 & 12,52 & 26,93 \\
\hline
\end{tabular}

Tabela 5.16 - Entropias de reação para as reações 5.1 a 5.8, calculadas com HF/6-31Gd(p) e B3LYP/6-31G(d).

\begin{tabular}{c|c|c}
\hline & \multicolumn{2}{|c}{$\Delta \mathbf{S}_{\mathbf{r}}^{\mathbf{0}}\left(\mathbf{c a l ~ m o l}^{-1} \mathbf{K}^{\mathbf{- 1}}\right)$} \\
\hline Reação & HF/6-31G(d) & B3LYP/6-31G(d) \\
\hline $\mathbf{5 . 1}$ & 6,95 & 46,22 \\
$\mathbf{5 . 2}$ & $-17,34$ & $-22,95$ \\
$\mathbf{5 . 3}$ & $-2,18$ & 41,57 \\
$\mathbf{5 . 4}$ & 37,73 & 39,02 \\
$\mathbf{5 . 5}$ & 42,07 & 41,61 \\
$\mathbf{5 . 6}$ & $-16,20$ & $-17,15$ \\
$\mathbf{5 . 7}$ & 3,39 & 43,81 \\
$\mathbf{5 . 8}$ & 34,79 & 35,53 \\
\hline
\end{tabular}

Kang e Musgrave (2001), apresentam uma revisão bibliográfica de uma série de reações cujas barreiras de ativação foram calculadas por diferentes níveis de 
teoria, algumas apresentando valores variando de 5,8 a $-0,5$ e 15,8 a $-4,0 \mathrm{kcal} \mathrm{mol}^{-1}$, dependo do modelo empregado. Resultados com valores variando de $-30,7$ a 31,6 kcal mol${ }^{-1}$, dependendo do modelo, foram obtidos para a reação $\mathrm{O}+\mathrm{CH}_{2} \mathrm{OH}$ por Hou e Wang, (2005). Discrepâncias semelhantes podem ser observadas nos resultados apresentados na Tabela 5.10, para a barreira de ativação, calculada como a diferença de energia entre a estrutura de transição e os reagentes para as reações 5.1, 5.3 e 5.7. Para a reação 5.1, os valores negativos indicam que a energia da estrutura de transição é menor que a dos reagentes e, portanto a reação não tem barreira de energia para a abstração de hidrogênio do dietilenoglicol pelo radical hidroxila.

Os resultados dos cálculos cinéticos são apresentados nas Tabelas 5.11, 5.12 e 5.13 para as reações 5.1, 5.3 e 5.7, respectivamente. Reações de abstração de hidrogênio pelo radical hidroxila têm constante de reação da ordem de $10^{9} \mathrm{Lmol}^{-1} \mathrm{~s}^{-1}$ e energia de ativação entre 1 e $3 \mathrm{kcal} \mathrm{mol}^{-1}$, de acordo com uma revisão feita para algumas reações do radical hidroxila apresentada por Buxton et al. (1998). Na Tabela 5.11, para os resultados cinéticos da reação 5.1, os únicos valores dentro desse intervalo de referência são os das constantes de reação calculadas com os modelos MP2/6-31G(d,p)//HF/6-31G(d) e MP2/6-31+G(d,p)//HF/6-31G(d) com valores de $3,14 \times 10^{+08}$ e $1,30 \times 10^{+10} \mathrm{~L} \mathrm{~mol}^{-1} \mathrm{~s}^{-1}$, respectivamente. Os valores das energias de ativação obtidos com o método Hartree-Fock não são confiáveis, devido à não consideração do efeito da correlação eletrônica, que é um fator importante no cálculo das barreiras de energia, resultando em valores da constante de reação com desvios da ordem de $10^{18}$. Porém, o método Möller-Plesset não foi capaz de calcular energias para estrutura de transição da reação 5.1 com basis set maiores que o 6-31G(d,p) utilizando $1 \mathrm{~GB}$ de memória RAM $(\%$ mem $=1 G B)$ e 19 GB de espaço em disco ( maxdisk $=19 G B$ ), no cluster Beowulf descrito na Tabela 5.1. Como recomendado por Heuts et al. (1995) o cálculo de energia de ativação requer a utilização de modelos mais sofisticados, por exemplo QCISD(T)/6-311G(d,p), o que não é factível para moléculas maiores, como os sistemas estudados.

As reações 5.3 e 5.7 de abstração de hidrogênio da cadeia do dietilenoglicol pelos radicais alquilperoxila secundário e primário, respectivamente, são as etapas determinantes de todo o processo oxidativo estudado, mas não foram encontrados dados cinéticos na literatura para comparação com os valores calculados. Jellinek 
(1978), apresenta como resultado experimental valores desta reação para a metiletilcetona em solução aquosa a $60{ }^{\circ} \mathrm{C}: \mathrm{k}=0,39 \mathrm{~L} \mathrm{~mol}^{-1} \mathrm{~s}^{-1}, \mathrm{~A}=1,26 \times 10^{5} \mathrm{~L} \mathrm{~mol}^{-1}$ $\mathrm{s}^{-1}$, e Ea=8,4 $\mathrm{kcal} \mathrm{mol}^{-1}$. Infelizmente não é possível uma comparação com esses dados, a não ser uma comparação aproximada da ordem de grandeza do fator préexponencial e da energia de ativação para a reação 5.3.

Uma comparação importante entre as reações 5.3 e 5.7 é o aumento da constante de velocidade de reação aproximadamente 80 vezes para o nível MP2, para a reação 5.7 em relação a 5.3. Apesar deste efeito ser esperado, pois radicais alquilperoxila primários são mais reativos que os secundários, a falta de dados experimentais para comparação destes resultados deixa a desejar em termos de validação da metodologia proposta. 


\subsection{Reações para Poliacrilamida}

Com base no mecanismo proposto para a degradação oxidativa de polímeros, secção 2.2, e no trabalho de Lichtin (1971), foram propostos três caminhos para o mecanismo de oxidação de PAM, levando aos produtos detectados nas análises de HPLC (secção 4.3.2) e também citados na literatura como possíveis intermediários da degradação de PAM: oxamida, ácido oxâmico, ácido fórmico, formaldeído e acrilamida. Este mecanismo deve ser visto apenas como uma tentativa, a qual incorpora características essenciais do mecanismo de oxidação do PEG proposto por Mantzavinos et al. (1996).

\section{Caminho 1}

O caminho 1 começa com a abstração de hidrogênio na posição correspondente à estrutura (c) da Figura 2.2. As reações 5.9 a 5.12 mostram o processo de oxidação desde a abstração de hidrogênio até a formação do radical alcoxila.

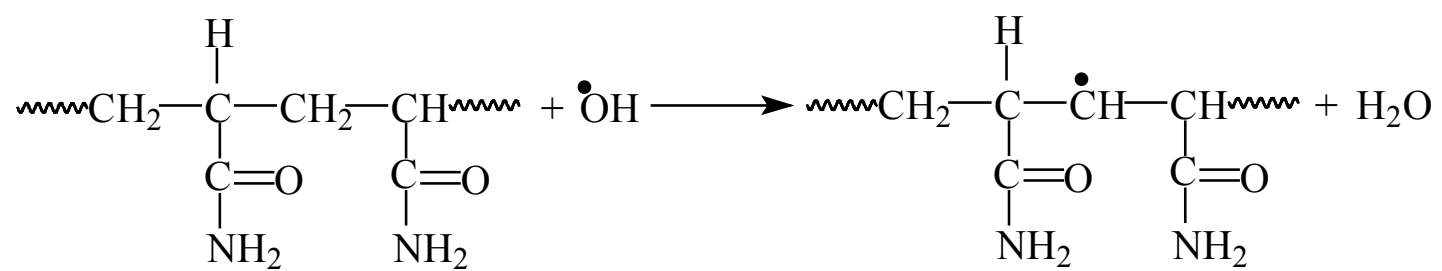<smiles>CCC(C(N)=O)[C@H](COCCCCC(C(N)=O)C([O])[C@H](C)C(N)=O)C(N)=O</smiles> 


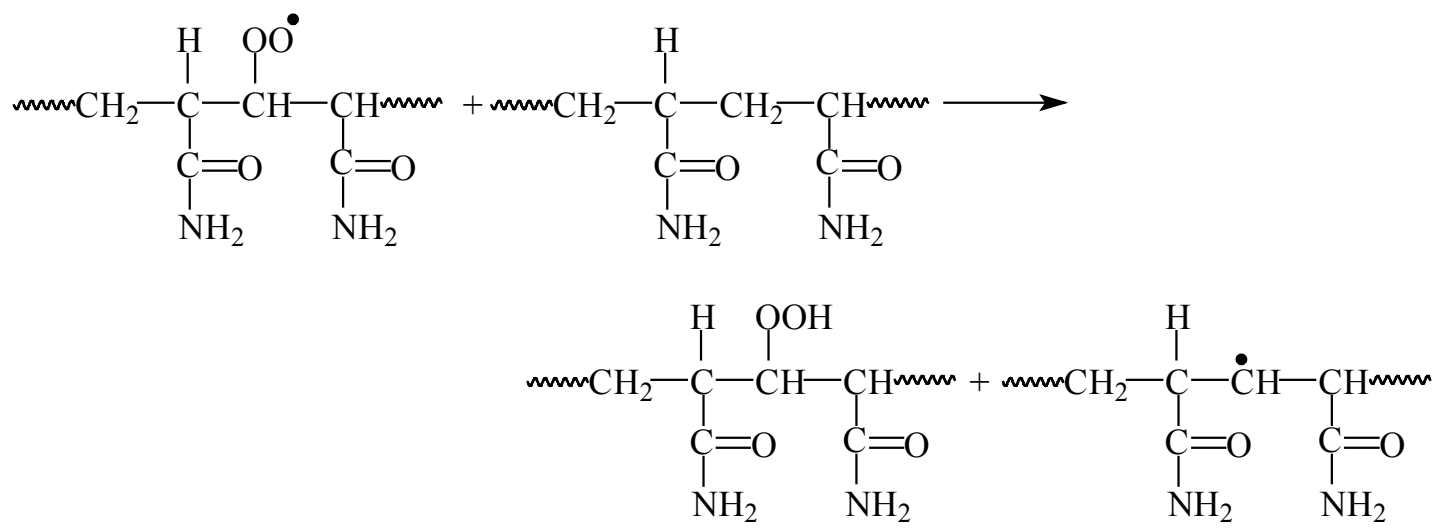<smiles>CCC(C(N)=O)C(OO)C(CCCCCC(O)C(O)C(N)=O)C(N)=O</smiles>

A cisão $\beta$ do radical alcoxila forma a espécie (A) e o macro-radical (B), de acordo com a reação 5.13 .<smiles>CCC(C(N)=O)C([O])[C@H](CCOC=CC(CCCC[CH]C(N)=O)C(N)=O)C(N)=O</smiles>

Supondo-se que haja sempre radicais hidroxila e oxigênio disponível, a espécie (A) pode sofrer nova abstração de hidrogênio, seguida da cadeia de reações do processo oxidativo, formando o radical alcoxila C (reação 5.14).<smiles>NC(=O)C(I)C(=O)C(C=O)C(O)C(O)C(C=O)C(N)=O</smiles>

(C) 
$\mathrm{O}$ radical alcoxila $\mathrm{C}$ pode sofrer cisão $\beta$ na posição 1 gerando novamente a espécie A e o radical D (reação 5.15), que sofre a seqüência de reações oxidativas formando o radical alcoxila $\mathrm{E}$ (reação 5.16).<smiles>C[C@@H](C=O)C(N)=O</smiles><smiles></smiles>

(E)

Para a cisão do radical E na posição 3 (reação 5.17) forma-se a 2-oxoacetamida, que posteriormente sofre oxidação formando ácido oxâmico (reação 5.18) e o radical formila $\mathrm{F}$.<smiles></smiles>

(E)<smiles></smiles>

$\mathrm{O}$ radical $\mathrm{F}$ pode reagir diretamente com o radical hidroxila ou abstrair hidrogênio de cadeias poliméricas, reação 5.19, formando aldeído fórmico que posteriormente se oxida formando ácido fórmico, reação 5.20. 


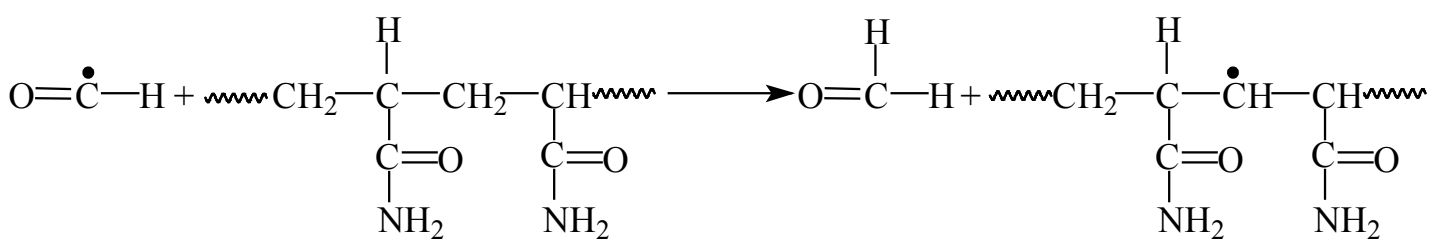<smiles></smiles>

Para a cisão do radical E na posição 4 (reação 5.21) formam-se etanodial, que posteriormente sofre oxidação formando ácido glioxílico e ácido oxálico (reações 5.22 e 5.23 ) e o radical G.

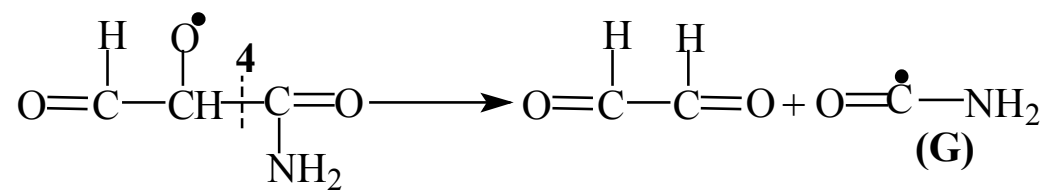

(E)<smiles></smiles><smiles></smiles>

A formação de oxamida é proposta pela reação de combinação de dois radicais $\mathrm{G}$ (reação 5.24) e também uma outra reação de formação de ácido oxâmico pela combinação dos radicais F e G (reação 5.25) com formação de 2-oxo acetamida e posterior oxidação de acordo com a reação 5.18 .<smiles></smiles><smiles></smiles> 
A cisão do radical alcoxila $C$, na posição 2 gera novamente B (reação 5.26), que sofre novamente a seqüência de reações oxidativas formando o radical alcoxila H (reação 5.27).<smiles></smiles>

(C)<smiles></smiles>

(H)

A cisão do radical alcoxila $H$ na posição 5, reação 5.28, forma o radical I que então levaria a uma reação de despolimerização com formação de acrilamida, reação 5.29, como proposto por Smith et al. (1997).<smiles>CC[C@H]1O[C@@H]1C(N)=O</smiles><smiles>C[C@@H]([CH][C@@H](C)/C=C/CC[C@H](CCC1CCCC1)C(N)=O)C(N)=O</smiles>

A quebra do radical alcoxila $H$ na posição 6 leva novamente à formação do radical G (reação 5.30). 
<smiles></smiles>

\section{Caminho 2}

A Figura 2.2 (d) mostra a posição relativa ao ataque dos radicais hidroxila para o caminho 2. As reações 5.31 a 5.35 mostram o processo de oxidação desde a abstração de hidrogênio até a formação do radical alcoxila J.<smiles></smiles><smiles>CC[C](CC(COCCCCC([O])(C[C@H](C)C(N)=O)C(N)=O)C(N)=O)C(N)=O</smiles><smiles>CCC(CCCCC(C)C(N)=O)CC([O])(CC)C(N)=O</smiles><smiles>CCC(O)(CC(CCCC([CH][C@@H](C)C(N)=O)C(N)=O)C(N)=O)C(N)=O</smiles><smiles>CCC(O)(C[C@H](CCCCC([O])(C[C@@H](C[Po+])C(N)=O)C(N)=O)C(N)=O)C(N)=O</smiles> 
$\mathrm{O}$ radical alcoxila $\mathrm{J}$ sofre cisão formando a espécie $\mathrm{K}$ e o radical $\mathrm{I}$ (reação 84), que sofre despolimerização, reação 5.29, formando acrilamida. A oxidação da espécie K forma o radical alcoxila L (reação 5.36) que quebra formando a espécie M e o radical N, reação 5.37 .<smiles>CC[C@@]([O])(CC(CCCCC(=O)C(N)=O)C(N)=O)C(N)=O</smiles>

(I)<smiles></smiles><smiles></smiles>

O radical N reage com o oxigênio formando o ácido oxâmico (reação 5.38).<smiles></smiles>

\section{Caminho 3}

O caminho 3 corresponde à abstração de um dos hidrogênios do nitrogênio do grupo amida, estrutura representada na Figura 2.2 (b). A reação 5.39 mostra o macroradical formado por esta abstração, mas não foi possível desenvolver um mecanismo a partir desta estrutura. 
<smiles>CCC(CC(CCCCCC(CC([18OH])C(N)=O)C(N)=O)C(N)=O)C(N)=O</smiles>

\subsection{Reações para Modelagem Molecular da Poliacrilamida}

A poliacrilamida também foi representada com 2 unidades monoméricas nas reações de oxidação. De todos os compostos propostos para representar o processo oxidativo de PAM, apenas a 2-metil pentanodiamida encontra-se registrada no Chemical Abstracts (14167-89-6). As reações foram propostas para os três caminhos possíveis de ataque do radical hidroxila e também como três opções para a reação de abstração de hidrogênio da 2-metil pentanodiamida pelo radical alquilperoxila, conforme ilustra a Figura 5.14.

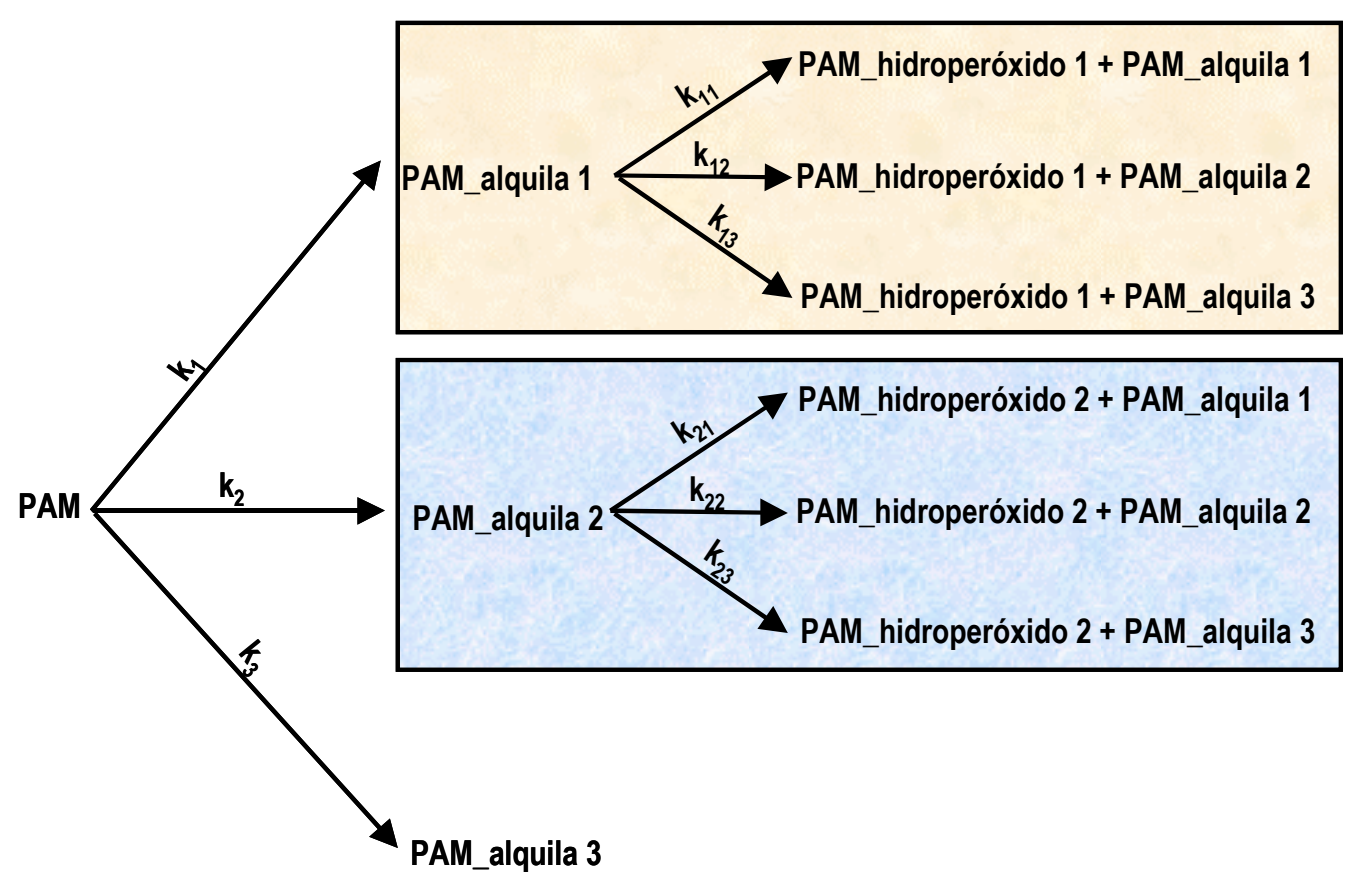

Figura 5.14 - Possíveis caminhos de reação para a poliacrilamida, considerando três locais para abstração de hidrogênio. 


\section{Caminho 1}

- Abstração de hidrogênio da 2-metil pentanodiamida pelo radical hidroxila e formação do radical PAM_alquila1.

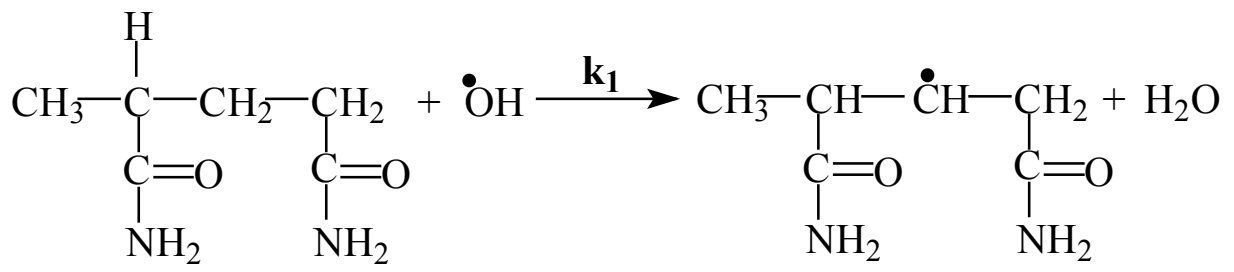

- Reação do radical PAM_alquila1 com o oxigênio formando o radical PAM_alquilperoxila1.

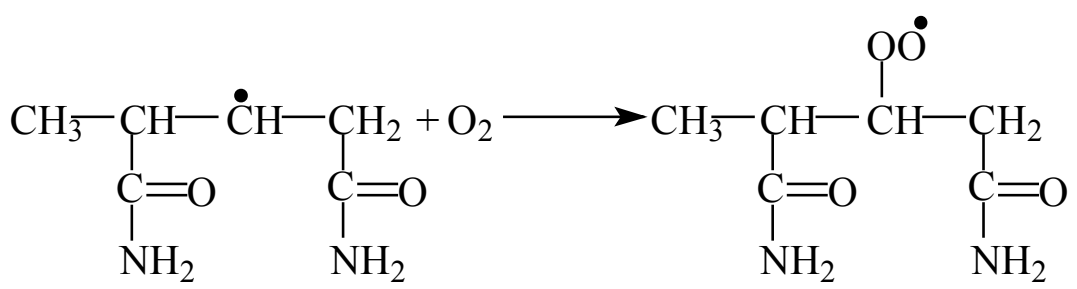

- Reação dos radicais PAM_alquilperoxila1 com a 2-metil pentanodiamida formando o PAM_hidroperóxido1 e os radicais PAM_alquila1 (reação 5.42), PAM_alquila2 (reação 5.43) e PAM_alquila3 (reação 5.44).<smiles>CC([CH+]CC(N)=O)CCC(N)=O</smiles> 
<smiles>CC(CCC(N)=O)C(O)C(O)C(C)C(N)=O</smiles><smiles>CCCCC(C)C(N)=O</smiles><smiles>CC(CCC(N)=O)C(N)=O</smiles>

As reações 5.40, 5.41, 5.42, 5.43 e 5.44 serão designadas de Reações 1, 2, 3_1, 3_2 e 3_3 do Caminho1. A estrutura de transição da Reação 1 do Caminho 1 receberá o código: PAM1_Reação1_TS e da Reação 3: PAM1_Reação3_1_TS, PAM1_Reação3_2_TS e PAM1_Reação3_3_TS.

\section{Caminho 2}

- Abstração de hidrogênio da 2-metil pentanodiamida pelo radical hidroxila e formação do radical PAM_alquila2. 
<smiles>CC(CCC(N)=O)C(N)=O</smiles>

- Reação do radical PAM_alquila2 com o oxigênio formando o radical PAM_alquilperoxila2.<smiles>C[C](CCC(N)=O)CO[C@H]([O])[C@]([O])(CCC(N)=O)C(N)=O</smiles>

- Reação dos radicais PAM_alquilperoxila2 com a 2-metil pentanodiamida formando o PAM_hidroperóxido2 e os radicais PAM_alquila1 (reação 5.47), PAM_alquila2 (reação 5.48) e PAM_alquila3 (reação 5.49).<smiles>CCCCC(C)C(N)=O</smiles><smiles>CC([CH+]CC(N)=O)C(N)=O</smiles> 
<smiles>C[C@H](CCC(N)=O)C(N)=O</smiles><smiles>CC(CCC(N)=O)C(N)=O</smiles><smiles>CCCCC(C)C(N)=O</smiles><smiles>CC(CCC(N)=O)C(N)=O</smiles>

As reações 5.45, 5.46, 5.47, 5.48 e 5.49 serão designadas de Reações 1, 2, 3_1, 3_2 e 3_3 do Caminho2. A estrutura de transição da Reação 1 do Caminho 2 receberá o código: PAM2_Reação1_TS e da Reação 3: PAM2_Reação3_1_TS, PAM2_Reação3_2_TS e PAM2_Reação3_3_TS.

\section{Caminho 3}

- Abstração de hidrogênio da 2-metil pentanodiamida pelo radical hidroxila e formação do radical PAM_alquila3. Esta será a Reação 1 do Caminho3, cuja estrutura de transição será denominada de PAM3_Reação1_TS. 
<smiles>CC(CCC(N)=O)C(N)=O</smiles>

\section{Formação de Acrilamida}

A reação 5.29 de formação de acrilamida, também foi proposta por Smith et al. (1997). O radical alquila foi representado por uma estrutura com quatro unidades monoméricas, conforme mostrado na reação 5.51 .<smiles>[CH]C(C=C(N)C(N)=O)CC(CC(CCC(N)=O)C(N)=O)C(N)=O</smiles>

\subsection{Resultados para Poliacrilamida}

Como no caso do PEG os cálculos para todas as espécies radicalares e para o oxigênio foram realizados com a opção unrestricted (U) e para as demais espécies: 2metil pentanodiamida, PAM_hidroperóxido 1 e 2 e água, utilizou-se a opção restricted $(\mathrm{R})$.

Os resultados obtidos para as reações 5.40 a 5.51 são apresentados da mesma forma que os do PEG na seção 5.3:

- Estruturas otimizadas com $o p t=t i g h t$ são apresentadas nas Figuras 5.15 a 5.33 e as matrizes $\mathbf{Z}$ correspondentes no Apêndice $\mathbf{C}$ nas Tabelas $\mathrm{C} 1$ a $\mathrm{C} 19$, respectivamente.

- Freqüências vibracionais corrigidas: Tabela 5.17, 5.18 e 5.19. 
- Os parâmetros termoquímicos: energia no ponto zero (ZPE), correção térmica da entalpia $\left(\mathrm{H}_{\text {corr }}\right)$ e correção térmica da energia livre de Gibbs $\left(\mathrm{G}_{\text {corr }}\right)$ : Tabela 5.20 .

- Energias eletrônicas: Tabelas 5.21 e 5.22 para as reações 5.40 a 5.50 e Tabela 5.25 para a reação 5.51 .

- Entalpia; energia livre de reação e entropia de reação, $\Delta \mathrm{H}_{\mathrm{r}}^{0}, \Delta \mathrm{G}_{\mathrm{r}}^{0}, \Delta \mathrm{S}_{\mathrm{r}}^{0}$, são apresentadas nas Tabelas 5.23, 5.24 e 5.26, respectivamente, para as reações 5.40 a 5.50

- Barreiras de ativação para as reações 5.40, 5.42, 5.43, 5.45, 5.47, 5.48 e 5,50, são apresentadas na Tabela 5.27.

- Energias $\left(\mathbf{E}_{\mathbf{a}}\right)$, entalpia $\left(\Delta^{\ddagger} \mathrm{H}^{0}\right)$, entropia $\left(\Delta^{\ddagger} \mathrm{S}^{0}\right)$ e energia livre de Gibbs $\left(\Delta^{\ddagger} \mathrm{G}^{0}\right)$ de ativação, fator de freqüência (A) e constante de velocidade de reação (k) são apresentadas nas Tabelas 5.28 a 5.34 para as reações 5.40, $5.42,5.43,5.45,5.47,5.48$ e 5,50 .

- Os seguintes resultados para a reação 5.51 de formação da acrilamida são apresentados na Tabela 5.35: entalpia; energia livre de reação e entropia de reação, $\Delta \mathrm{H}_{\mathrm{r}}^{0}, \Delta \mathrm{G}_{\mathrm{r}}^{0}, \Delta \mathrm{S}_{\mathrm{r}}^{0}$; energias $\left(\mathbf{E}_{\mathbf{a}}\right)$, entalpia $\left(\Delta^{\star} \mathrm{H}^{0}\right)$, entropia $\left(\Delta^{\dagger} \mathrm{S}^{0}\right) \mathrm{e}$ energia livre de Gibbs $\left(\Delta^{\dagger} \mathrm{G}^{0}\right)$ de ativação; fator de freqüência (A) e constante de velocidade de reação $(\mathbf{k})$. 


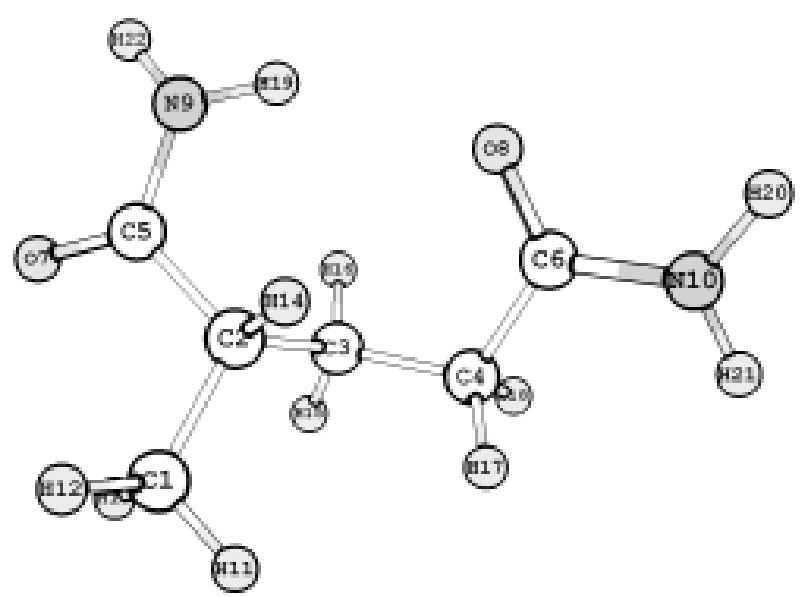

Figura 5.15 - Geometria do 2-metil pentanodiamida otimizada com o modelo químico $\mathrm{HF} / 6-31 \mathrm{G}(\mathrm{d})$.

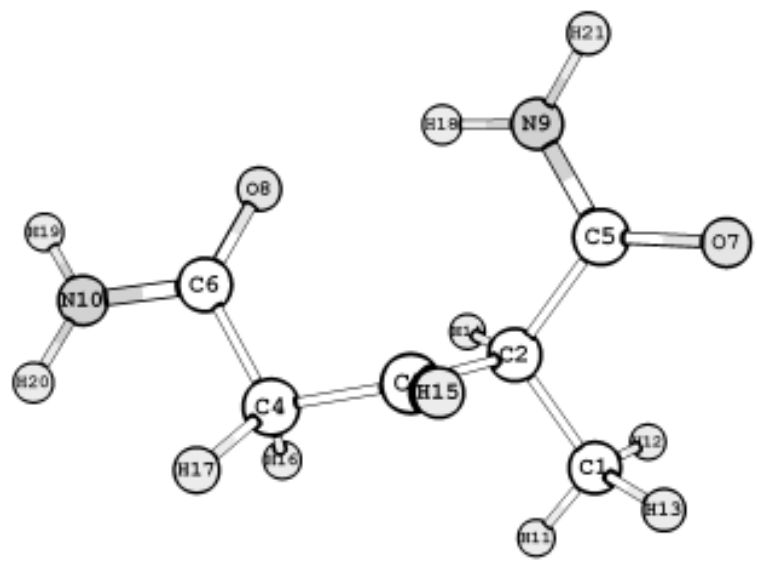

Figura 5.16 - Geometria do radical PAM_alquila1 otimizada com o modelo químico $\mathrm{HF} / 6-31 \mathrm{G}(\mathrm{d})$.

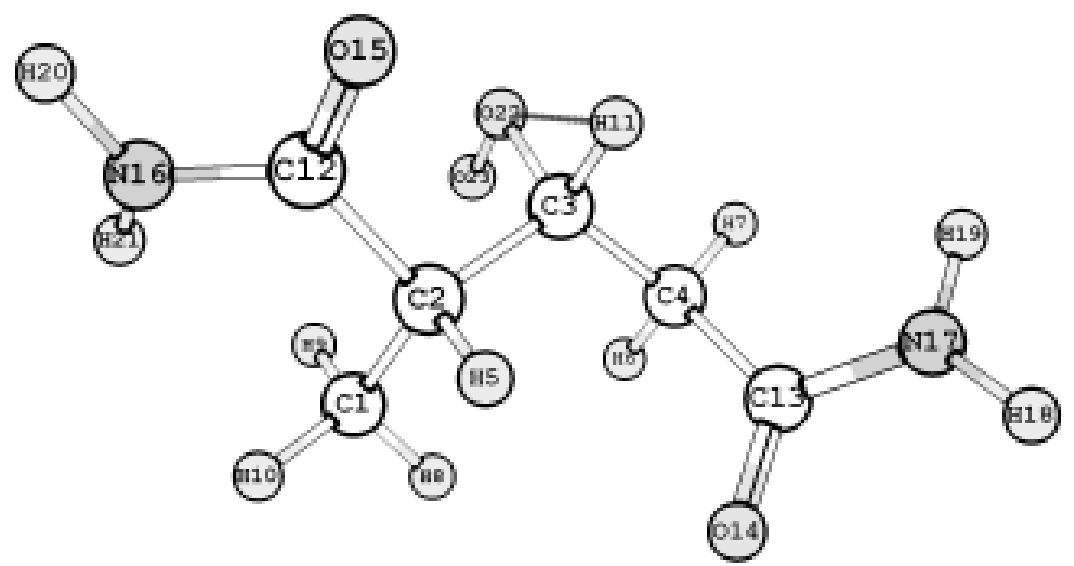

Figura 5.17 - Geometria do radical PAM_alquilperoxila1 otimizada com o modelo químico $\mathrm{HF} / 6-31 \mathrm{G}(\mathrm{d})$. 
(193)

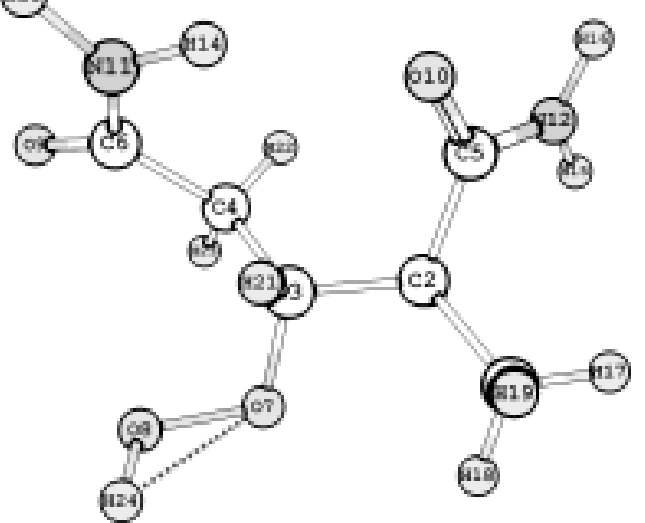

Figura 5.18 - Geometria do PAM_hidroperoxido1 secundário otimizada com o modelo químico $\mathrm{HF} / 6-31 \mathrm{G}(\mathrm{d})$.

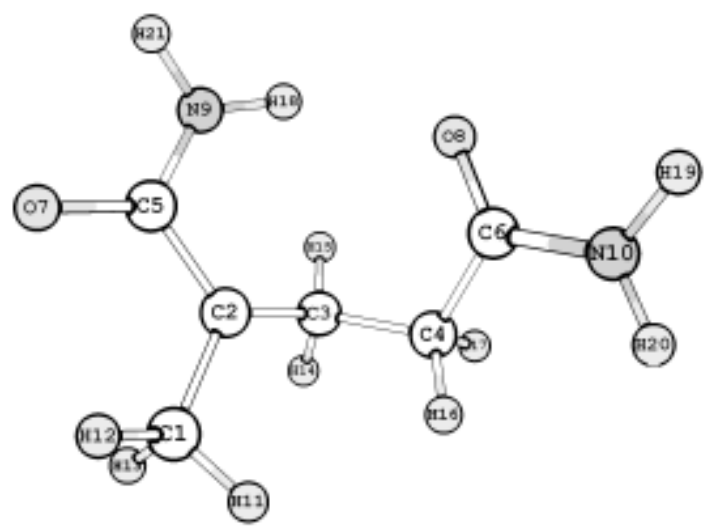

Figura 5.19 - Geometria do radical PAM_alquila2 otimizada com o modelo químico $\mathrm{HF} / 6-31 \mathrm{G}(\mathrm{d})$.

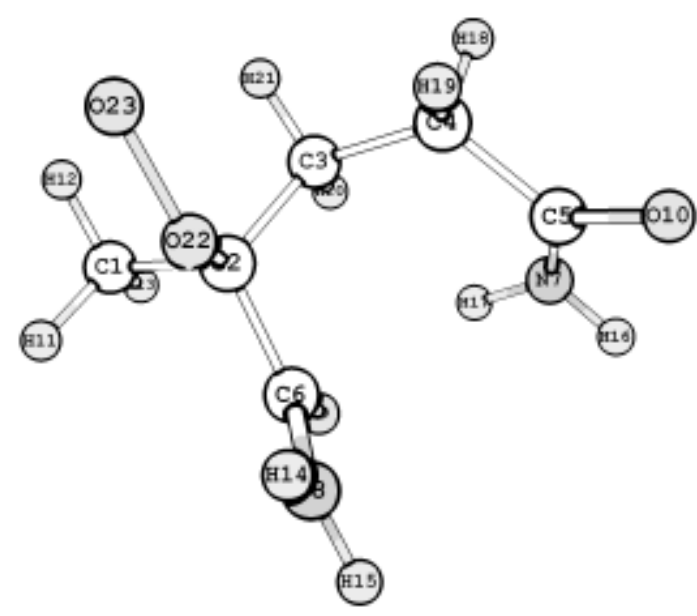

Figura 5.20 - Geometria do radical PAM_alquilperoxila2 otimizada com o modelo químico $\mathrm{HF} / 6-31 \mathrm{G}(\mathrm{d})$. 


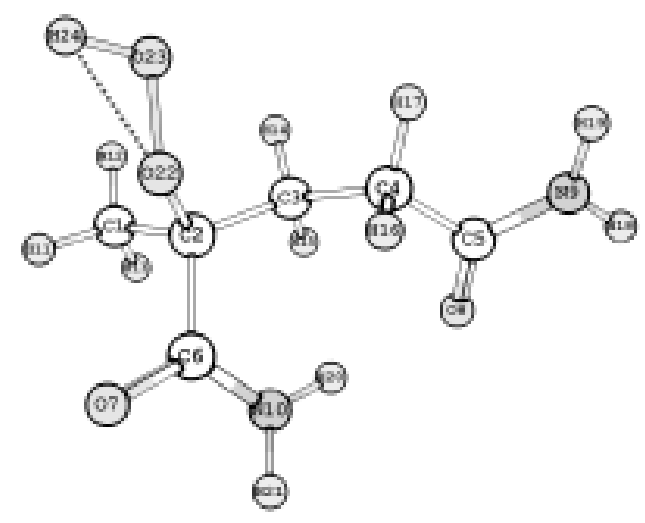

Figura 5.21 - Geometria do PAM_hidroperoxido2 secundário otimizada com o modelo químico $\mathrm{HF} / 6-31 \mathrm{G}(\mathrm{d})$.

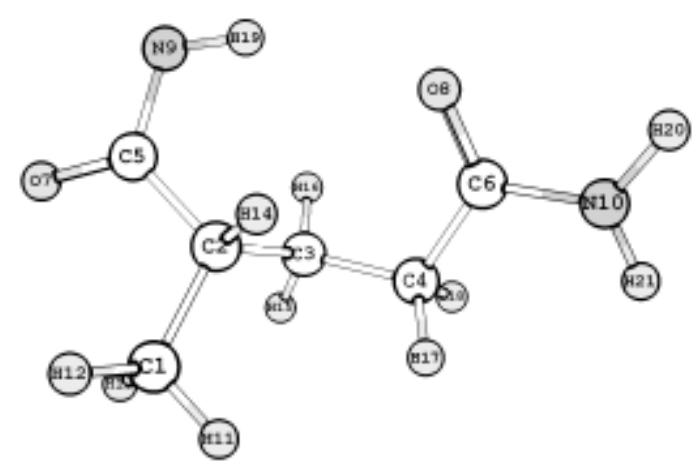

Figura 5.22 - Geometria do radical PAM_alquila3 otimizada com o modelo químico $\mathrm{HF} / 6-\overline{3} 1 \mathrm{G}(\mathrm{d})$.

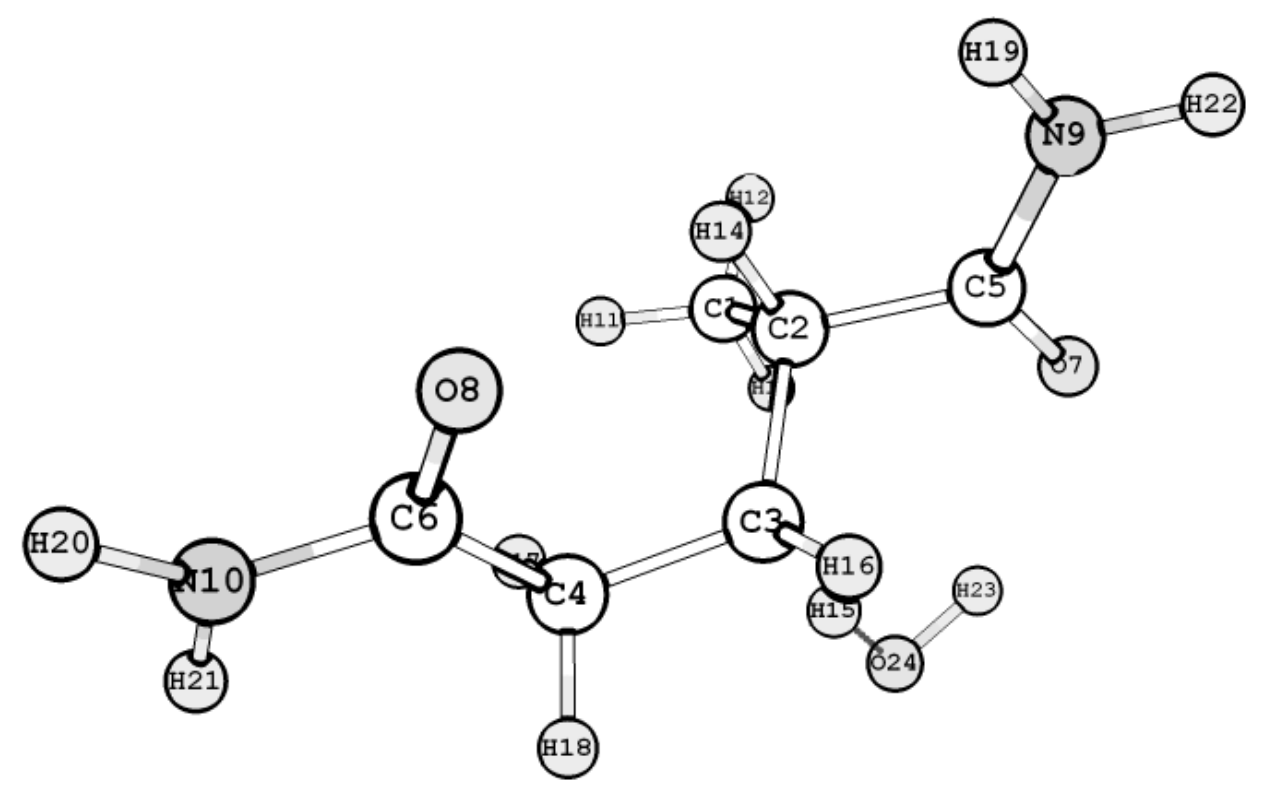

Figura 5.23 - Geometria da estrutura de transição para a reação 1 caminho1, PAM1_Reação1_TS, otimizada com o modelo químico HF/6-31G(d). 


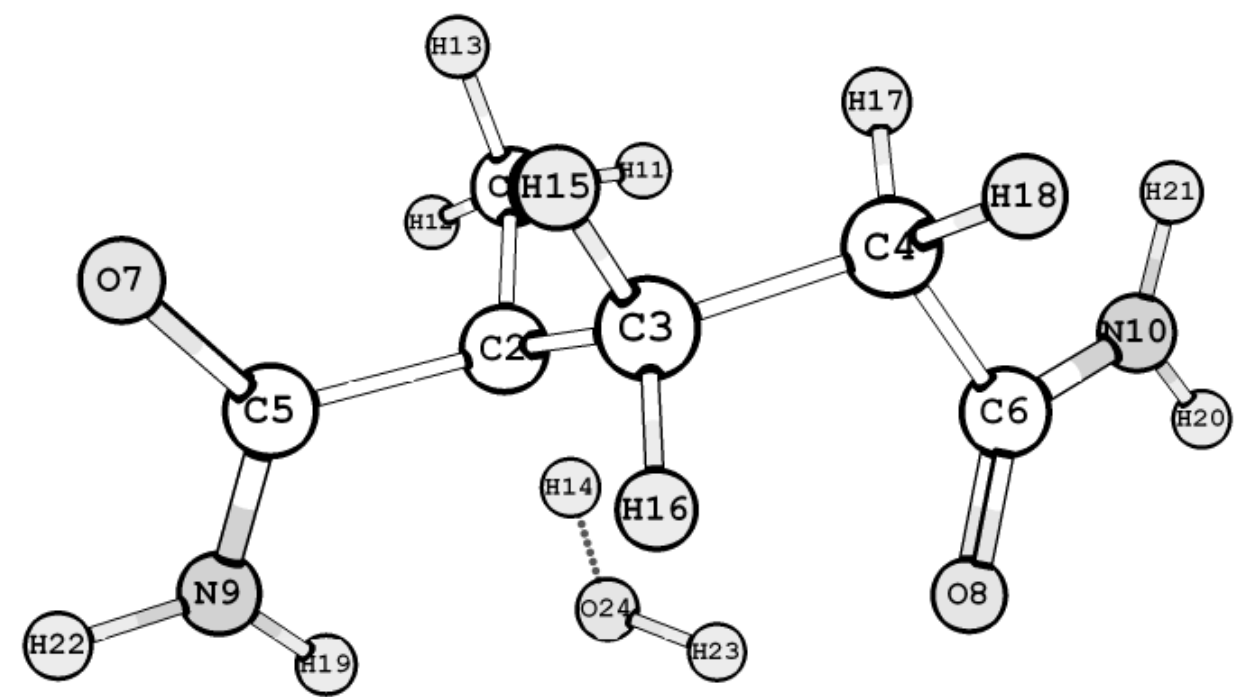

Figura 5.24 - Geometria da estrutura de transição da reação1 caminho2, PAM2_Reação1_TS, otimizada com o modelo químico HF/6-31G(d).

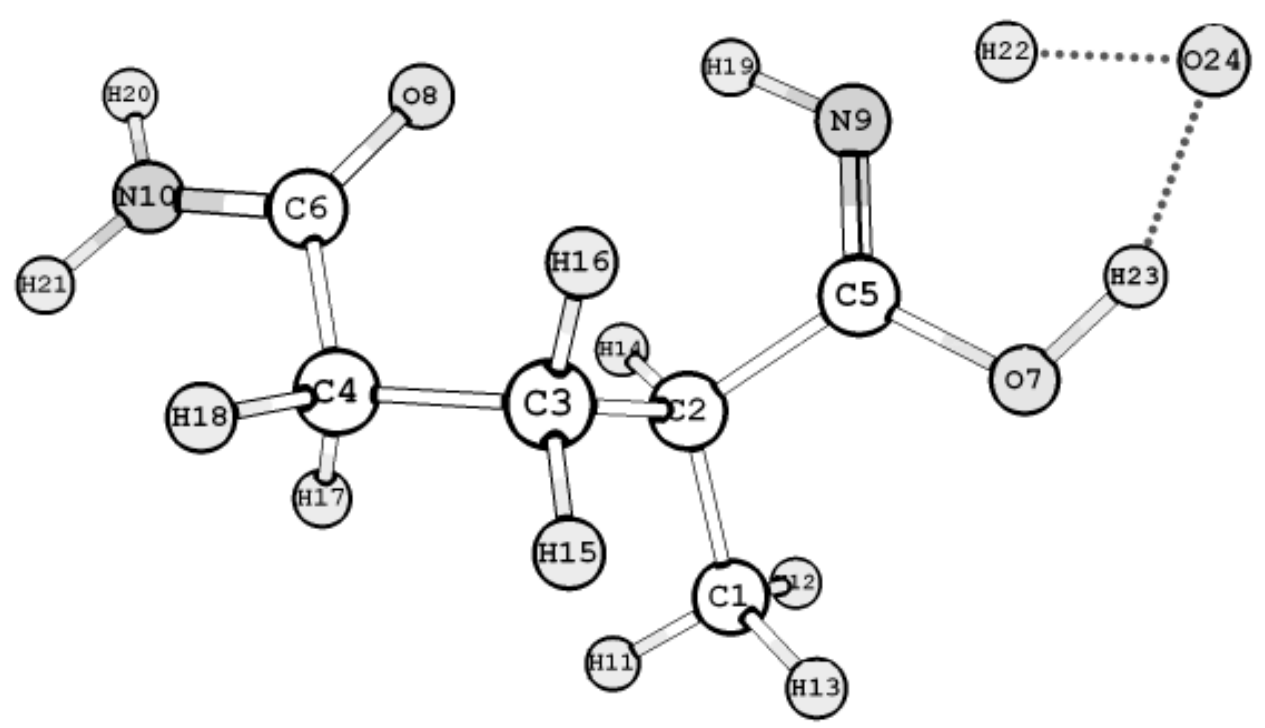

Figura 5.25 - Geometria da estrutura de transição da reação1 caminho3, PAM3_Reação1_TS, otimizada com o modelo químico HF/6-31G(d). 


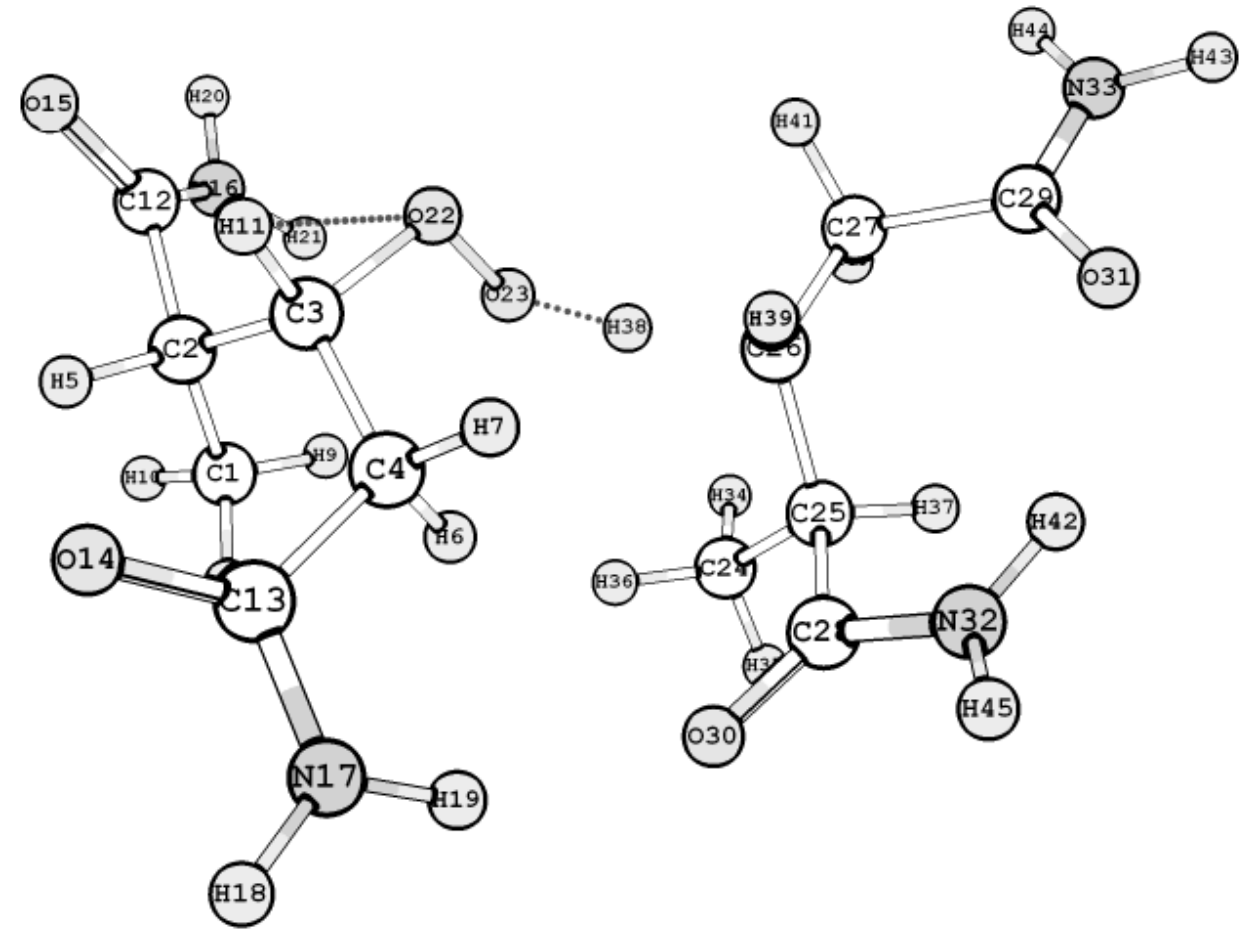

Figura 5.26 - Geometria da estrutura de transição da reação3 caminho1, PAM1_Reação3_1_TS, otimizada com o modelo químico HF/6-31G(d).
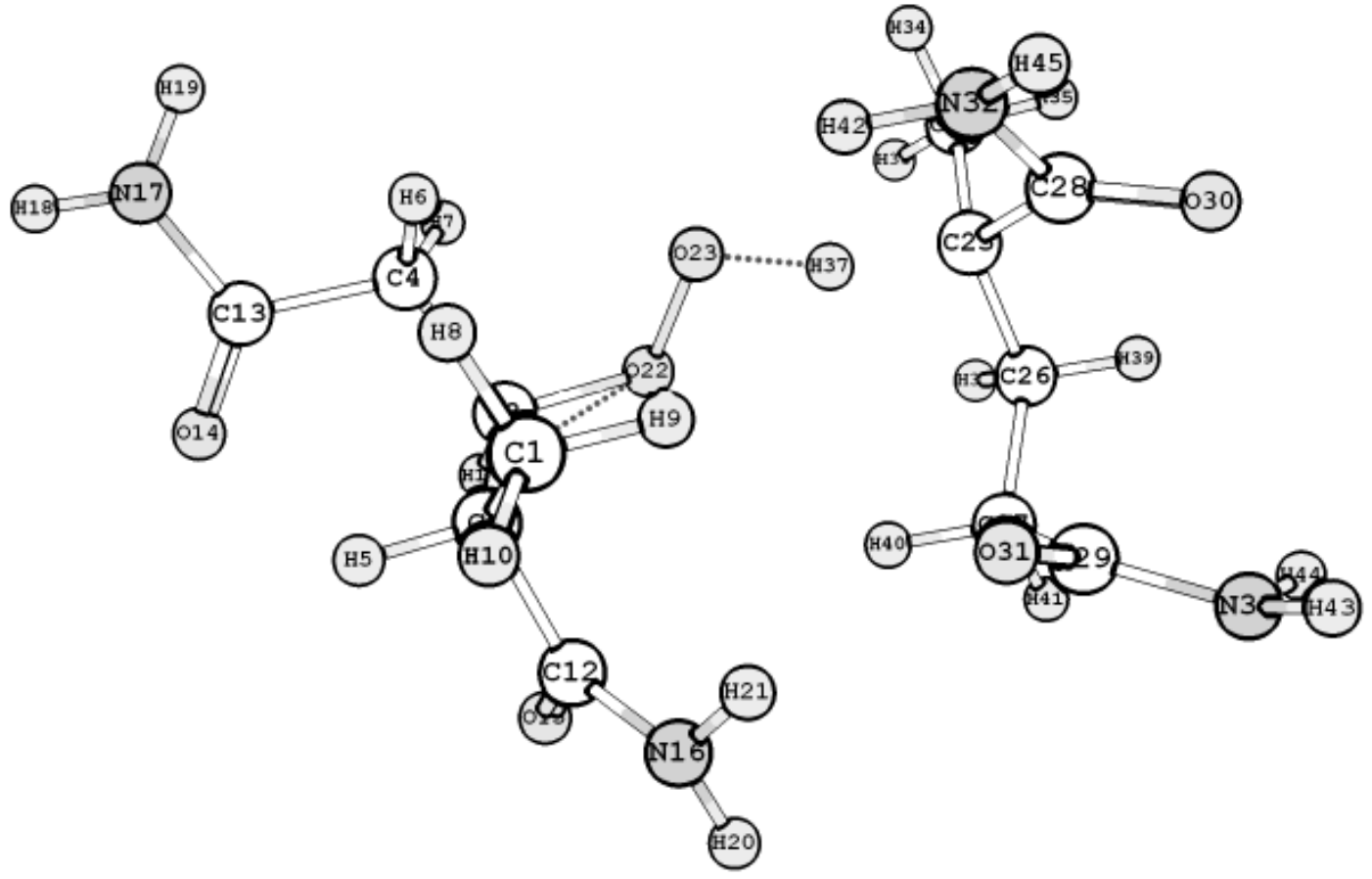

Figura 5.27 - Geometria da estrutura de transição da reação3 caminho1, PAM1_Reação3_2_TS, otimizada com o modelo químico HF/6-31G(d). 


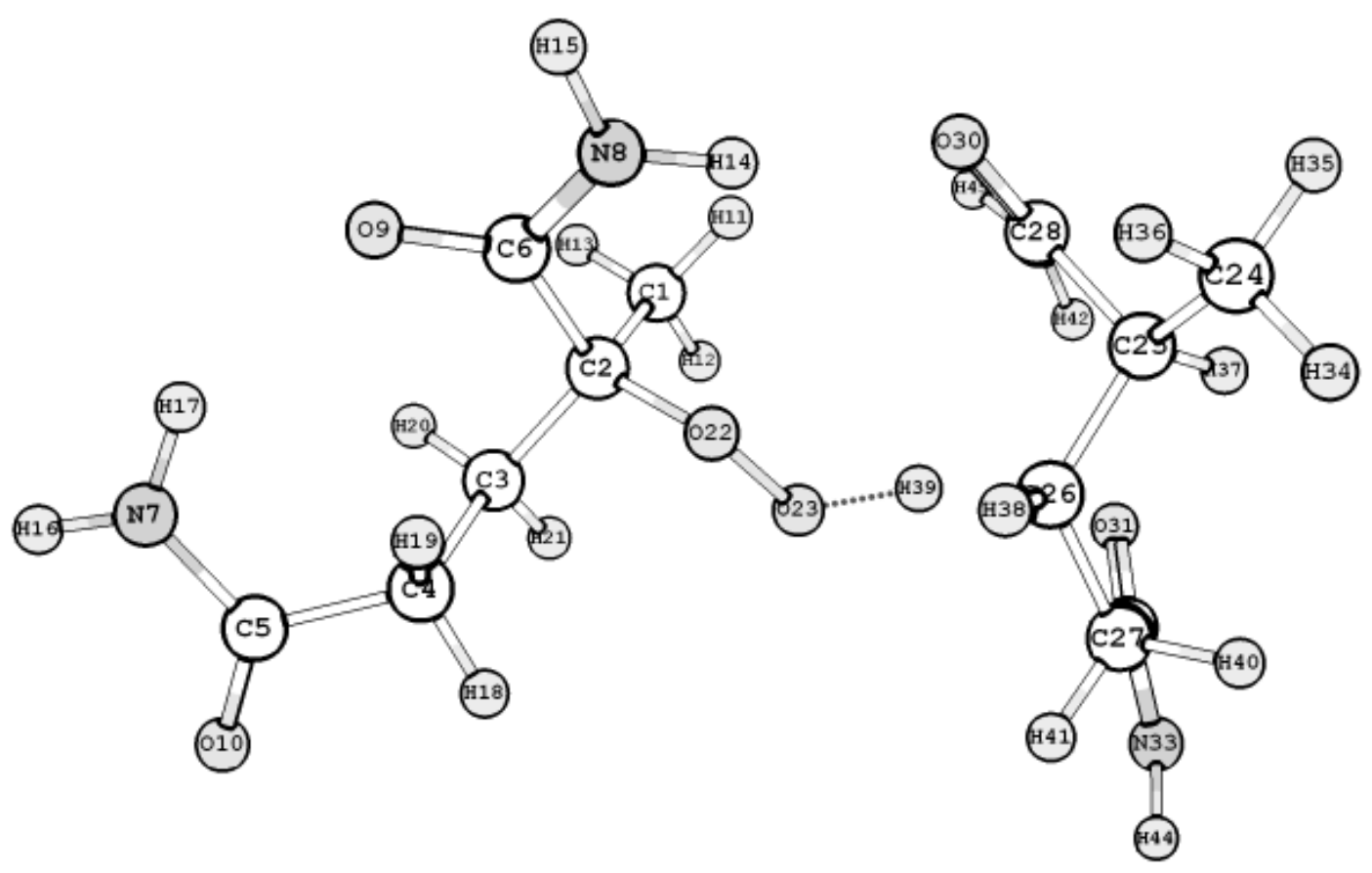

Figura 5.28 - Geometria da estrutura de transição da reação3 caminho2, PAM2_Reação3_1_TS, otimizada com o modelo químico HF/6-31G(d).

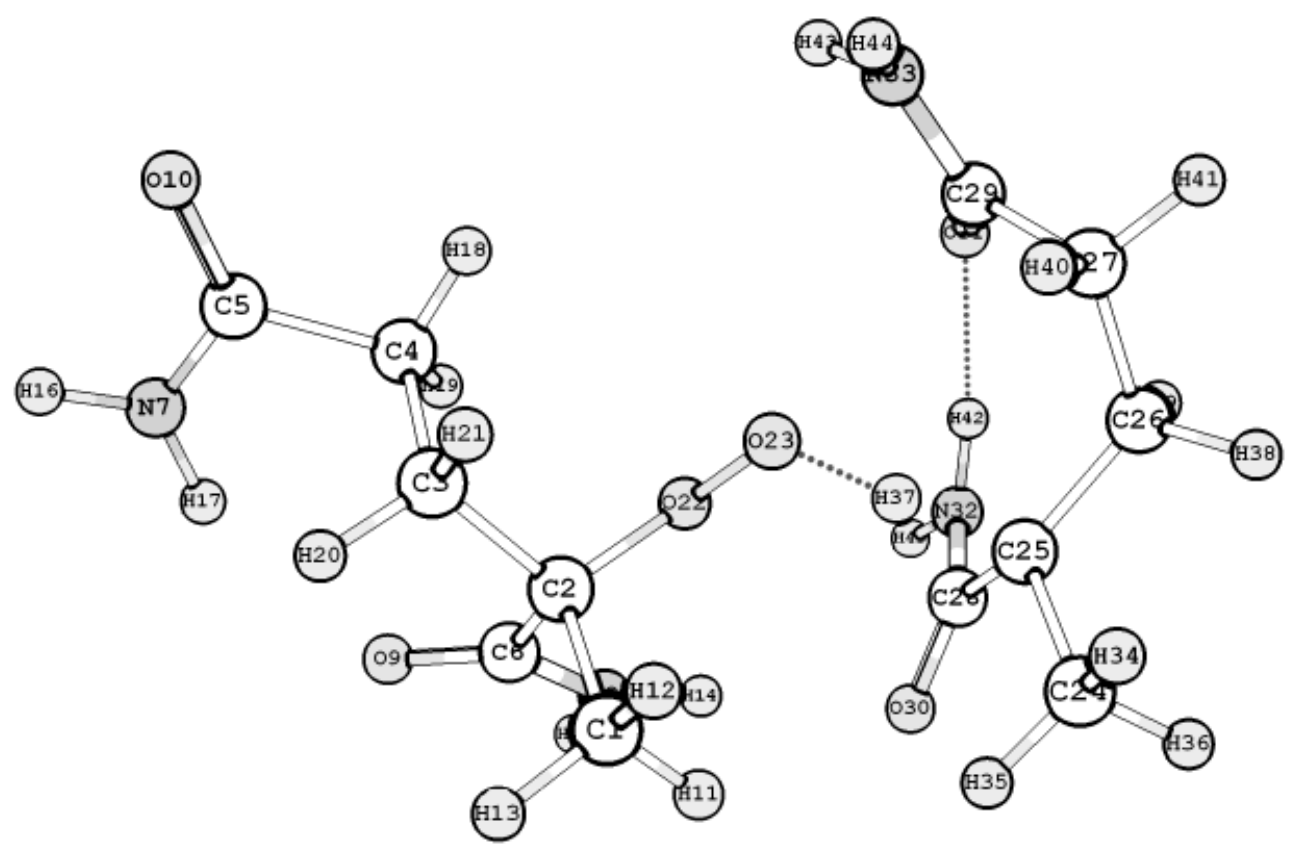

Figura 5.29 - Geometria da estrutura de transição da reação3 caminho2, PAM2_Reação3_2_TS, otimizada com o modelo químico HF/6-31G(d). 


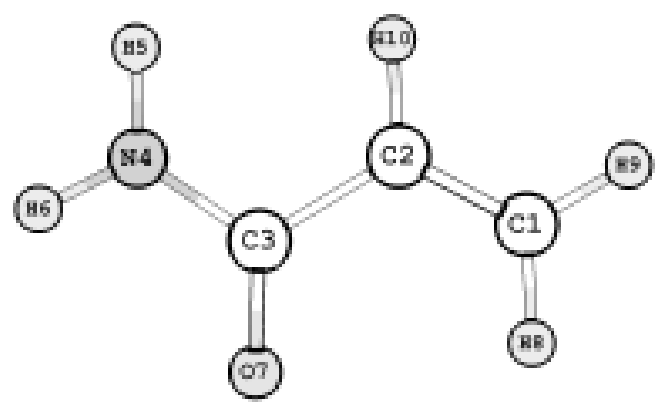

Figura 5.30 - Geometria da acrilamida, otimizada com o modelo químico HF/6$31 \mathrm{G}(\mathrm{d})$.

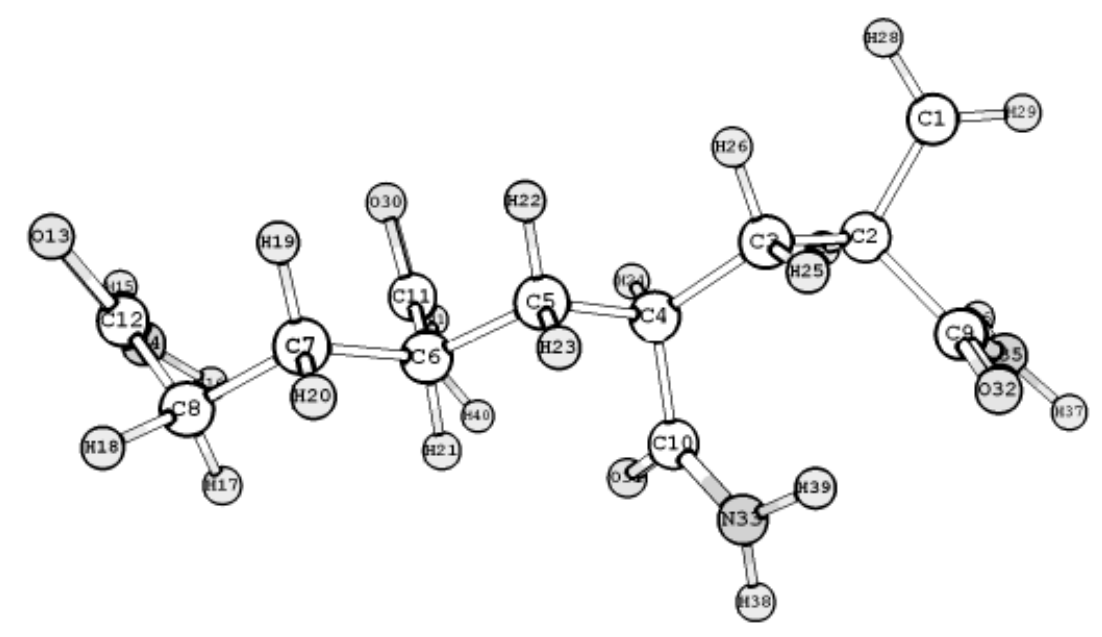

Figura 5.31 - Geometria do radical alquila PAM4_Radical otimizado com o modelo químico $\mathrm{HF} / 6-31 \mathrm{G}(\mathrm{d})$.

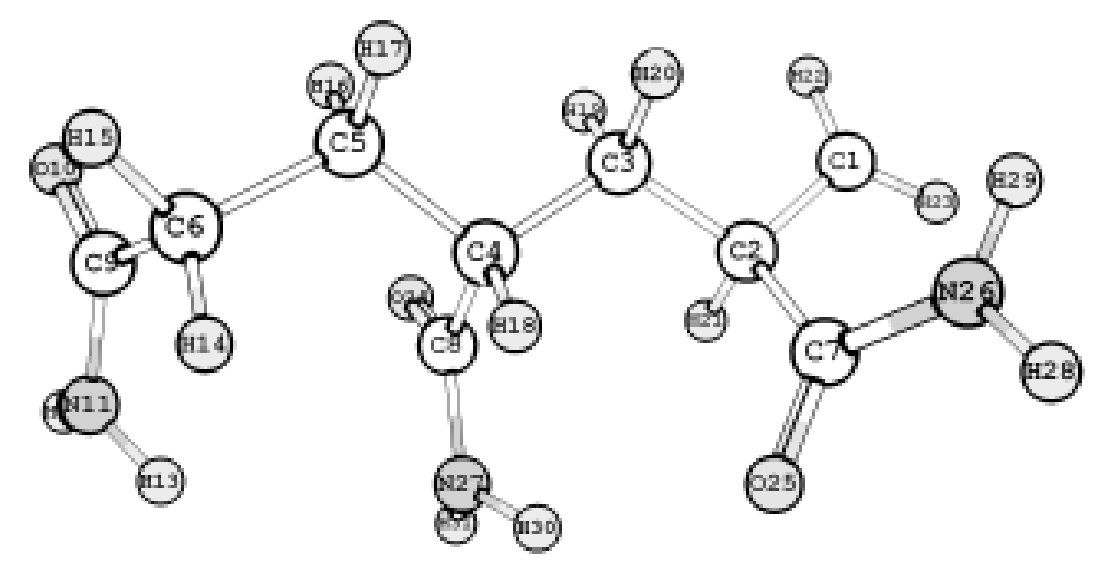

Figura 5.32 - Geometria do radical alquila PAM3_Radical otimizado com o modelo químico $\mathrm{HF} / 6-31 \mathrm{G}(\mathrm{d})$. 


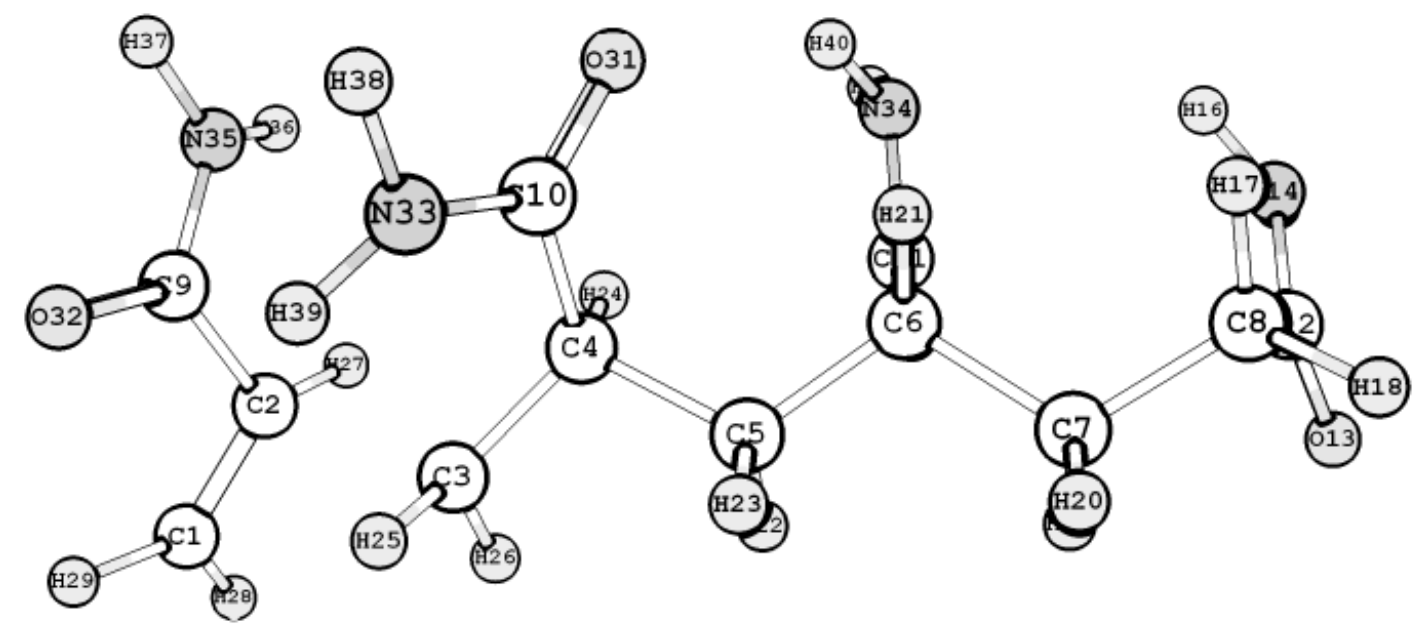

Figura 5.33 - Geometria da estrutura de transição da reação de formação da acrilamida, otimizada com o modelo químico HF/6-31G(d). 
Tabela 5.17 - Resultados para PAM: freqüências vibracionais corrigidas com o fator 0,8929, obtidas com o modelo HF/6-31G(d), para os reagentes e produtos das reações de 5.40 a 5.50 e para as estruturas de transição encontradas.

\begin{tabular}{|c|c|}
\hline Espécies & Freqüências $\left(\mathrm{cm}^{-1}\right)$ \\
\hline 2-metil pentanodiamida & $\begin{array}{l}39 ; 57 ; 63 ; 107 ; 161 ; 184 ; 221 ; 238 ; 260 ; 298 ; 341 ; 424 ; 457 ; 462 ; 489 ; 584 ; 589 ; 607 ; 626 ; 714 ; 755 ; 795 ; 847 ; 899 ; 939 ; 1009 ; 1038 ; 1061 ; \\
\text { 1074; } 1115 ; 1124 ; 1194 ; 1224 ; 1255 ; 1271 ; 1313 ; 1373 ; 1387 ; 1402 ; 1409 ; 1443 ; 1460 ; 1466 ; 1471 ; 1604 ; 1616 ; 1738 ; 1759 ; 2859 ; 2863 ; \\
2885 ; 2888 ; 2896 ; 2920 ; 2931 ; 2950 ; 3398 ; 3429 ; 3517 ; 3545 .\end{array}$ \\
\hline Radical PAM_alquila1 & $\begin{array}{l}23 ; 38 ; 55 ; 102 ; 168 ; 175 ; 201 ; 222 ; 240 ; 259 ; 297 ; 373 ; 433 ; 460 ; 483 ; 491 ; 590 ; 598 ; 613 ; 656 ; 713 ; 792 ; 797 ; 859 ; 926 ; 1018 ; 1046 ; 1057 ; \\
\text { 1074; } 1110 ; 1129 ; 1188 ; 1246 ; 1253 ; 1282 ; 1366 ; 1375 ; 1388 ; 1395 ; 1435 ; 1460 ; 1464 ; 1605 ; 1621 ; 1739 ; 1755 ; 2839 ; 2866 ; 2875 ; 2895 ; \\
2926 ; 2952 ; 2992 ; 3390 ; 3429 ; 3513 ; 3546 .\end{array}$ \\
\hline $\begin{array}{l}\text { Radical } \\
\text { PAM_alquilperoxila1 }\end{array}$ & $\begin{array}{l}24 ; 32 ; 43 ; 80 ; 107 ; 130 ; 168 ; 179 ; 229 ; 252 ; 260 ; 282 ; 310 ; 346 ; 412 ; 438 ; 474 ; 510 ; 538 ; 570 ; 576 ; 657 ; 693 ; 735 ; 780 ; 832 ; 880 ; 915 ; 942 ; \\
1029 ; 1040 ; 1059 ; 1079 ; 1106 ; 1121 ; 1144 ; 1187 ; 1276 ; 1285 ; 1322 ; 1333 ; 1362 ; 1370 ; 1393 ; 1408 ; 1469 ; 1477 ; 1487 ; 1607 ; 1609 ; 1746 ; \\
1755 ; 2877 ; 2897 ; 2910 ; 2932 ; 2957 ; 2962 ; 2977 ; 3430 ; 3433 ; 3548 ; 3553 .\end{array}$ \\
\hline PAM_hydroperoxido1 & $\begin{array}{l}\text { 41; 56; 64; 72; } 119 ; 146 ; 171 ; 200 ; 226 ; 230 ; 247 ; 262 ; 303 ; 330 ; 355 ; 418 ; 441 ; 450 ; 534 ; 563 ; 568 ; 596 ; 615 ; 671 ; 745 ; 795 ; 859 ; 884 ; 909 ; \\
986 ; 996 ; 1053 ; 1067 ; 1086 ; 1102 ; 1127 ; 1136 ; 1205 ; 1231 ; 1267 ; 1302 ; 1343 ; 1361 ; 1382 ; 1396 ; 1407 ; 1410 ; 1446 ; 1469 ; 1473 ; 1606 ; \\
1619 ; 1730 ; 1769 ; 2873 ; 2873 ; 2878 ; 2926 ; 2935 ; 2966 ; 2968 ; 3396 ; 3427 ; 3513 ; 3544 ; 3638 .\end{array}$ \\
\hline Radical PAM_alquila2 & 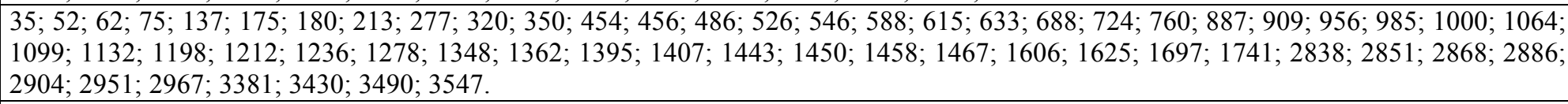 \\
\hline $\begin{array}{l}\text { Radical } \\
\text { PAM_alquilperoxila2 }\end{array}$ & $\begin{array}{l}21 ; 39 ; 54 ; 100 ; 138 ; 171 ; 196 ; 231 ; 238 ; 277 ; 313 ; 340 ; 360 ; 412 ; 413 ; 450 ; 460 ; 494 ; 536 ; 570 ; 584 ; 602 ; 643 ; 696 ; 753 ; 775 ; 839 ; 910 ; \\
937 ; 959 ; 1030 ; 1082 ; 1095 ; 1115 ; 1136 ; 1153 ; 1186 ; 1213 ; 1270 ; 1319 ; 1362 ; 1367 ; 1389 ; 1399 ; 1439 ; 1458 ; 1468 ; 1469 ; 1602 ; 1630 ; \\
1728 ; 1765 ; 2875 ; 2885 ; 2904 ; 2938 ; 2950 ; 2956 ; 2973 ; 3406 ; 3428 ; 3510 ; 3546 .\end{array}$ \\
\hline PAM_hydroperoxido2 & $\begin{array}{l}32 ; 58 ; 75 ; 82 ; 132 ; 167 ; 198 ; 225 ; 231 ; 244 ; 256 ; 274 ; 306 ; 341 ; 379 ; 393 ; 453 ; 501 ; 517 ; 549 ; 586 ; 598 ; 612 ; 675 ; 699 ; 764 ; 791 ; 852 ; 910 ; \\
936 ; 982 ; 1016 ; 1040 ; 1077 ; 1100 ; 1114 ; 1141 ; 1201 ; 1229 ; 1248 ; 1280 ; 1350 ; 1375 ; 1389 ; 1397 ; 1412 ; 1453 ; 1462 ; 1472 ; 1480 ; 1606 ; \\
1639 ; 1725 ; 1756 ; 2880 ; 2889 ; 2915 ; 2926 ; 2940 ; 2954 ; 2962 ; 3382 ; 3430 ; 3500 ; 3548 ; 3652 .\end{array}$ \\
\hline Radical PAM_alquila3 & $\begin{array}{l}\text { 42; 52; 69; } 105 ; 183 ; 187 ; 230 ; 239 ; 265 ; 298 ; 348 ; 456 ; 471 ; 487 ; 506 ; 576 ; 584 ; 623 ; 660 ; 755 ; 774 ; 845 ; 896 ; 935 ; 1003 ; 1011 ; 1036 ; \\
\text { 1065; 1115; 1118; } 1188 ; 1194 ; 1225 ; 1270 ; 1303 ; 1351 ; 1378 ; 1403 ; 1407 ; 1434 ; 1443 ; 1462 ; 1465 ; 1472 ; 1605 ; 1741 ; 2861 ; 2866 ; 2879 ; \\
\text { 2884; 2894; 2921; } 2925 ; 2942 ; 3290 ; 3427 ; 3543 .\end{array}$ \\
\hline PAM1_Reação1_TS & $\begin{array}{l}\text { 2857i; } 27 ; 31 ; 37 ; 76 ; 114 ; 134 ; 185 ; 199 ; 224 ; 231 ; 263 ; 280 ; 282 ; 311 ; 416 ; 451 ; 470 ; 503 ; 515 ; 570 ; 594 ; 608 ; 631 ; 741 ; 754 ; 775 ; 839 ; \\
\text { 848; 878; 934; 1023; 1050; 1068; 1078; 1099; 1116; 1169; 1199; 1246; 1260; 1302; 1343; 1392; 1398; 1415; 1443; 1470; 1473; 1484; 1605; } \\
\text { 1608; 1733; } 1753 ; 2873 ; 2876 ; 2896 ; 2912 ; 2926 ; 2940 ; 2964 ; 3424 ; 3425 ; 3539 ; 3543 ; 3560 .\end{array}$ \\
\hline PAM2_Reação1_TS & 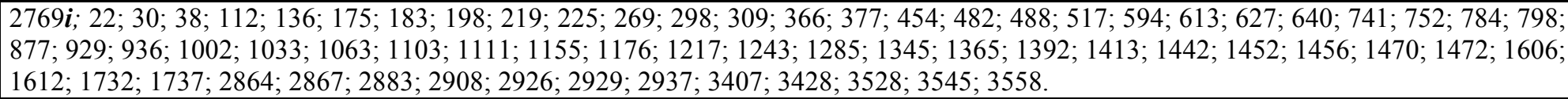 \\
\hline
\end{tabular}


Tabela 5.18 - Resultados para PAM: freqüências vibracionais corrigidas com o fator 0,8929, obtidas com o modelo HF/6-31G(d), para as estruturas de transição Espécies

\begin{tabular}{|c|c|}
\hline & \\
\hline Espécies & requêências $\left(\mathrm{cm}^{-1}\right)$ \\
\hline PAM3_Reação1_TS & $\begin{array}{l}151 i ; 32 ; 40 ; 62 ; 87 ; 110 ; 190 ; 200 ; 204 ; 237 ; 253 ; 279 ; 323 ; 386 ; 436 ; 462 ; 490 ; 581 ; 610 ; 642 ; 686 ; 736 ; 757 ; 771 ; 806 ; 867 ; 899 ; 942 ; \\
75 ; 1009 ; 1040 ; 1065 ; 1091 ; 1101 ; 1115 ; 1165 ; 1196 ; 1230 ; 1272 ; 1301 ; 1334 ; 1379 ; 1402 ; 1404 ; 1410 ; 1443 ; 1462 ; 1465 ; 1471 ; 1556 ; \\
605 ; 1668 ; 1740 ; 1819 ; 2423 ; 2863 ; 2871 ; 2888 ; 2896 ; 2915 ; 2928 ; 2939 ; 2953 ; 3415 ; 3426 ; 3543\end{array}$ \\
\hline PAM1_Reação3_1_TS & 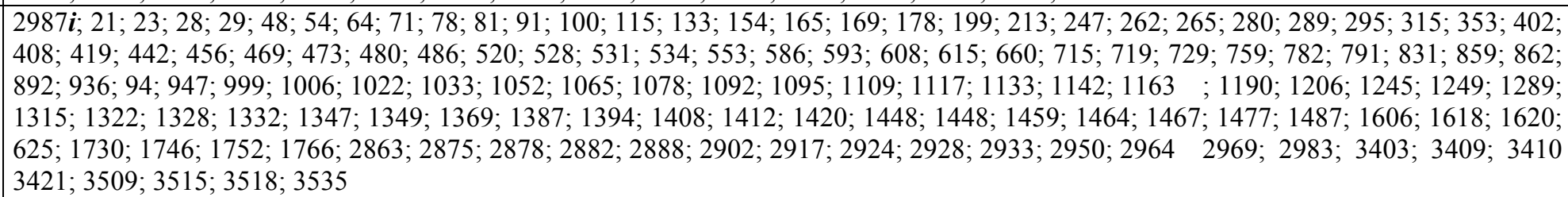 \\
\hline PAM1_Reação3_2_TS & 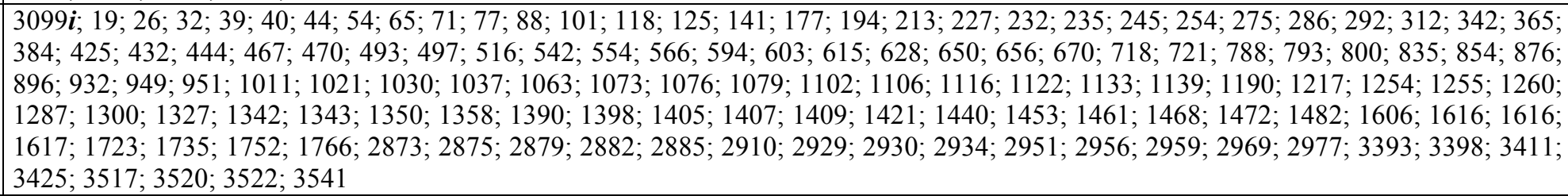 \\
\hline PAM2_Reação3_1_TS & 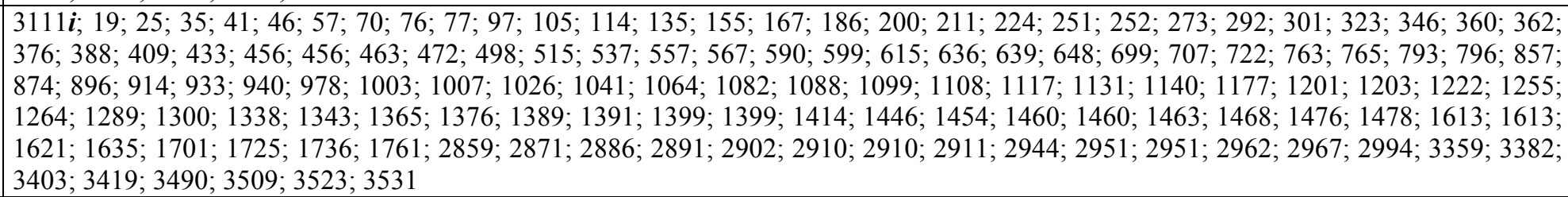 \\
\hline PAM2_Reação3_2_TS & 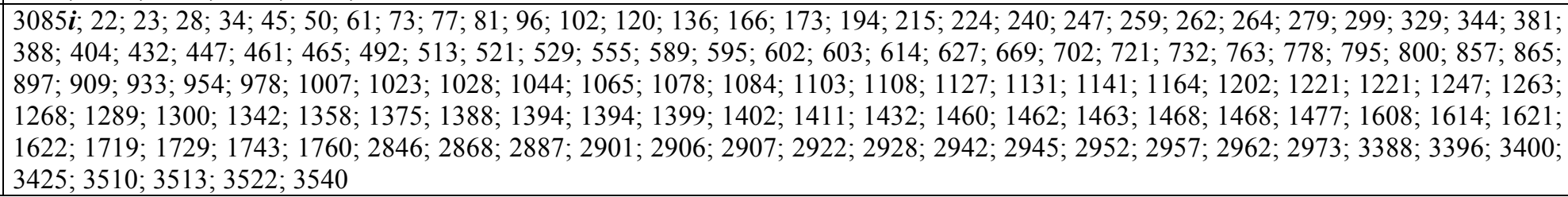 \\
\hline
\end{tabular}


Tabela 5.19 - Resultados para PAM: freqüências vibracionais corrigidas com o fator 0,8929, obtidas com o modelo $\mathrm{HF} / 6-31 \mathrm{G}(\mathrm{d})$, para os reagentes e produtos da reação 5.51 de formação da acrilamida.

\begin{tabular}{|c|}
\hline Freqüências $\left(\mathrm{cm}^{-1}\right)$ \\
\hline Acrilamida \\
\hline Acrian \\
\hline
\end{tabular}

$91 ; 161 ; 270 ; 450 ; 458 ; 583 ; 600 ; 793 ; 810 ; 993 ; 1020 ; 1023 ; 1093 ; 1259 ; 1321 ; 1414$; $1606 ; 1664 ; 1758 ; 2985 ; 3002 ; 3075 ; 3432 ; 3548$

\section{PAM4 Radical}

$20 ; 23 ; 35 ; 42 ; 52 ; 58 ; 65 ; 79 ; 93 ; 96 ; 109 ; 129 ; 136 ; 163 ; 181 ; 202 ; 218 ; 239 ; 248 ; 274$; $288 ; 294 ; 323 ; 385 ; 395 ; 405 ; 411 ; 443 ; 477 ; 487 ; 506 ; 524 ; 539 ; 554 ; 558 ; 564 ; 578 ; 582$; $594 ; 618 ; 647 ; 719 ; 731 ; 733 ; 748 ; 754 ; 784 ; 792 ; 807 ; 869 ; 896 ; 913 ; 952 ; 962 ; 1011$; $1015 ; 1022 ; 1029 ; 1054 ; 1065 ; 1078 ; 1091 ; 1109 ; 1118 ; 1123 ; 1165 ; 1176 ; 1199 ; 1215$; $1222 ; 1262 ; 1272 ; 1283 ; 1298 ; 1319 ; 1337 ; 1344 ; 1362 ; 1372 ; 1384 ; 1392 ; 1397 ; 1415$; $1432 ; 1454 ; 1461 ; 1465 ; 1471 ; 1606 ; 1621 ; 1628 ; 1630 ; 1714 ; 1739 ; 1764 ; 1772 ; 2803$; $2872 ; 2877 ; 2882 ; 2893 ; 2896 ; 2904 ; 2922 ; 2924 ; 2935 ; 2940 ; 2969 ; 3064 ; 3368 ; 3399$; $3405 ; 3428 ; 3474 ; 3505 ; 3511 ; 3545$

\section{PAM3 Radical}

$30 ; 43 ; 54 ; 60 ; 76 ; 81 ; 102 ; 122 ; 139 ; 153 ; 209 ; 235 ; 255 ; 269 ; 288 ; 293 ; 345 ; 398 ; 412$; 444; 474; 493; 512; 530; 554; 566; 585; 592; 595; 642; 718; 731; 744; 762; 788; 810; 874; 882 ; 925; 980; 1011; 1018; 1031; 1061; 1077; 1093; 1108; 1120; 1165; 1196; 1214; 1251; $1270 ; 1295 ; 1298 ; 1318 ; 1345 ; 1358 ; 1376 ; 1385 ; 1416 ; 1432 ; 1457 ; 1461 ; 1467 ; 1600$; $1620 ; 1628 ; 1723 ; 1765 ; 1773 ; 2858 ; 2869 ; 2876 ; 2881 ; 2904 ; 2922 ; 2923 ; 2941 ; 2959$; $3050 ; 3370 ; 3405 ; 3429 ; 3476 ; 3511 ; 3547$

\section{TS Acrilamida}

$410 i ; 16 ; 27 ; 36 ; 44 ; 53 ; 58 ; 77 ; 79 ; 94 ; 96 ; 110 ; 114 ; 143 ; 145 ; 192 ; 230 ; 234 ; 245 ; 258$; $270 ; 294 ; 304 ; 368 ; 396 ; 407 ; 432 ; 457 ; 465 ; 466 ; 475 ; 510 ; 526 ; 534 ; 550 ; 554 ; 582 ; 585$; $593 ; 598 ; 632 ; 643 ; 714 ; 719 ; 730 ; 747 ; 755 ; 763 ; 789 ; 793 ; 807 ; 875 ; 879 ; 908 ; 927 ; 964$; $1003 ; 1011 ; 1015 ; 1025 ; 1045 ; 1061 ; 1070 ; 1083 ; 1106 ; 1120 ; 1124 ; 1159 ; 1165 ; 1194$; $1215 ; 1257 ; 1262 ; 1279 ; 1298 ; 1313 ; 1322 ; 1344 ; 1359 ; 1381 ; 1385 ; 1410 ; 1417 ; 1445$; $1457 ; 1461 ; 1466 ; 1467 ; 1607 ; 1621 ; 1625 ; 1626 ; 1715 ; 1733 ; 1764 ; 1772 ; 2872 ; 2878$; $2883 ; 2895 ; 2916 ; 2924 ; 2927 ; 2942 ; 2950 ; 2981 ; 2989 ; 3021 ; 3077 ; 3371 ; 3405 ; 3409$; $3428 ; 3476 ; 3512 ; 3512 ; 3543$ 
Tabela 5.20 - Resultados para PAM: parâmetros termoquímicos obtidos com o modelo $\mathrm{HF} / 6-31 \mathrm{G}(\mathrm{d})$, corrigidos com o fator 0,9135, para reagentes e produtos das reações de 5.40 a 5.51 e para as estruturas de transição encontradas.

\begin{tabular}{|c|c|c|c|}
\hline Espécies & $\begin{array}{c}\text { ZPE } \\
\text { (Hartrees) } \\
\end{array}$ & $\begin{array}{c}\text { Hcorr } \\
\text { (Hartrees) } \\
\end{array}$ & $\begin{array}{c}\text { Gcorr } \\
\text { (Hartrees) }\end{array}$ \\
\hline 2-metil pentanodiamida & 0,1842 & 0,1969 & 0,1460 \\
\hline Radical PAM_alquila1 & 0,1696 & 0,1829 & 0,1295 \\
\hline Radical PAM_alquilperoxila1 & 0,1807 & 0,1955 & 0,1379 \\
\hline PAM_hydroperoxido1 & 0,1929 & 0,2080 & 0,1518 \\
\hline Radical PAM_alquila2 & 0,1711 & 0,1839 & 0,1316 \\
\hline Radical PAM_alquilperoxila2 & 0,1808 & 0,1950 & 0,1394 \\
\hline PAM_hydroperoxido2 & 0,1929 & 0,2077 & 0,1522 \\
\hline Radical PAM_alquila3 & 0,1695 & 0,1819 & 0,1308 \\
\hline PAM1_Reação1_TS & 0,1900 & 0,2041 & 0,1472 \\
\hline PAM2_Reação1_TS & 0,1907 & 0,2045 & 0,1486 \\
\hline PAM3_Reação1_TS & 0,1931 & 0,2068 & 0,1522 \\
\hline PAM1_Reação3_1_TS & 0,3609 & 0,3883 & 0,3009 \\
\hline PAM1_Reação3_2_TS & 0,3608 & 0,3882 & 0,3010 \\
\hline PAM2_Reação3_1_TS & 0,3608 & 0,3880 & 0,3014 \\
\hline PAM2_Reação3_2_TS & 0,3616 & 0,3883 & 0,3037 \\
\hline PAM4_Radical & 0,3372 & 0,3614 & 0,2815 \\
\hline PAM3_Radical & 0,2541 & 0,2724 & 0,2074 \\
\hline Acrilamida & 0,0779 & 0,0845 & 0,0491 \\
\hline TS_Acrilamida & 0,3341 & 0,3581 & 0,2787 \\
\hline
\end{tabular}


Tabela 5.21 - Resultados para PAM: energias eletrônicas, calculadas somando-se a energia single point, obtida com diferentes modelos químicos à energia do ponto zero corrigida com o fator 0,9135 , obtidas com o modelo $\mathrm{HF} / 6-31 \mathrm{G}(\mathrm{d})$, para reagentes e produtos das reações de 5.40 a 5.50 .

\begin{tabular}{|c|c|c|c|c|c|c|c|c|c|}
\hline \multicolumn{2}{|c|}{ Modelo Químico } & \multicolumn{8}{|c|}{ Energia (Hartrees) } \\
\hline $\begin{array}{l}\text { Nível de } \\
\text { Teoria }\end{array}$ & Basis set & $\begin{array}{c}\text { 2-metil } \\
\text { pentanodia } \\
\text { mida } \\
\end{array}$ & $\begin{array}{c}\text { Radical } \\
\text { PAM_alquila1 }\end{array}$ & $\begin{array}{c}\text { Radical } \\
\text { PAM_alquilpero } \\
\text { xila1 }\end{array}$ & $\begin{array}{l}\text { PAM_hydr } \\
\text { operoxido } 1\end{array}$ & $\begin{array}{l}\text { Radical } \\
\text { PAM_alquil } \\
\text { a2 }\end{array}$ & $\begin{array}{c}\text { Radical } \\
\text { PAM_alquilp } \\
\text { eroxila2 }\end{array}$ & $\begin{array}{l}\text { PAM_hydrop } \\
\text { eroxido2 }\end{array}$ & $\begin{array}{c}\text { Radical } \\
\text { PAM_alquila } \\
3\end{array}$ \\
\hline \multirow[t]{4}{*}{ HF } & $6-31 G(d)$ & $-492,6826$ & $-492,0718$ & $-641,6909$ & $-642,2789$ & $-492,0804$ & $-641,7235$ & $-642,2770$ & $-492,0083$ \\
\hline & $6-31 G(d, p)$ & $-492,7112$ & $-492,0991$ & $-641,7180$ & $-642,3121$ & $-492,1075$ & $-641,7235$ & $-642,3103$ & $-492,0327$ \\
\hline & $6-31+G(d, p)$ & $-492,7247$ & $-492,1134$ & $-641,7358$ & $-642,3309$ & $-492,1213$ & $-641,7407$ & $-642,2951$ & $-492,0462$ \\
\hline & $6-311+G(d, p)$ & $-492,8273$ & $-492,2156$ & $-641,8786$ & $-642,4738$ & $-492,2234$ & $-641,8836$ & $-642,4416$ & $-492,1492$ \\
\hline \multirow[t]{4}{*}{ B3LYP } & $6-31 G(d)$ & $-495,6674$ & $-495,0188$ & $-645,3698$ & $-645,9903$ & $-495,0316$ & $-645,3746$ & $-645,9922$ & $-494,9646$ \\
\hline & $6-31 G(d, p)$ & $-495,6927$ & $-495,0427$ & $-645,3936$ & $-646,0193$ & $-495,0554$ & $-645,3985$ & $-646,0214$ & $-494,9864$ \\
\hline & $6-31+G(d, p)$ & $-495,7174$ & $-495,0685$ & $-645,4253$ & $-646,0537$ & $-495,0807$ & $-645,4294$ & $-646,0251$ & $-495,0094$ \\
\hline & $6-311+G(d, p)$ & $-495,8335$ & $-495,1844$ & $-645,5820$ & $-646,2116$ & $-495,1961$ & $-645,5862$ & $-646,1846$ & $-495,1260$ \\
\hline MP2 & $6-31 \mathrm{G}(\mathrm{d}, \mathrm{p})$ & $-494,2311$ & $-493,5828$ & $-643,5569$ & $-644,1889$ & $-493,6314$ & $-643,5643$ & $-644,1923$ & $-493,5419$ \\
\hline
\end{tabular}


Tabela 5.22 - Resultados para PAM: energias eletrônicas, calculadas somando-se a energia single point, obtida com diferentes modelos químicos à energia do ponto zero corrigida com o fator 0,9135 , obtidas com o modelo HF/6-31G(d), para as estruturas de transição das reações $5.40,5.42,5.43,5.45,5.47,5.48$ e 5.50 .

\begin{tabular}{|c|c|c|c|c|c|c|c|c|}
\hline \multicolumn{2}{|l|}{ Modelo Químico } & \multicolumn{7}{|c|}{ Energia (Hartrees) } \\
\hline $\begin{array}{l}\text { Nível } \\
\text { Teoria }\end{array}$ & Basis Set & $\begin{array}{r}\text { PAM1_- } \\
\text { Reação1_TS }\end{array}$ & $\begin{array}{r}\text { PAM2_- } \\
\text { Reação1_TS }\end{array}$ & $\begin{array}{r}\text { PAM3_- } \\
\text { Reação1_TS }\end{array}$ & $\begin{array}{l}\text { PAM1_- } \\
\text { Reação3_1_TS }\end{array}$ & $\begin{array}{l}\text { PAM1_ } \\
\text { Reação3_2 }\end{array}$ & $\begin{array}{l}\text { PAM2_- } \\
\text { Reação3_1_TS }\end{array}$ & $\begin{array}{l}\text { PAM2_- } \\
\text { Reação3_2_TS }\end{array}$ \\
\hline HF & $\begin{array}{l}6-31 G(d) \\
6-31 G(d, p) \\
6-31+G(d, p) \\
6-311+G(d, p)\end{array}$ & $\begin{array}{l}-568,0185 \\
-568,0562 \\
-568,0748 \\
-568,1990\end{array}$ & $\begin{array}{l}-568,0219 \\
-568,0593 \\
-568,0776 \\
-568,2014\end{array}$ & $\begin{array}{l}-568,0121 \\
-568,0508 \\
-568,0666 \\
-568,1880\end{array}$ & $\begin{array}{l}-1134,3180 \\
-1134,3912 \\
-1134,4206 \\
-1134,6657\end{array}$ & $\begin{array}{l}-1134,3073 \\
-1134,3654 \\
-1134,3947 \\
-1134,6400\end{array}$ & $\begin{array}{l}-1134,3198 \\
-1134,3784 \\
-1134,4083 \\
-1134,6532\end{array}$ & $\begin{array}{l}-1134,3255 \\
-1134,3839 \\
-1134,4135 \\
-1134,6581\end{array}$ \\
\hline B3LYP & $\begin{array}{l}6-31 G(d) \\
6-31 G(d, p) \\
6-31+G(d, p) \\
6-311+G(d, p)\end{array}$ & $\begin{array}{l}-571,3901 \\
-571,4237 \\
-571,4587 \\
-571,5976\end{array}$ & $\begin{array}{l}-571,3980 \\
-571,4314 \\
-571,4657 \\
-571,6044\end{array}$ & $\begin{array}{l}-571,3657 \\
-571,3994 \\
-571,4294 \\
-571,5657\end{array}$ & $\begin{array}{l}-1141,0249 \\
-1141,0758 \\
-1141,1281 \\
-1141,4001\end{array}$ & $\begin{array}{l}-1141,0043 \\
-1141,0559 \\
-1141,1077 \\
-1141,3801\end{array}$ & $\begin{array}{l}-1141,0157 \\
-1141,0675 \\
-1141,1199 \\
-1141,3922\end{array}$ & $\begin{array}{l}-1141,0274 \\
-1141,0793 \\
-1141,1308 \\
-1141,1028\end{array}$ \\
\hline MP2 & $6-31 \mathrm{G}(\mathrm{d}, \mathrm{p})$ & $-569,7537$ & $-569,7598$ & $-569,7326$ & $-1137,7776$ & $-1137,7610$ & $-1137,7730$ & $-1137,7848$ \\
\hline
\end{tabular}


Tabela 5.23 - Entalpias de reação para as reações 5.40 a 5.50 .

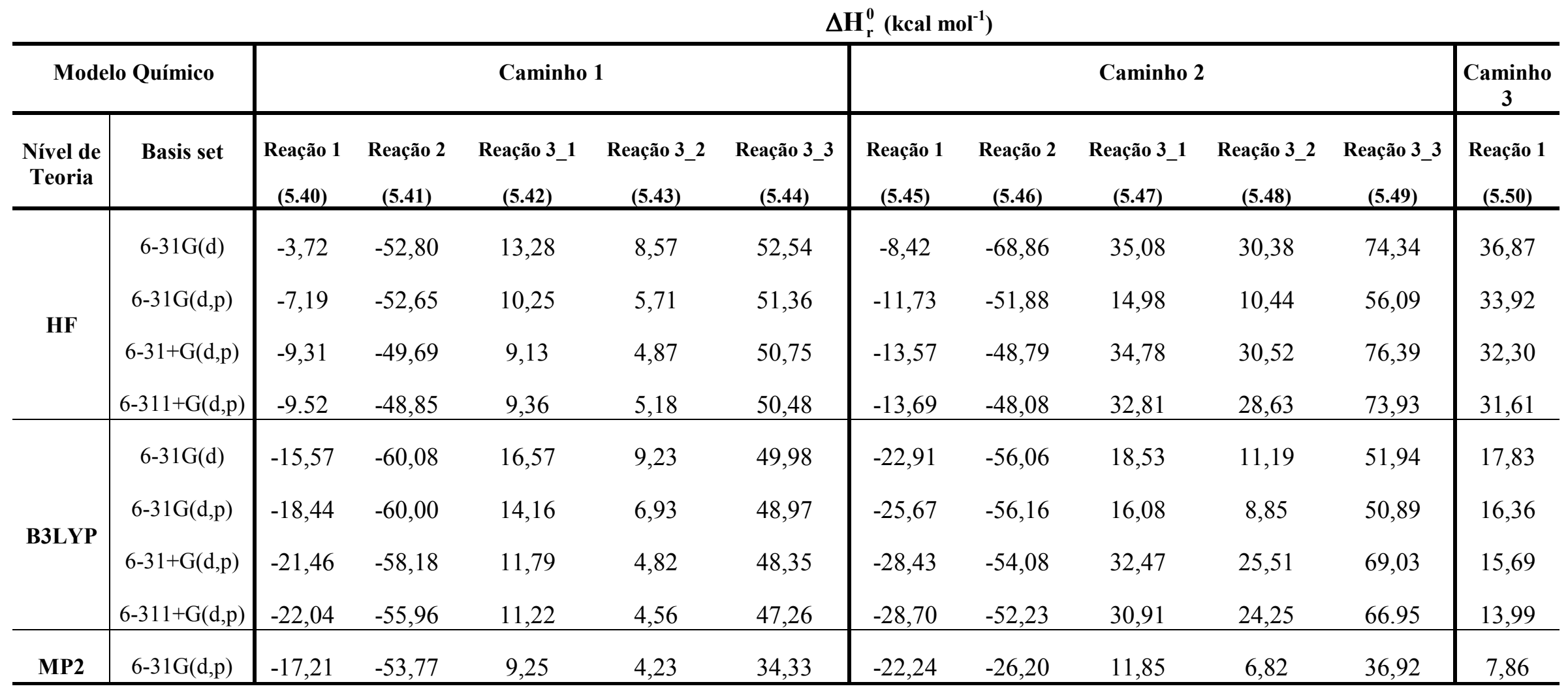


Tabela 5.24- Energia livre de Gibbs para as reações 5.40 a 5.50

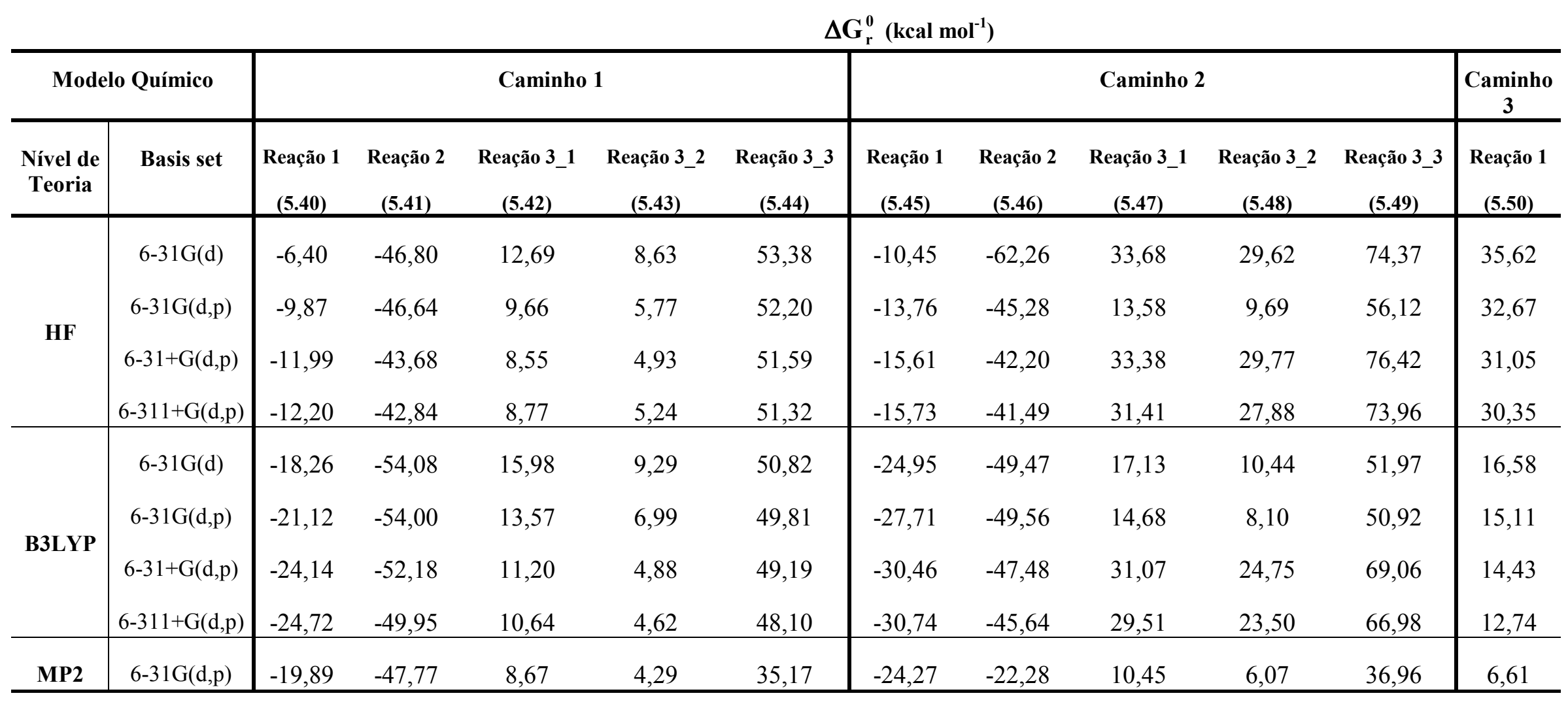


Tabela 5.25 - Resultados para PAM: energias eletrônicas, calculadas somando-se a energia single point, obtidas com diferentes modelos químicos à energia do ponto zero corrigida com o fator 0,9135 , obtidas com o modelo $\mathrm{HF} / 6-31 \mathrm{G}(\mathrm{d})$, para a reação 5.51 de formação da acrilamida.

\begin{tabular}{|c|c|c|c|c|c|}
\hline \multicolumn{2}{|c|}{ Modelo Químico } & \multicolumn{4}{|c|}{ Energias (Hartrees) } \\
\hline $\begin{array}{c}\text { Nível de } \\
\text { Teoria }\end{array}$ & Basis set & Acrilamida & PAM4_Radical & PAM3_Radical & TS \\
\hline \multirow{4}{*}{ HF } & $6-31 G(d)$ & $-245,7422$ & $-983,5968$ & $-737,8302$ & $-983,5527$ \\
\hline & $6-31 \mathrm{G}(\mathrm{d}, \mathrm{p}$ & $-245,7556$ & $-983,6488$ & $-737,8696$ & $-983,6051$ \\
\hline & $6-31+G(d, p)$ & $-245,7653$ & $-983,6756$ & $-737,8900$ & $-983,6321$ \\
\hline & $6-311+G(d, p)$ & $-245,8167$ & $-983,8798$ & $-738,0435$ & $-983,8364$ \\
\hline \multirow{4}{*}{ B3LYP } & $6-31 G(d)$ & $-247,2114$ & $-989,4866$ & $-742,2476$ & $-989,4496$ \\
\hline & $6-31 G(d, p)$ & $-247,2232$ & $-989,5327$ & $-742,2825$ & $-989,4959$ \\
\hline & $6-31+G(d, p)$ & $-247,2389$ & $-989,5808$ & $-742,3193$ & $-989,5446$ \\
\hline & $6-311+G(d, p)$ & $-247,2980$ & $-989,8113$ & $-742,4924$ & $-989,7756$ \\
\hline \multirow{3}{*}{ MP2 } & $6-31 G(d)$ & $-246,4506$ & $-986,4674$ & $-739,9749$ & $-986,4085$ \\
\hline & $6-31 G(d, p)$ & $-246,5227$ & $-986,6490$ & $-740,1130$ & $-986,5903$ \\
\hline & $6-31+G(d, p)$ & $-246,5128$ & $-986,7199$ & $-740,1475$ & $-986,6630$ \\
\hline
\end{tabular}


Tabela 5.26 - Entropias de reação para PAM, calculadas com HF/6-31Gd(p).

\begin{tabular}{l|c|c} 
& \multicolumn{1}{c}{ Reação } & $\Delta \mathbf{S}_{\mathbf{r}}^{\mathbf{0}}\left(\right.$ cal mol $\left.^{-1} \mathbf{K}^{-1}\right)$ \\
\hline \multirow{2}{*}{ Caminho 1 } & Reação 1 (5.40) & 8,99 \\
& Reação 2 (5.41) & $-20,14$ \\
& Reação 3_2 (5.43) & 1,97 \\
& Reação 3_3 (5.44) & $-0,20$ \\
& Reação 1 (5.45) & $-2,82$ \\
\hline \multirow{2}{*}{ Caminho 2 } & Reação 2 (5.46) & 6,82 \\
& Reação 3_1 (5.47) & $-22,12$ \\
& Reação 3_2 (5.48) & 4,69 \\
& Reação 3_3 (5.49) & 2,52 \\
\hline Caminho 3 & Reação 1 (5.50) & $-0,10$ \\
\hline
\end{tabular}


Tabela 5.27 - Barreira de ativação para as reações 5.40, 5.42, 5.43, 5.45, 5,47, 5,48 e 5,50.

\begin{tabular}{|c|c|c|c|c|c|c|c|c|}
\hline & & \multicolumn{7}{|c|}{ Barreira de Ativação (kcal mol ${ }^{-1}$ ) } \\
\hline \multicolumn{2}{|c|}{ Modelo Químico } & \multicolumn{3}{|c|}{ Caminho 1} & \multicolumn{3}{|c|}{ Caminho 2} & \multirow{2}{*}{$\begin{array}{c}\text { Caminho } 3 \\
\text { Reação } 1 \\
(5.50) \\
\end{array}$} \\
\hline $\begin{array}{l}\text { Nível de } \\
\text { Teoria }\end{array}$ & Basis Set & $\begin{array}{c}\text { Reação } 1 \\
(5.40)\end{array}$ & $\begin{array}{c}\text { Reação 3_1 } \\
(5.42)\end{array}$ & $\begin{array}{c}\text { Reação 3_2 } \\
(5.43)\end{array}$ & $\begin{array}{c}\text { Reação } 1 \\
(5.45)\end{array}$ & $\begin{array}{c}\text { Reação 3_1 } \\
(5.47)\end{array}$ & $\begin{array}{c}\text { Reação 3_2 } \\
(5.48)\end{array}$ & \\
\hline \multirow{4}{*}{ HF } & $6-31 G(d)$ & 23,87 & 34,86 & 41,53 & 21,77 & 54,15 & 50,59 & 31,69 \\
\hline & $6-31 G(d, p)$ & 21,97 & 23,82 & 40,01 & 20,01 & 35,35 & 31,87 & 25,34 \\
\hline & $6-31+G(d, p)$ & 21,83 & 24,98 & 41,27 & 20,07 & 35,78 & 32,52 & 27,01 \\
\hline & $6-311+G(d, p)$ & 21,76 & 25,30 & 41,39 & 20,21 & 36,22 & 33,13 & 28,62 \\
\hline \multirow{4}{*}{ B3LYP } & $6-31 G(d)$ & $-5,13$ & 7,72 & 20,64 & $-10,04$ & 16,51 & 9,13 & 10,25 \\
\hline & $6-31 G(d, p)$ & $-7,09$ & 6,68 & 19,04 & $-11,90$ & 14,88 & 7,47 & 8,13 \\
\hline & $6-31+\mathrm{G}(\mathrm{d}, \mathrm{p})$ & $-6,90$ & 9,19 & 21,94 & $-11,33$ & 16,85 & 10,02 & 11,44 \\
\hline & $6-311+G(d, p)$ & $-6,52$ & 9,63 & 22,20 & $-10,75$ & 17,25 & 10,59 & 13,52 \\
\hline MP2 & $6-31 G(d, p)$ & 0,58 & 6,53 & 16,98 & $-3,23$ & 14,03 & 6,67 & 13,84 \\
\hline
\end{tabular}


Tabela 5.28 - Resultados para a Reação1 do Caminho 1 (5.40).

\begin{tabular}{l|l|cccc}
\hline \multicolumn{4}{c|}{} & \multicolumn{4}{c}{ Caminho 1 - Reação 1 (5.40) } \\
\hline $\begin{array}{l}\text { Nível de } \\
\text { Teoria }\end{array}$ & Basis set & $\begin{array}{c}\Delta^{\ddagger} \mathbf{S}^{\mathbf{0}}-28,13 \\
\left(\mathrm{kcal} \mathrm{mol}^{\mathbf{0}}\right)\end{array}$ & $\begin{array}{c}\Delta^{\ddagger} \mathbf{H}^{\mathbf{0}} \\
\left(\mathrm{kcal} \mathrm{mol}^{-1}\right)\end{array}$ & $\begin{array}{c}\text { Ea } \\
\left(\mathrm{kcal} \mathrm{mol}^{-1}\right)\end{array}$ & $\begin{array}{c}\mathbf{k}_{\mathbf{1}} \\
\left(\mathrm{L} \mathrm{mol}^{-1} \mathrm{~s}^{-1}\right)\end{array}$ \\
\hline & $6-31 \mathrm{G}(\mathrm{d})$ & 30,02 & 21,63 & 22,22 & $6,15 \times 10^{-10}$ \\
& $6-31 \mathrm{G}(\mathrm{d}, \mathrm{p})$ & 28,11 & 19,73 & 20,32 & $1,52 \times 10^{-08}$ \\
& $6-31+\mathrm{G}(\mathrm{d}, \mathrm{p})$ & 27,98 & 19,60 & 20,19 & $1,91 \times 10^{-08}$ \\
& $6-311+\mathrm{G}(\mathrm{d}, \mathrm{p})$ & 27,91 & 19,52 & 20,11 & $2,16 \times 10^{-08}$ \\
\hline & $6-31 \mathrm{G}(\mathrm{d})$ & 1,02 & $-7,36$ & $-6,77$ & $1,11 \times 10^{+12}$ \\
& $6-31 \mathrm{G}(\mathrm{d}, \mathrm{p})$ & $-0,94$ & $-9,33$ & $-8,74$ & $3,06 \times 10^{+13}$ \\
B3LYP & $6-31+\mathrm{G}(\mathrm{d}, \mathrm{p})$ & $-0,75$ & $-9,13$ & $-8,54$ & $2,19 \times 10^{+13}$ \\
& $6-311+\mathrm{G}(\mathrm{d}, \mathrm{p})$ & $-0,37$ & $-8,75$ & $-8,16$ & $1,15 \times 10^{+13}$ \\
\hline MP2 & $6-31 \mathrm{G}(\mathrm{d}, \mathrm{p})$ & 6,73 & $-1,65$ & $-1,06$ & $7,21 \times 10^{+07}$ \\
\hline
\end{tabular}

Tabela 5.29 - Resultados para a Reação3_1 do Caminho 1 (5.42).

\begin{tabular}{|c|c|c|c|c|c|}
\hline \multicolumn{2}{|c|}{ Modelo Químico } & \multicolumn{4}{|c|}{$\begin{array}{c}\text { Caminho 1 - Reação 3_1 (5.42) } \\
\Delta^{\ddagger} \mathbf{S}^{\mathbf{0}}-44,66\left(\mathrm{cal} \mathrm{K}^{-1} \mathrm{~mol}^{-1}\right) ; \mathbf{A} 2,92 \times 10^{3}\left(\mathrm{~L} \mathrm{~mol}^{-1} \mathrm{~s}^{-1}\right)\end{array}$} \\
\hline $\begin{array}{l}\text { Nível de } \\
\text { Teoria }\end{array}$ & Basis set & $\begin{array}{c}\Delta^{\dagger} \mathbf{G}^{\mathbf{0}} \\
\left(\mathrm{kcal} \mathrm{mol}^{-1}\right)\end{array}$ & 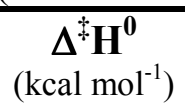 & $\begin{array}{c}\mathbf{E a} \\
\left(\mathrm{kcal} \mathrm{mol}^{-1}\right)\end{array}$ & $\begin{array}{c}\mathbf{k}_{11} \\
\left(\mathrm{~L} \mathrm{~mol}^{-1} \mathrm{~s}^{-1}\right)\end{array}$ \\
\hline \multirow{4}{*}{ HF } & $6-31 G(d)$ & 45,57 & 32,25 & 32,85 & $2,44 \times 10^{-21}$ \\
\hline & $6-31 \mathrm{G}(\mathrm{d}, \mathrm{p})$ & 34,52 & 21,21 & 21,80 & $3,06 \times 10^{-13}$ \\
\hline & $6-31+G(d, p)$ & 35,69 & 22,37 & 22,97 & $4,27 \times 10^{-14}$ \\
\hline & $6-311+\mathrm{G}(\mathrm{d}, \mathrm{p})$ & 36,00 & 22,69 & 23,28 & $2,52 \times 10^{-14}$ \\
\hline \multirow{4}{*}{ B3LYP } & $6-31 G(d)$ & 18,43 & 5,11 & 5,70 & $1,93 \times 10^{-01}$ \\
\hline & $6-31 \mathrm{G}(\mathrm{d}, \mathrm{p})$ & 17,38 & 4,07 & 4,66 & $1,12 \times 10^{0}$ \\
\hline & $6-31+G(d, p)$ & 19,90 & 6,58 & 7,17 & $1,61 \times 10^{-02}$ \\
\hline & $6-311+\mathrm{G}(\mathrm{d}, \mathrm{p})$ & 20,33 & 7,02 & 7,61 & $7,70 \times 10^{-03}$ \\
\hline MP2 & $6-31 G(d, p)$ & 17,24 & 3,92 & 4,51 & $1,43 \times 10^{0}$ \\
\hline
\end{tabular}


Tabela 5.30 - Resultados para a Reação3 2 do Caminho 1 (5.43).

\begin{tabular}{l|l|cccc}
\hline \multicolumn{4}{c|}{} & \multicolumn{4}{c}{ Caminho 1 - Reação 3_2 (5.43) } \\
\hline $\begin{array}{l}\text { Nível de } \\
\text { Teoria }\end{array}$ & Basis set & $\begin{array}{c}\Delta^{\ddagger} \mathbf{G}^{\mathbf{0}}-45,12 \\
\left(\mathrm{kcal} \mathrm{mol}^{-1}\right)\end{array}$ & $\begin{array}{c}\Delta^{\ddagger} \mathbf{H}^{\mathbf{0}} \\
\left(\mathrm{kcal} \mathrm{mol}^{-1}\right)\end{array}$ & $\begin{array}{c}\text { Ea } \\
\left(\mathrm{kcal} \mathrm{mol}^{-1}\right)\end{array}$ & $\begin{array}{c}\mathbf{k}_{12} \\
\left(\mathrm{~L} \mathrm{~mol}^{-1} \mathrm{~s}^{-1}\right)\end{array}$ \\
\hline & $6-31 \mathrm{G}(\mathrm{d})$ & 52,30 & 38,85 & 39,44 & $2,82 \times 10^{-26}$ \\
HF & $6-31 \mathrm{G}(\mathrm{d}, \mathrm{p})$ & 50,78 & 37,22 & 37,92 & $3,67 \times 10^{-25}$ \\
& $6-31+\mathrm{G}(\mathrm{d}, \mathrm{p})$ & 52,04 & 38,59 & 39,18 & $4,38 \times 10^{-26}$ \\
& $6-311+\mathrm{G}(\mathrm{d}, \mathrm{p})$ & 52,16 & 38,71 & 39,30 & $3,60 \times 10^{-26}$ \\
\hline \multirow{3}{*}{ B3LYP } & $6-31 \mathrm{G}(\mathrm{d})$ & 31,41 & 17,96 & 18,55 & $5,83 \times 10^{-11}$ \\
& $6-31 \mathrm{G}(\mathrm{d}, \mathrm{p})$ & 29,82 & 19,36 & 19,96 & $8,59 \times 10^{-10}$ \\
& $6-31+\mathrm{G}(\mathrm{d}, \mathrm{p})$ & 32,71 & 19,26 & 19,85 & $6,50 \times 10^{-12}$ \\
& $6-311+\mathrm{G}(\mathrm{d}, \mathrm{p})$ & 32,97 & 19,52 & 20,11 & $4,18 \times 10^{-11}$ \\
\hline \multirow{2}{*}{ MP2 } & $6-31 \mathrm{G}(\mathrm{d}, \mathrm{p})$ & 27,75 & 14,30 & 14,89 & $2,82 \times 10^{-08}$ \\
\hline
\end{tabular}

Tabela 5.31 - Resultados para a Reação 1 do Caminho 2 (5.45).

\begin{tabular}{|c|c|c|c|c|c|}
\hline \multicolumn{2}{|c|}{ Modelo Químico } & \multicolumn{4}{|c|}{$\begin{array}{c}\text { Caminho 2 -Reação 1 (5.45) } \\
\Delta^{*} \mathbf{S}^{\mathbf{0}}-29,99\left(\text { cal K}^{-1} \mathrm{~mol}^{-1}\right) ; \mathbf{A ~} 4,70 \times 10^{6}\left(\mathrm{~L} \mathrm{~mol}^{-1} \mathrm{~s}^{-1}\right)\end{array}$} \\
\hline $\begin{array}{l}\text { Nível de } \\
\text { Teoria }\end{array}$ & Basis set & $\begin{array}{c}\Delta^{\dagger} \mathbf{G}^{\mathbf{0}} \\
(\mathrm{kcal} \mathrm{mol})\end{array}$ & $\begin{array}{c}\Delta^{\dagger} \mathbf{H}^{\mathbf{0}} \\
\left(\mathrm{kcal} \mathrm{mol}^{-1}\right)\end{array}$ & $\begin{array}{c}\mathbf{E a} \\
\left(\mathrm{kcal} \mathrm{mol}^{-1}\right)\end{array}$ & $\begin{array}{c}\mathbf{k}_{\mathbf{2}} \\
\left(\mathrm{L} \mathrm{mol}^{-1} \mathrm{~s}^{-1}\right)\end{array}$ \\
\hline \multirow{4}{*}{ HF } & $6-31 G(d)$ & 28,75 & 19,81 & 20,40 & $5,20 \times 10^{-09}$ \\
\hline & $6-31 \mathrm{G}(\mathrm{d}, \mathrm{p})$ & 26,99 & 18,05 & 18,64 & $1,02 \times 10^{-07}$ \\
\hline & $6-31+G(d, p)$ & 27,06 & 18,12 & 18,71 & $9,07 \times 10^{-08}$ \\
\hline & $6-311+G(d, p)$ & 27,19 & 18,25 & 18,84 & $7,23 \times 10^{-08}$ \\
\hline \multirow{4}{*}{ B3LYP } & $6-31 G(d)$ & $-3,06$ & $-12,00$ & $-11,41$ & $1,08 \times 10^{+15}$ \\
\hline & 6-31G(d,p) & $-4,92$ & $-13,86$ & $-13,27$ & $2,50 \times 10^{+16}$ \\
\hline & $6-31+G(d, p)$ & $-4,35$ & $-13,29$ & $-12,70$ & $9,59 \times 10^{+15}$ \\
\hline & $6-311+G(d, p)$ & $-3,77$ & $-12,71$ & $-12,12$ & $3,59 \times 10^{+15}$ \\
\hline MP2 & $6-31 \mathrm{G}(\mathrm{d}, \mathrm{p})$ & 3,75 & 5,19 & 4,60 & $1,11 \times 10^{+10}$ \\
\hline
\end{tabular}


Tabela 5.32 - Resultados para a Reação 3 _1 do Caminho 2 (5.47).

\begin{tabular}{|c|c|c|c|c|c|}
\hline \multicolumn{2}{|c|}{ Modelo Químico } & \multicolumn{4}{|c|}{$\begin{array}{l}\text { Caminho 2 - Reação 3_1 (5.47) } \\
\Delta^{\ddagger} \mathbf{S}^{\mathbf{0}}-42,06\left(\mathrm{cal} \mathrm{K}^{-1} \mathrm{~mol}^{-1}\right) ; \mathbf{A} 1,09 \times 10^{4}\left(\mathrm{~L} \mathrm{~mol}^{-1} \mathrm{~s}^{-1}\right)\end{array}$} \\
\hline $\begin{array}{l}\text { Nível de } \\
\text { Teoria }\end{array}$ & Basis set & $\begin{array}{c}\Delta^{\ddagger} \mathbf{G}^{\mathbf{0}} \\
\left.(\mathrm{kcal} \mathrm{mol})^{-1}\right)\end{array}$ & 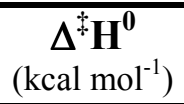 & $\begin{array}{c}\text { Ea } \\
\left(\mathrm{kcal} \mathrm{mol}^{-1}\right)\end{array}$ & $\begin{array}{c}\mathbf{k}_{21} \\
\left(\mathrm{~L} \mathrm{~mol}^{-1} \mathrm{~s}^{-1}\right)\end{array}$ \\
\hline \multirow{4}{*}{ HF } & $6-31 G(d)$ & 64,20 & 51,66 & 52,25 & $5,40 \times 10^{-35}$ \\
\hline & $6-31 G(d, p)$ & 45,40 & 32,86 & 33,45 & $3,26 \times 10^{-21}$ \\
\hline & $6-31+\mathrm{G}(\mathrm{d}, \mathrm{p})$ & 45,82 & 33,28 & 33,88 & $1,59 \times 10^{-21}$ \\
\hline & $6-311+G(d, p)$ & 46,26 & 33,72 & 34,31 & $7,59 \times 10^{-22}$ \\
\hline \multirow{4}{*}{ B3LYP } & $6-31 G(d)$ & 26,56 & 14,02 & 14,61 & $2,12 \times 10^{-07}$ \\
\hline & $6-31 G(d, p)$ & 24,92 & 12,38 & 12,98 & $3,33 \times 10^{-06}$ \\
\hline & $6-31+G(d, p)$ & 26,89 & 14,35 & 14,94 & $1,20 \times 10^{-07}$ \\
\hline & $6-311+G(d, p)$ & 27,30 & 14,76 & 15,35 & $6,06 \times 10^{-08}$ \\
\hline MP2 & $6-31 G(d, p)$ & 24,07 & 11,53 & 12,13 & $1,40 \times 10^{-05}$ \\
\hline
\end{tabular}

Tabela 5.33 - Resultados para a Reação 3 2 do Caminho 2 (5.48).

\begin{tabular}{|c|c|c|c|c|c|}
\hline \multicolumn{2}{|c|}{ Modelo Químico } & \multicolumn{4}{|c|}{$\begin{array}{c}\text { Caminho 2 - Reação 3_2 (5.48) } \\
\Delta \mathbf{S}^{\mathbf{0}}-46,34\left(\mathrm{cal} \mathrm{K}^{-1} \mathrm{~mol}^{-1}\right) ; \mathbf{A} 1,26 \times 10^{3}\left(\mathrm{~L} \mathrm{~mol}^{-1} \mathrm{~s}^{-1}\right)\end{array}$} \\
\hline $\begin{array}{l}\text { Nível de } \\
\text { Teoria }\end{array}$ & Basis set & $\begin{array}{c}\Delta^{\dagger} \mathbf{G}^{\mathbf{0}} \\
\left(\mathrm{kcal} \mathrm{mol}^{-1}\right)\end{array}$ & $\begin{array}{c}\Delta^{*} \mathbf{H}^{\mathbf{0}} \\
\left(\mathrm{kcal} \mathrm{mol}^{-1}\right)\end{array}$ & $\begin{array}{c}\mathbf{E a} \\
\left(\mathrm{kcal} \mathrm{mol}^{-1}\right)\end{array}$ & $\begin{array}{c}\mathbf{k}_{22} \\
\left(\mathrm{~L} \mathrm{~mol}^{-1} \mathrm{~s}^{-1}\right) \\
\end{array}$ \\
\hline \multirow{4}{*}{ HF } & $6-31 G(d)$ & 62,09 & 48,27 & 48,86 & $1,90 \times 10^{-33}$ \\
\hline & 6-31G(d,p) & 43,37 & 29,55 & 30,14 & $1,00 \times 10^{-19}$ \\
\hline & $6-31+\mathrm{G}(\mathrm{d}, \mathrm{p})$ & 44,02 & 30,21 & 30,80 & $3,32 \times 10^{-20}$ \\
\hline & $6-311+G(d, p)$ & 44,63 & 30,81 & 31,41 & $1,19 \times 10^{-20}$ \\
\hline \multirow{4}{*}{ B3LYP } & $6-31 G(d)$ & 20,63 & 6,81 & 7,41 & $4,67 \times 10^{-03}$ \\
\hline & 6-31G(d,p) & 18,97 & 5.15 & 5,74 & $7,77 \times 10^{-02}$ \\
\hline & $6-31+G(d, p)$ & 21,52 & 7,71 & 8,30 & $1,04 \times 10^{-03}$ \\
\hline & $6-311+G(d, p)$ & 22,09 & 8,27 & 8,87 & $3,98 \times 10^{-04}$ \\
\hline MP2 & $6-31 G(d, p)$ & 18,19 & 4,35 & 4,95 & $2,98 \times 10^{-01}$ \\
\hline
\end{tabular}


Tabela 5.34 - Resultados para a Reação 1 do caminho 3 (5.50).

\begin{tabular}{|c|c|c|c|c|c|}
\hline \multicolumn{2}{|c|}{ Modelo Químico } & \multicolumn{4}{|c|}{$\begin{array}{c}\text { Caminho 3 - Reação 1 (5.50) } \\
\Delta^{\ddagger} \mathbf{S}^{\mathbf{0}}-34,83\left(\mathrm{cal} \mathrm{K}^{-1} \mathrm{~mol}^{-1}\right) ; \mathbf{A ~} 4,11 \times 10^{5}\left(\mathrm{~L} \mathrm{~mol}^{-1} \mathrm{~s}^{-1}\right)\end{array}$} \\
\hline $\begin{array}{l}\text { Nível de } \\
\text { Teoria }\end{array}$ & Basis set & $\begin{array}{c}\Delta^{\dagger} \mathbf{G}^{\mathbf{0}} \\
\left(\mathrm{kcal} \mathrm{mol}^{-1}\right)\end{array}$ & $\begin{array}{c}\Delta^{\ddagger} \mathbf{H}^{\mathbf{0}} \\
\left(\mathrm{kcal} \mathrm{mol}^{-1}\right)\end{array}$ & $\begin{array}{c}\text { Ea } \\
\left(\mathrm{kcal} \mathrm{mol}^{-1}\right)\end{array}$ & $\begin{array}{c}\mathbf{k}_{3} \\
\left(\mathrm{~L} \mathrm{~mol}^{-1} \mathrm{~s}^{-1}\right)\end{array}$ \\
\hline \multirow{4}{*}{ HF } & $6-31 G(d)$ & 37,16 & 26,78 & 27,37 & $3,54 \times 10^{-15}$ \\
\hline & $6-31 G(d, p)$ & 34,61 & 24,23 & 24,82 & $2,63 \times 10^{-13}$ \\
\hline & $6-31+\mathrm{G}(\mathrm{d}, \mathrm{p})$ & 36,28 & 25,89 & 26,48 & $1,58 \times 10^{-14}$ \\
\hline & $6-311+G(d, p)$ & 37,89 & 27,50 & 28,09 & $1,04 \times 10^{-15}$ \\
\hline \multirow{4}{*}{ B3LYP } & $6-31 G(d)$ & 19,51 & 9,13 & 9,72 & $3,07 \times 10^{-02}$ \\
\hline & $6-31 G(d, p)$ & 17,39 & 7,01 & 7,60 & $1,10 \times 10^{-00}$ \\
\hline & $6-31+G(d, p)$ & 20,71 & 10,32 & 10,91 & $4,11 \times 10^{-03}$ \\
\hline & $6-311+\mathrm{G}(\mathrm{d}, \mathrm{p})$ & 22,79 & 12,40 & 12,99 & $1,23 \times 10^{-04}$ \\
\hline MP2 & $6-31 G(d, p)$ & 23,11 & 12,72 & 13,31 & $7,15 \times 10^{-05}$ \\
\hline
\end{tabular}


Tabela 5.35 - Resultados para a reação 5.51 de formação da acrilamida

\begin{tabular}{|c|c|c|c|c|c|c|c|c|}
\hline \multicolumn{2}{|c|}{ Modelo Químico } & \multicolumn{7}{|c|}{$\Delta \mathbf{S}_{\mathrm{r}}^{\mathbf{0}} 43,26\left(\mathrm{cal} \mathrm{K}^{-1} \mathrm{~mol}^{-1}\right) \Delta^{\ddagger} \mathbf{S}^{0}-1,18\left(\mathrm{cal} \mathrm{K}^{-1} \mathrm{~mol}^{-1}\right) \mathbf{A} 9,31 \times 10^{12}\left(\mathrm{~s}^{-1}\right)$} \\
\hline $\begin{array}{l}\text { Nível de } \\
\text { Teoria }\end{array}$ & Basis set & $\begin{array}{c}\Delta \mathrm{H}_{\mathrm{r}}^{0} \\
\left(\mathrm{kcal} \mathrm{mol}^{-1}\right) \\
\end{array}$ & $\begin{array}{c}\Delta G_{r}^{0} \\
\left(\mathrm{kcal} \mathrm{mol}^{-1}\right) \\
\end{array}$ & $\begin{array}{c}\text { Barreira } \\
\left(\text { kcal mol }^{-1}\right)\end{array}$ & $\begin{array}{c}\Delta^{\ddagger} G^{0} \\
\left(\text { kcal mol }{ }^{-1}\right)\end{array}$ & $\begin{array}{c}\Delta^{\ddagger} \mathbf{H}^{0} \\
\left(\mathrm{kcal}_{\mathrm{mol}}{ }^{-1}\right)\end{array}$ & $\begin{array}{c}\text { Ea } \\
\left(\text { kcal mol }^{-1}\right)\end{array}$ & $\begin{array}{c}\mathbf{k}_{4} \\
\left(\mathbf{s}^{-1}\right)\end{array}$ \\
\hline \multirow{4}{*}{$\mathbf{H F}$} & $6-31 \mathrm{G}(\mathrm{d})$ & 12,52 & $-0,38$ & 27,66 & 25,94 & 25,58 & 26,18 & $6,02 \times 10^{-07}$ \\
\hline & $6-31 G(d, p)$ & 11,99 & $-0,91$ & 27,43 & 25,71 & 25,36 & 25,95 & $8,85 \times 10^{-07}$ \\
\hline & $6-31+G(d, p)$ & 9,84 & $-3,06$ & 27,27 & 25,55 & 25,19 & 25,79 & $1,16 \times 10^{-06}$ \\
\hline & $6-311+G(d, p)$ & 9,49 & $-3,41$ & 27,27 & 25,54 & 25,19 & 25,78 & $1,17 \times 10^{-06}$ \\
\hline \multirow{4}{*}{ B3LYP } & $6-31 G(d)$ & 14,46 & 1,57 & 23,23 & 21,51 & 21,15 & 21,75 & $1,07 \times 10^{-03}$ \\
\hline & $6-31 G(d, p)$ & 14,13 & 1,23 & 23,08 & 21,36 & 21,01 & 21,60 & $1,37 \times 10^{-03}$ \\
\hline & $6-31+G(d, p)$ & 11,33 & $-1,57$ & 22,69 & 20,96 & 20,61 & 21,20 & $2,68 \times 10^{-03}$ \\
\hline & $6-311+G(d, p)$ & 10,32 & $-2,58$ & 22,40 & 20,67 & 20,32 & 20,91 & $4,37 \times 10^{-03}$ \\
\hline \multirow{3}{*}{ MP2 } & $6-31 \mathrm{G}(\mathrm{d})$ & 23,45 & 10,55 & 36,92 & 35,20 & 34,84 & 35,44 & $9,82 \times 10^{-13}$ \\
\hline & $6-31 G(d, p)$ & 23,59 & 10,70 & 36,80 & 35,07 & 34,72 & 35,31 & $1,21 \times 10^{-13}$ \\
\hline & $6-31 G+(d, p)$ & 34,57 & 21,67 & 35,72 & 33,99 & 33,64 & 34,23 & $7,49 \times 10^{-13}$ \\
\hline
\end{tabular}




\subsection{Discussões para Poliacrilamida}

Os cálculos para PAM seguiram os mesmos procedimentos descritos na secção 5.4 para PEG. Assim, não foram considerados efeitos do solvente, a otimização foi feita com o modelo $\mathrm{HF} / 6-31 \mathrm{G}(\mathrm{d})$ com o critério opt=tight, a estrutura de transição foi verificada com cálculo IRC e todas as estruturas foram submetidas a cálculos de energia single point com modelos químicos mais complexos.

As tabelas 5.17 a 5.19 mostram as freqüências vibracionais obtidas para as estruturas otimizadas com o modelo $\mathrm{HF} / 6-31 \mathrm{G}(\mathrm{d})$ corrigidas com o fator 0,8929 , para as reações 5.40 a 5.51. Como observado no caso do PEG, há freqüências muito baixas, 23 e $21 \mathrm{~cm}^{-1}$, para os radicais PAM_alquilperoxila 1 e 2, respectivamente. Estas freqüências não foram tratadas como rotações internas, provocadas pelo grande tamanho da molécula, portanto deve-se considerar este fato como possível fonte de erros no cálculo da constante de reação.

As Figuras 5.23, 5.24 e 5.25 mostram as estruturas de transição para as reações de abstração de hidrogênio pelo radical hidroxila: reações 5.40, 5.45 e 5.50, respectivamente. $\mathrm{O}$ deslocamento do átomo de hidrogênio em direção ao radical hidroxila corresponde à coordenada de reação referente às freqüências imaginárias $2857 i$ e $2769 i$ para as reações 1 dos caminhos 1 e 2 , reações 5.40 e 5.45 . A estrutura de transição da reação1 do caminho 3 foi a mais difícil de ser calculada, mesmo após os cálculos $o p t=Q S T 3$ seguida de $o p t=T S$. Obteve-se uma estrutura em que além da abstração do hidrogênio do grupo amida, átomo H22, Figura 5.25, há uma ligação entre o oxigênio do grupo amida $\mathrm{O} 7$ e o átomo de hidrogênio do radical hidroxila H23. A freqüência imaginária de $1151 \mathrm{~cm}^{-1}$ corresponde a um deslocamento grande do átomo de hidrogênio do grupo amida (H22) em direção ao oxigênio do radical hidroxila $(\mathrm{O} 24)$ e também a um pequeno movimento do hidrogênio H23 em direção ao O24. O cálculo IRC mostrou como produto uma estrutura parecida com a Figura 5.24, com a formação de uma ligação $\mathrm{O} 7-\mathrm{H} 23$ e a abstração do hidrogênio do grupo amida (ligação H22-O24). O reagente obtido no cálculo IRC mostra o H22 ainda unido ao átomo de nitrogênio do grupo amida, mas o H23 já desligado O24. 
Os cálculos de energia, Tabelas 5.21 e 5.22 mostram o mesmo comportamento, já discutido para PEG, de diminuição da energia com o aumento do basis set, para um mesmo nível de teoria. Outra característica em comum é a diferença da energia calculada com o método de Hartree-Fock e com o método da Teoria do Funcional de Densidade, B3LYP, que, por considerar o efeito da correlação eletrônica, apresenta valores de energia menores. A teoria de MöllerPlesset de segunda ordem (MP2) apresenta valores intermediários.

Para as reações de abstração de hidrogênio pelo radical hidroxila, reações 5.40 e 5.45, os valores da entalpia e energia livre de Gibbs de reação, Tabelas 5.23 e 5.24, são negativos para ambas as reações e semelhantes aos resultados da reação 5.1 de abstração de hidrogênio do dietilenoglicol pelo radical hidroxila. Estas reações também apresentam $\Delta \mathrm{H}_{\mathrm{r}}^{0}<0, \Delta \mathrm{G}_{\mathrm{r}}^{0}<0$ e $\Delta \mathrm{S}_{\mathrm{r}}^{0}>0$ (Tabela 5.26), sendo favoráveis aos produtos, como a reação 5.1 para o dietilenoglicol. Os resultados da barreira de ativação, Tabela 5.27, também apresentam uma inversão de sinal quando se muda do nível de teoria Hartree-Fock para B3LYP, apresentando valor positivo de 0,58 kcal $\mathrm{mol}^{-1}$ apenas para o caminho 1 , reação 5.40, com o modelo MP2/6-31G(d,P)//HF/6$31 \mathrm{G}(\mathrm{d})$. Os resultados cinéticos para as reações 5.40 e 5.45, Tabelas 5.28 e 5.31, também apresentam inversão de sinal para os valores de $\Delta^{\ddagger} \mathrm{H}^{0}, \Delta^{\ddagger} \mathrm{G}^{0}$ e Ea, quando se muda de modelo HF para B3LYP, com exceção do valor de $\Delta^{\ddagger} G^{0}$ para MP2/6$31 \mathrm{G}(\mathrm{d}, \mathrm{p})$, que é positivo para ambas as reações. Com relação a constante de velocidade de reação os resultados obtidos com MP2/6-31G(d,p)//HF/6-31G(d), foram $\mathrm{k}_{1}=7,21 \times 10^{+07}$ e $\mathrm{k}_{2}=1,11 \times 10^{+10} \mathrm{~L} \mathrm{~mol}^{-1} \mathrm{~s}^{-1}$, para as reações 5.40 e 5.45 , respectivamente. Na reação 5.45 o hidrogênio abstraído é terciário e, portanto apresenta uma menor energia de ligação com o carbono e uma constante de velocidade de reação maior que para a reação 5.40, na qual o hidrogênio a ser retirado é secundário. Entretanto, a falta de dados experimentais não permite avaliar se a diferença de entre $\mathrm{k}_{1}$ e $\mathrm{k}_{2}\left(\mathrm{k}_{2}=152,6 \mathrm{k}_{1}\right)$ representa a realidade.

Para o caminho 3, correspondente à abstração de hidrogênio do grupo amida, reação 5.50, todos os resultados: $\Delta \mathrm{H}_{\mathrm{r}}^{0}, \Delta \mathrm{G}_{\mathrm{r}}^{0}$ e $\Delta \mathrm{S}_{\mathrm{r}}^{0}$, Tabelas 5.23, 5.24 e 5.26; barreira de ativação, Tabela 5.27 e os cálculos cinéticos, Tabela 5.34, são completamente diferentes daqueles obtidos para as reações 5.40 e 5.45. A reação 5.50 é endotérmica e apresenta barreiras de ativação sempre positivas para todos os 
modelos químicos estudados. Os resultados de $\Delta^{\ddagger} \mathrm{H}^{0}, \Delta^{\ddagger} \mathrm{G}^{0}$ e Ea não apresentam inversão de sinal e a constante de reação $\mathrm{k}_{3}=7,15 \times 10^{-5} \mathrm{~L} \mathrm{~mol}^{-1} \mathrm{~s}^{-1}$ para o modelo MP2/6-31G(d,p)//HF/6-31G(d) indica que esta reação é mais lenta que as reações de abstração de hidrogênio pelo radical hidroperoxila para o dietilenoglicol (reação 5.3 e 5.7). Entretanto, os resultados do cálculo IRC deixam dúvidas se a estrutura de transição encontrada para esta reação de fato une reagentes a produtos.

As reações 5.42, 5.43, 5.47 e 5.48 de abstração de hidrogênio da 2-metil pentanodiamida pelos radicais PAM_alquilperoxila 1 e 2 são as etapas mais lentas do processo oxidativo. Suas estruturas de transição são mostradas nas Figuras 5.26 a 5.29. Para todas as estruturas o deslocamento do átomo de hidrogênio em direção ao radical hidroxila corresponde à coordenada de reação referente às freqüências imaginárias 2987i, 3099i, 3111i e 3085i, mostradas na Tabela 5.18.

As energias eletrônicas para os reagentes e produtos e para as estruturas de transição das reações 5.42, 5.43, 5.47 e 5.48 são apresentadas nas Tabelas 5.21 e 5.22. A Figura 5.34 mostra a diferença de energia entre as estruturas de transição das reações 5.42 e 5.43, para o caminho 1, das reações 5.47 e 5.48 para o caminho 2 .

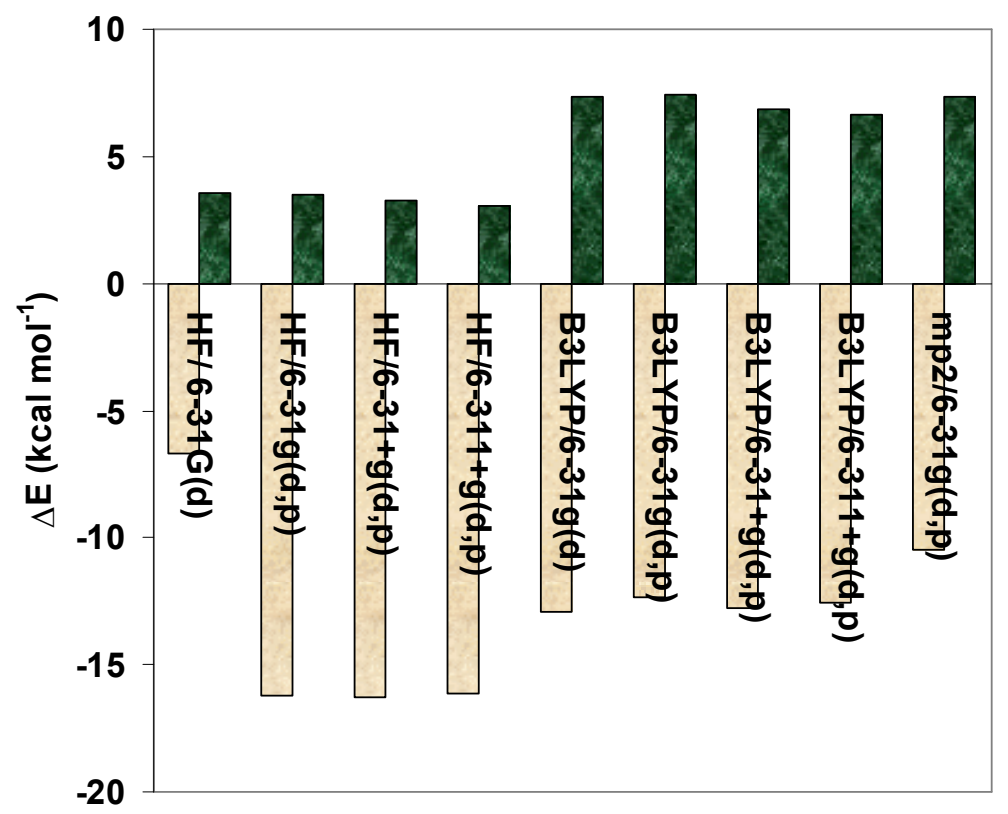

Figura 5.34 - Diferenças de energia eletrônica entre as estruturas de transição:

PAM1: Reação3_1_TS (reação 5.42) - Reação3_2_TS (5.43)

口 PAM2: Reação3_1_TS (reação 5.47) - Reação3_2_TS (5.48). 
As reações 5.42 e 5.47 correspondem a abstrações de um hidrogênio secundário e as reações 5.43 e 5.48 a abstrações de um hidrogênio terciário. Portanto seria esperado que a diferença de energia entre as estruturas de transição destas reações fossem ambas positivas, com as estruturas das reações mais "fáceis" de acontecer (5.47 e 5.48) com energia menor. Entretanto como pode ser visto na Figura 5.34 a diferença de energia para o caminho 1 é negativa, aproximadamente $12 \mathrm{kcal}$ $\mathrm{mol}^{-1}$ para o método Hartree-Fock.

A análise de $\Delta \mathrm{H}_{\mathrm{r}}^{0}>0$ (Tabela 5.23), $\Delta \mathrm{G}_{\mathrm{r}}^{0}>0$ (Tabela 5.24) e $\Delta \mathrm{S}_{\mathrm{r}}^{0}<0$ (Tabela 5.26) para a reação 5.43 indica que esta reação não é favorável aos produtos, já para as reações 5.42, 5.47 e $5.48 \Delta \mathrm{S}_{\mathrm{r}}^{0}$ é maior que zero e elas podem ser favoráveis aos produtos dependendo da magnitude de $\Delta \mathrm{H}_{\mathrm{r}}^{0}$ e $\Delta \mathrm{G}_{\mathrm{r}}^{0}$. A barreira de ativação para estas reações também segue a tendência da energia eletrônica, obtendo-se barreiras menores para a reação 5.42 , se comparada a 5.43 e maiores para a 5.47 comparandose com a 5.48 (Tabela 5.27). Outra comparação que pode ser feita em termos de barreiras de ativação é que se espera que o radical alquilperoxila secundário, que participa do caminho 1 , seja mais reativo que o terciário, que participa do caminho 2 , tendo barreiras de energia menores, o que só é observado para as reações 3_1, 5.42 e 5.47 .

Os resultados cinéticos para as reações 5.42 e 5.43, Tabelas 5.29 e 5.30, mostram valores próximos para $\Delta^{\ddagger} \mathrm{S}^{0}$ e para o fator pré-exponencial $\mathbf{A}$, porém os valores de $\Delta^{\star} \mathrm{H}^{0}, \Delta^{\ddagger} \mathrm{G}^{0}$ e energia de ativação, Ea, são sempre menores para a reação 5.42. Como resultado a constante de velocidade da reação 5.42 é $10^{8}$ vezes maior $\left(\mathbf{k}_{11}=5,60 \mathrm{~L} \mathrm{~mol}^{-1} \mathrm{~s}^{-1}\right)$ que a constante de velocidade da reação $5.43\left(\mathbf{k}_{\mathbf{1 2}}=2,82 \times 10^{-08}\right.$ $\left.\mathrm{L} \mathrm{mol}^{-1} \mathrm{~s}^{-1}\right)$. Para as reações do caminho 2, 5.47 e 5.48, os resultados cinéticos para a abstração do hidrogênio secundário são sempre maiores (tabela 5.32) que os para a abstração do carbono terciário (tabela 5.33). Assim a constante de velocidade para a reação 5.47 foi bem menor $\left(\mathbf{k}_{\mathbf{2 1}}=1,40 \times 10^{-05} \mathrm{~L} \mathrm{~mol}^{-1} \mathrm{~s}^{-1}\right)$ que a constante de velocidade da reação $5.48\left(\mathbf{k}_{22}=2,98 \times 10^{-01} \mathrm{~L} \mathrm{~mol}^{-1} \mathrm{~s}^{-1}\right)$.

Os resultados para o caminho 1 indicam que a abstração de hidrogênio secundário pelo radical PAM_alquilperoroxila 1 (reação 5.42) é mais favorecida que a abstração do hidrogênio terciário (reação 5.43). Embora este resultado não seja 
esperado é difícil procurar sua causa sem uma análise de impedimento estérico, já que os reagentes de todas estas reações possuem grupos laterais. Outra fonte de erro é a presença de freqüências muito baixas, que não foram tratadas como rotações internas.

As reações 5.41 e 5.42, entre os radicais PAM_alquila 1 e 2 e o oxigênio formando os radicais PAM_alquilperoxila 1 e 2, têm resultados semelhantes às reações equivalentes para o dietilenoglicol, 5.2 e 5.6. Para estas reações $\Delta \mathrm{H}_{\mathrm{r}}^{0}($ Tabela 5.23), $\Delta \mathrm{G}_{\mathrm{r}}^{0}$ (Tabela 5.24) e $\Delta \mathrm{S}_{\mathrm{r}}^{0}$ (Tabela 5.26), apresentam valores menores que zero. Neste caso não foram feitas tentativas de cálculo das estruturas de transição, pela metodologia proposta.

As reações 5.44 e 5.49, de abstração do hidrogênio do grupo amida pelos radicais alquilperoxila, para os caminhos 1 e 2, não são favoráveis aos produtos, pela análise de $\Delta \mathrm{H}_{\mathrm{r}}^{0}>0, \Delta \mathrm{G}_{\mathrm{r}}^{0}>0$ e $\Delta \mathrm{S}_{\mathrm{r}}^{0}<0$. Inúmeras tentativas de encontrar suas estruturas de transição, empregando-se a mesma metodologia utilizada nas demais reações, resultaram em falhas no cálculo opt $=Q S T 3$ ou $o p t=T S$, encontrando-se mais de uma freqüência negativa. Conclui-se que muito provavelmente estas reações não ocorrem ou o mecanismo de abstração direta, da forma como foi modelado, não acontece para estes casos.

A Figura 5.35 mostra a estrutura da acrilamida com os comprimentos de ligação entre os átomos e a Tabela 5.36 apresenta os valores correspondentes das mesmas ligações na estrutura de transição (Figura 5.33) e no radical PAM4_alquila (Figura 5.31).

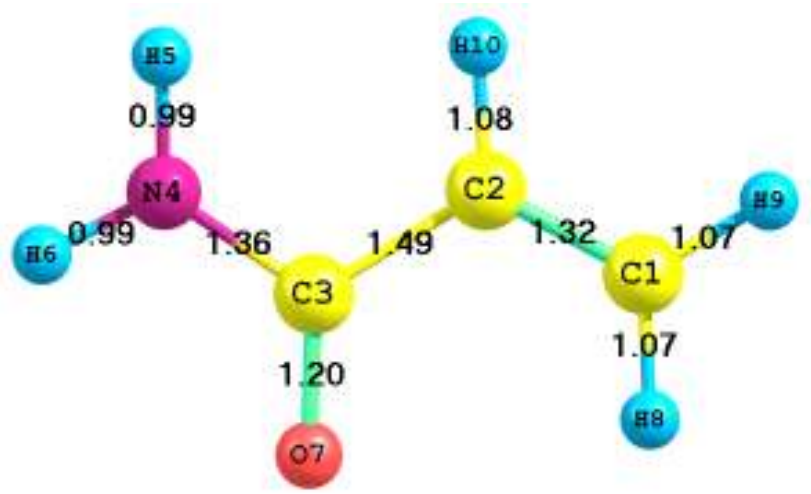

Figura 5.35 - Geometria da acrilamida com os valores de comprimento de ligação. 
Tabela 5.36 - Comprimentos de ligação para a acrilamida e as distâncias correspondentes na estrutura de transição e no reagente PAM4_Radical.

\begin{tabular}{c|c|c|c}
\hline $\begin{array}{c}\text { Distâncias } \\
\text { (Angstrons) }\end{array}$ & PAM4_Radical & $\begin{array}{c}\text { Estrutura de } \\
\text { Transição }\end{array}$ & Acrilamida \\
\hline C1-C2 & 1,51095 & 1,39365 & 1,31840 \\
C2-C3 & 1,52917 & 1,49327 & 1,49408 \\
C3-N4 & 1,34723 & 1,35080 & 1,35544 \\
C3-O7 & 1,20307 & 1,20510 & 1,20001 \\
C1-H8 & 1,07418 & 1,07294 & 1,07399 \\
C1-H9 & 1,07431 & 1,07400 & 1,07683 \\
C2-H10 & 1,09211 & 1,07665 & 1,07693 \\
N4-H5 & 0,99302 & 0,99309 & 0,99266 \\
N4-H6 & 0,99542 & 0,99546 & 0.99494 \\
\hline
\end{tabular}

Os parâmetros geométricos na Tabela 1 mostram a aproximação dos átomos C1 e C2 na estrutura de transição, para a formação da dupla ligação da acrilamida. Também se pode observar na estrutura de transição a aproximação dos átomos C2 e C3 e o afastamento de $\mathrm{C} 3$ e $\mathrm{N} 4$ e entre C3 e O7, aproximando estes valores dos parâmetros da acrilamida.

As freqüências vibracionais para os reagentes e produtos da reação 5.51 são apresentadas na Tabela 5.19. Observa-se o grande número de baixas freqüências que correspondem a movimentos de rotação da molécula, principalmente para PAM4_radical e para a estrutura de transição. A freqüência negativa de $410 \mathrm{~cm}^{-1}$ corresponde ao afastamento dos carbonos C2 e C3 da Figura 5.33. Apesar de representar a quebra da ligação desejada seu baixo valor, se comparado às freqüências imaginárias para a abstração de hidrogênio, da grandeza de $2900 \mathrm{~cm}^{-1}$, e a falta de dados para comparação não permitem avaliar este resultado.

Os resultados cinéticos apresentados na Tabela 5.35 apresentam todos os valores para o nível de teoria Möller Plesset (MP2) maiores que os resultados obtidos com Hartree-Fock: $\Delta \mathrm{H}_{\mathrm{r}}^{0}, \Delta \mathrm{G}_{\mathrm{r}}^{0}$, barreira de ativação, $\Delta^{\star} \mathrm{H}^{0}, \Delta^{\ddagger} \mathrm{G}^{0}$ e energia de ativação (Ea). Além disso, o fator pré-exponencial $A=9,31 \times 10^{12}\left(\mathrm{~s}^{-1}\right)$ foi ainda maior 
que os obtidos para a abstração de hidrogênio pelo radical hidroxila. O motivo deste alto valor de A é o baixo valor de $\Delta^{\ddagger} \mathrm{S}^{0}$ devido á proximidade dos valores de Hcorr e Gcorr para PAM4_Radical e TS_Acrilamida, mostrados na Tabela 5.20 (Hcorr: 0,3614 e 0,3581 e Gcorr: 0,2815 e 0,2787 Hartrees, respectivamente). Como $\Delta^{\sharp} \mathrm{S}^{0}$ é calculado de acordo com a equação:

$$
\Delta^{\ddagger} \mathrm{S}^{0}=\frac{\Delta^{\ddagger} \mathrm{H}^{0}-\Delta^{\ddagger} \mathrm{G}^{0}}{\mathrm{~T}}
$$

Em que:

$$
\begin{aligned}
\Delta^{\ddagger} \mathrm{H}^{0} & =\left(\varepsilon_{0}+\text { Hcorr }\right)_{\mathrm{TS}}-\left(\varepsilon_{0}+\text { Hcorr }\right)_{\text {Reagente }} \\
\Delta^{\ddagger} \mathrm{G}^{0} & =\left(\varepsilon_{0}+\text { Gcorr }\right)_{\mathrm{TS}}-\left(\varepsilon_{0}+\text { Gcorr }\right)_{\text {Reagente }}
\end{aligned}
$$

Substituindo na equação E11:

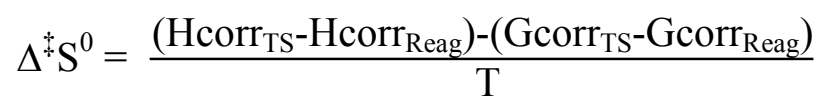

Devido à proximidade entre os valores de Hcorr para os reagentes e a estrutura de transição, o mesmo acontecendo para Gcorr, o valor de $\Delta^{\ddagger} \mathrm{S}^{0}$ calculado foi muito baixo: $-1,18 \mathrm{cal} \mathrm{K}^{-1} \mathrm{~mol}^{-1}$.

Considerando a constante de velocidade "correta" aquela obtida pelo nível de teoria MP2, como no caso das reações de abstração anteriores, ela será da ordem de $10^{-13} \mathrm{~s}^{-1}$, não considerando a variação do basis set. Embora não haja dados para comparação, esperava-se que esta reação tivesse uma constante de velocidade de muito baixa, já que a acrilamida não foi detectada experimentalmente, com um limite de detecção de 50 ppb. 


\subsection{Conclusões da Modelagem Molecular}

Os resultados das constantes de velocidades obtidas na modelagem molecular do dietilenoglicol e da 2-metil pentanodiamida, bem como da reação de formação de acrilamida são apresentados na Tabela 5.37.

Tabela 5.37 - Constantes de velocidades de reação calculadas com o modelo MP2/6-31G(d,p)//HF/6-31G(d).

\begin{tabular}{c|c}
\hline $\mathrm{PH}+{ }^{\bullet} \mathrm{OH} \rightarrow \mathrm{P}^{\bullet}+\mathrm{H}_{2} \mathrm{O}$ & $\mathbf{k}\left(\mathbf{L ~} \mathbf{s ~ m o l}^{-\mathbf{1}}\right)$ \\
\hline Reação 5.1 & $3,14 \times 10^{+08}$ \\
Reação 5.40 & $7,21 \times 10^{+07}$ \\
Reação 5.45 & $1,11 \times 10^{+10}$ \\
Reação 5.50 & $7,15 \times 10^{-05}$ \\
\hline POO + PH $\rightarrow \mathrm{P}^{\bullet}+$ POOH & $\mathbf{k}\left(\mathbf{L ~ s ~ \mathbf { ~ m o l } ^ { - 1 } )}\right.$ \\
\hline Reação 5.3 & $1,55 \times 10^{-03}$ \\
Reação 5.7 & $2,74 \times 10^{0}$ \\
Reação 5.42 & $1,43 \times 10^{0}$ \\
Reação 5.43 & $2,82 \times 10^{-08}$ \\
Reação 5.47 & $1,40 \times 10^{-05}$ \\
Reação 5.48 & $2,98 \times 10^{-01}$ \\
\hline Formação de acrilamida & $\mathbf{k}\left(\mathbf{s}^{-\mathbf{1}}\right)$ \\
\hline Reação 5.51 & $1,21 \times 10^{-13}$ \\
\hline
\end{tabular}

As reações de abstração de hidrogênio pelo radical hidroxila apresentam valores de $\mathrm{k}$ da mesma ordem de grandeza das constantes de velocidade para reações de ${ }^{\bullet} \mathrm{OH}$ apresentada por Buxton et al. (1998) e também com aquelas calculadas por Lichtin (1971), com exceção da reação 5.50. Segundo Gröllman e Schnabel (1982) a razão da reatividade dos três sítios de ataque para a abstração de hidrogênio pelo radical hidroxila, Figura 2.2, é de 1:2:8. Calculando a razão entre os k obtidos para 
as reações 5.50, 5.40 e 5.45, que representam o ataque a estes respectivos locais da molécula, a razão encontrada foi $1: 1 \times 10^{12}: 1,5 \times 10^{14}$.

Para as reações de abstração de hidrogênio pelos radicais alquilperoxila, representados por $\mathrm{POO}^{\bullet}$ na Tabela 5.37, a reação 5.43 apresentou o valor de k inesperadamente baixo. Como se tratava de um radical alquilperoxila secundário, abstraindo um hidrogênio terciário o valor de $\mathbf{k}$ deveria ser maior que o da reação 5.42 na qual o hidrogênio abstraído é secundário.

A principal dificuldade com as simulações realizadas foi o tamanho das estruturas modeladas. Tal fato impede o uso de modelos químicos mais sofisticados para otimização e cálculos dos parâmetros termoquímicos para reagentes e produtos e principalmente a busca da estrutura de transição. Neste trabalho todas as otimizações e cálculos de freqüência foram realizados com o modelo HF/6-31G(d). Segundo Heuts et al. (1995) e Huang et al. (1998) são necessários modelos químicos mais sofisticados (por exemplo, QCISD/6-311g(d,p)) para obterem-se energias de ativação razoáveis. Outra possível fonte de erros foi o não tratamento das rotações internas caracterizadas pelas baixas freqüências que afetam o cálculo de $\Delta^{\dagger} \mathrm{S}^{0}$ e conseqüentemente do fator pré-exponencial (Van Sreybroeck et al., 2001 e Van Sreybroeck e Waroquier, 2002).

Apesar destas possíveis fontes de erros a proposta inicial de estudar as principais reações envolvidas no processo oxidativo de polietilenoglicol e poliacrilamida foi cumprida satisfatoriamente. Foram otimizadas 10 estruturas para o dietilenoglicol, 18 para a 2 metil pentanodiamida e foram encontradas 11 estruturas de transição. Foi confirmada a presença de sítios preferenciais de ataque para a poliacrilamida, a baixa constante de velocidade para a etapa mais lenta do processo oxidativo, constantes de velocidade coerentes para as reações de abstração de hidrogênio pelos radicais hidroxila e a baixa constante de velocidade para a reação proposta por Smith et al. (1997) para a formação da acrilamida.

Um exemplo do tempo computacional utilizado nos cálculos da estrutura de transição e nos cálculos de energia para a reação 5.42 é dado na Tabela 5.38. Estes valores são apenas para dar uma noção do tempo necessário, já que havia mais de um trabalho sendo processado ao mesmo tempo "dividindo" memória e espaço em disco. A única exceção é para o cálculo de energia com MP2 para o qual foi especificado 
$1 \mathrm{~GB}$ de memória e $19 \mathrm{~GB}$ de espaço em disco. Não foram mostrados os tempos utilizados na otimização, cálculos de freqüência e energia de reagentes e produtos e também a busca da estrutura de transição seguindo o caminho de reação porque tais cálculos foram feitos em outros sistemas.

Tabela 5.38 - Tempo de processamento para a Reação 5.42. Cluster Beowulf, 4GB de memória e 23 GB de disco.

\begin{tabular}{l|c|c|c|c}
\hline & dias & horas & minutos & segundos \\
\hline Opt (QST3) & 11 & 16 & 22 & 19,0 \\
\hline Opt (tight, TS) & 2 & 15 & 52 & 4,6 \\
\hline Freqüência para TS & 2 & 21 & 35 & 20,5 \\
\hline IRC & 3 & 23 & 24 & 11,6 \\
\hline
\end{tabular}

Energia para a Estrutura de Transição

\begin{tabular}{l|c|c|c}
\hline HF/6-31G(d,p) & 1 & 16 & 47,4 \\
HF/6-31+G(d,p) & 8 & 7 & 26,5 \\
HF/6-311+G(d,p) & 15 & 24 & 28,3 \\
B3LYP/6-31G(d) & 1 & 26 & 5,8 \\
B3LYP/6-31G(d,p) & 2 & 9 & 26,7 \\
B3LYP/6-31+G(d,p) & 9 & 17 & 31,6 \\
B3LYP/6-311+G(d,p) & 15 & 24 & 28,3 \\
${ }^{a}$ MP2/6-31G(d,p) & 12 & 24 & 21,2 \\
\hline
\end{tabular}

$\overline{{ }^{a}}$ Para o cálculo MP2 foi especificado 1 GM de memória e 19 GB de disco. 


\section{CONCLUSÕES}

O presente trabalho mostra a viabilidade da aplicação dos processos oxidativos avançados foto-Fenton e $\mathrm{UV} / \mathrm{H}_{2} \mathrm{O}_{2}$ para o tratamento de efluentes industriais aquosos contendo PEG, PAM e PVP. A análise estatística indica que os níveis das variáveis [Fe(II)] e $\left[\mathrm{H}_{2} \mathrm{O}_{2}\right]$ podem ser reduzidos para PAM e PVP. Além disso, o estudo do processo $\mathrm{UV} / \mathrm{H}_{2} \mathrm{O}_{2}$ utilizando temperaturas menores, 30 e $40{ }^{\circ} \mathrm{C}$, seria bastante interessante, pois eliminaria a necessidade da utilização de ferro.

A análise de intermediários para o PEG mostrou a formação de ácidos orgânicos que são recalcitrantes e permanecem no meio reacional, principalmente o ácido acético. Porém, podem-se empregar os processos estudados como prétratamento apenas para quebrar o polímero e integrá-los a um processo convencional, para tratar os intermediários. A análise de intermediários para PAM não identificou a formação de acrilamida com concentrações acima de 50 ppb. O limite de emissão de acrilamida estabelecido pelo CONAMA é de $0,5 \mathrm{ppb}$, o que indica a necessidade de empregar um método mais preciso para eliminar a hipótese de formação desse composto.

Para a identificação de mais intermediários e diminuição do limite de detecção da acrilamida, é necessário o uso de técnicas de análises mais específicas, o que pode envolver um pré-tratamento das amostras por liofilização para eliminar a água, por exemplo, o que possibilitaria análises de infravermelho (FTIR).

O diferente comportamento das curvas de GPC para os processos foto-Fenton e $\mathrm{UV} / \mathrm{H}_{2} \mathrm{O}_{2}$, indicando a recombinação de macro-radicais e a formação de um composto não-identificado, nas análises de HPLC para o processo $\mathrm{UV} / \mathrm{H}_{2} \mathrm{O}_{2}$, mostra diferenças nos mecanismos destes processos. A presença de ferro no processo fotoFenton pode gerar um caminho adicional, por exemplo, promovendo a formação de ferrioxalato.

A modelagem molecular confirma que a reação de abstração de hidrogênio de uma cadeia polimérica pelos radicais alquilperoxila é de fato a etapa mais lenta do processo oxidativo para PEG e PAM. Para PAM os resultados da modelagem mostram que o ataque dos radicais hidroxila acontece preferencialmente no hidrogênio ligado ao carbono terciário e que a abstração de hidrogênio do grupo 
lateral amida parece pouco viável, ou acontece por outro mecanismo. A reação de formação da acrilamida de acordo com o mecanismo proposto também apresentou uma constante cinética muito baixa, o que está de acordo com os resultados experimentais, já que não foi detectada acrilamida como produto da degradação de poliacrilamida pelos processos foto-Fenton e $\mathrm{UV} / \mathrm{H}_{2} \mathrm{O}_{2}$.

Muitas outras reações importantes envolvidas nos processos oxidativos poderiam ter sido modeladas. Por exemplo, para o processo foto-Fenton seria interessante acrescentar as reações de formação de complexos dos polímeros e radicais poliméricos com o ferro, assim como a recombinação de radicais que foi observada experimentalmente por análises de GPC, e as reações intramoleculares, apontadas por Mantzavinos et al. (1996), como uma das possíveis vias de propagação dos radicais alquilperoxila na etapa de propagação da cadeia oxidativa.

Embora não tenha sido possível modelar todas as reações de importância no processo, o presente estudo indica que é possível, com a combinação de técnicas experimentais e de modelagem molecular, obter uma série de informações valiosas para entendimento do processo e dos caminhos possíveis na oxidação dos polímeros considerados. 


\section{REFERÊNCIAS BIBLIOGRÁFICAS}

ANDREOZZI, R.; CAPRIO, V.; INSOLA, A. Kinects and Mechanisms of Polyethylene Glycol Fragmentation by Ozone in Aqueous Solution. Wat. Res. v.30, No 12, p. 2955-2960, 1996.

ANDREOZZI, R.; CAPRIO, V.; MAROTTA, R.; SANCHIRICO, R. Advanced Oxidation Processes for the Treatment of Oil-Contaminated Wastewaters. Wat. Res. v.34, p.620, 2000.

ANDREOZZI, R.; CAPRIO, V.; MAROTTA, R. Oxidation of Benzothiazole, 2Mercaptobenzothiazole and 2-Hydroxybenzothiazole in Aqueous Solution by Means of $\mathrm{H}_{2} \mathrm{O}_{2} / \mathrm{UV}$ or Photoassisted Fenton System. J. Chem. Technol. Biotechnol. v.76, p.196, 2001.

BALCIOGLU I. A., ARSLAN, I. Treatment of Textile Industry Wastewater By Enhanced Photocatalytic Oxidation Reaction. J. Adv. Oxid. Tech. 4, 189, 1999.

BALCIOGLU I. A., ARSLAN, I. Partial Oxidation of Reactive Dyestuffs and Synthetic Textille Dye-Bath by the $\mathrm{O} 3$ and $\mathrm{O} 3 / \mathrm{H} 2 \mathrm{O} 2$ Processes. Wat. Sci. Thec. 43 (2) $221,2001$.

BATEMAN, L.; MORRIS, A. L. The autoxidation of 2:6-dimethylhepta-2:5-diene. Trans. Faraday Soc., 49, p. 1026-1032, 1953.

BAUER, R.; FALLMANN, H. The Photo-Fenton Oxidation - A Cheap and Efficient Wastewater Treatment Method. Res. Chem. Intermediat., v.23, p. 341-354, 1997.

BAYCAN, N.; SENGUN, F.; THOMANETZ, E. AOX Formation and Elimination in the Oxidative Treatment of Synthetic Wastewaters in a UV-Free Surface Reactor. Environ. Sci. \& Pollut. Res., 12 (3), p. 153-158, 2005. 
BECKE, A. D. Density-Functional Thermochemistry. III The Role of the Exact Exchange. J. Chem. Phys. v.98, Issue 7, p. 5648-5652, 1993.

BENITEZ, F. J.; BELTRÁN-HEREDIA, J.; ACERO, J. L.; RUBIO, F. J. Oxidation of Several Chlorophenolic Derivatives by UV Irradiation and Hydroxyl Radicals. J. Chem. Technol. Biotechnol., v.76, p.312, 2001.

BENSON, S. W.; Kinetics of Pyrolysis of Alkyl Hydroperoxides and Their O-O Bond Dissociation Energies. J. Chem. Phys. v.40, No. 4, p.1007-1013, 1964.

BHATKHANDE, D. S., PANGARKAR, V. N., BEENACKERS, A. A. C. M. Photocatalytic Degradation for Environmental Applications: A Review. J. Chem. Technol. Biothecnol. 77 (1), p. 102, 2002.

BIGDA, R.; Consider Fenton's Chemistry for Wastewater Treatment. Chem. Eng. Prog. p.62-66,1995.

BOSSMANN, S. H.; OLIVEROS, E.; GÖB, S.; SIEGWART, S.; DAHLEN, E. P.; PAYAWAN, L.; STRAUB, M.; WÖRNER, M.; BRAUN A. M.; New Evidence against Hydroxyl Radicals as Reative Intermediate in the Thermal and Photochemically Enhanced Fenton Reaction, J. Phys. Chem. A., 102. p.5542$5550,1998$.

BOSSMANN, S. H.; OLIVEROS, E.; GÖB, S.; KANTOR, M.; GÖPPERT, A.; BRAUN, A. M; LEI, L.; YUE, P. L.; Oxidative Degradation of Polyvinyl Alcohol by the Photochemically Enhanced Fenton Reaction. Evidence for the Formation of Super-Macromolecules. Prog. React. Kinet. Mech., v.26, p.113137, 2001a.

BOSSMANN, S. H.; OLIVEROS, E.; GÖB, S.; KANTOR, M.; GÖPPERT, A.; LEI, L.; YUE, P. L.; BRAUN, A. M. Degradation of Polyvinyl Alcohol by Homogeneous and Heterogeneous Photocatalysis Applied to the 
Photochemically Enhanced Fenton Reaction. Wat. Sci. Tech. v.44, n. 5, p. 257262, $2001 b$.

BOX, G. E.; HUNTER, W. G.; HUNTER, J. S., Statistics for Experimenters - An Introduction to Design, Data Analysis and Model Building, Ed. John Wiley \& Sons, 1978.

BRANDRUP, J.; IMMERGUT, E. H. Polymer Handbook. Ed. Wiley, New York, Ed. $3^{\mathrm{a}}, 1989$.

BUXTON, G. V.; GREENSTOCK, C. L.; HELMAN, W. P.; ROSS, A. B. Critical Review of the Rate Constants for The Reactions of Hydrated Electrons, Hydrogen Atoms and Hydroxyl Radicals $\left(\cdot \mathrm{OH} /{ }^{\circ} \mathrm{O}^{-}\right)$in Aqueous Solution. J. Phys. Chem. Ref. Data. v.17, No. 2, p.523-883,1998.

CAUlfiElD, J. M.; QIAO, G. G.; SOlOMON, D. H. Some Aspects of the Properties and Degradation of Polyacrylamides. Chem. Rev, 102, p.3067-3083, 2002.

CAUlFIELD, J. M.; HAO, X.; QIAO, G. G.; SOLOMON, D. H. Degradation on Polyacrylamides. Part I: Linear Polyacrilamide. Polymer. v.44 p.1331-1337, 2003.

CERIUS 2, Version 4.2 Accelrys Corp., San Diego, CA, 2001.

CHANG, P. B. L.; YOUNG, T. M. Kinetics of Methyl Tert-Butyl Ether Degradation and By-Product Formation During UV/Hydrogen Peroxide Water Treatment. Wat. Res. v.34, No 3, p.2233-2240, 2000.

COMO Cuidar da Nossa Água. São Paulo: BEI Comunicações, 2004. 176p. (Coleção Entenda e Aprenda). 
DAVIS, J. E.; SANGSTER, D. F.; SENOGLES, E. Pulse Radiolysis of Aqueous Solutions of $N$-Vinylpyrrolidin-2-one and $\operatorname{Poly}(N$-vinylpyrrolidin-2-one). Aust. J. Chem., v.34, p.1423-1431, 1981.

DE, A. K.; BHATTACHARJEE, S.; DUTTA, B. A. Kinetics of Phenol Photooxidation by Hydrogen Peroxide and Ultraviolet Radiation. Ind. Eng. Chem. Res., v.36, p.3607, 1997.

DEWAR, M. J. S.; THIEL, W. Ground States of Molecules. The MNDO Method Approximations and Parameters. J. Am. Chem. Soc. 99, p.4899-4907, 1978.

DEWAR, M. J. S.; ZOEBISCH E. G.; HEALY, E. F.; STEWART, J. J. P. A New General Purpose Quantum Mechanical Molecular Model. J. Am. Chem. Soc. 107, p.3902-3909, 1985.

DING, Z. Y.; FRISH, M. A.; Li, L.; GLOYNA, E. F. Catalytic Oxidation in Supercritical Water. Ind. Eng. Chem. Res. v.35, p.3257-3279, 1996.

DIXON, D. A.; FELLER, D. Computational Chemistry and Process Design, Chem. Eng. Sci., 54, p.1929-1939, 1999.

DWYER, D.; TIEDJE, J. M. Degradation of Polyethylene Glycol and Polyethylene Glycols by Methanogenic Consortia. Appl. Environ. Microb. Vol. 46, No. 1, p.185-190, 1983.

FAUST, B. C.; HOIGNÉ, J. Photolysis of Fe(III)-Hydroxi Complexes as Source of OH Radicals in Clouds Fog and Rain. Atmos. Environ. A - Gen. v.24, p.79-89, 1990.

FENTON, H. J. H., Oxidation of Tartaric Acid in the Presence of Iron, J. Chem. Soc., 65, p.899-910, 1894. 
FORESMAN, J. B.; FRISCH, Æ. Exploring Chemistry with Electronic Structure Methods. Gaussian Inc., Pittsburg PA, 1996.

FRISCH, M. J.; TRUCKS, G. W.; SCHLEGEL, H. B.; SCUSERIA, G. E.; ROBB, M. A.; CHEESEMAN, J. R.;ZAKREWSKI, V. G.; MONTGOMERY, J. A.; STRATMANN, Jr. R. E.; BURANT, J. C.; DAPPRICH, S.; MILLAM, J. M.; DANIELS, A. D.; KUDIN, K. N.; STRAIN, M. C.; KARKAS, O.; TOMASI, J.; BARONE, V.; COSSI, M.; CAMMI, R.; MENNUCCI, B.; POMELLI, C.; ADAMO, C.; CLIFFORD, S.; OCHTERSKI, J.; PETERSON, G. A.; AYALA, P. Y.; CUI, Q.; MOROKUMA, K.; MALIK, D. K.; RABUCK, A. D.; RAGHAVACHARI, K.; FORESMAN, J. B.; CIOSLOWSKI, J.; ORTIZ, J. V.; BABOUL, A. G.; STEFANOV, B. B.; LIU, G.; LIASHENKO, A.; PISKORZ, P.; KOMAROMI, I.; GOMPERTS, R.; MARTIN, R. L.; FOX, D. J.; KEITH, T.; AL-LAHAM, M. A.; PEHG, C. Y.; NANAYAKKARA, A.; GONZALEZ, C.; CHALlACOMBE, M.; GILL, C.; HEAD-GORDON, M.; REPLOGLE, E. S.; POPLE, J. A. Gaussian 98, Revision A.6; Gaussian Inc.; Pittsburg, PA, 1998.

GAO, J.; LIN T.; WANG W.; YU, J.; YUAN, S.; WANG, S. Accelerated Chemical Degradation of Polyacrylamide. Macromol, Symp., 144, p.179-185, 1999.

GIROTO, J. A.; TEIXEIRA, A. C. S. C.; GUARDANI, R. NASCIMENTO, C. A. O. Study on the Photo-Fenton Degradation of Polyvinyl Alcohol in Aqueous Solution. Chem. Eng. Proc., 45, p.523-532, 2006.

GOGATE P. R.; PANDIT A. B. A Review of Imperative Technologies for Wastewater Treatment I: Oxidation Technologies at Ambient Condition. Adv. Env. Res., v.8, p.501-551, 2001a.

GOGATE P. R.; PANDIT A. B. A Review of Imperative Technologies for Wastewater Treatment II: Hybrid Methods. Adv. Env. Res., v.8, p.553-597, $2001 b$. 
GONZALEZ, M. C.; BRAUN, A. M. VUVU Photolysis of Aqueous Solution of Nitrate and Nitrite. Res. Chem. Intermed. 21 p. 837-859, 1995.

GRÖLMANN, U.; SCHNABEL, W. On the Kinetics of Polymer Degradation in Solution, 9. Pulse Radiolysis of Poly(Ethylene Oxide). Makomol. Chem., v.181, p.1215-1226, 1980.

GRÖLMANN, U.; SCHNABEL, W. Free Radical-Induced Oxidative Degradation of Polyacrylamide in Aqueous Solution. Polym. Degrad. Stab., v.4, p.203-212, 1982.

GUNER, V.; KHUONG, K. S.; LEACH, A. G.; LEE, P. S.; BARTBERGER, M. D.; HOUK, K. N. A Standard Set of Pericyclic Reactions of Hydrocarbons for the Benchmarking of Computational Methods: The Performance of Ab Initio, Density Functional, CASSFC, CASPT2, and CBS-QB3 Methods for the Prediction of Activation Barriers, Reaction Energetics, and Transition State Geometries. J. Phys. Chem A. v.107, No.51, p.11445-11459, Dec., 2003.

HAINES, J. R.; ALEXANDER, M. Microbial Degradation of Polyethylene Glycols. Appl. Microb., v.29, No. 5, p.621-625, 1975.

HAMmOND, G. S. A Correlation of Reaction Rates J. Am. Chem. Soc., 77, p. 334$338,1955$.

HARBER, F.; WEISS, J. J.; Proc. Roy. Soc. London Ser A, No 147, p.332-345, 1934.

HARRIS, J. M. Poly(Ethylene Glycol) Chemisty. Biotechnical and Biomedical Applications. Plenum Press, New York, 1992. 
HEUTS, J. P. A., GILBERT, G. R. A Priori Prediction of Propagation Rate Coefficients in Free-Radical Polymerizations: Propagation of Ethylene. Macromolecules. v.28, p.8771-8781, 1995.

HIRVONEN, A.; TUHKANEN, T.; KALLIOKOSHI, P. Formation of Chlorinated Acetic Acids During UV/ $\mathrm{H}_{2} \mathrm{O}_{2}$-Oxidation of Ground Water Contaminated with Chlorinated Ethylenes. Chemosphere. v.32, No 6, p.1091-1102, 1996.

HORIKOSHI, S.; HIDAKA, H.; SERPONE, N. Photocatalysed Degradation of Polymers in Aqueous Semiconductor Suspensions V. Photomineralization of Lactam Ring-Pendant Polyvinylpyrrolidone at Titania/Water Interfaces. J. Photochem. Photob. A: Chem. 138, p.69-77, 2001.

HOU, W. J.; TSUNEDA, S.; HIRATA, A. TOC Removal of Raw Industrial Wastewater from LSI Photo-Resist Processing with $\mathrm{H}_{2} \mathrm{O}_{2} / \mathrm{UV}$ in a Batch Reactor. J. Chem. Eng. Jpn. v.34, No 3, p.444-447, 2001.

HOU, H.; WANG, B. Mechanistic and Kinetic Study of the $\mathrm{O}+\mathrm{CH}_{2} \mathrm{OH}$ Reaction. J. Phys. Chem. A. 109, p.4796-4803, 2005.

HUANG, D. M.; MONTEIRO, M. J.; GILBERT, R. G. A Theoretical Study of Propagation Rate Coefficients for Methacrylonitrile and Acrylonitrile. Macromol. 31, p.5175-5187, 1998.

IMAMURA, S.; TONOMURA, Y.; KAWABATA, N. Wet Oxidation of Watersoluble Polymers. Bull. Chem. Soc. Jpn., 54, p.1548-1553, 1981.

JELLINEK H. H. G. Aspects of Degradation and Stabilization of Polymers, p.79147, Elsevier, Amsterdam, 1978.

KACZMAREK, H.; KAMINSKA, A.; SWIATEK, M.; RABEK, J. F. PhotoOxidative Degradation of some Water-Soluble Polymers in the Presence of 
Accelerating Agents. Die Angew. Makromol. Chem. 261/262, No. 4622, p.109$121,1998$.

KAICHOUH, G.; OTURAN, N.; OTURAN, M. A.; KACEMI, K.; HOURCH, A. Degradation of the Herbicide Imazapyr by Fenton Reactions. Environ. Chem. Let. v. 2, No. 1, p.31-33, June 2004.

KANG, J. K.; MUSGRAVE, C. B. Prediction of Transition State Barriers and Enthalpies of Reaction by a New Hybrid Density-Functional Approximation. J. Chem. Phys. v.115, No.24. p.11040-11051, Dec., 2001.

KIM, S. M.; GEISSEN, S. U.; VOGELPOHL, A., Landfill Leachate Treatment By A Photoassisted Fenton Reaction, Wat. Sci. Tech., 35, 4, p.239-248, 1997.

KING, S. M.; VOGELPOHL, A. Degradation of Organic Pollutants by the PhotoFenton Process. Chem. Eng. Tech. v.21, p.187-191, 1998.

KRISHNAN, R.; POPLE, J. A. Approximate Fourth-Order Perturbation Theory of Electron Correlation Energy. Int. J. Quant. Chem., v. XIV, p.91-100, 1978.

KWON, B. G.; LEE, S. D.; KANG, N. AND YOON, J., Characteristics of pChlorophenol Oxidation by Fenton's Reagent, Wat. Res., 33, 9, p.2110-2118, 1999.

KU, Y.; WANG, L. S.; SHEN, Y.S. Decomposition of EDTA in Aqueous Solution by $\mathrm{UV} / \mathrm{H}_{2} \mathrm{O}_{2}$ Process. J. Haz. Mater. 60, 41, 1998.

KURENKOV, V. F.; TAZIEVA, É. D. Control of Molecular Weight of Polyacrylamide in its Degradation in Aqueous Solutions. Russian J. Appl. Chem., Vol. 67, No 7, p.1029-1033, 1994. 
KURNIAWAN, T. N.; LO, W. H.; CHAN, G. Y. S. Radicals-Catalyzed Oxidation Reactions for Degradation of Recalcitrant Compounds from Landfill Leachate. Chem. Eng. J., 125, p.35-37, 2006.

LEACH, A. R. Molecular Modelling. Principles and Applications. Pearson Education EMA, $2^{\mathrm{a}}$ ed., 2001.

LEI, L.; HU, X.; YUE, P. L.; BOSSMANN, S. H.; GÖB, S.; BRAUN, A. M., Oxidative Degradation of Polyvinyl Alcohol by the Photochemically Enhanced Fenton Reaction, J. Photochem. Photobiol. A: Chem., 116, p.159-166, 1998.

LICHTIN, N. N. Selectivity in Fast Reactions of Aqueous OH-Radicals with Amides. Israel J. Chem. v.9, p.397-403, 1971.

LIN, B., YAMAGUCHI, R., HOSOMI, M., MURAKAMI, A.; A New Treatment Process for Photo-processing Water using a Sulfur-oxidizing Bacteria/granular Activated Carbon System Followed by Fenton Oxidation. Wat. Sci. Technol., v.38, p.163-170, 1998.

MALATO, S., BLANCO, J.; RICHTER, C.; CURCÓ, D.; GIMÉNEZ, J., LowConcentrating CPC Collectors for Photocatalytic Water Detoxification: Comparison with a Medium Concentrating Solar Collector, Wat. Sci. Tech., 35, p.157-164, 1997.

MANTZAVINOS, D.; LIVINGSTONE, A. G.; HELLENBRAND, R.; METCALFE, I. S. Wet Air Oxidation of Polyethylene Glycols; Mechanisms, Intermediates and Implications for Integrated Chemical-Biological Wastewater Treatment. Chem. Eng. Sci., v. 51, p. 4219-4235, 1996.

MANTZAVINOS, D.; HELLENBRAND, R.; LIVINGSTONE, A. G.; METCALFE, I. S. Reaction Mechanism and Kinetic of Chemical Pretreatment of Bioresistant 
Organic Molecules by Wet Air Oxidation. Wat. Sci. Tech., v. 35, No.4, p. 119127, 1997.

MANTZAVINOS, D.; LAUER, E.; SAHIBZADA, M.; LIVINGSTON, A. METCALFE, I. S. Assessment of Partial Treatment of Polyethylene Glycol Wastewaters by Wet Air Oxidation. Wat. Res. v.34, No. 5, p.1620-1628, 2000a.

MANTZAVINOS, D.; HELLENBRAND, R.; LIVINGSTON A. G.; METCALFE, I. S. Benefical Combination of Wet Air Oxidation, Membrane Separation and Biodegradation Processes for Treatment of Polymer processing Wastewater. Canad. J. Chem. Eng., v.78, p.418-422, 2000b.

MAYO, S. L.; OLAFSON, B. D.; GODDARD, W. A. DREIDING: A Generic Force Field for Molecular Simulations. J. Phys. Chem. v. 84, p.8897-8909, 1990.

MCGINNIS, D. B; ADAMS, D. V.; MIDDLEBROOKS, J. E. Degradation of Ethylene Glycols in Photo-Fenton Systems. Wat. Res., v.34, No 8, p. 2346-2354, 2000.

MCQUARRIE, D. A.; SIMON, J. D. Physical Chemistry. A Molecular Approach. University Science Books, 1997.

MORLART, S.; GARDETTE, J. L. Phototransformation of Water-Soluble Polymers. I: Photo- and Thermooxidation of Poly(Ethylene Oxide) in Solid State. Polymer, 42, p.6071-6079, 2001.

MORLART, S.; GARDETTE, J. L. Phototransformation of Water-Soluble Polymers. Part II: Photooxidation of Poly(Ethylene Oxide) in Aqueous Solution. Polymer, 44, p.7891-7897, 2003.

NAKAMIA, K.; KINOSHITA, S. Isolation of Polyacrylamide-Degrading Bacteria. J. Ferment. Bioeng. v.80, No.4, p.418-420, 1995. 
NAKAMIA, K.; OOI, T.; KINOSHITA, S. Degradation o Synthetic Water-Soluble Polymers by Hydroquinone Peroxidase. J. Fermen. Bioeng. v.84, No. 3, p. 213218, 1997.

NIIRANEN, J. T.; GUTMAN, D. Kinects of the Reaction of Substituted Silyl Radicals $\left[\mathrm{Si}\left(\mathrm{CH}_{3}\right)_{3}\right.$ and $\left.\mathrm{SiCL}_{3}\right]$ with Molecular Oxygen. J. Phys. Chem. v.97. p.4106-4109, 1993.

NOGUEIRA, R. F. P.; ALBERICI, R. M.; MENDES, M. A.; JARDIM, W. F.; EBERLIN, M.N. Photocatalytic Degradation of Phenol and Trichloroethylene: On-Line and Real-Time Monitoring via Membrane Introduction Mass Spectrometry. Ind. Eng. Chem. Res., v.38, p.1754, 1999.

OLIVEROS E.; LEGRINI, O.; HOHL, M.; MÜLLER, T.; BRAUN, A. M., Large Scale Development of a Light-Enhanced Fenton Reaction by Optimal Experimental Design, Wat. Sci. Tech., 35, p.223-230, 1997.

OCHTERSKI, J. W. Thermochemistry in Gaussian. Gaussian Inc., 2000. Disponível em: $<$ http://www.gaussian.com>.

PANARIN, E. F.; GAVRILOVA, I. I. Degradation of Polyvinylpyrrolidone in Aqueous Solutions under the Action of Hydrogen Peroxide. Russian J. Appl. Chem. v.70, No. 12, p.1993-1995, 1997.

PANDIT, S. S.; JUVEKAR, V. A.; TRIVEDI, M. K. Stochastic Simulation of Polymer Reactions. Chem. Eng. Sci. v.48, No 7, p.1237-1250, 1993.

PARR, R. G.; YANG, W. Density-Functional Theory of Atoms and Molecules. Oxford University Press, New York, 1989. 
PÉREZ, M.; TORRADES, F.; DOMÉNECH, X.; PERAL, J. Fenton and PhotoFenton Oxidation of Textile Effluents. Wat. Res., v.36, p.2703-2710, 2002.

PÉREZ, M. H.; PEÑUElA, G.; MALDONADO, M. I.; MALATO, O.; FERNÁNDEZ-IBÁÑEZ， P.; OLLER， I.; GEMJAK，W.; MALATO, S. Degradation of Pesticides in Water Using Solar Advanced Oxidation Processes. Appl. Catal. B: Environ., 64, p.272-281, 2006.

PIGNATELLO, J. J.; LIU, DI.; HUSTON, P.; Evidence for an Additional Oxidante in the Photoassisted Fenton Reaction. Environ. Sci. Technol., 33, p. 1832-1839, 1999.

PLIEGO, J. R.; ALMEIDA, W. B. A New Mechanism for the Reaction of Carbenes with OH Groups. J. Phys. Chem. A. v.103, p.3904-3909, 1999.

POPLE, J. A.; BINKLEY, J. S.; SEEGER, R. Theoretical Models Incorporating Electron Correlation. Int. J. Quant. Chem. Symp. No. 10, p.1-19, 1976.

POPLE, J. A.; KRISHNAN, R.; SCHLEGEL, H. B; BINKLEY, J. S. Electron Correlation Theories and Their Application to the Study of Simple Reaction Potential Surfaces. Int. J. Quant. Chem. v. XIV, p.545-560, 1978.

RAMSDEN, D.; MCKAY, K. Degradation of Polyacrylamide Solution Induced by Chemically Generated Hydroxyl Radicals: Part I - Fenton's Reagent. Polym. Degrad. Stab. v.14, p. 217-229, 1986.

ROSIAK, J.; OLEJNACZAK, J.; PEKALA, W. Fast Reaction of Irradiated Polymers - I. Crosslinking and Degradation of Polyvinylpyrrolidone. Radiat. Phys. Chem. v.36, No. 6, p.747-755, 1990.

SILVA, H. S., Princípios de Tratamento de Efluentes Líquidos. Calquim, agosto, 1998. 
SMITH, E. A.; PRUES, S. L.; OEHME, F. W. Environmental Degradation of Polyacrylamides. I. Effects of Artificial Environmental Conditions: Temperature, Light and pH. Ecotox. Environ. Saf. v.35, p.121-135, 1996.

SMITH, E. A.; PRUES, S. L.; OEHME, F. W. Environmental Degradation of Polyacrylamides. II. Effects of Environmental (Outdoor) Exposure. Ecotox. Environ. Saf. v.37, p.76-91, 1997.

STALIKAS, C. D.; LUNAR, L.; RUBIO, S.; PEREZ-DENDITO, D. Degradation of Medical X-Ray Film Developing Wastewaters by Advanced oxidation Processes. Wat. Res. 35 (16), p.3845-3856, 2001.

STEWART, J. J. P. Optimization of Parameters for Semi Empirical Methods. I. Method. J. Comp. Chem. v.10, Issue 2, p209-220, 1989.

SUZUKI, J.; HARADA, H.; SUZUKI, S. Effect of Ozone Treatment upon Biodegradability of Water-Soluble Polymers. Environ. Sci. Technol. v.12, No 10. p.1180-1978, 1978.

SUZUKI, J.; HARADA, H.; SUZUKI, S. Ozone Treatment of Water Soluble Polymers. V. Ultraviolet Irradiation Effects on the Ozonization of Polyacrylamide. J. Appl. Pol. Sci., 24, p.999-1006, 1979.

SWISHER, R.D. In: Surfactant Biodegradation, Marcel Dekker, New York, 1970.

SWIFT, G. Requirements for Biodegradable Water-Soluble Polymers. Polym. Degrad. Stab. v.59, p.19-24, 1998.

SZPYRKOWICZ, L.; JUZZOLINO, C.; KAUL, S. N. A Comparative Study on Oxidation of Disperses Dyes by Electrochemical Process, Ozone, Hypoclorite and Fenton Reagent. Wat. Res. v.35, No 9, p.2129-2136, 2001. 
TEIXEIRA, A. C. S. C.; GUARDANI, R.; NASCIMENTO, C. A. O. Photo-Fenton Remediation of Wastewater Containing Silicones: Experimental Study and Neural Networking Modeling. Chem. Eng. Technol., v.27, p.800-810, 2004.

TRIMPIN, S., EICHHORN, P., RADER, H.J., MULLEN, K., KNEPPER, T.P. Recalcitrance of Poly(vinylpyrrolidone): Evidence through matrix-assisted laser desorption-ionization time-of-flight mass spectrometry. J. Chromat. A, 938 (12): 67-77, 2001.

VAN SPEYBROECK, V.; MARTELÉ, E.; M.; WAROQUIER, M.; SCHACHT, E. $\mathrm{Ab}$ Initio and Experimental Study on Thermally Degradable Polycarbonates: The Effect of Substituents on the Reaction Rates. J. Am. Chem. Soc. v.123, p.10650-10657, 2001.

VAN SPEYBROECK, V.; VAN NECK, D.; WAROQUIER, M. Ab Initio Study of Radical Reactions: Role of Coupled Internal Rotations on the Reaction Kinetics (III). J. Phys. Chem. A. v.106, p.8945-8950, 2002.

VERS, L M. V. Determination of Acrylamide Monomer In Polyacrylamide Degradation Studies by High-Performance Liquid Chromatography. J. Chrom. Sci., v.37, p.486-494, 1999.

WALling, C.; WAGNER, P. Positive Halogen Compounds. X. Solvent Effects in the Reactions of $t$-Butoxy Radicals. J. Am. Chem. Soc., 86, p.3368-3375, 1964

WALLING, C.; GOOSEN, A. Mechanism of Ferric Ion Catalysed Decomposition of Hydrogen-Peroxide - Effect of Organic Substrates. J. Am. Chem. Soc., 95 (9), p.2987-2991, 1973

WALling, C. Fenton's Reagent Revisited. Acc. Chem. Res., 8, p.125-131, 1975 
WATSON, G. K.; JONES, N. The Biodegradation of Polyethylene Glycols by Sewage Bacteria. Wat. Res., v.11, p.95-100, 1977.

YEN H. Y.; YANG M. H. The Ultrassonic Degradation of Polyacrylamide Solution. Polym. Testing. 22, p.129-131, 2003. 
APÊNDICE A - Valores de Carbono Orgânico Dissolvido (COD) 
Tabela A.1- Condições experimentais e valores de COD para PEG no processo foto-Fenton.

\begin{tabular}{|c|c|c|c|c|c|c|c|c|c|c|c|c|}
\hline \multirow{2}{*}{\multicolumn{3}{|c|}{$\begin{array}{c}\text { Condição Experimental } \\
\qquad=30^{\circ} \mathrm{C} ; \mathbf{p H}=\mathbf{3 , 0}\end{array}$}} & \multicolumn{10}{|c|}{ Tempo de Reação (min) } \\
\hline & & & 0 & 10 & 20 & 30 & 45 & 60 & 75 & 90 & 105 & 120 \\
\hline $\begin{array}{c}{[\mathrm{PEG}]} \\
\left(\mathrm{mgC} \mathrm{L}^{-1}\right)\end{array}$ & $\begin{array}{l}{\left[\mathrm{Fe}^{2+}\right]} \\
(\mathrm{mM})\end{array}$ & $\begin{array}{c}{\left[\mathrm{H}_{2} \mathrm{O}_{2}\right]} \\
(\mathrm{mM})\end{array}$ & \multicolumn{10}{|c|}{$\operatorname{COD}\left(\mathrm{mgC} \mathrm{L}^{-1}\right)$} \\
\hline 1500 & 1,5 & 160 & 1617,1 & 1604,6 & 1591,4 & 1541,4 & 1367,0 & 1143,2 & 961,2 & 757,0 & 614,0 & 596,5 \\
\hline 1500 & 1,5 & 60 & 1759,1 & 1667,7 & 1625,1 & 1587,3 & 1509,5 & 1474,5 & 1462,6 & 1443,7 & 1409,1 & 1404,8 \\
\hline 1500 & 0,5 & 160 & 1797,1 & 1629,9 & 1564,7 & 1514,1 & 1350,2 & 1159,4 & 954,8 & 762,7 & 569,0 & 556,0 \\
\hline 1500 & 0,5 & 60 & 1584,0 & 1562,5 & 1545,8 & 1513,3 & 1463,1 & 1414,3 & 1299,1 & 1293,7 & 1269,9 & 1248,5 \\
\hline 500 & 1,5 & 160 & 574,0 & 526,1 & 468,3 & 352,9 & 77,0 & 26,4 & 12,8 & 3,4 & 0,5 & 0,0 \\
\hline 500 & 1,5 & 60 & 585,0 & 573,4 & 539,6 & 507,1 & 447,5 & 382,6 & 311,7 & 250,9 & 207,8 & 191,0 \\
\hline 500 & 0,5 & 160 & 597,3 & 561,4 & 413,4 & 241,2 & 70,3 & 19,7 & 4,8 & 1,4 & 0,0 & 0,0 \\
\hline 500 & 0,5 & 60 & 613,7 & 603,3 & 567,8 & 538,3 & 432,6 & 278,0 & 160,7 & 93,2 & 66,6 & 50,0 \\
\hline 1000 & 1,0 & 110 & 1093,3 & 1015,5 & 1004,6 & 944,6 & 858,6 & 732,1 & 625,5 & 469,0 & 323,0 & 319,7 \\
\hline 1000 & 1,0 & 110 & 1108,0 & 1107,4 & 1082,3 & 1053,7 & 961,9 & 802,0 & 559,2 & 420,8 & 368,8 & 357,3 \\
\hline 1000 & 1,0 & 110 & 1129,3 & 1050,1 & 1011,6 & 976,9 & 869,5 & 676,4 & 558,8 & 403,2 & 344,0 & 340,8 \\
\hline
\end{tabular}


Tabela A.2- Condições experimentais e valores de COD para PEG no processo UV/ $\mathrm{H}_{2} \mathrm{O}_{2}$.

\begin{tabular}{|c|c|c|c|c|c|c|c|c|c|c|c|c|}
\hline \multirow{2}{*}{\multicolumn{3}{|c|}{ Condição Experimental }} & \multicolumn{10}{|c|}{ Tempo de Reação (min) } \\
\hline & & & $\mathbf{0}$ & 10 & 20 & 30 & 45 & 60 & 75 & 90 & 105 & 120 \\
\hline $\begin{array}{c}{[\text { PEG] }} \\
\left(\mathrm{mgC} \mathrm{L}^{-1}\right)\end{array}$ & $\begin{array}{l}{[\mathrm{T}]} \\
\left({ }^{\circ} \mathrm{C}\right)\end{array}$ & $\begin{array}{c}{\left[\mathrm{H}_{2} \mathrm{O}_{2}\right]} \\
(\mathrm{mM})\end{array}$ & \multicolumn{10}{|c|}{$\operatorname{COD}\left(\mathrm{mgC} \mathrm{L}^{-1}\right)$} \\
\hline 1500 & $\mathbf{5 0}$ & 160 & 1458,8 & 1458,6 & 1439,9 & 1376,6 & 1257,3 & 1091,5 & 860,3 & 590,1 & 479,9 & 474,2 \\
\hline 1500 & 50 & 60 & 1383,5 & 1393,3 & 1377,8 & 1359,8 & 1328,1 & 1280,0 & 1241,8 & 1181,3 & 1136,7 & 1144,3 \\
\hline 1500 & 30 & 160 & 1448,6 & 1434,8 & 1416,9 & 1397,4 & 1344,2 & 1277,8 & 1223,8 & 1109,2 & 985,4 & 823,1 \\
\hline 1500 & 30 & 60 & 1451,0 & 1461,0 & 1436,0 & 1473,4 & 1430,7 & 1434,3 & 1396,5 & 1388,8 & 1353,0 & 1346,0 \\
\hline 500 & 50 & 160 & 567,6 & 544,9 & 510,7 & 451,9 & 257,8 & 112,2 & 53,3 & 21,0 & 10,2 & 7,8 \\
\hline 500 & 50 & 60 & 532,5 & 528,4 & 514,4 & 493,4 & 449,3 & 386,7 & 289,9 & 173,1 & 99,8 & 86,5 \\
\hline 500 & 30 & 160 & 552,2 & 525,6 & 502,9 & 470,3 & 395,8 & 281,7 & 173,4 & 112,0 & 59,7 & 31,8 \\
\hline 500 & 30 & 60 & 594,99 & 581,49 & 573,10 & 555,31 & 527,32 & 486,15 & 425,27 & 350,89 & 249,98 & 174,28 \\
\hline 1000 & 40 & 110 & 948,7 & 959,7 & 944,5 & 908,2 & 839,2 & 720,1 & 588,1 & 455,3 & 353,5 & 315,2 \\
\hline 1000 & 40 & 110 & 931,1 & 926,0 & 901,4 & 876,8 & 811,1 & 731,9 & 537,1 & 453,1 & 367,6 & 338,1 \\
\hline 1000 & 40 & 110 & 977,7 & 982,7 & 966,5 & 944,8 & 874,5 & 767,2 & 642,4 & 500,1 & 377,3 & 293,4 \\
\hline
\end{tabular}


Tabela A.3- Condições experimentais e valores de COD para PAM no processo foto-Fenton.

\begin{tabular}{|c|c|c|c|c|c|c|c|c|c|c|c|c|c|}
\hline \multirow{2}{*}{\multicolumn{3}{|c|}{$\begin{array}{c}\text { Condição Experimental } \\
\qquad \mathbf{T}=50^{\circ} \mathrm{C}\end{array}$}} & \multicolumn{11}{|c|}{ Tempo de Reação (min) } \\
\hline & & & 0 & 15 & 30 & 45 & 60 & 75 & 90 & 105 & 120 & 150 & 180 \\
\hline $\begin{array}{c}{[\mathrm{PAM}]} \\
\left(\mathrm{mgC} \mathrm{L}^{-1}\right)\end{array}$ & $\begin{array}{l}{\left[\mathrm{Fe}^{2+}\right]} \\
(\mathrm{mM})\end{array}$ & $\begin{array}{l}{\left[\mathrm{H}_{2} \mathrm{O}_{2}\right]} \\
(\mathrm{mM})\end{array}$ & \multicolumn{11}{|c|}{$\operatorname{COD}\left(\mathrm{mgC} \mathrm{L}^{-1}\right)$} \\
\hline 1500 & 2,5 & 700 & 1399,0 & 1286,8 & 1224,8 & 1193,7 & 1110,8 & 1019,0 & 906,3 & 728,3 & 516,5 & 185,7 & 75,2 \\
\hline 1500 & 2,5 & 300 & 1428,0 & 1348,5 & 1343,5 & 1320,9 & 1302,3 & 1316,5 & 1271,8 & 1248,4 & 1136,5 & 473,3 & 393,7 \\
\hline 1500 & 0,5 & 700 & 1494,0 & 1432,8 & 1446,0 & 1267,5 & 1114,9 & 930,7 & 726,0 & 477,6 & 280,9 & 82,9 & 51,7 \\
\hline 1500 & 0,5 & 300 & 1589,0 & 1584,0 & 1522,7 & 1414,0 & 1261,8 & 1088,2 & 864,2 & 492,0 & 315,0 & 121,1 & 64,0 \\
\hline 500 & 2,5 & 700 & 526,0 & 501,6 & 487,7 & 410,4 & 314,5 & 222,2 & 140,6 & 87,8 & 57,3 & 29,5 & 22,0 \\
\hline 500 & 2,5 & 300 & 495,9 & 465,1 & 448,2 & 438,4 & 382,3 & 317,3 & 229,7 & 148,9 & 95,8 & 46,0 & 26,8 \\
\hline 500 & 0,5 & 700 & 610,0 & 605,7 & 465,2 & ----- & 131,8 & 57,3 & 16,5 & 9,5 & 5,2 & 3,3 & 0,0 \\
\hline 500 & 0,5 & 300 & 522,0 & 435,5 & 250,5 & 73,0 & 12,5 & 6,5 & 2,2 & 0,5 & 0,0 & 0,0 & 0,0 \\
\hline 1000 & 1,5 & 500 & 1110,0 & 1033,2 & 973,2 & 1008,3 & 841,8 & 737,7 & 584,2 & 420,2 & 258,3 & 121,0 & 68,2 \\
\hline 1000 & 1,5 & 500 & 1092,0 & 1054,5 & 919,3 & 891,5 & 800,0 & 774,0 & 667,0 & 569,3 & 407,7 & 158,7 & 95,0 \\
\hline 1000 & 1,5 & 500 & 939,7 & 858,7 & 869,1 & 842,8 & 780,8 & 665,7 & 537,3 & 382,3 & 268,7 & 110,1 & 53,1 \\
\hline
\end{tabular}


Tabela A.4- Condições experimentais e valores de COD para PVP no processo foto-Fenton.

\begin{tabular}{|c|c|c|c|c|c|c|c|c|c|c|c|c|c|}
\hline \multirow{2}{*}{\multicolumn{3}{|c|}{$\begin{array}{c}\text { Condição Experimental } \\
\qquad \mathbf{T}=50^{\circ} \mathrm{C}\end{array}$}} & \multicolumn{11}{|c|}{ Tempo de Reação (min) } \\
\hline & & & 0 & 15 & 30 & 45 & 60 & 75 & 90 & 105 & 120 & 150 & 180 \\
\hline $\begin{array}{c}{[\mathrm{PVP}]} \\
\left(\mathrm{mgC} \mathrm{L}^{-1}\right)\end{array}$ & $\begin{array}{l}{\left[\mathrm{Fe}^{2+}\right]} \\
(\mathrm{mM})\end{array}$ & $\begin{array}{c}{\left[\mathrm{H}_{2} \mathbf{O}_{2}\right]} \\
(\mathrm{mM})\end{array}$ & \multicolumn{11}{|c|}{$\operatorname{COD}\left(\mathrm{mgC} \mathrm{L}^{-1}\right)$} \\
\hline 1500 & 1,5 & 250 & 1589,0 & 1564,0 & 1499,0 & 1478,7 & 1397,3 & 1311,2 & 1170,2 & 937,8 & 601,7 & 287,2 & 169,5 \\
\hline 1500 & 1,5 & 150 & 1572,0 & 1493,4 & 1433,9 & 1388,0 & 1365,6 & 1388,4 & 1275,5 & 1162,0 & 1017,7 & 469,6 & 461,9 \\
\hline 1500 & 0,5 & 250 & 1664,1 & 1571,7 & 1518,8 & 1366,0 & 1247,3 & 948,0 & 643,0 & 319,5 & 127,4 & 26,0 & 19,9 \\
\hline 1500 & 0,5 & 150 & 1539,0 & 1515,1 & 1550,4 & 1476,1 & 559,5 & 383,0 & 333,0 & 325,0 & 303,0 & 171,3 & 121,3 \\
\hline 500 & 1,5 & 250 & 556,7 & 477,5 & 328,0 & 125,5 & 9,2 & 12,5 & 4,5 & 4,4 & 4,3 & 0,7 & 0,0 \\
\hline 500 & 1,5 & 150 & 526,0 & 478,0 & 71,8 & 22,7 & 3,9 & 1,8 & 0,0 & 0,0 & 0,0 & 0,0 & 0,0 \\
\hline 500 & 0,5 & 250 & 539,0 & 488,5 & 329,0 & 142,4 & 70,0 & 18,7 & 0,0 & 0,0 & 0,0 & 0,0 & 0,0 \\
\hline 500 & 0,5 & 150 & 562,0 & 147,7 & 56,3 & 23,2 & 8,2 & 4,9 & 4,8 & 4,6 & 4,5 & 3,0 & 2,7 \\
\hline 1000 & 1,0 & 200 & 1002,0 & 949,8 & 957,0 & 777,6 & 637,3 & 217,7 & 57,9 & 14,4 & 0,0 & 0,0 & 0,0 \\
\hline 1000 & 1,0 & 200 & 1081,0 & 1051,5 & 982,9 & 843,3 & 581,2 & 252,3 & 86,8 & 22,9 & 15,7 & 7,1 & 5,6 \\
\hline 1000 & 1,0 & 200 & 1187,0 & 1088,7 & 1010,1 & 867,5 & 660,7 & 337,3 & 113,3 & 27,5 & 11,2 & 6,7 & 5,0 \\
\hline
\end{tabular}




\section{APÊNDICE B - MATRIZES Z PARA AS ESTRUTURAS DAS REAÇÕES DO DIETILENOGLICOL}

Tabela B1 - Matriz Z para a estrutura do Dietilenoglicol otimizada com o modelo $\mathrm{HF} / 6-31 \mathrm{G}(\mathrm{d})$

\begin{tabular}{|c|c|c|c|c|c|c|}
\hline & \multicolumn{3}{|c|}{ Distâncias( $(\AA)$} & \multicolumn{2}{|l|}{ Ângulos( $\left(^{\circ}\right)$} & \multirow[t]{2}{*}{ Diedros $\left({ }^{\circ}\right)$} \\
\hline $\mathbf{O}$ & & & & & & \\
\hline C & 1 & 1.397105 & & & & \\
\hline $\mathbf{C}$ & 2 & 1.514022 & 1 & 111.465595 & & \\
\hline $\mathbf{O}$ & 3 & 1.400381 & 2 & 107.349625 & 1 & 61.065813 \\
\hline $\mathrm{C}$ & 4 & 1.395685 & 3 & 115.234381 & 2 & -175.966525 \\
\hline $\mathbf{C}$ & 5 & 1.518804 & 4 & 108.064440 & 3 & 178.922227 \\
\hline $\mathbf{O}$ & 6 & 1.401185 & 5 & 111.229056 & 4 & -179.800484 \\
\hline $\mathbf{H}$ & 1 & 0.948327 & 2 & 107.892694 & 3 & -54.450425 \\
\hline H & 2 & 1.082733 & 1 & 107.073989 & 3 & -120.162071 \\
\hline H & 2 & 1.087741 & 1 & 111.044261 & 3 & 122.040484 \\
\hline $\mathbf{H}$ & 3 & 1.087580 & 2 & 109.935179 & 1 & -58.755056 \\
\hline $\mathbf{H}$ & 3 & 1.089201 & 2 & 110.533972 & 1 & -178.378043 \\
\hline H & 5 & 1.090715 & 4 & 110.343005 & 3 & -60.637529 \\
\hline H & 5 & 1.087296 & 4 & 111.015151 & 3 & 58.577442 \\
\hline $\mathbf{H}$ & 6 & 1.086521 & 5 & 109.680293 & 4 & 56.120732 \\
\hline $\mathbf{H}$ & 6 & 1.081248 & 5 & 109.505269 & 4 & -61.880416 \\
\hline $\mathbf{H}$ & 7 & 0.946888 & 6 & 109.769332 & 5 & -75.408036 \\
\hline
\end{tabular}


Tabela B2 - Matriz Z para a estrutura do radical alquila otimizada com o modelo $\mathrm{HF} / 6-31 \mathrm{G}(\mathrm{d})$.

\begin{tabular}{|c|c|c|c|c|c|c|}
\hline & & Distâncias( $(\AA)$ & & Ângulos $\left({ }^{\circ}\right)$ & & $\operatorname{Diedros}\left({ }^{\circ}\right)$ \\
\hline H & & & & & & \\
\hline $\mathbf{O}$ & 1 & 0.984706 & & & & \\
\hline C & 2 & 1.430526 & 1 & 107.288914 & & \\
\hline C & 3 & 1.536021 & 2 & 110.210556 & 1 & -65.041777 \\
\hline $\mathbf{O}$ & 4 & 1.440836 & 3 & 107.085271 & 2 & -177.839483 \\
\hline C & 5 & 1.436972 & 4 & 113.272890 & 3 & -179.495941 \\
\hline C & 6 & 1.533328 & 5 & 108.566756 & 4 & 167.234717 \\
\hline $\mathbf{O}$ & 7 & 1.431565 & 6 & 110.585871 & 5 & 177.368426 \\
\hline H & 8 & 0.985595 & 7 & 107.075394 & 6 & 62.879193 \\
\hline H & 3 & 1.093714 & 2 & 109.373107 & 1 & 175.348867 \\
\hline H & 3 & 1.093520 & 2 & 110.702521 & 1 & 56.612611 \\
\hline H & 4 & 1.095325 & 3 & 108.873854 & 2 & 61.393311 \\
\hline H & 4 & 1.096847 & 3 & 108.196999 & 2 & -56.878173 \\
\hline H & 6 & 1.094635 & 5 & 111.120552 & 4 & -72.482859 \\
\hline H & 7 & 1.092608 & 6 & 108.898147 & 5 & 56.933979 \\
\hline H & 7 & 1.092253 & 6 & 108.940763 & 5 & -60.895993 \\
\hline
\end{tabular}


Tabela B3 - Matriz Z para a estrutura do radical alquilperoxila otimizada com o modelo HF/6-31G(d).

\begin{tabular}{|c|c|c|c|c|c|c|}
\hline & & istâncias( $(\AA)$ & & Ângulos $\left({ }^{\circ}\right)$ & & $\operatorname{Diedros}\left({ }^{\circ}\right)$ \\
\hline H & & & & & & \\
\hline $\mathbf{O}$ & 1 & 0.985713 & & & & \\
\hline C & 2 & 1.432482 & 1 & 107.758640 & & \\
\hline C & 3 & 1.542491 & 2 & 110.161674 & 1 & 66.695554 \\
\hline $\mathbf{O}$ & 4 & 1.443104 & 3 & 111.868351 & 2 & -165.993712 \\
\hline C & 5 & 1.451092 & 4 & 117.966323 & 3 & -85.258140 \\
\hline C & 6 & 1.556472 & 5 & 110.632419 & 4 & -174.972376 \\
\hline $\mathbf{O}$ & 7 & 1.438213 & 6 & 115.511036 & 5 & -55.793996 \\
\hline H & 8 & 0.981547 & 7 & 106.867613 & 6 & -179.514915 \\
\hline H & 3 & 1.093348 & 2 & 108.793172 & 1 & -173.018582 \\
\hline H & 4 & 1.094582 & 3 & 110.109693 & 2 & 67.446056 \\
\hline H & 6 & 1.094452 & 5 & 107.528444 & 4 & -59.604276 \\
\hline H & 7 & 1.092010 & 6 & 108.036198 & 5 & -177.736168 \\
\hline H & 7 & 1.092193 & 6 & 108.150894 & 5 & 65.102574 \\
\hline H & 3 & 1.094784 & 2 & 111.120437 & 1 & -54.877297 \\
\hline H & 4 & 1.092074 & 3 & 107.927549 & 2 & -48.971525 \\
\hline $\mathbf{O}$ & 6 & 1.438643 & 5 & 113.839290 & 4 & 56.621652 \\
\hline O & 17 & 1.316821 & 6 & 111.546367 & 5 & 63.080033 \\
\hline
\end{tabular}


Tabela B4 - Matriz Z para a estrutura do radical hidroperóxido secundário otimizada com o modelo HF/6-31G(d).

\begin{tabular}{|c|c|c|c|c|c|c|}
\hline & \multicolumn{3}{|c|}{ Distâncias( $(\AA)$} & \multicolumn{2}{|l|}{ Ângulos $\left({ }^{\circ}\right)$} & $\operatorname{Diedros}\left({ }^{\circ}\right)$ \\
\hline H & & & & & & \\
\hline O & 1 & 0.985073 & & & & \\
\hline C & 2 & 1.442033 & 1 & 107.382176 & & \\
\hline C & 3 & 1.546175 & 2 & 112.694944 & 1 & -177.781335 \\
\hline $\mathbf{O}$ & 4 & 1.448827 & 3 & 108.721246 & 2 & 75.495849 \\
\hline C & 5 & 1.444929 & 4 & 115.612749 & 3 & -179.329954 \\
\hline C & 6 & 1.539793 & 5 & 107.204987 & 4 & 178.039168 \\
\hline $\mathbf{O}$ & 7 & 1.426884 & 6 & 108.583459 & 5 & -60.846929 \\
\hline H & 8 & 0.990942 & 7 & 103.269774 & 6 & 46.204308 \\
\hline $\mathbf{O}$ & 4 & 1.441487 & 3 & 109.950287 & 2 & -165.624998 \\
\hline O & 10 & 1.321794 & 4 & 110.972143 & 3 & 72.852394 \\
\hline H & 11 & 0.986919 & 10 & 106.092827 & 4 & 133.895464 \\
\hline H & 3 & 1.091449 & 2 & 110.563667 & 1 & -57.307552 \\
\hline H & 3 & 1.091659 & 2 & 109.190728 & 1 & 61.730658 \\
\hline H & 4 & 1.095855 & 3 & 108.314083 & 2 & -44.562341 \\
\hline H & 6 & 1.095622 & 5 & 111.036567 & 4 & -62.556762 \\
\hline H & 6 & 1.094987 & 5 & 111.414238 & 4 & 59.204957 \\
\hline H & 7 & 1.093784 & 6 & 109.491491 & 5 & 59.071603 \\
\hline H & 7 & 1.094057 & 6 & 110.826575 & 5 & 178.933219 \\
\hline
\end{tabular}


Tabela B5 - Matriz Z para a estrutura do radical alcoxila otimizada com o modelo $\mathrm{HF} / 6-31 \mathrm{G}(\mathrm{d})$.

\begin{tabular}{|c|c|c|c|c|c|c|}
\hline & \multicolumn{3}{|c|}{ Distâncias( $(\mathbf{)})$} & \multicolumn{2}{|l|}{ Ângulos( $\left(^{\circ}\right)$} & \multirow[t]{2}{*}{ Diedros $\left({ }^{\circ}\right)$} \\
\hline H & & & & & & \\
\hline $\mathbf{O}$ & 1 & 0.982830 & & & & \\
\hline C & 2 & 1.436436 & 1 & 106.652612 & & \\
\hline C & 3 & 1.558311 & 2 & 114.843523 & 1 & -178.054173 \\
\hline $\mathbf{O}$ & 4 & 1.443925 & 3 & 116.416279 & 2 & -39.996291 \\
\hline C & 5 & 1.444748 & 4 & 118.808062 & 3 & -54.583290 \\
\hline C & 6 & 1.549098 & 5 & 116.393859 & 4 & -57.944899 \\
\hline $\mathbf{O}$ & 7 & 1.427203 & 6 & 110.369551 & 5 & -56.556278 \\
\hline H & 8 & 0.983199 & 7 & 106.877270 & 6 & -179.178930 \\
\hline $\mathbf{H}$ & 3 & 1.091548 & 2 & 107.731828 & 1 & 60.272407 \\
\hline H & 3 & 1.092737 & 2 & 109.025017 & 1 & -56.489839 \\
\hline $\mathbf{H}$ & 4 & 1.092211 & 3 & 109.314336 & 2 & -164.344914 \\
\hline H & 6 & 1.094061 & 5 & 109.958095 & 4 & 67.708562 \\
\hline H & 7 & 1.093562 & 6 & 109.163277 & 5 & -176.220128 \\
\hline $\mathbf{H}$ & 7 & 1.091052 & 6 & 110.547606 & 5 & 65.049447 \\
\hline $\mathbf{O}$ & 4 & 1.424147 & 3 & 109.067221 & 2 & 80.126240 \\
\hline H & 6 & 1.092204 & 5 & 106.003607 & 4 & -176.927363 \\
\hline
\end{tabular}


Tabela B6 - Matriz Z para a estrutura do etilenoglicol monoformato otimizada com o modelo HF/6-31G(d)

\begin{tabular}{|c|c|c|c|c|c|c|}
\hline & \multicolumn{3}{|c|}{ Distâncias( $(\AA)$} & \multicolumn{2}{|l|}{ Ângulos $\left({ }^{\circ}\right)$} & \multirow[t]{2}{*}{ Diedros $\left({ }^{\circ}\right)$} \\
\hline $\mathbf{H}$ & & & & & & \\
\hline $\mathbf{O}$ & 1 & 0.946819 & & & & \\
\hline C & 2 & 1.401364 & 1 & 109.818766 & & \\
\hline C & 3 & 1.518358 & 2 & 110.969630 & 1 & -76.286896 \\
\hline $\mathbf{O}$ & 4 & 1.401850 & 3 & 107.776929 & 2 & -179.729516 \\
\hline C & 5 & 1.354990 & 4 & 116.508722 & 3 & 177.142468 \\
\hline C & 6 & 1.497823 & 5 & 113.611216 & 4 & -177.268298 \\
\hline $\mathbf{O}$ & 7 & 1.401294 & 6 & 111.335943 & 5 & -170.167049 \\
\hline $\mathbf{H}$ & 8 & 0.947356 & 7 & 109.090670 & 6 & 63.559240 \\
\hline H & 3 & 1.081018 & 2 & 106.995976 & 1 & 164.247773 \\
\hline $\mathbf{H}$ & 3 & 1.086298 & 2 & 111.740425 & 1 & 46.558163 \\
\hline $\mathbf{H}$ & 4 & 1.087885 & 3 & 110.457611 & 2 & 59.883211 \\
\hline $\mathbf{H}$ & 4 & 1.086030 & 3 & 109.805488 & 2 & -59.107519 \\
\hline $\mathbf{H}$ & 6 & 1.080508 & 5 & 116.578243 & 4 & -33.997101 \\
\hline H & 7 & 1.085532 & 6 & 110.929094 & 5 & 71.897811 \\
\hline H & 7 & 1.087437 & 6 & 109.330773 & 5 & -46.105938 \\
\hline
\end{tabular}


Tabela B7 - Matriz Z para as estruturas dos radicais alquila primário e alquilperoxila primário, otimizadas com o modelo $\mathrm{HF} / 6-31 \mathrm{G}(\mathrm{d})$.

\begin{tabular}{|c|c|c|c|c|c|c|}
\hline & \multicolumn{2}{|c|}{ Distâncias $(\AA)$} & \multicolumn{3}{|c|}{ Ângulos $\left({ }^{\circ}\right)$} & $\operatorname{Diedros}\left({ }^{\circ}\right)$ \\
\hline \multicolumn{7}{|c|}{ PEG_alkylprimário } \\
\hline $\mathbf{H}$ & & & & & & \\
\hline $\mathbf{O}$ & 1 & 0.946285 & & & & \\
\hline $\mathbf{C}$ & 2 & 1.358778 & 1 & 110.237708 & & \\
\hline H & 3 & 1.072868 & 2 & 112.735659 & 1 & -178.539100 \\
\hline$\underline{\mathbf{H}}$ & 3 & 1.077776 & 2 & 117.693224 & 1 & -34.677699 \\
\hline \multicolumn{7}{|c|}{ PEG_alkylperoxila primário } \\
\hline $\mathbf{H}$ & & & & & & \\
\hline $\mathbf{O}$ & 1 & 0.980543 & & & & \\
\hline $\mathbf{C}$ & 2 & 1.428083 & 1 & 106.429564 & & \\
\hline $\mathbf{O}$ & 3 & 1.426687 & 2 & 107.937663 & 1 & 179.953593 \\
\hline $\mathbf{O}$ & 4 & 1.316032 & 3 & 108.257434 & 2 & 179.985833 \\
\hline $\mathbf{H}$ & 3 & 1.093441 & 2 & 109.692110 & 1 & -60.226196 \\
\hline $\mathbf{H}$ & 3 & 1.093924 & 2 & 109.633084 & 1 & 60.264046 \\
\hline
\end{tabular}


Tabela B8 - Matriz Z para as estruturas dos radicais hidroperóxido primário e alcoxila primário, otimizadas com o modelo $\mathrm{HF} / 6-31 \mathrm{G}(\mathrm{d})$.

\begin{tabular}{|c|c|c|c|c|c|c|}
\hline & & Distâncias $(\AA)$ & \multicolumn{2}{|r|}{ Ângulos $\left({ }^{\circ}\right)$} & & \multirow[t]{2}{*}{ Diedros $\left({ }^{\circ}\right)$} \\
\hline \multicolumn{6}{|c|}{ PEG_hidroperoxido primário } & \\
\hline $\mathbf{H}$ & & & & & & \\
\hline $\mathbf{O}$ & 1 & 0.983678 & & & & \\
\hline $\mathbf{C}$ & 2 & 1.418019 & 1 & & & \\
\hline $\mathbf{O}$ & 3 & 1.426102 & 2 & 101.994430 & 1 & -25.842100 \\
\hline $\mathbf{H}$ & 3 & 1.094092 & 2 & 104.951543 & 1 & -145.372166 \\
\hline $\mathbf{H}$ & 3 & 1.093278 & 2 & 110.366637 & 1 & 93.348976 \\
\hline $\mathbf{O}$ & 4 & 1.317249 & 3 & 108.227555 & 2 & 179.931489 \\
\hline $\mathbf{H}$ & 7 & 0.985894 & 4 & 105.994933 & 3 & -135.432332 \\
\hline \multicolumn{7}{|c|}{ PEG_alkoxyl primário } \\
\hline $\mathbf{O}$ & & & & & & \\
\hline $\mathbf{C}$ & 1 & 1.366295 & & & & \\
\hline $\mathbf{O}$ & 2 & 1.380168 & 1 & 114.485997 & & \\
\hline H & 2 & 1.082548 & 1 & 108.995877 & 3 & \\
\hline $\mathbf{H}$ & 2 & 1.090381 & 1 & 105.277844 & 3 & -123.639402 \\
\hline H & 3 & 0.948378 & 2 & 109.673725 & 1 & -55.872644 \\
\hline
\end{tabular}


Tabela B9- Matriz Z para a estrutura do estado de transição da reação 5.1, otimizada com o modelo HF/6-31G(d).

\begin{tabular}{|c|c|c|c|c|c|c|}
\hline & & Distâncias(Å) & & Ângulos( $\left(^{\circ}\right)$ & & Diedros $\left({ }^{\circ}\right)$ \\
\hline $\mathbf{O}$ & & & & & & \\
\hline C & 1 & 1.398816 & & & & \\
\hline C & 2 & 1.508201 & 1 & 111.99722 & & \\
\hline $\mathbf{O}$ & 3 & 1.371180 & 2 & 110.104167 & 1 & 64.479841 \\
\hline C & 4 & 1.406040 & 3 & 115.769684 & 2 & -172.329875 \\
\hline C & 5 & 1.518297 & 4 & 107.867570 & 3 & -178.272277 \\
\hline $\mathbf{O}$ & 6 & 1.400053 & 5 & 110.946659 & 4 & -178.821956 \\
\hline H & 1 & 0.948209 & 2 & 108.449030 & 3 & -58.876151 \\
\hline H & 2 & 1.080982 & 1 & 107.123306 & 3 & -119.879113 \\
\hline H & 2 & 1.087116 & 1 & 111.091112 & 3 & 122.038675 \\
\hline H & 3 & 1.085067 & 2 & 113.883011 & 1 & -63.760931 \\
\hline H & 3 & 1.292344 & 2 & 107.588448 & 1 & -176.964149 \\
\hline H & 5 & 1.086676 & 4 & 109.723952 & 3 & -57.564680 \\
\hline H & 5 & 1.085802 & 4 & 110.442878 & 3 & 61.588696 \\
\hline H & 6 & 1.086594 & 5 & 109.632624 & 4 & 57.155341 \\
\hline H & 6 & 1.081226 & 5 & 109.632624 & 4 & -60.9982480 \\
\hline H & 7 & 0.947006 & 6 & 109.899280 & 5 & -74.785796 \\
\hline H & 3 & 2.800130 & 2 & 99.053792 & 1 & 161.708760 \\
\hline O & 3 & 2.523676 & 2 & 108.157015 & 1 & 179.820702 \\
\hline
\end{tabular}


Tabela B10 - Matriz Z para a estrutura do estado de transição da reação 5.3 otimizada com o modelo $\mathrm{HF} / 6-31 \mathrm{G}(\mathrm{d})$.

\begin{tabular}{|c|c|c|c|c|c|c|}
\hline & & Distâncias( $(\AA)$ & & Ângulos( $\left(^{\circ}\right)$ & & $\operatorname{Diedros}\left({ }^{\circ}\right)$ \\
\hline H & & & & & & \\
\hline $\mathbf{O}$ & 1 & 0.946862 & & & & \\
\hline C & 2 & 1.404713 & 1 & 110.025534 & & \\
\hline C & 3 & 1.517882 & 2 & 111.076522 & 1 & 77.767643 \\
\hline O & 4 & 1.400843 & 3 & 107.228190 & 2 & 177.260334 \\
\hline C & 5 & 1.368726 & 4 & 116.484689 & 3 & -161.301289 \\
\hline C & 6 & 1.518213 & 5 & 109.502820 & 4 & -166.667895 \\
\hline $\mathbf{O}$ & 7 & 1.392791 & 6 & 111.603342 & 5 & -54.077647 \\
\hline H & 8 & 0.946526 & 7 & 109.172319 & 6 & -179.032695 \\
\hline H & 3 & 1.080253 & 2 & 107.146058 & 1 & -163.307908 \\
\hline H & 4 & 1.082558 & 3 & 109.725676 & 2 & 56.499440 \\
\hline H & 6 & 1.088192 & 5 & 111.302329 & 4 & -48.113061 \\
\hline H & 7 & 1.087328 & 6 & 107.303380 & 5 & -176.743109 \\
\hline H & 7 & 1.088101 & 6 & 106.770618 & 5 & 67.453264 \\
\hline H & 3 & 1.085586 & 2 & 111.605499 & 1 & -45.557629 \\
\hline H & 4 & 1.089951 & 3 & 110.847055 & 2 & -62.544120 \\
\hline $\mathbf{O}$ & 6 & 1.404519 & 5 & 113.276289 & 4 & 65.018387 \\
\hline $\mathbf{O}$ & 17 & 1.375634 & 6 & 111.017582 & 5 & 58.530903 \\
\hline O & 2 & 4.961556 & 1 & 150.240085 & 3 & -171.276058 \\
\hline C & 19 & 1.398477 & 2 & 10.362983 & 1 & -69.867861 \\
\hline C & 20 & 1.512860 & 19 & 111.614892 & 2 & -120.542550 \\
\hline $\mathbf{O}$ & 21 & 1.414311 & 20 & 107.242395 & 19 & 61.373619 \\
\hline C & 22 & 1.360604 & 21 & 117.580119 & 20 & -174.917224 \\
\hline C & 23 & 1.515111 & 22 & 111.898107 & 21 & 148.740512 \\
\hline $\mathbf{O}$ & 24 & 1.393117 & 23 & 111.309528 & 22 & 179.213419 \\
\hline H & 19 & 0.947955 & 2 & 103.024346 & 1 & 168.709962 \\
\hline H & 20 & 1.081886 & 19 & 107.129052 & 2 & 119.844158 \\
\hline H & 20 & 1.085881 & 19 & 111.313617 & 2 & 2.167558 \\
\hline H & 21 & 1.085545 & 20 & 110.086112 & 19 & -57.371807 \\
\hline H & 21 & 1.082785 & 20 & 110.380758 & 19 & -178.089860 \\
\hline H & 18 & 1.232261 & 17 & 104.546604 & 6 & -120.391494 \\
\hline H & 23 & 1.083720 & 22 & 114.562397 & 21 & 17.560744 \\
\hline H & 24 & 1.086698 & 23 & 109.275210 & 22 & 54.692309 \\
\hline H & 24 & 1.083949 & 23 & 108.884938 & 22 & -62.809665 \\
\hline $\mathbf{H}$ & 25 & 0.949562 & 24 & 108.893275 & 23 & -63.149049 \\
\hline
\end{tabular}


Tabela B11 - Matriz Z para a estrutura do estado de transição da reação 5.7 otimizada com o modelo $\mathrm{HF} / 6-31 \mathrm{G}(\mathrm{d})$.

\begin{tabular}{|c|c|c|c|c|c|c|}
\hline & & Distâncias(Å) & & Ângulos $\left({ }^{\circ}\right)$ & & $\operatorname{Diedros}\left({ }^{0}\right)$ \\
\hline $\mathbf{O}$ & & & & & & \\
\hline C & 1 & 1.397346 & & & & \\
\hline C & 2 & 1.512713 & 1 & 111.723882 & & \\
\hline $\mathbf{O}$ & 3 & 1.411974 & 2 & 107.163860 & 1 & 61.699142 \\
\hline C & 4 & 1.360734 & 3 & 116.424274 & 2 & -176.406721 \\
\hline C & 5 & 1.511585 & 4 & 111.375144 & 3 & 174.426205 \\
\hline $\mathbf{O}$ & 6 & 1.390248 & 5 & 111.654186 & 4 & 175.411068 \\
\hline H & 1 & 0.948058 & 2 & 108.265765 & 3 & -57.737560 \\
\hline H & 2 & 1.082446 & 1 & 107.001706 & 3 & -119.827950 \\
\hline H & 2 & 1.087323 & 1 & 111.150469 & 3 & 122.391112 \\
\hline H & 3 & 1.086019 & 2 & 110.181913 & 1 & -57.389559 \\
\hline H & 3 & 1.084572 & 2 & 111.069593 & 1 & -178.370220 \\
\hline H & 5 & 1.322665 & 4 & 108.505651 & 3 & -67.175353 \\
\hline H & 5 & 1.085770 & 4 & 114.246432 & 3 & 43.635179 \\
\hline H & 6 & 1.086596 & 5 & 109.063438 & 4 & 50.482913 \\
\hline H & 6 & 1.084555 & 5 & 108.598620 & 4 & -66.164944 \\
\hline H & 7 & 0.950955 & 6 & 108.939670 & 5 & -77.400048 \\
\hline H & 7 & 3.225810 & 6 & 80.353175 & 5 & -96.215229 \\
\hline $\mathbf{O}$ & 7 & 2.952005 & 6 & 91.697019 & 5 & -83.603444 \\
\hline C & 19 & 1.387657 & 7 & 124.496463 & 6 & 73.101730 \\
\hline $\mathbf{O}$ & 20 & 1.386806 & 19 & 112.929872 & 7 & -44.270119 \\
\hline $\mathbf{O}$ & 21 & 1.372740 & 20 & 109.355999 & 19 & 77.997696 \\
\hline H & 20 & 1.076954 & 19 & 106.947442 & 7 & 77.006112 \\
\hline H & 20 & 1.082233 & 19 & 111.200390 & 7 & -161.607412 \\
\hline
\end{tabular}


Tabela B12- Parâmetros estruturais para a água, oxigênio e radical hidroxila obtidos com o modelo HF/6-31G(d).

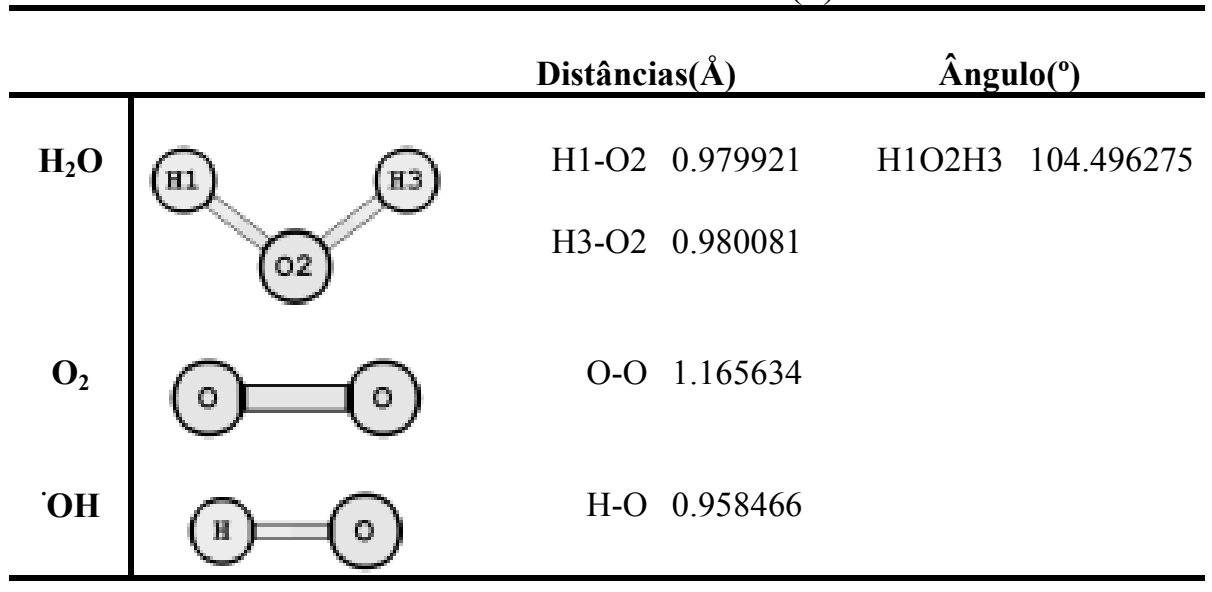




\section{APÊNDICE C - MATRIZES Z PARA AS ESTRUTURAS DAS REAÇÕES DA 2 METIL PENTANODIAMIDA}

Tabela C1- Matriz Z para a estrutura do 2-metil pentanodiamida otimizada com o modelo $\mathrm{HF} / 6-31 \mathrm{G}(\mathrm{d})$

\begin{tabular}{|c|c|c|c|c|c|c|}
\hline \multirow[b]{2}{*}{ C } & & \multicolumn{2}{|l|}{ Distâncias(Å) } & \multicolumn{2}{|l|}{ Ângulos $\left({ }^{\circ}\right)$} & \multirow[t]{2}{*}{$\operatorname{Diedros}\left({ }^{\circ}\right)$} \\
\hline & & & & & & \\
\hline C & 1 & 1.526889 & & & & \\
\hline C & 2 & 1.549830 & 1 & 112.082451 & & \\
\hline C & 3 & 1.527043 & 2 & 113.367204 & 1 & -92.465319 \\
\hline C & 2 & 1.525646 & 1 & 111.142099 & 3 & 123.102100 \\
\hline C & 4 & 1.521258 & 3 & 112.801417 & 2 & -71.181440 \\
\hline O & 5 & 1.200798 & 2 & 123.050922 & 1 & -21.216665 \\
\hline O & 6 & 1.203881 & 4 & 123.234138 & 3 & -4.207238 \\
\hline $\mathbf{N}$ & 5 & 1.353266 & 2 & 114.065014 & 1 & 158.739605 \\
\hline $\mathbf{N}$ & 6 & 1.349835 & 4 & 115.087883 & 3 & 176.092953 \\
\hline H & 1 & 1.086786 & 2 & 110.615398 & 5 & 178.592923 \\
\hline H & 1 & 1.083956 & 2 & 111.122900 & 5 & -61.472311 \\
\hline H & 1 & 1.082421 & 2 & 110.677037 & 5 & 58.150443 \\
\hline H & 2 & 1.084763 & 1 & 108.973477 & 5 & 117.026182 \\
\hline H & 3 & 1.085073 & 2 & 108.971287 & 1 & 29.071090 \\
\hline H & 3 & 1.082508 & 2 & 110.668197 & 1 & 146.024745 \\
\hline H & 4 & 1.087145 & 3 & 111.243973 & 2 & 51.287343 \\
\hline H & 4 & 1.087820 & 3 & 110.114360 & 2 & 168.848972 \\
\hline H & 9 & 0.997497 & 5 & 120.592390 & 2 & 11.351170 \\
\hline H & 10 & 0.995167 & 6 & 118.614522 & 4 & 177.241494 \\
\hline H & 10 & 0.993031 & 6 & 122.528588 & 4 & 2.702946 \\
\hline H & 9 & 0.995142 & 5 & 117.571507 & 2 & 170.883960 \\
\hline
\end{tabular}


Tabela C2 - Matriz Z para a estrutura do radical PAM_alquila2 otimizada com o modelo HF/6-31G(d).

\begin{tabular}{|c|c|c|c|c|c|c|}
\hline & & Distâncias(Å) & & Ângulos $\left({ }^{\circ}\right)$ & & $\operatorname{Diedros}\left({ }^{\circ}\right)$ \\
\hline $\mathrm{C}$ & & & & & & \\
\hline C & 1 & 1.501833 & & & & \\
\hline C & 2 & 1.510295 & 1 & 118.393522 & & \\
\hline C & 3 & 1.535060 & 2 & 114.618819 & 1 & -76.824891 \\
\hline C & 2 & 1.478749 & 1 & 117.193181 & 3 & 168.355366 \\
\hline C & 4 & 1.518242 & 3 & 113.597311 & 2 & -71.790031 \\
\hline $\mathbf{O}$ & 5 & 1.207444 & 2 & 120.531703 & 1 & -6.295235 \\
\hline $\mathbf{O}$ & 6 & 1.203885 & 4 & 122.844694 & 3 & -20.473849 \\
\hline $\mathbf{N}$ & 5 & 1.364854 & 2 & 117.477395 & 1 & 175.767176 \\
\hline $\mathbf{N}$ & 6 & 1.348082 & 4 & 115.384537 & 3 & 161.548583 \\
\hline H & 1 & 1.086332 & 2 & 111.323590 & 5 & -151.304743 \\
\hline H & 1 & 1.080241 & 2 & 111.313425 & 5 & -29.420006 \\
\hline H & 1 & 1.089470 & 2 & 110.460130 & 5 & 89.829414 \\
\hline H & 3 & 1.088205 & 2 & 107.894601 & 1 & 42.581896 \\
\hline H & 3 & 1.080713 & 2 & 111.115460 & 1 & 159.127551 \\
\hline H & 4 & 1.085208 & 3 & 111.029416 & 2 & 52.473182 \\
\hline H & 4 & 1.087921 & 3 & 109.224071 & 2 & 169.511176 \\
\hline H & 9 & 0.998842 & 5 & 118.338899 & 2 & -30.852394 \\
\hline H & 10 & 0.995263 & 6 & 118.600463 & 4 & 177.029501 \\
\hline H & 10 & 0.992737 & 6 & 122.706203 & 4 & -1.984825 \\
\hline H & 9 & 0.996717 & 5 & 113.596359 & 2 & -171.015175 \\
\hline
\end{tabular}


Tabela C3 - Matriz Z para a estrutura do radical PAM_alquillperoxila2 otimizada com o modelo $\mathrm{HF} / 6-31 \mathrm{G}(\mathrm{d})$.

\begin{tabular}{|c|c|c|c|c|c|c|}
\hline & & Distâncias( $(\AA)$ & & Ângulos $\left({ }^{\circ}\right)$ & & $\operatorname{Diedros}\left({ }^{\circ}\right)$ \\
\hline C & & & & & & \\
\hline C & 1 & 1.527865 & & & & \\
\hline C & 2 & 1.536586 & 1 & 111.472494 & & \\
\hline C & 3 & 1.535542 & 2 & 117.052026 & 1 & 170.187364 \\
\hline C & 4 & 1.524423 & 3 & 121.102749 & 2 & 74.259731 \\
\hline C & 2 & 1.532166 & 1 & 108.061521 & 3 & -122.316232 \\
\hline $\mathbf{N}$ & 5 & 1.359454 & 4 & 117.824675 & 3 & 33.655740 \\
\hline $\mathbf{N}$ & 6 & 1.336802 & 2 & 117.863495 & 1 & -115.027919 \\
\hline $\mathbf{O}$ & 6 & 1.204641 & 2 & 118.561188 & 1 & 64.102816 \\
\hline $\mathbf{O}$ & 5 & 1.199129 & 4 & 119.782695 & 3 & -152.666679 \\
\hline H & 1 & 1.084280 & 2 & 110.393829 & 6 & 59.206544 \\
\hline H & 1 & 1.082144 & 2 & 110.171392 & 6 & 179.289925 \\
\hline H & 1 & 1.080971 & 2 & 109.622659 & 6 & -60.463144 \\
\hline H & 8 & 0.993333 & 6 & 122.295361 & 2 & -5.118496 \\
\hline $\mathbf{H}$ & 8 & 0.995592 & 6 & 117.962511 & 2 & -177.937142 \\
\hline H & 7 & 0.997221 & 5 & 114.357038 & 4 & -175.981893 \\
\hline H & 7 & 0.995565 & 5 & 120.384282 & 4 & -32.775192 \\
\hline H & 4 & 1.087005 & 3 & 107.232216 & 2 & -166.305784 \\
\hline H & 4 & 1.080689 & 3 & 110.837460 & 2 & -50.816772 \\
\hline H & 3 & 1.082587 & 2 & 107.517827 & 1 & -63.318503 \\
\hline H & 3 & 1.083501 & 2 & 106.735835 & 1 & 50.277231 \\
\hline $\mathbf{O}$ & 2 & 1.439033 & 1 & 109.489058 & 6 & -115.105742 \\
\hline $\mathbf{O}$ & 22 & 1.300223 & 2 & 112.950077 & 1 & -61.829078 \\
\hline
\end{tabular}


Tabela C4 - Matriz Z para a estrutura do radical PAM_ hidroperoxido2 secundário otimizada com o modelo $\mathrm{HF} / 6-31 \mathrm{G}(\mathrm{d})$.

\begin{tabular}{|c|c|c|c|c|c|c|}
\hline & \multicolumn{3}{|c|}{ Distâncias( $(\AA)$} & \multicolumn{2}{|l|}{ Ângulos $\left({ }^{\circ}\right)$} & \multirow[t]{2}{*}{$\operatorname{Diedros}\left({ }^{\circ}\right)$} \\
\hline C & & & & & & \\
\hline C & 1 & 1.530050 & & & & \\
\hline C & 2 & 1.532060 & 1 & 111.057342 & & \\
\hline C & 3 & 1.541119 & 2 & 114.286620 & 1 & 172.432752 \\
\hline C & 4 & 1.516254 & 3 & 112.663122 & 2 & 130.945187 \\
\hline C & 2 & 1.547397 & 1 & 106.723663 & 3 & -126.651706 \\
\hline $\mathbf{O}$ & 6 & 1.198520 & 2 & 119.623596 & 1 & -69.001223 \\
\hline O & 5 & 1.207007 & 4 & 121.760382 & 3 & -39.138838 \\
\hline $\mathbf{N}$ & 5 & 1.345407 & 4 & 116.359466 & 3 & 142.781304 \\
\hline $\mathbf{N}$ & 6 & 1.347308 & 2 & 117.561025 & 1 & 106.512659 \\
\hline H & 1 & 1.082157 & 2 & 109.631941 & 3 & -176.712058 \\
\hline H & 1 & 1.082494 & 2 & 110.678539 & 3 & -55.739508 \\
\hline H & 1 & 1.084838 & 2 & 110.150043 & 3 & 63.994250 \\
\hline H & 3 & 1.081532 & 2 & 107.473930 & 1 & 51.435155 \\
\hline $\mathbf{H}$ & 3 & 1.081647 & 2 & 108.983742 & 1 & -63.503242 \\
\hline $\mathbf{H}$ & 4 & 1.085584 & 3 & 110.687854 & 2 & 12.575309 \\
\hline H & 4 & 1.082988 & 3 & 110.374632 & 2 & -104.289412 \\
\hline H & 9 & 0.995385 & 5 & 118.601217 & 4 & 175.196325 \\
\hline H & 9 & 0.992608 & 5 & 122.514472 & 4 & -0.274557 \\
\hline H & 10 & 0.998464 & 6 & 124.714161 & 2 & 17.699072 \\
\hline H & 10 & 0.996056 & 6 & 115.642645 & 2 & 179.893025 \\
\hline O & 2 & 1.418425 & 1 & 111.247945 & 6 & -110.849490 \\
\hline $\mathbf{O}$ & 22 & 1.394207 & 2 & 109.330958 & 1 & -62.408824 \\
\hline $\mathbf{H}$ & 23 & 0.949566 & 22 & 101.609443 & 2 & 118.620852 \\
\hline
\end{tabular}


Tabela C5 - Matriz Z para a estrutura do radical PAM_alquila1 otimizada com o modelo HF/6-31G(d).

\begin{tabular}{|c|c|c|c|c|c|c|}
\hline & & Distâncias( $(\AA)$ & & Ângulos $\left(^{(}\right)$ & & $\operatorname{Diedros}\left({ }^{\circ}\right)$ \\
\hline C & & & & & & \\
\hline C & 1 & 1.533287 & & & & \\
\hline C & 2 & 1.509329 & 1 & 111.793289 & & \\
\hline C & 3 & 1.498072 & 2 & 122.509798 & 1 & -103.028020 \\
\hline C & 2 & 1.532209 & 1 & 110.707323 & 3 & 122.805424 \\
\hline C & 4 & 1.526514 & 3 & 114.031279 & 2 & -78.322329 \\
\hline O & 5 & 1.201117 & 2 & 122.427265 & 1 & -14.835116 \\
\hline O & 6 & 1.202906 & 4 & 123.371230 & 3 & 15.473128 \\
\hline $\mathbf{N}$ & 5 & 1.349540 & 2 & 114.478098 & 1 & 164.835435 \\
\hline $\mathbf{N}$ & 6 & 1.348927 & 4 & 114.862176 & 3 & -165.890153 \\
\hline H & 1 & 1.086009 & 2 & 110.253333 & 3 & 58.802156 \\
\hline H & 1 & 1.083540 & 2 & 110.832348 & 3 & 178.912962 \\
\hline H & 1 & 1.082198 & 2 & 110.750888 & 3 & -61.548788 \\
\hline H & 2 & 1.086461 & 1 & 109.026079 & 3 & -119.619524 \\
\hline H & 3 & 1.075963 & 2 & 118.625450 & 1 & 75.307139 \\
\hline H & 4 & 1.090237 & 3 & 110.504769 & 2 & 41.291608 \\
\hline H & 4 & 1.085803 & 3 & 110.585755 & 2 & 158.773982 \\
\hline H & 9 & 0.998245 & 5 & 120.692635 & 2 & 12.620486 \\
\hline H & 10 & 0.995243 & 6 & 118.598594 & 4 & -176.539730 \\
\hline H & 10 & 0.992882 & 6 & 122.673556 & 4 & 0.029613 \\
\hline H & 9 & 0.995128 & 5 & 117.274273 & 2 & 172.175615 \\
\hline
\end{tabular}


Tabela C6- Matriz Z para a estrutura do radical PAM_alquilperoxila1 otimizada com o modelo HF/6-31G(d).

\begin{tabular}{|c|c|c|c|c|c|c|}
\hline & & 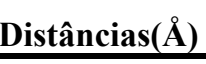 & & Ângulos( $\left(^{\circ}\right)$ & & Diedros $\left({ }^{\circ}\right)$ \\
\hline $\mathrm{C}$ & & & & & & \\
\hline C & 1 & 1.531232 & & & & \\
\hline C & 2 & 1.537292 & 1 & 115.634140 & & \\
\hline C & 3 & 1.532185 & 2 & 116.534375 & 1 & -57.426170 \\
\hline H & 2 & 1.083916 & 1 & 107.283793 & 3 & -117.557223 \\
\hline H & 4 & 1.079075 & 3 & 111.115203 & 2 & 58.186381 \\
\hline H & 4 & 1.084653 & 3 & 107.654217 & 2 & 176.083375 \\
\hline H & 1 & 1.081496 & 2 & 110.074034 & 3 & 60.186411 \\
\hline H & 1 & 1.084091 & 2 & 112.988007 & 3 & -60.771570 \\
\hline H & 1 & 1.084628 & 2 & 110.027734 & 3 & 177.695998 \\
\hline H & 3 & 1.079022 & 2 & 106.968857 & 1 & 179.505505 \\
\hline C & 2 & 1.532641 & 1 & 116.166033 & 3 & 126.707111 \\
\hline C & 4 & 1.518643 & 3 & 111.673876 & 2 & -61.793330 \\
\hline O & 13 & 1.200522 & 4 & 121.646439 & 3 & 82.157177 \\
\hline $\mathbf{O}$ & 12 & 1.201178 & 2 & 120.037687 & 1 & 175.463107 \\
\hline $\mathbf{N}$ & 12 & 1.350181 & 2 & 118.021185 & 1 & -2.556684 \\
\hline $\mathbf{N}$ & 13 & 1.349708 & 4 & 115.861778 & 3 & -96.989980 \\
\hline H & 17 & 0.995422 & 13 & 118.441961 & 4 & 176.913644 \\
\hline H & 17 & 0.992609 & 13 & 122.871298 & 4 & 0.841236 \\
\hline H & 16 & 0.995683 & 12 & 116.869438 & 2 & -174.743054 \\
\hline H & 16 & 0.991696 & 12 & 122.590751 & 2 & -13.672872 \\
\hline $\mathbf{O}$ & 3 & 1.435780 & 2 & 111.112653 & 1 & 69.257967 \\
\hline O & 22 & 1.300653 & 3 & 113.581006 & 2 & -80.541684 \\
\hline
\end{tabular}


Tabela C7 - Matriz Z para a estrutura do radical PAM_ hidroperoxido1 secundário otimizada com o modelo $\mathrm{HF} / 6-31 \mathrm{G}(\mathrm{d})$.

\begin{tabular}{|c|c|c|c|c|c|c|}
\hline & & Distâncias(Å) & & Ângulos $\left({ }^{\circ}\right)$ & & $\operatorname{Diedros}\left({ }^{\circ}\right)$ \\
\hline C & & & & & & \\
\hline C & 1 & 1.538976 & & & & \\
\hline C & 2 & 1.533078 & 1 & 112.275647 & & \\
\hline C & 3 & 1.542394 & 2 & 113.530465 & 1 & -177.148305 \\
\hline C & 2 & 1.522553 & 1 & 108.579032 & 3 & 121.241210 \\
\hline C & 4 & 1.521598 & 3 & 115.881000 & 2 & -137.546776 \\
\hline $\mathbf{O}$ & 3 & 1.410980 & 2 & 104.860601 & 1 & -56.498729 \\
\hline $\mathbf{O}$ & 7 & 1.389797 & 3 & 108.218953 & 2 & 176.099091 \\
\hline $\mathbf{O}$ & 6 & 1.198283 & 4 & 122.019813 & 3 & -131.504843 \\
\hline $\mathbf{O}$ & 5 & 1.205609 & 2 & 122.314442 & 1 & -92.485250 \\
\hline $\mathbf{N}$ & 6 & 1.356428 & 4 & 115.246897 & 3 & 49.861692 \\
\hline $\mathbf{N}$ & 5 & 1.346484 & 2 & 115.824967 & 1 & 86.024140 \\
\hline H & 11 & 0.995525 & 6 & 116.589410 & 4 & 170.213409 \\
\hline H & 11 & 0.997552 & 6 & 120.825872 & 4 & 14.389694 \\
\hline H & 12 & 0.992979 & 5 & 122.629411 & 2 & 0.049105 \\
\hline H & 12 & 0.995559 & 5 & 118.585618 & 2 & -175.244269 \\
\hline H & 1 & 1.084863 & 2 & 110.996714 & 5 & -57.360089 \\
\hline $\mathbf{H}$ & 1 & 1.080756 & 2 & 110.405777 & 5 & -177.488773 \\
\hline H & 1 & 1.084894 & 2 & 110.460527 & 5 & 62.362176 \\
\hline H & 2 & 1.086792 & 1 & 108.901776 & 5 & 118.851682 \\
\hline H & 3 & 1.081063 & 2 & 108.700794 & 1 & 59.134863 \\
\hline H & 4 & 1.086430 & 3 & 110.366219 & 2 & -16.515135 \\
\hline H & 4 & 1.079717 & 3 & 109.066031 & 2 & 101.405958 \\
\hline H & 8 & 0.950296 & 7 & 102.698866 & 3 & -105.608354 \\
\hline
\end{tabular}


Tabela C8- Matriz Z para a estrutura do radical PAM_alquila3 otimizada com o modelo HF/6-31G(d).

\begin{tabular}{|c|c|c|c|c|c|c|}
\hline & & 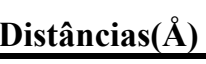 & & Ângulos( $\left(^{\circ}\right)$ & & Diedros $\left({ }^{\circ}\right)$ \\
\hline C & & & & & & \\
\hline $\mathrm{C}$ & 1 & 1.528028 & & & & \\
\hline C & 2 & 1.549316 & 1 & 111.974604 & & \\
\hline C & 3 & 1.526903 & 2 & 113.528100 & 1 & -89.703856 \\
\hline C & 2 & 1.525005 & 1 & 111.870393 & 3 & 124.339466 \\
\hline C & 4 & 1.521367 & 3 & 112.462159 & 2 & -71.462400 \\
\hline O & 5 & 1.228834 & 2 & 121.788718 & 1 & -13.380384 \\
\hline O & 6 & 1.203125 & 4 & 122.960781 & 3 & -3.236957 \\
\hline $\mathbf{N}$ & 5 & 1.368446 & 2 & 119.917721 & 1 & 166.576257 \\
\hline $\mathbf{N}$ & 6 & 1.350050 & 4 & 115.181542 & 3 & 176.710929 \\
\hline H & 1 & 1.086161 & 2 & 110.564534 & 5 & -179.347491 \\
\hline H & 1 & 1.083912 & 2 & 111.203726 & 5 & -59.493204 \\
\hline H & 1 & 1.083344 & 2 & 111.034960 & 5 & 60.412971 \\
\hline H & 2 & 1.085611 & 1 & 108.610113 & 5 & 116.472263 \\
\hline H & 3 & 1.085498 & 2 & 108.884133 & 1 & 32.059191 \\
\hline H & 3 & 1.082981 & 2 & 110.768363 & 1 & 148.823423 \\
\hline H & 4 & 1.086982 & 3 & 111.385297 & 2 & 50.943470 \\
\hline H & 4 & 1.087592 & 3 & 110.067053 & 2 & 168.568197 \\
\hline H & 9 & 1.010588 & 5 & 109.965515 & 2 & 0.707234 \\
\hline H & 10 & 0.995316 & 6 & 118.481773 & 4 & 176.215257 \\
\hline H & 10 & 0.993133 & 6 & 122.448931 & 4 & 4.801354 \\
\hline
\end{tabular}


Tabela C9 - Matriz Z para a estrutura do estado de transição da reação 1 caminho 1, PAM2 Reação1_TS, otimizada com o modelo HF/6-31G(d).

\begin{tabular}{|c|c|c|c|c|c|c|}
\hline & & Distâncias( $(\AA)$ & & Ângulos( $\left({ }^{\circ}\right)$ & & $\operatorname{Diedros}\left({ }^{\circ}\right)$ \\
\hline C & & & & & & \\
\hline C & 1 & 1.521305 & & & & \\
\hline C & 2 & 1.529334 & 1 & 116.854241 & & \\
\hline C & 3 & 1.529087 & 2 & 117.049371 & 1 & -48.196568 \\
\hline C & 2 & 1.523259 & 1 & 111.008186 & 3 & 126.715638 \\
\hline C & 4 & 1.518243 & 3 & 114.790523 & 2 & -70.998447 \\
\hline O & 5 & 1.203371 & 2 & 119.805271 & 1 & -64.498937 \\
\hline $\mathbf{O}$ & 6 & 1.205333 & 4 & 122.908387 & 3 & -21.699218 \\
\hline $\mathbf{N}$ & 5 & 1.341622 & 2 & 116.545512 & 1 & 115.673773 \\
\hline $\mathbf{N}$ & 6 & 1.347188 & 4 & 115.342833 & 3 & 160.254649 \\
\hline H & 1 & 1.083625 & 2 & 111.497880 & 5 & -171.336632 \\
\hline H & 1 & 1.083773 & 2 & 110.618301 & 5 & -51.685382 \\
\hline H & 1 & 1.085871 & 2 & 110.083567 & 5 & 67.675810 \\
\hline H & 2 & 1.303612 & 1 & 104.463371 & 5 & 112.857520 \\
\hline H & 3 & 1.085834 & 2 & 106.677738 & 1 & 72.777042 \\
\hline H & 3 & 1.083726 & 2 & 109.060773 & 1 & -172.147646 \\
\hline H & 4 & 1.084356 & 3 & 111.488602 & 2 & 54.949376 \\
\hline H & 4 & 1.088015 & 3 & 108.128351 & 2 & 171.142995 \\
\hline H & 9 & 0.996061 & 5 & 121.489418 & 2 & -0.839411 \\
\hline H & 10 & 0.995441 & 6 & 118.522213 & 4 & 175.186083 \\
\hline H & 10 & 0.992949 & 6 & 122.643037 & 4 & 1.055755 \\
\hline H & 9 & 0.994940 & 5 & 118.295594 & 2 & -179.284632 \\
\hline H & 8 & 2.025434 & 6 & 117.243837 & 4 & 72.703774 \\
\hline O & 2 & 2.513788 & 1 & 106.913279 & 5 & 110.123004 \\
\hline
\end{tabular}


Tabela C10 - Matriz Z para a estrutura do estado de transição da reação 1 caminho2, PAM1_Reação1_TS, otimizada com o modelo HF/6-31G(d).

\begin{tabular}{|c|c|c|c|c|c|c|}
\hline & & Distâncias( $(\AA)$ & & Ângulos( $\left({ }^{\circ}\right)$ & & $\operatorname{Diedros}\left({ }^{\circ}\right)$ \\
\hline C & & & & & & \\
\hline C & 1 & 1.535228 & & & & \\
\hline C & 2 & 1.528144 & 1 & 113.876318 & & \\
\hline C & 3 & 1.515268 & 2 & 117.937569 & 1 & -59.715070 \\
\hline C & 2 & 1.523534 & 1 & 109.152461 & 3 & 121.477896 \\
\hline C & 4 & 1.522663 & 3 & 113.234924 & 2 & -69.615335 \\
\hline $\mathbf{O}$ & 5 & 1.205754 & 2 & 122.128754 & 1 & -59.998856 \\
\hline $\mathbf{O}$ & 6 & 1.200460 & 4 & 123.180898 & 3 & -2.455113 \\
\hline $\mathbf{N}$ & 5 & 1.347247 & 2 & 115.984173 & 1 & 119.291349 \\
\hline $\mathbf{N}$ & 6 & 1.353846 & 4 & 114.672104 & 3 & 177.039617 \\
\hline H & 1 & 1.084090 & 2 & 110.857763 & 5 & -173.630977 \\
\hline H & 1 & 1.085108 & 2 & 110.478145 & 5 & -54.784322 \\
\hline H & 1 & 1.081474 & 2 & 110.872699 & 5 & 65.544787 \\
\hline H & 2 & 1.084562 & 1 & 108.834854 & 5 & 118.877541 \\
\hline H & 3 & 1.314159 & 2 & 106.966306 & 1 & 56.808591 \\
\hline H & 3 & 1.081375 & 2 & 112.158102 & 1 & 168.666651 \\
\hline H & 4 & 1.084634 & 3 & 111.432043 & 2 & 53.715842 \\
\hline H & 4 & 1.086950 & 3 & 108.954114 & 2 & 170.433461 \\
\hline H & 9 & 0.993116 & 5 & 122.033089 & 2 & 8.643948 \\
\hline H & 10 & 0.995386 & 6 & 118.058698 & 4 & 173.685217 \\
\hline H & 10 & 0.993454 & 6 & 122.042928 & 4 & 9.100923 \\
\hline H & 9 & 0.995681 & 5 & 118.247837 & 2 & 175.775722 \\
\hline H & 7 & 2.135856 & 5 & 115.505299 & 2 & -23.826752 \\
\hline O & 3 & 2.505307 & 2 & 103.644085 & 1 & 57.505890 \\
\hline
\end{tabular}


Tabela C11 - Matriz Z para a estrutura do estado de transição da reação 1 caminho3, PAM3 Reação1_TS, otimizada com o modelo HF/6-31G(d).

\begin{tabular}{|c|c|c|c|c|c|c|}
\hline & & Distâncias(Å) & & Ângulos( $\left(^{\circ}\right)$ & & $\operatorname{Diedros}\left({ }^{\circ}\right)$ \\
\hline C & & & & & & \\
\hline C & 1 & 1.529208 & & & & \\
\hline C & 2 & 1.552078 & 1 & 112.314931 & & \\
\hline $\mathrm{C}$ & 3 & 1.527244 & 2 & 113.024931 & 1 & -93.564354 \\
\hline C & 2 & 1.511449 & 1 & 112.517384 & 3 & 124.248502 \\
\hline C & 4 & 1.521999 & 3 & 112.630949 & 2 & -70.676442 \\
\hline O & 5 & 1.286661 & 2 & 117.862834 & 1 & -20.758549 \\
\hline O & 6 & 1.203592 & 4 & 122.938696 & 3 & 2.366900 \\
\hline $\mathbf{N}$ & 5 & 1.283254 & 2 & 122.241340 & 1 & 160.198042 \\
\hline $\mathbf{N}$ & 6 & 1.348652 & 4 & 115.153368 & 3 & -178.109341 \\
\hline H & 1 & 1.085681 & 2 & 109.832027 & 5 & -178.562985 \\
\hline H & 1 & 1.083673 & 2 & 111.379164 & 5 & -59.057320 \\
\hline H & 1 & 1.082405 & 2 & 111.230992 & 5 & 61.412671 \\
\hline H & 2 & 1.082544 & 1 & 108.893238 & 5 & 116.010452 \\
\hline H & 3 & 1.084772 & 2 & 109.012621 & 1 & 27.929138 \\
\hline H & 3 & 1.081909 & 2 & 110.547820 & 1 & 145.112692 \\
\hline H & 4 & 1.087364 & 3 & 111.329104 & 2 & 51.438393 \\
\hline H & 4 & 1.087036 & 3 & 109.868659 & 2 & 168.862983 \\
\hline H & 9 & 1.000219 & 5 & 118.089811 & 2 & 1.206605 \\
\hline H & 10 & 0.995434 & 6 & 118.510719 & 4 & 177.328684 \\
\hline H & 10 & 0.993196 & 6 & 122.537849 & 4 & 4.989973 \\
\hline H & 9 & 1.162716 & 5 & 110.572269 & 2 & 178.358428 \\
\hline H & 7 & 1.022770 & 5 & 107.602334 & 2 & -178.711741 \\
\hline O & 3 & 2.440444 & 2 & 95.092849 & 1 & 178.513876 \\
\hline
\end{tabular}


Tabela C12 - Matriz Z para a estrutura do estado de transição da reação 3 caminho2, PAM1 Reação3 1 TS, otimizada com o modelo HF/6-31G(d).

\begin{tabular}{|c|c|c|c|c|c|c|}
\hline & & Distâncias(Å) & & Ângulos $\left({ }^{\circ}\right)$ & & $\operatorname{Diedros}\left({ }^{\circ}\right)$ \\
\hline $\mathbf{C}$ & & & & & & \\
\hline C & 1 & 1.534754 & & & & \\
\hline $\mathbf{C}$ & 2 & 1.542301 & 1 & 116.599647 & & \\
\hline $\mathbf{C}$ & 3 & 1.521804 & 2 & 116.186062 & 1 & -42.808841 \\
\hline $\mathbf{H}$ & 2 & 1.081211 & 1 & 107.687909 & 3 & -117.080152 \\
\hline $\mathbf{H}$ & 4 & 1.078876 & 3 & 111.172938 & 2 & 63.878905 \\
\hline $\mathbf{H}$ & 4 & 1.086055 & 3 & 107.757903 & 2 & -179.671444 \\
\hline $\mathbf{H}$ & 1 & 1.083957 & 2 & 110.255501 & 3 & 63.587869 \\
\hline $\mathbf{H}$ & 1 & 1.082554 & 2 & 113.545184 & 3 & -57.205049 \\
\hline $\mathbf{H}$ & 1 & 1.084052 & 2 & 109.859425 & 3 & -178.470161 \\
\hline $\mathbf{H}$ & 3 & 1.079740 & 2 & 106.856674 & 1 & -165.610755 \\
\hline $\mathrm{C}$ & 2 & 1.528395 & 1 & 114.739115 & 3 & 127.314455 \\
\hline $\mathrm{C}$ & 4 & 1.516898 & 3 & 115.229445 & 2 & -60.897162 \\
\hline $\mathbf{O}$ & 13 & 1.201945 & 4 & 123.067857 & 3 & -14.704085 \\
\hline $\mathbf{O}$ & 12 & 1.198268 & 2 & 120.895521 & 1 & 149.278094 \\
\hline $\mathbf{N}$ & 12 & 1.361997 & 2 & 117.239548 & 1 & -29.577366 \\
\hline $\mathbf{N}$ & 13 & 1.347323 & 4 & 113.546084 & 3 & 166.503037 \\
\hline $\mathbf{H}$ & 17 & 0.994818 & 13 & 118.296047 & 4 & 176.016499 \\
\hline $\mathbf{H}$ & 17 & 0.998230 & 13 & 122.009435 & 4 & 1.145979 \\
\hline $\mathbf{H}$ & 16 & 0.996941 & 12 & 114.747052 & 2 & -168.262100 \\
\hline $\mathbf{H}$ & 16 & 0.994202 & 12 & 119.328112 & 2 & -24.563612 \\
\hline $\mathbf{O}$ & 3 & 1.431132 & 2 & 112.540111 & 1 & 83.891575 \\
\hline $\mathbf{O}$ & 22 & 1.365559 & 3 & 111.719899 & 2 & -66.850046 \\
\hline $\mathrm{C}$ & 23 & 3.355814 & 22 & 139.097702 & 3 & -67.000074 \\
\hline $\mathrm{C}$ & 24 & 1.529981 & 23 & 79.758492 & 22 & -43.936918 \\
\hline $\mathrm{C}$ & 25 & 1.538734 & 24 & 113.362594 & 23 & -17.620564 \\
\hline $\mathbf{C}$ & 26 & 1.516085 & 25 & 116.318127 & 24 & -91.373107 \\
\hline $\mathrm{C}$ & 25 & 1.526883 & 24 & 111.815796 & 23 & 106.884406 \\
\hline $\mathrm{C}$ & 27 & 1.522727 & 26 & 111.973925 & 25 & -74.166179 \\
\hline $\mathbf{O}$ & 28 & 1.207684 & 25 & 122.922447 & 24 & -21.416812 \\
\hline $\mathbf{O}$ & 29 & 1.205065 & 27 & 122.744424 & 26 & 6.396126 \\
\hline $\mathbf{N}$ & 28 & 1.343075 & 25 & 114.168025 & 24 & 159.215689 \\
\hline $\mathbf{N}$ & 29 & 1.346394 & 27 & 115.208879 & 26 & -174.347319 \\
\hline $\mathbf{H}$ & 24 & 1.085840 & 23 & 77.904868 & 22 & -157.514488 \\
\hline $\mathbf{H}$ & 24 & 1.083783 & 23 & 164.334838 & 22 & 88.334477 \\
\hline H & 24 & 1.080893 & 23 & 56.554311 & 22 & 80.607202 \\
\hline $\mathbf{H}$ & 25 & 1.084972 & 24 & 108.193134 & 23 & -136.341841 \\
\hline $\mathbf{H}$ & 26 & 1.188336 & 25 & 108.667215 & 24 & 26.290230 \\
\hline $\mathbf{H}$ & 26 & 1.081471 & 25 & 113.938406 & 24 & 137.633015 \\
\hline $\mathbf{H}$ & 27 & 1.087205 & 26 & 111.089215 & 25 & 47.209624 \\
\hline $\mathbf{H}$ & 27 & 1.086150 & 26 & 109.779413 & 25 & 164.900992 \\
\hline $\mathbf{H}$ & 32 & 0.998216 & 28 & 121.138599 & 25 & 5.890543 \\
\hline $\mathbf{H}$ & 33 & 0.995403 & 29 & 118.600888 & 27 & 177.812432 \\
\hline H & 33 & 0.993250 & 29 & 122.439452 & 27 & 5.652588 \\
\hline $\mathbf{H}$ & 32 & 0.995028 & 28 & 118.633267 & 25 & 175.282516 \\
\hline
\end{tabular}


Tabela C13 - Matriz Z para a estrutura do estado de transição da reação 3 caminho2, PAM1 Reação3 2 TS, otimizada com o modelo HF/6-31G(d).

\begin{tabular}{|c|c|c|c|c|c|c|}
\hline & & Distâncias(Å) & & Ângulos $\left({ }^{\circ}\right)$ & & $\operatorname{Diedros}\left({ }^{\circ}\right)$ \\
\hline $\mathbf{C}$ & & & & & & \\
\hline C & 1 & 1.532790 & & & & \\
\hline $\mathbf{C}$ & 2 & 1.537146 & 1 & 116.710940 & & \\
\hline $\mathbf{C}$ & 3 & 1.529486 & 2 & 115.812904 & 1 & -60.777307 \\
\hline $\mathbf{H}$ & 2 & 1.084869 & 1 & 108.003049 & 3 & -117.063345 \\
\hline $\mathbf{H}$ & 4 & 1.082694 & 3 & 112.043159 & 2 & 56.006438 \\
\hline $\mathbf{H}$ & 4 & 1.086738 & 3 & 107.558459 & 2 & 172.579226 \\
\hline $\mathbf{H}$ & 1 & 1.084233 & 2 & 110.733327 & 3 & 54.010119 \\
\hline $\mathbf{H}$ & 1 & 1.081049 & 2 & 112.724055 & 3 & -67.070831 \\
\hline $\mathbf{H}$ & 1 & 1.084258 & 2 & 109.931102 & 3 & 172.041257 \\
\hline $\mathbf{H}$ & 3 & 1.077869 & 2 & 106.485843 & 1 & 178.371547 \\
\hline $\mathrm{C}$ & 2 & 1.533586 & 1 & 115.285373 & 3 & 128.518793 \\
\hline $\mathrm{C}$ & 4 & 1.518156 & 3 & 113.632999 & 2 & -68.548576 \\
\hline $\mathbf{O}$ & 13 & 1.197907 & 4 & 123.498569 & 3 & -9.151582 \\
\hline $\mathbf{O}$ & 12 & 1.201324 & 2 & 120.246592 & 1 & 177.863219 \\
\hline $\mathbf{N}$ & 12 & 1.354763 & 2 & 117.855928 & 1 & 1.438359 \\
\hline $\mathbf{N}$ & 13 & 1.357527 & 4 & 114.401608 & 3 & 170.654352 \\
\hline $\mathbf{H}$ & 17 & 0.995706 & 13 & 117.361759 & 4 & 170.792660 \\
\hline $\mathbf{H}$ & 17 & 0.993640 & 13 & 121.604930 & 4 & 11.931118 \\
\hline $\mathbf{H}$ & 16 & 0.996795 & 12 & 114.601745 & 2 & -175.839599 \\
\hline $\mathbf{H}$ & 16 & 0.996410 & 12 & 121.411156 & 2 & -28.956472 \\
\hline $\mathbf{O}$ & 3 & 1.425674 & 2 & 113.560533 & 1 & 67.027767 \\
\hline $\mathbf{O}$ & 22 & 1.392185 & 3 & 109.511884 & 2 & -79.458265 \\
\hline $\mathrm{C}$ & 23 & 3.074022 & 22 & 113.553318 & 3 & -168.246337 \\
\hline $\mathrm{C}$ & 24 & 1.524340 & 23 & 54.449953 & 22 & -86.139274 \\
\hline $\mathrm{C}$ & 25 & 1.522504 & 24 & 113.473655 & 23 & 120.654927 \\
\hline $\mathbf{C}$ & 26 & 1.539040 & 25 & 116.942186 & 24 & -162.256014 \\
\hline $\mathrm{C}$ & 25 & 1.520366 & 24 & 110.810656 & 23 & -109.179388 \\
\hline $\mathrm{C}$ & 27 & 1.517152 & 26 & 114.799740 & 25 & -59.251071 \\
\hline $\mathbf{O}$ & 28 & 1.201417 & 25 & 120.028359 & 24 & -92.024346 \\
\hline $\mathbf{O}$ & 29 & 1.206332 & 27 & 121.805606 & 26 & 97.486244 \\
\hline $\mathbf{N}$ & 28 & 1.351123 & 25 & 116.594124 & 24 & 82.884183 \\
\hline $\mathbf{N}$ & 29 & 1.352929 & 27 & 116.329745 & 26 & -84.491623 \\
\hline $\mathbf{H}$ & 24 & 1.082869 & 23 & 78.071492 & 22 & 146.471335 \\
\hline $\mathbf{H}$ & 24 & 1.086795 & 23 & 163.862295 & 22 & -98.675563 \\
\hline H & 24 & 1.083273 & 23 & 82.485280 & 22 & 35.691759 \\
\hline $\mathbf{H}$ & 23 & 1.216675 & 22 & 102.756578 & 3 & 155.247107 \\
\hline $\mathbf{H}$ & 26 & 1.083849 & 25 & 108.150275 & 24 & -41.522388 \\
\hline $\mathbf{H}$ & 26 & 1.086237 & 25 & 107.016662 & 24 & 73.354437 \\
\hline $\mathbf{H}$ & 27 & 1.079987 & 26 & 109.505741 & 25 & 61.508607 \\
\hline $\mathbf{H}$ & 27 & 1.085527 & 26 & 108.044682 & 25 & 178.651078 \\
\hline $\mathbf{H}$ & 32 & 0.995342 & 28 & 119.724428 & 25 & 24.917236 \\
\hline $\mathbf{H}$ & 33 & 0.997007 & 29 & 115.718265 & 27 & 165.714401 \\
\hline H & 33 & 0.995064 & 29 & 119.294294 & 27 & 20.936809 \\
\hline $\mathbf{H}$ & 32 & 0.996674 & 28 & 115.848757 & 25 & 172.871895 \\
\hline
\end{tabular}


Tabela C14 - Matriz Z para a estrutura do estado de transição da reação 3 caminho2, PAM2 Reação3 1 TS, otimizada com o modelo HF/6-31G(d).

\begin{tabular}{|c|c|c|c|c|c|c|}
\hline & & $\operatorname{Distâncias}(\AA ̊)$ & & Ângulos $\left({ }^{\circ}\right)$ & & $\operatorname{Diedros}\left({ }^{\circ}\right)$ \\
\hline $\mathbf{C}$ & & & & & & \\
\hline $\mathrm{C}$ & 1 & 1.531406 & & & & \\
\hline $\mathbf{C}$ & 2 & 1.527993 & 1 & 111.288717 & & \\
\hline C & 3 & 1.543893 & 2 & 114.054022 & 1 & 176.001481 \\
\hline $\mathbf{C}$ & 4 & 1.518079 & 3 & 111.860386 & 2 & 143.116012 \\
\hline $\mathrm{C}$ & 2 & 1.541685 & 1 & 107.750008 & 3 & -121.753075 \\
\hline $\mathbf{N}$ & 5 & 1.352728 & 4 & 114.248622 & 3 & -73.036292 \\
\hline $\mathbf{N}$ & 6 & 1.336146 & 2 & 115.892029 & 1 & -77.188014 \\
\hline $\mathbf{O}$ & 6 & 1.207176 & 2 & 120.831268 & 1 & 100.228610 \\
\hline $\mathbf{O}$ & 5 & 1.201347 & 4 & 122.793249 & 3 & 107.257984 \\
\hline $\mathbf{H}$ & 1 & 1.081514 & 2 & 110.681937 & 3 & -178.153821 \\
\hline $\mathbf{H}$ & 1 & 1.081060 & 2 & 110.684951 & 3 & -57.036034 \\
\hline $\mathbf{H}$ & 1 & 1.084197 & 2 & 109.079612 & 3 & 62.435779 \\
\hline $\mathbf{H}$ & 8 & 0.998881 & 6 & 122.807425 & 2 & 4.294079 \\
\hline H & 8 & 0.995230 & 6 & 117.473791 & 2 & 173.110242 \\
\hline $\mathbf{H}$ & 7 & 0.994722 & 5 & 117.980823 & 4 & 172.939263 \\
\hline $\mathbf{H}$ & 7 & 0.997444 & 5 & 120.966875 & 4 & 8.946601 \\
\hline $\mathbf{H}$ & 4 & 1.080199 & 3 & 110.603411 & 2 & -96.921533 \\
\hline $\mathbf{H}$ & 4 & 1.083162 & 3 & 110.528907 & 2 & 22.257766 \\
\hline H & 3 & 1.081465 & 2 & 107.354766 & 1 & -60.995160 \\
\hline $\mathbf{H}$ & 3 & 1.083776 & 2 & 108.210197 & 1 & 54.026321 \\
\hline $\mathbf{O}$ & 2 & 1.422812 & 1 & 112.381504 & 6 & -114.048824 \\
\hline $\mathbf{O}$ & 22 & 1.383062 & 2 & 110.405183 & 1 & -52.181889 \\
\hline C & 22 & 4.662963 & 2 & 138.133880 & 1 & 49.083905 \\
\hline C & 24 & 1.531613 & 22 & 49.574656 & 2 & -86.691564 \\
\hline $\mathrm{C}$ & 25 & 1.534312 & 24 & 110.779818 & 22 & -50.491620 \\
\hline $\mathrm{C}$ & 26 & 1.515968 & 25 & 117.813675 & 24 & -104.465478 \\
\hline $\mathrm{C}$ & 25 & 1.525964 & 24 & 110.521111 & 22 & 71.834354 \\
\hline $\mathrm{C}$ & 27 & 1.522010 & 26 & 114.348667 & 25 & -65.052494 \\
\hline $\mathbf{O}$ & 28 & 1.207283 & 25 & 122.134158 & 24 & -36.348160 \\
\hline $\mathbf{O}$ & 29 & 1.203700 & 27 & 123.261770 & 26 & 13.871895 \\
\hline $\mathbf{N}$ & 28 & 1.344150 & 25 & 114.758524 & 24 & 143.150111 \\
\hline $\mathbf{N}$ & 29 & 1.347442 & 27 & 114.802742 & 26 & -167.973777 \\
\hline $\mathbf{H}$ & 24 & 1.085889 & 22 & 115.977021 & 2 & 177.818362 \\
\hline $\mathbf{H}$ & 24 & 1.084462 & 22 & 135.823387 & 2 & -8.686370 \\
\hline $\mathbf{H}$ & 24 & 1.082001 & 22 & 62.429169 & 2 & 79.286249 \\
\hline $\mathbf{H}$ & 25 & 1.081078 & 24 & 109.177641 & 22 & -169.947612 \\
\hline $\mathbf{H}$ & 26 & 1.081008 & 25 & 112.099929 & 24 & 27.200079 \\
\hline $\mathbf{H}$ & 23 & 1.206681 & 22 & 100.339259 & 2 & 142.965786 \\
\hline $\mathbf{H}$ & 27 & 1.089994 & 26 & 109.901997 & 25 & 55.831328 \\
\hline $\mathbf{H}$ & 27 & 1.085051 & 26 & 109.458108 & 25 & 172.406805 \\
\hline $\mathbf{H}$ & 32 & 0.998022 & 28 & 119.267137 & 25 & 18.111613 \\
\hline $\mathbf{H}$ & 33 & 0.995654 & 29 & 118.160174 & 27 & 176.860803 \\
\hline $\mathbf{H}$ & 33 & 0.993379 & 29 & 122.336656 & 27 & 10.234420 \\
\hline $\mathbf{H}$ & 32 & 0.995868 & 28 & 117.364034 & 25 & 171.269985 \\
\hline
\end{tabular}


Tabela C15 - Matriz Z para a estrutura do estado de transição da reação 3 caminho2, PAM2 Reação3 2 TS, otimizada com o modelo HF/6-31G(d).

\begin{tabular}{|c|c|c|c|c|c|c|}
\hline & & $\operatorname{Distâncias(\AA ̊)}$ & & Ângulos $\left({ }^{\circ}\right)$ & & $\operatorname{Diedros}\left({ }^{\circ}\right)$ \\
\hline $\mathbf{C}$ & & & & & & \\
\hline $\mathrm{C}$ & 1 & 1.530100 & & & & \\
\hline $\mathbf{C}$ & 2 & 1.526901 & 1 & 111.512102 & & \\
\hline $\mathbf{C}$ & 3 & 1.543109 & 3 & 113.908198 & 1 & 174.898661 \\
\hline $\mathrm{C}$ & 4 & 1.517592 & 3 & 111.672988 & 2 & 145.419901 \\
\hline $\mathrm{C}$ & 2 & 1.542501 & 1 & 108.003411 & 3 & -121.830756 \\
\hline $\mathbf{N}$ & 5 & 1.352263 & 4 & 114.172753 & 3 & -73.731196 \\
\hline $\mathbf{N}$ & 6 & 1.336356 & 2 & 116.121724 & 1 & -75.344311 \\
\hline $\mathbf{O}$ & 6 & 1.206586 & 2 & 120.660591 & 1 & 101.818621 \\
\hline $\mathbf{O}$ & 5 & 1.201216 & 4 & 122.758287 & 3 & 106.384414 \\
\hline $\mathbf{H}$ & 1 & 1.082037 & 2 & 110.890415 & 3 & -177.502079 \\
\hline $\mathbf{H}$ & 1 & 1.081529 & 2 & 110.607283 & 3 & -56.339354 \\
\hline $\mathbf{H}$ & 1 & 1.084043 & 2 & 109.285603 & 3 & 62.951777 \\
\hline $\mathbf{H}$ & 8 & 0.999157 & 6 & 123.375117 & 2 & 1.203583 \\
\hline $\mathbf{H}$ & 8 & 0.995330 & 6 & 117.448204 & 2 & 174.666082 \\
\hline $\mathbf{H}$ & 7 & 0.994740 & 5 & 118.169652 & 4 & 173.369309 \\
\hline $\mathbf{H}$ & 7 & 0.997189 & 5 & 121.069486 & 4 & 8.083055 \\
\hline $\mathbf{H}$ & 4 & 1.080356 & 3 & 110.612105 & 2 & -94.667562 \\
\hline $\mathbf{H}$ & 4 & 1.082804 & 3 & 110.554471 & 2 & 24.551693 \\
\hline $\mathbf{H}$ & 3 & 1.081198 & 2 & 107.281458 & 1 & -62.250190 \\
\hline $\mathbf{H}$ & 3 & 1.083656 & 2 & 108.360648 & 1 & 52.830721 \\
\hline $\mathbf{O}$ & 2 & 1.426908 & 1 & 112.050321 & 6 & -114.240007 \\
\hline $\mathbf{O}$ & 22 & 1.368734 & 2 & 111.021577 & 1 & -55.643627 \\
\hline $\mathbf{C}$ & 23 & 3.300965 & 22 & 106.289134 & 2 & 96.078473 \\
\hline $\mathbf{C}$ & 24 & 1.518147 & 23 & 47.714372 & 22 & 82.441751 \\
\hline C & 25 & 1.538441 & 24 & 113.607106 & 23 & 115.754785 \\
\hline $\mathbf{C}$ & 26 & 1.533301 & 25 & 115.990327 & 24 & -108.549118 \\
\hline $\mathbf{C}$ & 25 & 1.519828 & 24 & 113.235476 & 23 & -104.056501 \\
\hline $\mathrm{C}$ & 27 & 1.519157 & 26 & 113.735182 & 25 & -77.158918 \\
\hline $\mathbf{O}$ & 28 & 1.210781 & 25 & 120.003015 & 24 & 21.239925 \\
\hline $\mathbf{O}$ & 29 & 1.205528 & 27 & 122.044007 & 26 & -21.871545 \\
\hline $\mathbf{N}$ & 28 & 1.340973 & 25 & 117.530139 & 24 & -159.835951 \\
\hline $\mathbf{N}$ & 29 & 1.347324 & 27 & 115.780991 & 26 & 162.891288 \\
\hline $\mathbf{H}$ & 24 & 1.084971 & 23 & 85.024384 & 22 & -154.243651 \\
\hline $\mathbf{H}$ & 24 & 1.078002 & 23 & 84.289730 & 22 & -44.282334 \\
\hline $\mathbf{H}$ & 24 & 1.087504 & 23 & 157.336674 & 22 & 79.679757 \\
\hline $\mathbf{H}$ & 23 & 1.214473 & 22 & 102.658434 & 2 & 120.044136 \\
\hline $\mathbf{H}$ & 26 & 1.084582 & 25 & 107.257273 & 24 & 11.431999 \\
\hline $\mathbf{H}$ & 26 & 1.080896 & 25 & 110.861307 & 24 & 127.029556 \\
\hline $\mathbf{H}$ & 27 & 1.084786 & 26 & 111.287685 & 25 & 48.274030 \\
\hline $\mathbf{H}$ & 27 & 1.087154 & 26 & 108.669847 & 25 & 165.174178 \\
\hline $\mathbf{H}$ & 32 & 1.000539 & 28 & 121.328034 & 25 & -18.516659 \\
\hline $\mathbf{H}$ & 33 & 0.996401 & 29 & 117.102219 & 27 & -174.656373 \\
\hline $\mathbf{H}$ & 33 & 0.993821 & 29 & 121.008632 & 27 & -20.092740 \\
\hline $\mathbf{H}$ & 32 & 0.996229 & 28 & 115.748074 & 25 & -170.760815 \\
\hline
\end{tabular}


Tabela C16 - Matriz Z para a estrutura da acrilamida, otimizada com o modelo $\mathrm{HF} / 6-31 \mathrm{G}(\mathrm{d})$.

\begin{tabular}{|c|c|c|c|c|c|c|}
\hline & & $\operatorname{Distâncias(\AA ̊)}$ & \multicolumn{3}{|c|}{ Ângulos( $\left(^{\circ}\right)$} & $\operatorname{Diedros}\left({ }^{\circ}\right)$ \\
\hline $\mathbf{C}$ & & & & & & \\
\hline $\mathbf{C}$ & 1 & 1.318414 & & & & \\
\hline $\mathbf{C}$ & 2 & 1.494076 & 1 & 120.627591 & & \\
\hline $\mathbf{N}$ & 3 & 1.355436 & 2 & 114.794054 & 1 & 179.292586 \\
\hline H & 4 & 0.992665 & 3 & 122.389184 & 2 & -9.143313 \\
\hline $\mathbf{H}$ & 4 & 0.994939 & 3 & 117.909493 & 2 & -174.996620 \\
\hline $\mathbf{O}$ & 3 & 1.200009 & 2 & 122.966335 & 1 & -1.440627 \\
\hline H & 1 & 1.073989 & 2 & 120.466021 & 3 & 0.066798 \\
\hline $\mathbf{H}$ & 1 & 1.074783 & 2 & 121.681188 & 3 & -179.983637 \\
\hline $\mathbf{H}$ & 2 & 1.076829 & 1 & 121.111076 & 3 & -179.899910 \\
\hline
\end{tabular}

Tabela C17 - Matriz Z para a estrutura do PAM3_Radical, otimizada com o modelo $\mathrm{HF} / 6-31 \mathrm{G}(\mathrm{d})$.

\begin{tabular}{|c|c|c|c|c|c|c|}
\hline & & $\operatorname{Distâncias(\AA ̊)}$ & \multicolumn{3}{|c|}{ Ângulos( $\left(^{\circ}\right)$} & $\operatorname{Diedros}\left({ }^{\circ}\right)$ \\
\hline $\mathbf{C}$ & & & & & & \\
\hline $\mathrm{C}$ & 1 & 1.504801 & & & & \\
\hline $\mathbf{C}$ & 2 & 1.547160 & 1 & 110.961016 & & \\
\hline $\mathbf{C}$ & 3 & 1.538241 & 2 & 115.589634 & 1 & 175.174128 \\
\hline C & 4 & 1.537962 & 3 & 110.295958 & 2 & 177.001332 \\
\hline $\mathrm{C}$ & 5 & 1.542287 & 4 & 114.418543 & 3 & -175.209299 \\
\hline $\mathbf{C}$ & 2 & 1.527448 & 1 & 113.556797 & 3 & -124.949737 \\
\hline $\mathbf{C}$ & 4 & 1.525446 & 3 & 109.313817 & 2 & -60.695661 \\
\hline $\mathbf{C}$ & 6 & 1.521591 & 5 & 113.399557 & 4 & -93.901523 \\
\hline $\mathbf{O}$ & 9 & 1.197862 & 6 & 121.026552 & 5 & -68.250634 \\
\hline $\mathbf{N}$ & 9 & 1.360189 & 6 & 116.364976 & 5 & 114.926346 \\
\hline $\mathbf{H}$ & 11 & 0.997034 & 9 & 115.189960 & 6 & -168.828987 \\
\hline $\mathbf{H}$ & 11 & 0.995447 & 9 & 119.360861 & 6 & -24.254906 \\
\hline $\mathbf{H}$ & 6 & 1.085754 & 5 & 110.792807 & 4 & 32.230007 \\
\hline $\mathbf{H}$ & 6 & 1.083488 & 5 & 108.765499 & 4 & 149.764031 \\
\hline $\mathbf{H}$ & 5 & 1.082704 & 4 & 110.198963 & 3 & 61.086958 \\
\hline $\mathbf{H}$ & 5 & 1.085465 & 4 & 107.233697 & 3 & -55.196193 \\
\hline $\mathbf{H}$ & 4 & 1.083411 & 3 & 109.206910 & 2 & 58.388744 \\
\hline $\mathbf{H}$ & 3 & 1.084159 & 2 & 107.731323 & 1 & 53.846764 \\
\hline $\mathbf{H}$ & 3 & 1.086427 & 2 & 108.908484 & 1 & -62.059566 \\
\hline $\mathbf{H}$ & 2 & 1.087496 & 1 & 108.616043 & 3 & 119.139496 \\
\hline $\mathbf{H}$ & 1 & 1.074803 & 2 & 119.616967 & 7 & -152.713898 \\
\hline $\mathbf{H}$ & 1 & 1.076213 & 2 & 119.954995 & 7 & 48.021152 \\
\hline $\mathbf{O}$ & 8 & 1.199372 & 4 & 121.643154 & 3 & -68.232788 \\
\hline $\mathbf{O}$ & 7 & 1.206873 & 2 & 121.440497 & 1 & -148.489345 \\
\hline $\mathbf{N}$ & 7 & 1.345883 & 2 & 116.837455 & 1 & 34.247418 \\
\hline $\mathbf{N}$ & 8 & 1.362622 & 4 & 115.650352 & 3 & 113.563937 \\
\hline $\mathbf{H}$ & 26 & 0.995334 & 7 & 118.409470 & 2 & 179.104206 \\
\hline $\mathbf{H}$ & 26 & 0.992759 & 7 & 122.390580 & 2 & -6.056798 \\
\hline $\mathbf{H}$ & 27 & 1.000025 & 8 & 117.359054 & 4 & -28.462969 \\
\hline $\mathbf{H}$ & 27 & 0.998337 & 8 & 114.593659 & 4 & -168.541755 \\
\hline
\end{tabular}


Tabela C18 - Matriz Z para a estrutura do PAM4 Radical, otimizada com o modelo $\mathrm{HF} / 6-31 \mathrm{G}(\mathrm{d})$.

\begin{tabular}{|c|c|c|c|c|c|c|}
\hline & & $\operatorname{Distâncias(\AA ̊)}$ & & Ângulos $\left({ }^{\circ}\right)$ & & $\operatorname{Diedros}\left({ }^{\circ}\right)$ \\
\hline $\mathbf{C}$ & & & & & & \\
\hline $\mathrm{C}$ & 1 & 1.510946 & & & & \\
\hline $\mathbf{C}$ & 2 & 1.541894 & 1 & 111.227120 & & \\
\hline C & 3 & 1.539795 & 2 & 116.231026 & 1 & 147.701734 \\
\hline $\mathbf{C}$ & 4 & 1.548171 & 3 & 109.290424 & 2 & -172.695047 \\
\hline $\mathrm{C}$ & 5 & 1.538773 & 4 & 115.684259 & 3 & 172.702411 \\
\hline $\mathbf{C}$ & 6 & 1.538222 & 5 & 110.249597 & 4 & 176.974277 \\
\hline $\mathbf{C}$ & 7 & 1.542326 & 6 & 114.517051 & 5 & -175.068766 \\
\hline C & 2 & 1.529166 & 1 & 107.502828 & 3 & -123.972197 \\
\hline C & 4 & 1.526843 & 3 & 117.657518 & 2 & 62.541960 \\
\hline $\mathrm{C}$ & 6 & 1.525179 & 5 & 109.272308 & 4 & -60.778265 \\
\hline $\mathbf{C}$ & 8 & 1.521437 & 7 & 113.451984 & 6 & -93.455481 \\
\hline $\mathbf{O}$ & 12 & 1.197971 & 8 & 121.077116 & 7 & -68.788520 \\
\hline $\mathbf{N}$ & 12 & 1.360425 & 8 & 116.361204 & 7 & 114.328083 \\
\hline H & 14 & 0.997013 & 12 & 115.163167 & 8 & -168.783616 \\
\hline $\mathbf{H}$ & 14 & 0.995507 & 12 & 119.326307 & 8 & -24.292772 \\
\hline $\mathbf{H}$ & 8 & 1.085739 & 7 & 110.771527 & 6 & 32.661568 \\
\hline $\mathbf{H}$ & 8 & 1.083461 & 7 & 108.731566 & 6 & 150.185246 \\
\hline $\mathbf{H}$ & 7 & 1.082789 & 6 & 110.192432 & 5 & 61.158375 \\
\hline H & 7 & 1.085287 & 6 & 107.174953 & 5 & -55.090317 \\
\hline H & 6 & 1.083440 & 5 & 109.327507 & 4 & 58.403359 \\
\hline H & 5 & 1.084157 & 4 & 108.024474 & 3 & 51.506856 \\
\hline $\mathbf{H}$ & 5 & 1.085911 & 4 & 108.884604 & 3 & -64.624967 \\
\hline H & 4 & 1.084332 & 3 & 107.627503 & 2 & -55.145498 \\
\hline H & 3 & 1.083183 & 2 & 109.000894 & 1 & -84.919343 \\
\hline H & 3 & 1.083818 & 2 & 107.537995 & 1 & 29.552708 \\
\hline H & 2 & 1.092106 & 1 & 108.497566 & 9 & -116.541434 \\
\hline H & 1 & 1.074176 & 2 & 119.414668 & 9 & -165.248757 \\
\hline H & 1 & 1.074314 & 2 & 121.073953 & 9 & 28.684209 \\
\hline $\mathbf{O}$ & 11 & 1.199631 & 6 & 121.715534 & 5 & -67.427811 \\
\hline $\mathbf{O}$ & 10 & 1.209375 & 4 & 120.292262 & 3 & -144.521043 \\
\hline $\mathbf{O}$ & 9 & 1.203729 & 2 & 122.877940 & 1 & 96.700702 \\
\hline $\mathbf{N}$ & 10 & 1.347365 & 4 & 117.964091 & 3 & 40.978812 \\
\hline $\mathbf{N}$ & 11 & 1.363554 & 6 & 115.679364 & 5 & 114.405271 \\
\hline $\mathbf{N}$ & 9 & 1.347227 & 2 & 115.176845 & 1 & -81.224941 \\
\hline H & 35 & 0.993023 & 9 & 122.723004 & 2 & -2.178159 \\
\hline $\mathbf{H}$ & 35 & 0.995422 & 9 & 118.631078 & 2 & 175.830788 \\
\hline $\mathbf{H}$ & 33 & 0.996847 & 10 & 115.683822 & 4 & -176.876939 \\
\hline $\mathbf{H}$ & 33 & 0.996822 & 10 & 121.333327 & 4 & -27.032673 \\
\hline $\mathbf{H}$ & 34 & 1.000175 & 11 & 117.067152 & 6 & -29.485522 \\
\hline $\mathbf{H}$ & 34 & 0.998397 & 11 & 114.392289 & 6 & -168.621021 \\
\hline
\end{tabular}


Tabela C19 - Matriz Z para a estrutura do estado de transição da reação de formação da acrilamida, otimizada com o modelo $\mathrm{HF} / 6-31 \mathrm{G}(\mathrm{d})$.

\begin{tabular}{|c|c|c|c|c|c|c|}
\hline & & $\operatorname{Distâncias(\AA ̊)}$ & & Ângulos $\left({ }^{\circ}\right)$ & & $\operatorname{Diedros}\left({ }^{\circ}\right)$ \\
\hline $\mathbf{C}$ & & & & & & \\
\hline $\mathrm{C}$ & 1 & 1.393652 & & & & \\
\hline $\mathbf{C}$ & 2 & 2.202893 & 1 & 105.197887 & & \\
\hline C & 3 & 1.516344 & 2 & 117.242812 & 1 & 173.638131 \\
\hline $\mathbf{C}$ & 4 & 1.556920 & 3 & 108.402508 & 2 & -163.903275 \\
\hline $\mathrm{C}$ & 5 & 1.538503 & 4 & 116.476393 & 3 & 172.202650 \\
\hline $\mathbf{C}$ & 6 & 1.538852 & 5 & 109.905529 & 4 & 179.282946 \\
\hline $\mathbf{C}$ & 7 & 1.542363 & 6 & 114.514886 & 5 & -175.298217 \\
\hline C & 2 & 1.493275 & 1 & 117.767284 & 3 & -108.024975 \\
\hline C & 4 & 1.527020 & 3 & 117.216905 & 2 & 72.035663 \\
\hline $\mathrm{C}$ & 6 & 1.524407 & 5 & 109.412689 & 4 & -58.626394 \\
\hline $\mathbf{C}$ & 8 & 1.521456 & 7 & 113.367386 & 6 & -93.760535 \\
\hline $\mathbf{O}$ & 12 & 1.198034 & 8 & 121.073607 & 7 & -68.371945 \\
\hline $\mathbf{N}$ & 12 & 1.360144 & 8 & 116.359308 & 7 & 114.673059 \\
\hline H & 14 & 0.996978 & 12 & 115.228849 & 8 & -168.994183 \\
\hline $\mathbf{H}$ & 14 & 0.995450 & 12 & 119.349759 & 8 & -24.163264 \\
\hline $\mathbf{H}$ & 8 & 1.085631 & 7 & 110.800690 & 6 & 32.354258 \\
\hline $\mathbf{H}$ & 8 & 1.083477 & 7 & 108.749612 & 6 & 149.912364 \\
\hline $\mathbf{H}$ & 7 & 1.082817 & 6 & 110.231677 & 5 & 60.950670 \\
\hline H & 7 & 1.085330 & 6 & 107.173878 & 5 & -55.286502 \\
\hline H & 6 & 1.082078 & 5 & 109.339191 & 4 & 60.710760 \\
\hline H & 5 & 1.083663 & 4 & 107.462621 & 3 & 50.976989 \\
\hline $\mathbf{H}$ & 5 & 1.085965 & 4 & 108.583278 & 3 & -64.717909 \\
\hline H & 4 & 1.084581 & 3 & 108.555780 & 2 & -46.845294 \\
\hline H & 3 & 1.077317 & 2 & 99.547416 & 1 & -58.045645 \\
\hline H & 3 & 1.076835 & 2 & 94.206793 & 1 & 55.194261 \\
\hline H & 2 & 1.076647 & 1 & 118.282571 & 9 & -149.759924 \\
\hline H & 1 & 1.073998 & 2 & 120.877064 & 9 & 167.909065 \\
\hline H & 1 & 1.072940 & 2 & 120.388744 & 9 & -18.118537 \\
\hline $\mathbf{O}$ & 11 & 1.199699 & 6 & 121.834722 & 5 & -65.500309 \\
\hline $\mathbf{O}$ & 10 & 1.208225 & 4 & 120.110869 & 3 & -156.808523 \\
\hline $\mathbf{O}$ & 9 & 1.205101 & 2 & 122.400276 & 1 & 36.495823 \\
\hline $\mathbf{N}$ & 10 & 1.350801 & 4 & 118.416896 & 3 & 28.649903 \\
\hline $\mathbf{N}$ & 11 & 1.363913 & 6 & 115.548155 & 5 & 116.361972 \\
\hline $\mathbf{N}$ & 9 & 1.350804 & 2 & 115.399634 & 1 & -145.365728 \\
\hline H & 35 & 0.993090 & 9 & 122.359208 & 2 & 10.767460 \\
\hline $\mathbf{H}$ & 35 & 0.995456 & 9 & 118.128686 & 2 & 176.566858 \\
\hline $\mathbf{H}$ & 33 & 0.997187 & 10 & 114.802621 & 4 & -175.826058 \\
\hline $\mathbf{H}$ & 33 & 0.995530 & 10 & 121.015361 & 4 & -30.724093 \\
\hline $\mathbf{H}$ & 34 & 0.999817 & 11 & 116.693165 & 6 & -29.814952 \\
\hline $\mathbf{H}$ & 34 & 0.998360 & 11 & 114.446735 & 6 & -168.809369 \\
\hline
\end{tabular}

